INTERNATIONAL PHASE OF OCEAN DRILLING (IPOD)

DEEP SEA DRILLING PROJECT

DEVELOPMENT ENGINEERING

TECHNICAL REPORT NO. 19

\title{
OPERATIONS RESUMES PART VIII LEG 85 THROUGH LEG 96
}

SCRIPPS INSTITUTION OF OCEANOGRAPHY UNIVERSITY OF CALIFORNIA AT SAN DIEGO CONTRACT NSF C-482

PRIME CONTRACTOR : THE REGENTS, UNIVERSITY OF CALIFORNIA 


\section{DISCLAIMER}

This report was prepared by the Deep Sea Drilling Project, Unfversity of California, San Diego, as an account of work sponsored by the United States Government's National Science Foundation. Neither the University nor any of their employees, nor any of their contractors, subcontractors, or their employees, makes any warranty, express or implied, or assumes any legal liability or responsibility for the accuracy, completeness or usefulness of any information, apparatus, product or process disclosed, or represents that its use would not infringe privately owned rights. 
TECHNICAL REPORT NO. 19

Operationa1 Resumes

Leg 85 through Leg 96

\author{
Prepared for the \\ National Science Foundation \\ National Ocean Sediment Coring Program \\ Under Contract $\mathrm{C}-482$ \\ by the \\ University of California \\ Scripps Institution of Oceanography \\ Prime Contractor for the Project
}

Apri1 1984

W. A. Nierenberg, Director

Scripps Institution of Oceanography
M. N. A. Peterson

Principal Investigator and Project Manager

Scripps Institution of Oceanography 


\section{INTRODUCTION}

IPOD/DSDP Technical Report Number 19 is the eighth edition published since the inception of Deep Sea Drilling Project operations in August, 1968.

This volume relates operational and engineering procedures used aboard D/V GLOMAR CHALLENGER from Leg 85 through Leg 96.

Technical Report Number 19 follows the format of the previous seven volumes citing Operations Resumes. This report documents technical achievements, drilling and coring results, drill bit performance, deployment of new coring systems, coring equipment modifications and procedural improvements. Problem areas are identified and remedial actions taken or proposed are presented. In addition, operational ramifications of weather, communications, personnel, port calls and under way periods are related. 
Achievements of the technical staff of the International Phase of Ocean Drilling of the Deep Sea Drilling Project have, to a great extent, been responsible for successful operations and for the resulting contributions to basic earth research credited to the Deep Sea Drilling Project.

To V. Robson, Head of Operations; to V. Larson and S. Serocki, who served as Head of Engineering and to their staffs; P. Porter, R. Knapp, G. Foss, P. Dempsey, P. Thompson, B. Adams, M. Storms, D. Bellows, D. Huey, D. Cameron, R. Keefe and P. Duley, the Project gratefully acknowledges your dedication, talents and expertise.

The DSDP Logistics Department, headed by R. Olivas, provided invaluable support for the efforts of the Operations, Engineering and Scientific groups involved with at-sea operations.

The professionalism and cooperation of the crew and management of the $D / V$ GLOMAR CHALLENGER were the final and all-important factor in the Project's operational achievements. Ship's Managers B. Perkins and J. Duke; Captains J. Clarke, L. Dill and S. Shuman; Drilling Superintendents J. Guess, J. Ruddell and $\mathrm{A}$. Wheeler and their dedicated staffs have earned the appreciation to all involved with the Project.

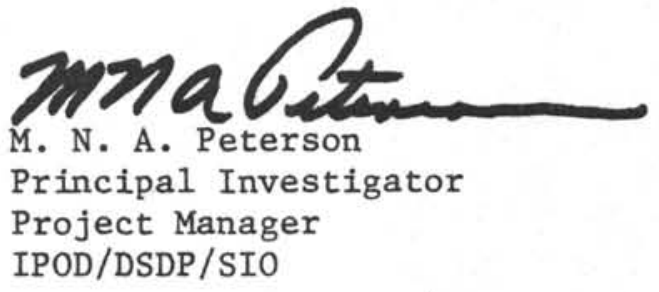


OPERATIONS RESUMES

CONTENTS

Leg 85 - Los Angeles Harbor, California to Honolulu, Hawaii

March 3, 1982 to May 2, 1982

Cruise Co-Chief Scientists:

Dr. Larry Mayer, University of Rhode Island

Dr. Fritz Theyer, Hawaii Institute of Geophysics

Cruise Operations Manager:

Mr. STanley T. Serocki, Deep Sea Drilling Project

Leg 86 - Honolulu, Hawaii to Yokohama, Japan

May 2, 1982 to June 19, 1982

Cruise Co-Chief Scientists:

Dr. Lloyd H. Burckle, Lamont-Doherty Geological Observatory

Dr. G. Ross Heath, Oregon State University

Cruise Operations Manager:

Mr. Michael A. Storms, Deep Sea Drilling Project

Leg 87 - Yokohama, Japan to Hakodate, Japan

June 19, 1982 to August 18, 1982

Cruise Co-Chief Scientists:

Dr. Hideo Kagami, University of Tokyo

Dr. Daniel E. Karig, Cornill University

Cruise Operations Manager:

Mr. Glen N. Foss, Deep Sea Drilling Project

Leg 88 - Hakodate, Japan to Yokohama, Japan

August 18, 1982 to September 19, 1982

Cruise Co-Chief Scientists:

Dr. Frederick G. Duennebier, Hawaii Institute of Geophysics

Dr. Ralph A. Stephen, Woods Hole Oceanographic Institution

Cruise Operations Manager:

Mr. V. Barry Robson, Deep Sea Drilling Project

Leg 89 - Yokohama, Japan to Noumea, New Caledonia

September 19, 1982 to November 29, 1982

Cruise Co-Chief Scientists:

Dr. Ralph Moberly, Hawaii Institute of Geophysics

Dr. Seymour 0. Schlanger, Northwestern University

Cruise Operations Manager:

Mr. Glen N. Foss, Deep Sea Drilling Project 
Leg 90 - Noumea, New Caledonia to Wellington, New Zealand

November 29, 1982 to January 9, 1983

Cruise Co-Chief Scientists

Dr. James P. Kennett, University of Rhode Island

Dr. Chris Von der Borch, Flinders University of South Australia Cruise Operations Manager

Mr. David P. Huey, Deep Sea Drilling Project

Leg 91 - Wellington, New Zealand to Papeete, Tahiti

January 9, 1983 to February 20, 1983

Cruise Co-Chief Scienitsts:

Dr. H. William Menard, Scripps Institution of Oceanography

Dr. James H. Natland, Deep Sea Drilling Project

Cruise Operations Manager;

Mr. Glen N. Foss, Deep Sea Drilling Project

Leg 92 - Papeete, Tahiti to Balboa, Panama

February 20, 1983 to April 19, 1983

Cruise Co-Chief Scientists:

Dr. David K. Rea, University of Michigan

Dr. Margaret Leinen, University of Rhode Island

Cruise Operations Manager:

Mr. Michael A. Storms, Deep Sea Drilling Project

Balboa, Panama to Norfolk, Virginia

April 19, 1983 to April 27, 1983

Cruise Laboratory officer:

Mr. Michael Lehman, Deep Sea Drilling Project

Leg 93 - Norfolk, Virginia to Norfolk, Virginia

Apri1 27, 1983 to June 17, 1983

Cruise Co-Chief Scientists:

Dr. Sherwood Wise, Florida State University

Dr. Jan E. Van Hinte, Instituut Voor Aardwetenschappen Vrye Universiteit (Netherlands)

Cruise Operations Manager:

Mr. Glen N. Foss, Deep Sea Drilling Project

Leg 94 - Norfolk, Virginia to St. Johns, Newfoundland, Canada

June 17, 1983 to August 17, 1983

Cruise Co-Chief Scientists:

Dr. Robert B. Kidd, Institute of Oceanographic Sciences (UK)

Dr. William F. Ruddiman, Lamont-Doherty Geological Observatory

Cruise Operations Manager:

Mr. Donald H. Cameron, Deep Sea Drilling Project 
Leg 95 - St Johns, Newfoundland to Port Everglades, Florida

August 17, 1983 to September 26, 1983

Cruise Co-Chief Scientists:

Dr. C. Wylie Poag, U. S. Geological Survey

Dr. A. B. Watts, Lamont-Doherty Geological Observatory

Cruise Operations Manager:

Mr. David P. Huey, Deep Sea Drilling Project

Leg 96 - Port Everglades, Florida to Mobile, Alabama

September 26, 1983 to November 8, 1983

Cruise Co-Chief Scientists:

Dr. Arnold H. Bouma, Gulf Research and Development Company

Dr. James M. Coleman, Louisiana State University

Cruise Operations Manager:

Mr. Glen N. Foss, Deep Sea Drilling Project 


\section{INTERNATIONAL PHASE OF OCEAN DRILLING}

DEEP SEA DRILLING PROJECT

OPERATIONS RESUME

LEG 85

Leg 85 was planned as a transect of core holes for fine scale stratigraphic and paleoenvironmental studies of the central equatorial Pacific. The requisite undisturbed core and depth of penetration required double hydraulic piston cores at each site. To complete the stratigraphic record, each site was to be rotary cored, time permitting, from the base of the deepest piston core hole to basement. The magnetic orientation of the cores was to be measured downhole.

The major operational objectives were successfully met with the drilling of 17 holes at 5 sites in water depths ranging from 3903 to 4572 meters. The Variable Length Hydraulic Piston Corer (VLHPC) penetrated stiff calcareous oozes to a maximum penetration of 206.5 meters below the seafloor and recovered the complete section with minimal core disturbance.

The voyage began on March 10, 1982 at San Pedro, California and ended on May 2, 1982 at Honolulu, Hawail. The leg required 59.6 days; of which 28.7 days were spent on site, 7.1 days in a scheduled port call, and 23.8 days in transit.

$\underline{\text { San Pedro Port Cal1 }}$

Leg 85 began officially at 1539 hours, March 3, with the mooring at Pier 244, Terminal Island, San Pedro, California.

A major effort was made to resupply the ship with drill pipe and to inspect onboard and incoming drill pipe for flaws. A total of 277 joints of drill pipe were unloaded from the vessel onto dockside racks for inspection. One joint was rejected for internal defects and held ashore. The remaining 276 joints were reloaded aboard. The vessel also took on 348 new joints of drill pipe which had just been inspected in a nearby holding yard. In addition, 190 joints of premium pipe were shipped from Houston. The availability of crane service and labor greatly facilitated the drill pipe handling.

Other major port call work items included the offload and return of nine heavy wall drilling joints after thread recut and inspection, the loading of 4 re-entry cones and 24 joints of $113 / 4$ inch casing, and the exchange of a 30,000 ft. of new logging cable for the shipboard spare 20,000 ft. cable. Also loaded were 2200 sacks of barite and 1000 sacks of gel. After taking 
on the computer van, routine freight anc resupply, and fueling with 193,000 gallons of diese1, the CHALLENGER departed port at 1800 hours on 10 March, 1982 bound for the central equatorial Pacific.

Hole 571

The transit to the first site was on an almost due south course of $172.5^{\circ}$. The long voyage of 1675 miles was made in 8.2 days at an average speed of 8.5 knots. The site vicinity was reached at 2321 hours on 18 March. After profiling for about an hour, the site approach was made at steaming speed and a beacon was dropped 0038 hours, 19 March. Within two hours, profiling had been completed and the ship positioning in automatic.

Hole 571 was primarily a heat flow/pore water site and piston cores of the heat flow intervals were desired as a second priority. Site time was to be held to 48 hours. In order to accomplish both objectives, the heat flow tool was made up to a special inner barrel configuration so that the variable length hydraulic piston corer (VLHPC) and bottom hole assembly (BHA) would be fully compatible with the heat flow tool. This would allow taking heat flow/pore water measurements in piston core holes or in offsetting heat flow holes without pulling the drill pipe back to the rig floor for a BHA change. The heat flow probe would be held in place with rig pump pressure locked in by the piston corer wireline blowout preventer.

The hole was spudded at 1730 hours in 3968.5 meters of water on 19 March. A 9.5 meter VLHPC recovered the mudline and 7.1 meters of core. The hole was then washed down 192 meters with 4 heat flow and 2 heat flow/pore water runs being made at intervening points. While pulling out of the hole on the No. 3 run, the single shot pressure case separated by backing off at the bottom plug connection. The fish was recovered using a core barrel dressed with a hard formation core catcher.

The first five heat flow runs failed as the landing sub in the heat flow assembly landed on top of the piston corer seal sleeve allowing fluid to bypass the seals. On the last run the landing sub was changed out for an inner barrel sub. The seal assembly landed normally and a heat flow measurement was taken with 500 pounds per square inch of rig pressure locking the probe firmly in place for a 30 minute measurement. The hydraulic lock was maintained by the blowout preventer while the bit was taking 10,000 pounds of weight as well as some bumper sub pounding. The heat flow probe was recovered undamaged and brought into the core lab for data recovery. Unfortunately, the data was lost during the attempt to read out the memory. Time was not available for additional runs and the drill string was pulled and the vessel secured for a short cruise to the next site.

Hole 572

The 142 miles to Site 572 was covered in a short voyage of 16.4 hours and 
with an average speed of 8.5 knots. The CHALLENGER arrived in the vicinity of the site at 1845 hours, March 21 and after a 2.2 hour survey at normal cruising speed, a $16 \mathrm{kHz}$ positioning beacon was dropped at 2136 hours. The beacon signal was normal for one hour but deteriorated rapidly without any sign of recovery. A $13.5 \mathrm{kHz}$ beacon was then dropped at 2250 hours. Within an hour the vessel had been positioned and in automatic. After two hours from drop, the beacon signal strength weakened at an abnormal rate but leveled out allowing satisfactory positioning.

A VLHPC bottom assembly was made up and the drill string run to mudline. The first run came up with a water core and the second run was empty with a collapsed liner. The bit was pulled clear of the mudline to spud another hole without vessel offset.

\section{Hole 572A}

Hole 572A was spudded in 3903 meters of water at 1520 hours on March 22 . Continuous 9.5 meter VLHPC coring proceeded routinely through Core 17 in soft calcareous ooze to a total depth (T.D.) of 4057 meters (154 meters below seafloor). Core 18 required 60,000 to 65,000 pounds of overpull to come free. When the piston corer was recovered the quick release was found parted, with the cap sub and inner core barrel left in the hole. The dogs on the quick release shoulder sub had been deformed to a wedge shape and had stripped through or split the cap sub parting the quick release. Previous overpulls were in the 5,000 to 10,000 pound range. The corer had fully stroked out. Apparently, a sharp sedimentary boundary had been penetrated and a much firmer or cohesive material cored. A deeper penetration was desired if possible. The bit was pulled to mudline to spud 572B using the 5-meter VLHPC in the hope of recovering core at lower overpulls.

\section{Hole 572B}

Hole 572B was spudded without vessel offset at 1531 hours on March 23 and washed to 4057 meters, the base of the cored interval in Hole 572A. Four cores were taken with the 5-meter VLHPC in the interval 4057-4075.1 meters. Overpulls varied from 10,000 to 35,000 pounds for the last core. The last core run did not show full stroke. Further coring was likely to lead to the loss of another inner barrel with little prospect of penetrating deeper. A third hole, 572C, was planned as the double piston core hole.

\section{Hole $572 \mathrm{C}$}

This final piston core hole at Site 572C was spudded at 0224 hours, March 25, in 3903 meters of water. Twenty cores were taken in reaching the total depth of 4072.4 meters ( 169.5 meters subbottom). The 5-meter VLHPC was alternated with the 9.5 meter VLHPC whenever the 9.5 meter tool encountered high pull out forces. Pullout in the firms ooze fluctuated with depth and was not predictable. Abnormal pull out forces varied from 15,000 to 40,000 pounds. 
The last core reached 169.5 meters subbottom and required 35,000 pounds to pull out. This was at approximately the depth level of excessive overpulls in Holes $572 \mathrm{~A}$ and $572 \mathrm{~B}$ and it was decided that further piston coring was not feasible. Hole $572 \mathrm{C}$ had reached a T.D. of 4072.5 meters. A rotary core hole was to be drilled next to complete the site. The drill string was pulled out of the hole and the piston coring bit "Amy" was on the derrick floor at 0307 hours, March 25.

Hole 572D

Hole 572D was spudded at 2100 hours, March 25 and washed to 4054 meters, 21 meters above the T.D. of Höle 572B, the deepest piston core holes at the site. Rotary coring continued in a routine fashion, through stiff oozes and chalks to 5367.5 meters. The hole was washed down 15 meters to 4302.5 meters where rough drilling indicated basalt had been reached. The final core barrel was drilled down 6.5 meters in 42 minutes. The drill string was pulled with the core barrel in the drill string. When pulled from the outer barrel at the derrick floor the core barrel was found with . 3 meters of broken basalt. The site objectlves had been met and vessel was underway for the long transit to Site 573 at 0900 hours, March 28.

Hole 573

The 1190 mile transit from Site 572 was completed in 5.3 days with an average vessel speed of 9.3 knots. The site was approached at full speed. After a half hour of profiling a $3.5 \mathrm{kHz}$ positioning beacon was dropped at 1644 hours, April 2, 1982.

Site 573 was spudded using a 9.5 meter VLHPC in 4311.5 meters of water on April 3. The 9.5 meter corer worked well, recovering cores 2 through 15 with nominal overpulls of 5,000 to 10,000 pounds. Core 17 had apparently cored a stiff ooze section and required 50,000 pounds of overpull to retrieve the cores. On recovery, the quick release shoulder sub and cap sub dog bearing surfaces showed evidence of incipient metal yielding but were reusable. Nine meters of stiff ooze were recovered. The VLHPC had stroked out fully, as it was positioned to penetrate 8.8 meters. All previous 9.5 meter coring runs had fully stroked out. A 5-meter VLHPC was then deployed to extend coring depth by reducing overpull. Two cores of ooze were subsequently recovered with overpulls of only 5,000 to 10,000 pounds. Stiffer ooze was penetrated on the third 5-meter core run. Overpulls to 75,000 pounds failed to pull the inner barrel from the stiff ooze and the VLHPC returned with the lower section of the quick release (cap sub) and inner barrel gone. Hydraulic pressure had vented normally indicating again, that full stroke had been reached. The quick release had failed from overloading. The limits of piston coring were reached at 163 meters BSF or 4474.5 meters below the rig floor. Core quality was excellent and recovery was $100 \%$. The drill bit was pulled to mudline, without vessel offset, to piston core the twin hole, 573A. 
Hole 573A

Hole $573 \mathrm{~A}$ was spudded with a 9.5 meter VLHPC in 4311.5 meters of water at 1745 hours on April 4. Five cores of calcareous ooze were recovered in a routine fashion. During recovery of the sixth core from 4369.2 meters ( 57.7 meters BSF) the sandline parted at 1200 meters below the derrick floor. The drill string was pulled and the sandline was found 47 stands from bottom. The line and the full No. 6 core were recovered and the bit was at the derrick floor at 1320 hours, April 5. The sandline length was down to 4300 meters and scheduled for replacement at the next port call. It was dumped and the drawworks line transferred to the sandline reel.

Hole 573 had recovered a $100 \%$ section of core to the depth limits of the VLHPC. Rather than continue twin hole piston coring, a rotary core hole 573B was to be drilled to provide a continuous stratigraphic section from the mudline to basement at this site.

Hole 573B

The hole was to be washed to some 20 meters above the base of the piston coring in Hole 573. During the wash down stops were to be made for heat flow measurements at 53 and 100 meters BSF.

A rotary coring bottom hole assembly was madeup, the drill pipe run and the hole was spudded at 0430 hours on April 6. The vessel was not offset from the previous holes. The bit was washed down to the heat flow/ pore water sampling depth of 53 meters BSF. A wash barrel was recovered and the sampler pumped down. During sampler retrieval, the sandline parted leaving 1200 meters of line and the instrument in the drill pipe. Operational capability was quickly recovered. Within 9 hours, the sandline was restrung, a wireline spear made up, the parted line caught on the first try and recovered, and the instrument brought back undamaged. The pore water data was valid, the heat flow data questionable. The planned second heat flow sampling was cancelled and operations resumed at 1715 hours on April 6. The bit was washed from 53 to 138.5 meters BSF. Coring continued uneventually in stiff ooze and chalk through Core 40 . Cores 41 and 54 recovered limestone, clay and basalt to a total depth of 4840.5 meters (529 meters BSF).

The major scientific objectives at the site were met and the vessel departed for Site 574 at 2332, April 9.

\section{Hole 574}

The CHALLENGER arrived at the site area at 2350 hours, 10 April. Profiling and site approach were at full speed and a $16 \mathrm{kHz}$ beacon was dropped at 0105 hours, 11 April. The vessel returned to the beacon, positioned, and was in automatic by 0202 hours. The water depth reading by PDR was 4571 meters, corrected to the derrick floor elevation. A VLHPC bottom hole assembly was 
made up, the drill pipe run and the hole was spudded at 1248 hours, April 11 . Mudline was found at 4571 meters in the first core.

Coring operations continued routinely in calcareous ooze using the 9.5 meter barrel until core No. 13, which penetrated stiff ooze and would not come free with overpulls to 30,000 pounds at the corer depth of 118 meters BSF. Rather than increase overpul1 and risk a failure, a wash-over procedure was successfully used to free the barrel and continue coring. To washover, the drill pressure was first vented-off at the standpipe. With any pressure above the seal sleeve now released, a 8,000 pound tension was taken and maintained on the piston corer. The bit was then slowly rotated and drilled down until the seal sleeve was below and clear of the top sub body seals. With 25 psi, and the bit carefully washed over the stuck inner barrel. After washing over four meters in some three minutes, the VLHPC came free with a 5,000-10,000 pound overpull.

Piston coring continued using the 5-meter VLHPC. Core No. 15 came to the surface with a cracked liner jammed in the barrel. Efforts to free the liner with tuggers were to no avail. The 5-meter barrel was then made up to a recently modified hydraulic piston core extruder and the hydraulic piston handily extruded the core and liner, preserving most of the core.

Coring conditions improved with depth and the 5-meter barrel was used routinely through core No. 31. Core No. 32 could not be recovered and parted at the quick disconnect with an overpull of 30,000 pounds. The attempt to wash over the inner barrel failed. Nevertheless the stratigraphic section between the mudline and 209 meters below the seafloor had been fully recovered with minimal core disturbance. The drill string was raised to the mudline preparatory to spudding 574A, a twin piston core hole to 574 .

Hole 574A

Hole 574A was spudded at 025 hours on 13 April using a 9.5 meter VLHPC. The first core established the mudline at 4577.5 meters, some six meters below the PDR depth of 4571 meters. Piston coring continued through soft and firm calcareous ooze. The 5-meter VLHPC was used through the interval 107-126 meters BSF where abnormally high overpulls were expected based on the nearby Hole 574. No high overpulls were required through the zone but four out of five of the 5-meter cores from that section were recovered with cracked and split liners. Apparently the liner failures were related to the firmer more cohesive ooze intervals.

Coring proceeded to a total depth of 4547.4 meters (180.2 meters BSF) without incident, with a total 23 core taken. Coring was halted at that point as Hole 574 had recovered a complete section of 206.5 meters BSF and allocated site time was running. In addition, deeper penetration posed a potential for additional equipment losses. Excessive (15,000 to 40,000 pounds) overpulls were required in Hole 574 starting at $187 \mathrm{BSF}$, and led to the loss of a quick 
release and inner barrel section at total depth. With the site piston coring completed, the drill string was pulled and the bit was on the derrick floor at 1945 hours, April 14.

Hole 574B

A rotary hole, 574B, was spudded at 0830 hours, April 15. Water depth was 4571 meters. Rotary coring was planned for the interval between basement and the deepest piston core penetration at the site. Accordingly the hole was washed down from 4571 to 4756 meters in 2.8 hours and rotary coring initiated. The second core run, however, brought only the latch and swivel assembly to the surface. A back-off at the swivel had left the inner barrel in the drill string.

Five wireline fishing runs were made using the CHALLENGER-fabricated prong spear and the Bowen releasing spear. On the first run, using the prong spear, the fish was brought to within 305 meters of the derrick floor before slipping off the spear. Only about a meter of liner was recovered. Subsequent runs were not successful and the drill string was pulled out of the hole. The inner barrel was easily pulled free on the deck with the liner in short pieces. Apparently the broken liner prevented the fishing tools from entering the inner barrel.

As a rotary core hole at the site was required, preparations were made to spud a replacement hole, $574 \mathrm{C}$.

Hole $574 \mathrm{C}$

A rotary core, Hole $574 \mathrm{C}$, was spudded at 1617 hours on April 16, in 4571 meters of water. The hole was washed down 195 meters in two hours to a depth of 4765.6 meters. Continuous rotary coring continued uneventfully for 37 cores to a T.D. of 5103.5 meters. The final core runs 36 and 37 recovered only .3 meters of broken basalt each. The top of basalt was placed at 5091 meters. The 12.5 meters of basalt had been drilled at a rate of 12.5 meters per hour with a bit weight of: 20,000 to 25,000 pounds and with the heave compensator in line. Vessel motion measurements were made coincident with the basalt coring. Average vessel heave motion was plus or minus 2 feet with heaves of plus or minus 4 feet at 2 to 5 minute intervals. Heave compensator stroking was plus or minus 1-2 feet, in fair agreement with average vessel heave measurements.

The drill string was pulled and the bit was on the deck at 2254 hours on April 19. The bit inserts on the $97 / 8$ F93CK were in excellent condition and only one insert tooth was broken. One cone was loose, however, and 'the bit was graded T-1, B-6; not suitable for rerun. The bottom hole assembly was magnafluxed on the trip out. With site objectives met, the CHALLENGER profiled in the vicinity of the site for $1 \frac{1}{2}$ hours and then headed underway for Site 575 at 0100 hours, April 20. 
$\underline{\text { Hole } 575}$

After a transit of $15 \frac{1}{2}$ hours the CHALLENGER arrived in the vicinity of Site 575 and began profiling at 1625 hours, April 20. A $13.5 \mathrm{kHz}$ beacon was dropped at 1740 hours and the vessel returned over the beacon to position. Currents were erratic, however, and changed direction $180^{\circ}$ on one occasion. Positioning proved difficult but stabilized and the ship was in automatic at 1950 hours. The drill string was made up with a piston coring bottom hole assembly and lowered to the mudline to spud Hole 575 at 0432 hours on April 21. The mudline was found at 4550.2 meters by drill pipe.

Eleven 9.5 meter VLHPC cores were taken routinely to a total depth of 4648.8 meters in calcareous ooze. Core No. 12 would not come free with normal overpulls. Apparently, the sediment type had once again changed abruptly, sticking the inner barrel. While working to free the inner barrel, the drill string was caught on an upward heave and over 40,000 pounds of pull was suddenly applied. On recovery of the corer, the quick release was found separated and the inner barrel left in the hole. The rectangular locking dogs on the quick release shoulder sub tube had deformed to a typical wedge shape.

The drill string was pulled out of the hole clearing the mudline at 1834 hours, April 21. A second piston core hole was to be put down without vessel offset.

Hole 575A

Hole 575A was spudded 18 minutes after cleartrig a mudline at the abandoned Hole 574. The bit was washed down 94 meters in one hour to 4644 meters to continue piston coring in the stratigraphic section not reached in Hole 575 . The 5-meter VLHPC was used to continue coring. The first core penetrated a full 5-meters. To ensure penetration and recovery of this deeper section the next four cores were positioned with the core shoe 2 meters above the base of the previous core. Thus, on each stroke 2 meters of overlap and 3 meters of new section would be cored. Core No. 6 reverted to a full 5-meter stroke and required 10,000 to 15,000 pounds to pull the 5-meter barrel free. Coring continued without incident until core No. 20 at $4705-4708$ meters. Though only penetrating 3 meters, 15,000 pounds of overpull were required to free the core. Coring continued without further incident in this fashion through core No. 33 at a total depth of 4696 meters. High quality piston cores had been taken through an interval of alternating firm and very stiff ooze with thin chalk interbeds which had previously required rotary coring at other sites. With time running out the drill string was pulled out of the hole above mudline to spud a twin piston core hole. Mudline was cleared at 1043 hours on April 23.

Hole 575B

The twin piston core hole was spudded at 1210 hours, April 23 without vesse1 
offset in 4550.2 meters of water. Twelve cores were taken using the 9.5 meter VLHPC to 4640 meters. A two-meter overlap was used as in the previous 575 hole. The 5-meter VLHPC was used for the last two cores to lower the risk of equipment failure on pullout. The hole was completed to a depth of 4650 meters without incident. As additional mudline and near mudline cores were required, the drill string was pulled to the mudline to core at an adjacent location.

Hole 575C

The "C" site was spudded at 0530 hours, April 24. Mudline was found at 4549.2 meters and a second core taken for a total penetration of 15.8 meters. These two final cores for Leg 85 came up virtually undisturbed preserving the core structure.

The drill pipe was pulled out of the hole and the bit on deck at 1630 hours. Major leg objectives have been fully met and CHALLENGER departed for Honolulu at 1650 hours, April 24.

\section{Site 575 to Honolulu}

The 1641 mile transit to Honolulu was made in 7.6 days with an average speed of 9.1 knots. The voyage proved uneventful and Leg 85 ended officially at 0630 hours, May 2 with the first line at Honolulu, Hawaii.

Drilling Pipe and Coring Equipment

Drill Pipe

All the steel drill pipe aboard the CHALLENGER was offloaded during the port call at San Pedro, California in a program of pipe upgrading and replenishments. One hundred and eighty nine joints were shipped to Houston for storage pending an evaluation of usability for further service. The remaining pipe, made up of 268 joints of new pipe recently placed aboard and 9 joints of older pipe, was set up for dockside "Sonoscope" standard rack inspection. One joint was rejected for an internal defect and "blue-banded", the remainder was to be reloaded. Also loaded was premium pipe which arrived from Houston and a load of new pipe which had been recently inspected. All pipe placed in the racker had to pass a 3.891 -inch diameter by 6 -inch long drift rabbit through the end areas. Pipe falling to drift, but otherwise free of defects was stored.

When all the available new and near new drill pipe was racked the pipe count for Leg 85 was as follows:

582 joints (5300 meters) in racker, new and premium.

33 joints new, stored, did not drift 3.891

9 joints premium pipe stored, reloaded. 
203 joints premium pipe from Houston, stored

49 joints, aluminum, in racker

\section{Drill Pipe Drift Diameter}

The 3.891-inch drift diameter is equal to the $37 / 8$-inch diameter of the piston coring top sub cap plus a $1 / 64-i n c h$ tolerance. Thus it is the minimum diameter for normal operations but with tight clearance. For Leg 85 , the piston corer top sub cap diameter was reduced $1 / 16$-inch to $313 / 16$ inches, the same O.D. as the landing sub used in rotary coring. At the reduced diameter wireline runs both for piston core and rotary coring were at normal speeds and coring operations were not affected.

At $37 / 8$-inches the drift diameter is only $1 / 16$-inch smaller than the latch sleeve which, at 3 15/16-inches I.D., had been the smallest restriction in the rotary coring drill string above the landing sub. Tools larger than 3 13/16-inch in diameter should not be run through the drill string except with spectal care, and in no event should be larger than 3.891-inch, the drift diameter.

\section{Sandline/Core Barre1}

There were two sandline breaks and one rotary coring swivel back-off during the course of the leg. The back-off and one wireline break were successfully fished and the other line break required a trip. The incidence of wireline breaks and backing off may be reduced by using a $27 / 8$-inch swivel above the core barrel when rotary coring. Sandline backlash at the Otis overshot disconnect is much greater with the rotary barrel than with the piston coring operation which uses a swivel above the core barrel.

\section{Bottom Hole Assembly}

The rather standard bottom assembly was used for the VLHPC operations. The make up was as follows: bit, bit sub, outer core barrel, two stabilizers, one $8 \frac{1}{4}$-inch drill collar, top sub, head sub, gammaloy sub, two $8 \frac{1}{4}-$ inch drill collars, two bumper subs, two $8 \frac{1}{4}$-inch drill collars, a crossover and one $7 \frac{1}{4}$-inch drill collar. Total length 81.99 meters. The non-magnetic gammalloy sub is used with the Kuster orientation system electronic timer and functions as a "timer-on" trigger as the Kuster orientation case and timer pressure passes through it.

For rotary coring the bottom hole assembly was the following: bit, bit sub, head sub, outer core barrel, top sub, head sub, three $8 \frac{1}{4}$-inch drill collars, two bumper subs, two $8 \frac{1}{4}-$ inch drill collars, crossover, one $7 \frac{1}{4}-$ inch drill collar. Total length was 109.43 meters. 
Bits

Rotary coring was minimal and only one rotary bit, a $97 / 8$-inch F93, was used. After 18.6 hours of use, the bit was graded at T-1, B-6. One cone was loose. The inserts were in near new condition with only one insert broken. The HPC 11-inch "AMY"bit remains in good condition for piston coring.

\section{Piston Corer}

The Variable Length Hydraulic Piston Corer continued to recover relatively undisturbed core providing the detailed stratigraphy required for high resolution scientific studies. The section piston cored varied from calcareous and siliceous soft aoze to very firm chalky ooze with chalk interbeds. Primarily two and sometimes three shear pins were used to pressure up the drill string to a maximum 2600 psi. With rare exception, the corer stroked out completely.

In contrast to much of past experience, overpul1, rather than the inability to stroke out, limited the depth of piston coring during Leg 85 . The corer did, however, prove capable of penetrating oozes with stiff and chalky intervals to subbottom depths of 206.5 meters on Site 574 and 196.8 meters on Site 575. Site 572 was cored to 172.1 and Site 573 to 158.6 meters subbottom. The overpull required to free the inner barrel varied unpredictably with depth. Overpulls of 5000 to 10,000 pounds would typically pull the inner barrel from the sediment. A high strength section would be penetrated on a succeeding core and overpulls of 20,000 to 40,000 pounds would be required to free the barrel. Deeper coring would continue at normal overpulls until another high strength interval was suddenly penetrated.

The high pullout forces led to the loss of two 5-meter and two 9.5 meter inner barrels. The overpulls at failure ranged up to 75,000 pounds with the average 50,000 pounds. Failure modes were similar in all cases. When the upper section of the VLHPC was wirelined to surface the male part of the quick release (the shoulder sub) was recovered and the female cap sub and inner barrel left in the sediment. The pullout force is applied against two rectangular one-inch wide by two-inch long dogs on the shoulder sub. The dogs deform to a wedge shape allowing the cap sub to strip over the dogs and part the release.

A quick release overpull failure leaves only the steel tube of the 9.5 or 5 -meter inner barrel, the core catcher, seal and cap subs in the hole. The upper working parts, pistons, piston rods, shaft, seal subs, etc. are recovered intact with the wireline and are made up to another inner barrel to continue coring. During Leg 85, after a 9.5 VLHPC barrel loss, the drill string was pulled back to mudline and a new hole washed down to continue coring with a 5-meter barrel to lower the overpull. Alternatively a new hole could be spudded. In either case the loss of coring time due to barrel loss was only about three hours. 
In general, where overpulls reached 30,020 pounds using a 9.5 meter barrel, the 5-meter barrel was picked up. Coring with the short barrel was terminated where possible at overpulls of $30,000-35,000$ pounds.

The orientation system improved with use. The percent of readable single shot orientation film discs rose from about $45 \%$ at the beginning of the leg to $80 \%$ at the end of the leg. The weather was calm to moderate for most of the leg. The electronic timer was used throughout the leg and worked reliably. Mechanically, the systems worked to design. Improvements in technique and operator handling should improve results. The main cause of unclear orientation photos appears to be moisture condensing on the camera lens as the pressure case travels through the near freezing deep water. Care must be taken to dry out the case on recovery. Loading the camera in the cool low humidity core lab rather than on the derrick floor should also reduce pressure case moisture. Drill string motion downhole during exposure may also blur the orientation photos. The instrument case is unavoidably exposed to some impact from drill pipe and handling at the rig floor while being inserted into the pressure case/sinker bar assembly. Improved damping and $a$ heavier instrument case would appear desirable to lower picture blurring and protect the instrumentation from impact damage. Moisture condensation is likely to be less of a problem in cooler climates.

Penetration of over 200 meters were made through intervals of stiff and chalky ooze using the VLHPC. Still deeper penetrations in similar sediments are possible if the pull out force could be reduced. Possible concepts for reducing the force include a larger cutting shoe outside diameter clearance and means to circulate high pressure water around the outside inner barrel surface.

The hydraulic piston corer continued to recover finely detailed cores with full recovery, from depths reaching 4777 meters. Over two kilometers of relatively undisturbed core, providing 20,000 samples, were recovered in meeting the objectives of Leg 85 .

Heat flow/pore water sampling was attempted at Site 571 and 573B. At Site 571 the heat flow tool was made up to a special inner barrel configation so that the piston coring bottom hole assembly would be compatible with the heat flow tool. This would allow heat flow/pore water sampling at piston core sites without the need to trip the drill string. The conventional heat flow/pore water tool requires a rotary coring assembly so that the latch sleeve can exert hold-down force on the heat flow tool. In the special configuration, hold-down is provided by rig pump pressure which is hydraulically locked-in between the top sub cap seals of the piston corer and the closed wireline blowout preventer at the surface. Five mis runs were made as the landing sub in the heat flow assembly was landing on top of the piston corer seal sleeve allowing fluid to bypass the seals. For the last run, the landing sub was changed out for an inner barrel sub. The seal assembly landed normally and 500 pounds per square inch (psi) of hydraulic pressure locked the probe firmly in place for a 30-minute measurement with no leakage. A hold down force of 5000 pounds was applied by 500 psi pressure. On recovery, however, the data stored in the instrument was 
lost during the attempt to readout the memory. The allocated 48 hours site time was fast running out and there was no time remaining for further runs. Although only 500 psi was applied to lock the probe, higher pressure could be applied if needed. The special configuration was made up of the heat probe, heat flow assembly and pressure case, upper liner seal sub, quick release cap sub, quick release shoulder sub with bulkhead to prevent flow below the seal sleeve, outer seal sub, lower outer body sub, inner barrel subs, seal assembly and top sub cap.

At Site 573B the heat flow/pore water sampler was deployed at 53 meters subbottom in the course of washing to 140 meters with the rotary coring assembly. A valid pore water sample was taken, the heat flow data was in question.

Dynamic Positioning and Beacons

Six beacons were deployed at five sites. All but two beacons worked well. AT Site 572, a single life $16 \mathrm{kHz}$ beacon functioned normally for about one hour enabling good acquisition for positioning. At that point the signal decayed rapidly and a $13.5 \mathrm{kHz}$ was dropped. The second beacon also lost power at an abnormal rate. The power loss leveled off, however, and positioning was maintained by altering base gains to accommodate reduced signal strength. One $16 \mathrm{kHz}$ and two $13.5 \mathrm{kHz}$ beacons used on the remaining three sites exhibited unusually stable signal strengths.

Positioning was very good at all sites in the mild to medium weather and seas.

\section{Weather}

The usual mild to medium weather prevailed for the central equatorial Pacific and made for favorable drilling and positioning conditions.

\section{Communications}

A11 communications for the Deep Sea Drilling Project was handled via WWD radio station at La Jolla, California. All traffic was by CW with the exception of two radio telephone phone patches via WWD. No equipment problems encountered during: the trip. Total overall traffic was light compared with other trips.

\section{Personnel}

Leg 85 proved to be a high morale work intensive cruise as coring progressed. Over two $\mathrm{km}$ of core were recovered and the scientific party took over 20,000 samples of core. 
As usual, the Deep Sea Drilling Project technical staff and GMI crew provided professional and interested support to the scientific party.

Although there were no major injuries during the cruise, several minor injuries incurred. Two rig crew members were injured; one suffered a mashed finger and the other a bruised kneecap. One DSDP technician had his arm lacerated when a cutting knife slipped and struck his arm. None of the accidents resulted in lost time.

S. T. Serocki

Cruise Operations Manager

Deep Sea Drilling Project 


\section{INTERNATIONAL PHASE OF OCEAN DRILLING \\ DEEP SEA DRILLING PROJECT \\ OPERATIONS RESUME \\ LEG 85}

Tota1 Days (March 03, 1982 - May 02, 982) . . . . . . . 59.6

Total Days in Port . . . . . . . . . . . . . . . 7.1

Total Days Cruising Including Site Survey . . . . . . . . . 23.8

Total Days on Site ... . . . . . . . . . . . 28.7

$\begin{array}{lc}\text { Trip Time } & 7.48 \\ \text { Drilling Time } & .54 \\ \text { Coring Time } & 17.86 \\ \text { Downhole Measurement } & 0.82 \\ \text { Stuck Pipe } & 0.0 \\ \text { Wait on Weather } & 0.0 \\ \text { Re-entry } & 0.0 \\ \text { Other } & 2.25\end{array}$

Total Distance Traveled Including Survey (nautical Miles) . . . 5020

Average Speed (knots) . . . . . . . . . . . . . 8.9

Number of Sites................... . . . . . 5

Number of Holes Drilled . . . . . . . . . . . . . . 17

Number of Cores Attempted . . . . . . . . . . . . . 299

Number of Cores with Recovery . . . . . . . . . . . . . 297

Total Meters Cored . . . . . . . . . . . . . . . . 2431.0

Total Meters Recovered . . . . . . . . . . . . . 2350.9

Percent Recovery ................... 88.0

Total Meters Drilled. . . . . . . . . . . . . . 1128.7

Total Meters of Penetration . . . . . . . . . . . 3479.6

Percent of Penetration Cored. . . . . . . . . . . . . . . 69.9

Maximum Penetration (meters). . . . . . . . . . . . . 532

Minimum Penetration (meters). . . . . . . . . . . . 15.8

Maximum Water Depth (meters). . . . . . . . . . . 4572.2

Minimum Water Depth (meters). . . . . . . . . . 3903 


\section{INTERNATIONAL PHASE OF OCEAN DRILLING DEEP SEA DRILLING PROJECT \\ LEG 85}

TOTAL TIME DISTRIBUTION
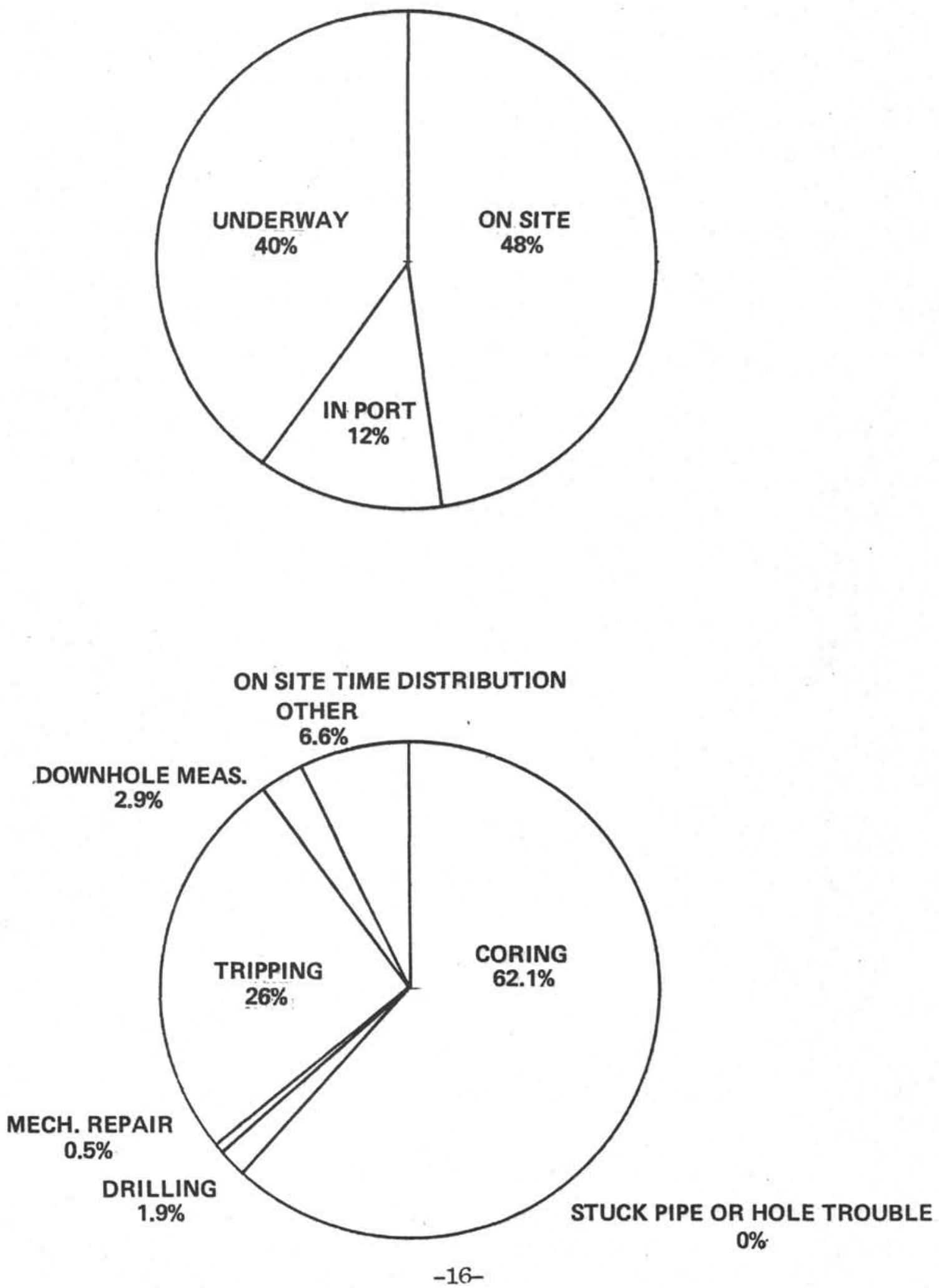


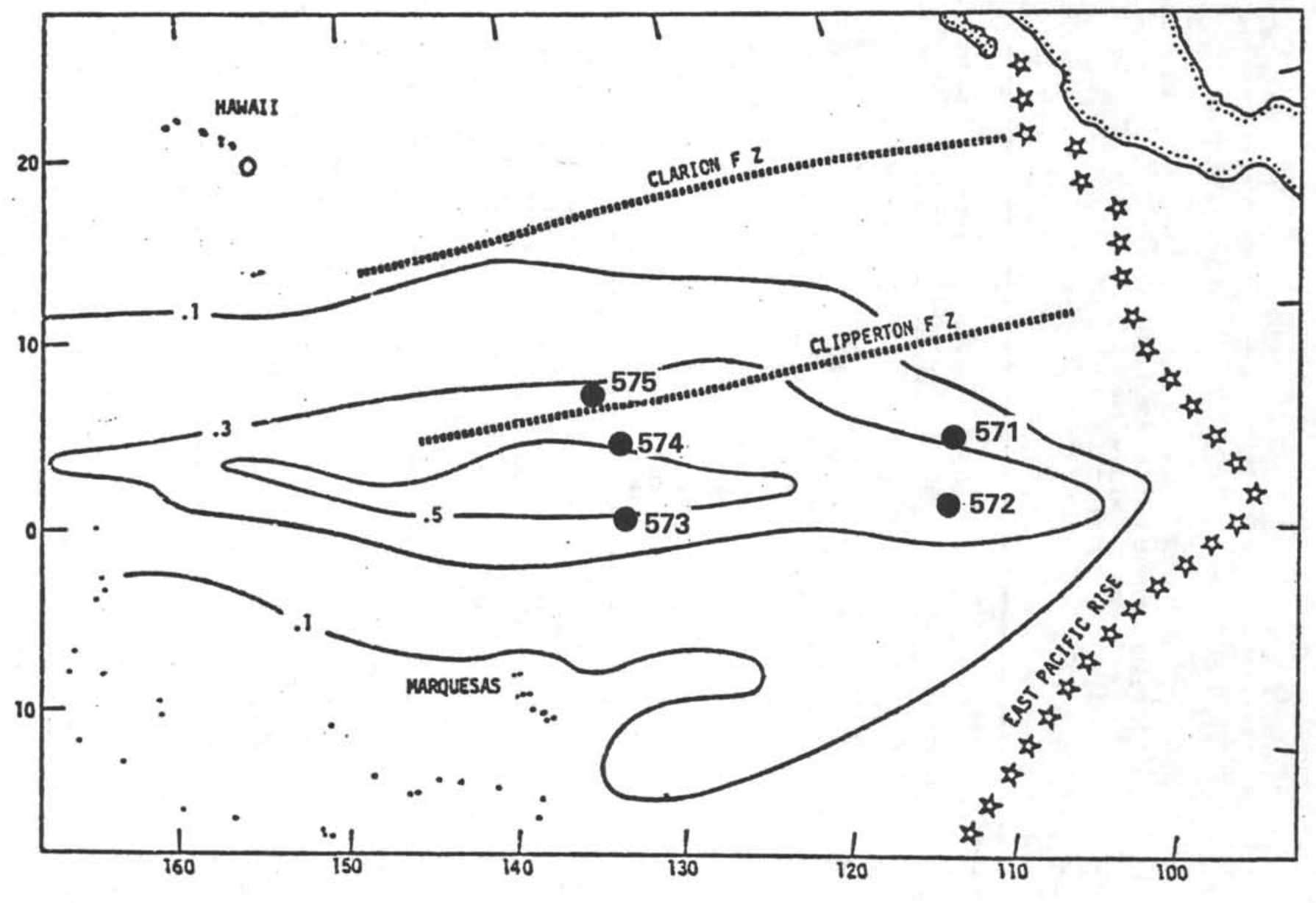

FIGURE 1

LEG 85 SITES 
INTRRNATIONAL PHASB OP OCEAN DRILLING

DEEP SEA DRILLING PROJECT

SITE SUMMARY

LEG 85

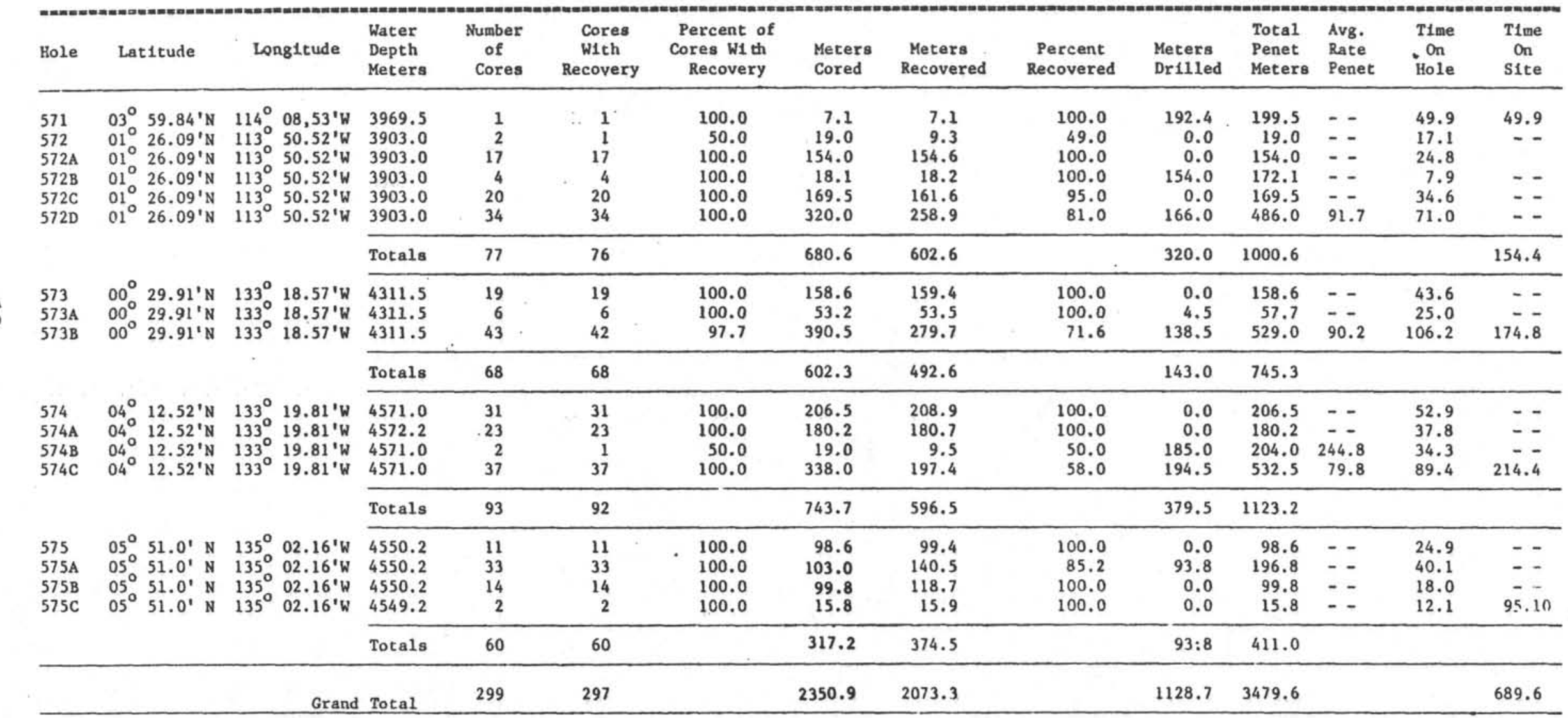


INTERNATIONAL PHASE OP OCEAN DRILLING

DEEP SEA DRILLING PROJBCT

BIT SUMMARY

LEG 85

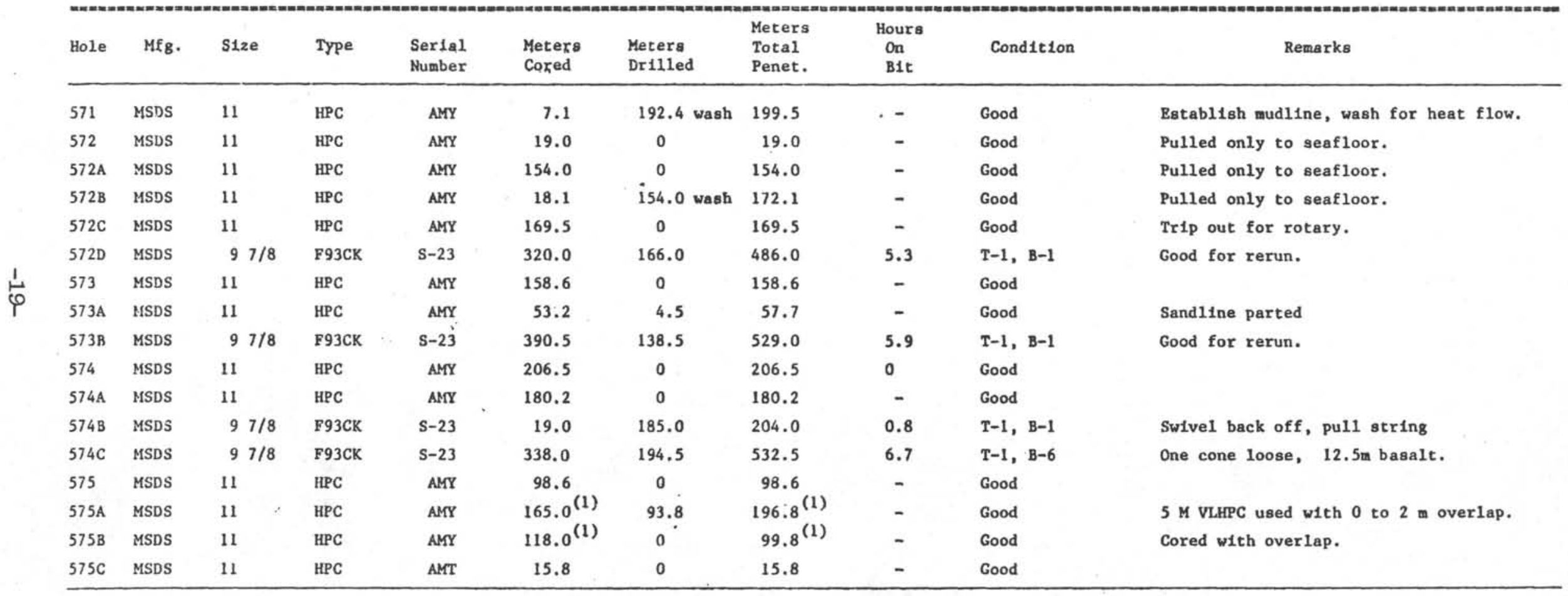

(1) NOTE: 575A and 575B cored with overlap in same hole. Botton of shoe usually two meters

above penetration of last core. 
INTERNATIONAL PHASE OF OCEAN DRILLING

DEEP SEA DRILLING PROJECT

BEACON SUMMARY

LEG 85

\begin{tabular}{|c|c|c|c|c|c|c|}
\hline & $\begin{array}{l}\text { SITE } \\
\text { NO. }\end{array}$ & MAKE & $\begin{array}{l}\text { RREQ. } \\
\mathrm{kHz}\end{array}$ & $\begin{array}{l}\text { SERIAL } \\
\text { NUMBER }\end{array}$ & $\begin{array}{l}\text { SITE TIME } \\
\text { HOURS }\end{array}$ & REMARKS \\
\hline \multirow{5}{*}{ సે } & 571 & ORE & $13.5 \mathrm{SL}$ & 116 & 49.9 & Satisfactory \\
\hline & $\begin{array}{l}572 \text { to } \\
572 \mathrm{D}\end{array}$ & $\begin{array}{l}\text { ORE } \\
\text { ORE }\end{array}$ & $\begin{array}{l}16.0 \mathrm{SL} \\
13.5 \mathrm{SL}\end{array}$ & $\begin{array}{l}106 \\
117\end{array}$ & 155.4 & $\begin{array}{l}\text { Beacon No. } 106 \text { lost power rapidly. Dropped } \\
\text { No. } 117,75 \text { minutes after drop of No. } 106 . \\
\text { No. } 117 \text { deteriorated slowly, base gains } \\
\text { changed to position. }\end{array}$ \\
\hline & $\begin{array}{l}573 \text { to } \\
573 B\end{array}$ & $\begin{array}{l}\text { ORE } \\
\text { ORE }\end{array}$ & $\begin{array}{l}13.5 \mathrm{SL} \\
13.5\end{array}$ & $\begin{array}{l}120 \\
120\end{array}$ & 174.8 & Unusually stable signal strength. \\
\hline & $\begin{array}{l}574 \text { to } \\
574 \mathrm{C}\end{array}$ & $\begin{array}{l}\text { ORE } \\
\text { ORE }\end{array}$ & $\begin{array}{l}16.0 \mathrm{DL} \\
16.0 \mathrm{DL}\end{array}$ & $\begin{array}{l}110 \\
110\end{array}$ & 21.4 & Unusually stable signal strength. \\
\hline & $\begin{array}{l}575 \text { to } \\
575 \mathrm{C}\end{array}$ & $\begin{array}{l}\text { ORE } \\
\text { ORE }\end{array}$ & $13.5 \mathrm{DL}$ & 121 & 95.1 & Unusually stable signal strength. \\
\hline
\end{tabular}




\section{DEEP SEA DRILLING PROJECT \\ TIME DISTRIBUTION}

$\angle E G-85$

\begin{tabular}{|c|c|c|c|c|c|c|c|c|c|c|c|c|c|c|}
\hline Daite & \begin{tabular}{|c|} 
Site \\
No.
\end{tabular} & cruise & Trips & Drill & Core & $\begin{array}{l}\text { Stuck } \\
\text { PIpe }\end{array}$ & W.0.ss. & $\begin{array}{l}\text { POWNHOLE } \\
\text { MEAS: }\end{array}$ & $\begin{array}{l}\text { Mech. } \\
\text { Repair }\end{array}$ & $\begin{array}{l}\text { Port } \\
\text { Time }\end{array}$ & $\begin{array}{c}\text { Re- } \\
\text { Entry }\end{array}$ & Other & $\begin{array}{l}\text { Totial } \\
\text { Time } \\
\end{array}$ & Remarks \\
\hline $\begin{array}{l}3 / 03 / 82 \\
3 / 10 / 82\end{array}$ & & & & & & & & & & 170.4 & & $\therefore$ & 170.4 & \\
\hline $\begin{array}{l}3 / 10 / 82 \\
3 / 19 / 82 \\
\end{array}$ & & 197.4 & & & & & & & & & & 1.2 & 198.6 & Survey \\
\hline $\begin{array}{l}3 / 19 / 82 \\
3 / 21 / 82 \\
\end{array}$ & 571 & & 22.6 & 2.5 & 3.1 & & & 15.1 & 1.0 & & & 5.6 & 49.9 & \\
\hline $3 / 21 / 82$ & & 16.4 & & & & & & & . & & & 2.7 & 19.1 & Survey \\
\hline $\begin{array}{l}3 / 21 / 82 \\
3 / 22 / 82\end{array}$ & 572 & & 2.5. & & 3.2 & & & & & & & 4.4 & 17.1 & \\
\hline $\begin{array}{r}3 / 22 / 82 \\
-3 / 23 / 82 \\
\end{array}$ & $522 \mathrm{~A}$ & & 0.8 & . & 24.0 & & & & & & & & 24.8 & . \\
\hline $3 / 23 / 82$ & $572 B$ & & 0.9 & 1.0 & 6.0 & & & & & & & & 7.9 & \\
\hline $\begin{array}{l}3723 / 82 \\
3 / 25 / 82\end{array}$ & $572 c$ & & 8.0 & & 14.2 & & & & & & & 2.4 & 34.6 & \\
\hline $\begin{array}{l}3 / 25 / 82 \\
3 / 28 / 82 \\
\end{array}$ & $572 \mathrm{D}$ & & 18.4 & 1.9 & 49.7 & & & & & & - & $1: 0$ & 71.0 & \\
\hline $\begin{array}{l}3 / 28 / 82 \\
4 / 2 / 82 \\
\end{array}$ & & 127.1 & & & & & & & & & & 0.6 & 127.7 & \\
\hline $\begin{array}{l}4 / 02 / 82 \\
4 / 04 / 82 \\
\end{array}$ & 573 & & 9.3 & & 30.5 & & & & 1.5 & & & 2.3 & 43.6 & \\
\hline $\begin{array}{l}4 / 04 / 82 \\
4 / 05 / 82 \\
\end{array}$ & $573 \mathrm{~A}$ & & 8.5 & & 14.3 & & & & & & & 2.2 & 25.0 & \\
\hline $\begin{array}{l}4 / 05 / 82 \\
4 / 09 / 82 \\
\end{array}$ & 573B & & 19.9 & 1.8 & 66.2 & & & 4.5 & & & & 14.7 & 106.2 & \\
\hline $\begin{array}{l}4 / 69 / 82 \\
4 / 11 / 82 \\
\end{array}$ & & 24.3 & & & & & & & & & & 1.3 & 25.6 & \\
\hline $\begin{array}{l}4 / 11 / 82 \\
4 / 13 / 82 \\
\end{array}$ & 574 & & 11.8 & & 39.2 & & & & & & & 1.9 & 52.9 & \\
\hline $\begin{array}{l}4 / 13 / 82 \\
4 / 14 / 82\end{array}$ & $574 \mathrm{~A}$ & E & 9.3 & & 28.5 & & & & & & & & 37.8 & \\
\hline $\begin{array}{l}4 / 14 / 82 \\
4 / 16 / 82 \\
\end{array}$ & $574 \mathrm{~B}$ & & 20.5 & 2.5 & 4.3 & & & & & & & 7.0 & 34.3 & \\
\hline $\begin{array}{l}4 / 16 / 82 \\
4 / 19 / 82\end{array}$ & & & 21.4 & 2.2 & 63.7 & & & & & & & 2.1 & 89.4 & \\
\hline $\begin{array}{l}4 / 19 / 82 \\
4 / 20 / 82\end{array}$ & $574 \mathrm{C}$ & 15.4 & & & & & & & & & & 2.8 & 18.2 & \\
\hline & & & & & & & & & & & & & & \\
\hline
\end{tabular}




\section{DEEP SEA DRILLING PROJECT \\ TIME DISTRIBUTION \\ $\angle E G-85$}

\begin{tabular}{|c|c|c|c|c|c|c|c|c|c|c|c|c|c|c|}
\hline Da.te & $\begin{array}{c}\text { Sife } \\
\text { No. }\end{array}$ & cruise & Trips & Drill & Core & $\begin{array}{l}\text { Stuck } \\
\text { Ploee }\end{array}$ & W.0.Wh & $\begin{array}{l}\text { OowNHOL.E } \\
\text { MRAS. }\end{array}$ & $\begin{array}{l}\text { Mech. } \\
\text { Pepair }\end{array}$ & $\begin{array}{l}\text { Port } \\
\text { Time }\end{array}$ & $\begin{array}{c}R e- \\
\text { Entry }\end{array}$ & orther & \begin{tabular}{|l} 
Total \\
Tims
\end{tabular} & Remarks \\
\hline $4 / 20 / 82$ & 5 & & 9.5 & & 13.8 & & & & & & & 1.6 & 24.9 & \\
\hline $\begin{array}{l}4 / 21 / 82 \\
4 / 23 / 82 \\
423 / 8\end{array}$ & $575 \mathrm{~A}$ & & 1.5 & 1.1 & 37.5 & & & & & & & & 40.1 & \\
\hline $\begin{array}{l}\frac{1 / 23 / 82}{42382} \\
4 / 24 / 82\end{array}$ & 5750 & & 0.7 & & 17.3 & & & & & & & & 18.0 & \\
\hline $4 / 24 / 82$ & 575 & & 77 & & 3.1 & & & & 1.0 & & & 0.3 & 12.1 & Repair Bowen \\
\hline $\begin{array}{l}4 / 24 / 82 \\
5 / 12 / 82\end{array}$ & & 181.7 & & & & & & & & & & & | 181.7 & \\
\hline & & & & & & & & & & & & & & \\
\hline $\begin{array}{l}\text { Leg } \\
\text { Total }\end{array}$ & & 562.3 & 179.4 & 13.0 & 428.6 & & & 19.6 & 3.5 & 170.4 & & 54.1 & 1430.9 & \\
\hline & & & & & & & & & & & & & & \\
\hline & & & & & & & & & & & & & & \\
\hline & & & & & & & & & & & & & & \\
\hline & & & & & & & & & & & & & & \\
\hline & & & & & & & & & & & & & & \\
\hline & & & & & & & & & & & & & & \\
\hline & & & & & & & & & & & & & & \\
\hline & & & & & & & & & & & & & & \\
\hline & & & & & & & & & & & & & & \\
\hline & & & & & & & & & & & & & & \\
\hline & & & & & & & & & & & & & & \\
\hline & & & & & & & & & & & & & & \\
\hline & & & & & & & & & & & & & & \\
\hline
\end{tabular}




\section{INTERNATIONAL PHASE OF OCEAN DRILLING \\ DEEP SEA DRILLING PROJECT \\ OPERATIONS RESUME \\ LEG 86}

Leg 86 was planned to address one of the long standing goals of the Deep Sea Drilling Project; that of studying the oceanic paleoenvironment in the western Pacific. The primary goal of this particular leg was to assess the Neogene subarctic to subtropical paleoceanography of the northwest Pacific basin for comparison with the southwest Pacific sites to be drilled on Leg 90. In addition to the basic program, three other sites were planned; one site east of the Shatsky Rise to study red clays, one sites on the Japanese continental margin to study watermass boundary migrations and a final site north of the modern Subarctic Front primarily to serve as a pilot hole for the downhole seismometer emplacement (DARPA) planned for Leg 88 .

All operational objectives were met with the exception of the Japan site which was cancelled due to time limitations. A total of 11 holes were drilled on 6 sites with water depths ranging from 2677.6 meters to 6220.3 meters. The maximum penetration achieved with the Variable Length Hydraulic Piston Corer (VLHPC) was 176.8 meters in a very stiff dark brown pelagic clay.

Accomplishments of Leg 86 included: excellent undisturbed recovery of the. Cretaceous/Tertiary boundary, longest drill string deployed during piston coring operations, first heat flow data collected while piston coring, and first use of a $3.5 \mathrm{kHz}$ drill pipe pinger. The voyage began on May 2, 1982 in Honolulu, Hawaii and ended 48.3 days later on June 20, 1982 in Yokohama, Japan. Cruising time for the leg made up 23.7 days; 21.2 days were utilized on site and 3.4 days were spent in port.

Leg 86 began officially at 0630 hours, May 2, 1982, with the first line dockside Pier 19, Honolulu, Hawaii.

In addition to the normal resupply and loading of all air and ocean freight, several major items were tackled. Both the 15 and 50 ton cranes were inspected. A top overhaul of $\mathrm{Nr}$. 11 engine was performed, the $\mathrm{Nr} .1$ air compressor was serviced and the $\mathrm{Nr}$. 9B generator was installed and aligned. The major work item on the rig floor was the installation, testing and Coast Guard inspection of the Baylor brake for the drawworks. This proved to be the pacing item of the port call.

The heave compensator was inspected and it was found that the piston sleeve on the slave cylinder was cracked in three places. There was no replacement 
sleeve available and there was insufficient time to fabricate a new one. The heave compensator was therefore not available for use on Leg 86 .

Scripps had several work items scheduled including offloading of cores and replacement of the Sat Nav antenna cable. The "piccolo," to be used as a backup system to the Knobby drilling joints was loaded and stored on the casing rack. The Xerox 3100 was installed and the 3400 serviced.

The Schlumberger logging cable was changed out for a spliced one in preparation for the HIG experiment to be conducted on Leg 88 . The remaining hardware required for the experiment was loaded, and a new sandline for the coring reel was put aboard.

One hundred ninety six thousand gallons of fuel were taken aboard and upon completion of the Coast Guard Baylor brake inspection, the vessel was ready to depart. At 1524 hours on May 5, 1982, the last line was off the dock and the vessel got under way for Site 576 .

\section{Enroute Site 576 (NW9)}

While steaming to Site 576 (NW9), three time changes of one hour were made. In addition, the vessel crossed the $180^{\circ}$ meridian (date line) on Tuesday, May 11, 1982, necessitating the advancement of all clocks 24 hours. This resulted in the deletion of Wednesday, May 12, from the ship's calendar. The total steaming time of over nine days were well used. Besides the usual job of getting the vessel shipshape, all of the Continental-Emsco drill pipe was to be hardness tested. Of the 194 stands of drill pipe on the pipe racker, 168 stands were tested while under way. Each joint was tested five times in each of three places. Three feet from each end and in the middle of each joint. The testing was very subjective due to the inability to achieve the desired surface finish. The tests did, however, serve the purpose of ensuring that no joints inordinately high in hardness would be run in the hole. The maximum hardness ranged from 30.4 to $38.5 \mathrm{R}_{\mathrm{C}}$.

The remaining time under way was spent laying out the 26 stands of premium drill pipe removed from the hold in Honolulu, deck testing the new MOD IV hydraulic bit release and spacing out both 9.5 and 5.0 meter HPC barrels. The standard rotary core barrels were spaced out as well as a special VLHPC/heat flow/pore water sampler. All barrels were checked in the outer coring assembly prior to deployment. A temporary stop of 30 minutes was made to dispose of the coring reel sandline which was much too short for the Leg 86 sites. A new sandline was then installed and tensioned while under way.

There were many seismic lines in the area of Site NW9 so no pre-site surveying was required. Since this site was being determined from $3.5 \mathrm{kHz}$ records, the profiling gear was retrieved on approaching the vicinity of the site. Arrival was uneventful and a $16 \mathrm{kHz}$ single life beacon $\mathrm{S} / \mathrm{N} 123$ was dropped at 0759 hours on May 16, 1982. Average speed for the transit from Honolulu was 9.84 knots. 
Site 576

Hole 576 was the first of three holes to be drilled at this site. The weather was calm and positioning of the ship over the beacon was accomplished in short order. At 0900 hours on May 16, 1982, the trip in the hole began. It was to be a relatively long trip since 26 stands of drill pipe remained to be hardness tested and the water depth was relatively deep (227 m PDR).

At 0312 hours the morning of May 17, the first hole of the leg was spudded at 6220 meters and the first signs of trouble arose. After pulling approximately 150 feet, the core barrel became jammed. Forty five minutes were spent attempting to retrieve the barrel to no avail. The barrel was moving very, very slowly on each pull but the rate of progress was much too slow. It was felt that rust from the premium pipe was the culprit because all of the new pipe had been drifted. At 0400 hours, the decision was made to shear the over shot pin, retrieve the wireline, then attempt to dislodge the HPC barrel by pumping a core barrel without core catchers in on top of it. After one hour of trying to shear the overshot pin, the barrel came free and core No. 1 was retrieved. Because of the inability to shear the pin it was felt that rust may have jammed the large diameter swivel used in the sinker bar assembly therefore it was removed prior to core No. 2. No other obvious signs were noted as to the reason for the jamming.

No other problems were encountered during the continuous HPC coring until core No. 7. While retrieving this core the sandline became lodged in the sheaves and parted leaving the core barrel and approximately 4000 feet of sandline in the hole. Fortunately the line snagged in the first joint of drill pipe above the rotary table negating the need for a fishing job. The line was removed from the drill string and wireline BOP before continuous coring began again at 0900 hours on May 18. The swivel had been reinstalled in the sinker bar string. The cause of the sandline parting was most likely due to an over-run sandline while running in the hole. The tendency of the HPC barrel to float in the undersized drill pipe and the lack of a wireline swivel contributed greatly to the cause of the failure. Where as normally the coring reel is run at 400-500 feet/min this site had to be completed at approximately 250 feet per minute.

This hole was completed without any additional incidents. Eight cores were taken to a total depth of 6289.5 meters ( $69.2 \mathrm{~m} \mathrm{BSF}$ ). Recovery was good at $99 \%$. The last core terminated in calcareous nanno ooze.

Three combination heat flow/pore water runs were made. All pore water samples were good and only partial heat flow data were collected from the third run. In addition, the new VLHPC/heat flow coring shoes were deployed for the first time. In spite of several weaknesses, the system appears very promising. Five runs were made with good data collected on two of the five.

The mudline was cleared at 1300 hours on May 18, ending Hole 576 and beginning H01e $76 \mathrm{~A}$. 
Hole 576A

Hole 56A was spudded at 1435 hours on May 18, 1982 with an attempt at lapping the first eight cores taken on Hole 576. These cores were to be left unsplit and shipped vertically back to the Project for geotechnical research. Three steps were taken in an attempt to prevent downhole problems such as those experienced on 576. First, the swivel was used in the sinker bar string; second, the rate of lowering was reduced to approximately $250-300 \mathrm{ft} / \mathrm{min}$; and, third, circulation was increased to $25-30 \mathrm{spm}$.

There were no incidents on this hole. Seven cores were taken to a total depth of 6284.5 meters ( $65.7 \mathrm{~m} \mathrm{BSF}$ ). A total recovery of $101 \%$ was attained.

Since the automatic sensor in the orientation system was not providing good data (blurred film disks apparently due to movement or improper timing), the mechanical timer was fused and no additional orientation difficulties arose.

The VLHPC/heat flow shoes were run three times this site and all three were successful. The drill string was pulled clear of the mudline at 0850 hours, May 19, 1982, ending Hole 576A and beginning Hole 576B.

\section{Hole 576B}

Hole 576B was spudded at 1035 hours on May 19, 1982. This hole was to be a duplication of Hole 576A. All systems were go on this hole. Nine cores were taken with a recovery of $99 \%$. The HPC heat flow system was run twice. The first deployment obtained good data and the second deployment (on core No. 9) failed. It may be noted, however, that core No. 9 recovered no core, only a few chert ships. The heat flow system, therefore, took quite a jolt on impact.

The "mechanical clock" orientation system worked quite we1l; however, on several occasions a wide black line could be found across the middle of the film disk. It is believed this may be caused by partial exposure of the disk either during the loading or unloading operation.

Hole 576B was terminated in chert at 6294.1 meters ( $74.8 \mathrm{~m} \mathrm{BSF).} \mathrm{After}$ setting back the power sub, and clearing the mudline by three stands, all ship's systems were shut down in an effort to obtain a bottom profile with a $3.5 \mathrm{kHz}$ transducer trapped on the drill pipe 99 meters above the bit. This test was unsuccessful due to a failure to receive any kind of recognizable return pulse. The test was abandoned and the trip out of the hole commenced. After approximately three stands had been pulled, it was determined that an in-line amplifier had been putting noise into the $3.5 \mathrm{kHz}$ receiving system. This was disconnected, the bit was run back to slightly above bottom (6218 m), and fair record was obtained. The signal strength of the return pulse was weak but the mudline pulses for subbottom reflector were recognizable. 
The trip out of hole continued without incident other than a stop to cut and slip the drilling line. The bit was on deck at 2400 hours May 20 completing Hole 576B and Site 576 and the vessel got under way at 0022 hours, May 22.

\section{Hole 577}

The transit to Site 577 was uneventful. The total distance of 347.9 miles was covered at an average speed of 9.02 knots. At 1534 hours on May 22, 1982 , a $13.5 \mathrm{kHz}$ single-1ife beacon, serial number 135, was dropped. By 1745 hours, the vessel was positioning nicely over the beacon and operations commenced.

After running three of the six stands of pipe required before installing the drill pipe pinger, the slips failed to hold properly. This necessitated an hour delay while new dies were installed in the slips. The trip in the hole then proceeded without incident.

The $3.5 \mathrm{kHz}$ drill pipe pinger was used to find bottom and Hole 577 was spudded at 0400 hours. It is interesting to note that the PDR depth even using the new Mathews Tables had been consistently seven meters too high on both Sites 576 and 577. The PDR depth for Site 577 was 2685 meters. The drill pipe pinger showed a depth of 2679.5 meters and this was ultimately supported with a drill pipe measurement of 2678 meters.

Continuous HPC coring proceeded until 2045 hours when the last core was on deck. The total depth for Hole 577 was 2797.0 meters ( $118.8 \mathrm{~m} \mathrm{BSF}$ ). Core Nr. 13 did not stroke out fully and it was assumed that the chert horizon had been reached. To verify this, the drill bit was washed down until the formation began to take weight. This occurred at approximately 7.5 meters below the shooting point for core Nr. 13. Recovery for the core was 6.4 meters, therefore, all indications were in fairly close agreement.

Heat flow shoes were run a total of six times this hole with four runs successful. The first failure was due to operator error when the instrument package was inadvertently plugged into the computer before it had completed its recording cycle. The second failure appeared to be a malfunction in the delay time programming of the unit.

Hole 577 was officially ended when the bit cleared the mudline at 2200 hours, May 23.

\section{Hole 577A}

Hole 577 had a great deal of trouble with inconsistent shear pressures of the pins in the HPC. The pressure for three pins would go as low as 1400 psi and as high as 2750 psi. Part of the problem stemmed from using 500 psi hold-down pressure while awaiting the orientation photo. The wide variance 
was improved when the hold-down pressure was reduced to 100-200 psi, however, the problem was not totally solved. It was decided another one half to one full shear pin was required to boost shear pressures up and help prevent some of the flow-in disturbance seen on several cores. A shear pin assembly was modified to provide this capability and was installed on the 9.5 meter HPC barrel prior to running in the hole.

AT 2335 hours, Hole 577A was spudded and HPC coring resumed. Coring proceeded without incident until 2100 hours, May 24, when it was discovered that the vessel was approximately 400 feet off station due to a faulty CRT display. Core $\mathrm{Nr}$. 12 was being retrieved at that time and the problem was quickly resolved without affecting operations.

The experiment with increased shear pins was only a partial success. Shear pressures as low as 1900 psi still plagued the operation even with $3 \frac{1}{2}$ pins installed. A means to lock the corer while running in the hole, so that the shear assembly is not loaded, would most effectively prevent this problem in the future.

Heat flow shoes were again run. This time six "independent" runs were made with five successful. The only failure was due to a broken wire. In addition, three "combination" runs were made with the old heat flow probe assembly. On the first two runs, the probe unit worked flawlessly; unfortunately, the heat flow shoes both malfunctioned. Once the undiscovered broken wire was to blame and on the other a malfunction in delay time programming occurred.

On the third "combination" run, both units performed well, giving a good comparison of the two systems.

Hole 577A was terminated at 2158 hours with a total depth achieved of 2801.0 meters ( $123.4 \mathrm{~m} \mathrm{BSF}$ ).

\section{Hole 577B}

Because of the extreme scientific interest in the Cretaceous/Teriary boundary recovered on core $\mathrm{Nr} .12$ of both 577 and $577 \mathrm{~A}$, it was decided to wash down to that interval and recover one more sample.

Hole 577B was spudded at 2205 hours on May 24 and 104.4 meters were washed to a coring point of 2782.0 meters. Core Nr. 1 was taken to 2791.5 meters (113.9 m BSF) and recovered on deck at 0035 hours, May 25. At 1242 hours the bit was on deck and preparations were made to get under way. The trip out of the hole at 577B was slightly longer than usual. One hour of downtime was required while a broken hydraulic hose on the pipe racker was repaired. In addition, every connection on the drill pipe was retorqued. This was done because several stands, when picked up from the pipe racker, were found to have connections which broke at less than $800 \mathrm{ft}-1 \mathrm{bs}$ of torque when make-up should have been 24,000 ft-1bs. A total of nine joints were found under torqued while coming out of the hole. At 1312 hours, May 25, 1982, the vessel got under way for Site 578 . 
Site 578

The transit to Site 578 (NW-7A) took longer than anticipated. A cold front trailing the cyclonic depression, earlier known as Typhoon "Pat," caused some building of seas and increased wind velocity. This coupled with fairly strong and variable surface currents slowed the vessel's surface speed considerably. The 336.1 mile transit to Site 578 was made at an average speed of 8.26 knots. On May 27, 1982 at 0600 hours, the beacon, a single life $16 \mathrm{kHz} \mathrm{Nr}$. 125, was dropped.

By 0715 hours the vessel was positioning in automatic and the rig crew began running in the hole. This trip took a little longer than usual as the remaining 26 stands of drill pipe on the racker were to be retorqued. Out of 194 stands, a total of 34 connections were found under-torqued.

As the BHA approached spudding depth, a survey of the drill pipe pinger record raised some question as to the proper water depth. The PDR, registering 6020 meters, had been low by 7 meters on the two previous sites. The drill pipe pinger, which was within $1 \frac{1}{2}$ meters on the last site, showed a water depth of 5987 meters. At 2240 hours an attempted spud was made from 5984.5 meters drill pipe depth but, alas, this resulted in a water core. At this point it was decided to lower the drill pipe to just above PDR depth, feeling for bottom along the way. Upon reaching 6006 meters, the weight indicator appeared to steady somewhat. This process was repeated and again the needle steadied out. The pipe was raised to 6000.0 meters and at 0142 hours on May 27, Hole 578 was spudded. Official water depth was 005.7 meters.

Continuous HPC coring then commenced with spectacular success. Recovery was an excellent $99 \%$ through core $\mathrm{Nr}$. 16. Barrels $17-20$ failed to scope out all the way even with shear pressures at 2800-3000 psi. These barrels recovered 7.68 meters, 6.20 meters, 4.57 meters and 0.81 meters, respectively; the latter terminating on chert. Disturbance was minimal and shear strengths in these cores ranged from an average of about 500 grams per square $\mathrm{cm}$ to a high of 1700 grams per square $\mathrm{cm}$. Pull out forces of 20,000 1bs were in evidence on the last four cores. Core orientation was successful on 19 of 25 attempts for a $79 \%$ success ratio.

Heat flow shoes were run eight times with seven of them obtaining good data. The last run failed, most likely from an improperly loaded program due to operator fatigue.

At 0027 hours on May 29, 1982, coring was terminated. Total depth for Site 578 was 6181.5 meters ( $176.8 \mathrm{~m} \mathrm{BSF})$.

By 1300 hours the afternoon of May 30, the bit was on deck, and at 1354 hours the ship was under way for Site 579 (NW-7A). It is interesting to note that because the coring went so well, i.e., very low disturbance and excellent recovery, the previously scheduled "A" hole was deemed unnecessary. 


\section{Site 579}

Heavy weather was encountered enroute to Site 579. Head winds of up to 30 knots combined with sea swell and variable current conditions slowed the vessel speed considerably. At one point the vessel was making 7.5 knots. These conditions dramatically improved upon arrival. Overall speed for the 201.7 mile distance of 8.93 knots. At 0006 hours on June 1, a $13.5 \mathrm{kHz}$ single-life beacon $\mathrm{Nr} .133$ was dropped. All profiling gear was retrieved and the vessel was positioning in automatic by 0115 hours that day.

The trip in the hole was routine and at 1535 hours, Hole 579 was spudded. This time the PDR was 10 meters lower than the drill pipe depth of 5746.6 meters. Two cores were taken but the weather was rapidly deteriorating as two cyclonic depressions bore down on the location. The prognosis was for a continued deterioration of the weather for several hours until both fronts moved through. At 1920 hours, June 1, 1982, while running in the hole for core $\mathrm{Nr}$. 3, it was decided to pull above the mudline and ride out the weather. The mudline was cleared at 2115 hours, ending Hole 579. Five joints of knobby drill pipe were picked up and the drill bit was maintained two stands above the mudline. The pipe in the horn was raised and lowered in accordance with standard waiting on weather operating procedure.

The weather continued to rapidly deteriorate; by midnight the seas were 8-10 feet and building. The wind was gusting to 40 knots. This Force 7 gale continued throughout the night. By the afternoon of June 2, conditions had improved considerably. The vessel was again positioning nicely in automatic with no loss of acoustics. Roll and pitch has fallen off to an acceptable operating level at 1515 hours June 2, operations were initiated once more. The knobby pipe was laid down and the bit was washed to 5760.6 meters $(14.0 \mathrm{~m} \mathrm{BSF})$. Hole $579 \mathrm{~A}$ was spudded at 1625 hours.

Continuous coring continued throughout the evening. Because of marginal operating conditions and the uncertainty of the weather window, it was decided to temporarily refrain from core orientation and heat flow measurements. On the morning of June 3, heat flow measurements were again initiated on core Nr. 9. Continuous coring with heat flow continued until 0510 hours on June 4, 1982, when core Nr. 15 arrived on deck. Total depth of the hole was 5896.1 meters ( $149.5 \mathrm{~m} \mathrm{BSF})$. The hole was terminated in gray-green siliceous clay.

Seven heat flow measurements were taken, with all of them successful. At 1702 hours on June 4, the drill bit reached the rig floor and by 1732 hours, the vessel was on its way for Site 580 (NW-5A).

\section{Site 580}

The vessel departed Site 579 in dense fog which continued throughout the night and most of the following day. At 1436 hours on June 5, 1981, the vessel arrived on station and a $13.5 \mathrm{kHz}$ single-life beacon $\mathrm{Nr} .136$ was 
dropped. By 1630 hours the vessel was positioning in automatic mode and the trip in the hole for Site 580 began. The trip was uneventful until 2130 hours on June 5, 1982, when the drawworks "B" motor shorted to ground through the armature circuit, causing a flash back in $\mathrm{Nr} .2$ generator. Cause of the failure was determined to be a breakdown of insulation on one set of brush holders on the drawworks motor. The faulty components were replaced and the trip in the hole resumed after four hours lost time.

It was not much later, 0400 hours June 6, when a second incident occurred. This time a wire broke on the pipe racker skate. Another two hours were spent repairing this before the trip could continued. At 1104 hours, June 6, an attempted spud was made. Since PDR reading had varied from 7-13 meters below the actual mudline, the shooting depth was set at 5372 meters or 13 meters above the 5385 meter PDR depth. A water core was taken and the second spud at 1330 hours placed the mudline at 5386.7 meters or 1.7 meters below PDR. This was the first time this leg that the PDR reading was actually above the drill pipe mudline.

At 2130 hours, June 7, 1982, a test of the pressure measurement instrument (PMI) was made. This tool was developed to be run in conjunction with the heat flow pore water sampling equipment. On this occasion the new heat shoe was also run as a check on the heat flow data. At 0030 hours on June 8 , the tool was back on deck. The test had failed. A small tubing connector in the line to the lower pressure port leaked, causing the tool to flood while running in the hole. As a result, all of the remaining functions failed. No data was gathered other than with the by now "old stand by" heat flow shoe.

The next core taken (Nr. 15) was the first to give an indication of potential pull out problems. It required 60,000 bs to pull free of the mud. This was in spite of washing down approximately two meters (the maximum possible with remaining pipe on hook). Cores $\mathrm{Nr}$. 16 and 17 were washed over nearly seven meters and still required 50,000 lbs to pull free.

Early morning on June 8, 1982, word was received from Headquarters indicating that a requested 24-hours extendion to the leg could not be granted. As a result coring was terminated on Site 580 at 0902 hours, immediately upon receipt of core $\mathrm{Nr}$. 17. Total depth of the hole was 5542.0 meters (155.3 $\mathrm{m}$ BSF). This hole was terminated before reaching its scientific goal due to the pressing time commitments for the remainder of the leg.

Heat flow shoes were deployed a total of eleven times this site. All runs were successful.

At 1930 hours, the bit was on deck and by 1954 hours, June 8, 1982, the vessel was under way for its sixth and final site.

\section{Site 581}

The transit to Site 581 was made in good time despite the dense fog which 
accompanied the vessel all the way. Average speed for the 196 mile distance was 9.84 knots. The vessel was undouttedly helped along by the Kuroshio Current which was in the stern the entire distance. Nearly four hours were spent profiling around the proposed site location in an attempt to better define the area. At 0754 hours on June 10, 1982, the Co-Chief Scientists were satisfied that the site met all of the DARPA criterion and a $16-\mathrm{kHz}$ beacon $\mathrm{Nr} .127$ was deployed.

By 0925 hours, the vessel was in auto positioning mode and the trip in the hole commenced. Since it was imperative that an accurate depth measurement of the mudline, casing point and basement be made, the drill pipe was "strapped" while running in the hole. At 2220 hours Hole 581 was spudded and the mudline core was on deck by 0017 hours the morning of June 11, 1982 .

Upon determination of the mudline, a wash test was made to determine the amount of conductor pipe which could be attached to the re-entry cone scheduled for Leg 88. The drill bit was washed in without rotation until no further penetration could be made. The total depth at this point was 5583.5 meters or 96.0 meters BSF. A hasty calculation showed that this would be more than enough to support the cone, conductor pipe and approximately 350 meters of $113 / 4$ inch diameter surface casing.

At this point, it was determined that the primary objective, that of determining basement, could only be achieved, in the remaining time frame, by washing through some of the upper sediments. Since these were to be piston cored on Leg 88, it was decided to wash to a BSF depth of 181.5 meters. The wash barrel was pulled and continuous coring commenced from this point. A F93CK (long tooth) core bit, manufactured by the Marine Science and Development Shop, was used for the coring program since the basement penetration was to be minimal and the bulk of the coring would be through clay.

Coring proceeded without incident until core $\mathrm{Nr}$. 11 at 267.0 meters BSF. It was at this point that the clay became interbedded with chert. The pipe began torquing intermittently. The hole would pack off while retrieving the core barrels. This condition was severe enough that 50 barrels of gel mud had to be spotted after core $\mathrm{Nr} .12$. This interbedded formation was 70 plus meters in thickness and was situated directly over the basement contact. The penetration rate was acceptable, taking only 6 to 20 minutes cutting time per core, however, the recovery was a miserable $4 \%$.

Basement was reached almost immediately upon cutting core $\mathrm{Nr} .19$ at 4832.0 meters ( $344.5 \mathrm{~m} \mathrm{BSF}$ ). The hole was terminated, 8.0 meters into basement at 5840.0 meters, since the objective had been reached and time was running short.

One final operation remained before abandoning the hole. That of releasing the core bit to test out the new Mod IV hycraulic bit release (HBR). This was accomplished in short order with the bit departing four minutes after seating of the go devil and approximately 1500 psi circulating pressure.

At 0030 hours June 13, 1982, the rig crew began its last drill pipe trip of Leg 86. At 1055 hours, while the trip was taking place, a $13.5 \mathrm{kHz}$ 
double-1ife beacon No. 140 was dropped. It was decided to let go the beacon prior to departure for several reasons; first, its signal strength could be checked and verified. Second, we could drop it as close to the pilot hole as possible, and, third, the distance and azimith to the existing $16 \mathrm{kHz}$ beacon could be determined for future reference as to the exact site location. By 1130 hours the pipe had been racked and the BHA was being pulled. This went somewhat slower since the BHA was to be magnafluxed while coming out of the hole. Upon completion of the BHA inspection program, the Bowen power sub was inspected and the rig was then secured for getting under way.

At 1732 hours, June 13, 1982, the vessel got under way for Yokohama, Japan, officially ending Site 581 .

\section{Enroute Yokohama}

The transit to Yokohama was relatively uneventful save for the interspersion of fog, overcast skies, a force 7-gale with 50 knot headwinds, and even some sun. The vessel, going into the Kuroshio Current the entire distance with headwinds some of the time, at one point was going as slow as 3.5 knots. The fastest interval was 10.2 knots.

The pilot for Uraga Suido channel came aboard at 2148 hours, June 29 and took the vessel to anchorage, since no vessels were allowed to enter or leave port at night. The following morning the pilot for Yokohama came aboard for the transit to the berth. The first line on the deck occurred at 0840 hours on June 20, 1982, officially terminating Leg 86 .

\section{Drill Pipe}

One hundred ninety four stands of Continental-Emsco drill pipe were hardness tested prior to running in the hole on the first site of Leg 86 . The maximum hardness ranged from 28.5 to $38.5 \mathrm{R}_{\mathrm{c}}$. This check was designed to be conservative and prevent any joints harder than API specification from being run in the hole. No joints were found in this category.

While coming out of the hole on Site 577A, some drill pipe connections were 
found to be torqued at less than $8,000 \mathrm{ft} / 1 \mathrm{bs}$ when they should be 24,000 $\mathrm{ft} / \mathrm{lbs}$. All connections were retorqued prior to running in the hole on Site 578. A total of 34 connections were found undertorqued. It was nnt determinable if the reason was due to the use of the new drill pipe but may have been the result of stopping the use of back-up tongs too soon when running in the hole. It is now recommended that 125 stands be run in the hole using back-up tongs rather than the previously used "rule of thumb" of 75 stands.

Variable Length Hydraulic Piston Corer

The Variable Length Hydraulic Piston Corer (VLHPC) continues to function we11. It consistently recovered undisturbed core in $9.5 \mathrm{~m}$ lengths even in sediment approaching shear strengths of 1200 grams per square centimeter.

Several areas requiring improvement still exist, however. One problem area is that of prematurely yielding the shear pins while running in the hole. This tends to give eratic shearing pressured (i.e., 1200-2800 psi) and consequently underpowers the corer particularly in still sediment. This problem can occur even in relatively calm seas if enough drill string motion or surging is present. A means to lock the system until landed and pressured up is sorely needed. Hopefully, the new vented HPC system will be activated without shear pins and go-deviled in place without a wireline attached. This will be a major improvement. On Leg 6, the problem was partially corrected for by modifying one shear pin assembly to accept two additional shear pins in single shear. This allowed more flexibility to increase pin strength when yielding was occuring consistantly. Three thousand psi shearing pressures were then achieved for the first time.

There is a great deal of twist built up in the wireline during piston coring operations. The only swivel available to alleviate this problem is a large diameter, cumbersome one which will not fit through the oil saver. Wireline swivels, $27 / 8$ inch 0. D., have been ordered and should save many thousands of feet of sandline in the future.

Retrieving speed on this leg was severely hampered by the undersized drill pipe. Even with the top sub cap turned down a mere 5/64 inch clearance was available on the diameter. This tight clearance, coupled with surging in the drill pipe due to vessel motion, led directly to an overrun sandline on the first site and ultimately the loss of 4,000 feet of sandline. Coring reel speeds running in the hole had to be reduced from 450 feet per minute to 300 feet per minute before the problem was overcome. Wireline swivels and if possible a digital speed indicator for the coring reel, would serve to improve operating efficiency and reduce losses of sandline and corresponding science.

Pull out forces this leg did not exceed 60,000 1bs. Several 50,000 pound forces were experienced even with 7-meters of washover prior to the pull out attempt. No deformation of the quick disconnect assembly, or any other HPC components, was apparent and no failures occurred. The minor design 
changes and improved heat treatment of this batch of quick release assemblies apparently was successful.

Core orientation still appears to be a hit or miss situation. The system and operating procedure appears to be adequate at best. Core orientation was attempted on three sites with success ratios of $70 \%, 63 \%$, and $79 \%$. Overall core orientation on Leg 86 was successful $70 \%$ of the time. The major problems associated with the system were motion of drill string or unit causing a blurred picture or a dark black exposure line running across the face of the disk preventing an accurate reading. Motion problems can usually be traced to improper timing. On this leg it was found that the 90 second delay time of the non-magnetic sensor was not adequate. A three to four minute delay time is required. If the mechanical clock is used this is not a problem and in fact, when used in conjunction with the heat flow shoes, is quite an efficient system. It was felt that grease and or smudges on the Kuster tool body sometimes may have prevented proper seating of the developer tank leading to partial exposure of the film disk. In addition, it was felt that at one time one of the film loaders may have been leaking light. Neither of these proved to consistantly be causing the problem. The best improvement in this area would be the development of a downhole HPC barrel indexing system together with a drill pipe orientation method. Then the Kuster tool would only need to be run every 10 cores or so to ensure that the core orientation remains correct.

\section{Hydraulic Bit Release}

The Hydraulic Bit Release (HBR) unit was lightly greased, assembled and deck tested on May 10, 1982, in anticipation of being run on site NW-7A, the fourth site of the leg. The deck test consisted of cycling the HBR to release three times. Release pressure was approximately 500 psi. The MOD IV unit, utilizing a 3.875 inch go-devil, represented the first deployment of the HBR since a major redesign effort was initiated to improve its reliability. It was hoped that the new unit would release relatively quickly, consistantly, and without having to set the bit on bottom and/or rotate the drill pipe.

As it turned out, site NW-7A was only HPC cored and no rotary hole was spudded. This meant the only opportunity to test the HBR was on the last site of the leg. The DARPA pilot hole MSS-82C (Site 581).

At 2306 hours on June 12, 1982 (some 33 days after the deck test), the go-devil was pumped downhole at 30 SPM $(200-300 \mathrm{psi})$. It was felt that this would be a good test of the release system due to the relatively bad hole conditions on this site. The core bit had spent over 20 hours drilling through an interbedded clay and chert layer totaling 70 plus meters in thickness. In addition, several hours were spent drilling 8 meters into a massive basalt layer. The drill pipe had become stuck several times and 50 barrels of mud had been spotted through the system. This was as rugged a test possible. 
At 2346 hours the go-devil reached bottom and seated. Circulating pressure was increase to 800 psi, however the surge of the drill pipe rapidly pushed the pressure to $1200 \mathrm{psi}$. After one minute nothing appeared to happen and all but the stout of heart began to have doubts. The pressure was bleed off at the stand pipe. The bit was left off bottom and again pressured up, this time to 1500 psi. At 2350 hours, slight1y over a minute after repressurizing, the bit released and the Cruise Operations Manager began breathing again.

No explanation was evident as to why the bit did not release upon the first fressurizing attempt. It is possible that enough time was not given for the go-devil to seat completely at the sleeve to fully shift the first time. Three reasons for the relatively slow response time can be suggested. First the grease used to lubricate the unit may have become very viscous at the reduced temperature gumming up the activation. Second, the 33 day wait prior to deployment of the unit may have allowed some corrosion to begin to develop inhibiting freedom of actuation. Third, the fluid may not be allowed to effectively be displaced from behind the sleeve during actuation.

All things considered the release system passed with flying colors and should be a very reliable tool for the future. Operational recommendations include:

1) Deck test unit only within 24 hours of deployment.

2) Liberally grease pack into all cavities in the assembly.

3) Investigate the possibility of increasing flow area for displaced water.

4) Allow pressure to remain on go-devil for minumum of ten minutes before bleeding off standpipe.

\section{Heat Flow}

The new heat flow shoes developed for use with the variable length piston corer (VLHPC) were a resounding success. A total of 45 measurements were attempted this leg and 38 were successful for an incredible $84 \%$ success ratio. This is a remarkable achievement for a prototype tool.

Several minor improvements could be made to improve the tool but the basic concept is very good. Some improvement and streamlining of the computer program is also necessary if the tool is to be used routinely. It very definitely requires that a full time heat flow technician or specialist be aboard. The best operating procedure seems to be to leave the tool in the mud for five to ten minutes, preferably while waiting for the core orientation camera to take its' picture. Taking a tension on the sandline after firing the VLHPC and slacking off one to two meters with the drawworks to unseat the seals seems to help keep the probe motionless during the measurement period. Overall the data gathered was excellent. 
Pressure Measurement Instrument (PMI)

The Prototype Pressure Measurement Instrument (PMI) was run for the first time on Site 580. Unfortunately a tubing connector to the lower pressure port leaked causing the tool to flood while running in the hole. No definitive conclusions can therefore be reached concerning the merits of this tool.

Based on the deck testing and calibration experiments of the unit prior to running in the hole, it appears to have potential. It is also quite likely that this tool or variation thereof will be very useful in the upcoming core barrel instrumentation program.

The PMI currently measures ambient and in situ pore water pressure while recording heat flow data and taking a pore water sample.

\section{$3.5 \mathrm{kHz}$ Drill Pipe Pinger}

The experiment of strapping a $3.5 \mathrm{kHz}$ pinger onto the drill pipe was only a moderate success. Subbottom reflectors from the pinger on Sites 576 and 578 had a higher resolution than those from the hull mounted transducer, however, only extremely weak return echoes were present. Some corrosion was present due to the aluminum pressure case being strapped to the steel drill pipe. The $3.5 \mathrm{kHz}$ pinger may be a valuable asset in the future if the signal strength is significantly increased and a means of insulating the pressure case from the drill pipe is developed.

\section{$\underline{\text { Re-Entry Cone Drift Diameters }}$}

Five lower re-entry cone sections were drifted for possible warpage in the area of the diverter pipes. The specification called for a 24 " medium internal diameter. A $233 / 4^{\prime \prime}$ drift, same 0.D. as a $16^{\prime \prime}$ casing hanger, was fabricated. Two sections, obviously from an older batch because of their weathered condition drifted alright. The three newer sections would not drift the minimum $233 / 4$ inches. The interference was, as suspected, in the area of the diverter pipe welds.

\section{Dynamic Positioning \& Beacons}

The dynamic positioning system, Elmer, et al, performed very well save for two instances. The first occurred while coring on Site 577A. The vesse1 was found to be nearly 400 feet off station due to a faulty CRT display. The problem was quickly solved without any affect on the coring program. Cause of the problem was eventually found to be a faulty signal processor in the heading control.

The second incident occurred while attempting to maintain position on Site 579. Operations had to be halted on this occasion due to a constant loss of acoustics. This problem was due only to weather conditions and the vessel eventually ended up riding out a Force 7 gale. 
Beacon performance on this leg was flawless. Three $13.5 \mathrm{kHz}$ and three $16.0 \mathrm{kHz}$ single life beacons were deployed without any problem. One $13.5 \mathrm{kHz}$ double life beacon was deployed upon departing Site 581 (DARPA) and was performing well on last contact.

\section{Core Bits}

Good old "HPC AMY" was the primary HPC core bit for this leg. Since she was minimally rotated and not mistreated at all she survived quite well and should be around for many more legs.

The only rotary core bit utilized as on MSDS F93CK S-25 core bit deployed on the DARPA Site $\mathrm{Nr} .581$ (MSS-82C). This bit drilled admirably, punishing its way through 70 plus meters of interbedded clay and chert. The hole terminated 8.0 meters into a massive basalt which drilled at a rate of 5.49 meters per hour.

The bit could not be graded due to a successful test of the new MOD IV bit ease system.

\section{Bottom Hole Assembly}

The bottom hole assemblies (BHA) used this leg were none other than these standard ones used in the past.

On Sites 576 and 580 where only piston coring was done, the BHA was as follows: bit $(.34 \mathrm{~m})$; bit sub $(.64 \mathrm{~m})$; outer core barrel $(8.89 \mathrm{~m})$; two $97 / 8$ stabilizers $(0.98 \mathrm{~m}$ and $0.71 \mathrm{~m}) ; 81 / 4$ drill collar $(9.10 \mathrm{~m})$; top sub $(0.61 \mathrm{~m})$; seal sub $(0.34 \mathrm{~m})$; monel drill collar $(3.72 \mathrm{~m})$; two $81 / 4$ drill collars (18.31 m); two bumper subs $(10.24 \mathrm{~m})$; two $81 / 4$ drill collars $(18.10 \mathrm{~m})$; crossover $(0.82 \mathrm{~m})$; and one $71 / 4$ drill collar $(9.19 \mathrm{~m})$. Total length $81.99 \mathrm{~m}$.

On Site 581, the only rotary cored hole, the bottom hole assembly was varied as follows: bit $(0.34 \mathrm{~m})$; hydraulic bit release $(1.09 \mathrm{~m})$; head sub $(0.34 \mathrm{~m})$; outer core barrel $(8.89 \mathrm{~m})$; top sub $(0.61 \mathrm{~m})$; head sub $(0.33 \mathrm{~m})$; three $8 \frac{1}{4}$ D.C. $(27.40 \mathrm{~m})$; bumper sub $(5.12 \mathrm{~m})$; three $81 / 4$ drill collars $(27.41 \mathrm{~m})$; two bumper subs $(10.24 \mathrm{~m})$; two $81 / 4$ drill collar $(18.10 \mathrm{~m})$; crossover $(0.82 \mathrm{~m})$; and one $71 / 4$ drill collar $(9.19 \mathrm{~m})$. Total length $109.88 \mathrm{~m}$.

Three stands of new drill pipe were run immediately above the BHA then 26 stands of premium grade drill pipe were run.

\section{$\underline{\text { Communications }}$}

Communications for the leg began poorly and proceeded to get worse as the vessel moved further north. It became exceedingly more difficult to work with WWD because of the difference in time zones. WWD was normally off the 
air by 1200 or 1300 hours LCT. Rarely were the bands open at that time or would fade out by the time WWD was on the air.

Heavy interference made reception of the WWD signals difficult to impossible on all frequencies except $22419 \mathrm{kHz}$ which was usable when propagation conditions were good and then only during daylight hours, i.e., 19302 to $2000 \mathrm{Z}$ or 2100Z). As soon as CHOSI, a large Japanese station on WWD's frequency, began to transmit, our communications were shut down. Solar disturbances, such as those which occurred the latter part of May and early June, served to aggravate the already poor propagation conditions common to this area of the world.

Use of the USCG Radio Station GUAM/NRV is no longer a viable alternative for the CHALLENGER because the majority of the operators are inexperienced and cannot handle "CW" traffic at all or are very slow and have great difficulty. The "Navy" stations used in the past are no longer in existance.

It can be anticipated that communications will again be poor to non-existent when the CHALLENGER returns to this area on Leg 88 . It is highly advisable that some alternative communications system be initiated, such as the use of commercial stations like San Francisco/KPH or CHOSI/JCS. It may be less expensive in the long run to utilize telephones through Japan and tape record the daily reports when conditions are extremely bad.

\section{Weather}

Leg 86 began with relatively fine weather, both in terms of drilling conditions and crew moral. This was soon to pass, however, as the leg progressed to the more northern sites above latitude $38^{\circ} \mathrm{N}$. At this point fog, rain and cool weather became the order of the day. A series of lows would track from the southwest to the northeast on 24 to 48 hour intervals. Most of these fronts fortunately passed to the east of the vessel without causing much exctement. One which did pass to the west was packing 40 knot winds and did shut down operations for nearly 20 hours. During the passage of these fronts the winds would usually shift from east to north to northwest at about 20-25 knots. On that one occasion where WOW was required, the winds were strong southerly. The last few weeks of the leg were plagued with problems in the satellite weather equipment. The worst was immediately feared; that the Alden VHF receiver was down. Suspected also was the OMNI antenna preamp.

As it turned out the problem was relatively minor. That of a flooded coaxial cable from the antenna to the receiver.

It is interesting to note that the weather forecasting capability of the CHALLENGER is highly dependent on satellite photos. Both the "NOAW Polar Orbiter" and the "WEFAX" broadcast from the "GOES" satellite. Without this capability the CHALLENGER loses a minimum of $40 \%$ of its weather forecasting ability. The ALDEN VHF receiver is required for both of these satellites. 
and there is no spare aboard. In addition, there is no spare preamp for

the OMNI directional antenna without which the polar satellite cannot be received. Since so much work is programmed in areas where there is little forecasting capability, the shipboard weather monitoring equipment and procedures should be re-evaluated at the earliest opportunity.

\section{Personne1}

This proved to be an exceptional cruise with regard to shipboard moral. The scientific party was a very cohesive group and worked well with each other. The technical staff, although busy with many unique tools being fielded for the first time, remained motivated and performed well. The co-chief scientists also complimented each other quite well, were able to get the most of their staff and were very understanding, in spite of numerous set backs early in the leg. The GMI drilling and marine crews again performed very professionally doing their utmost to ensure that the scientific mission was accomplished to the best of their ability.

A special note of gratitude to radio officer for his tenacious efforts in attempting to keep communications open. In addition Captain Joe Clarke, Harland Voight, the Chief Engineer, and Jim Ruddel, the Drilling Superintendent, deserve many thanks for the skill and professionalism with which they performed. From the supervisors down to the roughnecks and seamen it would be difficult to duplicate a crew with more devotion to duty.

Their special blend of experience and resourcefulness has been responsible, in no small part, for the success experienced by the Deep Sea Drilling Project over the last 14 years.

Michael A. Storms

Cruise Operations Manager

Deep Sea Drilling Project 
INTERNATIONAL PHASE OF OCEAN DRILLING

DEEP SEA DRILLING PROJECT

OPERATIONS RESUME

LEG 86

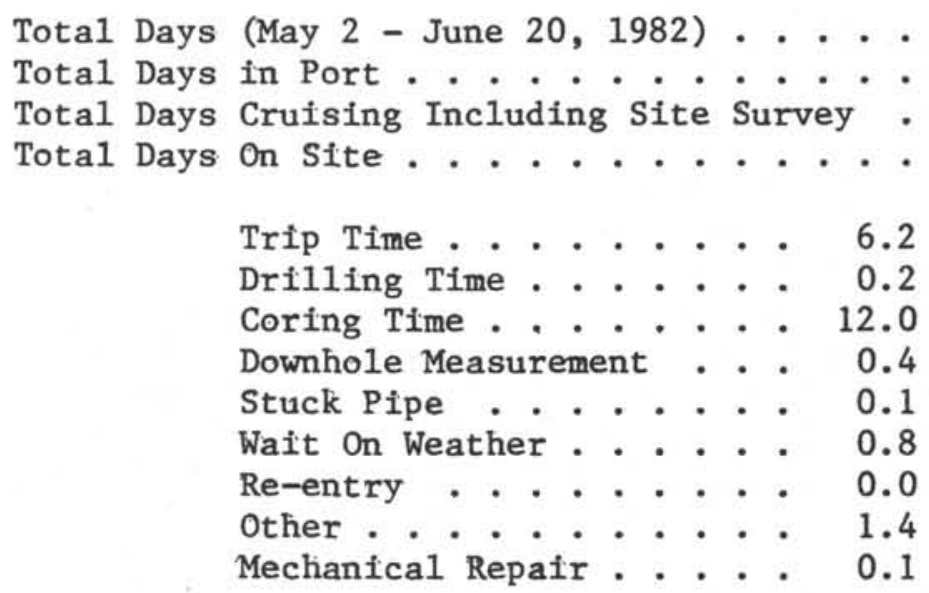

Total Distance Traveled Including Survey (nautical miles). . . . 4861.4

Average Speed (knots) ................ 8.73

Number of Sites .................... 6

Number of Holes Drilled ................... 11

Number of Cores Attempted . . . . . . . . . . . . . . 126

Number of Cores With Recovery . . . . . . . . . . . . . 124

Total Meters Cored . . . . . . . . . . . . . . . 1109.9

Total Meters Recovered . . . . . . . . . . . . . . . 9 956.25

Percent Recovery .. . . . . . . . . . . . . . . . 86.2

Total Meters Drilled ................... 307.9

Total Meters of Penetration . . . . . . . . . . . . . 1417.8

Percent of Penetration Cored . . . . . . . . . . . . . . 78.3

Maximum Penetration (meters) . . . . . . . . . . . . 352.5

Minimum Penetration (meters) .. . . . . . . . . . . . . 17.9

Maximum Water Depth (meters) . . . . . . . . . . . . 6 6220.3

Minimum Water Depth (meters) . . . . . . . . . . . 2677.6 


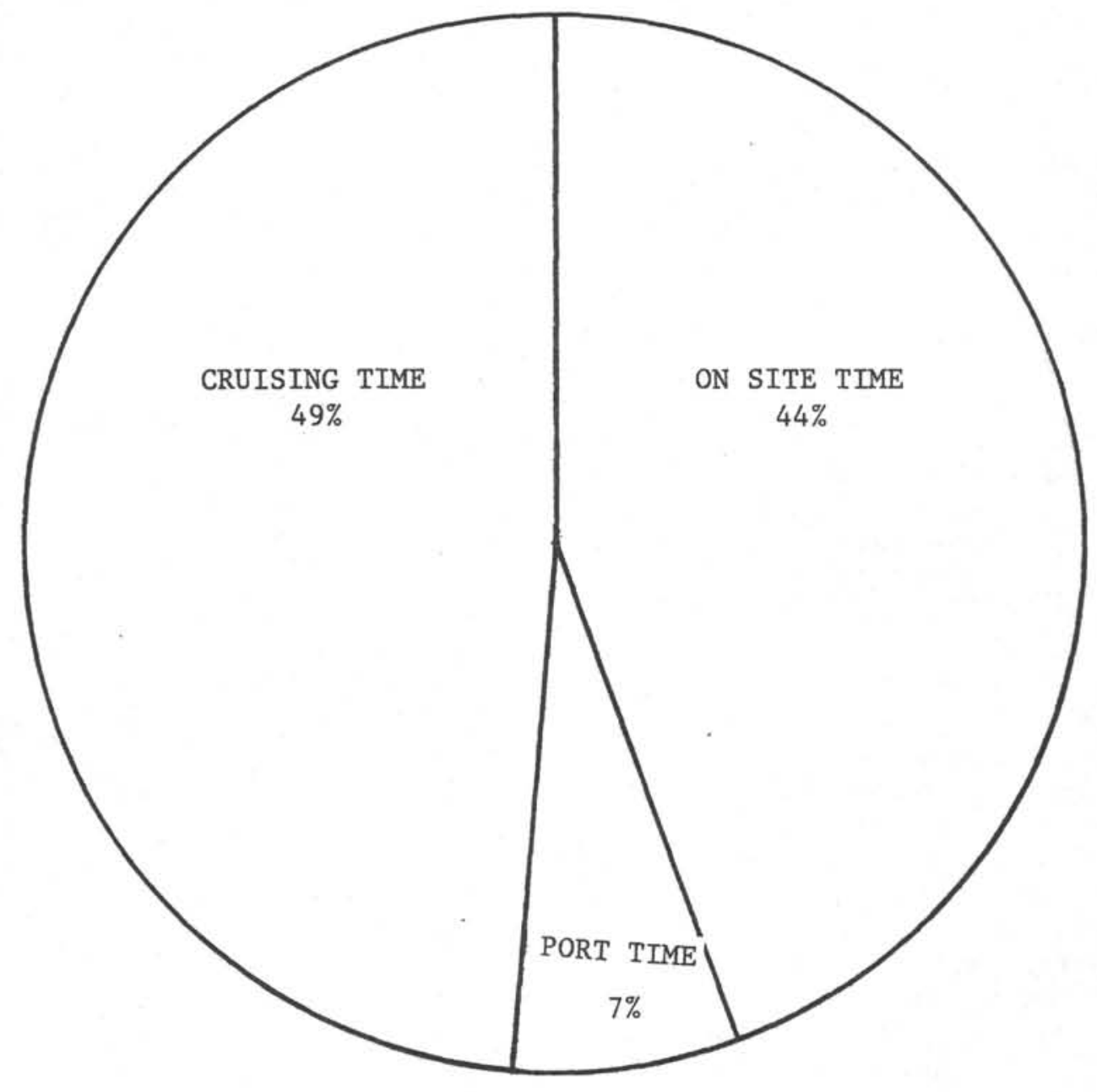

LEG 86

TIME DISTRIBUTION 

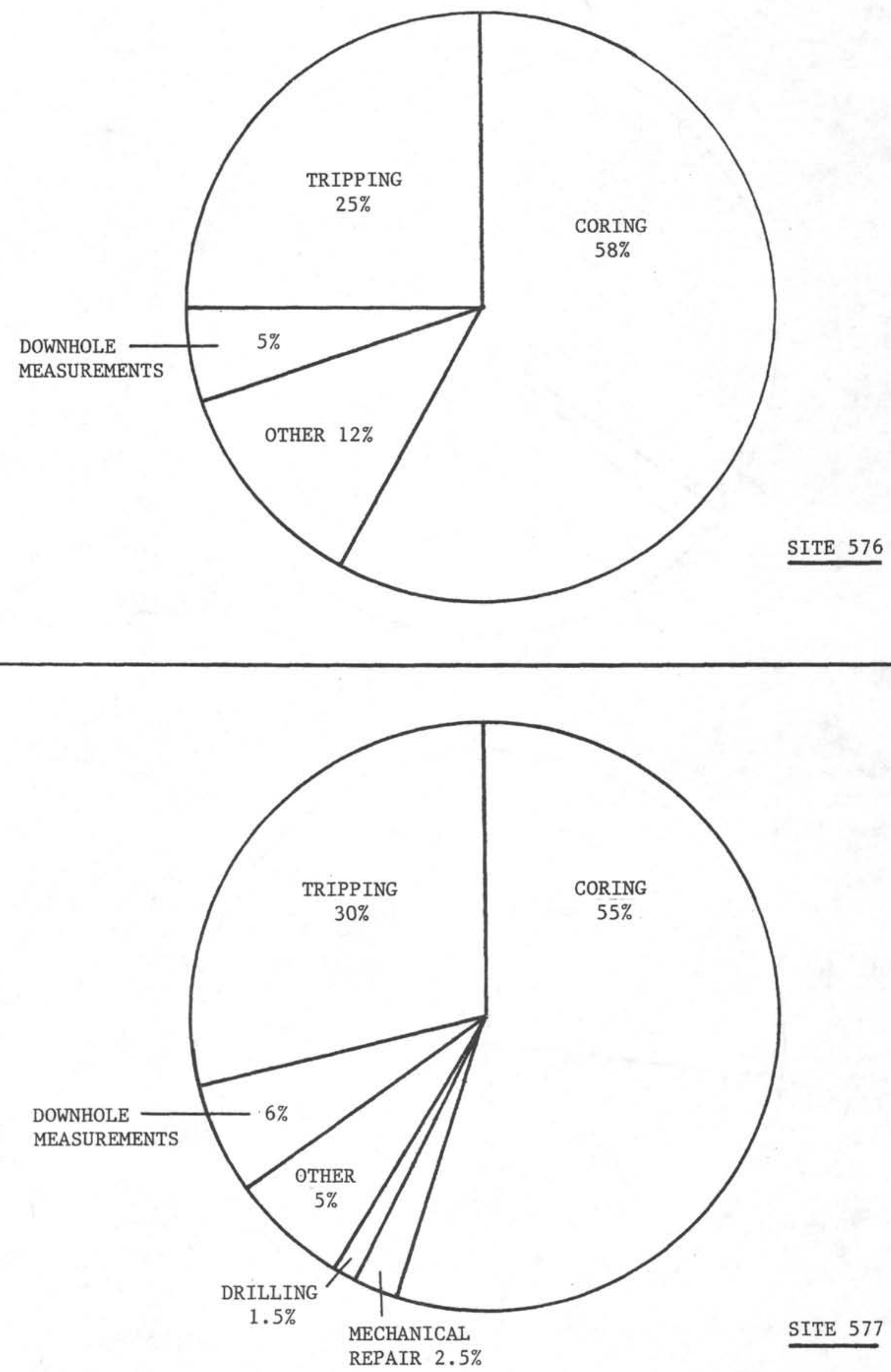

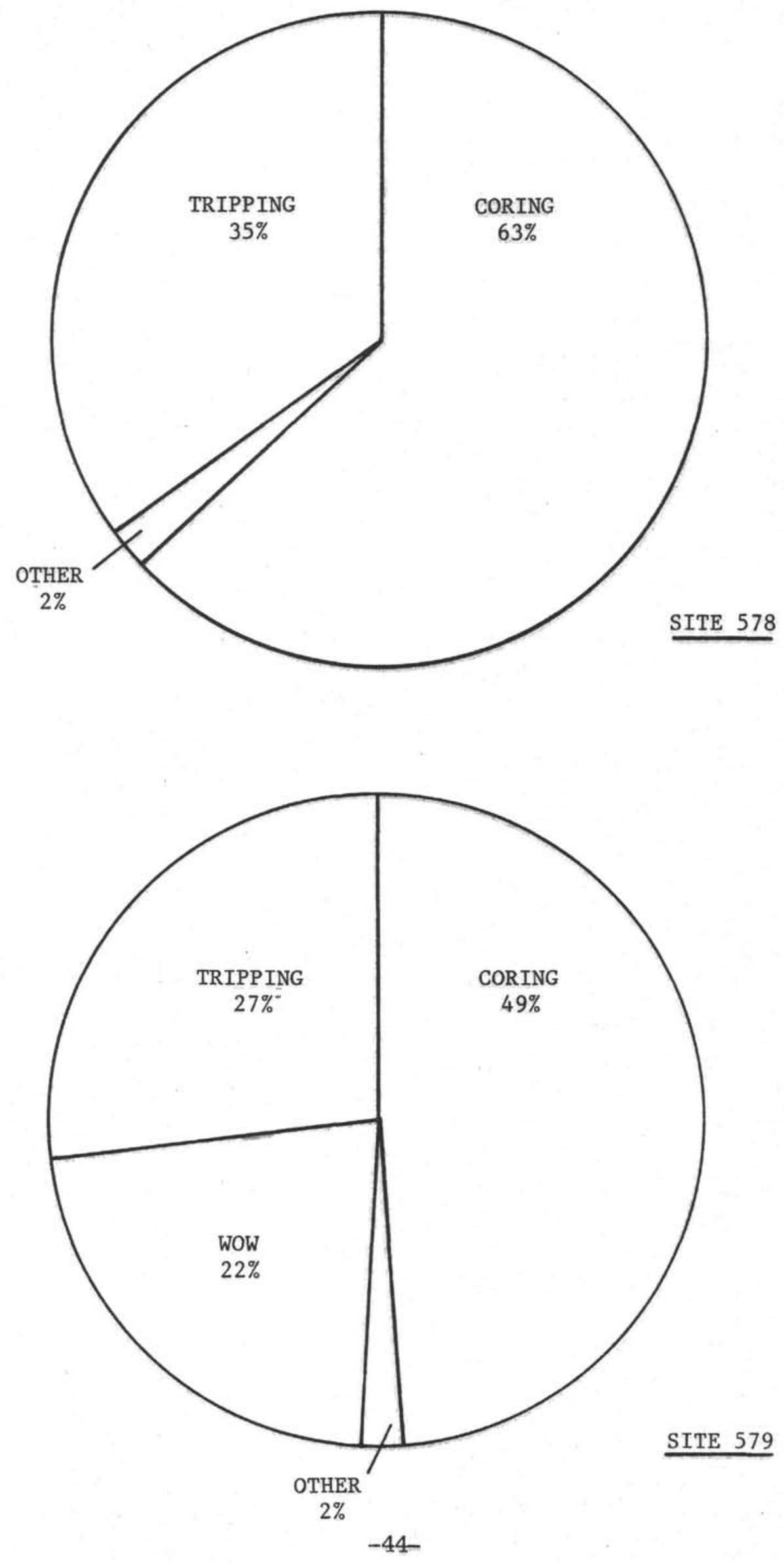
DEEP SEA DRILLING PROJECT

TIME DISTRIBUTION

$\angle E G-86$

\begin{tabular}{|c|c|c|c|c|c|c|c|c|c|c|c|c|c|c|}
\hline Date & $\begin{array}{l}\text { Site } \\
\text { No. }\end{array}$ & cruise & Trips & Drill & Core & $\begin{array}{l}\text { Stuck } \\
\text { Ploe }\end{array}$ & Ho. O.li? & $\begin{array}{l}\text { POWNHOLE } \\
\text { MEAS. }\end{array}$ & $\begin{array}{l}\text { Merh. } \\
\text { Pepair }\end{array}$ & $\begin{array}{l}\text { Port } \\
\text { Time }\end{array}$ & $\begin{array}{l}\text { Fe- } \\
\text { Entry }\end{array}$ & other & $\begin{array}{l}\text { Total } \\
\text { Timo }\end{array}$ & Remarks \\
\hline $\begin{array}{l}5 / 2 / 82 \\
5 / 5 / 82\end{array}$ & & . & & & & & & & & 80.9 & & . & 80.9 & Port Honoluly \\
\hline $\begin{array}{l}5 / 5 / 82 \\
5 / 16 / 82 \\
\end{array}$ & & 235.6 & & & & & & & & & & & 235.6 & $\begin{array}{l}\text { Cruising to } \\
\text { Site } 576\end{array}$ \\
\hline $\begin{array}{l}5 / 16 / 82 \\
5 / 18 / 82 \\
\end{array}$ & 576 & & 13.5 & & 21.9 & & & 6.0 & & & & 11.6 & 53.0 & \\
\hline $\begin{array}{l}5 / 18 / 82 \\
5 / 19 / 82\end{array}$ & $575 \mathrm{~A}$ & & مـ & & 18.8 & & & & & & & & 19.8 & \\
\hline $\begin{array}{l}5 / 19 / 82 \\
5 / 20 / 82 \\
5 / 20 / 82\end{array}$ & $576 \mathrm{~A}$ & & 14.0 & & 24.5 & & & & & & & 0.7 & 39.2 & \\
\hline $\begin{array}{l}5 / 20 / 82 \\
5 / 22 / 82 \\
\end{array}$ & & 15.6 & & . & & . & & & & & & & 15.6 & $\begin{array}{l}\text { Cruising to } \\
\text { Site } 577\end{array}$ \\
\hline $\begin{array}{l}5 / 22 / 82 \\
5 / 23 / 82 \\
5 / 2 / 82\end{array}$ & 577 & & 9.2 & & 18.0 & & & & 1.0 & & & 2.2 & 30.4 & \\
\hline $\begin{array}{l}5 / 22 / 82 \\
5 / 24 / 82 \\
5 / 2 / 8 n\end{array}$ & $577 \mathrm{~A}$ & & 1.0 & & 17.8 & & & 4.5 & & & & 0.7 & 24.0 & - \\
\hline $\begin{array}{l}5 / 24 / 82 \\
5 / 25 / 82 \\
\end{array}$ & $577 \mathrm{~B}$ & & 10.8 & 1.0 & 2.2 & & & & 0.7 & & $=$ & 0.5 & 15.2 & \\
\hline $\begin{array}{l}5 / 25 / 82 \\
5 / 27 / 82\end{array}$ & & 40.8 & & & & & & & & $\therefore$ & & & 40.8 & $\begin{array}{l}\text { Cruising to } \\
\text { Site } 578\end{array}$ \\
\hline $\begin{array}{l}5 / 27 / 82 \\
5 / 30 / 82 \\
5 / 30 / 82\end{array}$ & 578 & & 27,9 & & 50.3 & & & & & & & 1.7 & 79.9 & \\
\hline $6 / 01 / 82$ & & 34.2 & & & - & & & & & & & & 34.2 & $\begin{array}{l}\text { Cruising to } \\
\text { Site } 579\end{array}$ \\
\hline $6 / 01 / 82$ & 579 & & 13.2 & & 4.9 & & 1.8 & & & & & 1.2 & 21.1 & Positioning \\
\hline $\begin{array}{l}6 / 01 / 82 \\
6 / 04 / 82\end{array}$ & & & 11.0 & & 38.7 & & 18.1 & & & & & 0.5 & 68.3 & \\
\hline $\begin{array}{l}6 / 04 / 82 \\
6 / 05 / 82 \\
\end{array}$ & & 21,1 & & & & . & & & & & & . & 21.1 & $\begin{array}{l}\text { Cruising to } \\
\text { Site } 580\end{array}$ \\
\hline $\begin{array}{l}6 / 05 / 82 \\
6 / 08 / 82 \\
\end{array}$ & 580 & 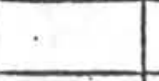 & 21.7 & & 47.3 & & & & 6.0 & & & 2.3 & 77.3 & \\
\hline $\begin{array}{l}6 / 08 / 82 \\
6 / 10 / 82 \\
\end{array}$ & & 36.0 & & & & & & & & & & & 36.0 & $\begin{array}{l}\text { Cruising to } \\
\text { Site } 81\end{array}$ \\
\hline $\begin{array}{l}6 / 10 / 82 \\
6 / 13 / 82 \\
6 / 13 / 82\end{array}$ & 581 & & 24.5 & 3.5 & 43.8 & 1.5 & & & & & & 8.2 & 81.6 & \\
\hline $\begin{array}{l}6 / 13 / 82 \\
5 / 20 / 82 \\
\end{array}$ & & 161.2 & & & & & . & $\%$ & & & & & $161: 2$ & $\begin{array}{l}\text { Cruising to } \\
\text { Yokohama }\end{array}$ \\
\hline & & & & & & & - & & & & & & & \\
\hline
\end{tabular}


INTERNATIONAL PHASE OF OCEAN DRILLING

DEEP SEA DRILLING PROJECT

BEACON SUMMARY

LEG 86

\begin{tabular}{|c|c|c|c|c|c|c|}
\hline & Site No. & Make & $\begin{array}{l}\text { Freq } \\
\mathrm{kHz}\end{array}$ & $\begin{array}{l}\text { Serial } \\
\text { Number }\end{array}$ & $\begin{array}{l}\text { Site Time } \\
\text { Hours }\end{array}$ & Remarks \\
\hline \multirow{7}{*}{ 南 } & 576 & ORE & 16.0 & SN 123 & 113 & \\
\hline & 577 & ORE & 13.5 & SN 135 & 67 & \\
\hline & 578 & ORE & 16,0 & SN 125 & 80 & \\
\hline & 579 & ORE & 13,5 & SN 133 & 100 & \\
\hline & 580 & ORE & 13.5 & SN 136 & 79 & \\
\hline & 581 & ORE & 16.0 & SN 126 & 82 & \\
\hline & 581 & ORE & $13.5 \mathrm{DL}$ & SN 140 & 7 & Dropped at 1055 hours $6 / 13 / 82$-double life \\
\hline
\end{tabular}


INTERNATIONAL PHASE OF OCEAN DRILLING

DEEP SEA DRILLIN PROJECT

BIT SURMARY

LEG 86

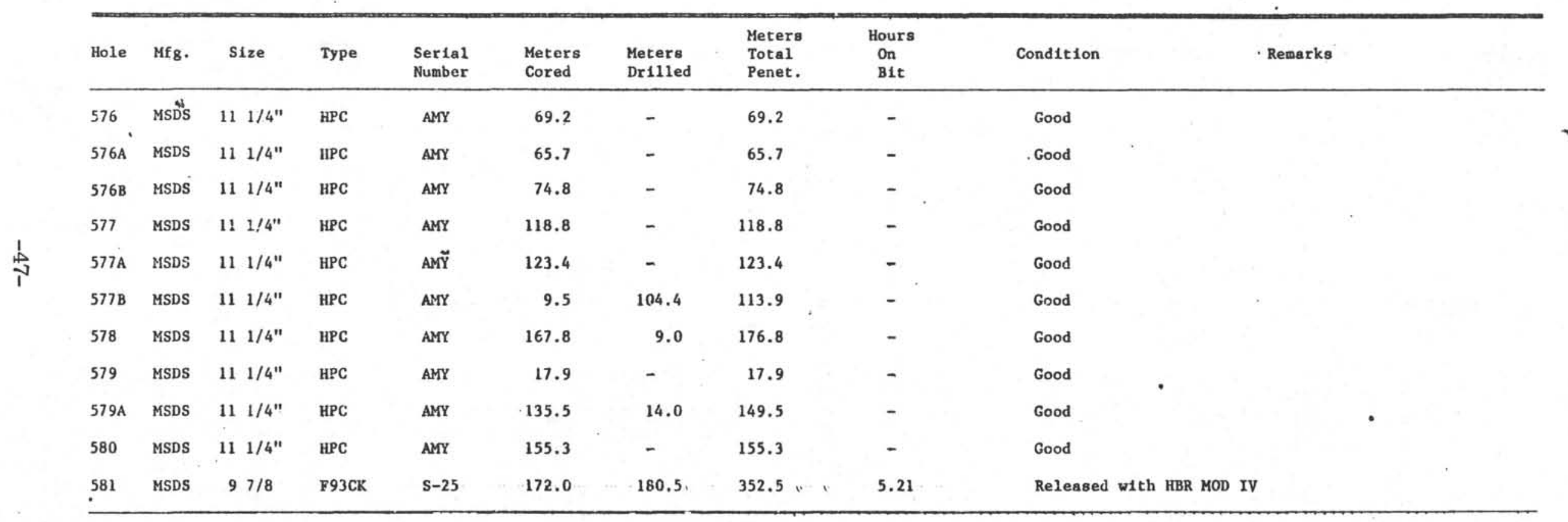


INTERNATIONAL PHASE OF OCEAN DRILLING

DEEP SEA DRILLING PROIECT

SITE SUMMARY

LEG 86

\begin{tabular}{|c|c|c|c|c|c|c|c|c|c|c|c|c|c|c|}
\hline Hole & Latitude & Longitude & $\begin{array}{l}\text { Water } \\
\text { Depth } \\
\text { Meters }\end{array}$ & $\begin{array}{l}\text { Number } \\
\text { of } \\
\text { Core }\end{array}$ & $\begin{array}{l}\text { Cores } \\
\text { With } \\
\text { Recovery }\end{array}$ & $\begin{array}{l}\text { Percent of } \\
\text { Cores With } \\
\text { Recovery }\end{array}$ & $\begin{array}{l}\text { Meters } \\
\text { Cored }\end{array}$ & $\begin{array}{c}\text { Meters } \\
\text { Recovered }\end{array}$ & $\begin{array}{c}\text { Percent } \\
\text { Recovered }\end{array}$ & $\begin{array}{l}\text { Meters } \\
\text { Drilled }\end{array}$ & $\begin{array}{l}\text { Total } \\
\text { Penet } \\
\text { Meters }\end{array}$ & $\begin{array}{l}\text { Avg } \\
\text { Rate } \\
\text { Penet }\end{array}$ & $\begin{array}{l}\text { Time } \\
\text { On } \\
\text { Hole }\end{array}$ & $\begin{array}{l}\text { Time } \\
\text { On } \\
\text { Site }\end{array}$ \\
\hline $\begin{array}{l}576 \\
576 \mathrm{~A} \\
576 \mathrm{~B}\end{array}$ & $\begin{array}{ll}32^{\circ} & 21.36^{\prime} \mathrm{N} \\
32^{\circ} & 21.38^{\prime} \mathrm{N} \\
32^{\circ} & 21.37^{\prime} \mathrm{N}\end{array}$ & 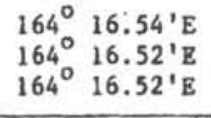 & $\begin{array}{l}6220.3 \\
6218.8 \\
6229.3\end{array}$ & $\begin{array}{l}8 \\
7 \\
9\end{array}$ & $\begin{array}{l}8 \\
7 \\
9\end{array}$ & $\begin{array}{l}100.0 \\
100.0 \\
100.0\end{array}$ & $\begin{array}{l}69.2 \\
65.7 \\
74.8\end{array}$ & $\begin{array}{l}68.52 \\
66.20 \\
74.07\end{array}$ & $\begin{array}{r}99.0 \\
101.0 \\
99.0\end{array}$ & $\bar{z}$ & $\begin{array}{l}69.2 \\
65.7 \\
74.8\end{array}$ & $\begin{array}{l}\text { HPC } \\
\text { HPC } \\
\text { HPC }\end{array}$ & $\begin{array}{l}53.0 \\
19.8 \\
39.2\end{array}$ & $\begin{array}{l}- \\
-\end{array}$ \\
\hline TOTAL & & & & 24 & 24 & 100.0 & 209.7 & 208.79 & 100.0 & & 209.7 & HPC & - & 112.0 \\
\hline $\begin{array}{l}577 \\
577 \mathrm{~A} \\
577 \mathrm{~B}\end{array}$ & $\begin{array}{l}32^{\circ}{ }^{\circ} 26.51^{\prime} \mathrm{N} \\
32^{\circ} \\
32^{\circ} \\
26.53^{\prime} \mathrm{N} \\
\end{array}$ & $\begin{array}{l}157^{\circ} 43.40^{\prime} \mathrm{E} \\
157^{\circ} 43.39^{\prime} \mathrm{B} \\
157^{\circ} 43.39^{\prime} \mathrm{B}\end{array}$ & $\begin{array}{l}2678.2 \\
2677.6 \\
2677.6 \\
\end{array}$ & $\begin{array}{r}13 \\
13 \\
1\end{array}$ & $\begin{array}{r}13 \\
13 \\
1\end{array}$ & $\begin{array}{l}100,0 \\
100.0 \\
100.0\end{array}$ & $\begin{array}{r}118.8 \\
123.4 \\
9.5\end{array}$ & $\begin{array}{r}111.07 \\
110.64 \\
9.63\end{array}$ & $\begin{array}{r}93.0 \\
90.0 \\
101.0\end{array}$ & $10 \overline{4.4}$ & $\begin{array}{l}118.8 \\
123.4 \\
113.9\end{array}$ & $\begin{array}{l}\text { HPC } \\
\text { HPC } \\
\text { HPC }\end{array}$ & $\begin{array}{l}30.4 \\
24.0 \\
15.2\end{array}$ & $\overline{-}$ \\
\hline TETAL & & & & 27 & 27 & 100.0 & 251.7 & 231.34 & 92.0 & 104.4 & 356.1 & $\mathrm{HPC}$ & - & 69.6 \\
\hline 578 & $33^{\circ} 55.56^{\prime} \mathrm{N}$ & $151^{\circ} 37.74^{\prime} \mathrm{B}$ & 6004.7 & 21 & 20. & 95,0 & 167.8 & 165.02 & 98.0 & 9,0 & 176.8 & HPC & 79.9 & - \\
\hline TOTAL & & & & 21 & 20 & 95.0 & 167.8 & 165.02 & 98,0 & 9.0 & 176.8 & HPC & - & 79.9 \\
\hline $\begin{array}{l}579 \\
579 \mathrm{~A} \\
\end{array}$ & $\begin{array}{ll}38^{\circ} & 37.68^{\prime} \mathrm{N} \\
38^{\circ} & 37.61^{\prime} \mathrm{N} \\
\end{array}$ & $\begin{array}{l}153^{\circ} 50.17^{\prime} \mathrm{E} \\
153^{\circ} 50.28^{\prime} \mathrm{E}\end{array}$ & $\begin{array}{l}5746,6 \\
5746.6 \\
\end{array}$ & $\begin{array}{r}2 \\
15 \\
\end{array}$ & $\begin{array}{r}2 \\
15 \\
\end{array}$ & $\begin{array}{l}100.0 \\
100.0\end{array}$ & $\begin{array}{r}17.9 \\
135.5 \\
\end{array}$ & $\begin{array}{r}16.90 \\
115.87 \\
\end{array}$ & $\begin{array}{l}94,0 \\
86.0 \\
\end{array}$ & 14.0 & $\begin{array}{r}17.9 \\
149.5 \\
\end{array}$ & $\begin{array}{l}\mathrm{HPC} \\
\mathrm{HPC}\end{array}$ & $\begin{array}{l}21.1 \\
68.3 \\
\end{array}$ & - \\
\hline TOTAL & & & & 17 & 17 & 100.0 & 153.4 & 132.77 & 87.0 & 14.0 & 167.4 & HPC & - & 89.4 \\
\hline 580 & $41^{\circ} 37.47^{\prime} \mathrm{N}$ & $153^{\circ} 58.58^{\prime} \mathrm{B}$ & 5386.7 & 18 & 17 & 24.0 & 155.3 & 140.74 & 91.0 & - & 155.3 & HPC & 77.3 & - \\
\hline TOTAL & & & & 18 & 17 & 94.0 & 155.3 & 140.74 & 91.0 & $=$ & 155.3 & $\mathrm{HPC}$ & - & 77.3 \\
\hline 581 & $43^{\circ} 55.62^{\prime} \mathrm{N}$ & $159^{\circ} 47.76^{\circ} \mathrm{B}$ & 5487.5 & 19 & 19. & $10 a .0$ & $172, a$ & 77,59 & 45.0 & 180.5 & 352.5 & 65.9 & 81.6 & - \\
\hline TOTAL & & & & 19 & 19 & 100.0 & 172.0 & 77.59 & 45.0 & 180.5 & 352.5 & 65.9 & - & 81.6 \\
\hline
\end{tabular}




\section{INTERNATIONAL PHASE OF OCEAN DRILLING \\ DEEP SEA DRILLING PROJECT \\ OPERATIONS RESUME \\ LEG 87}

Leg 87 of the Deep Sea Drilling Project was devoted to the investigation of two convergent plate margins off the coast of Japan. The Nankai Trough in the south and the Japan Trench in the north posed differing tectonic and sedimentational problems. The mechanics of accretion/subduction of the sediments and the physical effects on the sediments were primary research objectives of Leg 87.

As in earlier active margin efforts, loose sands and fractured and apparently overpressured sediments resulted in serious hole problems and low core recovery. In addition, a rash of mechanical failures and a typhoon frustrated attempts to reach the ultimate scientific objectives.

The voyage commenced on June 19, 1982, at Yokohama, Japan and terminated at Hakodate, Japan on August 18, 1982. An interim port call in Yokohama had been scheduled for an exchange of scientific staff members. It was made several days early because of the need for emergency derrick repairs. Total length of the voyage was 59.2 days, of which 41.3 days were spent on site, 11.4 days under way and 6.5 days in port. One day of operating time was lost to equipment breakdowns.

\section{Yokohama Port Call}

Leg 87 began officially at'2353 hours, June 29, 1982, when the GIOMAR CHALLENGER dropped anchor at the quarantine anchorage outside the harbor of Yokohama, Japan. As docking was not permitted during late night hours, it was necessary to wait until morning to move to a pierside berth. The first mooring line was put across to Berth E of Yokohama's South Pier at 0840 hours, June 20. This was one day later than the scheduled beginning of the leg, due to delays experienced by the vessel when strong currents were encountered during the transit from the Leg 86 operating area to Toky.o Wan.

Important work items during the port call were: major overhaul of Number 7 engine and replacement of Number 2 and four propulsion motors in accordance with the ship's maintenance schedule, repair of the heave compensator accumulator piston, magnetic drill pipe inspection and clearing of nylon fish net that had become fouled in the vessel's main screws and rudder during Leg 86. Normal on and offgoing freight shipments were handled, and nearly 32,000 gallons of fresh water was taken on. Four upper re-entry cones were offloaded to provide deck space for Leg 88 operations and three lower cones were shipped 
to California for dimensional modification. Thirty two joints of new drill pipe were sent to NKK steel mill to have internal restrictions machined out.

The ship's departure was delayed an additional half day as technicians attempted to provide a working spare heading encoder for the dynamic positioning system. (These efforts were unsuccessful, but the shipboard spare was later repaired at siea).

The last mooring line was cast off at 1200 hours, June 25, and the vessel departed for the Leg 87 operating area.

Yokohama to Site 582

The CHALLENGER proceeded southward from Tokyo Wan past Miyake Jima before turning southwestward toward the operating area. The more direct coastwise route was eschewed to avoid bucking the strong Kuroshio current and to minimize the risk of fouling with more fishing gear in the heavily fished coastal waters. The strategy was successful in that the current had little effect and an average speed of 9.1 knots was achieved. This was partially the result of strong following winds from the nearby passage of Typhoon Ruby. Seismic records were adversely affected by the six to seven foot pooping swells and four foot seas, but these conditions abated on the morning of the second day as the first drill site was approached. A direct approach to the site was made, and preliminary profiling was limited to a reduction in speed for the final hour of the transit. A positioning beacon was launched at 1117 hours, June 27, initiating operations at Site 582 .

Hole 582 - Nankai Trough

The first Leg 87 drill site was located about 70 miles southeast of Ashizuri Zaki, the southernmost point of the Island of Shikoku. Water depth was 4889 meters, as read by the precision depth recorder.

The initial pipe trip was slowed somewhat by the process of measuring the drill string and by the usual first site "rough edges". A spud attempt was made at 0309 hours, June 28, and first resistance was noted from the rig weight indicator at 4897 meters. The seafloor sediments, sand turbidites and mud, could not be penetrated by the usual method of "punching"--simply lowering the pipe and letting the weight of the lowermost drill collars force the bit into the sediment. It was necessary to rotate the bit to dig through the sand and occasionally to apply all the bottom hole assembly (BHA) weight below the lowermost bumper sub, as the heave compensator was inoperative.

Two sandline trips were made in efforts to "find" the inner core barrel, but no weight indication of engagement was noted and the overshot came up empty each time. Since no previous wireline runs had been made, there was no reference flag on the line to indicate the depth of the end of the drill string. After the second run, a circulating pressure check was made and open ended pipe was indicated. It was concluded that the BHA had broken 
during the spudding attempt, and the drill string was pulled. On recovery of the BHA, it was found that the hydraulic bit release had actuated spontaneously, dropping the bit and associated components.

A mechanical bit release assembly was then made up and the pipe trip was repeated. Hole 582 was spudded at 0530 hours, June 29. The first core barrel was retrieved nearly full and the water depth was revised to 4892 meters. Two more cores were cut and, as core number three was being retrieved, a 900-foot positioning excursion occurred when wind and current forces temporarily exceeded the vessel's stationkeeping capability. The next core barrel was pumped into place at the bit with normal seating pressure indication, and core number four was attempted. Irregular torque and reduced penetration rate were noted to begin after about half the interval had been cored. Three sandline runs were unsuccessful in engaging the core barrel, and a subsequent circulating pressure check again indicated open-ended pipe. Another spontaneous bit release was suspected, and an attempt was made to wash over and recover the inner core barrel. This was unsuccessful and the drill string was again recovered. The lowermost bumper sub was found to be bent in the spline section and the outer core barrel assembly was missing below the head sub. The rotary shouldered connection between the head and top subs had failed, apparently as the result of lateral bending forces from the positioning excursion.

Hole 582A

About five hours were required to reassemble the BHA and to space out the core barrel assembly. The connections of the lowermost stand of drill collars were magnafluxed to check for damage. The ensuing pipe trip was extended by about one hour when a loose tool joint was found and it was considered prudent to retorque all drill pipe connections as the string was made up.

The heave compensator was left out of the string since no repair time estimate could be given, and it was again necessary to spud without its benefit. Hole 582A was started at 1535 hours, June 30 , and was drilled ahead to 29.1 meters below seafloor (BSF) before coring began. Two cores were taken, and then the first instrumented probe run of the site was made. During the temperature/ pressure/water sampler deployment, the heave compensator was finally pronounced operational. For the safety of the BHA, it was decided to terminate Hole 582A and to pull above the seafloor before picking up the heave compensator. The bit cleared the mud line at 2128 hours, June 30 .

Hole 582B

The power sub was set back so that the heave compensator could be deployed. When the heave compensator and power sub had again been rigged, routine operational checks were made, and it was found that the antislingshot safety valve on the heave compensator could not be closed. An hour of troubleshooting determined the problem to be electrical but did not pinpoint it. The compensator system was then locked out to avoid further delays. 
Hole 582B was spudded at 0010 hours, July 1 and was drilled to 4940.5 meters before circulation was reduced and the first core was cut to 4989 meters (145.2 m BSF.) This was followed by an instrumented probe run. (The heave compensator was finally repaired just after the measurement was completed). A second probe run was made after an additional 48.2 meters had been cored. Cuttings apparently settled around the BHA during the measurement, and about 90,000 pounds of overpull was required to work the bit loose. Probe runs were then discontinued for the safety of the drill string.

Coring continued through alternating turbiditic and hemipelagic muds of Pleistocene age with no further indication of hole instability, though lowrecovery intervals were attributed to the presence of loose sands and possibly undercompacted mud. The absence of sticking tendencies or hole fill between cores was considered, and another instrumented probe run was made at 499 meters BSF to satisfy great scientific interest in the geophysical measurements. On bottom time was held to 20 minutes, but hole fill again caused the pipe to stick on bottom before being pulled free. Hole trouble then persisted as coring continued to a total depth of 749.4 meters BSF. Frequent mud flushes were not particularly effective in cleaning the hole, but conditions appeared to stabilize on two or three occasions. The scientific target, Pliocene claystone, was finally recovered and coring operations were terminated after a Pliocene penetration of about 25 meters.

Core recovery had averaged less than 40 per cent at Hole 582B, and well $\log$ information was eagerly anticipated to fill large data gaps. The hole was flushed with mud in preparation for logging. A hydraulic bit release go-devil was pumped into place to disconnect the terminal drilling equipment with its diameter restrictions. The bit release, however, failed to actuate even after 20 minutes of pressuring and manipulating the pipe. At this point the string began sticking as hole fill material settled around the BHA. Two joints of pipe were set back, and the go-devil was retrieved with the sandline. A second go-devil was then sent down the pipe, but this attempt was also unsuccessful and efforts were abandoned after about 30 minutes.

Hydrocarbon gas of apparently biogenic origin had been present in considerable quantity in the soft upper sediments, but had decreased with depth. The presence of gas hydrates in the upper portion of the hole was suspected, but was not confirmed. The hole was therefore filled with barite-weighted mud before it was abandoned.

The drill string was then recovered. Considerable overpull was necessary to pull the BHA through the interval of about 320 to 150 meters BSF. A keyseat condition was suspected, as hole drift measurements of up to $81 / 2$ degrees had been recorded. The bit arrived on deck at 0245 hours, July 8 . The bit release assembly was found to be packed full of silty mud and fine sand which had prevented actuation of the mechanism.

Hole 583

The second drill site was only about four miles northwest of Site 582 . 
As location of the site along a reference profile was critical, a careful profiling survey was made, using the Site 582 positioning beacon as a reference. After an initial pass over the proposed location, the vessel returned to the Site 582 beacon and repeated the transit before dropping a new beacon at 0717 hours, July 8 .

The hydraulic piston coring (HPC) bottom hole assembly was assembled and a routine pipe trip was made. The vessel was offset 400 meters to the northnorthwest during the trip to locate on the desired geographic coordinates. As a firm, sloping bottom was indicated, the pipe was lowered for a weight indicator reading before the HPC assembly was deployed. The seafloor was "felt" at 4673 meters, 29 meters below PDR depth.

When the 9.5 meter HPC unit had been lowered to the bit, the drill pipe was pressured and Hole 583 was spudded with the first core "shot" from 4669 meters at 2131 hours. Only about $140 \mathrm{~cm}$ of sediment was recovered, but water depth was fixed at 4673 meters based on the weight indication.

Piston-coring performance was substandard in Hole 583 with apparently erratic shearing pressures, incomplete stroke, low core recovery and disturbed cores. Mechanical problems in the HPC unit were suspected, as full-stroke indication was noted on only four of the first 13 core attempts. The corer was then replaced by the alternate unit, which was dressed for five-meter cores. It soon became apparent that the corer was functioning normally and that the problems resulted from the prevalence of coarse sand turbidites in the sediment being cored. Fourteen cores were attempted with the five-meter unit. There was only one full stroke indication, and average core recovery had decreased to about $50 \mathrm{~cm}$ at 150 meters BSF. The next attempt produced no recovery, and coring operations were terminated due to lack of progress.

A special core catcher/cutter shoe assembly with a self-contained temperature recorder was deployed on seven core attempts in this hole. Its success was limited, however, by battery failures.

The hole was pumped full of weighted mud, and the bit was pulled clear of the seafloor at 1620 hours, July 10 .

Positioning offsets were entered to move the ship an additional 400 meters to the north-northwest. The pipe was then lowered to tag bottom with the first weight indication at about 4634 meters, comparing favorably with the PDR reading of 4628 .

The five meter HPC unit was deployed and the first core was shot from 4631 meters. A good 3.9 meter core was recovered, and water depth was set at 4632 meters. Continuous piston coring continued in sediment comprised of mud with only minor sand layers to a depth of 54 meters BSF. Recovery and HPC performance had been good, and coring was discontinued because scientific objectives had been achieved.

The HPC assembly was deployed a final time with a special lower section modified to carry the temperature/pressure/pore water instrumentation 
(normally used in rotary coring) as well as the HPC temperature shoe. All four instruments operated successfully, providing an opportunity for comparison of the two heat flow measurement techniques. The BHA was then pulled clear of the seafloor at 1257 hours, July 11.

\section{Hole 583B}

The drill string was hung off with heavy "drilling" joints extending below the keel due to the relatively long planned offset and choppy weather. The vessel was then offset a total of 875 meters to the south-southeast to a point 75 meters south-southeast of the beacon.

PDR depth at the new location was 4687 meters, and the pipe was again lowered to tag bottom before picking up the HPC assembly. Behavior of the rig weight indicator registered contact with bottom, in the opinion of all observers, at about 4703 meters. The five meter HPC unit was deployed and was "shot" from 4700.7 and 4705.7 meters with only "water cores" recovered. More pipe was then added to the string and positive weight indication was finally noted at about 4759 meters. The next core, shot from 4758.7 meters, was recovered nearly full. This water depth corresponded closely to a second "side echo" on the PDR record.

Good progress was then made, with good core recovery and good data from the temperature shoe. Then, without warning, about 50,000 pounds of overpull was required to pull free after core number six had been shot. On retrieval of the corer, it was found that the threaded connection at the bottom of the lower shaft had failed, leaving about half the HPC assembly (and one of the two temperature shoes) in the hole.

The bit was once more pulled clear of the seafloor while the lost HPC components were replaced with new spare parts.

Hole 583C

Hole 583C was to be a continuation of Hole 583B, so no offset changes were made. The soft mud permitted "washing down" 25 meters to the depth of the final core attempt of the previous hole. Incomplete stroke indication was noted on the first core attempt, and the core barrel brought up only $25 \mathrm{~cm}$ of core. The piston head was found at the top of the core, having been detached from the piston rod. The piston locking pin had sheared. A zone of calcareous concretions was found in the core and was the probable cause of both mechanical failures. Four additional cores were taken, with incomplete stroke on the final two in stiffening sediments. This was considered to be "refusal" depth, and piston coring was terminated in favor of the standard rotary coring equipment.

The pipe trip was interrupted for 1-1/4 hours to replace the pipe stabber head. AT 0147 hours, July 13, the bit was brought on deck and conversion to the rotary bit and BHA began immediately. 
Hole 583D

The pipe trip back to the seafloor was slowed when the pipe developed floating tendencies and it was necessary to pump it full of water on three occasions. This was an indication that the inner core barrel had come unlatched, and the barrel was retrieved for inspection prior to spud-in. No fault was found, so the barrel was pumped back into place and Hole 583D was spudded at 1452 hours, July 13. The initial penetration was made difficult by the firm mud and sandy turbidites and by the approximately 20 per cent slope of the seafloor. Lack of lateral support dictated lightweight and low RPM for the safety of the BHA. The hole was drilled to the depth of Hole 583C in a 1ittle over $1-1 / 2$ hours. The plastic core liner of the "wash" core barrel was collapsed, and the core catcher contained only a handful of pebbles and a piece of wood.

A single-shot drift measurement taken on this first wireline trip indicated a hole angle of $5-1 / 2$ degrees at less than 50 meters. This is considered an excessive dog leg, and would normally warrant respudding. However, the two earlier HPC holes at this location had assumed similar drift angles and dips of up to $45^{\circ}$ had been noted in the cores. Since little chance of improving the situation was perceived, operations continued in Hole 583D.

An instrument probe run was made before coring commenced, and temperature and pressure data gave a strong indication that the inner barrel had been latched properly. When slow penetration and lack of recovery persisted on the first few cores, unlatching was again suspected. The inner core barrels were measured, and the instrument barrel was noted to be a fraction of an inch shorter than the coring barrels. The coring barrels were shortened to the length of the instrument barrel in the event that a spacing error had somehow occurred. Coring continued in Pleistocene mud and sandy turbidites with a disappointing overall recovery rate of less than 25 per cent. The poor coring results were attributed to the nature of the sediment. A total of seven instrument probe runs were made, with the final one after the completion of coring at the hole's total depth of 326.6 meters.

Hole 583B, C and D, were drilled as a safety measure to penetrate a prominent thrust plane (as shown on seismic profiles) at shallow depth to assess the potential for hydrocarbon entrapment beneath the fault. It was generally agreed that the fault(s) had been crossed, and gas samples were collected and analyzed. No significant changes in gas composition were noted and no real indication of migrated mature hydrocarbons was seen.

With the objectives attained, the hole was filled with cement in accordance with safety panel recommendations. No hole problems had been experienced during coring, instrument probe or cement operations, but the pipe was found to be firmly stuck immediately after the cement had been displaced into the hole. The cementing head was reinstalled and free circulation was established with no difficulty. After one hour of circulating and working the stuck pipe (with no progress), the pipe suddenly came free. By this time the cement had been displaced out of the hole. It was inferred that the drill string had been differentially stuck at highly permeable sand strata by the hydrostatic 
head of the 15 pound/gallon slurry. For safety of the drill string, no further attempt was made to fill the hole. More drag was experienced as the string was withdrawn from the hole, possibly due to keyseating at the $51 / 1$ degree dog leg near the seafloor. Drift had increased to 9 degrees at total depth.

\section{Hole 583E}

The vesse1 was next offset to the location of primary scientific interest, about 450 meters north-iorthwest of the positioning beacon and only 50 meters northnorthwest of Hole 583. The seafloor was "felt" at 4665 meters, 26 meters below PDR depth.

Spud time was 0300 hours, July 17, and the hole was drilled to 150.4 meters before the inner barrel was recovered. The wash barrel contained over nine meters of sediment, and the coring system appeared to the functioning normally. The ensuing four cores, however, produced a total of only $44 \mathrm{~cm}$. The lack of recovery, together with data from recent instrument runs suggested strongly that the inner barrels were not latched into the outer core barrel. Chalk and paint on the latch fingers was relatively undisturbed when the barrels were retrieved.

A fifth core was attempted while heavy mud was being displaced to fill the hole. The drill string was then pulled (with inner barrel in place) to investigate the nature of the coring malfunction. The outer core barrel was disassembled upon arrival at the rig floor. The inner barrel was found latched in the proper position, and it contained $55 \mathrm{~cm}$ of core.

Inspection of the latch sleeve, bit and all other components revealed no mechanical reason for latch-in failure. A recheck of core barrel spacing indicated that the inner barrels could, indeed, have been slightly too long before they were shortened early in Hole 583D operations. This would not have been a factor subsequent to the shortening.

Hole $583 \mathrm{~F}$

The hydraulic bit release was actuated, inspected and redressed prior to the reassembly of the BHA. No irregularities were found and the unit was judged fully operational. After a routine pipe trip, Hole $583 \mathrm{~F}$ was spudded at 1324 hours, July 18.

Coring attempts again began at 150.4 meter BSF, with early results just as disappointing as in Hole 583E. Only small amounts of sand and soft mud were recovered, until core number 12 brought up $3-1 / 2$ meters of fissile mudstone from about 265 meters. Core recovery averaged a little over 20 per cent beyond that point, providing representative sediment and sufficient gas for sampling. Four instrument probe runs were made, with the fourth, at 324 meters, encountering hole fill and sticking tendencies. Probe measurements were discontinued at that point, but coring continued, with no real hole 
problems, to 440 meters.

The steel latch finger on core barrel number 30 had been deformed, indicating that it had been forced past the latch sleeve. The next inner barrel showed no pressure kick indicative of proper seating at the bit. It was inferred that the bit throat was plugged with sediment, as is often the case when inner barrels become unseated. A wireline trip was then made to retrieve the barrel so that a bit deplugger could be deployed. The sandline did not produce proper weight indications, even when run "past the flag." The wire was retrieved and was found to be severed about 24 meters above the overshot. This meant that the pipe was open-ended and that the inner barrel and overshot/sinker bar assemblies were at the bottom of the hole. No significant loss of string weight was noted, and it appeared that the bit release had self-actuated.

Although the objective of the site had not been reached, the hole was judged to be deep enough to provide valuable logging data. The hole was pumped full of weighted mud and the pipe was pulled to logging depth.

The first $\log$ attempt was made with the combination long-spaced sonic/dual induction/gamma ray/caliper sonde. Even with this heavy tool, a bridge or plug at 274 meters BSF blocked off the lower part of the hole. Good electrical and gamma ray curves were recorded. Quality of the sonic log was only fair, probably because of the washed out condition of the hole. A sonic wave form log was then run using the same downhole equipment. The next logging tool was the formation density/neutron porosity/gamma ray combination. The $10 g$ obtained was of good quality, except in zones of severely washed out and/or irregular hole. Hole diameter was found to be in excess of the maximum 13 inch caliper reading for virtually the entire interval. The high-resolution thermometer (temperature $\log$ ) was then deployed in an effort to verify temperature probe results. The first run was aborted after the tool had reached about 3000 meters. A circuit breaker tripped on the circuit supplying the air conditioners on the logging computer van. The computer subsequently overheated and lost the temperature log program. It was then necessary to retrieve and recalibrate the tool and to reprogram the computer. The second attempt was successful in recording a good temperature log. Logging equipment was then rigged down, and the drill string was recovered.

During logging operations, a potentially serious structural flaw had been discovered in the course of a derrick inspection conducted by rig personnal. Cracks were found in the hangoff padeye of the starboard derrick guide rail. (Failure of this part caused extensive damage to the derrick on Leg 46). Phone contact was made with GMI management in San Diego, and solutions to the problem were explored while the pipe trip proceeded with caution.

At the end of the pipe trip, the BHA was given its bimonthly magnaflux inspection. The outer core barrel assembly was brought on deck at 0410 hours, July 23. The hydraulic bit release top connector, as suspected, was found to be fully shifted but otherwise in good condition. Disassembly of the outer core barrel revealed that the latch sleeve had been severely deformed by the upward force of inner barrel latch fingers. This explained the apparent unlatching of instrument probe barrels and low core recovery in the lower part of Hole 583F. 
Preliminary work then began on the derrick repairs, and the starboard guide rail was hung off on safety slings. At this time word was received from San Diego directing the vessel to proceed to Yokohama for completion of repairs, instead of fabricating and installing a new padeye on site. The CHALLENGER departed Site 583 at 0930 hours, July 23.

\section{Site 583 to Yokohama}

A brief seismic profile was made on departure from the site. The vessel headed seaward, crossing the Site 582 beacon and extending the JAPEX reference line to seaward before turning left onto the base course for Yokohama at 1200 hours. The vessel made good speed on the transit to Yokohama with favorable weather and the following Kuroshio current. Arrival at the Uraga pilot station was at 0600 hours, July 25, and the first line was put over at 0849 hours at the same berth the vessel had departed exactly one month earlier.

\section{Yokohama Interim Port Cal1}

A midleg port call had been scheduled at Yokohama for emergency resupply and exchange of scientific and technical personnel. The emergency repairs dictated that the port call be made four days early. Fortunately most of the preparations had been carried out in advance, and potential logistical delays were avoided.

An engineer had been dispatched by GMI to oversee the derrick repair work. A prefabricated padeye assembly was delivered about two hours after the vessel berthed, and welding repairs then commenced without delay. The work continued in light rain and mist, with heavy raid and wind forecast for the afternoon. Commissary supplies and air freight shipments were loaded concurrently with the repairs, and all oncoming scientists arrived during the day.

Welding repairs were completed at 1600 hours, and sailing time was set for 0830 hours the following morning. By 1830 hours the vessel was prepared for departure, but three DSDP personnel had not yet arrived from the U. S. Their plane had been diverted from Narita Airport, delaying their arrival at the ship until 0230 hours.

\section{Yokohama to Site 583}

The last moorning line was cast off at 0833 hours, Ju1y 26, and the CHALLENGER made good speed on the return trip to the Nankai Trough area for the first day. Speed decreased on the second afternoon, however, as the ship headed into the Kuroshio Current. That evening it was necessary to run for four hours at reduced speed on the port shaft only while repairs were made to the starboard shaft reduction gear lube oil pump. This resulted in approximately $2 \frac{1}{2}$ hours delay. 
The drill site was again approached from seaward, across Site 582 , with the seismic gear retrieved during the approach. The Site 582 beacon was not detected on this pass, but the Site 583 beacon was acquired at a distance of nearly a mile.

Hole 583G

The vessel was stationed on the beacon with the offsets used for Holes 583E and $583 \mathrm{~F}$. The signal strength remained adequate for positioning, but had dropped to about 30 per cent of its original level. A replacement beacon was therefore launched at the beginning of the pipe trip as a precautionary measure. During the trip, error readings were checked and offsets were calculated to correct for beacon drift. Further corrections were made, using SATNAV fixes received during the trip and PDR soundings, before referencing was switched to the new beacon. (The final mean position of Hole 583G was found to be about ninety meters east of Holes 583E and 583F.)

Spud-in came at 2108 hours, July 28, in 4663 meters of water. The hole was drilled to 200.7 meters BSF before the first "wash barrel" was retrieved. The core liner in this barrel was found to be collapsed and twisted, and there was no recovery. Four more "spot" core barrels were pulled, at regular intervals, as drilling continued to 306.6 meters. This was done for the purpose of monitoring gas composition, but the sediment recovered (totaling 19.5 meters) was studied with interest because of the low core recovery in this interval in the earlier holes.

Continuous coring then began, but after two cores, fluid suddenly started to leak copiously from the compensator cylinder of the heave compensator. Hole cleaning problems, increasing swell from an approaching typhoon and spillage of caustic hydraulic fluid all dictated that the compensator should be removed from the traveling string instead of being merely locked out of service. Since about six meters of hole fill had been encountered on the previous connection, three joints of pipe were set back. When the heave compensator had been removed and the power sub redeployed, about 16 meters of fill had accumulated in the hole. Forty barrels of weighted mud was circulated through the hole as it was cleaned to total depth.

Coring recommenced about $2 \frac{1}{4}$ hours of lost time. Core recovery remained quite good, and periodic mud flushes prevented the recurrence of significant hole cleaning trouble. Since gas composition was the subject of considerable concern, gas samples from cores taken from below 400 meters BSF were analyzed before succeeding cores were cut. Gas composition was found to be consistent with that of Holes 583 and 583F. The Pleistocene mud and sand turbidite sequence became more indurated with depth, fractures and dipping beds were noted below about 370 meters.

With attainment of the site's scientific objectives seemingly only about one day away, nature dealt the final blow to Site 583. Typhoon Bess had moved northwestward after several days of nearly stationary development and had 
become a direct threat to the safety of the vessel. The storm's track had been plotted anxiously during the final day of coring, and it was judged necessary to terminate coring operations at midnight, July 30 , to allow the slow CHALLENGER enough time to evade the typhoon. Simultaneously, storm generated swells had begun to produce occasional rolls in excess of seven degrees, the vessel motion limit for safe operation with drill pipe suspended. The final core was cut to 450 meters BSF as the hole was being pumped full of weighted mud. No sandline trip was made, and the core was brought to the surface with the drill string. The bit was on deck at 0920 hours, July 31 , and the vessel was underway at 0946 hours.

\section{Site 583 to Site 584}

Departure from Site 583 had been timed for the vessel to clear the track of the storm center by more than 200 miles. With Japan to the north and the typhoon to the south, an easterly course was the only choice open to the CHALLENGER for evasion. Typhoon Bess proved to be an unpredictable lady, however, and did not follow her projected leisurely course to the westnorthwest. The storm recurved sharply to the northeast and increased its speed of advance to overtake the vessel. The barometer fell rapidly, and easterly wind and seas increased through the morning of August 1. By noon the CHALLENGER could only heave to using thrusters to hold her head into the wind while riding out the storm. Maximum winds had decreased to about 65 knots, but 40 foot swells and 30 foot seas provided a rough ride. At about 1830 hours on August 1, the eye of the storm passed close aboard, with clear skies and nearly calm winds. With renewed winds now westerly, the vessel again headed east and rapidly gained speed as weather conditions moderated.

After passage south of the island of Hachijo Jima, course was set northeastward for Site 584, which lay off northern Honshu, about 100 miles east of Hachinohe. Excellent speed was made with the wind and the Kuroshio Current astern, and 258 miles was logged in one 24-hour period. Benefit of the current was lost on the final day, however, and speed was adjusted downward to optimize the timing of SATNAV fixes during the approach to the drill site.

The northeasterly course was held until a point $6 \frac{1}{2}$ miles due east of the proposed site had been reached. The vessel then turned west and profiled across the site. The seismic gear was retrieved before the ship reversed course. The positioning beacon was dropped at 1651 hours, August 4, using the PDR for depth/longitude control and LORAN for latitude.

Hole 584 - Lower Continental Slope Japan Trench

A routine pipe trip was made, and the power sub was picked up in preparation for spudding. The heave compensator remained out of the string pending repair. The PDR reading was 4088 meters, but the bit was lowered to about 
4125 meters before a weight indication was noted. This corresponded to a strong "side reflector" on the PDR record. The sediment was very firm, and both rotation and circulation were required to complete the first core to 4134.3 meters. A full 9.6 meter core was recovered, and the water depth was set at 4124 meters.

Continuous coring continued through a thick section of early Pliocene and late and middle Miocene claystones. Instrument probe runs were made at $77.0,103.7,230.8$ and 278.3 meters BSF. Hole conditions and rate of penetration were excellent and core recovery was good, especially in the highly diatomaceous upper 600 meters. Fractures, mostly at high angles with the hole, increased with depth, and core recovery decreased due to jamming in the core barrel. Hole conditions remained good, with occasional instances of hole fill which was lifted out of the hole with mud flushes. An intensely fractured zone a few meters thick was penetrated at about 900 meters, and about 12 meters of hole fill was encountered on the connection for the subsequent core.

Four additional cores were cut, but the hole would not clean up despite repeated mud flushed. Core number 98 recovered on $1 y$ rubble and, during attempts to clean the hole to total depth for the next core, the drill string became stuck. In addition to vertical sticking, the capabilities of rotating and circulating were also lost to apparent packing off of the hole/drill collar annulus. Slow upward progress was made by "working" the pipe. The pipe was not free in all respects until one hour had been spent and eleven joints of pipe had been pulled. The hole was then found to be clean down to about 907 meters BSF, where a bridge or tight spot was encountered. The bit was "drilled" past the spot repeatedly, but overtorquing and high pump pressure inevitably followed after three to five meters. Chances of successful deepening the hole appeared slim with the risk to the BHA equally high, and it was necessary to abandon the hole at a total depth of 941 meters.

The hole was then pumped full of barite weighted mud. The drill string was pulled without resistance until only six stands remained in the hole. Overpull of up to 125,000 pounds was necessary to pull these final stands. A keyseat situation would explain the phenomenon, but a constant hole angle of only two degrees had been measured from 18 meters BSF. The bit cleared the seafloor at 0300 hours, August 12, with only 23 cumulative rotating hours.

Hole $584 \mathrm{~A}$

An offset of 524 meters west was entered into the vessel's positioning system, and Hole 584A was spudded at 0511 hours, August 12, in a second attempt at deep penetration. The seafloor was "felt" at 4125 meters by weight indicator, 31 meters deeper than the PDR reading.

The hole was drilled to 901.5 meters with no significant drilling problems. Spot cores were taken at 600,700 and 800 meters for stratigraphic control. Hole $584 \mathrm{~A}$ was found to be structurally high to Hole 584 by about 50 meters, and continuous coring was to begin after the "wash barre1" had been pulled 
to 501.5 meters. When the core barrel had been pumped into place for the first core of the series, however, the bit could not be worked back to total depth. The symptoms of annular packing and sticking of the BHA experienced in Hole 584 were again fought without success. The problem zone appeared to be at about 865 meters BSF, and about five hours were spent in trying to clean the hole past that depth.

A wireline trip was made to retrieve the inner core barrel, and the pipe was lowered until the bit contacted hole fill at 879 meters. A second core barrel, fitted with a shifting tool, was then pumped down. During the wireline trip to retrieve the barrel and release the bit, the hole continued to fill. The bit and associated components were left at 868 meters.

The hole was then filled with weighted mud and the pipe was pulled to logging depth. The sonic velocity/dual induction/caliper/gamma ray sonde was assembled first and started down the pipe. The sonic signal was noted almost immediately to be noisy, and the tool was brought back on deck. After about four hours, problems in the circuitry had not been resolved and difficulties with the sonic surface interface module were suspected. The formation density/neutron porosity/ gamma ray tool was then assembled and deployed, as time constraints precluded further efforts with the sonic equipment. The tool descended unobstructed into open hole to about 505 meters BSF, where a bridge or ledge was encountered With much "working", the tool appeared to be going down the hole, but dragging and stopping frequently. At 660 meters BSF, an abbreviated $10 g$ was recorded up to 400 meters to cover an interval of particular interest before possibly damaging the tool in attempting to work it down the hole. On the second attempt the sonde would not pass the obstruction at 510-515 meters. A full log run was then made, with gamma ray and neutron curves recorded to the seafloor. The cable and tool were then recovered, and a large knot was found in the cable about 330 meters above the head. (Subsequent review of the logs revealed that the tool had never gone past about 510 meters.) The cable was still electrically functional, and an additional $1 \frac{1}{4}$ hours were spent in troubleshooting the sonic velocity equipment. With no resolution in sight and only 60 hours of site time remaining, logging efforts were terminated in favor of one final thrust to reach a major scientific objective of the voyage.

The drill string was tripped for a new bit, and the pipe was on deck at 2230 hours, August 14. The vessel was then offset to the final drilling location some 700 meters east of the positioning beacon. The bi-monthly magnaflux inspection of the power sub/swivel assembly was conducted concurrently and continued for $1 \frac{1}{4}$ hours after the move had been completed.

\section{Hole 584B}

The PDR reading at the new location was 4096 meters. A "mudline" core had been included in the coring plan, and the bit was lowered with extra caution below the indicated depth to ensure acquisition of the sediment/water interface without overfilling the core barrel. Unfortunately, weight indicator readings were misinterpreted, and two "water cores" were pulled before a 
positive reading was seen. A successful 1.6 meter core was received after the bit had been lowered to 4153.4 meters, and water depth was set at $4152 \mathrm{~m}$ 56 meters below PDR depth.

With time running out, the hole was drilled toward the target depth of 940 meters (total depth of Hole 584), where continuous coring was to begin. "Wash" core barrels were retrieved from 509.7, 644.1, 846.8 and 943.1 meters. A spot core was cut at 644.1-753.8 meters for stratigraphic control. No hole problems were encountered during the drilling ahead operation. On the first attempt to retrieve the final wash inner barre1, the overshot malfunctioned and dropped the barrel during the sandline trip. As preparations were being made for the second retrieval attempt, the drill string began torquing and the pump pressure began climbing. Two joints were set back and the pipe came free. During the ensuing wireline trip, about 25 meters of fill accumluated in the hole. An inner barrel was pumped down and the bit was washed down through the fill to total depth. A final core was then cut to 954 meters. Eight joints were set back before the wireline trip, and the bit took weight about 80 meters off bottom after the core had been retrieved. A good quality three meter core was recovered from a badly collapsed core liner. The hole was then filled with weighted mud, and the pipe trip began only two hours ahead of the projected deadline. The bit arrived on deck at 0800 hours, August 17, and the vessel departed for Hakodate at 0815 hours.

\section{Site 584 to Hakodate}

The final leg of the voyage was a transit of 185 miles to the port of Hakodate near the southern tip of Hokkaido. Winds and seas were light, but fog, heavy fishing traffic and adverse currents limited the vessel's speed to 7.6 knots. Leg 87 came to its official end at 0711 hours, August 18, when the anchor was let go at the quarantine anchorage outside Hakodate Harbor.

\section{$\underline{\text { Drilling and Coring Equipment }}$}

The standard DSDP bottom hole assembly was deployed in all rotary cored holes. This consisted of a bit release, one $8 \frac{1}{4} "$ drill collar, coring top and head subs, three $8 \frac{1}{4} "$ drill collars, one five foot stroke bumper sub, three $8 \frac{1}{4} "$ drill collars, two bumper subs, two $8 \frac{1}{4} "$ drill collars, crossover sub and one $7 \frac{1}{4}$ " drill collar. A blade stabilizer was added about 20 meters above the bit for Holes 584 and 584A. It was removed for Hole $584 \mathrm{C}$ because of the severe annular plugging experienced in the offset holes. An abbreviated BHA was used in the HPC holes. It was made up of a bit sub, one $8 \frac{1}{4} "$ drill collar, two stabilizers (for spacing), one $8 \frac{1}{4} "$ drill collar, top sub, HPC seal sub, one 12 foot gammaloy drill collar (for magnetic core orientation), two $8 \frac{1}{4} "$ drill collars, two bumper subs, two $8 \frac{1}{4} "$ drill collars, crossover sub and one $7 \frac{1}{4} "$ drill collar. An outer core barrel assembly, with bit and bit release, was lost at Hole 582 when the vessel took a positioning excursion of about 275 meters with the BHA only partially below the seafloor. 
The newly redesigned hydraulic bit release was used at six holes. Premature release occurred on two occasions, and the only attempt at actuation failed because of mud in the mechanism. Further design review is in progress. The mechanical bit release was used in five holes. The only release attempt was routinely successful. On recovery, the top connector was found to contain a considerable amount of mud and cuttings. However a solid plug did not form and block passage of logging tools, as has occurred several times previously.

The heave compensator was the source of multiple problems on Leg 87 and was disabled for the final third of the voyage. Electrical wiring problems in the hydraulic pump timer control and antislingshot valve control circuits kept the compensator out of service much of the time at the first site. Severe fluid leakage from the compensator cylinder put the unit out of service for the duration of the voyage--just as heavy typhoon generated swells were building and compensation was most needed. The source of the leakage is undetermined pending disassembly of the cylinder during the Hakodate port call.

Scheduled preventive maintenance inspections were effective in detecting cracks in two locations of potentially catastrophic failure. A set of 350 ton drill pipe elevators was being cleaned for magnetic inspection when a large crack in the upper hinge was detected visually. This crack could easily have led to serious injury to rig personnel and/or loss of a drill string. Visual inspection also detected small cracks in the welds of the hangoff padeye for the starboard derrick guide rail. Dye penetrant inspection revealed additional cracking and possibly imminent failure. This resulted in the interruption of operations at Site 583 and the premature return to Yokohama for repairs. The cracked padeye was the replacement of the one that failed on Leg 46, causing severe damage to the derrick and early termination of the cruise.

The only significant problem with DSDP coring equipment resulted from a core barrel latch sleeve which had been fabricated from steel much softer than had been specified for the part. The steel deformed under upward pressure from the inner barrel latch fingers, permitting the barrels to unseat and to be pushed upward out of the bit. After several unseatings, severe damage rendered the latching shoulder ineffective. This resulted in several instrument probe misruns and extremely low core recovery in the lower portion of Hole 583F. All latch sleeves on board have been tested for hardness and only properly hardened units remain on the rig.

\section{Special Tools}

The hydraulic piston corer was used at Holes 583, 583A, 583B, and 583C. In general, coring results were good in clay lithologies and poor when sand predominated. Incomplete stroke and low core recovery were experienced from the outset at Hole 583, and mechanical difficulties were suspected. The section penetrated was subsequently found to contain numerous unconsolidated sand turbidites. The incompressibility of the sand apparently reduced the penetrating ability of the HPC severely. In many cases the loose sand appeared 
to have been lost through the core catchers during retrieval of the inner barrel. On occasion both flapper and finger core catchers were stuck in the open position by sand and grit in the hinge mechanisms.

Core quality and recovery were good, but not remarkable in the other three holes, where the sediment was mostly still clay with a few interbedded turbidites. Refusal depth for the five meter coring assembly was reached at only about 50 meters BSF in Hole 583C. Full cores were being recovered from $583 \mathrm{~A}$ when the hole was terminated at 54 meters after objectives were achieved.

Hole 583B was terminated by the failure of the threaded connection between the lower shaft and the inner seal sub. A five meter core had been attempted from 25 meters BSF, and pressure had not bled off to indicate full stroke. After a ten minute delay for a heat flow measurement, the string was raised with the drawworks to withdraw the core barrel from the sediment. The failure occurred when overpul1 had reached 50,000 pounds.

The Kuster single shot instrument was used for core orientation in the HPC holes and for monitoring hole angle in the rotary cored holes. A wide variety of problems were experienced, and only about 30 per cent of the shots were of usable quality. Commonplace troubles were malfunctioning mechanical timers which failed to ignite flashbulbs, downhole motion, films exposed by light leaking into film loaders and underexposed or underdeveloped film discs. This equipment requires more maintenance and skill to produce quality results than had been anticipated.

The instrumented core barrel probe also saw extensive use on Leg 87 . The new probe can extract a pore water sample while measuring temperature and pressure, all under in situ conditions. The scientific potential of this tool is undeniably great, and some valuable data were collected on this cruise. Several partial and total misruns resulted from battery, wiring and internal plumbing problems, however. In addition, misruns resulted from a defective core barrel latch sleeve and from a float valve which had not been properly modified. The expenditure of rig time on Leg 87 was relatively great for the amount of usable data collected. The combination of three functions also dictates increased "in the mud" time. Minimum time is now 30 minutes on bottom without circulation or rotation. This greatly increases the risk of sticking the BHA in any but the best of hole conditions.

The self contained heat flow shoe was also used several times in HPC holes. This instrument has little impact on operations and consumes only a few minutes of rig time per measurement, as compared with $1 \frac{1}{2}$ to $2 \frac{1}{2}$ hours per probe run. The effect on the mechanism of leaving the corer fully stroked for prolonged intervals before withdrawal should be studied. The HPC shaft connection failure occurred immediately after a heat flow measurement had been taken. Quality of the HPC shoe instrument data is under evaluation, and the tool could prove to be a valuable addition to DSDP capabilities. A special HPC assembly was put together for a direct comparison test of the two temperature instruments at the conclusion of coring in Hole 583A. Unfortunately the results were somewhat inconclusive due to a slight malfunction in the probe circuitry. 
Core Bits

Core bit performance on Leg 87 was excellent in the relatively soft sediments penetrated. Model F93CK bits were used exclusively in the rotary cored holes, with excellent penetration rates. The bit released in Hole 584A had drilled and cored 1843 meters in just 38 rotating hours and showed no sign of failure.

\section{Beacons}

A total of five ORE positioning beacons were expended during Leg 87 . A11 beacons launched remained strong for the duration of site occupancy. The original Site 583 beacon ( $16 \mathrm{kHz}$ single life) was operating at 30 to 40 per cent of its original strength 20 days after it was dropped on the vessel's return from the midleg port call. It was detected on the ship's first pass across the site and was used for positioning until a replacement beacon was dropped. A $13.5 \mathrm{kHz}$ single life unit was found to be "dead" when it was removed from the shipping carton. It will be returned for inspection and repair.

\section{Dynamic Positioning}

"Elmer" performed his stationkeeping duties well and faithfully in sometimes complex combinations of wind, current and swell. Positioning was actually the least stable in the northern operating area where lack of wind or current forces resulted in some "hunting" and overcorrection of position. The 275 meter positioning excursion which caused the loss of part of a BHA was no fault of the positioning system.

Vertical reference gyros were again the primary source of trouble, with three units failing. The first failure occurred during coring operations, but alert action of watch personnel held the excursion to about 90 meters as the standby unit was put into service. The second unit failed during the final pipe trip only two hours prior to departure for Hakodate. The backup gyro then failed on starting, leaving the vessel with only two operational units at the end of the cruise.

\section{$\underline{\text { Engineering }}$}

Problems with the ship's propulsion, generating and auxiliary equipment had little impact on operations, but an abnormally high level of behind the scenes maintenance activity was necessary to keep the various systems functioning. A pervasive'problem on Leg 87 was that of moisture. Condensation resulting from the extreme humidity and incessant rain caused problems throughout the vessel in motors, wiring and electrical/electronics equipment. The ship's electrician had few dull moments. Condensation contamination also necessitated frequent lube oil changes on rig and other outdoor machinery. 
A burnt out electric motor on the lube oil pump for the starboard shaft reduction gear caused a delay of about $2 \frac{1}{2}$ hours during the transit from Yokohama back to Site 583. An adapter was fabricated so that a spare motor with a different shaft size could be used as a replacement.

Minor flooding and some damage to records resulted from the failure of a deteriorated hot water line in the overhead of the GMI storekeeper's office. A considerable length of wasted plumbing had to be removed before sound pipe suitable for attaching repair fittings was found.

\section{$\underline{\text { Logging }}$}

We1l logging operations were performed at two of the 14 holes drilled. Good quality logs were recorded, but hole bridging precluded reaching the interval of greatest interest near the bottom of the hole in both cases. A full suite of logs were obtained from Hole 583F. Only the formation density/neutron porosity/caliper/gamma ray log run was made in Hole 584A. Equipment problems with both sonic velocity $\log$ tools deleted this $\log$ from the program, and the dual induction $\log$ alone was not considered valuable enough to warrant the operating time. Numerous crossplots and special presentations were prepared by the logging engineer in consultation with the scientists.

\section{Hydrocarbons}

Hydrocarbon gas was present in the cores at all three sites. Gas samples were collected from the core liners and analyzed chromatographically with composition and methane/ethane ratios plotted against depth. Traces of heavier gases through the pentane family caused some doubt as to whether the gas had been formed biogenically in the shallow sediments cored. This generated safety concerns at Site 584 , where coarse sand strata and potential structural traps were present. Methane/ethane ratios, however, remained well above levels indicative of thermogenic hydrocarbons and the heavier gas concentrations remained minute. There were no signs of liquid hydrocarbons.

\section{Weather and Currents}

Leg 87 was conducted in the Western Pacific during typhoon season and, as expected, tropical cyclones had an impact on operations. Typhoon Ruby passed to the east and provided strong following winds during the CHALLENGER's initial transit to the Nankai area. The distant passage of Tropical Storm Van caused large swells on July 4th during Hole 582B operations. The swells resulted in considerable heave and string weight fluctuation, but were well enough aligned with wind and current that vessel operating limits were not exceeded. Typhoons Andy and Bess produced swells which made operating conditions marginal before Bess's approach forced termination of Site 584 operations. Bess than changed course and overtook the vessel, causing light damage and one minor injury. 
The Nankai Trough sites were located near the main flow of the Oyashio Current. Current velocity was estimated frequently to exceed one knot. It was a definite operational factor when not aligned with wind and/or swe11, and it was the primary cause of the positioning excursion which resulted ina BHA failure and loss of Hole 582. The warm Oyashio water combined with relatively cooler air to produce excessively humid and rainy weather. This resulted in electrical and other condensation-related problems such as mildew and damage from water accumulating on decks.

Weather conditions did not affect on-site operations in the northern operating area (Site 584). Persistent fog made transits to and from the site somewhat difficult, considering the heavy fishing and merchant traffic of the area. Currents on the site were nil, despite the fact that the area is influenced by two major current systems.

\section{Communications}

Due to the distance and radio propagation conditions, communications with SIO radio station WWD were sporadic at best. Nearly all the Leg $87 \mathrm{CW}$ message traffic, both incoming and outgoing, was handled through the U.S. Coast Guard radio station in Guam. The Coast Guard's cooperation and assistance were excellent and were vital to the operational success of the leg.

Several radiotelephone calls were made as a result of mechanical/operational crises. Two of these were handled by the Coast Guard in Guam and the remainder were made through commercial stations in Japan. As usual, numerous "ham" radio patches were made to the U. S. for the benefit of shipboard personnel. This again proved, on occasion, to be our most effective and dependable means of communication with the U. S. There were no failures of the vessel's communications equipment during Leg 87.

\section{Personne1}

Leg 87 was a long and frustrating one. The disappointments of lost objectives, together with persistently gloomy weather, took a toll on shipboard morale. There were no serious illnesses, but it was necessary for a member of the scientific staff to receive dental attention during the midleg port call in Yokohama. Several minor injuries occurred, the most serious of which was a fractured hand suffered by a marine technician. He was repatriated to the U.S. from Yokohama at the midleg port call, and another technician replace him. A rotary helper sustanced a knee injury during the typhoon while he was securing gear that was adrift on the main deck.

The GMI crew and the DSDP technical staff are to be commended for turning in professional performances under trying circumstances.

Glen N. Foss

Cruise Operations Manager

Deep Sea Drilling Project 


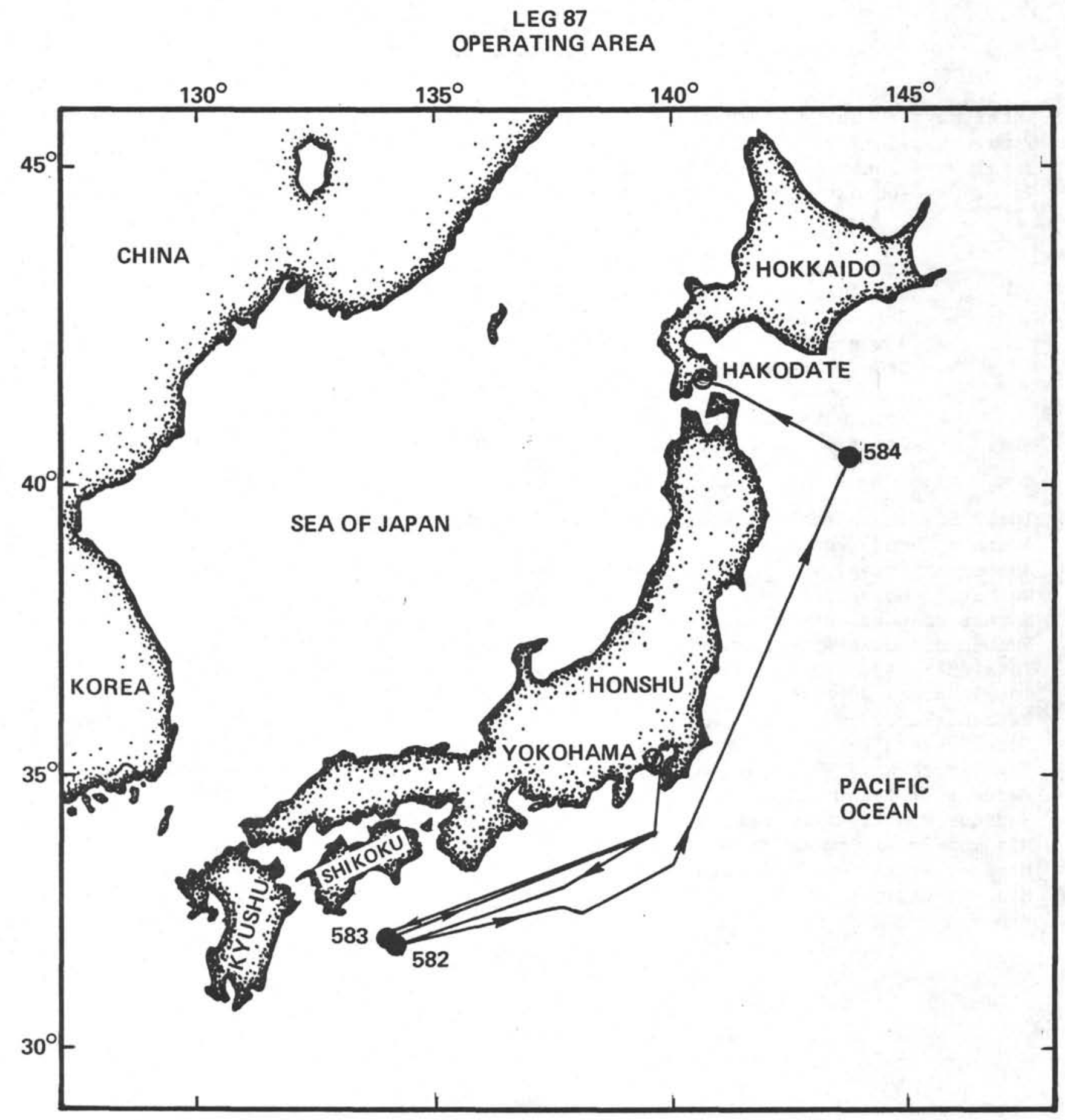




\section{INTERNATIONAL PHASE OF OCEAN DRILLING \\ DEEP SEA DRILLING PROJECT \\ OPERATIONS RESUME \\ LEG 87}

Total Days (June 19, 1982-August 18, 1982) . . . . . . . . . . 59.26

Total Days in Port . . . . . . . . . . . . . . . . . . 6.51

Total Days Under Way Including Site Survey . . . . . . . . . . . . 11.42

Total Days on Site.................... . . . 41.33

\begin{tabular}{|c|c|c|}
\hline Drilling Time & . & \\
\hline Coring Time. & & - \\
\hline Downhole Measureme & ent. & \\
\hline Stuck Pipe \& Hole & Trouble & e \\
\hline Wait on Weather . & & • \\
\hline Mechanical Repair & & \\
\hline her & 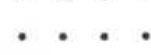 & \\
\hline
\end{tabular}

Total Distance Traveled Including Survey (nautical miles) . . . . . 2301

Average Speed (knots) ................. . 8.5

Number of Sites ....................... . . . . . . 3

Number of Holes Drilled .. . . . . . . . . . . . . . . 14

Number of Cores Attempted .................... . 311

Number of Cores with Recovery . . . . . . . . . . . . . . 293

Total Meters Cored . . . . . . . . . . . . . . . . . 27698

Total Meters Recovered . . . . . . . . . . . . . . . . 1158.4

Percent Recovery . . . . . . . . . . . . . . . . . . 41.8

Total Meters Drilled . . . . . . . . . . . . . . . 2561.4

Total Meters of Penetration . . . . . . . . . . . . . 5331.2

Percent of Penetration Cored . . . . . . . . . . . . . . 52.0

Maximum Penetration (meters) . . . . . . . . . . . . . 954.0

Minimum Penetration (meters) . . . . . . . . . . . . . 28.0

Maximum Water Depth (meters) . . . . . . . . . . . . . 4892.0

Minimum Water Depth (meters) . . . . . . . . . . . . 4124.0 
TOTAL TIME DISTRIBUTION

LEG 87

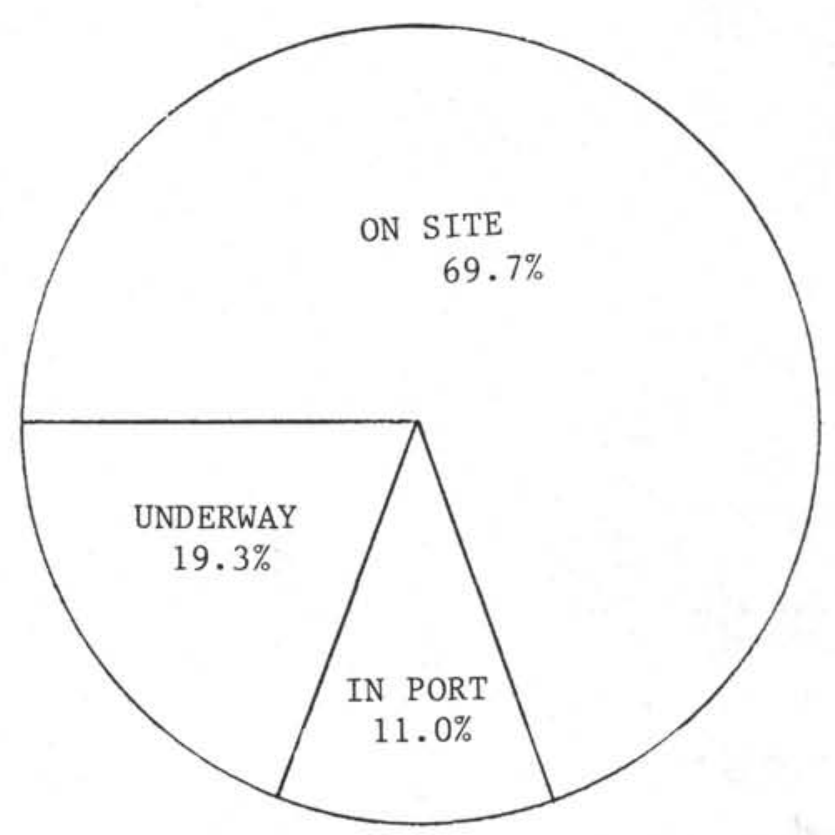

ON-SITE TIME BREAKDOWN

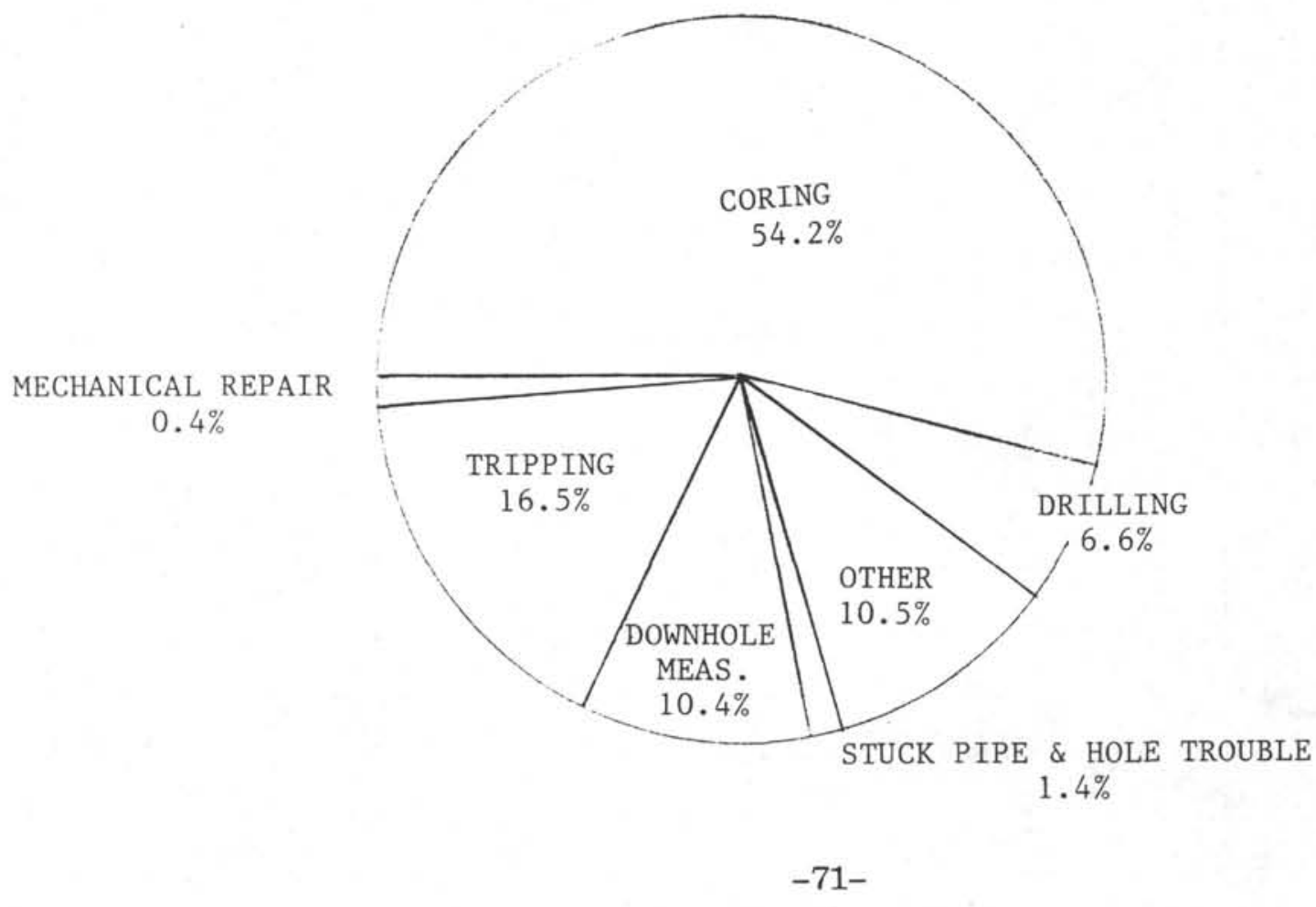


DEEP SEA DRILLING PROJECT

TIME DISTRIBUTION

\section{$\angle E G-87$}

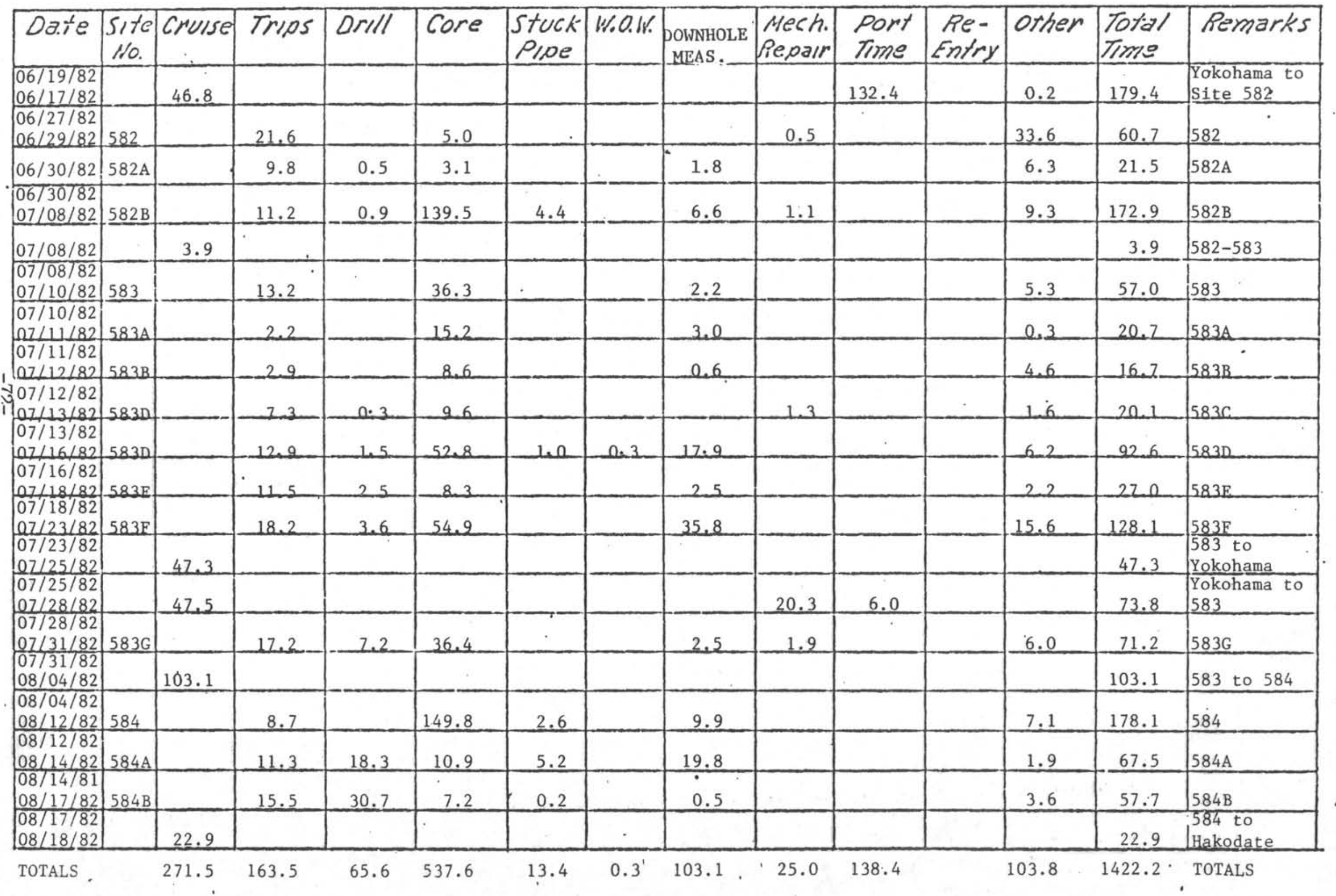


INTERNATIONAL PHASE OP OCEAN DRILLING DEEP SEA DRILLING PROJECT

SITE SUMMARY

LEG 87

Hole Latitude Long1tude

$\begin{array}{cccc}\text { Water } & \text { Number } & \text { Cores } & \text { Percent of } \\ \text { Depth } & \text { of } & \text { w1th } & \text { Cores W1th }\end{array}$

with Cores W1th

Meters

Metere

Cored Recovered

Percent

Recovered

Meters Total Avg. Time Time

Meters

$283^{\circ} 46.51 \mathrm{~N}-133^{\circ} 24.81 \mathrm{~B}-4892$

\begin{tabular}{lllll}
582 & $31^{\circ}$ & $46.5^{\prime} \mathrm{N}$ & $133^{\circ}$ & $54.8^{\prime} \mathrm{B}$ \\
$582 \mathrm{~A}$ & $31^{\circ}$ & $46.5^{\prime} \mathrm{N}$ & $133^{\circ}$ & $54.8^{\prime} \mathrm{B}$ \\
$582 \mathrm{~B}$ & $21^{\circ}$ & $46.5^{\prime} \mathrm{N}$ & $133^{\circ}$ & $54.8^{\circ} \mathrm{B}$ \\
\hline
\end{tabular}

4892
4892
4892

TOTALS $\quad 73 \quad 79$

\begin{tabular}{rrrr}
3 & 75.0 & 38.8 & 18 \\
2 & 100.0 & 19.4 & 16 \\
69 & 94.5 & 700.9 & 269 \\
\hline 74 & 93.7 & 759.1 & 304 \\
\hline
\end{tabular}

\begin{tabular}{|c|c|c|c|c|c|}
\hline 583 & $31^{\circ} 50.0^{\prime} \mathrm{N}$ & $133^{\circ}$ & $51.4^{\prime} \mathrm{E}$ & 4673 & 27 \\
\hline $3 \mathrm{~A}$ & $31^{\circ} 50.0^{\prime} \mathrm{N}$ & $133^{\circ}$ & $51.4 \mathrm{~B}$ & 4632 & 11 \\
\hline 33B & $31^{\circ} 49.8^{\prime} \mathrm{N}$ & $133^{\circ}$ & $51.3^{\prime} \mathrm{B}$ & 4758.7 & 6 \\
\hline 3C & $31^{\circ} 49.8^{\prime} \mathrm{N}$ & $133^{\circ}$ & $51.3^{\prime} \mathrm{B}$ & 4758.7 & 5 \\
\hline 583D & $31^{\circ} 49.8^{\prime} \mathrm{N}$ & $133^{\circ}$ & $51.3^{\prime} \mathrm{B}$ & 4759.0 & 29 \\
\hline & $31^{\circ} 50.1^{\prime} \mathrm{N}$ & $133^{\circ}$ & $51.3^{\prime} \mathrm{B}$ & 4665.0 & 5 \\
\hline & $31^{\circ} 50.1^{\prime} \mathrm{N}$ & $133^{\circ}$ & $51.3^{\prime} \mathrm{E}$ & 4665 & 30 \\
\hline & $31^{\circ} 50.1^{\prime} \mathrm{N}$ & $133^{\circ}$ & 51.4 ' B & 4663 & 15 \\
\hline
\end{tabular}

\begin{tabular}{llll}
$583 \mathrm{G} \quad 31^{\circ} 50.1^{\prime} \mathrm{N} \quad 133^{\circ} 51.4^{\prime} \mathrm{B} \quad 4663$ \\
\hline
\end{tabular}

TOTALS 12

\begin{tabular}{rrrrrrrrrr}
22 & 81.5 & 152.0 & 83.9 & 55.2 & 0 & 152.0 & -- & 57.0 & \\
11 & 100.0 & 54.0 & 47.8 & 88.5 & 0 & 54.0 & & 20.7 \\
5 & 83.3 & 28.0 & 24.7 & 88.2 & 0 & 28.0 & -- & 16.7 & \\
5 & 100.0 & 24.0 & 17.9 & 74.0 & 25.0 & 49.0 & -- & 20.1 & \\
28 & 96.6 & 279.8 & 68.5 & 24.5 & 46.8 & 326.6 & 33.2 & 92.6 \\
2 & 40.0 & 48.3 & 1.0 & 2.0 & 150.4 & 198.7 & 85.8 & 27.0 & \\
27 & 90.0 & 289.3 & 46.8 & 16.2 & 150.4 & 439.7 & 35.4 & 128.1 & \\
15 & 100.0 & 143.4 & 62.1 & 43.3 & 306.6 & 450.0 & 35.0 & 71.2 & \\
\hline 115 & 89.8 & 1018.8 & 352.7 & 34.6 & 679.2 & 1698.0 & -- & $-\ldots$ & 433.4 \\
\hline
\end{tabular}

\begin{tabular}{|c|c|c|c|c|c|c|c|c|c|c|c|c|c|c|}
\hline $\begin{array}{l}584 \\
584 \mathrm{~A} \\
584 \mathrm{~B} \\
\end{array}$ & $\begin{array}{ll}40^{\circ} & 28.0^{\prime} \mathrm{N} \\
40^{\circ} & 28.0^{\prime} \mathrm{N} \\
40^{\circ} & 28.0^{\prime} \mathrm{N} \\
\end{array}$ & $\begin{array}{l}143^{\circ} 57.1^{\prime} \mathrm{B} \\
143^{\circ} 56.7^{\prime} \mathrm{B} \\
143^{\circ} 57.6^{\prime} \mathrm{B} \\
\end{array}$ & $\begin{array}{l}4124 \\
4125 \\
4152 \\
\end{array}$ & $\begin{array}{r}98 \\
3 \\
3 \\
\end{array}$ & $\begin{array}{r}98 \\
3 \\
3 \\
\end{array}$ & $\begin{array}{l}100.0 \\
100.0 \\
100.0 \\
\end{array}$ & $\begin{array}{r}941.0 \\
28.9 \\
22.0 \\
\end{array}$ & $\begin{array}{r}478.7 \\
10.7 \\
11.9 \\
\end{array}$ & $\begin{array}{l}50.9 \\
36.9 \\
54.0 \\
\end{array}$ & $\begin{array}{c}0 \\
872.6 \\
932.0 \\
\end{array}$ & $\begin{array}{r}941.0 \\
901.5 \\
954.0 \\
\end{array}$ & $\begin{array}{l}39.5 \\
59.4 \\
58.6 \\
\end{array}$ & $\begin{array}{r}178.1 \\
67.5 \\
57.7 \\
\end{array}$ & \\
\hline & & & TOTALS & 104 & 104 & 100.0 & 991.9 & 501.3 & 50.5 & 1804.6 & 2796.5 & 51.5 & $\cdots$ & 303.3 \\
\hline & & GRAND & TOTALS & 311 & 293 & 94.2 & 2769.8 & 1158.4 & 41.8 & 2561.4 & 5331.2 & . & & \\
\hline
\end{tabular}


INTERNATIONAL PHASE OF OCEAN DRILLING

DEEP SRA DRILLING PROJECT

$$
\begin{aligned}
& \text { BIT SUPAARY } \\
& \text { LEG } 87
\end{aligned}
$$

Hole Mfg. S1ze

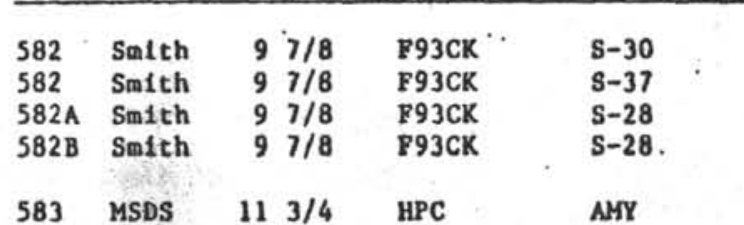

$\begin{array}{lllll}583 & \text { MSDS } & 11 & 3 / 4 & \text { HPC } \\ 583 A & \text { MSDS } & 11 & 3 / 4 & \text { HPC } \\ \text { 583 } & \text { MSDS } & 11 & 3 / 4 & \text { HPC }\end{array}$

5838 MSDS $113 / 4$ HPC

AMY

AMY

AMY

$5830 \mathrm{Smith}$

\section{$9717 \quad$ F93CK}

$583 \mathrm{E}$ Smith $97 / 8$. F93CK

$583 F$ Smith

$\begin{array}{lll}97 / 8^{\circ} & \text { F93CK } \\ 9 / 8 & \text { F93CK }\end{array}$

$\mathrm{s}-38$

s-38

$\mathrm{s}-38$

583G Sm1th

$97 / 8 \quad$ P93CK

S-28

0
38.8
19.4
700.9
152.0
54.0
18.0
24.0

0
0
29.1

29.1

Meters
Total

Total

0
0
0
25.0

Penet.

0

29.1
749.4

0.6

0.6
1.0

1.0
19.0

152.0

54.0

28.0

49.0

Hour

on

Condition

Remarka

284 sateh 718 Bgack

$\begin{array}{lllll}584 & \text { Smith } & 97 / 8 & \text { F93CK } & 8 \\ 584 A & \text { Sm1th } & 9 / 8 & \text { F93CK } & 8 \\ & & & & \end{array}$

584B Smith

$97 / 8$ F93CK

$s-40$

279.8
48.3

25.0

326.6

$\begin{array}{rr}46.8 & 326.6 \\ 150.4 & 198.7\end{array}$

150.4

439.7

TOTAL

965.0

306.6

450.0

TOTAL

1286.7

9.8
2.3
12.4
24.5
12.9
33.5

Good

$\begin{array}{ll} & \text { Lost on trip-HBR failur } \\ & \text { Lost when BHA broke. } \\ \text { Respud w/o round trip } \\ \text { T } \phi \text {-B2SQ-I } & \text { Suitable for rerun }\end{array}$

Ngt Inspected.

TP-BISE-I

Unknown

$T$ T $-B 5-I$

941.0

22.8

872.6

901.5

15.2

38.0

Unknown

Unknown

TOTAL

1842.5

22.0

932.0

954.0

16.3

$T \phi-B 1 S E-I$

Sultable for rerun.

Respud w/o round trip.

Released by HBR

Loose cone.

Respud w/o round trip.

Released for logging.

No sign of fallure.

Suitable for reuse. 
DEEP SEA DRILLING PROJECT

BEACON SUMMARY

LEG 87

\begin{tabular}{|c|c|c|c|c|c|c|}
\hline & $\begin{array}{c}\text { Site } \\
\text { Number }\end{array}$ & Make & $\begin{array}{l}\text { Freq. } \\
\mathrm{kHz}\end{array}$ & $\begin{array}{l}\text { Serial } \\
\text { Number }\end{array}$ & $\begin{array}{c}\text { Site Time } \\
\text { Hours }\end{array}$ & Remarks \\
\hline & $\begin{array}{l}582 \\
582 \mathrm{~A} \\
482 \mathrm{~B}\end{array}$ & $\begin{array}{l}\text { ORE } \\
\text { ORE } \\
\text { ORE }\end{array}$ & $\begin{array}{l}13.5 \\
13.5 \\
13.5\end{array}$ & $\begin{array}{l}141 \\
141 \\
141\end{array}$ & $\begin{array}{r}60.7 \\
21.5 \\
172.9 \\
255.1\end{array}$ & $\begin{array}{l}\text { Double life. } \\
\text { Strong for duration. }\end{array}$ \\
\hline$\stackrel{1}{\mathrm{~T}}$ & $\begin{array}{l}583 \\
583 \mathrm{~A} \\
583 \mathrm{~B} \\
583 \mathrm{C} \\
583 \mathrm{D} \\
583 \mathrm{E} \\
583 \mathrm{~F}\end{array}$ & $\begin{array}{l}\text { ORE } \\
\text { ORE } \\
\text { ORE } \\
\text { ORE } \\
\text { ORE } \\
\text { ORE } \\
\text { ORE }\end{array}$ & $\begin{array}{l}16.0 \\
16.0 \\
16.0 \\
16.0 \\
16.0 \\
16.0 \\
16.0\end{array}$ & $\begin{array}{l}127 \\
127 \\
127 \\
127 \\
127 \\
127 \\
127\end{array}$ & $\begin{array}{r}57.0 \\
20.7 \\
16.7 \\
20.1 \\
92.6 \\
27.0 \\
128.1 \\
362.2\end{array}$ & $\begin{array}{l}\text { Strong for duration. } \\
(\simeq 40 \% \text { strength on return to site } 20 \text { days } \\
\text { after drop) }\end{array}$ \\
\hline & $\begin{array}{l}583 G \\
583 G \\
584 \\
584 A \\
584 B\end{array}$ & $\begin{array}{l}\text { ORE } \\
\text { ORE } \\
\text { ORE } \\
\text { ORE } \\
\text { ORE }\end{array}$ & $\begin{array}{l}13.5 \\
13.5 \\
16.0 \\
16.0 \\
16.0\end{array}$ & $\begin{array}{l}137 \\
134 \\
111 \\
111 \\
111\end{array}$ & $\begin{array}{r}69.9 \\
-- \\
178.1 \\
67.5 \\
57.7 \\
303.3\end{array}$ & $\begin{array}{l}\text { Single life-strong for duration. } \\
\text { Single life-dead in the box. } \\
\text { Double-1ife. } \\
\text { Strong for duration. }\end{array}$ \\
\hline
\end{tabular}


DEEP SEA DRILLING PROJECT

I.OGGING SUMMARY

LEG 87

\begin{tabular}{|c|c|c|c|c|c|c|c|c|c|c|c|}
\hline HOLE & $\begin{array}{l}\text { TOTAL } \\
\text { DEPTH } \\
(M)\end{array}$ & $\begin{array}{c}\text { WATER } \\
\text { DEPTH } \\
(M)\end{array}$ & $\begin{array}{c}\text { OPEN } \\
\text { ENDED } \\
\text { PIPE AT } \\
(M)\end{array}$ & $\begin{array}{l}\text { FLUID } \\
\text { IN } \\
\text { HOLE }\end{array}$ & $\begin{array}{l}\text { BIT } \\
\text { SIZE }\end{array}$ & $\begin{array}{l}\text { TOTAL } \\
\text { TIME FOR } \\
\text { LOGG ING } \\
\text { (HOURS) }\end{array}$ & $\begin{array}{l}\text { RUN } \\
\text { NO. }\end{array}$ & $\begin{array}{c}\text { LOGS } \\
\text { RECORDED }\end{array}$ & $\begin{array}{c}\text { FROM } \\
\text { (M) }\end{array}$ & $\begin{array}{l}\text { T0 } \\
\text { (M) }\end{array}$ & OBSERVATIONS \\
\hline 582 & 4930.8 & 4892.0 & & $\cdot$ & & & & & & & Lost hole-BHA failure. \\
\hline $582 \mathrm{~A}$ & 4940.5 & 4892.0 & & & & & & & & & Too shallow. \\
\hline $582 \mathrm{~B}$ & 5641.4 & 4892.0 & & & & & & & & & Could not release bit-HBR failure. \\
\hline 583 & 4825.0 & 4673.0 & & & & & & & & & HPC hole-no logging. \\
\hline $583 \mathrm{~A}$ & 4686,0 & 4632.0 & & & & & & & & & HPC hole-no logging. \\
\hline $583 \mathrm{~B}$ & 4786.7 & 4758.7 & & & & & & & & & HPC hole-no logging. \\
\hline $583 \mathrm{C}$ & 4807.7 & 4758.7 & & & & & & & & & HPC hole-no logging. \\
\hline $583 \mathrm{D}$ & 5085.6 & 4759.0 & & & . & & & & & & No logs requested. \\
\hline $583 \mathrm{E}$ & 4863.7 & 4665.0 & & & & & & & & & $\begin{array}{l}\text { Terminated for lack of recovery. } \\
\text { Too shallow to log. }\end{array}$ \\
\hline $583 \mathrm{~F}$ & 5104.7 & 4665.0 & 4754.0 & $12 \mathrm{ppg}$ & $97 / 8$ & 5.0 & 1 & $\begin{array}{l}\text { PDBHC/DISFL } \\
\text { CAL/GR }\end{array}$ & 4935.0 & 4753.5 & Bridge in hole; DDBHC no gooc. \\
\hline $583 \mathrm{~F}$ & 5104.7 & 4665.0 & 4754.0 & 12 ppg & $97 / 8$ & 3.7 & 2 & SWF/GR & 4930.0 & 4753.5 & Good sonic TT curve. \\
\hline $583 \mathrm{~F}$ & 5104.7 & 4665.0 & 4754.0 & $\begin{array}{l}12 \mathrm{ppg} \\
12 \mathrm{mud}\end{array}$ & $97 / 8$ & 5.8 & 1. & FGT-CNL-GR & 4935.0 & 4753.5 & $\begin{array}{l}\text { GR \& CNL curves to seatloor at } \\
4662 \text { meters ( } 108 \text { depth) }\end{array}$ \\
\hline $583 \mathrm{~F}$ & 5104.7 & 4665.0 & 4783.0 & $\begin{array}{rl}12 & \mathrm{Ppg} \\
\vdots, \mathrm{mud} \\
\end{array}$ & $97 / 8$ & 3.0 & 1 & $\mathrm{HRT}$ & -- & -- & $\begin{array}{l}\text { Computer oyerheated } \\
\text { Air conditioner falled. }\end{array}$ \\
\hline $583 \mathrm{~F}$ & 5104.7 & 4665.0 & 4783.0 & $\begin{array}{r}12 \mathrm{ppg} \\
\text { mud }\end{array}$ & $27 / 8$ & 5.3 & 2 & HRT & 4560.0 & 4937.0 & Maximum temperature $9^{\circ} \mathrm{C}$. \\
\hline & & & & & . & $2.5=$ & $25.3 \mathrm{hgh}$ & urs total & & & Rig sheaves, troubleshoot tools, etc. \\
\hline $583 \mathrm{G}$ & 5113.0 & 4663.0 & & & &. & & & & & No logs-abandoned due to weather. \\
\hline 584 & 5065.0 & 4124.0 & & & & & & & & & Lost to hole trouble-no logs requeste \\
\hline $584 \mathrm{~A}$ & 5026.5 & 4125.0 & 4216.0 & $\begin{array}{l}12 \text { ppg } \\
12 \mathrm{mug} \\
12\end{array}$ & $97 / 8$ & 1.0 & 1 & CABHC/GISFL & --- & -- & $\begin{array}{l}\text { Tool malfunctioned on starting down- } \\
\text { Aborted } l o g \text { run. }\end{array}$ \\
\hline $584 \mathrm{~A}$ & 5026.5 & 4125.0 & 4216.0 & $\begin{array}{l}12 \text { ppg } \\
\text { mud }\end{array}$ & $97 / 8$ & 9.5 & 1 & FGT-CNL-GR & 4635.0 & 4216.0 & $\begin{array}{l}\text { Tool stopped by bridge in hole. } \\
\text { Overran \& knotted line } 330 \mathrm{M} \text { up. } \\
\text { CR \& CNP curves to seafloor. }\end{array}$ \\
\hline & & & & & & $8.2=$ & 18.7 hou & rs total & & & $\begin{array}{l}\text { Rig sheaves, troubleshoot tools, } \\
\text { repair depth cable. }\end{array}$ \\
\hline $584 \mathrm{~B}$ & 5106.0 & 4152.0 & & & & . & & & & & No logs requested-no more time. \\
\hline & & & & & & & $\therefore$ & & & & \\
\hline & & . & & & & & & & & & - \\
\hline & 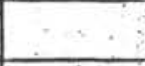 & & & & & & & 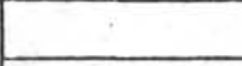 & & & \\
\hline & $\therefore$ & & & & in & & & & & & . \\
\hline
\end{tabular}




\section{INTERNATIONAL PHASE OF OCEAN DRILLING \\ DEEP SEA DRILLING PROJECT \\ OPERATIONS RESUME \\ LEG 88}

The prime objectives of Leg 88 were to deploy two permanent borehole seismometer instruments in the seafloor of the Northwest Pacific Ocean off the Kurile Islands. One instrument was a three component seismometer, the Marine Seismic System (MSS), built by the Defense Advanced Research Projects Agency (DARPA). The second instrument was a Hawaii Institute of Geophysics (HIG) system. In addition hydraulic piston coring of the site was planned to complete the work accomplished on Leg 87.

Unfortunately, only the HIG instrument was successfully employed. Deployment of the DARPA system could not even be attempted as equipment failure and downhole conditions prevented the completion of the re-entry hole required for the emplacement. Stormy weather conditions prevented the HPC work from being accomplished.

A first test, somewhat abbreviated, of the wireline re-entry system designed by DSDP engineers was conducted. Even this test was accompanied by equipment problems and only part of the test completed.

Leg 88 begain officially at 0711 hours, August 18, 1982, when the GIOMAR CHALLENGER dropped anchor outside the harbor of Hakodate, Japan. The leg ended at 1918 hours, on September 19, 1982, when the anchor was dropped at the quarantine anchorage outside the harbor of Yokohama, Japan.

\section{HAKODATE PORT CALL}

The first mooring line was put across the Hakodate Shipyard berth at 0920 hours, August 18 and work immediately began on the installation of equipment required for the DARPA MSS experiment. Major items were the installation of an instrument van, winch, A-frame and a container of recovery line on the main deck aft of the moonpool. In addition numerous additional items were loaded and stored aboard.

No major maintenance items were planned for the port call, however, seals were replaced in the heave compensator piston. The piston rod of the compensator was ultrasonically tested to ensure that a crack was not the cause of the leak. No crack was found and the unit was reassembled. The unit could not be tested immediately as the Ohmsted valve was found to be nonfunctional. A flooded junction box was identified and the valve was eventually repaired on the transit to Site 581 . 
Minor supplies and fresh produce were loaded and the vessel departed at 1150 hours Friday, August 20, some 18 hours ahead of schedule.

Hakodate to Site 581

The positioning thrusters were tested immediately on clearing Hakodate Harbor before the vessel proceeded directly to Site 581. The majority of the voyage was made in dense fog although the seas were calm and an average speed of 9.3 knots was achieved. Twenty four hours before arriving on site the weather picked up and a moderate gale was blowing as the site was approached. The $13.5 \mathrm{kHz}$ beacon left on site during Leg 86 could not be picked up by the ship's positioning system and a $16.0 \mathrm{kHz}$ beacon was dropped at 1410 hours on Tuesday, August 24. Sea three conditions were unsuitable for commencing rig floor operations and approximately four and one half hours of additional profiling was done in the immediate area before the vessel took up station over the beacon. Although the weather and seas had abated somewhat, night had fallen and it was felt to be prudent, because of the A-frame on the port side, to wait on daylight before attempting to pick up and keelhaul the re-entry cone. The vessel thus held position over the beacon and waited on the weather to abate further.

Hole $581 \mathrm{~A}$

The pilot hole for Site 581 was drilled on Leg 86. In this hole (581) 96 meters was washed in without rotation, $85.5 \mathrm{~m}$ was then drilled before coring commenced. Basalt was encountered $345 \mathrm{~m}$ below seafloor and a total depth of $353 \mathrm{~m}$ sub-bottom was obtained.

Hole $581 \mathrm{~A}$ was located $183 \mathrm{~m}$ south of Hole 581 and the water depth was determined to be $5483 \mathrm{~m}$ (PDR).

At first light on August 25, a re-entry cone was keelhauled and $72.15 \mathrm{~m}$ of 16-inch casing was made up and latched into the cone beneath the vessel. The drill pipe running string with a 15-inch core bit was made up and attached to the cone and casing the the assembly was then run to the seafloor. After picking up the power sub, Hole 581A was spudded at 0235 hours, August 26. Drill pipe measurements indicated a water depth of $5480 \mathrm{~m}$.

The cone and 16-inch casing washed in without difficulty for approximately $60 \mathrm{~m}$ at which point progress slowed considerably. With the casing shoe at 5552 m below rig floor no further progress could be made and the cone was released from the running string at this point.

A 15-inch hole was washed and drilled to $364 \mathrm{~m}$ below seafloor (BSF) at which point continuous coring began. Considerable torquing was experienced during this drilling operation with a maximum of $8000 \mathrm{feet} /$ pounds, the 1 imit set on the Bowen power swivel. While retrieving core No. 1, the drill pipe became stuck and required some 15 minutes and overpulls of 70,000 pounds before coming free. NOTE: 70,000 pounds overpull was the maximum allowable under the existing conditions of drill string weight. 
Torquing continued throughout the cored interval and was consistently between 6000 and 8000 feet/pounds. Basalt was intersected some 360 meters below mudline $(5840 \mathrm{~m})$. Coring was stopped $14.8 \mathrm{~m}$ into basalt and a short pipe trip to the 16-inch casing shoe was made to check the hole condition prior to running $113 / 4$ inch casing.

With the bit approximately $8 \mathrm{~m}$ below the casing shoe, the travelling block was set down while the drilling line was slipped and cut. It was subsequently discovered that the drill string had parted during this cutting and slipping operation. When the travelling block had been picked up once again, the pipe was run back to total depth. No resistance was noted and it was assumed that the hole was thus clear. Three hundred barrels of 9.0 pounds/gal mud was displaced to fill the hole and maintain hole stability for running the $113 / 4$ inch casing. When the drill pipe was recovered it was found that the joint of drill pipe immediately above the BHA had failed $0.5 \mathrm{~m}$ from the pin end, leaving the entire BHA in the hole. Careful examination of the drilling recorder chart verified that the pipe had parted during the time the drilling line was being cut and slip.

Recovery of the BHA could not be attempted due to the presence of the casing running tool latch sleeve in the throat of the cone. This sleeve, which is normally recovered by the running tool in the BHA, has an internal diameter of $8 \mathrm{l} / 2$ inch thus preventing access to a suitable fishing tool. Although it was considered possible to fish first the latch sleeve and then the BHA, it was decided that it would be quicker and more prudent to set a new re-entry cone and thus Hole 581A was officially abandoned at 2145 hours, August 27.

$\underline{\text { Hole 581B }}$

A second re-entry cone and a replacement BHA were picked up. The cone was made up and keelhauled beneath the vessel at 1900 hours, August 21, less than 24 hours after Hole 581A had been abandoned. 72.27 meters of 16-inch casing were made up and latched into the cone and the whole assembly was run to the mudline.

Hole 581 B was spudded at 1615 hours, August 29 at a position 305 meters due north of Hole-581A and 122 meters north of Hole 581 .

Washing in of the casing and cone proceeded smoothly to a point where the bit was 57 meters below the mudline. Subsequent progress was very slow and only another three meters was achieved before the casing became stuck. After making a connection at this point, a 50,000 pound weight loss was noted. The drill string was raised 10 meters and the weight was regained. At the same time the bridge reported a 200 foot vessel excursion. This excursion could not be verified and was attributed to a faulty display, however, it could have caused the noted weight loss with the additional pipe compensating for the move.

Attempts to wash the casing assembly further proved futile and the cone had to be released at this position. The top of the cone was 17 meters above the mudline $(5483 \mathrm{~m})$ as determined by PDR. Four wireline trips were required to release the cone. Resistance to the shifting tool was noted immediately 
above the running tool indicating bent or kinked drill pipe. It was felt that the string had probably been placed in compression during the last pipe connection or alternately had bent at the time of the reported excursion if indeed it had been valid. The drill pipe was thus pulled to the rig floor to check the BHA. On retrieval it was found that the spline of the lowermost bumper sub was bent in the extended position. Some 363 meters of 1 oose sand was recovered from the core barrel. This formation was not anticipated and could explain the sticking of the casing.

New bumper subs were picked up and the drill pipe run back to a position just above the re-entry cone. Re-entry sheaves were rigged up and the scanning sonar tool run to the bit. At 0610 hours, August 31, scanning for the cone commenced. The cone was identified at a range of $152 \mathrm{~m}$ (500 feet) and 2 hours 26 minutes of maneuvering were required to position the bit above the cone and make the re-entry. The sonar tool was recovered and the bit was run to bottom.

A $147 / 8$ inch hole was washed to $5830.5 \mathrm{~m}$ (360.5 BSF) where basalt formation was encountered. Considerable torque was experienced during the operation and the pipe became stuck immediately above the basement contact as it had in Hole 581A. Thirty minutes was required to free the pipe before coring operations could commence. $\quad 14.5$ meters of basalt were cored to a point $375 \mathrm{~m}$ BSF before the bit was pulled from the hole to pick up $113 / 4$ inch casing. This left sufficient $147 / 8$ inch at hole in case the re-entry cone settled towards the mudline.

A "short trip" to the 16-inch casing shoe was made to check that the hole was clean and 300 barrels of mud were displaced into the hole. The drill pipe was then pulled above the top of the cone and the scanning sonar tool run to check that the cone had not settled. A brief 15-minute scan verified that the cone was still at its original height and the sonar tool was retrieved and the drill pipe pulled to the rig floor.

364.43 meters of $113 / 4$ inch casing were made up to a running string and the assembly run in hole to a point just above the re-entry cone.

Three runs were required with the scanning sonar tool before a successful re-entry was accomplished. On the first two runs the line wiper at the top of the drill string failed preventing sufficient hold down pressure to be applied to the sonar tool. As a result the sonar tool "bounced" on its landing shoulder and in both instances the tool failed before a stab could be made. The line wiper was changed for the third sonar tool run and re-entry proceeded smoothly with the cone being stabbed after some 64 minutes of scanning time.

The $113 / 4$ inch casing string was then run to a point where drill pipe measurements indicated that the casing hanger should be latched into the re-entry cone assembly. Latch in was confirmed by a gain in string weight when the drill pipe was raised. In addition no further downward progress could be made. 
Some difficulty was experienced releasing from the casing. However free rotation, loss of drill string weight and a drop in circulating pressure when the pipe was raised seemed to indicate that a release had been achieved.

The casing string was cemented in this position using 750 sacks of Class G cement mixed to a density of 15.8 pounds/gallon. The slurry was displaced with 341 barrels of water and the latch down plug bumped with 2500 psi.

When an attempt was made to pull the cementing stinger from the casing shoe weight was immediately picked up to a level which indicated that the running string had somehow relatched to (or indeed had never released from) the casing. All attempts to free the running string were unsuccessful, however the casing was moved nine meters up hole.

With Typhoon Gordon forecast to shut down operations within 18 hours there was no alternative but to sever the drill string above the running tool and recover the drill pipe.

This operation was successfully achieved when the pipe was severed at 5436 meters and the severed section was on deck at 1415 hours on September 5 .

\section{Wireline Re-entry System Test}

With a major storm rapidly approaching there was insufficient time to attempt any coring operations and a first test was conducted of a wireline re-entry system (WRS) designed by DSDP engineers.

The WRS consists of an EDO scanning sonar tool mounted in a fin structure that fits in the standard re-entry cone. The sonar tool used had been modified to include a north seeking device which produces a brightening of the sweepline on the shipboard display console each time the sonar head rotates through magnetic north.

The fin structure was assembled and a $12 \mathrm{kHz}$ pinger attached in order to monitor the depth off bottom of the structure. A $13.5 \mathrm{kHz}$ beacon was also attached to the assembly so that its position relative to the ship could be monitored.

Unfortunately the sonar tool failed before the assembly was even put into the water and no re-entry attempt could be made. A program to monitor the structure movement relative to vessel movement was thus conducted.

The end of the logging cable was keelhauled and made up to the WRS on the main deck. A cable grip was attached to the logging cable so that the WRS could be put into the water by the ship's crane. When the crane lifted the WRS it was noticed that the cable grip was not holding due to incorrect installation and the logging cable had become damaged. The cable was reheaded and an eight foot sling attached to the WRS frame. The structure was lifted with this sling and placed over the side. The sling was tied to the logging cable some 30 feet from its end to aid in retrieval. 
The WRS was run to a point 3000 meters below the vessel and the test program initiated. The first phase of the test was to attempt to hold the challenger stationary and check the position of the WRS. Because the ship's positioning system can only receive one signal at a time the ship had to be controlled in the manual mode while tracking the WRS. It was found that the ship could drift about 200 feet in the three minute period that the beacon on the WRS was being monitored. A number of readings were taken in this' mode.

The second phase of the program was to move the CHALLENGER 500 feet and to monitor the movement of the WRS. Offsets necessary to accomplish this move were put into the positioning system.

Data was recorded during the time avallable and as the weather got progressively worse, the tool was returned to the deck.

As the tool neared the surface the 80 foot sling tied to the logging cable was attached to a keelhaul line and pulled through the moonpool to the port side of the vesse1. It was discovered that the 80 foot sling length was too short as the WRS was pulled into the lower end of the guide horn before the outer end of the sling was accessible. At this point the logging cable pulled out of the cable head and the WRS fell free. Fortunately, the manilla keelhaul line held firm and prevented the loss of the equipment. The WRS was then recovered by the ship's crane and was on the main deck by 0100 hours, on September 6 .

The conclusions of the test are summarized as follows:

1) At least to a depth of $3000 \mathrm{~m}$ the WRS remains within $100 \mathrm{~m}$ of the ship, almost directly below.

2) WRS motions are generally slower than vessel motions. General indications are that the WRS follows vessels position with a 10 to 15 minute delay.

\section{Hole 581C}

The effects of Typhoon Gordon were starting to be felt during the test of the WRS and the weather and seas were building rapidly. Although the closest point of approach of the storm was 210 miles to the north it was 67 hours before conditions moderated sufficiently to allow the drill string to be picked up.

The standard coring BHA, including a Mechanical Bit Release, was picked up and the drill string run to the mudline. Hole 581C was spudded at 0830 hours, September 9. The hole was washed $357.6 \mathrm{~m}$ below mudline with only minor difficulty although considerable torque was experienced from a point $289 \mathrm{~m}$ below the mudline. Basalt was encountered at $355 \mathrm{~m}$ below mudline. Coring then commenced and $16.11 \mathrm{~m}$ of basalt core were recovered from the $20.8 \mathrm{~m}$ interval cored. A shifting tool was run and the bit released at 1330 hours, September 10 . 
The Hawaii Institute of Geophysics (HIG) Ocean Subbottom Seismometer (OSS) was attached to the logging cable and run out the end of the drill pipe into open hole. After initial testing of the tool, the logging cable was cut at the rig floor and the drill pipe stripped from around the cable. This operation went smoothly except for an initial problem when the stripping cable head became stuck in the undersized tool joint areas. The OD of the head was machined down and no further problems were experienced. The weather was once again building during the stripping operation and handling of the BHA particularly was a slow and difficult operation.

The logging cable was rejoined using a torpedo splice and the good health of the OSS was reconfirmed. The tool was then run to bottom and the pad arm extended to clamp the tool in the hole.

The CHALLENGER was moved 8250 feet from the hole and a $13.5 \mathrm{kHz}$ beacon was dropped. The ship positioned on this beacon for the duration of the shooting program.

While waiting on the support vessel USNS DE SIEIGUER to start a shooting program, an air gun was lowered into the water and fired for a 15-minute period. The oSS and shipboard recording instruments all were found to be in good working condition. A Woods Hole hydrophone was deployed over the side of the ship to record ranges of shots during the shooting program. One hundred eighty five shots were fired from the DE STEIGUER and recorded by the OSS and the program was terminated at 1030 hours, September 13.

The logging cable was keelhauled and attached to the recording package. After a short period to check the condition of the recording package and to allow it to stabilize, it was lowered into the water and deployment of the recovery system commenced.

Two problems were encountered during the deployment of this line. The line tensioner which is utilized to maintain constant tension on the rope was apparently installed backwards. This cause the line to continuously rise up out of the guide grooves and jam. The feed in sheave position was moved to align the rope correctly and no further problems were encountered. The tensioner could not be turned around due to the rope being installed and under tension.

The second problem was that the rope splices were somewhat large and jammed in the sheaves. At one point when the line jammed in the tensioner at a splice, the rope had to be cut and respliced.

The brake system, which had been installed on the large recovery line storage drum, was a great improvement over the previous installation, however it could not keep a constant tension on the spool and an "Oke" brake was used in conjunction with it.

When the end of the rope was reached the ship was moved to allow all tension to be removed from the rope. The rope was then removed from the tensioner 
and sheaves and attached to the anchor and transponder/float assemblies. The anchor assembly was lifted over the side and released at 2245 hours, September 13. This concluded operations at Hole 581C.

Once again the weather had built up considerably and $50 \mathrm{mph}$ winds and high seas were forecast for the following 24-hours. This precluded picking up drill pipe and with only 48 hours remaining (including the forecast wait-onweather time) before the scheduled departure for Yokohama, Japan, it became obvious that the scheduled Hydraulic Piston Coring program could not be attempted. The vessel thus secured for getting underway and departed Site 581 at 0034 hours, September 14.

\section{Site 581 to Yokohama}

The area around Site 581 had been profiled extensively on Leg 86 during the approach to site on this leg, and by the USNS DE SIEIGUER. No additiona1 profiling was required and once the vessel was secured departure was made for Yokohama.

The inclement weather on site was soon left behind and the vessel made good speed for most of the transit to Yokohama. A short stop enroute was made to remove a sandline from the Bowen sandline winch. This line was too short for the upcoming Leg 89 operations. All the drill pipe was layed down during the transit in preparation for repairs to the I.D. and inspection in Yokohama.

Arrival at the Yokohama quarantine anchorage was at 1918 hours, September 19, and the first line was put over at the NKK Asano Shipyard Facility at 1139 hours the following day some 31 days after departing Hakodate.

\section{Drilling and Coring Equipment}

A major failure occurred when a joint of 5 inch drill pipe failed after completion of drilling a 15-inch hole at Hole 581A. The joint of pipe immediately above the BHA failed approximately 18-inches from the pin end. Although the failed end of the recovered portion of the pipe had been damaged downhole, there was evidence that the failure had initiated at an inclusion in the pipe body. The point of failure was very close to the upset area of the pipe. This area of the pipe is subjected to some "abuse" during handling in that it hits the restraining bumper when being picked up from the pipe racker. It is also the area where the pipe spinner grips the pipe during make up. The failed joint of pipe had undergone extensive inspection in Los Angeles, March 1982, prior to being loaded on board and a routine inspection in Yokohama in June 1982. However, the inspections are linown to be suspect near the upset areas where the wall thickness changes.

Problems were also experienced with both the 16-inch and $113 / 4$ inch casing running tools at Hole 581B. While deck testing the 16-inch running tool it was found that the paddles which support the casing were oversized. The 
paddles were ground down to size and did appear to operate as designed. One paddle was found to be cracked when recovered and all three units were somewhat distorted where they support the load. Releasing problems were found to have been caused by a bent bumper sub immediately above the running tool.

The $113 / 4$ inch casing running tool apparently failed to release after the casing had been set. The cause of the failure could not be determined as the unit was lost downhole when the drill pipe was severed. The length of the $113 / 4$ inch casing string was the longest, and the setting depth the deepest attempted during DSDP operations. The high drill string weight coupled with the relatively low casing string weight and the larger weight fluctuations caused by vessel movement, made interpretation of downole events very difficult

The weight of the drill string at the water depths encountered is approximately $86 \%$ of minimum yield for new drill pipe, i.e. $100 \%$ wall. The maximum allowable safe operating stresses are $90 \%$ of minimum yield. This leaves very little additional pull that can be applied to the drill string under stuck pipe conditions. In the case of the $113 / 4$ inch casing the weight of casing and drill pipe below the running tool exceeded the maximum allowable overpull. This meant that the downward force which resulted in the pipe becoming stuck was greater than the available force to free the pipe.

During re-entry operations at Hole 581B, the Saunders line wiper repeatedly jumped out of its latch groove. This prevented adequate pressure from being put on the scanning tool at the bit thus allowing it to bounce on the landing collar. Two scanning tools were damaged as a result. An old line wiper was located and used successfully on the final re-entry run.

\section{General}

Over and above the normal drilling and instrument emplacement operations two out of the ordinary operations were successfully completed.

At 2120 hours, August 31, the No. 2 lifeboat was launched to pick up 1500 pounds of electronic equipment from the USNS DE STEIGUER. These parts had been transported from Adak by the DE STEIGUER and were required for the DARPA recording package. The transfer was accomplished without incident.

On August 3, a U. S. Navy aircraft made an air drop of additional electronic spares. The DE STEIGUER recovered the package from the water and transferred it to the CHALLENGER, this time by means of a line passed from the CHALLENGER.

Weather

Site weather was excellent to reasonable from our arrival, August 24 , to the presence of a major storm previously Typhoon Gordon. This storm passed northwest of Site 581 about 200 miles on September 6. On site we had gale force winds with heavy seas and swell on September 7 and 8 . 
A second storm, previously Judy, approached site September 13 and prevented the hydraulic piston coring operations from commencing and caused an early departure from site.

The first of the true fall season gales forming on the quasi-stationary front south of Japan was encountered enroute to Yokohama. This storm passed over and continued on a path over Site 581 and further northeast.

\section{Communications}

The leg was characterized by very heavy traffic and very long hours. Fortunately, radio propagation conditions were exceptionally good during most of the leg, with only a few days of poor to marginal conditions.

At the beginning of the leg WWD was off the air with equipment problems, so it was necessary to utilize the facilities of the U. S. Coast Guard Station at Guam. After the first few days we changed over and were able to maintain direct communications with WWD for the remainder of the leg.

Guam was utilized for transmission of numerous priority messages during night hours when WWD was closed.

Whenever conditions permitted WWD's SSB facilities were used for phone patches. Many business radiotelephone calls via KMI and Japanese stations were made. Also maintained both radiotelegraph and radiotelephone communications with the USNS DE STEIGUER, made radiotelephone broadcasts to Wake Island during the HIG experiment, and kept in contact with ship's agents on both radiotelephone and radiotelegraph via Choshi Radio, Japan. Weather observations were transmitted to Japanese stations three times daily and storm advisories and weather broadcasts were received daily from Tokyo Radio.

V. B. Robson

Cruise Operations Manager Deep Sea Drilling Project 


\section{INTERNATIONAL PHASE OF OCEAN DRILLING \\ DEEP SEA DRILLING PROJECT \\ OPERATIONS RESUME \\ LEG 88}

Total Days (August 18 - September 19, 1982) . . . . . . . . .

Total Days in Port . . . . . . . . . . . . . . . . . . . . .

Total Days Cruising Including Site Survey . . . . . . . . . .

Total Days on Site . . . . . . . . . . . . . . . .

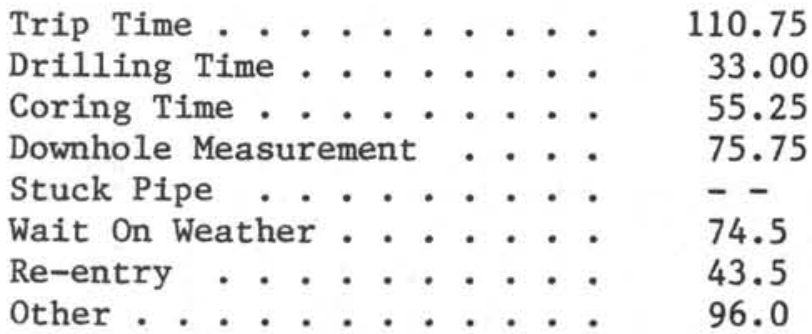

Total Distance Traveled Including Survey (nautical miles)......

2023.7

Avererage Speed (knots) . . . . . . . . . . . . . . .

Number of Sites.........................

Number of Holes Drilled . . . . . . . . . . . . . . . . .

Number of Cores Attempted ....................

Number of Cores with Recovery ....................

Total Meters Cored . . . . . . . . . . . . . . . . .

Total Meters Recovered .....................

Percent Recovery .........................

Total Meters Drilled ....................

Total Meters of Penetration . . . . . . . . . . . . . .

Percent of Penetration Cored ..................

Maximum Penetration (meters) . . . . . . . . . . . . . .

Minimum Penetration (meters) . . . . . . . . . . . . . .

Maximum Water Depth (meters) . . . . . . . . . . . . . .

Minimum Water Depth (meters) 


\section{DEEP SEA DRILLING PROJECT \\ TIME DISTRIBUTION}

$\angle E G-88$

\begin{tabular}{|c|c|c|c|c|c|c|c|c|c|c|c|c|c|c|}
\hline Da.te & \begin{tabular}{|l|} 
site \\
No.
\end{tabular} & Cruise & Trips & Drill & Core & $\begin{array}{l}\text { Stuck } \\
\text { Ploe }\end{array}$ & W.0.Wr & $\begin{array}{l}\text { POWNHOLE } \\
\text { MEAS. }\end{array}$ & $\begin{array}{l}\text { Mech. } \\
\text { Pepair }\end{array}$ & $\begin{array}{l}\text { Port } \\
\text { Time }\end{array}$ & $\begin{array}{c}\text { Re- } \\
\text { Entryy }\end{array}$ & Other & $\begin{array}{l}\text { Total } \\
\text { Time } \\
\end{array}$ & Remarks \\
\hline $8 / 18 / 82$ & & . & & & & & & & & 14.6 & & . & 14.6 & . \\
\hline $8 / 19 / 92$ & & & & & & & & & & 24.0 & & - & 24.0 & - \\
\hline $8 / 20 / 82$ & & 12.0 & & & & & & & & 12.0 & & - & 24.0 & \\
\hline $8 / 21 / 82$ & & 24.0 & & & & & & & & & & & 24.0 & \\
\hline $8 / 22 / 82$ & & 23.0 & & & & & & & & & & & 23.0 & Time Change \\
\hline $8 / 23 / 82$ & & 24.0 & & & & & & & & & & & 24.0 & \\
\hline $8 / 24 / 82$ & $581 \mathrm{~A}$ & 14.0 & & & & & 2.0 & & & & & 8.0 & 24.0 & \multirow{2}{*}{$\begin{array}{l}\text { Position ship } \\
\text { Rig R/E cone } \\
\text { Make up } R / E \\
\text { cone } \& \text { csg. } \\
\end{array}$} \\
\hline $8 / 25 / 82$ & & & 12.5 & & & & 5.5 & & & & & 6.0 & 24.0 & \\
\hline $8 / 26 / 82$ & & & 1.0 & 12.75 & 10.25 & & & & & & - & . & 24.0 & \\
\hline \multirow[t]{2}{*}{$8 / 27 / 82$} & & & 10.75 & & 8.75 & & & & & 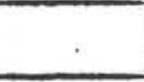 & & 4.5 & 24.0 & \multirow{2}{*}{$\begin{array}{l}\text { Cut line, fif } \\
\text { hole with mudd } \\
\text { pick up cone }\end{array}$} \\
\hline & & & . & & & & & & & & & & & \\
\hline \multirow[t]{2}{*}{$8 / 28 / 82$} & $581 \mathrm{~B}$ & & 4.0 & & & & & & & & & 20.0 & 24.0 & \multirow{2}{*}{$\begin{array}{l}\text { Rig R/E cone } \\
\text { Pick up DC } \\
\text { from hold, }\end{array}$} \\
\hline & & & & & & & & & & & & & & \\
\hline \multirow[t]{2}{*}{$8 / 29 / 82$} & & & 10.0 & 1.75 & & & & & & & & 12.25 & 24.0 & \multirow{2}{*}{$\begin{array}{l}\text { Run R/E cone } \\
\text { rig csg } \\
\text { wireline trít }\end{array}$} \\
\hline & & & & & & & & & & & & & & \\
\hline $8 / 30 / 82$ & & & 18.5 & & & & & & & & & 5.5 & 24.0 & \begin{tabular}{|l|} 
Release conf \\
Slip line
\end{tabular} \\
\hline $8 / 31 / 82$ & & - & 2.5 & 6.00 & 6.0 & & & & & & 8.0 & 1.5 & 24.0 & Retrieve banr \\
\hline $9 / 01 / 82$ & & & 4.25 & & 16.25 & & & & & & & 3.5 & 24.0 & \begin{tabular}{|l|} 
Plugged bit \\
spot mud
\end{tabular} \\
\hline $9 / 02 / 82$ & & & 8.0 & & 0.25 & & & & & & & 15.75 & 24.0 & $\begin{array}{l}\text { Check R/E eqn } \\
\text { cut \& slip }\end{array}$ \\
\hline & & & & & & & & & & & & & & $\begin{array}{l}\text { line, } \\
113 / 4 " \text { Cso }\end{array}$ \\
\hline
\end{tabular}




\section{DEEP SEA DRILLING PROJECT \\ TIME DISTRIBUTION \\ $\angle E G-88$}

\begin{tabular}{|c|c|c|c|c|c|c|c|c|c|c|c|c|c|c|}
\hline Date & $\begin{array}{l}\text { Site } \\
\text { No. }\end{array}$ & Cruise & Trips & Drill & Core & $\begin{array}{l}\text { Stuck } \\
\text { Ploe }\end{array}$ & W.0.Wr. & $\begin{array}{l}\text { POWNHOLE } \\
\text { MEAS. }\end{array}$ & $\begin{array}{l}\text { Mech. } \\
\text { Peparr }\end{array}$ & $\begin{array}{l}\text { Port } \\
\text { Time }\end{array}$ & $\begin{array}{c}\text { Pe- } \\
\text { Entry }\end{array}$ & other & $\begin{array}{l}\text { Totial } \\
\text { Time }\end{array}$ & Remarks \\
\hline $9 / 03 / 82$ & & & & & & & & & & & & . & & . \\
\hline $9 / 04 / 82$ & & & 1.5 & & & & & & & & 15.00 & 7.5 & 24.0 & $\begin{array}{l}\text { cement } \text { fsg } \\
\text { stuck csg }\end{array}$ \\
\hline & & & & & & & & & & & & . & & $\begin{array}{l}\text { run string } \\
\text { shot }\end{array}$ \\
\hline $9 / 05 / 82$ & & & 7.0 & & & & & & & & w1 test & 7.25 & 24.0 & sever DP \\
\hline $9 / 06 / 82$ & Wow & & & & & & 23.0 & & & & $\begin{array}{c}\text { wirelin } \\
1.00\end{array}$ & & 24.0 & \\
\hline 9/07/82 & wow & & & . & & & 24.0 & & & & & & 24.0 & \\
\hline $9 / 08 / 82$ & $581 C$ & & 4.0 & & & & 20.0 & & & & & & 24.0 & \\
\hline $9 / 09 / 82$ & & & 8.0 & 12.5 & 3.0 & & & i & & & & 0.5 & 24.0 & $\cdot$ \\
\hline $9 / 10 / 82$ & & & 5.0 & & 10.75 & & & 5.0 & & & - & 3.25 & 24.0 & $\begin{array}{l}\text { run HIG, cut } \\
\text { line, release }\end{array}$ \\
\hline $9 / 11 / 82$ & & & & & & & & 24.0 & & . & & & 24.0 & HIG \\
\hline $9 / 12 / 82$ & & & . & & & & & 24.0 & & & & & 24.0 & HIG \\
\hline $9 / 13 / 82$ & & & & & 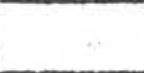 & & & 22.75 & & & & 1.25 & 24.0 & $\begin{array}{l}\text { HIG - Secure } \\
\text { for underway }\end{array}$ \\
\hline $9 / 14 / 82$ & & 23.5 & & & & & & & & & & 0.5 & 24.0 & \begin{tabular}{l|} 
secure for \\
underway
\end{tabular} \\
\hline $9 / 15 / 82$ & & 25.0 & & & & & & & & & & & 25.0 & \\
\hline $9 / 16 / 82$ & & 24.0 & & & & . & & & & & & . & $24.0^{\circ}$ & \\
\hline $9 / 17 / 82$ & & 24.0 & & & & & & & & & & & 24.0 & \\
\hline 9/18/82 & & $24.0^{\circ}$ & & & & & & & & & & & 24.0 & . \\
\hline $9 / 19 / 82$ & & 19.25 & & & & & & & & & & 4.75 & 24.0 & At Anchor \\
\hline & & & & & & & & & & & & & & \\
\hline & & & 110.75 & 33.0 & 55.25 & & 74.5 & 75.75 & & 50.6 & 43.5 & 96.0 & & \\
\hline
\end{tabular}


INTERNATIONAL PHASE OF OCEAN DRILLING

DEEP SEA DRILLING PROJECT

BEACON SUMMARY

LEG 88

\begin{tabular}{|c|c|c|c|c|c|}
\hline $\begin{array}{l}\text { Site } \\
\text { No. }\end{array}$ & Make & $\begin{array}{l}\text { Freq. } \\
\mathrm{kHz}\end{array}$ & $\begin{array}{l}\text { Serial } \\
\text { Number }\end{array}$ & $\begin{array}{l}\text { Site Time } \\
\text { Hours }\end{array}$ & Remarks \\
\hline $581 \mathrm{~A}, \mathrm{~B}, \mathrm{C}$ & ORE & 16.0 & 130 & 460 & Good beacon - no problems \\
\hline $581 \mathrm{C}$ & ORE & 16.0 & 139 & 35 & $\begin{array}{l}\text { Used for wireline re-entry test and for } \\
\text { positioning ship during HIG experiment. }\end{array}$ \\
\hline
\end{tabular}

ф) 
INTERNATIONAL PHASE OF OCEAN DRILLING DEEP SEA DRILLING PROJECT

$$
\begin{aligned}
& \text { BIT SUMMARY } \\
& \text { LEG } 88
\end{aligned}
$$

\begin{tabular}{|c|c|c|c|c|c|c|c|c|c|c|c|}
\hline Hole & Mf $_{\mathbf{g}}$. & $\begin{array}{c}\text { S1ze } \\
.\end{array}$ & Type & $\begin{array}{l}\text { Serial } \\
\text { Number }\end{array}$ & $\begin{array}{l}\text { Meters } \\
\text { Cored }\end{array}$ & $\begin{array}{l}\text { Meters } \\
\text { Drflled }\end{array}$ & $\begin{array}{l}\text { Meters } \\
\text { Total } \\
\text { Penet } 1\end{array}$ & $\begin{array}{l}\text { Hours } \\
\text { On } \\
\text { B1t } \\
\end{array}$ & Condition & Remarks & 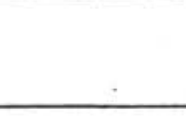 \\
\hline $581 \mathrm{~A}$ & Sm1th & $15^{\prime \prime}$ & $94-4$ & 794AN & 38.6 & 336.2 & 374.8 & 13.75 & Unknown & Lost in hole & · \\
\hline $581 \mathrm{~B}$ & Smith & $147 / 8$ & P94CK & $179 F K$ & 24.5 & 347.5 & 372.0 & 16.8 & TI-B1 & & \\
\hline \multirow[t]{2}{*}{$581 \mathrm{C}$} & Sm1th & $97 / 8$ & F93CK & $s-40$ & 20.6 & 357.6 & 378.2 & 11.9 & Unknown & Rerun/Released & \\
\hline & & & & TOTAL & 42.6 & 1289.6 & 1332.2 & 28.1 & & & \\
\hline
\end{tabular}


INTERNATIONAL. PHASE OF OCEAN DRILLING DEEP SEA DRILLING PROJECT

SITE SURMARY

LEG 88

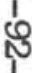

\begin{tabular}{|c|c|c|c|c|c|c|c|c|c|c|c|c|c|c|}
\hline Hole & Latitude & Long1tude & $\begin{array}{l}\text { Water } \\
\text { Depth } \\
\text { Meters }\end{array}$ & $\begin{array}{l}\text { Number } \\
\text { of } \\
\text { Cores }\end{array}$ & $\begin{array}{c}\text { Cores } \\
\text { With } \\
\text { Recovery }\end{array}$ & $\begin{array}{l}\text { Percent of } \\
\text { Cores With } \\
\text { Recovery }\end{array}$ & $\begin{array}{l}\text { Meters } \\
\text { Cored }\end{array}$ & $\begin{array}{l}\text { Meters } \\
\text { Recovered }\end{array}$ & $\begin{array}{l}\text { Percent } \\
\text { Recovered }\end{array}$ & $\begin{array}{r}\text { Meters } \\
\text { Dr1lled }\end{array}$ & $\begin{array}{l}\text { Total } \\
\text { Penet. } \\
\text { Meters }\end{array}$ & $\begin{array}{l}\text { Av8. } \\
\text { Rate } \\
\text { Penet. }\end{array}$ & $\begin{array}{c}\text { Time } \\
\text { Ma } \\
\text { Hole }\end{array}$ & $\begin{array}{l}\text { T1me } \\
\text { On } \\
\text { Site }\end{array}$ \\
\hline $581 \mathrm{~A}$ & $43^{\circ} 55.46^{\prime} \mathrm{N}$ & $159^{\circ} 47.79^{\circ} \mathrm{B}$ & 5480 & 4 & 2 & 50.0 & 38.6 & 4.29 & 11.1 & 336.2 & 374.8 & 27.3 & 103.75 & \\
\hline $581 B$ & $43^{\circ} 55.66^{\prime} \mathrm{N}$ & $159^{\circ} 47.77^{\prime} \mathrm{B}$ & 5478 & 4 & 4 & 100.0 & 24.5 & 13.12 & 53.5 & 347.5 & 372.0 & 22.1 & 208.5 & . \\
\hline $581 \mathrm{C}$ & $43^{\circ} 55.44^{\prime} \mathrm{N}$ & $159^{\circ} 47.84^{\prime} \mathrm{B}$ & 5482 & 3 & 3 & 100.0 & 20.6 & 16.11 & 78.2 & 357.6 & 378.2 & 32.9 & 124.5 & 491.25 \\
\hline
\end{tabular}




\section{INTERNATIONAL PHASE OF OCEAN DRILLING DEEP SEA DRILLING PROJECT OPERATIONS RESUME \\ LEG 89}

The 89th scientific voyage of the GLOMAR CHALLENGER returned to the West Central Pacific Ocean to study the ocean's oldest sediments. Two primary sites had been selected where early Cretaceous and Jurassic sedimentary rocks were believed to lie within reach of the drill. Both of these sites lay in deep water and the objective strata were overlain by great thicknesses of sediment and rock.

The cruise was a relatively smooth one, from an operational and technical standpoint, but operational limitations and unexpected thicknesses of volcanic material prevented reaching the Jurassic objective. Nevertheless the first site was cored to nearly 900 meters and the second (re-entry Hole 462A) was deepened to over 1200 meters. At a third drill site, a record penetration of 305.3 meters was made with the hydraulic piston corer. Successful well logs were recorded at two sites.

The voyage commenced on September 19, 1982 at Yokohama, Japan and terminated on November 29, 1982 at Noumea, New Caledonia. Total length of the leg was 70.7 days, of which 30.3 days were spent on site, 21.2 days in port and 19.2 days in transit. Weather delays accounted for 0.9 day and mechanical repair for 0.2 day.

Yokohama Port Call/Drydocking

Leg 89 began with the arrival of the GLOMAR CHALLENGER in Yokohama Harbor, Japan. The anchor was let go at 1918 hours, September 19, 1982. The following morning the vessel moved to a wet berth at Nippon Kokan's Asano Shipyard.

The rig's entire string of drill pipe was offloaded and sent to NKK's Keihin Steel Works for inspection and/or remedial machining. Refurbishment of major drilling rig and engine room machinery also commenced upon arrival. A shipboard science computer system was onloaded and installation was begun. DARPA machinery and instrumentation were offloaded.

On September 22nd, the vessel entered the Asano Yard's drydock for extensive repairs to propulsion, thruster and drilling equipment, as well as work on the hull, derrick and mooring and steering gear. The work schedule was among the most extensive of the CHALLENGER'S history. U. S. Coast Guard and ABS inspections were conducted and deficiencies were corrected for recertification.

The ship was refloated and moved back to the wet berth on the afternoon of October 3rd. Major shipyard jobs continued and the loading of drill pipe began. 
Departure for sea trials had been scheduled for 0900 hours, October 6 th, but electrical problems in the engine room delayed sailing until 1330 hours. (A rotary exciter which had been sent to the United States for overhaul was found to be miswired internally.) The vessel proceeded to the northern part of Tokyo Wan for tests of propulsion, steering and positioning systems, along with other refurbished equipment. A ground in the D.C. generator No. $9 \mathrm{~B}$ and a malfunction in a bow thruster tachometer generator were discovered.

That evening the CHALLENGER returned to a berth at Yokohama's Shinko (Center) Pier, and preparations for the operational portion of Leg 89 began in earnest. The engineering problems found during sea trials were rectified, but additional electrical troubles resulted in the loss of one day of loading drill pipe. In addition to the remainder of the drill string, casing, re-entry cones, drill collars, core liners and bulk mud materials were onloaded. Consumable supplies, fresh water, lube oil and 452,000 gallons of fuel were loaded, as well as shipments of miscellaneous GMI and SIO freight. SIO cores and freight were offloaded. Departure of the vessel had been scheduled for the morning of October 10th, but it was rescheduled to 0100 hours, October 11 th to allow time to complete the drill pipe loading.

Yokohama to Site 585

The last mooring line was cast off at 0055 hours, October 11 th, and the GLOMAR CHALLENGER proceeded south out of Tokyo Wan. She was greeted by a northeasterly gale from a low pressure disturbance which had developed unexpectedly in the area. The vessel's course was altered to the southwest to clear the storm and to minimize its effects. This was considered prudent since a considerable amount of cargo was still on deck awaiting stowage and most of the drill pipe was stowed on the casing racks. With improving conditions, a southeasterly track was resumed and the ship passed south of Hachijo Shima enroute the operating area.

Relatively strong head winds and moderate swells kept cruising conditions on the "sloppy" side for most of the transit. Late on October 16th, Tropical Storm Owen passed about 300 miles to the southwest, slowing the CHALLENGER with 30 -knot head winds and rough seas. Weather conditions improved during the final two days, and speed increased to over 11 knots with the aid of a following current. The approach to the drill site was made from the north, and speed was reduced for the final 12 miles to improve seismic record quality. The positioning beacon was launched on the first pass at 2122 hours, October 18th. Average speed for the 1642 mile transit was 9.0 knots.

Hole 585 - East Mariana Basin

The first drill site of the voyage was located about 350 miles west-northwest of Eniwetok Ato 11 and 700 miles east of Guam. Water depth according to the precision depth recorder (PDR) was $6119 \mathrm{~m}$.

Operations were off to a slow start with a pipe trip that consumed over 23 hours. The drill pipe had to be measured, and nearly one-third was new 
pipe, which required special time-consuming makeup procedures. Breakdowns to pipe handling equipment lengthened the trip by $21 / 4$ hours.

Since this was a possible re-entry site, a "mudline" punch core for water depth determination and a jet-in test for casing length determination were necessary. Hole 585 was spudded at 0105 hours, October 20th. The core barrel was not retrieved on the first wireline attempt due to the failure of the overshot to engage the pulling neck of the inner core barrel. The second wireline retrieval attempt was successful, but the core barrel was empty with only smears of clay on the outside of the liner to indicate that the proper interval (to $6129.1 \mathrm{~m}$ ) had been cored. A second punch core attempt produced the same lack of results, and the problem was blamed on leaky ball check valves on the new quick-release inner barrel swivel assemblies being used. A third attempt was successful and a partial core was recovered to establish the water depth at $6122.3 \mathrm{~m}$. The bit was then "washed" ahead without rotation to determine the depth to which support casing for a re-entry cone could be jetted. Firm sediment (probably clay) halted progress at $39 \mathrm{~m}$ BSF (below seafloor), dictating that only a relatively short length of 16-inch casing could be deployed.

Rotation and full circulation were then employed to drill to $256 \mathrm{~m} \mathrm{BSF}$, as the upper sediment section had previously been cored at a nearby site. Continuous coring then commenced. Several intervals bearing chert and siliceous limestone strata slowed penetration and severely reduced core recovery to a depth of about $630 \mathrm{~m}$ BSF. Below that depth, chert virtually disappeared and recovery improved dramatically in a thick sequence of turbidites which were comprised of material ranging from clay to coarse volcaniclastic material.

Good progress was made to $763.7 \mathrm{~m}$ BSF when pump circulation was suddenly plugged off as core barrel No. 56 landed at the bit. A wireline trip was made to recover the inner barrel, but it was found to be firmly stuck in place. The overshot release pin was finally sheared and the overshot was recovered. A quick check of coring equipment revealed that the newly installed landing sub on the core barrel was from a batch of subs that had recently been modified. The other subs in the batch were measured and found to be oversized. It was then surmised that the landing sub was wedged into either the outer barrel latch sleeve or the bit release liner. Two additional sandline runs were made, but the weight of the long sandline prohibited sufficient overpull on the core barrel to dislodge it. Consequently there was no choice but to trip the drill pipe to dislodge the core barrel, thereby terminating drilling in Hole 585.

The drill string was recovered, with the bit arriving on deck just after 0400 hours, October $27 \mathrm{th}$. The bit, after only $293 / 4$ rotating hours, was found to be in the early stages of failure. One cone bearing was quite loose and the volcaniclastic material had caused considerable abrasion to shirttails, inserts and cone shells. The stuck inner barrel was then extricated from the hydraulic bit release liner and a new bit and bit release assembly were made up as the rig was prepared for the next pipe trip. 
$\underline{\text { Hole 585A }}$

The high drill string weight fluctuations noted on Hole 585 resulted in a decision not to risk deploying a re-entry cone and casing string. The additional stresses imposed on the pipe by this operation had the potential of exceeding the yield strength of the drill pipe. The good hole conditions and the generally high penetration rate were encouraging, however, for a second single bit attempt to reach. Jurassic sedimentary rocks.

Hole 585A was spudded, after an uneventful pipe trip, at 2008 hours, October 27th. The hole was drilled to the total depth of Hole 585 with ten "spot" cores taken in intervals that were found to be poorly recovered and/or of high scientific interest in Hole 585. Unfortunately core recovery was no better the second time around. Hole conditions were again favorable, and rotating time on the bit was about $91 / 2$ hours less than at the equivalent depth in Hole 585.

Continuous coring then resumed in the volcanogenic sandstones with the core recovery rate remaining high in this lithology. At about $800 \mathrm{~m} \mathrm{BSF}$, the material became much more thoroughly cemented and therefore much harder. The rate of penetration fell to about eight meters per hour and remained there. The low ROP and the highly abrasive nature of the rock spelled doom for the bit, which had performed so well.

Operations were interrupted after Core 17 at $848 \mathrm{~m}$ when vessel motion caused drilled string weight fluctuations to reach preset operating limits. The bit was pulled to $292 \mathrm{~m}$ BSF to reduce string weight to within limitations. After about eleven hours, the six foot swell subsided somewhat and the current permitted a more favorable heading for the vessel. Coring resumed after a 19 3/4 hour delay and four more cores were taken before string weight again began hitting the limits. As a core barrel was being pumped down, it was decided that the core could be cut before the string was raised, but that the wireline recovery trip would be made after the bit had been pulled to a safer depth. As this core was being cut, the bit failed completely and locked up at $892.8 \mathrm{~m} \mathrm{BSF}$ (total depth $7015.1 \mathrm{~m}$ ).

Conditions were continuing to deteriorate, and the bit was pulled to $280 \mathrm{~m}$ BSF as quickly as possible. The final core barrel was recovered, and again it was necessary to wait on weather. The weight/motion combination precluded running back to total depth to make the wireline run to actuate the mechanical bit release. Releasing the bit was necessary for the planned logging program, but chances of the bit/bit sub assembly falling freely to the bottom of the eroded hole were considered to be too slim to warrant an attempt. Logging tools could easily have become stuck in attempting to pass the bit in the hole. Weather conditions failed to improve, and another $115 \mathrm{~m}$ of pipe was pulled to lighten the string further. After ten hours of waiting, weather forecasts predicted no relief within 48 hours and the decision was made to abandon the site.

The drill string was pulled and was all on board at 0300 hours, November $3 \mathrm{rd}$. Al1 four of the bit cones were missing, and the shanks had been worn down to $1 / 2$ inch under gauge. 
Site 585 to Site 462

The rig was secured for sea and the CHALLENGER departed the site at 0211 hours, November 3rd. After a brief departure survey, the vessel profiled across Ita Maitai Guyot (DSDP Site 202) about 30 miles to the south before turning southeastward toward Site 462. Excellent weather and an apparent following current aided the ship in achieving an exceptional average speed of 10.1 knots over the 587 mile transit.

Site 462 is located in the northern Nauru Basin almost midway between Kusaie Island and Kwajalein Atoll and was drilled on Leg 61. As the objective was to deepen re-entry Hole $462 \mathrm{~A}$, it was necessary to locate the vesse1 within scanning sonar range of the re-entry cone (about 100 meters). The towed seismic gear was retrieved well before arrival at the site so that it would not interfere with precise maneuvering on the approach. The site approach was timed to take advantage of a good satellite navigation (SATNAV) fix shortly before beacon launch. The signal was masked by "crosstalk" from another satellite, however, and the fix could not be used. The vessel was then slowed so that a later satellite could be interrogated. Although this fix had less than optimum parameters, it plotted squarely on the ship's track and it was used to determine speed of advance. A $13.5 \mathrm{kHz}$ positioning beacon was dropped on a direct approach at 1832 hours, November 5 th.

Hole 462A - First Re-entry

Temperature Log

All preparations for the trip short of actually running pipe were made as more SATNAV fixes were received to verify the ship's position. It was then necessary to wait an additional $13 / 4$ hours for enough good fixes to ascertain the position relative to that of the re-entry cone. A close grouping of three fixes indicated that the beacon had been launched a little more than one kilometer too soon--to the northwest. This placed the cone near the limit of the offsetting range of the vessel's positioning system. Offsets were therefore used to move the ship to a position calculated to coincide with the coordinates of the cone, where a second $(16 \mathrm{kHz})$ beacon was dropped at 0042 hours, November 6 th.

The pipe trip began immediately with the assembly of a special abbreviated logging BHA. A special bit was attached which would permit re-entry, logging and hole cleaning--but not drilling or coring. During the trip to re-entry depth, more SATNAV fixes were received and the vessel's position was refined further by a $150 \mathrm{~m}$ north offset. The logging/re-entry sheaves were rigged, and the re-entry sonar was connected and given a final deck check. After an initial $11 / 2$ hour delay for weight indicator problems, the sonar began its descent through the drill pipe. This trip required an excruciating four hours because of the drag of spring loaded profile keys on the sonar tool (required for open ended pipe re-entries) and because of requirements to run slow and to stop occasionally to detorque the new logging cable. 
Sonar scanning started at 1502 hours, and the re-entry cone target was detected almost immediately at a range of only about $45 \mathrm{~m}$. The end of the pipe was lowered to $5178.5 \mathrm{~m}$, only four meters above the re-entry cone based on Leg 61 drill pipe measurements. The pipe was quickly brought to short range and several attempts were made to move the pipe across the cone for a re-entry stab. There were consistent indications, however, that the cone and the seafloor were too far below the sonar to provide a proper target presentation. It was eventually necessary to lower the pipe an additional $71 / 2 \mathrm{~m}$ before the final approach was made. The drill string was also found to be quite unresponsive to movements of the ship, possibly due to the lightweight logging BHA. In all, five hours and 14 minutes of scanning were required before the pipe swung over the cone and a successful stab was made. The sonar tool was then recovered and the re-entry was verified by the addition of more pipe to the string.

This was the sixteenth re-entry into Hole $462 \mathrm{~A}$ and the first since July 1978 . A rare opportunity was thus provided for temperature measurements in a completely equilibrated borehole. The sonar tool was replaced by a temperature logging sonde, and the logging cable was again run down the pipe. The temperature log was recorded as the tool passed down through the pipe, into cased hole and then into open hole. Hole conditions were surprisingly good, and the tool hesitated only once before it stopped on an obstruction at $517 \mathrm{~m}$ BSF. Attempts to work the tool past this bridge were unsuccessful, but a highly interesting log of good quality had been recorded through the upper half of the hole.

When the logging tool had been recovered, the drill string was run into the hole to clean out the sediment interval. Although there were apparent minor bridges at the point where the logging tool had stopped and near the top of the basalt, the string did not take sufficient weight at any point to warrant picking up the power sub for circulation and rotation. The cleanout bit was run to $5772 \mathrm{~m}$, well below the top of the basalt, and it was felt that danger of sidetracking the hole with the core bit had been minimized. The drill string was then tripped for the installation of a coring bit and BHA. Pipe was on deck at 1720 hours, November 7 th.

Second Re-entry - Core Bit

The bit and the sonar tool were again positioned at re-entry depth and sonar scanning commenced. The offsets of the first re-entry remained in the positioning system, but the vessel was on an almost reciprocal heading because of weather conditons. The target was acquired at a range of about $100 \mathrm{~m}$, and plotting and maneuvering were initiated to close the distance. The pipe was quickly brought to within 12-15 m, and the tedious process of coaxing the bit to pass over the cone began again. The stab was made after 153 minutes of scanning. The re-entry was verified two hours later when the sonar had been recovered and an additional stand of pipe had been run. 
The long trip to the bottom of the hole then began. The bit proceeded without impediment to $5779 \mathrm{~m}$. A solid bridge was encountered only seven meters beyond the point reached by the cleanout bit, and it was necessary to pick up the power sub. Progress then proceeded more slowly with three widely scattered ledges or bridges providing only momentary resistance. About 38 meters of fill was washed from the bottom of the hole without undue difficulty and total depth was reached at $6257 \mathrm{~m}, 3.8 \mathrm{~m}$ below the Leg 61 recorded depth.

A corresponding pipe depth correction was made and continuous coring commenced at $1071.7 \mathrm{~m} \mathrm{BSF}$. Very hard sheet flow basalts were cored with excellent core recovery, but with a rate of penetration of only about $1.5 \mathrm{~m}$ per hour. A drilling break at core No. 99 raised hopes that the bit had broken through into sediment. Core recovery was limited to $1.32 \mathrm{~m}$ of fractured, softer basalt, but traces of green clay were also recovered. Core No. 100 was to be the final core of the bit run based on rotating hours and reduced core diameter which indicated early stages of bearing failure. After three meters of slow, hard drilling, the bit began torquing. This could indicate either bit failure or formation change, and coring operations were halted to minimize chances of losing a bit cone in the hole.

The inner core barrel was left in place to save a time consuming sandline trip, and the drill string was pulled. The bit was brought on deck at 0334 hours, November 11th. It was found to have three very loose cones and considerable damage to the cutting structure.

\section{Third Re-entry - Second Bit}

The BHA was reassembled with rebuilt bumper subs replacing the three worn units recovered on the previous trip. Breakdowns of pipe handling equipment resulted in a one hour delay, but the pipe trip and re-entry preparations were otherwise routine.

Sonar scanning and maneuvering consumed 98 minutes before a successful re-entry had been verified and the pipe trip continued. The hole was found to be clean, and the power sub was deployed after the bit had been run to just 33 meters off total depth. Intermittent reaming was required through the last ten to twelve meters. This had been expected, since the previous bit had been worn nearly $1 / 4$ inch out of gauge.

Coring then continued in very hard basalt with an average penetration rate of 1.4 meters per hour. Core recovery was fairly good on the first two cores, but the following two cores produced a total of only 3.7 meters. Circulating pump pressure was noted to be too high following retrieval of core No. 103 . A chisel type core breaker was made up to an inner core barrel and pumped down the drill pipe.

The low rates of penetration and core recovery indicated that bit damage was a strong possibility. Since only three days of site operating time remained, 
it was decided that the remaining coring time could most effectively be used by tripping for a fresh bit. At the same time, wind and swell conditions had resulted in vessel motion which caused drill string weight fluctuations to reach the operating limit. The string was therefore pulled, with the bit arriving on deck at 2115 hours, November $13 \mathrm{th}$. No obstruction was found in the bit throat, but the bit was found to be nearly as badly worn as the previous one.

Fourth Re-entry - Third Bit

A very quick turnaround and return pipe trip were made, and the re-entry sonar was deployed. On commencement of scanning, the cone target was acquired at a range of 15 meters. An arbitrary offset was entered into the positioning system, and the pipe began to move directly toward the cone. The re-entry was made after only seven minutes of scanning time.

The sonar tool became stuck briefly in the BHA during its retrieval. Subsequent inspection of all components failed to reveal the cause. After re-entry verification, the pipe was run to $610 \mathrm{~m}$ BSF where a bridge was encountered. This was washed out by using the circulating head, and the bit was run to three joints off total depth before the power sub was picked up. Only two meters of hole fill were encountered.

Coring continued in extremely hard rock, again with good recovery on the first two cores. Circulating pressure was too low when core barrel No. 107 landed, indicating an obstruction; probably a piece of core in or just above the bit. The barrel was retrieved and a bit deplugger on an inner core barrel was pumped down the pipe. Seating pressure was again too low when this barrel landed, but when it was retrieved, markings on the landing sub and latch finger indicated that it had seated and latched properly. The coring inner barrel was pumped down and this time gave a normal pressure indication. A core was attempted and the barrel was retrieved. It was found to be stuck in place and had to be worked free at the bit. Only one small lump of basalt was recovered. All indications were normal on the subsequent attempt and $4.2 \mathrm{~m}$ of core were recovered. The core diameter was reduced, however, and bit bearing failure was suspected. Though rotating time was low, vessel motion had caused considerable weight fluctuation and pounding on the bit.

With time running out on the operating schedule, one final core (No. 109) was cut and was retrieved with the drill string. When the drill pipe had been racked, the core was recovered from the BHA. The BHA was then given its bimonthly magnetic inspection as it was broken down. All bit bearings were found to be in good condition, but there were several broken cutting inserts.

The "piccolo" drill pipe guide was then laid down and the rig was secured for sea. The GLOMAR CHALLENGER departed Site 462 at 1654 hours, November 16th. 
Site 462 to Site 586

The final drill site of Leg 89 lay some 610 miles southwest of Site 462 , about 300 miles northeast of Bougainville Island and about 250 miles east southeast of Kapingamarangi Atoll. Excellent weather prevailed, and the vesse1 again achieved an average speed of 10.1 knots.

This portion of the expedition was enlivened by a view of the beautiful island of Kusaie (from about 20 miles) on November 17 th and by a spirited equator crossing ceremony on November 18 th.

Pinpoint accuracy was not required to locate Site 586, and survey activities were limited to slowing to seven knots one hour before beacon drop. Based on SATNAV fixes and dead reckoning, the positioning beacon was launched at 0527 hours, November 19th.

Hole 586 - Ontong-Java Plateau

The drill site was located in $2217 \mathrm{~m}$ of water (by PDR) about $11 / 2 \mathrm{~km}$ west of DSDP Site 289, which had been cored to basement. Primary objectives at Site 586 included recovering a complete and undisturbed core record of the upper 200-300 meters of the sediment section by means of the hydraulic piston corer (HPC) and using well logs to determine the nature of seismic reflectors in the area.

The drill string was run to place the bit just off the seafloor, and the variable length hydraulic piston corer (VLHPC) assembly was deployed. The first 9.6 meter "shot" was made from 2214.8 meters at 1404 hours, November 19th. A 1.3 meter core obviously containing the sediment water interface was recovered, and water depth was established as 2223.1 meters. (This was later changed to $2218.0 \mathrm{~m}$ based on gamma ray logs.)

Continuous piston coring then proceeded in soft calcareous ooze. Core No. 6 was to include a temperature measurement with a special instrumented catcher sub, and the VLHPC assembly was retrieved after a five minute delay for equilibration following actuation of the piston corer. Only about half of the corer arrived on deck, however, as the assembly was found to have parted into the outer body section. This left the lower portion of the outer body and the core barrel (with heat flow sub) in the hole. This terminated the hole after a cored penetration of only 39.3 meters, and the bit was pulled above the seafloor for a second attempt.

Hole 586A

The VLHPC was then redressed with new components replacing those that had been lost. The second hole was spudded at 2204 hours, November 19 th and the bit was "washed" to the depth of Hole 586 before the coring apparatus was picked up. 
The sediment proved to be extraordinarily soft and well suited to piston coring and 9.6 meter cores were taken to 286 meters BSF. The corer was still achieving full stroke at that depth, but withdrawal overpull of up to 40,000 pounds prompted the decision to switch to the five meter unit. Four more cores were taken before the hole was terminated at 305.3 meters BSF to conform to the operating schedule.

$\underline{\text { Hole 586B }}$

When the bit had been pulled clear of the seafloor, the 9.5 meter VLHPC was redressed with new seals and preparations were made to core the same section a second time. No positioning offset was made, and the bit was lowered to 2218.5 meters for the first core to establish an overlapping sequence for the duplicate coring effort. The first core barrel was recovered completely ful1, however, indicating that water depth was at least 3.7 meters less than had been measured with the first core of Hole 586.

Coring continued at an exceptionally smooth and rapid pace, with nearly 100 percent core recovery and an absence of mechanical problems. The core laboratory received 25 cores totaling 234.9 meters in just over 17 hours. A time limit had been set for coring Hole 586B to provide time for drilling and logging a final hole prior to departure. This time expired coincident with the first minor problem--a plastic liner failure that caused the piston to become jammed in the top of the core barrel. Coring was terminated at a total pipe depth of 2458.3 meters.

The VLHPC assembly was laid out and the drill string was recovered, with the bit arriving on deck at 0008 hours, November 22 .

$\underline{\text { Hole 586C }}$

Minor modifications were made to the BHA and a hydraulic bit release with a used $97 / 8^{\prime \prime}$ core bit was made up to the outer core barrel. The pipe was run to the seafloor and Hole $586 \mathrm{C}$ was spudded at 0541 hours.

The soft ooze and chalk drilled effortlessly and over 600 meters of hole was made in less than seven hours. The "wash" core barrel was then retrieved and a clean barrel was pumped into place for a final rotary core to the total depth of 2841.1 meters.

Upon retrieval of the core, a "go-devil" was pumped down the pipe to actuate the hydraulic bit release. The bit and associated components were detached on the first attempt, and the hole was promptly filled with fresh water/ bentonite mud for logging. The pipe was then pulled to logging depth and the logging sheaves were rigged.

The sonic velocity/induction/gamma ray/caliper $10 \mathrm{~g}$ sonde was run first. The hole was found to be clean to total depth and nearly to bit size for most of the interval. An excellent quality $10 \mathrm{~g}$ was recorded on all traces. The sonde 
was recovered and was exchanged for the formation density/neutron porosity/ gamma ray/caliper tool. Again the equipment performed flawlessly and a good $\log$ was recorded from total depth. Both gamma ray logs indicated a seafloor depth of about 2218 meters.

The logging tools were rigged down, the short pipe trip was made, and the rig was secured for sea--all in less than five hours, and the vessel departed the final drill site at 0810 hours, November 23.

Site 586 to Noumea

With good weather persisting, the CHALLENGER averaged over eleven knots for the first two days of her southward journey to New Caledonia. The speed decreased somewhat after that in light to moderate winds and seas, but remained quite good due to the ship's clean bottom and lightened load of fuel and water.

The ship's party was again treated to the sight of land as the island of Malaita remained in plain view for most of Thanksgiving Day, November 25 . That evening we transited the straits between MaIaita, San Cristobal and Guadalcanal Islands of the Solomon Archipelago.

The final transit of 1520 miles was completed with a somewhat phenomenal average speed of 10.3 knots. Leg 89 came to its official end at 1441 hours, November 29, 1982 when the first mooring line was put over at the passenger terminal dock in the port of Noumea, New Caledonia.

Dri11 String

The GLOMAR CHALLENGER'S drill string was restocked from scratch at the Yokohama port call. All existing drill pipe was offloaded to the local NKK steel works for inspection and dimensional modification. Used pipe returned to the rig totaled 610 joints, of which 444 joints were graded Premium and 166 were in need of tool joint refacing. In addition 562 joints of new NKK pipe were loaded.

During the transit to the first drill site, the working string was made up into triple stands and rubber pipe protectors were installed on all but 50 stands of premium pipe, which was to be positioned at the bottom of the string. An additional 41 joints of new pipe were picked up during coring operations at Site 585. The working string on the pipe rack at the end of Leg 89 thus consists of 444 joints of used Premium Grade pipe below 263 joints of new NKK pipe.

The uppermost 186 joints were transferred down to be run just above the Premium pipe following the ultradeep operations at Site 585. This was done to equalize the axial fatigue cycles through the string as more deep work was to be done in Hole 462A. 
Clamp on style rubber protectors were instailed approximately each two meters on the working string, and most were cemented in place with epoxy resin. Only minor pipe handing problems have been caused by the protectors and most have remained in place.

Various bottom hole assemblies were employed during the voyage. The rotary coring BHA used at Holes 585, 585A and 462A, consisted of bit, bit sub or bit release, head sub (for spacing), one $81 / 4^{\prime \prime}$ drill collar, top sub, head sub, three 8 1/4" drill collars, one five-foot stroke Baash-Ross bumper sub, three 8 1/4" drill collars, two bumper subs, two 8 1/4" drill collars, crossover sub and one $71 / 4^{\prime \prime}$ drill collar. A stabilizer was originally included about 19 meters above the bit, but it was removed after some pipe sticking problems occurred on the first bit run in Hole 462A. The rotary coring assembly at Hole $586 \mathrm{C}$ was the same except that the lower stand of three $81 / 4^{\prime \prime}$ drill collars and the single bumper sub were left out. The extra weight was not needed in the soft sediment. The BHA was further abbreviated for the logging re-entry at Hole 462A to a special re-entry/logging/cleanout bit attached to the lowermost of three $81 / 4^{\prime \prime}$ drill collars, one bumper sub, two $81 / 4^{\prime \prime}$ drill collars, crossover sub and one 7 1/4" drill collar. The VLHPC coring assembly used in Holes 586,586A, and 586B was made up of a special HPC bit, bit sub, one $81 / 4^{\prime \prime}$ drill collar, two stabilizers (for spacing), one 8 1/4" drill collar, top sub, HPC seal sub, one 12 foot gammaloy drill collar (for magnetic core orientation), two $81 / 4^{\prime \prime}$ drill collars, one bumper sub, two 8 1/4" drill collars, crossover sub and one $71 / 4^{\prime \prime}$ drill collar. In all cases two joints of range three $51 / 2^{\prime \prime} 21.9$ pound drill pipe were placed between the 7 1/4" drill collar and the 5" drill pipe to provide a tapering section modulus for the distribution of bending stresses.

The weight and the strength of the drill string imposed operating limitations which had a profound effect upon the operations at Site 585 and which possibly prevented achievement of the primary scientific objectives of the cruise. Weight limitations prevented the setting of a re-entry cone and casing string as had been planned originally. During coring operations with a drill string length of nearly seven kilometers, six foot swells produced weight fluctuations of up to eighty thousand pounds above and below static string weight on one or two occasions. This stressed the pipe to about 95 per cent of minimum yield strength and forced immediate cessation of operations to pull the bit to a shallower depth until vessel motion conditions abated. Weight fluctuations also reached marginal levels on two occasions at Site 462, causing concern but not directly affecting operations.

\section{Bit Releases}

Only one bit separation was attempted on Leg 89. This was accomplished in Hole $586 \mathrm{C}$ with the latest model hydraulic bit release. The mechanism performed according to design and actuated on the initial pressurization with the bit about one meter off the bottom of the hole. The hydraulic bit release was also run in Hole 585, which was lost when an oversized landing sub became wedged in the HBR liner. An unsuccessful attempt was made to actuate the HBR after the landing sub had been removed. It was discovered, on disassembly, 
that the liner had become detached from its bearing support and had been displaced downward, possibly preventing proper hydraulic action. A mechanical bit release was used in Hole $585 \mathrm{~A}$, but no release was attempted since the bit could not be run to total depth due to vessel motion/string weight limitations.

Drilling and Coring Equipment

Two minor innovations to the wireline coring system were introduced during Leg 89. A specially designed swivel is now run directly above the wireline sinker bars for both rotary and HPC coring. Unlike the earlier version used only for HPC work, it is slim enough to pass through the wireline blowout preventer. The swivel eliminates the inconvenience and hazard of "spinning overshots" and should increase sandline life expectancy. The quick release connector developed for the HPC inner barrel has been adapted for use between the top of the rotary inner barrel and its latch/swivel assembly. This connection is broken prior to the removal of each core from the barre1-formerly requiring two men, a 36" pipe wrench and chain tongs. The worn threaded connections have, on occasion, backed out and left core barrels in the pipe. The new connection streamlines the operation, but it lengthens the core barrel assembly by about 19 inches. Leakage around the ball check valve at the bottom of the connector resulted in lost time and difficulty in obtaining a seafloor core at Hole 585. This feature is being redesigned.

The heave compensator was used only during the first sandline trip in Hole 585 . Although maximum usage had been planned, it was found that insufficient air bank pressure could be maintained to support the weight of the drill string. The air bank safety relief valve had been set for a maximum pressure of 3550 psi by order of the U. S. Coast Guard, and the valves began leaking at 400-500 psi less. This limitation prevented use of the compensator at either Site 585 or Site 462. The heave compensator was not deployed at Site 586 because of piston coring operations and extremely soft sediments. The antislingshot valve malfunctioned during the short time the compensator was in use. Shipboard personnel discovered that the valve body had become eroded, allowing fluid leakage past 0-ring seals; the problem was solved by replacement of the body.

The TOTCO drilling recorder produced records of minimal value throughout the cruise, since important traces (including the critical hookload) were out of calibration, and the clocks driving the drum were undependable.

\section{Core Bits}

Long chisel insert model F93CK bits were used in Holes 585 and $585 \mathrm{~A}$ to achieve the maximum penetration rate through the expected thick sediment section. The penetration rates were not disappointing, but the rotating lives were. The abrasive nature of the volcaniclastic turbidites caused excessive shirttail wear, exposing the seals to accelerate seal and subsequent bearing failure. Gauge, cone she1l and insert wear were also apparent. This is 
consistent with wear phenomena noted in drilling volcaniclastics in the Mariana Island Arc on Leg 59. Bits with special abrasion resistant features would be desirable if such material is to be cored in the future.

Type F94CK bits were used for the deepening of Hole 462A. The medium length chisel insert cutting structure was rather severely damaged, especially in the drive rows. This indicated that the dense basalt was too hard for this model bit. Unfortunately string weight limitations prevented running the additional drill collars that experience has shown to be necessary for acceptable penetration rates with the F99CK "button" bit. Bearing life was also quite short in these bits. This is attributed primarily to the pounding caused by the weight fluctuations produced by even mild swell conditions. The lack of heave compensation was undoubtedly a factor in the reduced bit life.

\section{Piccolo}

The long drill pipe restraint, known as the piccolo, was utilized at Sites 585 and 462 to reduce dynamic stress on the long drill strings by distributing the bending component through a longer interval than is possible with the standard guide horn. The assembly presented no problems once it was in place, and its presence was comforting when vessel rolls reached six to seven degrees on occasion.

The problems of the piccolo lie in its handling and transportation. The $131 / 2$ ton middle section cannot safely be picked up or laid down if there is any amount of vessel motion. This section can be transported vertical (suspended from the travelling block), but if the lower section is attached to it, the block must be raised to a position where damage to the guide rails is quite likely. Attaching the lower section at sea is also difficult and hazardous due to the weight and top heavy nature of the middle section.

\section{Special Tools}

The variable length hydraulic piston corer was used with great success at Site 586. The calcareous ooze encountered at that site is highly amenable to this mode of coring and a record HPC penetation of 305.3 meters was achieved without reaching the full stroke penetration limit for the five meter corer.

The only serious problem was the outer body link connection failure which ended Hole 586. The failed unit had seen considerable use and the zone of failure was apparently a fatigue crack which had propagated from a corrosion pit. There were a few instances of plastic liner failure and premature shear pin failure, but these had only minor impact on operations.

The Kuster single shot orientation system was used in all HPC holes and was also used for drift determination in the deep holes at Site 585 and 462 . The system again produced many problems and only marginal results. Both of 
the mechanical clock timers were out of service much of the time, and the "automatic" electronic timers consistently yielded motion blurred and unusable photographs. The timers apparently were being triggered at the wrong time and were exposing the photos during the wireline trip. Light leakage into the film disc loader ruined several photos and many discs were wasted by frequent jamming of the loader mechanism.

\section{Logging}

Three logging runs were made at two sites during Leg 89 . The logging operations proceeded smoothly with no equipment problems. The high resolution thermometer log run following the first re-entry into Hole 462A was stopped by a bridge in the hole, but not before a successful log had been recorded for about 508 meters. In Hole $586 \mathrm{C}$ a full standard suite of logs was obtained in two runs in a hole that was clean and in good condition to total depth. In addition to the basic logs, the Schlumberger engineer produced a "computed" acoustic impedance log from the sonic velocity and formation density curves.

\section{$\underline{\text { Re-entry }}$}

Four re-entries were made into Hole 462A (bringing the total in that hole to twenty) with no equipment malfunctions of any kind. Distinct target reflector. patterns were observed in each case, indicating that the re-entry cone remains undamaged and uncovered.

\section{Dynamic Positioning}

The ship's dynamic positioning system (DPS) also performed well and reliably for the entire voyage and no problems of operational significance occurred. Re-entry offsets required at various headings indicated that the headinginduced positioning error describes a circle about 100 meters in diameter in water 5200 meters deep.

ORE self-contained positioning beacons were used for DPS referencing at all sites. The beacons performed flawlessly and caused no positioning problems.

\section{$\underline{\text { Engineering }}$}

The vessel's power generating and propulsion systems were kept in operation by the ship's engineers despite some difficult working conditions. The most serious mechanical problems involved D.C. generator No. 9B. The armature indicated a short to ground during sea trials, and the generator was removed to the shipyard electrical shop where the armature was replaced. The unit was tested with satisfactory results before the vessel sailed, but the commutator end bearing failed after a very few hours of operation at sea. The bearing was replaced, but it promptly failed again. Electrical assignments 
were then rewired to give the normal $9 \mathrm{~B}$ tasks to generator 10B, whose assignments are of a "backup" nature except during rough weather. Full repairs to $9 B$ were deferred to the Noumea port call.

Problems with a rotary exciter and a bow thruster tachometer generator also occurred during sea trials, but they were rectified during the remaining days of the port call.

Engineering department personnel designed, fabricated, fitted and installed a new type of seawater intake strainer on each of the twelve Caterpillar engines. During this work, the stems of two of the seawater isolation valves became detached from the gates. This left the valves shut and the engines out of service (one at a time) until temporary repairs could be made. Impact on operations was minimal.

Both of the engine room supply blowers located on the boat deck failed within a period of a few days. Because of the high sea temperatures, engine room air temperature had been running at about $125^{\circ} \mathrm{F}$. It reached $136^{\circ} \mathrm{F}$ while the repairs were being made.

\section{Weather and Currents}

Though the tropical climate produced many uncomfortably warm days and late night "deckwashers", the voyage enjoyed very pleasant weather conditions overal1. The only rough weather was encountered on the initial transit from Japan to Site 585. Tropical Storm Owen moved off Site 585 as the CHALLENGER approached it, then stayed in the general area for about ten days, as it nearly circled the operating area before dissipating.

On-site weather was never severe, but divergent wind, swell and current conditions caused vessel motion that affected operations on several occasions. Operations were halted twice at Hole 585A when weight fluctuations of the long drill string reached the operating limits. A total of 21.1 hours were spent waiting for conditions to improve. The site was finally abandoned without logging when the weather forecast was for no change in conditions. Maximum swell height was about six feet.

Currents were a factor in positioning at all sites. They were variable in direction and velocity at the first two sites; from the west but varying in velocity at Site 586. The positioning and vessel motion problems occurred when wind and/or current forced the vessel into the trough. Although the "piccolo" decreased the bending stress imposed by roll, it was found that string weight fluctuations were greater when vesse 1 motion was in a rolling mode than they were with an equivalent pitch. Unfortunately the CHALLENGER has no direct means of measuring current, swell or heave.

Communications

Because of distance and radio propagation conditions, only a very few messages 
were handled through the Scripps Radio Station WWD. Outgoing traffic had to be relayed through the U. S. Coast Guard Station NRV in Guam. Incoming messages were copied from NRV's "Mercast" schedule. The exceptional

cooperation of NRV was essential and invaluable to the Leg 89 communications effort.

Two commercial radio-telephone calls to DSDP were made, but oonditions were marginal. Numerous personal telephone calls to the U. S. were made via amateur radio operator networks and two "hams" in the ship's crew.

\section{Personne1}

The leg began on a tragic note when a shipyard worker was fatally injured during the drydock period. The vessel's rudder was being removed when it fell and struck the worker. Accidents continued, and during the port call the rig mechanic suffered three cracked ribs and a cracked vertebra in a fall on the rig floor. Within the next week, a rotary helper sustained facial and chest injuries when struck by a falling chainfall, and a drilling foreman lost the end of his middle finger when it was caught in the air spinning wrench. Fortunately the remainder of the voyage passed without significant accident or illness.

Morale among the scientific staff suffered when the primary scientific goals were seen to be slipping away, but most remained philosophical. The workload for the GMI crew and for the SIO technicians was heavy at times, but the transit periods provided a change of pace or at least a variation in the nature of the work. In general, a positive work attitude was maintained throughout the cruise.

Glen N. Foss

Cruise Operations Manager

Deep Sea Drilling Project 
LEG 89 OPERATING AREA

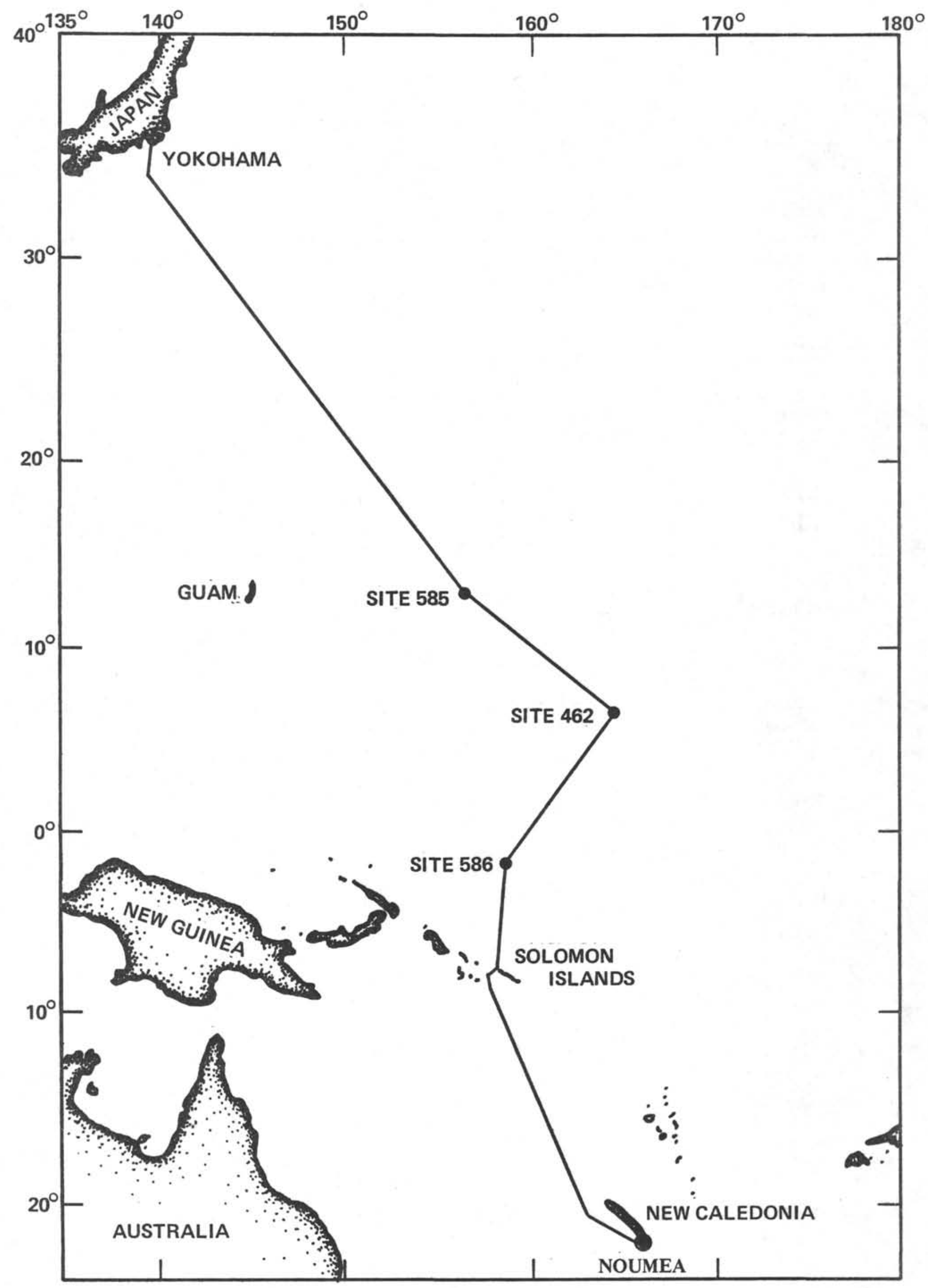


INTERNATIONAL PHASE OF OCEAN DRILLING

DEEP SEA DRILLING PROJECT

TOTAL TIME DISTRIBUTION

LEG 89

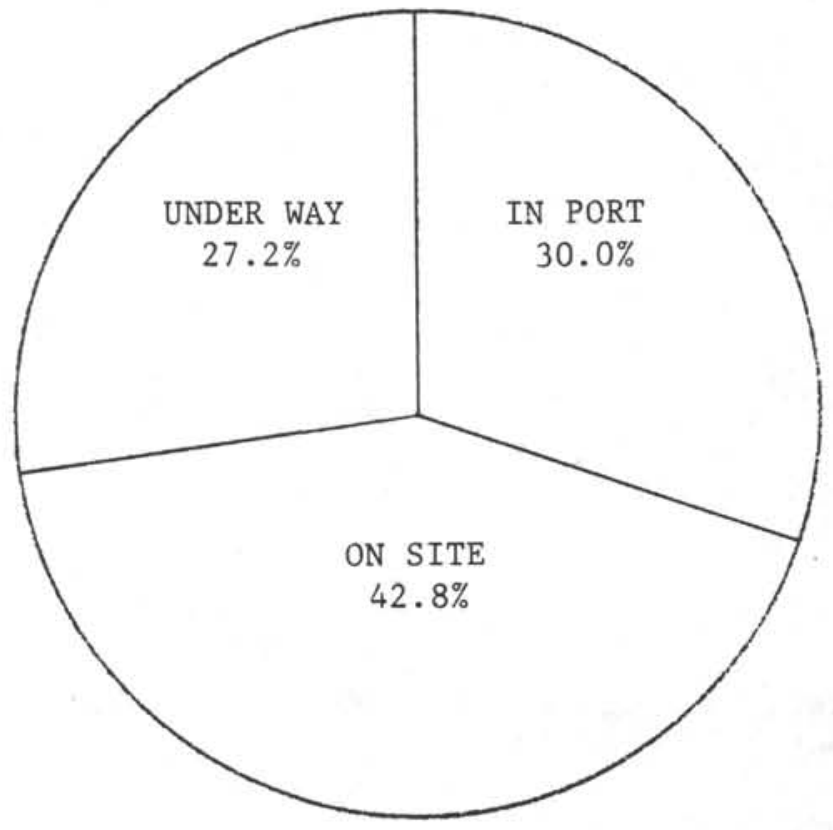

ON SITE TIME BREAKDOWN

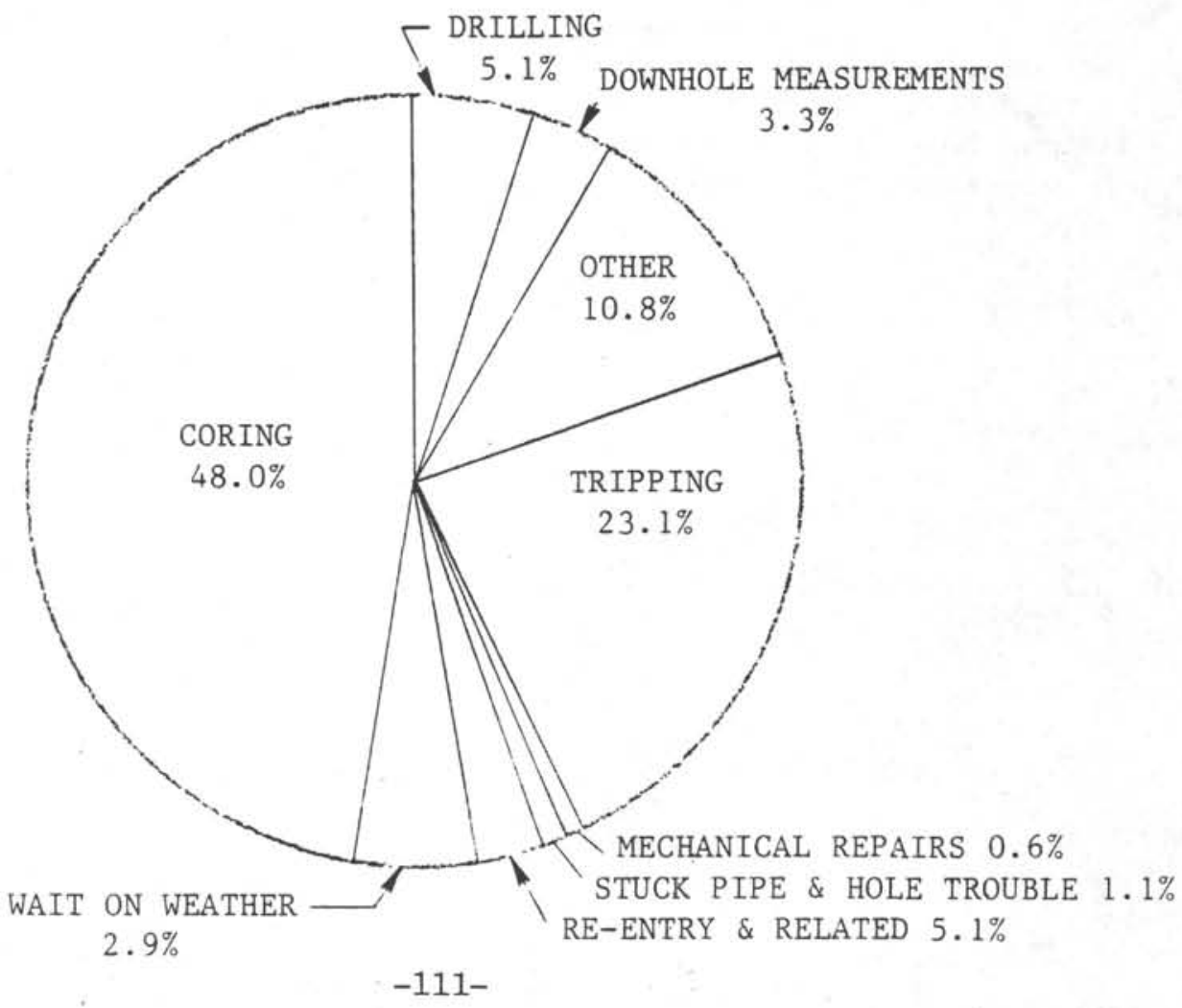




\section{INTERNATIONAL PHASE OF OCEAN DRILLING \\ DEEP SEA DRILLING PROJECT \\ OPERATIONS RESUME \\ LEG 89}

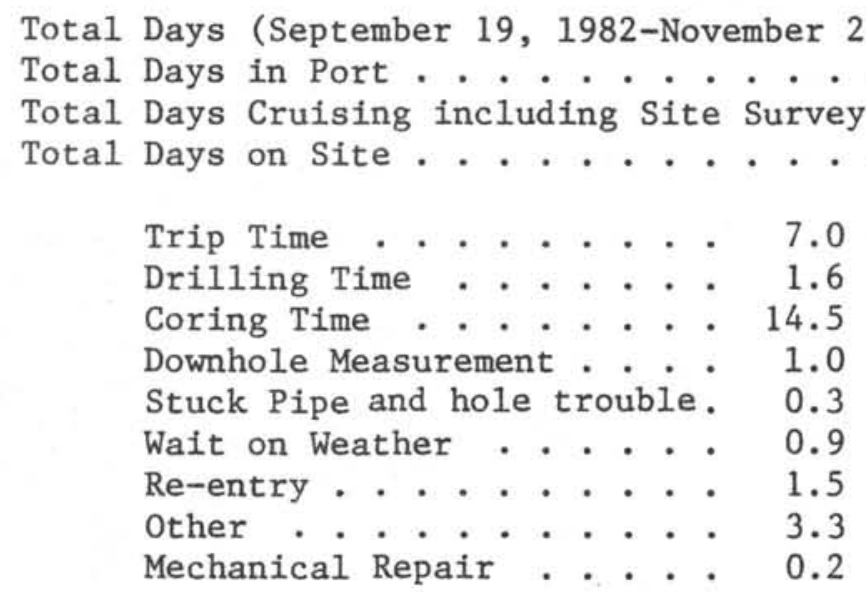

Total Distance Traveled including Survey (Nautical Miles) . . .

4459.5

Average Speed (Knots) . . . . . . . . . . . . . . . . .

Number of Sites . . . . . . . . . . . . . . . . . .

Number of Holes Drilled . . . . . . . . . . . . . . . .

Number of Cores Attempted . . . . . . . . . . . . . . .

Number of Cores with Recovery . . . . . . . . . . . . . . .

Total Meters Cored .. . . . . . . . . . . . . . . .

Total Meters Recovered . . . . . . . . . . . . . . . .

Percent Recovery .. . . . . . . . . . . . . . . . . . .

Total Meters Drilled . . . . . . . . . . . . . . . .

Total Meters of Penetration . . . . . . . . . . . . . . .

Percent of Penetration Cored . . . . . . . . . . . . . . . . .

Maximum Penetration (meters) . . . . . . . . . . . . .

Minimum Penetration (meters) . . . . . . . . . . . . . .

Maximum Water Depth (meters) . . . . . . . . . . . . . .

Minimum Water Depth (meters) . . . . . . . . . . . . .
70.7

21.2

19.2

30.3 
DEEP SEA DRILLING PROJECT

TIME DISTRIBUTION

\section{$\angle E G-89$}

\begin{tabular}{|c|c|c|c|c|c|c|c|c|c|c|c|c|c|c|}
\hline Datie & $\begin{array}{l}\text { Site } \\
\text { No. }\end{array}$ & Cruise & Trips & Drill & Core & $\begin{array}{l}\text { Stuck } \\
\text { Plpe }\end{array}$ & W. O.W. & $\begin{array}{l}\text { POWNHOLE } \\
\text { MEAS. }\end{array}$ & $\begin{array}{l}\text { Mech. } \\
\text { Pepair }\end{array}$ & $\begin{array}{l}\text { Port } \\
\text { Time }\end{array}$ & $\begin{array}{l}\text { Re- } \\
\text { Entry }\end{array}$ & other & $\begin{array}{l}\text { Total } \\
\text { Time }\end{array}$ & Remarks \\
\hline 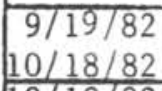 & & 187.5 & & & & & & & & 50.9 .6 & & . & 697.1 & $\begin{array}{l}\text { Yokohama to } \\
\text { Site } 585\end{array}$ \\
\hline $\begin{array}{l}10 / 18 / 82 \\
10 / 27 / 82 \\
10 / 27 / 82\end{array}$ & 585 & & 28.7 & 4.0 & 127.9 & 2.7 & & 0.8 & 2.3 & & 0.7 & 31.6 & 198.7 & $1-x+2 x$ \\
\hline $\begin{array}{l}11 / 03 / 82 \\
11\end{array}$ & $585 \mathrm{~A}$ & & 35.1 & 26.2 & 64.4 & & 21.1 & 1.0 & & & & 18.3 & 166.1 & \\
\hline $\begin{array}{l}\begin{array}{l}11 / 03 / 82 \\
11 / 05 / 82\end{array} \\
\frac{11 / 05 / 82}{1105 / 82}\end{array}$ & & 63.3 & & & & & & & & & & & 63.3 & $\begin{array}{l}\text { Site } 585 \text { to } \\
\text { Site } 462\end{array}$ \\
\hline $\begin{array}{l}11 / 16 / 82 \\
11 / 16 / 82\end{array}$ & $462 \mathrm{~A}$ & & 82.9. & & 110.4 & 5.6 & & 9.0 & 1.7 & & 36.6 & 16.2 & 262.4 & \\
\hline $\begin{array}{l}11 / 16 / 82 \\
11 / 19 / 82\end{array}$ & & 60.6 & & & & & & & & & & & 60.6 & $\begin{array}{l}\text { Site } 462 \text { to } \\
\text { Site } 586\end{array}$ \\
\hline $11 / 19 / 82$ & 586 & & 4.6 & & 3.4 & & & 0.4 & & & & 5.4 & 13.8 & \\
\hline $\begin{array}{l}11 / 19 / 82 \\
11 / 20 / 82 \\
1\end{array}$ & $586 \mathrm{~A}$. & & 1.7 & 0.3 & 23.1 & & & & & & & 2.7 & 27.8 & - \\
\hline $\begin{array}{l}11 / 22 / 82 \\
11 / 22 / 82\end{array}$ & $586 \mathrm{~B}$ & & 4.0 & & 17.9 & & & & & & . & 3.1 & 25.0 & \\
\hline $11 / 23 / 82$ & $586 \mathrm{C}$ & & 10.5 & 6.7 & 1.6 & & & 12.4 & & & & 0.9 & 32.1 & \\
\hline $\begin{array}{l}11 / 29 / 82 \\
11 / 29 / 82 \\
\end{array}$ & & 150.5 & - & & & & & & & & & & 150.5 & $\begin{array}{l}\text { Site } 586 \\
\text { to Noumea } \\
\end{array}$ \\
\hline & & 461.9 & 167.5 & 37.2 & 348.7 & 8.3 & 21.1 & 23.6 & 4.0 & 509.6 & 37.3 & 78.2 & 1697.4 & TOTALS \\
\hline & & & & & & & & & & & & & & \\
\hline & & $=$ & & & & & & & & & & . & . & \\
\hline & & . & & & & & & & & & & & & \\
\hline & & - & & & & & & & & & & & & . \\
\hline & & & & & & & & & & & & & & \\
\hline & & & & & & & . & : & & & & & & \\
\hline & & & & & & & $\cdots$ & & & & & & & \\
\hline
\end{tabular}


INTERNATIONAL PHASE OF OCEAN DRILLING

DEEP SEA DRILLING PROJECT

SITE SUMMARY

LEG 89

\begin{tabular}{|c|c|c|c|c|c|c|c|c|c|c|c|c|c|c|}
\hline Hole & Lat1tude & Long1tude & $\begin{array}{l}\text { Water } \\
\text { Depth } \\
\text { Matara }\end{array}$ & $\begin{array}{c}\text { Number } \\
\text { of } \\
\text { Cores }\end{array}$ & $\begin{array}{c}\text { Cores } \\
\text { With } \\
\text { Recovery }\end{array}$ & $\begin{array}{l}\text { Percent of } \\
\text { Cores With } \\
\text { Recovery }\end{array}$ & $\begin{array}{l}\text { Meters } \\
\text { Cored }\end{array}$ & $\begin{array}{c}\text { Meters } \\
\text { Recovered }\end{array}$ & $\begin{array}{l}\text { Percent } \\
\text { Recovered }\end{array}$ & $\begin{array}{r}\text { Meters } \\
\text { Drilled }\end{array}$ & $\begin{array}{l}\text { Total } \\
\text { Penet } \\
\text { Meters }\end{array}$ & $\begin{array}{l}\text { Avg } \\
\text { Rate } \\
\text { Penet. }\end{array}$ & $\begin{array}{l}\text { Time } \\
\text { On } \\
\text { Hole }\end{array}$ & $\begin{array}{l}\text { Time } \\
\text { On } \\
\text { Site }\end{array}$ \\
\hline \multirow[t]{2}{*}{$\begin{array}{l}585 \\
585 \mathrm{~A} \\
\end{array}$} & $\begin{array}{l}13^{\circ} 29.0^{\prime} \mathrm{N} \\
13^{\circ} 29.0^{\prime} \mathrm{N} \\
\end{array}$ & $\begin{array}{l}156^{\circ} 48.9^{\prime} \mathrm{E} \\
156^{\circ} 48.9^{\prime} \mathrm{E}\end{array}$ & $\begin{array}{l}6122.3 \\
6122.3 \\
\end{array}$ & $\begin{array}{l}55 \\
22 \\
\end{array}$ & $\begin{array}{l}54 \\
22 \\
\end{array}$ & $\begin{array}{r}98.2 \\
100.0 \\
\end{array}$ & $\begin{array}{l}514.6 \\
208.8 \\
\end{array}$ & $\begin{array}{l}164.5 \\
101.5 \\
\end{array}$ & $\begin{array}{l}32.0 \\
48.6 \\
\end{array}$ & $\begin{array}{l}249.1 \\
684.0 \\
\end{array}$ & $\begin{array}{l}763.7 \\
892.8 \\
\end{array}$ & $\begin{array}{l}25.5 \\
26.4 \\
\end{array}$ & $\begin{array}{l}192.7 \\
166.1 \\
\end{array}$ & \\
\hline & & & & 77 & 76 & 98.7 & 723.4 & 266.0 & 36.8 & 933.1 & 1656.5 & 26.0 & $\cdots$ & 364.8 \\
\hline $462 \mathrm{~A}$ & $7^{\circ} 14.5^{1} \mathrm{~N}$ & $165^{\circ} 01.9^{\prime} \mathrm{E}$ & 5186.0 & 17 & \multirow{2}{*}{ j } & 100.0 & 137.3 & 74.4 & 54.2 & 0 & 137.3 & 1.7 & $\cdots$ & 262.4 \\
\hline $\begin{array}{l}586 \\
536 \mathrm{~A} \\
586 \mathrm{~B} \\
586 \mathrm{C} \\
\end{array}$ & $\begin{array}{l}0^{\circ} 29.8^{\prime} \mathrm{s} \\
0^{\circ} 29.8^{\prime} \mathrm{s} \\
0^{\circ} 29.8^{\prime} \mathrm{s} \\
0^{\circ} 29.8^{\prime} \mathrm{s} \\
\end{array}$ & $\begin{array}{ll}158^{\circ} & 29.9^{\prime} \mathrm{E} \\
158^{\circ} & 29.9^{\prime} \mathrm{E} \\
158^{\circ} & 29.9^{\prime} \mathrm{E} \\
158^{\circ} & 29.9^{\prime} \mathrm{E} \\
\end{array}$ & $\begin{array}{l}2218.0 \\
2218.0 \\
2218.0 \\
2218.0 \\
\end{array}$ & $\begin{array}{r}5 \\
31 \\
25 \\
1 \\
\end{array}$ & & $\begin{array}{l}100.0 \\
100.0 \\
100.0 \\
100.0 \\
\end{array}$ & $\begin{array}{r}44.4 \\
260.9 \\
240.3 \\
9.6 \\
\end{array}$ & $\begin{array}{r}39.0 \\
257.0 \\
234.9 \\
2.2 \\
\end{array}$ & $\begin{array}{l}97.8 \\
22.7 \\
\end{array}$ & $\begin{array}{c}0 \\
44.4 \\
0 \\
613.5 \\
\end{array}$ & $\begin{array}{r}44.4 \\
305.3 \\
240.3 \\
623.1 \\
\end{array}$ & $\frac{-.}{165.4}$ & $\begin{array}{l}13.8 \\
27.8 \\
25.0 \\
32.1 \\
\end{array}$ & -.-- \\
\hline \multirow{2}{*}{$586 \mathrm{C}$} & & & & 62 & 62 & 100.0 & 555.2 & 533.1 & 97.8 & 657.9 & 1213.1 & --- & --- & 98.7 \\
\hline & TOTALS & & & 156 & 155 & 99.4 & 1415.9 & 873.5 & 61.7 & 1591.0 & 3006.9 & --- & $-\cdots$ & 725.9 \\
\hline
\end{tabular}


INTERNATIONAL PHASE OF OCEAN DRILLING

DEEP SEA DRILLING PROJECT

$$
\text { BIT SUMDARY }
$$

LEG 89

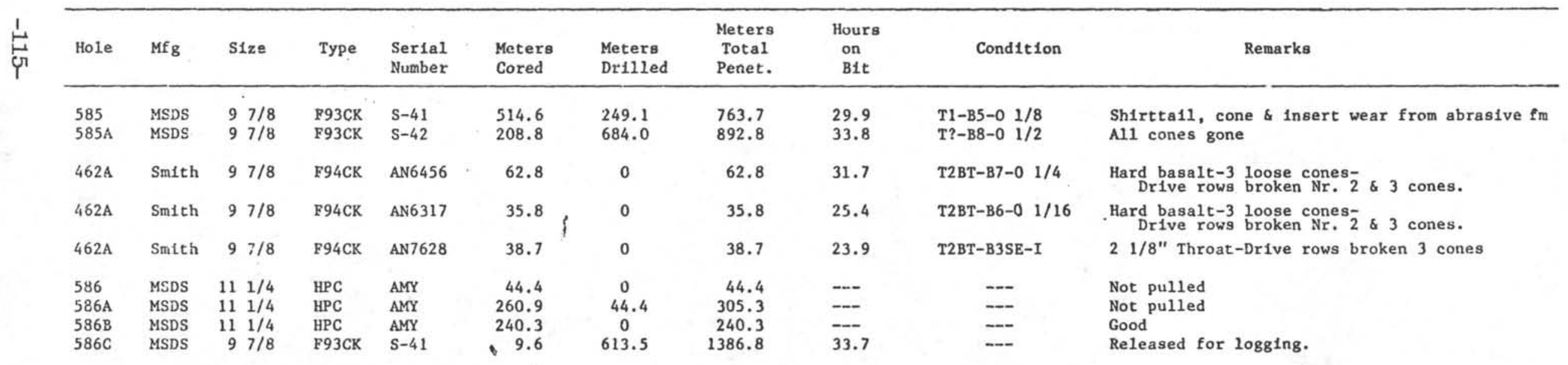


INTERNATIONAL PHASE OF OCEAN DRILLING

DEEP SEA DRILLING PROJECT

BEACON SUMMARY

LEG 89

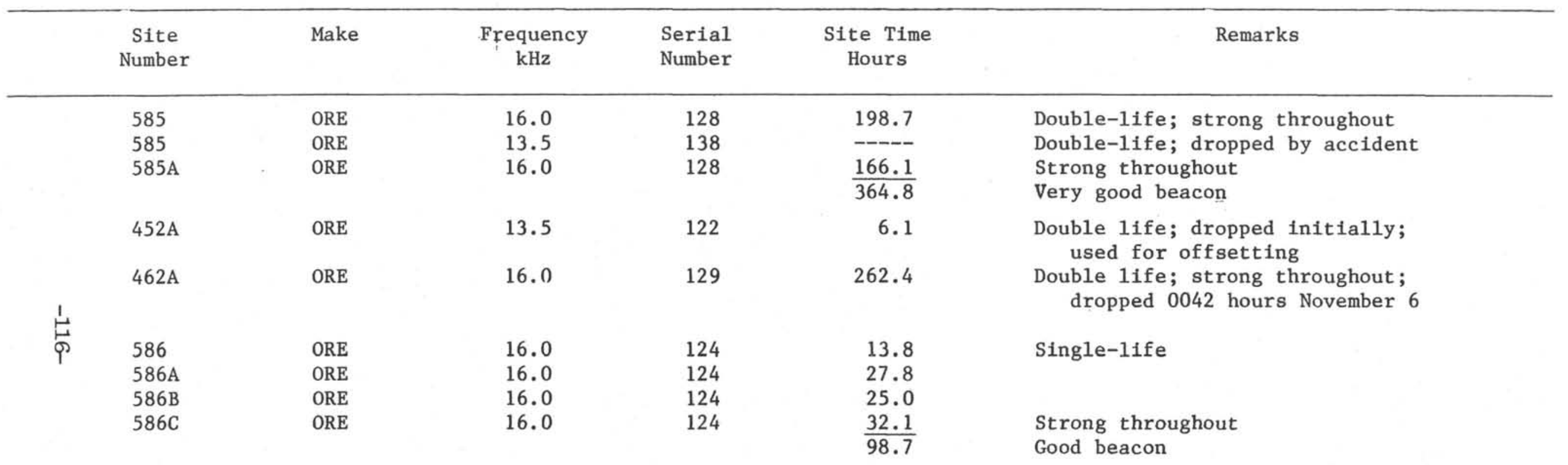


DLEP STA IDRII.LING PROJECT LOGGING SUHATRYY

LEG 89

\begin{tabular}{|c|c|c|c|c|c|c|c|c|c|c|c|}
\hline HOLE & $\begin{array}{l}\text { TOSAL } \\
\text { DEPTH } \\
\text { (M) }\end{array}$ & $\begin{array}{l}\text { WATER } \\
\text { DEPTII } \\
(M)\end{array}$ & $\begin{array}{l}\text { OPEII } \\
\text { ENDED } \\
\text { PIPE AT } \\
(M)\end{array}$ & $\begin{array}{l}\text { FLUID } \\
\text { IN } \\
\text { HOLE }\end{array}$ & $\begin{array}{l}\text { BIT } \\
\text { SIZE }\end{array}$ & $\begin{array}{l}\text { TOTAL } \\
\text { TIME FOR } \\
\text { LOGG ING } \\
\text { (HOURS) }\end{array}$ & $\begin{array}{l}\text { RUN } \\
\text { NO. }\end{array}$ & $\begin{array}{l}\text { LOGS } \\
\text { RECORDED }\end{array}$ & $\begin{array}{l}\text { FROM } \\
\text { (M) }\end{array}$ & $\begin{array}{l}\text { T0 } \\
(\mathrm{M})\end{array}$ & OBSERVAT I GIS \\
\hline$\underline{585}$ & 6886.0 & 6122.3 & & & & & & & & & $\begin{array}{l}\text { Lost hole with stuck inner barrel- } \\
\text { ho logs possible }\end{array}$ \\
\hline $585 \mathrm{~A}$ & 7015.1 & 6122.3 & & & & & & & & & $\begin{array}{l}\text { Weather/string weight conditions } \\
\text { forced abandonment w/o bit released }\end{array}$ \\
\hline \multirow[t]{4}{*}{$462 \mathrm{~A}$} & 6261.5 & 5186.0 & 5267 & $\begin{array}{l}\text { sea } \\
\text { water }\end{array}$ & $97 / 8$ & 7.5 & 1 & HRT & 5186.0 & 5701.0 & Good $\log$ \\
\hline & & & & & & 0.9 & & & & & Rig tool, etc. \\
\hline & & & & & & 8.4 & & & & & TOTAL TIME \\
\hline & & & & & & & & & & & $\therefore$ \\
\hline 586 & 2262.4 & 2218.0 & & & & & · & & & & HPC hole - aborted by HPC failure \\
\hline $586 \mathrm{~A}$ & 2523.3 & 2218.0 & & & & & & & & & No logs - HPC hole \\
\hline $586 \mathrm{~B}$ & 2458.3 & 2218.0 & & & & & & & & & No iogs - HPC hole \\
\hline $586 \mathrm{C}$ & 2841.1 & 2218.0 & 2289 & mWhatge1 & $97 / 8$ & 3.9 & 1 & $\begin{array}{l}\text { DDBHC. DISFL } \\
\text { G.R./CAL }\end{array}$ & 2840.0 & 2289.0 & $\begin{array}{l}\text { Sood log - G.R. recorded to show } \\
\text { seafloor at } 2218 \mathrm{~m}\end{array}$ \\
\hline \multirow[t]{2}{*}{$586 \mathrm{C}$} & 2841.1 & 2218.0 & 2289 & FW/ge1 & $97 / 8$ & 4.8 . & 1 & $\begin{array}{l}\text { FDC/CNL } \\
\text { G.R./CAL } \\
\end{array}$ & 2840.0 & 2289.0 & $\begin{array}{l}\text { Good log - G.R recorded to show } \\
\text { seafloor at } 2218 \mathrm{~m}\end{array}$ \\
\hline & & & & & & 3.7 & & & & & Rig sheaves, Ch. tools \& heads, etc. \\
\hline & & & & & & 12.4 & & & & & TOTAL TIME \\
\hline & & & & & & & & & $\cdot$ & & \\
\hline & & & & & . & & & & & & \\
\hline & & & & & & & & & & & \\
\hline & & & & & & & & $\cdot$ & & & \\
\hline & & & & & & & & & & & 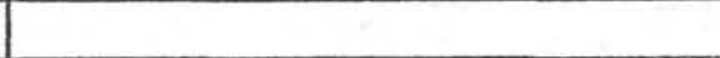 \\
\hline & & & & & & & & & & & \\
\hline & & & & & & & & & & & \\
\hline & & & & & & & & & & & \\
\hline & & & & & & & & & & & \\
\hline & & & & & & & & & & 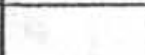 & \\
\hline & & & & & & & & & & & \\
\hline & & & & & & & & & & & \\
\hline & & & & & & & & & & & \\
\hline
\end{tabular}


DEEP SEA DRILLING PROJECT

LOGGING SUIMMARY

LEG 89

\begin{tabular}{|c|c|c|c|c|c|c|c|c|c|c|c|}
\hline HOLE & $\begin{array}{l}\text { TOTAL } \\
\text { DEPTH } \\
\text { (M) }\end{array}$ & $\begin{array}{l}\text { WATER } \\
\text { DEPTH } \\
\text { (M) }\end{array}$ & $\begin{array}{l}\text { OPEN } \\
\text { ENDED } \\
\text { PIPE AT } \\
\text { (M) }\end{array}$ & $\begin{array}{l}\text { FLUID } \\
\text { IN } \\
\text { HOLE }\end{array}$ & $\begin{array}{c}\text { BIT } \\
\text { SIZE. }\end{array}$ & $\begin{array}{l}\text { TOTAL } \\
\text { TIME FOR } \\
\text { LOGG ING } \\
\text { (HOURS) }\end{array}$ & $\begin{array}{l}\text { RUN } \\
\text { NO. }\end{array}$ & $\begin{array}{l}\text { LOGS } \\
\text { RECORDED }\end{array}$ & $\begin{array}{l}\text { FROM } \\
(M)\end{array}$ & $\begin{array}{l}\text { T0 } \\
\text { (M) }\end{array}$ & OBSERVATIONS \\
\hline 585 & 6886,0 & 6122.3 & & & & & & & & & $\begin{array}{l}\text { Lost hole with stuck inner barrel- } \\
\text { ho logs, possible }\end{array}$ \\
\hline $585 \mathrm{~A}$ & 7015.1 & 6122.3 & & & & & & & & & $\begin{array}{l}\text { Weather/string weight conditions } \\
\text { forced abandonment w/o bit released }\end{array}$ \\
\hline \multirow[t]{4}{*}{$462 \mathrm{~A}$} & 6261.5 & 5186.0 & 5267 & $\begin{array}{l}\text { sea } \\
\text { water }\end{array}$ & $97 / 8$ & 7.5 & 1 & HRT & 5186.0 & 5701.0 & Good log \\
\hline & & & & & & 0.9 & & & & & Rig tool, etc. \\
\hline & & & & & & 8.4 & & & & & TOTAL TIME \\
\hline & & & & & & & & & & & 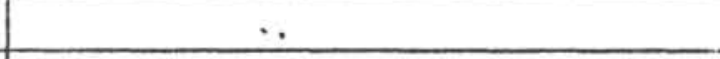 \\
\hline 586 & 2262.4 & 2218.0 & & & & & $\cdot$ & & & & HPC hole - aborted by HPC failure \\
\hline $586 \mathrm{~A}$ & 2523.3 & 2218.0 & & & & & & & & & No logs - HPC hole \\
\hline 586B & 2458.3 & 2218.0 & & & & & & & & & No logs - HPC hole \\
\hline $586 \mathrm{C}$ & 2841.1 & 2218.0 & 2289 & mulge1 & $97 / 8$ & 3.9 & 1 & $\begin{array}{l}\text { DDBHC.DISFL } \\
\text { G.R. } / \text { CAL }\end{array}$ & 2840,0 & 2289.0 & $\begin{array}{l}\text { Good log - G.R recorded to show } \\
\text { seafloor at } 2218 \mathrm{~m}\end{array}$ \\
\hline $586 \mathrm{C}$ & 2841.1 & 2218.0 & 2289 & mudgeI & $97 / 8$ & 4.8. & 1 & G.R./CAL & 2840.0 & 2289.0 & $\begin{array}{l}\text { Good log }-G \cdot R \text { recorded to show } \\
\text { seafloor at } 2218 \mathrm{~m}\end{array}$ \\
\hline \multirow[t]{2}{*}{$\vec{t}$} & & & & & & 3.7 & & & & & Rig sheaves, Ch. tools \& heads, etc. \\
\hline & & & & & & 12.4 & & & & & IOTAL TIME \\
\hline & & & & & & & & & · & & \\
\hline & & & & & . & & & & & & \\
\hline & & & & & & & & & & & \\
\hline & & & & & & & & - & & & \\
\hline & & & & & & & & & & & \\
\hline & & & & & & & & & & & \\
\hline & & & & & & & & & & & \\
\hline & & & & & & & & & & & \\
\hline & & & & & & & - & & & & \\
\hline & & & & & & & & & & & \\
\hline & & & & & & & & & & & \\
\hline & & & & , & & & & te & & & . \\
\hline & & & & & & & & & & & 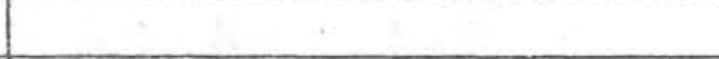 \\
\hline
\end{tabular}




\section{INTERNATIONAL PHASE OF OCEAN DRILLING \\ DEEP SEA DRILLING PROJECT \\ YOKOHAMA SHLPYARD PERIOD \\ OPERATIONAL RESUME}

\section{$\underline{\text { Introduction }}$}

The GLOMAR CHALLENGER arrived on September 20, 1982 at Asano dockyard (NKK) Yokohama, Japan.

Shipyard work was completed on October 6 and sea trials were conducted on this date. Upon completion of sea trials, the vessel returned to a commercial pier for loading supplies.

The vessel departed 0100 hours, October 11, 1982, for Leg 89 drilling operations. More than 125 shipyard tasks were completed. The following is a summary of major work items.

\section{Thrusters}

The bow thruster gear boxes were removed to a shipyard shop for refurbishment and seal replacement. All work was supervised by Schottel personnel. The same units were reinstalled.

Shipboard spares were used to replace the stern thruster gear boxes. All new seals were installed in gear boxes prior to installation.

The stern thruster motors were removed, overhauled and reinstalled. This was a major rigging effort as an opening had to be cut on the starboard side of the fantail to rig out and in.

\section{Engine Room and Main Propulsion}

One D.C. Generator ( $9 B$ dual bearing) was removed for overhaul. While loading/ testing the generator on sea trials, a short between the windings and shaft occurred. The unit was removed to a shipyard shop and parts from the shipboard spare were used for replacement. The generator tested satisfactorily prior to ship's departure.

The main propulsion motors, one and three, were replaced with overhauled units previously removed from the ship.

Both tail shafts were pulled. The shipboard spare was used to replace the starboard shaft. The bearing for the starboard shaft had to be "bored" prior to replacing the starboard shaft. The port shaft was overhauled and reinstalled. 
Both rudders were removed to allow for bushing replace in rudder posts.

The engine room exhaust ducting (port side) was removed, cleaned, refurbished and reinstalled.

The emergency A.C. switchboard, main A.C. switchboard, and main propulsion switchboard were cleaned and inspected by the USCG.

\section{Rig Floor}

The travelling block and crown block were removed for refurbishment. All sheaves were replaced.

The forward crane was set off for bearing base replacement. The engine replacement on the aft crane was postponed. A major modification to new parts were required, therefore, the decision was made to defer work.

Refurbishment of guide rail supports and replacement of selected derrick support members were accomplished.

The drawworks clutch coupling was replaced by the drilling department.

The pipe racker and associated equipment received an in-depth cleaning and maintenance work by the drilling department.

The Baylor brake power back up system was checked and problem areas corrected by GMDC personnel.

\section{Hull and Deck Work}

Both lifeboats were removed and the davits received an in-depth overhaul. After rigging lifeboats aboard, both received a complete inspection by USCG.

The hul1, moonpool, and thruster tunnels were sandblasted and painted. This appeared to be one of the better hull paint jobs.

Al1 zinc anodes were replaced.

All overboard-discharge, sanitary overboard discharge and sea valves were removed for cleaning and/or replacement

The anchor and anchor chains were laid out for sandblasting, painting and remarking.

All retractable hydrophones were removed and wells were cleaned and painted. Two (2) hydrophones were replaced with shipboard spares.

Several air conditioning ducts were removed and cleaned.

Overall the ship received scaling and painting as required. 
The casing hold hatchway was replaced. Tank top G-25-H was repaired.

A11 DARPA equipment was offloaded and placed in storage.

Project Work Items

The major work items were drill pipe rework and installation of the shipboard (Science) computer. A number of maintenance items were accomplished including the following:

Drill Pipe Rework (Continental-Emsco Pipe)

A total of 597 joints were offloaded to NKK for inspection and repair. of this total, 585 joints were successfully bored to $4-1 / 8$ " and drifted to 4". Ten (10) joints were rejected before boring because the tool joints were not concentric with the drill pipe tube body and two (2) joints were rejected for thin wall, after boring. The allowable wall thickness variation, in accord with API Specifications is $-12 \frac{1}{2} \%$ maximum variation.

Inspection and Reface (Continental-Emsco Pipe)

A total of 585 joints were inspected by AMF Tuboscope. The inspection showed all pipe to be Premium Grade. Most of the tool joints, however, had shoulder or thread damage. Sixty two percent of the pipe (362 joints) required shoulder repair, four percent (26 joints) showed thread damage and only 34 percent (197 joints) did not require rework. The final status of the 597 joints of $\mathrm{C} / \mathrm{E}$ pipe is as follows:
a) 12 joints - Reject in rework. Returned to Houston.
b) 26 joints - Thread damage. Returned to Houston
c) 197 joints - No rework required. Placed aboard ship.
d) 197 joints - Refaced. Placed aboard ship.
d) 165 joints - Refacing required. Were not repaired. Placed aboard ship. Will be used at bottom of the drill string if required.

\section{Premium Pipe Inspection}

A total of 191 joints was offloaded for external inspection by AMF Tuboscope. The results of the inspection are as follows:

a) 51 joints - Premium. Placed aboard ship.

b) 36 joints - Premium, but with shoulder damage. Returned to Houston. 

c) joints - Premium, but with thread damage. Returned to
Houston.

d) 87 joints - Class 2. Returned to Houston.

e) 12 joints - Class 3. Returned to Houston.

New Pipe

A total of 562 joints of new pipe was received from NKK and placed aboard the ship.

\section{Computer Installation}

A Hewlett Packard 1000 Computer was installed and five (5) working stations (terminals ) were placed in an operational mode. Other labs/terminals are to be connected as time permits and as science requirements dictate.

A pre-installed van, starboard side of the core van area, is used to house the computer. Cable and wiring were completed prior to the shipyard period which aided in setting up the computer and associated hardware.

Global Marine installed a dedicated AC power transformer for the computer van.

\section{Service Calls}

The following equipment was serviced by vendor representatives:
a) Xerox copying machines
b) Alden weather equipment
c) Magnavox navigational equipment
d) EDO Western Seismic Recorders
e) IBM typewriters
f) Microscopes
g) Electronic test equipment
h) H.P. computer

Logging Winch

The logging winch cab received a general clean up. Al cabling versus work function was checked and verified to be correct. A drawing showing all working connections was made. 
The shooting panel was relocated from the deck to a bulkhead area. This will allow easy access to equipment for use and repair.

A 30,000 foot logging cable was placed on the winch and the empty reel returned to Houston.

\section{Electronic Shop/Van}

A new air conditioning unit (complete) was installed by the shipyard.

\section{Drill Pipe Instrumentation Equipment}

The Drill Bit Motion Instrument (DBMI) and the Instrumented Drill String Sub (IDSS) equipment was loaded aboard. The equipment will be used to measure drill pipe characteristics on Site 585.

\section{$\underline{\text { Re-entry Equipment }}$}

All re-entry equipment was bench tested and only one tool had a problem. Due to late arrival of spares, the defective tool is to be corrected while underway.

\section{Core Lab}

A new/updated core cutter and saw was installed.

Fue1

Some 450,000 gallons of fuel was loaded.

Major Logistic Items Loaded
a) Core Liner -3 boxes
b) Aluminum Pipe - 10 joints
c) Heavy Wa11 "knobby" Pipe - 10 joints
d) 11-3/4" Casing - 40 joints
e) Barite - 2000 sacks
f) Bentonite Gel - 1500 sacks
g) Re-entry Cones - 3 Lower Sections \& 4 Upper Sections 
h) Coring Equipment

i) 8-1/4" Drill Collars - 10 joints

j) 5-1/2" Heavy Weight Drill Pipe - 6 joints

k) Logging Cable - 30,000 feet

1) Drill Pipe Protectors - 1800 ea

m) New Drill Pipe - 562 joints

\section{Asano Dockyard}

The Asano dockyard was a very efficient and well managed shipyard. It appeared that this was one of the better scheduled shipyard periods for the GLOMAR CHALL ENGER.

Personne1

As usual, both SIO and GMI personnel gave their best during the shipyard period.

Global Marine, San Diego Office personnel, handled the shipyard period as efficiently and competently as possible.

Japan Marine, the ship's agent, was a very efficient and cooperative agency.

Schottel, National and GMDC representatives were present and exhibited a high level of professionalism at their assigned tasks.

Paul Porter

Assistant Operations Manager

Deep Sea Drilling Project 


\section{INTERNATIONAL PHASE OF OCEAN DRILLING \\ DEEP SEA DRILLING PROJECT \\ OPERATIONS RESUME \\ LEG 90}

The 90th scientific voyage of the GLOMAR CHALLENGER will assuredly be remembered as one of the most successful in the Project's 14-year history. The scientific objectives of high resolution Neogene paltoceanography from tropical to subantarctic water masses were achieved and surpassed.

All sites including a low priority contingency site were occupied and drilled successfully with results ranging from quite good to exceptional. The cruise was virtually trouble free from an operational standpoint with the exception of a two-day failure of the dynamic positioning computer. Smooth operations along with the closely located, shallow sites led to a very rapid rate of coring resulting in a record $3708.6 \mathrm{~m}$ of core recovered--shattering the old record by nearly a factor of two. Other records achieved included the most cores ever attempted on a single leg (494) and the deepest penetration ever by the hydraulic piston corer $(315.6 \mathrm{~m})$. The core lab scientists and technicians extracted over 30,000 samples from the cores.

Another breakthrough recorded on the voyage was the first completely successful deployment of the Extended Core Barrel (XCB)--a-through-the-bit rotary coring tool which enables rotary coring to continue immediately after piston coring refusal without the necessity of tripping the drill string to change bits. The XCB was tested, modified, and ultimately deployed successfully--coring $1467.3 \mathrm{~m}$ of sediments and recovering $969.17 \mathrm{~m}$.

The voyage began November 29, 1982 at Noumea, New Caledonia and ended January 9, 1983 at Wellington, New Zealand.

\section{Noumea Port Call}

Leg 90 began with the arrival of the GLOMAR CHALLENGER at the passenger terminal dock at Noumea, New Caledonia. The first line was over at 1441 hours. November 19, 1982, about 15 hours ahead of schedule to a very swift passage to Noumea from the final site on Leg 89.

The vessel spent just over three days in the idyllic port of Noumea. Port call activities were relatively limited compared to average five day stops and were completed with dispatch. Major items included loading and partial installation of a replaccment $9 \mathrm{~B}$ generator, overhaul of the TOTCO Drilling Recorder System by a TOTCO service representative, check out and repair of the new shipboard HP1000 computer system by an HP representative, inspection 
and evaluation of the heave compensator by a service representative from Brown Brothers and a review of Schlumberger logging equipment and radioactive source storage aboard the vessel.

All incoming SIO and GMI freight was onloaded and consumable supplies were purchased and taken on board. Several problems worth noting which occurred during the port call were: the seismic interface to the HP1000 computer could not be repaired by the HP representative and was left to the skills of the seagoing crew; the $9 \mathrm{~B}$ generator installation was not completed; and the No. 1 gyrocompass would not stabilize. All of these systems had adequate back ups, thus none of the deficiencies were deemed sufficient to prevent the vessel from performing its normal functions. Since all other scheduled port call activities had been completed, the decision was made to depart for Site 587 at 1600 hours, on Thursday, December 2, 1982, some sixteen hours ahead of the original schedule.

\section{Noumea to Site 587}

The last mooring line was cast off at 1620 hours and the GLOMAR CHALLENGER cleared the barrier reef bordering New Caledonia's southwest coast at 2042 hours after having tested thrusters. Aboard were the normal complement of 45 GMI personnel plus 28 Scripps staff and scientists.

The vessel proceeded without delay toward Site 587 (SW-8) in delightful weather. Minimal seismic profiling was done during the approach to the site and the first of two positioning beacons was launched on the first pass at 2243 hours, December 3, 1982. A second beacon was required when the first proved too ërratic for automatic positioning.

Aided by favorable weather and currents, the ship averaged 10.6 knots for the 170.2 mile transit.

Site 587 (SW-8) South of Landsdowne Bank Northern Tip of Lord Howe Rise

A special bottom hole assembly (BHA) was assembled and checked for spacing to accommodate the latest version of the Extended Core Barrel (XCB), a through-the-bit rotary coring tool which was being deployed for the first time since Leg 84 . The BHA was configured to also accommodate the conventional VLHPC. By this means piston coring to refusal could be followed immediately by rotary $(\mathrm{XCB})$ coring to the objective without requiring a pipe round trip to chance bits. A short hook-up BHA was used to expedite operations. It was nonetheless expected to provide adequate weight on the bit since desired penetration was to be confined to the uppermost unlithified sediments. A special $\mathrm{XCB} / \mathrm{VLHPC}$ core bit, bit sub, two $81 / 4$ drill collars, two 3-foot DC spacers, top sub and head sub were assembled. A fully dressed XCB was then inserted at the rig floor to check for diametral clearance and critical extension of the XСB cutting shoe beyond the bit. Immediately, an out-of-spec Head Sub with an undersize bore was discovered and replaced. A little juggling of 
Outer Core Barrels was then done to achieve the optimum extension beyond the bit of the XCB. Following this a VLHPC was inserted to check its clearance and space-out.

With all tools checked out, the remainder of the BHA was run as normal. The routine pipe trip was begun with the added precaution of running a 4.00 inch diameter rabbit through all pipe to assure adequate drift for the slighty larger than normal new tools. Very quickly problems were encountered. Three of 30 joints taken from the starboard pipe racker (premium pipe earmarked for deployment just above the BHA) failed to let the rabbit pass. It became obvious that despite a thorough pipe inspection during the Yokohama drydock period, much of the older Continental Emsco pipe was still undersize where the tool joints jointed the pipe bodies. (Subsequent investigation located only two undersize joints.) It was thought that the new NKK pipe recently purchased in Japan would be more reliable, but no obvious means was available to identify it on a joint-by-joint basis.

Operations then shifted to the pipe on the port side pipe racker. This pipe, later determined definitely to be the new NIK pipe, drifted the 4-inch rabbit easily; however, rubbers on twelve stands had to be removed to avoid deploying them below the seafloor. The remainder of the pipe for the site was taken from the port side racker and the rest of the pipe trip was accomplished routinely.

Hole 587 was spudded at 1355, December 4, 1982, with a mudline VLHPC core containing $3.1 \mathrm{~m}$ of calcareous ooze. Drill pipe measured (DPM) depth of $1115 \mathrm{~m}$ proved to be $4 \mathrm{~m}$ greater than the depth measured by the Precision Depth Recorder (PDR).

All appeared well until Core No. 2 came up empty, apparently due to a core catcher failure. Since the BHA was so near the mudline, a second shot was taken at Core No. 2. This resulted in very little core. Upon inspection the piston head was found to be sheared of $f$ of the lower piston rod and resting on top of the core. The cause was determined to be incorrect internal spacing within the VLHPC, brought about by an improperly positioned spacer barrel which allowed the Quick Release Shoulder Sub to impact the piston head and shear its retaining pin. This was quickly rectified, the tool was realigned for orientation, and coring continued with a third and successful attempt to get Core No. 2 .

VLHPC coring continued with good results until Core No. 12. At this point ( $99.1 \mathrm{~m} \mathrm{BSF}$ ), a sudden change in lithology occurred as the sediment became brittle, coarse and loosely cemented as compared to fine, consolidated ooze encountered up to that point. Penetration of the corer fell off markedly and recovery dropped to mere traces. Virtually no usable core was recovered on VLHPC Cores Nos. 12 and 13.

It was decided that the time had come to give the XCB its chance, and it was deployed for Cores 14 through 17. Despite all indications that the tool functioned properly, only traces of the sedimentary material could be found in the core barrel when retrieved. Various penetration, flow rates and core catcher configurations were attempted, but the gravel-like carbonate and coral fragments proved completely elusive. It could not be conclusively established 
whether the cored material was entering the core liner and then lost on retrleval or never getting in at all. Later testing and ultimate successful use of the $\mathrm{XCB}$ after modifications demonstrated that the fault may have resided with the XCB coring tool. It cannot be seid whether or not the particular formation encountered at this site could have been successfully cored with the $\mathrm{XCB}$ as later modified.

Three Von Herzen Heat Flow runs were made with optimum results, including a run on Core No. 12, in spite of the fact that no core was recovered when the tool was retrieved.

The hole was terminated when it became apparent that the scientific data achievable would be minimal at best and a point of diminishing returns had long since been passed, especially in view of higher priorities at sites to come. The pipe was tripped and the vessel got underway for Site 588 at 1505 hours, December 6, 1982.

\section{Site 587 to Site 588}

Steaming between sites was routine amidst ideal Tasman Sea summer weather and aided by a quartering current. The ship covered the 295.6 nautical miles at an average speed of 10.5 knots. Site 588 was to be a more thorough reoccupation of old DSDP Site 208 drilled on Leg 21, thus the vessel made directly for the geographic coordinates of Site 208 and dropped the beacon $(13.5 \mathrm{kHz})$ on the first pass at a point selected on the basis of a combination of Sat Nav fixes and dead reckoning. Pinpoint accuracy was not sought due to the fact that local stratigraphy and topography were quite uniform. The beacon hit the water at 1921 hours, December 6, 1982.

\section{S1te 588 (SW-7) Northern Lord Howe Rise}

As at Site 587 a special BHA was run which was compatible to both piston coring and XCB rotary coring. The operational plan for Site 588 called for taking duplicate unbroken piston cored sequences through the Neogene and following with rotary ( $\mathrm{XCB}$, if feasible) to the base of the Miocene.

A preliminary PDR reading placed the water depth at $1546 \mathrm{~m}$. A later reading just before spud in was $1548 \mathrm{~m}$. The first VLHPC core was taken with the bit at $1544 \mathrm{~m}$ and recovered a $5.65 \mathrm{~m}$ core which established the mudline at $1548 \mathrm{~m}$. Hole 588 was thus spudded at 0140 hours, December 7, 1982.

Piston coring continued easily through calcareous ooze ranging from soupy to stiff for the first $216.8 \mathrm{~m}$. Recovery was consistently near $100 \%$ except for Core No. 8 which came up empty for reasons unknown. During this interval $239.5 \mathrm{~m}$ VLHPC cores were taken, achieving full stroke on all using only two shear pins. Cores Nos. 24 and 25 were shot using three shear pins. Overpulls to free the tool after shoot off slowly increased to a maximum of 20,000 pounds. 
Core No. 26 vented properly, indicating full stroke had been attained, but would not pull free at 80,000 pounds overpull. The bit was washed $5 \mathrm{~m}$ over the extended barrel and a further atttempt was made to pull it free. Somewhat more than 100,000 pounds was inadvertently applied to free the tool before the driller could stop the drawworks. Resistance suddenly ceased, Indicating the tool had either come free or parted. The tool was recovered with the lower, scoping section missing, due to a failure of the lugs on the Quick Release Shoulder Sub and the mating holes in the Quick Release Cap Sub.

Consideration was given to the possibility of attempting to wash the bit down past the fish by sidetracking, but the potential difficulties outweighed the advantages, thus the hole was terminated.

Hole 588A

The bit was pulled to the mudline and Hole 588A was spudded at 0025 hours, December 8,1982 , and washed to the termination point of Hole 588--236.0 m BSF. One more $9.5 \mathrm{~m}$ VLHPC was deployed. When it experienced full stroke, followed by excessive overpull, the bit was washed down over the entire $9.5 \mathrm{~m}$ until the tool was washed free.

It was then decided to employ the $5 \mathrm{~m}$ VLHPC for as far as possible. Overpull was taken to a limit of $20,30,000$ pounds on each core. If the corer could not be freed by pulling at that limit, the bit was washed over the scoped section. This technique was recognized to be somewhat risky since it was possible that the bit could gouge into the extended tool rather than guide smoothly over it. However, the quality of the piston cores being recovered and the unusual circumstance of getting full stroke at such depths made the risk of some tool damage worthwhile.

$\Lambda$ new record depth for piston coring was reached in this manner-- $315.6 \mathrm{~m} \mathrm{BSF}$, and the oldest sediments ever successfully piston cored were recovered-17 to 20 million year old material from the middle Miocene epoch. However, as the sediments stiffened, it became impossible to wash the bit over the portruding inner barrel without gouging the extended tool. Therefore, VLiPC work was terminated at Core No. 15. Surprisingly, full stroking continued throughout the piston cored sequence despite the total depth of penetration. Core quality was excellent.

The XCB was then deployed for Cores Nos. 16, 17, and 18. The first two attempts resulted in less than three meters total recovery and it appeared obvious that when the core formed a solid plug in the liner no further core was taken. The immediate suspicion was that lack of proper venting was preventing entry of the core into the liner. To test the theory, Core No. 18 was attempted with a critical grease fitting removed which would allow the water in the upper liner ta vent. This also invited excessive pressure to be felt on the outside of the liner, however, so a collapsed liner became probable. A collapsed liner did result, but a high quality core was recovered up to the point of liner collapse, proving that a proper vent was essential. 
Since modifications to the XCB were clearly needed before it could be successfully used it was decided to terminate Hole 588A and perform the repeat piston core sequence while using the time to modify the XCB system.

\section{Hole 588B}

Onice again the bit was pulled to the mudline to spud a new hole. The vessel was offset 100 feet north to assure a clean seafloor for a mudline core and Hole $588 \mathrm{~B}$ was spudded at 2210 hours, December 8 . A good mudline core was taken from $1546 \mathrm{~m}$ and established the water depth at $1548 \mathrm{~m}$ as before.

Piston coring proceeded smoothly again through calcareous ooze with scattered ash layers. Again full stroke of the $9.5 \mathrm{~m}$ VLHPC was routinely achieved with two shear pins. The same scenario of increasing overpull requirements was experienced as in the previous hole, this time beginning about $30 \mathrm{~m}$ higher. At Core No. 22 washing over the barrel was again required to free the tool, and this technique was used until the piston coring was terminated at Core No: $28,248.6 \mathrm{~m}$ BSF. Cores Nos. $25-28$ were taken with the $5 \mathrm{~m}$ VLHPC.

Again the XCB was deployed, now modified to allow proper venting through a ball valve check while being sealed to prevent pump pressure from collapsing the plastic core liners. This design modification provided some improvement, and cores were taken on all three deployments but they were not of good quality. The new seals failed to fully isolate the liners and partial liner collapse and splitting occurred on all three attempts.

The XCB obviously needed further work and the scientific objective of rotary coring to the Neogene/Paleogene unconformity had not been achieved, so it was decided to trip the pipe in order to change the bit and BHA for conventional rotary coring.

Hole $588 \mathrm{C}$

The pipe was tripped and a standard BHA with a long tooth F93XK core bit was assembled and run back to the seafloor. Hole $588 \mathrm{C}$ was spudded at 1307 hours, December 10. The bit was quickly washed to a depth of $305.7 \mathrm{~m}$ BSF to provide a slight overlap with the deepest penetration of the piston coring done earlier.

Routine rotary coring then followed with good core recovery through foram beäring nannofossil chalk with green ash layers and abundant burrows. The only delay was a 45 minute wait on weather while the vessel took a 400 foot excursion under the influence of a brief but dramatic line squall bearing 50 mph winds. At $488.1 \mathrm{~m}$ BSF the scientific objective was reached and the hole was terminated. The pipe was tripped after cutting and slipping the drill 1 ine. A beacon was soaked, the rig was made secure for sea, and the vessel got underway for Site 589 at 1536 hours, December 11, 1982.

Site 588 to Site 589

Transit between sites was completely routine. Again, fair weather and a 
following current combined to help the vessel average 10.3 knots for the 304.3 mile distance. The ship made directly for the coordinates of the site as selected in the scientific prospectus. Precise site selection and presite surveying were not required, so the beacon (16 kHz) was dropped on the first pass at 2110 hours, December 12, 1982.

Hoe 589 (SW-4) Central Lord Howe Rise

The vessel was steadied over the beacon with some difficulty, owing to a bad combination of wind, current and swell coming from three different directions. Nonetheless, the pipe trip commenced at 2255 hours. A combination short hook up BHA for both piston coring and $\mathrm{XCB}$ coring was again used. The bit was lowered to $1396 \mathrm{~m}$ and the first $9.5 \mathrm{~m}$ VLHPC was shot at 0338 hours, December 13, recovering 7.3 meters of sediment at the mudline and officially spudding Hole 589. Water depth was thus determined to be $1398 \mathrm{~m}$ by drill pipe measurement. Four $9.5 \mathrm{~m}$ VLHPC cores were taken, including a successful Von Herzen heat flow with Core No. 4.

As Core No. 5 was about to be taken, the Dynamic Positioning Computer experienced a total breakdown. Within minutes it became clear that the vessel had probably taken a severe offset since the computer was providing no position reference information which could be used for manual positioning. The rig crew was given orders to recover the core barrel and immediately pull the pipe clear of the mudline. The mudline was cleared thirty minutes after the computer had failed. It was interesting to note that although the VLHPC was not actuated before being recovered, the Kuster orientation tool did record a hole drift angle about the same time as the computer failure was discovered. The angle of drift was more than 11 degrees and angled in the direction the ship would have drifted due to the local current. The BHA had apparently been dragged to at least this angle in the soft upper sediments as the ship moved of $\mathrm{f}$ station.

One hour and forty-five minutes after clearing the mudline the positioning computer still was not functioning, so the drill string was tripped for safety's sake. The bit arrived on deck at 1230 hours. Inspection of the drill string as it came on deck showed that no damage had been done to the pipe of BHA. Since the computer was still down at this time and the probability of an Immediate repair was low, the decision was made to get underway for an alternate site to the south some eight hours distant. The vessel was underway for the alternate site at 1239 hours, December 13, 1982.

\section{$\underline{\text { Site } 589 \text { to Site } 590}$}

Proceeding south to the alternate site was done to permit three things to happen: 1) it would provide time to find the problem with the positioning computer and effect repairs; 2 ) if repairs to the computer could not be made in eight hours, it would place the ship that much closer to New Zealand where the repairs would ultimately have to be made with expert assistance, and; 3 ) it would allow time to take seismic profiles and get approval to drill at the newly chosen sites (alternates to $\mathrm{SW}-4$ and $S W-6$ ) which were felt to be geologically identical to the original sites but had never been formally approved by the JOIDES Safety Panel. 
However, all of this became academic when, after reaching and surveying over the chosen alternate sites, the problem with the computer still had not been

- identified. At 2003 hours, December 13, the course was changed for Auckland, New Zealand.

After steaming towards Auckland for over 17 hours, good fortune intervened-the problem was located and repaired. The vessel immediately turned about and

- proceeded back to the newly chosen Site SW-4. Following a track close to the one profiled upon departure from the new site, the desired area was selected and the beacon $(13.5 \mathrm{kHz})$ was dropped at 0533 hours, December 15, 1982. The total distance traversed since departure from Site 589 was $413 \mathrm{miles}$ at an average speed of 10.09 knots.

\section{Site 590 (New SW-4) Central Lord Howe Rise}

The new Site SW-4 was chosen at a point at an equivalent water depth on the

$\therefore$ Lord Howe Rise and roughly south of the original site specified in the scientific prospectus. Seismic profiling showed a subbottom character similar to the original SW-4. Since that original site had been chosen somewhat arbitrarily, based on its generalized characteristics plus availability of - existing seismic records in the vicinity, no detriment to scientific objectives - was expected by changing to the new site. In fact, after comparison with the -old site, the new SW-4 looked signficantly better to the shipboard scientists.

$-. . .$.

$\therefore$ Authorization to piston core the new site was received via radio before reaching

- the selected coordinates, so no delay in operations was experienced. Once again

$\Rightarrow$ a dual purpose BHA was run to enable piston coring, followed by XCB rotary coring

- The bit was lowered to $1305 \mathrm{~m}$ and a mudline VLHPC core containing $7 \mathrm{~m}$ of sediment

- was taken at 1210 hours, December 15, after an initial mudline core was

:.discarded when the core liner shattered.

-Three $9.5 \mathrm{~m}$ VLHPC cores were then taken routinely. Core No. 4 had problems.

-: As the tool was about to be run into the hole on the wireline, the dog teeth

sicon the Otis overshot snapped off, allowing the barrel to fall several feet and land with a violent jar on the lifting clamp. A new overshot was fitted to

- the sinker bar assembly and the VLHPC was lifted--still in the pipe--to check

-:- the-shear pins. Both pins were found sheared and the tool scoped out. It

was: then hung off in the pipe, scoped back together and fitted with new shear

c. pins. At that time no one thought to pull the tool further out of the pipe to inspect the Quick Release Assembly, since the damage was logically thought to be limited to the shear pins. The lugs on the Quick Release had apparently

E: failed, however, allowing the lower section of the tool to fall freely down the pipe and out the bottom of the bit. This can be deduced from the fact that

- when the tool was retrieved, no overpull was experienced; yet, the lugs on the

$\therefore$ Quick Release Shoulder Sub had failed, losing the lower position of the corer.

$=2-\therefore=$

: The greatest tragedy was that a Von Herzen Heat Flow package was installed in

- its special catcher sub on the lost tool. Only one Von Herzen Heat Flow electronic unit had been available at the start of the leg, and its value to the

= scientific objectives of the cruise was quite high. Because of this, an effort

$=\cdots$
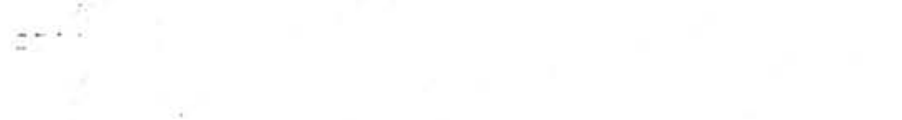

$$
\text { (1) }
$$


was made to fish for the lost barrel which was belleved to be stuck in the mud only about 3 feet below the bit. About $2 \frac{1}{2}$ hours were spent making up a special fishing spear and deploying it through the bit, but the results were nil. The spear and/or sinker bar assembly tended to get stuck in the flapper valve when retrieved, so the operation was abandoned for fear of losing the sinker bar assembly or even having to trip the pipe to get it unstuck.

\section{Hole 590A}

The bit was pulled to the mudline and washed back to the point where Core No. 4 was to have been taken. Hole 590A was thus spudded at 1810 hours, December 15, and routine piston coring operations resumed.

At Core No. 13 the sandline parted at the rope socket on top of the sinker bar assembly. The sinker bars and VLHPC were successfully fished on the first at tempt and very little time was lost.

As at the previous sites, full stroke of the piston corer was achieved continuously, generally with only two shear pins. At $275.8 \mathrm{~m} \mathrm{BSF}$, overpulls of 45,000 pounds made it necessary to wash the bit over the protruding corer in order to retrieve the tool. At $5 \mathrm{~m}$, VLHPC was then deployed but it too had to be washed over to release. Therefore, piston coring was deemed too dangerous to continue in spite of the fact that high quality full stroke cores were still being taken.

\section{Hole 590B}

Authorization to rotary core this new site had not yet been received, so the repeat piston core sequence was begun by pulling to the mudline and reestablishing water depth with a mudline core after the vessel was given a token of fset of 100 feet. The first core was shot with the bit at $1301 \mathrm{~m}$ to intentionally overlap the piston cores with those from the A hole. Hole 590B was of ficially spudded at 2110 hours, December 16 .

Twenty seven $9.5 \mathrm{~m}$ VLHPC cores were taken without any difficulties in calcareous sediment grading from soupy ooze to firm chalk. Piston coring was terminated at $250.7 \mathrm{~m} \mathrm{BSF}$, when the now familiar pattern of increasing overpull symptoms repeated themselves.

By this time official Safety Panel approval for rotary coring had been received, so at Core No. 28 the XCB was deployed. The XCB tools had been modified again to vent the water in the liners while sealing off the bit back pressure from the outside of the liners. Using the soft formation saw tooth cutting shoes, excellent quality cores at high percentage recovery rates were achieved.

Seven of the first nine cores were retrieved with the liner partially collapsed, but always in the top three feet or less. This problem was completely eliminated by drilling a quarter inch hole in the tops of all the remaining XCB liners.

A total of 26 cores were taken with the XCB to a depth of $499.1 \mathrm{~m}$ BSF. At this point the hole was terminated when the quality of the recovered fossils 
deteriorated to the point that useful paleoceanographic analyses of the sediment became impossible.

The pipe was tripped and the rig floor was secured for sea. The vessel got underway for Site 591 at 2248 hours, December 18, 1982.

Site 590 to Site 591

The transit to Site 591 was a very brief one of 61.8 nautical miles at an average speed of 9.7 knots to a location down the eastern slope of the Lord Howe Rise. The beacon drop point was chosen by the seismic survey as the selected coordinates were approached and a $16 \mathrm{kHz}$ beacon was dropped at 0510 hours, December 19, 1982

Site 591 (SW-6) Downslope of Central Lord Howe Rise

The ship was positioned over the beacon with some difficulty since wind, current, and swell were again all present from different directions. A combination VLHPC/XCB bottom hole assembly was made up and run to the seafloor. Hole 591 was spudded at 1150 hours, December 19, with a mudline core which verified the water depth as $2142 \mathrm{~m}$.

Piston coring proceeded using the $9.5 \mathrm{~m}$ VLHPC, employing only two shear pins. A near perfect series of cores were taken to a total depth of $283.1 \mathrm{~m}$ BSF in gradually stiffening carbonate ooze. Favorable conditions of vessel motion repeated full stroke of the piston corer and excellent core quality made this an exceptionally well preserved piston cored sequence which was marked by greater than $98 \%$ recovery. The hole was terminated despite continued full stroke when excessive pullout loads endangered the coring tool.

\section{Hole 591A}

The bit was pulled to the mudline and the vessel was offset 100 feet in preparation for a repeat piston core sequence. The new hole was spudded at 2012 hours, December 20. Cores were staggered to overlap Hole 591. Rougher weather had increased vessel heave considerably, resulting in a deterioration of core quality and recovery percentage in the repeat piston core sequence. Again, full stroke was achieved on all cores.

Piston coring was stopped at $246.5 \mathrm{~m}$ BSF to avoid excess overpull. The XCB was then deployed a total of six times. Each of the six attempts resulted in a severely shattered liner which made havoc of removing the liners and/or cores from the core barrels.

The second XСВ barrel, which was dropped, stuck in the BHA some 70-80 m above its normal landing point. This was discovered after the interval had been drilled when the sandline and overshot encountered the tool too high. The tool was unjammed with the wireline jars and recovered. The next barrel was dropped, the interval was drilled, and the tool was again found stuck well up 
in the BHA, apparently at the same point as the previous barrel. Again, some working with the wireline reel was required to free the barrel. The next barrel also stuck, but this time the sandine and overshot were sent down before drilling the interval to see if the tool had reached the bit. After pulling the tool loose, it was about to be lowered without resistance to its normal landing point. A core was then taken with the wireline still attached to the tool.

At this point the new style XCB latch was suspected as being the cause of the stuck barrels, even though no such problems had been encountered at Hole 590B where the XCB with its latch functioned perfectly. A spare, unused XCB latch was installed and the next XCB barrel was dropped and checked for seat with the wireline and overshot. The barrel had seated in its proper location so the interval was drilled normally. The next barrel, still with the new latch, again stuck at the same point as the previous ones, so suspicion shifted from the XCB latch to a possible backed-off bumper sub wash pipe.

The combined problems of barrels sticking in the BHA and completely shattered liners spelled the end for Hole $591 \mathrm{~A}$ and the pipe was tripped to change over to the standard rotary system and inspect the BHA to determine the cause of the stuck core barrels. Two rabbits were dropped before the pipe trip began in hopes that one or both would hang up in the BHA and identify the problem area. Unfortunately, one rabbit made it all the way down to the landing sleeve and the other stopped in a joint of pipe well above the BHA, so no information was derived in this manner. Subsequent inspection of all BHA components, including disassembly and servicing of the bumper subs, failed to reveal the cause of the stuck barrels. (Events at Hole 593 later shed light on the mystery.)

During the pipe trip the vessel was subjected to a severe combination of wind, swell, and current. In an attempt to hold the roll to a minimum for safety of personnel on the rig floor, while pulling out of the hole, the vessel was allowed to wander about three miles from the beacon. Upon returning to the beacon, increasingly adverse conditions made positioning exceedingly difficult unless the ship's heading was such that the rolls made running in the hole unsafe. After seven hours of seeking optimum positioning, while waiting on the weather, the wind abated enough to allow the vessel to position in automatic with a safe level of vessel motion.

\section{Hole 591B}

A short hookup BHA, spaced out for standard rotary drilling, was run back to the seafloor and the bit was washed to $270.6 \mathrm{~m} \mathrm{BSF}$ to begin rotary coring. After retrieving the wash barrel, 24 rotary cores were taken to a depth of $500.4 \mathrm{~m}$ BSF. At this point, fossil preservation had deteriorated too much for valuable analysis, so the hole was terminated.

Core quality was mediocre and recovery was below average, largely due to unfavorable sea conditions and vessel motion. The pipe was tripped, the rig secured for sea and the ship was underway for second priority Site $\mathrm{SW}-3$ at 0950 hours, December 24. 
Site 591 to site 592

At this point in the voyage, operations were determined to be substantially ahead of schedule in spite of the time losi when the Positioning Computer malfunctioned. This situation was caused by a combination of factors: average speed between sites had consistently been greater than anticipated: Site 587 had been terminated more quickly than planned; normal mechanical breakdowns (or slowdowns) had been virtually non-existent; time lost waiting on weather had been minimal; the success of the XCB had negated the necessity of a time consuming pipe trip at Site 590; and no downhole drilling problems had been encountered. Continued use of the XCB and continuation of the excellent vessel speed was expected to further improve the schedule outlook. Given all this, the decision was made to proceed to Site SW-3, which had been included in the prospectus as a contingency site only, but had taken on a greater scientific potential based on information garnered at the previous sites.

The vessel made its way south to the chosen site coordinates without incident, allowing all aboard to enjoy a lavish midday holiday feast. The beacon ( $16.0 \mathrm{kHz}$, D.L.) was dropped on the first pass at 1416 hours on Christmas Day, 1982 .

\section{Site 592 (SW-3) Southern Lord Howe Rise}

The operating plan for the site was to obtain a good piston cored sequence through the Neogene sediments to refusal and follow with deployment of the $X C B$. The usage of the $X C B$ was for two reasons. First, to enable testing of the tool under modified operational practices to see if the problem of 1 iner shattering could be solved and, if so, to core into the stiffer sediments as far as the Oligocene/Eocene boundary, if possible. In any case, the time on site was to be limited to 48 hours.

Although weather conditions were not good, the vessel was able to be positioned with her bow into the prevailing wind and swell so that positioning in automatic with tolerable roll and pitch was possible.

A combination XCB/VLHPC bottom hole assembly was made up as before and run to the chosen height above the bottom for the mudline core attempt. Hole 592 was spudded at 2035 hours with a VLHPC mudline core which established the water depth to be 1099.8 by drill pipe measurement.

While making up the connection prior to running VLHPC in for the second core, the Monel Single Shot Pressure Case parted at the bottom threaded connection while poised over the mousehole. This was apparently caused by severe pounding brought on by the weather and rough seas which banged the travelling block and Bowen sub noisely around in the derrick. The lower Monel sinker bar, overshot, Monel saver sub, and lower pressure case plug, all fell down the mousehole into the moonpool and were lost. This was the only weather related mishap it the site. Fortunately, the plan had been to deploy the Kuster tool, starting with the third core, so it was not installed at that time to be lost as well.

Piston coring with the $9.5 \mathrm{~m}$ VLHPC using two shear pins continued smouthly despite blustery weather. Full stroke was achieved on all cores in calcareous ooze similar to that encountered at each of the previous holes. Core quality 
was not up to normal VLHPC standards, due mainly to-significant henve of the vessel. At the 25 th VLHPC core overpull of 25,000 pounds was required while literally inching the tool free--a hair raising process in heavy weather. Thus, piston coring was terminated and the sinker bars were changed over in preparation for XCB coring.

Two problems had to be overcome with the XCB before reliable use could be expected: elimination of shattered liners and resolving the question of what caused the tools to become stuck in the pipe or BHA before landing. The shattered liners were believed to be the result of explosion of trapped air at impact with the water in the pipe when the barrels were free falled. To avold this, the pipe was filled with water with the mud pumps just before the final connection was broken to insert a clean tool. Following this procedure, no further shattered liners were encountered at this site.

The first $\mathrm{XCB}$ was deployed and recovered with a good core and no problems. The second XCB stuck at a location apparently in or near the $5 \frac{1}{2}$ inch heavy wall drill pipe at the top of the BHA. Two sets of overshot dog teeth were broken off in attempts to jar the tool loose with the wireline. Before tripping the pipe to remove the stuck barrel, a third, somewhat long shot, procedure was tried. A deplugger barrel was go-deviled to impact the latch rod and, with luck, loosen the latch dogs which were apparently jammed in a box thread bore back. Fortunately, this trick worked and the tool scated properly at the bit. Since the interval had already been drilled without the barrel in place, it was retrieved before drilling the next interval to clean out any residue core material left in the pipe after the wash.

It was clear that the new XСB latch could not be trusted to keep from sticking the barrel without some further design modifications, so the remainder of the hole was cored by running the XCB in on the wireline. This disabled the latch dogs and reduced the chance of jamming. One other XCB barrel, Core No. 36, did become stuck, probably because the wireline overran the tool on the trip in. The tool was dislodged after hammering with the deplugger barrel on the wireline. When retrieved some minor damage to the XCB latch body showed clearly how the latch dogs were becoming pinched at the tops of their "windows" and causing the barrel to become stuck at wide spots in the pipe.

The hole was cored to its full scientific objective, plus two to three extra cores and terminated to allow pulling the pipe and getting underway within the original 48 hours time limit. In spite of some irritating problems associated with the XCB latch, the site provided a classic example of the potential of the dual compatibility VLHPC/XCB system to achieve maximum scientific/coring objectives in a minimal time frame.

\section{Site 592 to Site 593}

The pipe was pulled out the hole, the rig floor made secure for sea, and the vesse 1 was underway for Site 593 at 1242 hours, December 27 . The trip south was made in very pleasant weather. As had become customary, a straight in approach was made and the $13.5 \mathrm{kHz}$ beacon was dropped on the first pass 
at 1632 hours, December 28. The transit took 27.9 hours and covered 264.8 nautical miles at an average 9.5 knots.

Site 593 (SW-2) Challenger Plateau

The routine short hookup BHA for XCB and VLHPC work was made up and run to the shoot off point for the first. piston core attempt. A good mudline core was recovered, establishing the water depth at $1080 \mathrm{~m}$, thus spudding Hole 593 at 2155 hours, December 28

Using the $9.5 \mathrm{~m}$ VLHPC with two shear pins, coring progressed easily through unusually soft carbonate ooze. Full stroke of the piston corer was achieved on all cores. At Core No. 22, (206.7 m BSF) a crumpled liner indicated that adhesive properties of the sediment were becoming significant. Two cores later the barrel could not be withdrawn with 30,000 pounds overpull and was partially washed over to get free.

The VLHPC was then rigged down and the XCB made ready for deployment. The dogs on the XCB latch had been machined down more than one quarter inch on the diameter in an attempt to improve on the recurring tendency of the latch to hang up the corer in the pipe or BHA before reaching the bit. With this latest modification, the XСВ was dropped and promptly became stuck in the pipe some 300 feet below the rig floor. After engaging the overshot, the tool was worked loose and run to the bit. The interval was then cored successfully.

A different $\mathrm{XCB}$ latch mod was attempted next in which the dog windows on the latch body were enlarged. This apparently was a bona fide improvement because the next 23 cores were taken without incident.

At Core No. 49, the shattered liner phenomenon reappeared for unknown reasons even though the practice was routinely being followed of filling the pipe with water just before dropping the tool. Each odd numbered core for the next three experienced a shattered liner, suggesting that one of the two XCB tools being alternated was faulty. Nothing wrong could be discovered, however. To deal with the problem, the remaining cores in the hole were taken by running the $X C B$ tools in on the wireline. By this means good cores with liners intact were achieved for the rest of the hole. To complicate matters, Core No. 51 became stuck in the BHA before reading the bit and was not worked loose with the wireline until after the interval had been drilled, thus no core was recovered. No action was taken to further modify the latch mechanism, however, and no other barrels became stuck.

Starting in Core No. 58 at about $550 \mathrm{~m} \mathrm{BSF}$, a $10 \mathrm{~m}$ interval of very hard volcanogenic turbidites was encountered and successfully cored using the soft formation XCB cutting shoes. This would have been the proner place to change over to the Stratapax hard rock cutting shoes, except that the interval was interbedded in soft pelagic ooze and occurred and ended without warning, so the hard rock shoes were never utilized.

The hole was terminated at $571.5 \mathrm{~m}$ BSF when the sought after sediments of the Eocene were recovered. 
The bit was pulled to the mudline and the vessel offset 100 feet north by 100 feet west in preparation for the repeat piston core sequence.

Hole 593A

Hole 593A was spudded with a mudline piston core at 2337 hours, December 30 . Piston coring continued as in the previous hole with no difficulties at all up to Core No. 22 at $2093 \mathrm{~m}$ BSF. At this point no further cores in the piston corer "zone" were desired. Next, the XCB was deployed and washed to $448.8 \mathrm{~m}$ BSF in order to recover the section which was lost during the interlude of shattered liners and associated poor recovery in the inftial hole. The XCB tool used as the wash barrel was recovered and each of the five XCB cores was then taken by running in on the wireline. Recovery was good through the stratigraphic boundary, except for Core No. 24, which apparently suffered a slight core blockage and recovered only $3.15 \mathrm{~m}$. The hole was terminated after the fifth XCB core at a total depth of $496.8 \mathrm{~m} \mathrm{BSF}$. The pipe was then pulled out of the hole and the bit arrived on deck just 15 minutes after the start of the New Year, 1983.

\section{Site 593 to Site 594}

The transit between the final two sites provided some of the most pleasant weather and the finest scenery of the voyage. From Site 593 northwest of New Zealand the ship sailed through Cook Strait between New Zealand's North and South Islands and then south to Site 594 close to the Chatham Rise. One of the six diesel engines assigned to the shafts was down for repairs until shortly before entering the Strait, but fair weather and following currents kept the ship's speed at over 9 knots, despite the reduction in power. During one section of the passage through the Strait, the vessel made good a current assisted 16 knots. The site was approached directly along the Eltanin 43 survey line and the beacon was dropped at 1449 hours, January 3 , on the basis of a good seismic profile. The 603.9 mile trip was completed in two days 12.6 hours at an average speed of 10.0 knots.

\section{Site 594 (SW-1) Chatham Rise and Bounty Trough}

The PDR depth was questionable since the location of the site was almost exactly on the border between two adjacent water mass areas listed in Matthews Tables. By one, the corrected depth was $1214 \mathrm{~m}$ and by the other, $120 \mathrm{~s}$. So the combination VLHPC/XCB bottom hole assembly was made up and run to $1208.1 \mathrm{~m}$ for the first mudline attempt. A successful core with $5.95 \mathrm{~m}$ recovery was achieved, thus the water depth was set as $1211.8 \mathrm{~m}$. Later inspection of the first core. showed it to be unusually firm and some suspicion was raised as to whether or not it contained the actual mudline.

Since the hemipelagic sediment became firm at such a shallow subbottom depth, the flapper core catcher usually used in the soupy upper sediments was abandoned at $44.3 \mathrm{~m} \mathrm{BSF}$. This was a mistake which was rectified only after achieving very poor recovery over four of the next five cores. 
Piston coring quickly reached its 1 imit with a mangled core liner and a barrel requiring wash over at Core No. 14. The XCB was then rigged and deployed and immediately cut a full core of exceptionally undisturbed quality. More XCB cores followed as the formarion changed from firm blue-gray hemipelagic sediment to primarily pelagic white ooze, beginning at about $210 \mathrm{~m} \mathrm{BSF}$. At $300 \mathrm{~m} \mathrm{a}$ strong siliceous element began to emerge and core recovery fell of $f$ correspondingly.

Problems with the XCB latch resulted in a mere $30 \mathrm{~cm}$ of recovery in both Cores 32 and 33 combined. The remainder of the hole was cored with the XCB run in on the wireline which made the balky latch much less of a nuisance. Cores 17 and 22 also had no recovery resulting probably from latch problems.

As coring approached $500 \mathrm{mBSF}$, the weather began to deteriorate rapidly. Fifteen foot swells and 40-50 knot winds plus a weather prognosis from RMS Melbourne showing three low pressure cells and two cold fronts heading our way left no choice but to pull the pipe for safety's sake and terminate the hole. The pipe trip was completed successfully and the bit arrived on deck at 2035 hours, January 5th.

After waiting for 9.5 hours, the weather had improved noticeably. This, plus more recent weather charts from Melbourne showed that the severe prognosis chart received earlier had been badly in error. Therefore, starting at 0100 hours, January 6 , the pipe was again run in to take the repeat piston core sequence plus use the ХСВ to spot core those intervals lost in the initial hole and attempt to continue from the termination point of the other hole to reach the scientific objectives somewhere between 500 and $800 \mathrm{~m} \mathrm{BSF}$.

Hole 594A

The same BHA was run and the hole was spudded at 0435 hours, January 6 . The bit was quickly washed to $41.3 \mathrm{~m}$ BSF to help bury the bumper subs as soon as possible in that weather conditions were still questionable. The upper five piston cores taken in the first hole were very complete, so skipping that interval the second time around was a reasonable expediency. Nine $9.5 \mathrm{~m}$ VLHPC cores were then taken with excellent recovery on all.

The bit was next washed to $149.9 \mathrm{~m} \mathrm{BSF}$ and the XCB deployed to take a core which was missed in Hole 594. This procedure was repeated to recover the $9.6 \mathrm{~m}$ interval starting at $197.5 \mathrm{~m} \mathrm{BSF}$. The XCB was then used as a wash barrel and the bit was washed to $495.5 \mathrm{~m} \mathrm{BSF}$ to commence continuous XCB coring to the objective.

Running the XСB on the wireline to forestall latch problems, coring continued through sticky chalk and short interbedded sequences of partially and fully lithified turbidites. The firm, chalky sediment had a tendency to block off in the cutting shoes and limited the amount of core recnvery. The XCB captured the turbidite sections largely intact, but the chalk layers in between were disturbed.

At $639.5 \mathrm{~m}$ BSF the Oligocene objective had not been reached, but microfossil preservation had become too poor for useful analysis, so the hole was terminated 
Hole 594B

The bit was pulled to the mudline and, since time and weather permitted, the VI.KPC was again deployed. A mudline core was verified beyond further duubt by the presence on top of the core of one amputated leg of an Orphuoroid (Brittle Star) whose lucky day it was not. Whater depth was thus determined to be $1212.8 \mathrm{~m}$. The upper five piston cores previously skipped in Hole $594 \mathrm{~A}$ were taken quickly and the hole was terminated. Spud in occurred at 1052 hours and the final core was on deck at 1335 hours, January 7, 1983.

The pipe was then pulled and the BHA and Bowen units were magnaflux inspected for incipient cracks. None were found.

Site 594 to Wellington, New Zealand

Once the rig floor was secured, time was taken to perform a calibration of the thrusters which had originally been scheduled for the Yokohama post overhaul sea trials but was not done at that time. The calibration was completed and the vessel got underway at 2215 hours, January 7.

A seismic profile track was laid out from Site 594 to v'ellington designed to use the remaining time to maximum scientific advantage. The seismic records using the new water gun had been so good during the cruise that the opportunity was enthusiastically seized to examine certain interesting submarine features south of New Zealand enroute to ivellington. In particular, it was desired to correlate Miocene turbidites found at Site 594 with the regional seismic stratigraphy and to more closely document the true dip of a series of major imbrications on the north flank of the Chatham Rise.

The transit and seismic profile were completed as planned and Leg 90 officially came to an end when the first line was put over at the Aotea fuel dock, Port Nicholson, Wellington, New Zealand at 0943 hours, January 9, 1983.

\section{Drill String}

The plan for Leg 90 was to use the drill pipe as it had been organized on the pipe rackers following ultra-deep deployment on Leg 89 . This required using premium, rubberless pipe (U. S. made) from the starboard racker immediately above the BHA. The aluminum pipe which, at the beginning of the leg was broken into singles and stored in the casing rack, was not used. The Extended Core Barrel/VLHPC system required running coring tools with 4.00 inch diameter landing shoulders. The aluminum pipe, being slightly smaller on the inner diameter than the steel pipe, was thought to be questionable in drifting four inches, thus was not picked up during the voyage.

Because of the larger than normal landing shoulders, a 4.00 inch diameter rabbit was run through all pipe as it was first picked up at Site 587 . Though this precaution should have been unnecessary so soon after a complete pipe inspection during the Yokohama drydock prior to Leg 89 , it proved to be a very good idea. Three of the first 30 premium joints from the starboard 
racker falled to pass the rabbit. In each the rabbit stuck hard at the slight internal upset where the tool joints met the bodies. The three bad joints were laid down in the casing rack. Several other tight feeling joints still on the starboard racker were found by hand testing the rabbit.

To prevent further delay, the remainder of the pipe used for the leg was taken from the port side racker. This pipe (apparently all NKK pipe recently purchased in Japan) drifted the 4-inch rabbit easily. Rubbers had to be removed from 12 stands of pipe to avoid deploying them below the mudline.

Several bottom hole assemblies (BHA) were used during the leg. At Site 587, a "short hook-up" combination BHA was assembled to allow VLHPC and XCB coring interchangeably. It was carefully spaced out to assure proper extension of the XCB cutting shoe beyond the bit. This BHA consisted of an XCB/VLHPC $117 / 16 \times 3.80$ F93DK core bit, bit sub, outer core barrel, $81 / 4^{\prime \prime} \mathrm{drill}$ collar, two 3-foot drill collar spacers, top sub, head sub, Monel drill collar, two $81 / 4 "$ drill collars, two bumper subs, two $81 / 4 "$ drill collars, crossover sub, 7 1/4" drill collar and two $51 / 2 " \mathrm{R}-3$ heavy wall drill pipe. This BHA was designed to be run in a minimum time, yet still provide adequate weight on the bit for penetration in the upper sediments which were the objectives of the operations for the entire voyage.

At Site 588, an additional 8-1/4" drill collar was added to the BHA immediately above the Monel drill collar to facilitate storage of the drill collars in the derrick between sites. Later in the cruise as we proceeded further south weather conditions worsened and vessel motion became more significant. Thus, at Site 594, an additional bumper sub was added to allow for more heave.

Conventional rotary coring was done at Holes $588 \mathrm{C}$ and $591 \mathrm{~B}$. The BHA for Hole 588C was $97 / 8$ " F93CK core bit, bit sub, head sub, outer core barrel, top sub, head sub, four $81 / 4^{\prime \prime}$ drill collars, bumper sub, three $81 / 4 " \mathrm{drill}$ collars, two bumper subs, two $81 / 4$ " drill collars, crossover sub, $71 / 4 "$ drill collar, two $51 / 2 "$ R-3 heavy wall drill pipe. At Hole 591B an abbreviated BHA was arranged similar to Hole 588C, but eliminating the lower bumper sub and the three drill collars just above it.

All of the BHA combinations attempted were successful. The formations drilled did not cause any hole problems and placed minimal demands on the bits and BHA's.

Drilling and Coring Equipment

The last of two newly introduced sinker bar swivels was used continuously throughout the voyage. It functioned for 513 wireline runs and proved to be a real asset. The loads placed on it, especially by the heavy XCB barrels, resulted in significant wear and the bearings were very near the end of their life by the last site.

On three occasions Otis overshots failed when the dogs engaging the pulling necks of the coring tools failed at the teeth. The first failure was at the rig floor when a VLHPC tool was dropped on its hang off clamp just before being run in the hole. Two of the three dogs falled suddenly--apparently 
victims of long term corrosion fatigue. Twice a single overshot dog failed when attempts were being made to shear the pin in the overshot to release it from an XCB tool stuck in the pipe. It was felt that the new XCB was simply too heavy for the present design of the overshot dogs.

The heave compensator was not used during the voyage. Since much of the operations involved XCB/VLHPC work where the heave compensator is not compatible, the opportunity was taken to work on the limit torque valves and automatic power actuator as requested by GMI in San Diego. The one occasion when the heave compensator would have been useful occurred at a time when the unit was being disassembled and inspected.

\section{Extended Core Barrel (XCB)}

On its third trial at sea and after several years of development, the XCB finally earned its wings. At the first two sites on this voyage where it was deployed following termination of VLHPC, coring results were very poor and indicated that significant redesign and shipboard modification of the vent system was called for. Fortunately, the basic components were already in the tool so the required changes could be made within the limited capabilities of the shipboard machine shop, welding and spare parts.

The first vent modifications showed that the correct steps had been taken but partial collapse of the core liners indicated that the new seals added were probably leaking due to the presence of an oversized seal gap.

The vent mods were redone by weld overlay and machining to tighten the seal extrusion gap prior to the fourth deployment. This improvement brought about a miraculous transformation in the XCB which was then used extensively throughout the rest of the cruise with outstanding results.

Later problems involving badly shattered liners were eliminated by filling the drill pipe with water just before dropping the tools and/or running the XCB barrels in on the wireline. Later in the leg the new style XCB latches, which had functioned flawlessly at first, began to cause the tools to become stuck in the pipe or BHA before reaching the latch sleeve. Several modifications were made to the latches with some success, but only by running the tools in slowly on the wireline could the barrels be landed each time with assurance. On two or three deployments the tools stuck momentarily even though on the wireline. It was clear that the new style latch required further design evaluation but was useable--with caution--for the time being.

In spite of the minor difficulties encountered (and mostly overcome) the XCB was used extensively throughout the voyage to great advantage. Four or five pipe round trips were saved by the ability of the BHA to accept either the VLHPC or XCB interchangeably. The dual purpose BHA functioned exactly as desired. The versatility made possible in planning, coring and multiple hole exploitation at a given site cannot be overestimated with this powerful new system.

Two types of cutting shoes for the XCB were available. One was a soft formation design with hard faced, saw teeth and the other was a hard rock design 
with diamond stratapax discs. Only the soft formation shoes were used, although several sequences of fully lithified turbidites were encountered without warning. This hard rock was cored quite successfully with the soft formation shoes which stood up very well overail.

Core quality was exceptional in most cases. Some odd "spiral" disturbance patterns were observed in softer formations but as the cored material became firmer the cores often approached HPC quality. The scientific staff was enthusiastic in their praise of the core quality in general which was unquestionably superior to conventional rotary cores in terms of disturbance and percent recovery.

\section{Core Bits}

Coring with the dual VLHPC/XCB system required the use of special $117 / 16^{\prime \prime}$ $\mathrm{x} 3.80$ core bits. Two such bits with F93CK TC inserts were used during the cruise. Two others with F94CK TC inserts were available but not required. The first F93CK type was set aside after the second site when two of the four cones were found to be rubbing excessively on the core guides. The other F93CK bit was used with the VLHPC/XCB BHA throughout the remainder of the operations and was in quite good condition at the end.

The two holes completed with the standard rotary system were cored with a conventional $97 / 8$ " F93CK core bit.

\section{Special Tools}

The Kuster single shot magnetic orientation tool was used extensively throughout the voyage. With three mechanical clocks on hand (two new) at the beginning of the trip results were quite good. However, wear and tear on the clocks and the one useable camera assembly slowly deteriorated the quality and reliability of the tool until virtually no useable data was acquired during piston coring at the last site. The tool by its nature has many failure modes by which no picture or a very poor picture may result--light leaks, weak batteries, bad connections, clock breakdowns, mishandling, moisture in the film cavity and human error--to name just a few. We experienced all of these in a delightfully varied and unpredictable pattern throughout the voyage.

A Von Herzen VLHPC Heat Flow probe was brought aboard for the leg and was used with absolutely perfect results a total of four times at Sites 587 and 589. On its first deployment at Site 590 (Core No. 4) it was lost along with the lower section of the VLHPC and could not be retrieved.

\section{Beacons and Positioning.}

The first beacon dropped at the first site had a signal too erratic for automatic dynamic positioning and had to be supplanted with a second beacon before operations could begin. The remainder of the beacons dropped throughout the leg functioned perfectly and signal strength in the shallow water was 
maximum. One beacon would not turn on when tested in the mudroom and was never deployed.

The dynamic positioning computer suffered a major breakdown just as coring operations were commencing at Site 589 and the site had to be abandoned. The source of the problem eluded the GMI electronic technician for 13.3 hours at which time the vessel got underway for Auckland, New Zealand, the nearest port where expert computer repair service could be obtained. Forty-one hours later the computer problem was corrected with the replacement of a bad card in the CPU. The course was reversed immediately to return to the next site. The remainder of the operations throughout the trip were performed with very good positioning, despite shallow water restrictions and some difficult weather conditions.

\section{Weather and Currents}

The voyage began in equatorial waters north of New Caledonia in balmy weather. Each succeeding site was to the south and the weather conditions became correspondingly unsettled. At Sites 589, 590, and 591, significant currents were encountered which put demands on the vessel's positioning system. At Site 591 the combination of wind, current and swell all from different directions actually cost seven hours of operating time while the ship could not be positioned in automatic. Although none of the three conditions alone would have been troublesome, the combination of the three plus their different directional effects on the attitude of the ship was too much for the dynamic positioning system to handle. After seven hours the wind changed direction and operations resumed as before.

At the final site south of New Zealand, global Antarctic influences greatly affected the weatier pattern and changes occurred in our operating area almost daily. At one point heavy swells and 40-50 knot winds caused considerable difficulty in positioning and the coring operations were stopped. A weather prognosis sent out by RMS Melbourne showing several days of severe storms headed our way forced abandoning the hole. The weather quickly improved, however, and later weather maps from Melbourne showed that the previous prognosis had been badly in error. Operations concluded at the site without further difficulties.

\section{$\underline{\text { Communications }}$}

Direct radio communication with WWD/La Jolla was not possible during the voyage as the distances involved were too great. By sending weather observer reports to Guam Coast Guard Station NRV, we were able to make maximum use of their good will and relay inconing and outgoing radio telegraph traffic through them. Sadly, their personnel were generally not proficient at morse code so outgoing messages of ten had to be sent repeatedly at agonizingly slow rates, sometimes as slow as 2-3 wpm. There were times when Coast Guard Guam seemed on the verge of refusing to allow us to tie up their system any further. This did not occur, but if it had, no other recourse would have been available except commercial routes. 
It was an ironic fact (with Catch 22 overtones) that while our radio officer was working up to 18 hours a day trying to plow slowly through the inefficient CW radio telegraph system, the ham operators on board were able to chat easily and at length with operators throughout the U. S. and make numerous phone patches for personnel on board to their families and friends.

\section{Personne1}

The cruise was short and extremely work-intensive, especially for personnel involved in core processing. Cores were recovered at a rate of over $100 \mathrm{~m}$ per day for every day spent at sea. In spite of this (or perhaps because of 1t) morale was very high--helped out by a favorable "chemistry" between the individuals in the crew and scientific team. A feeling of satisfaction was felt by all at the unquestionably high level of success achieved during the voyage. Almost everything went well and this was reflected in the attitude of all on board.

No injuries were suffered, the weather was generally good, the holiday meals were remarkable and the work was engrossing.

DSDP legs are always marked by high levels of professionalism and cooperation amongst the scientists, technicians and crew, but Leg 90 will surely stand out as one of the finest in this regard.

David P. Huey

Cruise Operations Manager

Deep Sea Drilling Project 
INTERNATIONAL PHASE OF OCEAN DRIILLING

DEEP SEA DRILLINGPROJECT

OPERATIONS RESUMF.

LEG 90

Total Days (November 29, 132 - January 9, 1983) . . . . . . .

Total Days in Port . . . . . . . . . . . . . . . . . . . . .

40.71

Total Days Cruising Including Site Survey . . . . . . . . . .

Total Days on Site. . . . . . . . .

10.97

26.68

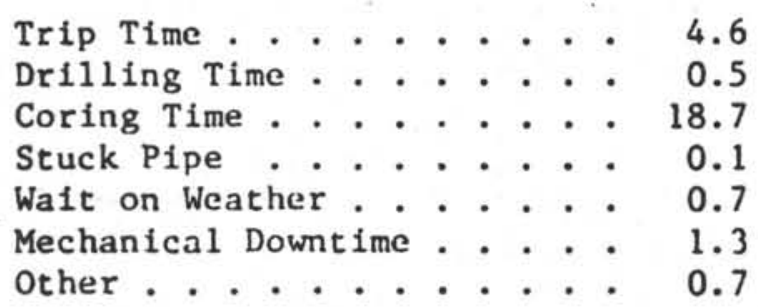

Total Distance Traveled Including Survey (nautical miles)

2773.0

Average Speed (knots). . . . . . . . . . . . . . . .

Number of Sites . . . . . . . . . . . . . . . . . . .

Number of Holes Drilled . . . . . . . . . . . . . . . . .

Number of Cores Attempted . . . . . . . . . . . . . . . . 494

Number of Cores with Recovery . . . . . . . . . . . . . . . . 480

Total Meters Cored..................... . 4579.6rk

Total Meters Recovered . . . . . . . . . . . . . . . . 3708.9

Percent Recovery . . . . . . . . . . . . . . . . . . 81.0

Total Meters Drilled.................... . 1467.98

Total Meters of Penetration . . . . . . . . . . . . . . . . . $6047.5 \mathrm{~V}$

Percent of Penetration Cored . . . . . . . . . . . . . 75.7

Maximum Penetration (meters) . . . . . . . . . . . . 639.5

Minimum Penetration (meters) . . . . . . . . . . . . . 26.2

Maximum Water Depth (meters) . . . . . . . . . . . . 2142.2

Minimum Water Depth (meters)................ 1079.9 


\section{INTERNATIONAL PHASE OF OCEAN DRILLING \\ DEEP SEA DRILLING PROJECT \\ BEACON SUMMARY \\ LEG 90}

\begin{tabular}{|c|c|c|c|c|c|c|c|c|}
\hline & Site No. & & Make & $\begin{array}{l}\text { Freq. } \\
\mathrm{kHz}\end{array}$ & & $\begin{array}{l}\text { Serial } \\
\text { Number }\end{array}$ & $\begin{array}{l}\text { Site Time } \\
\text { Hours }\end{array}$ & Remarks \\
\hline \multirow{9}{*}{ 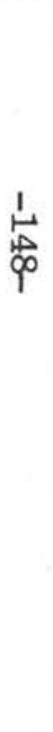 } & 587 & & ÓRE & 13.5 & & 153 & 0 & $\begin{array}{l}\text { Double pulsing erratic signal--could not } \\
\text { position. }\end{array}$ \\
\hline & 587 & $\cdot$ & ORE & 16.0 & & $104 \mathrm{~A}$ & 40 & Good beacon--no problems. \\
\hline & 588 & & ORE & 13.5 & & 155 & 116 & Good--no problems. \\
\hline & 589 & & ORE & 16.0 & $\cdot$ & 143 & 11 & Computer CPU failed--abandoned site. \\
\hline & 590 & & ORE & 13.5 & & 154 & 100 & Good--no problems. \\
\hline & 591 & & ORE & 16.0 & & 145 & 125 & Good--no problems. \\
\hline & 592 & & ORE & 16.0 & & 131 & 47 & Good--no problems. \\
\hline & 593 & & ORE & 13.5 & & 142 & 80 & Good--no problems. \\
\hline & 594 & & ORE & 16.0 & & 132 & 104 & Good--no problems. \\
\hline
\end{tabular}


IMTER:UTI :NAL PHASE OP OCEAN DRILLING

DEEP SEA TRILLING PROJECT

SITE SU:MARY

LEC 90

\begin{tabular}{|c|c|c|c|c|c|c|c|c|c|c|c|c|c|c|c|}
\hline Hole & Latitude & & $\begin{array}{c}\text { ongitude, } \\
:\end{array}$ & $\begin{array}{l}\text { Water } \\
\text { Depth } \\
\text { Meters }\end{array}$ & $\begin{array}{l}\text { Nuater } \\
\text { of } \\
\text { Cores }\end{array}$ & $\begin{array}{l}\text { Cores } \\
\text { With } \\
\text { Recovery }\end{array}$ & $\begin{array}{l}\text { Percent of } \\
\text { Cores with } \\
\text { Recovery }\end{array}$ & $\begin{array}{l}\text { Meters } \\
\text { Cored }\end{array}$ & $\begin{array}{c}\text { Meters } \\
\text { Recovered }\end{array}$ & $\begin{array}{l}\text { Percent } \\
\text { Recovered }\end{array}$ & $\begin{array}{l}\text { Meters } \\
\text { Drilled }\end{array}$ & $\begin{array}{l}\text { Total } \\
\text { Penet } \\
\text { Meters }\end{array}$ & $\begin{array}{l}\text { Avg. } \\
\text { sate } \\
\text { Penet } \\
\text { M/HR }\end{array}$ & $\begin{array}{l}\text { Tine } \\
\text { on } \\
\text { Hole }\end{array}$ & $\begin{array}{l}\text { Time } \\
\text { on } \\
\text { site }\end{array}$ \\
\hline 587 & $21^{\circ} 11.1^{\prime} \mathrm{s}$ & $161^{\circ}$ & $20.0^{\prime} \mathrm{E}$ & 1115.1 & 17 & 11 & 64.7 & 147.0 & 88.81 & 60.4 & 0 & 147.0 & - & -- & 40.4 \\
\hline $\begin{array}{l}588 \\
5881 \\
5883 \\
583 C \\
\end{array}$ & 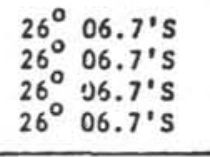 & $\begin{array}{l}161^{\circ} \\
161^{\circ} \\
161^{\circ} \\
161^{\circ}\end{array}$ & $\begin{array}{l}13.6^{\prime} \mathrm{E} \\
13.6^{\prime} \mathrm{E} \\
13.6^{\prime} \mathrm{W} \\
13.6^{\prime} \mathrm{W}\end{array}$ & $\begin{array}{l}1548.0 \\
1548.0 \\
1547.8 \\
1548.0 \\
\end{array}$ & $\begin{array}{l}25 \\
18 \\
31 \\
19\end{array}$ & $\begin{array}{l}25 \\
18 \\
31 \\
19\end{array}$ & $\begin{array}{l}100.0 \\
100.0 \\
100.0 \\
100.0\end{array}$ & $\begin{array}{l}236.0 \\
108.4 \\
271.4 \\
182.4\end{array}$ & $\begin{array}{r}220.76 \\
84.27 \\
255.87 \\
134.61 \\
\end{array}$ & $\begin{array}{l}93.5 \\
77.7 \\
92.2 \\
73.8\end{array}$ & $\begin{array}{c}0 \\
236.0 \\
0 \\
305.7\end{array}$ & $\begin{array}{l}236.0 \\
344.4 \\
277.4 \\
488.1\end{array}$ & $\begin{array}{l}71.2 \\
\overline{4.2}\end{array}$ & $\begin{array}{l}29.0 \\
20.4 \\
35.5 \\
31.4\end{array}$ & $\begin{array}{l}-- \\
-- \\
--\end{array}$ \\
\hline \multicolumn{2}{|c|}{ TOTAL 588} & & & & 93 & 93 & $\begin{array}{l}100.0 \\
\cdots \ldots .\end{array}$ & 04.2 & 695.51 & 86.5 & 541.7 & 1345.9 & & \multirow{2}{*}{\multicolumn{2}{|c|}{116.3}} \\
\hline 589 & $30^{\circ} 42.72^{\prime} \mathrm{s}$ & $163^{\circ}$ & $38.39^{\prime} \mathrm{E}$ & 1398.3 & 4 & 4 & 100.0 & 36.1 & 35.08 & 97.2 & 0 & 36.1 & - & & \\
\hline $\begin{array}{l}590 \\
593 A \\
5908\end{array}$ & $\begin{array}{l}31^{\circ} 10.02 \text { 's } \\
31^{\circ} 10.02 \text { 's } \\
31^{\circ} 10.02 \text { 's }\end{array}$ & $\begin{array}{l}163^{\circ} \\
163^{\circ} \\
163^{\circ}\end{array}$ & $\begin{array}{l}21.52 \mathrm{E} \\
21.52^{\prime} \mathrm{E} \\
21.52^{\circ} \mathrm{E}\end{array}$ & $\begin{array}{r}1307.6 \\
1307.6 \\
.1309 .4\end{array}$ & $\begin{array}{r}3 \\
27 \\
53\end{array}$ & $\begin{array}{r}3 \\
26 \\
53\end{array}$ & $\begin{array}{r}100.0 \\
96.3 \\
100.0 \\
\end{array}$ & $\begin{array}{r}26.2 \\
254.6 \\
499.1\end{array}$ & $\begin{array}{r}26.36 \\
228.17 \\
665.26\end{array}$ & $\begin{array}{r}100.6 \\
88.0 \\
93.2\end{array}$ & $\begin{array}{c}0 \\
26.2 \\
0\end{array}$ & $\begin{array}{r}26.2 \\
280.8 \\
499.1\end{array}$ & $\overline{--}$ & $\begin{array}{l}12.5 \\
26.5 \\
49.7\end{array}$ & $=$ \\
\hline \multicolumn{2}{|c|}{ TOTAL 590} & & & & 83 & 82 & 98.8 & 779.9 & 715.79 & 91.8 & 26.2 & 806.1 & $\cdots$ & - & 88.7 \\
\hline $\begin{array}{l}591 \\
591 \mathrm{~A} \\
591 \mathrm{~B} \\
\end{array}$ & $\begin{array}{l}31^{\circ} 35.06 \text { 's } \\
31^{\circ} 35.06 \text { 's } \\
31^{\circ} 35.06 ' \mathrm{~s}\end{array}$ & $\begin{array}{l}164^{\circ} \\
164^{\circ} \\
164^{\circ}\end{array}$ & $\begin{array}{l}26.92^{\prime} \mathrm{E} \\
26.92^{\prime} \mathrm{E} \\
26.92^{\prime} \mathrm{E}\end{array}$ & $\begin{array}{l}2142.2 \\
2140.9 \\
2140.9\end{array}$ & $\begin{array}{l}31 \\
30 \\
24\end{array}$ & $\begin{array}{l}31 \\
28 \\
24\end{array}$ & $\begin{array}{r}100.0 \\
93.3 \\
100.0 \\
\end{array}$ & $\begin{array}{r}283.1 \\
284.6 \\
229.8 \\
\end{array}$ & $\begin{array}{l}278.21 \\
233.15 \\
130.86\end{array}$ & $\begin{array}{l}98.3 \\
81.9 \\
56.9\end{array}$ & $\begin{array}{c}0 \\
0 \\
270.6\end{array}$ & $\begin{array}{l}283.1 \\
284.6 \\
500.4\end{array}$ & $\begin{array}{c}-- \\
\overline{-} \\
109.4\end{array}$ & $\begin{array}{l}39.4 \\
40.4 \\
46.8\end{array}$ & $\overline{-}$ \\
\hline \multicolumn{2}{|c|}{ TOTAL 591} & & & & 85 & 83 & 97.6 & 797.5 & 642.22 & 80.5 & 270.6 & 1068.1 & -- & - & 124.6 \\
\hline 592 & $35^{\circ} 28.40^{\prime} \mathrm{s}$ & $165^{\circ}$ & $26.53^{\prime} \mathrm{E}$ & 1099.7 & 41 & 40 & 97.6 & 388.5 & 340.12 & 87.5 & 0 & 389.5 & - & $\cdots$ & 46.4 \\
\hline $\begin{array}{l}593 \\
593 A \\
\end{array}$ & $\begin{array}{ll}40^{\circ} & 30.52 ' \mathrm{~s} \\
40^{\circ} & 30.52^{\prime} \mathrm{s}\end{array}$ & $\begin{array}{l}167^{\circ} \\
167^{\circ}\end{array}$ & $\begin{array}{l}40.48^{\prime} \mathrm{E} \\
4 \mathrm{C} .48^{\prime} \mathrm{E}\end{array}$ & $\begin{array}{l}1079.9 \\
1080.3\end{array}$ & $\begin{array}{l}60 \\
27 \\
\end{array}$ & $\begin{array}{l}59 \\
27\end{array}$ & $\begin{array}{r}98.3 \\
100.0 \\
\end{array}$ & $\begin{array}{l}571.5 \\
257.3\end{array}$ & $\begin{array}{l}468.21 \\
227.71\end{array}$ & $\begin{array}{l}81.9 \\
88.5\end{array}$ & $\begin{array}{c}0 \\
239.5\end{array}$ & $\begin{array}{l}571.5 \\
496.8\end{array}$ & -- & $\begin{array}{l}56.0 \\
26.2\end{array}$ & - \\
\hline ro? & AL 593 & & & & 87 & 86 & 98.8 & 828.8 & 695.92 & 84.0 & 239.5 & 1068.3 & - & $\cdots$ & 80.2 \\
\hline
\end{tabular}




\begin{tabular}{|c|c|c|c|c|c|c|c|c|c|c|c|c|c|c|}
\hline Sole & Latitude & Long1tude & $\begin{array}{l}\text { Water } \\
\text { Depth } \\
\text { Meters }\end{array}$ & $\begin{array}{l}\text { Nunber } \\
\text { of } \\
\text { Cores }\end{array}$ & $\begin{array}{c}\text { Cores } \\
\text { w1th } \\
\text { Recovery }\end{array}$ & $\begin{array}{l}\text { Percent of } \\
\text { Cores with } \\
\text { Recovery }\end{array}$ & $\begin{array}{l}\text { Meters } \\
\text { Cored. }\end{array}$ & $\begin{array}{l}\text { Metero } \\
\text { Recovered }\end{array}$ & $\begin{array}{c}\text { Percent } \\
\text { Recovered }\end{array}$ & $\begin{array}{l}\text { Metare } \\
\text { Drilled }\end{array}$ & $\begin{array}{c}\text { Total } \\
\text { Penet } \\
\text { Metera }\end{array}$ & $\begin{array}{l}\text { Avg. } \\
\text { Rate } \\
\text { PEVET } \\
\text { H/HR }\end{array}$ & $\begin{array}{c}\text { Time } \\
\text { on } \\
\text { Hole }\end{array}$ & $\begin{array}{c}\text { Time } \\
\text { on } \\
\text { Hole }\end{array}$ \\
\hline $\begin{array}{l}594 \\
594 A \\
594 \mathrm{~B}\end{array}$ & $\begin{array}{l}45^{\circ} 31.41 ' s \\
45^{\circ} 31.41 ' s \\
45^{\circ} 31.41 ' s\end{array}$ & $\begin{array}{l}174^{\circ} 56.88^{\prime} \mathrm{E} \\
174^{\circ} \mathrm{S6.88} \cdot \mathrm{E} \\
174^{\circ} \mathrm{S6.88^{ \prime } \mathrm { E }}\end{array}$ & $\begin{array}{l}1211.8 \\
1211.8 \\
1212.2\end{array}$ & $\begin{array}{r}53 \\
26 \\
5\end{array}$ & $\begin{array}{r}50 \\
26 \\
5\end{array}$ & $\begin{array}{r}94.3 \\
100.0 \\
100.0\end{array}$ & $\begin{array}{r}505.1 \\
249.6 \\
42.9\end{array}$ & $\begin{array}{r}299.72 \\
161.55 \\
34.18\end{array}$ & $\begin{array}{l}59.3 \\
64.7 \\
79.7\end{array}$ & $\begin{array}{c}0 \\
389.9 \\
0\end{array}$ & $\begin{array}{r}505.1 \\
639.5 \\
42.9 \\
\end{array}$ & $\begin{array}{l}-- \\
--\end{array}$ & $\begin{array}{l}57.2 \\
34.3 \\
10.7\end{array}$ & $=$ \\
\hline \multicolumn{2}{|c|}{ TOTAL 594} & & & 84 & 81 & 96.4 & 797.6 & 495.45 & 62.1 & 389.9 & 1187.5 & - & $\therefore$ & 103.2 \\
\hline \multicolumn{2}{|c|}{ GSALD TOTALS } & & & 494 & 480 & 97.2 & 4579.6 & 3708.90 & 81.0 & 1467.9 & 6047.5 & - & - & 614.3 \\
\hline
\end{tabular}




\section{INTERNATIONAL PHASE OF OCEAN DRTLLING}

$$
\text { DEEP SEA DRILLING PROJECT }
$$

$$
\frac{\text { BIT } S L ? \text { ? AR }}{\text { LEC } 90}
$$

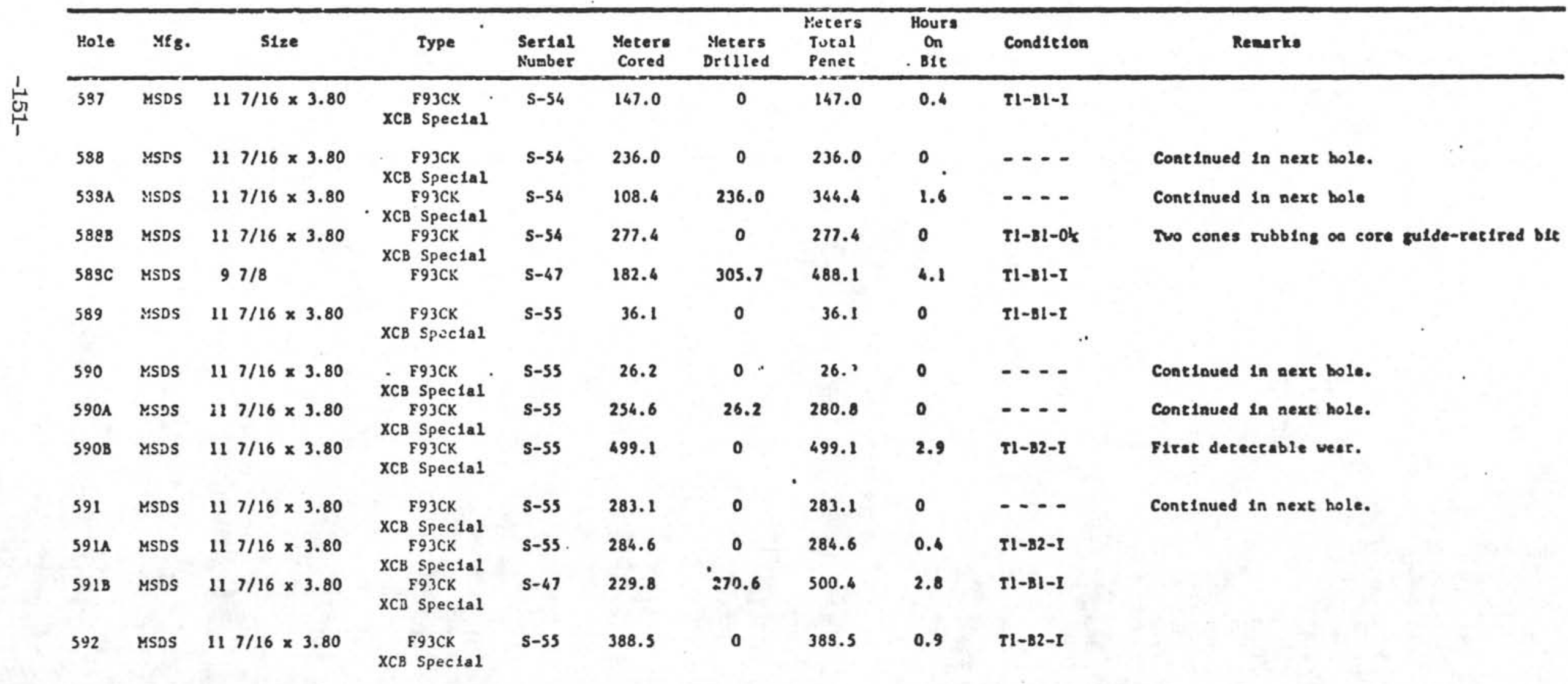




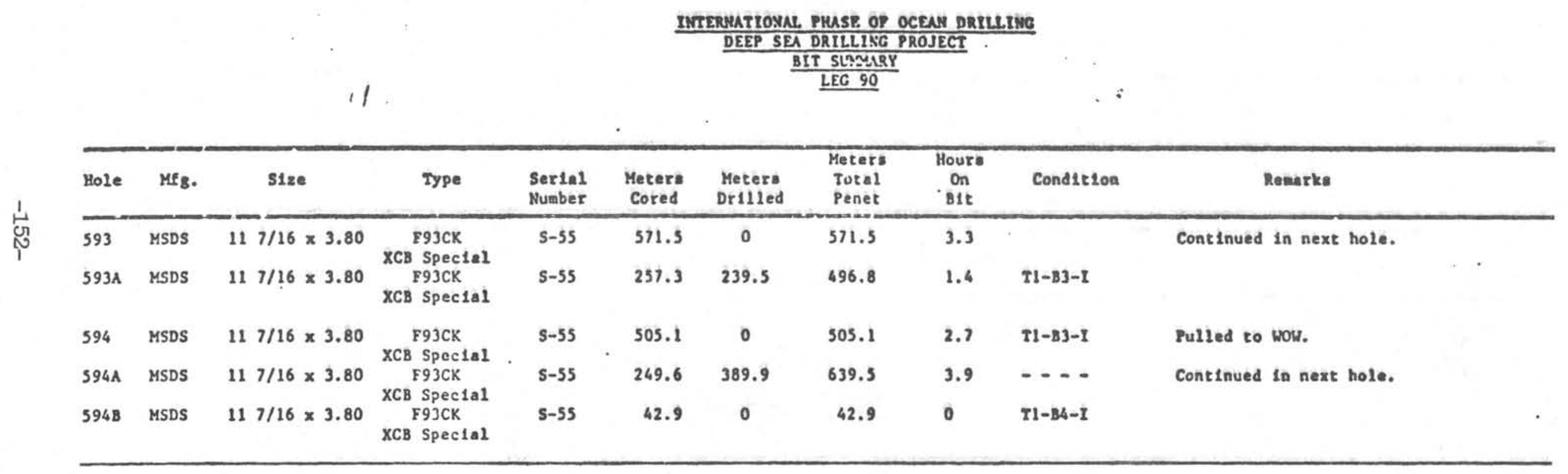


DEEP SEA DRIILING PFOJECT

TIASE DISTRIBUTION

$\angle E G-90$

\begin{tabular}{|c|c|c|c|c|c|c|c|c|c|c|c|c|c|c|}
\hline Date & \begin{tabular}{|l|}
$s, t e$ \\
$1 i c$ \\
\end{tabular} & Cruise & Trips & Drill & Core & $\begin{array}{l}\text { Stuik } \\
\text { Plpe }\end{array}$ & W. o.? & $\begin{array}{l}\text { Position } \\
\text { Shis }\end{array}$ & $\begin{array}{l}\text { liesh. } \\
\text { repair }\end{array}$ & $\begin{array}{l}\text { Port } \\
\text { Tirne }\end{array}$ & $\begin{array}{c}\text { Re- } \\
\text { Entry }\end{array}$ & ortier & $\begin{array}{l}\text { Tot:al } \\
\text { Tryos }\end{array}$ & Pemicks \\
\hline $\begin{array}{l}11729 / 32 \\
12 / 05 / 82\end{array}$ & 587 & 30.4 & 15.2 & & 21.1 & & & & 1.0 & & & 3.1 & 40.4 & - \\
\hline $\begin{array}{l}12 / 05 / 82 \\
12 / 08 \angle 82\end{array}$ & $588-1$ & 28.2 & 6.7 & & 21.3 & & & & & & & 1.0 & 29.0 & \\
\hline $12 / 08 / 82$ & $588 \mathrm{~A}$ & & 1.2 & 1.4 & 17.8 & & & & & & & & 20.4 & \\
\hline $\begin{array}{l}12 / 08 / 82 \\
12 / 10 / 82\end{array}$ & $588 \mathrm{~B}$ & & 4.2 & & 29.8 & $\therefore$ & & & & & & 1.5 & 35.5 & \\
\hline \begin{tabular}{|l|}
$12 / 10 / 82$ \\
$12 / 11 / 82$
\end{tabular} & $588 \mathrm{C}$ & & 9.8 . & & 20.9 & & 0.7 & & & & & & 31.4 & \\
\hline $\begin{array}{l}12 / 11 / 82 \\
12 / 13 / 82\end{array}$ & 582 & 22.6 & 4.2 & & 3.2 & & & & & & & . & 26 & \\
\hline $\begin{array}{l}12 / 13 / 82 \\
12 / 15 / 82\end{array}$ & 590 & 16.3 & 4.3 & & 3.3 & 2.5 & & & & & & 2.4 & 12.5 & \\
\hline $\begin{array}{l}12 / 15 / 82 \\
12 / 16 / 82\end{array}$ & 5904 & 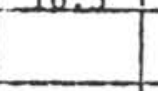 & 1.5 & . & 24.2 & & & & & & & & 26.6 & \\
\hline $\begin{array}{l}12 / 16 / 82 \\
12 / 18 / 82\end{array}$ & $590 B$ & & 3.7 & & -45.5 & & & & & & & 0.5 & 49.7 & \\
\hline $\begin{array}{r}12 / 18 / 82 \\
12 / 20 / 82 \\
120 / 8\end{array}$ & 591 & & 7.2 & & 30.4 & & & & & & & 1.8 & 39.4 & \\
\hline $\mid \begin{array}{l}12 / 20 / 82 \\
\left|\frac{12}{12} \angle 22<\frac{82}{\mid 22}\right|\end{array}$ & $521 \mathrm{~A}$ & & 5.0 & & -34.9 & & & & & - & & 0.5 & 40.4 & \\
\hline $\begin{array}{l}12 / 22 / 82 \\
12 / 24 / 82 \\
12 / 24 / 82\end{array}$ & $591 B$ & & 12.5 & 2.6 & 22.7 & & 7.0 & & & & & & 44.8 & \\
\hline$\frac{12 / 27 / 82}{12 / 27 / 82}$ & 592 & 28.5 & 8.0 & & 36.7 & & & & & . & & 1.7. & 46.4 & \\
\hline $\begin{array}{l}12 / 27 / 82 \\
12 / 30 / 82 \\
12 / 30 / 82\end{array}$ & 593 & 27.8 & 5.2 & & 47.1 & & & & & & & 1.0 & 54.0 & \\
\hline $\begin{array}{l}12 / 30 / 82 \\
01 / 02 / 83\end{array}$ & $593 \mathrm{~A}$ & & 3.2 & 3.3 & 19,2 & & & & & & & & 26.2 & \\
\hline $\begin{array}{l}01 / 02 / 83 \\
01 / 0.5 / 83\end{array}$ & 59 & 60.1 & مــــ & & 43.2 & & 8.5 & & & & & 1.5 & 57.2 & \\
\hline $\begin{array}{l}01 / 05 / 83 \\
01 / 07 / 83 \\
\end{array}$ & $594 \mathrm{~A}$ & & 5.1 & 4.5 & 23.7 & & 1.0 & & & & & & 34.3 & \\
\hline $01 / 07 / 83$ & $594 \mathrm{~B}$ & & 7.8 & & 2.9 & & & & & & & & 10.7 & \\
\hline & & & & & & & & & & & & & & \\
\hline TOTALS & & 263.2 & 110.5 & 12.2 & 448.4 & 2.5 & 17.2 & 0 & 31.5 & 73.6 & 0 & 17.9 & 977.0 & \\
\hline
\end{tabular}




\section{INTERNATIONAL PHASE OF OCEAN DRILLING \\ DEEP SEA DRILLING PROJECT \\ OPERATIONS RESUME \\ LEG 91}

Leg 91 of the Deep Sea Drilling Project marked the culmination of years of preparation by researchers representing various agencies and institutions. The voyage successfully accomplished important geophysical, geological and technological objectives through the application of specialized deep ocean drilling technology. In a period of three weeks, a cased hole was drilled into crustal igneous rocks and an automated, recoverable seismological observatory was installed on the seafloor with its sensors at the bottom of the borehole. All this was accomplished in water more than three miles deep, and the three re-entries into the hole were the deepest ever executed.

The system emplaced was provided by the U. S. Defense Advanced Research Projects Agency (DARPA). This Marine Seismic System (MSS) was used, along with an array of ocean bottom seismometers (OBS), in a coordinated two-ship refraction seismology experiment with $R / V$ MELVILLE of Scripps Institution of Oceanography to study the earth's crustal structure in the area. The MSS was left in place to record the earthquakes of one of the planet's most active seismic zones until the planned retrieval of its recording package by MELVILLE in March, 1983.

The expedition was the first of $D / V$ GLOMAR CHALLENGER into the vast southwest Pacific Basin in her 14-year research drilling history. The drill holes in the operating area yielded some of the oldest oceanic sediments ever cored, and the unusual mineralogy of these sediments will be the basis of considerable future research.

The voyage commenced on January 9, 1983 at We1lington, New Zealand and terminated on February 20, 1983 at Papeete, Tahiti. Total length of the leg was 43.2 days, of which 25.3 days were spent on site, 6.9 days in port and 10.9 days in transit. Weather delay accounted for 0.7 day and mechanical repair for 0.1 day.

\section{Wellington Port Call}

Leg 91 began officially at 0943 hours, January 9 with the first mooring line put over to the fueling pier in Wellington Harbor, New Zealand. GLOMAR CHALLENGER had arrived two days ahead of schedule, and fueling was done first to accommodate arrangements for the extensive dockside work load. A total of 290,000 gallons of marine gas/oil were loaded during the afternoon and evening hours. By 0900 hours the following morning, the vessel had moved to Queen's 
Wharf. The second day ir port was devoted to the off-loading of DSDP cores and air freight shipments and to the onloading of high priority GMI and DSDP Freight. Major work items accomplished during the port call included the loading of equipment and supplies for the Leg 91 DARPA experiment, the off-loading of all Schlumberger well logging equipment and assembly of the re-entry cone to be used at the prime drill site. DC generator Number 9B was reinstalled and DC generator assignments at the switchboard were returned to the pre-Leg 89 configuration. A spare DC generator was sent to Auckland, converted from dual bearing to single bearing design, and returned to the ship. The heave compensator relief valves were reset and tested at a local repair facility.

Wellington to Site 595

At 0812 hours, January 16, the last line was cast off in Wellington, and the vessel departed from the operating area. Winds were gusting as high as sixty knots, but decreased through the morning as CHALLENGER cleared the approaches to Wellington Harbor and stopped briefly to test the thrusters and dynamic positioning system. The ship then exited Cook Strait and turned northeastward along the coast of the North Island of New Zealand.

The windy and choppy conditions gradually diminished during the northeastward voyage into subtropical waters. With good weather prevailing, an excellent average speed of 9.9 knots was made good over the 1480 -mile transit to the operating area, which was located about 350 miles west-southwest of Rarontonga Island and about 500 miles east of the Tonga Trench.

Daily communication was maintained with $R / V$ MELVILLE, as she was enroute to the joint operating area from the north. MELVILLE arrived in the site area about 30 hours prior to CHALLENGER and began profiling the region in search of the optimum drill site. An area of maximum sediment thickness was identified by MELVILLE and CHALLENGER was then vectored to that location where the drill ship launched a positioning beacon, after a $1 \frac{1}{4}$-hour preliminary profile, at 170 hours, January 21 .

Hole 595

The initial pipe trip was slowed for measuring pipe and for removing three unsatisfactory joints of pipe from the drill string. The precision depth recorder indicated a water depth of $5606 \mathrm{~m}$ from the rig floor. Since Hole 595 was to be an exploratory hole for a re-entry site, an accurate water depth determination was essential. After the pipe had been run, the power sub was deployed and the core bit was lowered to $5614 \mathrm{~m}$. When the inner core barrel was recovered, the core catcher contained only a handful of manganese nodules and traces of clay. Since the sediment apparently had washed out of the barrel, a second punch core attempt was made, with the bit lowered only to $5613 \mathrm{~m}$. This time the barrel was retrieved completely clean, and water depth was set at $5613.5 \mathrm{~m}$. 
A jet-in test was then made to determine the maximum depth to which 16-inch conductor casing could be set. The seafloor sediment was found to be soft clay which was penetrated easily with a low circulation rate. A quite firm stratum was encountered at only $33 \mathrm{~m} \mathrm{BSF}$ (Below Seafloor), however, and neither increased weight nor circulation resulted in further progress.

This was considered to be insufficient soft sediment to support the re-entry cone/casing system or to provide lateral support for the bottom hole assembly (BHA) during the drilling of hard material. It was therefore decided that an effort should be made to find a more suitable location. Satellite navigation (SAT NAV) fixes received on site and further consultation with MELVILLE scientists indicated that the positioning beacon was located near the edge of the area identified by MELVILLE, and that somewhat thicker soft sediments lay to the east of CHALLENGER within offsetting range of the dynamic positioning system. The bit was pulled clear of the seafloor at 1000 hours, January 22 .

Hole 595A

The vessel was offset $457 \mathrm{~m}$ east and $15 \mathrm{~m}$ north. The new PDR depth was $5624 \mathrm{~m}$, and the bit was lowered to $5631.8 \mathrm{~m}$ for a seafloor punch core. Core recovery was $2.7 \mathrm{~m}$ and water depth was established at $5629 \mathrm{~m}$.

Again, the casing jet-in test found extremely soft sediment, but the thickness had increased by only three meters and the bit was stopped at $36 \mathrm{~m}$ BSF. The hole was then continuously cored from the seafloor. The first $36 \mathrm{~m}$ consisted of soft brown pelagic clay. The hard stratum was found to be porcellanite and chert. This was interbedded with brown clay for an additional $32 \mathrm{~m}$, and typically poor core recovery was achieved through this interval of alternating hard and soft material. Igneous rock was encountered at only $70 \mathrm{~m} \mathrm{BSF}$. This was a second disappointment, as about $100 \mathrm{~m}$ of sediment is required to provide lateral support for the BHA for safe and efficient drilling operations. Coring continued in andesitic and basaltic basement rocks to a total depth of $5717.5 \mathrm{~m}, 88.5 \mathrm{~m}$ BSF. The basement rocks were found to be favorable for the seismic instrument implantation except that rubbly material from the upper (andesitic) unit was falling into the hole, resulting in bottom fill between cores. This was indicative of the need for surface casing if the re-entry installation were to be made.

With all the objectives of the exploratory hole achieved, the drill string was recovered, and the bit arrived on deck at 0857 hours, January 24 . The BHA was given a magnaflux inspection due to the pounding endured during the shallow hard rock drilling, and the bumper subs were replaced.

Hole 595B

Further review of the now extensive profiling accomplished by MELVILLE failed to disclose a location more favorable for drilling in the locality of primary scientific interest. The consensus of investigators and managers 
on board favored an attempt to emplace the marine seismic system at Site 595 despite the unfavorable drilling conditions over the option of moving to a distant and less desirable contingency site. Design of a dual casing re-entry installation was then undertaken.

The re-entry cone, which had been assembled in Wellington and secured on the port side main deck bulwark, was keelhauled and hung off below the vessel's moonpool. An abbreviated conductor casing string was then assembled using three joints of 16-inch, 75 pound, Range 2 casing and a cutoff "pup" shoe joint designed to place the casing shoe just $34 \mathrm{~m}$ below the seafloor. A BHA comprised of drill collars and the casing running tool was spaced to place the 14-7/8 inch core bit at the casing shoe. The BHA was latched, first into the casing hanger and then into the re-entry cone, as bumper subs and more drill collars were added. The cone slings were then removed and the drill string was run toward the seafloor.

The first half of the pipe trip was smooth until the surge of vessel heave began to cause the casing/cone assembly to float. This caused the bumper subs above the cone to close partially and then open with hammer blows that jarred the entire vessel. This condition became worse as the trip progressed, apparently as the vertical elasticity of the long drill string contributed to the surge dynamics.

Hole 595B was spudded at 0524 hours, January 25. The casing was jetted in easily at a low circulation rate, and the mud skirt stopped at $5630 \mathrm{~m}$ below the derrick floor. An expendable $12 \mathrm{kHz}$ pinger attached to the skirt gave an altered pulse repetition rate at this time and then died, indicating contact with the seafloor. A shifting tool was then run on the sandline and the casing/cone assembly was released with difficulty.

The 14-7/8 inch hole was then drilled through most of the chert/clay interval (which began only two meters below the casing shoe), to $66 \mathrm{~m} \mathrm{BSF}$ before coring began. Hard drilling was encountered at $68 \mathrm{~m}$. Unfortunately the first core failed to recover the lowermost sediments, which had been poorly recovered in Hole 595A and only one chunk of the andesitic uppermost basement rock unit was retrieved--jammed into the core catcher. The second core took the large diameter hole to a total depth of $81.5 \mathrm{~m}$ BSF. with $1.8 \mathrm{~m}$ of core recovered. The bit was then pulled into the casing and run to total depth as a "wiper trip". Though no fill was "felt", a mud flush was circulated to ensure the cleanest possible hole for setting casing. A round trip of the drill string was then begun for the $11-3 / 4$ casing string.

\section{First Re-entry - Surface Casing}

Eight joints of Range Two $113 / 4$ inch, 54 pound, Grade K-55 casing were made up to the re-entry casing hanger and hung off in the rig's moonpool. A special BHA of drill pipe and bumper subs was then assembled below the threaded casing running tool, which was screwed into the casing hanger to engage the casing string. 
The drill string was run to place the casing shoe seven meters above the re-entry cone. When the logging sheaves and cable had been rigged, the re-entry sonar tool was attached. The tool began to malfunction during the rig floor check, which is the final test before lowering through the pipe. A backup sonar tool was then deployed, after a three quarter hour delay, and started down the drill pipe. This wireline trip was extended by an additional two hours when it was necessary to repair a leaking oil line on the transmission of the logging winch. Sonar scanning began at 1230 hours, January 27, and the re-entry cone was noted to be almost directly beneath the casing shoe. The casing was lowered an additional two meters, based on sonar range to the seafloor, and it was necessary only to wait a few more minutes before the drill string swung back over the cone. No ship movements were necessary, and a successful re-entry stab was made after only fourteen minutes of scanning.

The sonar was recovered and an additional stand of drill pipe was added to verify the re-entry. When the casing had been run into the hole, a bridge or hole fill was encountered about three meters above the setting depth of $74 \mathrm{~m}$ BSF, but the shoe was circulated into place without difficulty. The casing was landed in the re-entry cone and latching was checked by picking up on the string and noting the weight gain. The casing string was released by setting its weight onto the re-entry cone and then rotating the drill string to the right with the power sub.

Cementing lines were then rigged and 70 sacks of Class $\mathrm{G}$ neat cement were mixed to $15 \mathrm{lbs} / \mathrm{gal}$ slurry and pumped into the drill pipe. An aluminum latch-down top plug was launched and followed by an additional four barrels of slurry and ten barrels of fresh water. The cement was displaced with seawater until the plug landed at the shoe at 1740 hours, January 27 . The round trip for a coring BHA began immediately.

\section{Second Re-entry - $97 / 8^{\prime \prime}$ Core Bit}

The initial re-entry sonar tool again failed--this time after it had been run $1800 \mathrm{~m}$ down the pipe. After a $2 \frac{1}{2}$-hour delay, the backup unit was lowered to the bit and scanning began.

Vertical motion of the core bit, resulting from vessel heave in four-foot swells and from the amplification of a $3 \frac{1}{2}-m i l e$ drill string, was about three meters total amplitude. The surge effect occasionally caused the sonar tool to float up and then to slam down upon the lower support bearing during the scanning phase of the operation despite downward pressure applied with the rig pump. Though the re-entry cone was originally acquired at close range and the pipe had swung close over the cone on several occasions, a centered target had not been achieved after $3-3 / 4$ hours. At this point, the repeated pounding finally caused an electrical failure within the system and it was necessary to retrieve the sonar tool. On recovery, it was found that the lowermost portion of the logging cable had been damaged by the vertical cycling. About $100 \mathrm{~m}$ of line was cut off and the cable was reheaded. Scanning recommenced when a replacement sonar had been landed at the bit. A proper target presentation was finally seen after an additional $2 \frac{1}{4}$ hours 
of scanning and maneuvering, and the re-entry was made at 0623 hours, January 29.

When the sonar had been retrieved and the re-entry had been verified, an inner core barrel equipped with a center bit was pumped into place. The power sub was then deployed and used to drill out about eight meters of cement, the latch-down plug, and the casing shoe. The hole beneath the shoe was found to be open to total depth and the center bit was tripped for a standard inner core barrel.

Coring then resumed in hard basalt. The coring operation was still hazardous since there was not yet adequate support for the BHA and the risk of losing the entire installation to a failure in the BHA was great. A considerably increased drilling rate through the interval of about 105-115 m BSF was welcomed at first, but was soon found to be the result of intensely fractured basalt. The subsequent core encountered harder drilling, but hole cleaning problems had already begun--apparently originating in the fractured interval above. Two meters of hard fill accumulated during the sandline trip for Core No. 7.

Risks of continued penetration were assessed at this point. Chances of the drill string's becoming stuck, though only slight to moderate, were considered to be real. Since sufficient open hole had been made in basement rocks for the seismic instrument implantation, the scientific benefits of further penetration were foregone and coring was terminated at a total depth of $5753.8 \mathrm{~m}$ (123.8 m BSF).

A 40-barrel weighted mud flush was circulated to clear as much detritus from the hole as possible. The bit was pulled above the casing shoe and then run back to total depth finding the hole clean all the way. The string was then pulled with the well-worn core bit arriving on deck at 0445 hours, January 31 .

Accrued ton-miles dictated that the rig's drilling line be changed before the beginning of the next pipe trip. Time and working space considerations prompted the decision to move the rig off site and dispose of the line before beginning the Marine Seismic System (MSS) deployment. When the new line had been strung, the vessel was moved ten miles northeast of the site and the 1800-foot line was jettisoned from the drawworks drum. The ship then returned to within range of the positioning beacon, where a 45-minute drift test was conducted with the vessel dead in the water to aid in projecting the effect of local wind and current forces on the planned deployment of MSS ropes and cables. The ship then resumed positioning over the re-entry cone after a total operational hiatus of $7 \frac{1}{4}$ hours.

Third Re-entry - MSS Re-entry Sub

The lowermost (stinger) portion of the MSS re-entry assembly was moved to the rig floor and the electro-mechanical (EM) cable was keelhauled over the side and up through the moonpool. Assembly of the re-entry sub, together with testing and installation of the bottom instrument package (BIP), consumed 11 hours. About half of this time was due to minor, though time-consuming, 
mechanical problems.

A re-entry sonar tool was then attached to the sonar sinker bar and the entire assembly was lowered into the assembled re-entry sub for a final check of clearances and vertical spacing. About $20 \mathrm{~cm}$ was added to the sonar assembly to assure adequate protrusion of the transducer below the stinger. The step of rigging the logging sheaves and attaching the logging cable was deleted in the interest of saving time. This was regretted later.

The upper portion of the BHA was then made up and the pipe trip began. Problems with the electrical signals from the BIP began almost immediately, however, and the pipe trip was halted after only six stands had been run.

The malfunction turned out to be a serious one which was ultimately traced to damaged cable in the uppermost (cable isolator) section of the BIP. The mechanical damage had permitted water to enter the cable which, in turn, thwarted attempts to make an acceptable electrical termination. The cable isolator was modified to remove the cause of the cable damage and the EM cable was completely reheaded, both electrically and mechanically.

When the equipment was again in readiness after a delay of $2 \frac{1}{2}$ days, the weather had deteriorated to conditions that were marginal for handling the BIP and the drill string and prohibitive for re-entry operations. An additional delay of 17 hours ensued while wind and swell conditions abated.

Trip preparations went more smoothly the second time around and it was established that a coordinated pipe and cable trip could be made at about half the rate of a normal pipe trip. A routine was quickly developed for orienting the pipe and feeding out cable, but interruptions for repairs to the DARPA winch totaled five hours. The stinger reached re-entry depth at 0830 hours, February 5.

The logging sheaves were rigged and the sonar/sinker bar assembly was made up without undue difficulty. The sonar tool then failed almost immmediately on the rig floor test. The electronics package was replaced without resolving the problem and it was necessary to dismantle the entire assembly. It was found that conductors had been twisted off in the logging cable head during final attachment to the pipe sinker bars. The cable was reheaded and the long apparatus was reassembled with care taken to protect the cable head. The sonar functioned normally as it started down the pipe, but was not receiving at the $1500 \mathrm{~m}$ check. On retrieval, it was found that more wires had been broken at the cable head. While the cable was being reheaded, the spring centralizer of the sinker bar assembly was modified to permit free rotation and detorquing of the logging cable.

Sonar function was normal on the third lowering, after a nine-hour delay, and the sonar seated properly in the re-entry sub. After 76 minutes of scanning and maneuvering, a smooth and gentle re-entry was made at 2128 hours. The drill string was lowered cautiously for the final few meters to seat the stinger and to actuate two bumper subs. 
The bumper subs were used to decouple vessel heave motion while the sonar tool was recovered and while a Baker equalizing valve was pumped into place at the top of the re-entry sub assembly. The rig unud pump was then used to pressure the pipe to 2500 psi. This actuated the hydraulic system of the BIP carriage to shear the restraining pins and move the BIP into release position above the bore of the stinger. A sudden weight gain was noted on the EM cable as the BIP was released into the stinger.

The BIP was lowered through the upper (cased) hole and into open hole. By cable measurement, it came to rest about 20 meters short of total depth. This could not be verified because of the great cable length and doubts as to the accuracy of the winch depthometer. All parties were satisfied that the BIP had been emplaced in open hole in igneous rock, and drill string recovery was initiated.

The vessel was offset 60 meters southeast (up current) and the pipe was pressured to about 3700 psi with the cementing pump to open the gate in the stinger for release of the cable. The re-entry sub was then pulled clear of the re-entry cone. The cable weight indicator showed no effect of the pipe movement--an indication that separation of cable and pipe had been accomplished. The positioning offset was increased to $150 \mathrm{~m}$ in the same direction, and four "wet" stands of drill pipe were pulled before the equalizing valve was recovered with the sandline and overshot. The ensuing pipe trip was routine until the re-entry sub assembly came into view. It was then discovered that the stinger was missing. All ten attachment bolts remained hanging in the flange at the base of the BIP carriage. All the bolts showed virtually identical tensional failures in the threaded portion.

\section{Refraction Experiment and IRR Deployment}

CHALLENGER then held position, recording seismic refraction shots through the BIP until MELVILLE completed the shot line in progress. The offsets were then changed to place the vessel about $75 \mathrm{~m}$ south of the re-entry cone, where a transponder for an acoustic transponder navigation (ATNAV) system was launched. The EM cable was then slowly paid out as the ship was offset to a position about $1420 \mathrm{~m}$ bearing $310^{\circ}$ True bearing from the cone. About $850 \mathrm{~m}$ of EM cable remained on the winch at this time.

CHALLENGER remained at this station in a "listening" mode for four additional days. The BIP was constantly monitored with shipboard recording equipment connected directly to the EM cable. Periods of coordinated refraction shooting by MELVILLE were alternated with long intervals of passive recording or teleseismic events (earthquakes). A small boat rendezvous was made for a brief personnel exchange between the two ships for planning purposes. A $13.5 \mathrm{kHz}$ positioning beacon was sent to MELVILLE and was subsequently launched about $1500 \mathrm{~m}$ northwest of CHALLENGER'S position on the afternoon of February 9.

At 1300 hours, February 10, the initial steps of the instrument recovery and reinstallation (IRR) system deployment were begun. The vessel was offset an additional $280 \mathrm{~m}$ west (to the maximum north and west offsets possible) 
while the EM cable was paid out to the safe minimum on the winch drum. The winch was then modified for the IRR phase, the bottom processing package (BPP) was moved into position on the main deck and the EM Cable tension was transferred from the winch to the ship's structure by means of a cable grip.

The EM cable was disconnected from the shipboard recording instruments early on February 11 and made up to the BPP for final electronic checks. It was found that some of the vital BIP functions could not be recorded or interfaced with the BPP. Troubleshooting placed the malfunction in the interfacing circuitry within the BIP. Nothing could be done to remedy the situation short of recovering the BIP, and this was not considered to be a viable alternative for several reasons. After considerable discussion, the decision was made to continue the deployment with the system not fully operational.

With only light breezes and very little swell, the final, critical phases of the deployment were undertaken. The BPP, which weighs over four tons in air, was lifted over the side by the ship's crane. The precarious operations of first transferring the weight of the EM cable to the BPP and then the entire weight to the IRR isolation cable on the winch were accomplished with only minor difficulties. The BPP was lowered into the water at 1400 hours, February 11.

After only a few minutes of paying out the $1-1 / 8^{\prime \prime}$ steel isolation cable, it was necessary to shut down for three hours for modifications and repairs to the winch. During this time there was some interference of the state-of-health acoustic telemetering beacon with the ship's dynamic positioning system, as the BPP was hanging close beneath the vessel.

When the $450 \mathrm{~m}$ isolation cable had been paid out, a controlled vessel drift to the northwest was resumed as the 1-3/4" power braid riser line was deployed. Within minutes, CHALLENGER was able to switch to automatic positioning and controlled offsetting on the preplaced $13.5 \mathrm{kHz}$ beacon. The BPP was landed on the seafloor when the vessel had passed over the beacon and moved about $500 \mathrm{~m}$ to the northwest. Again, the winch depthometer reading was considerably short as compared with the concurrent readings of the ship's PDR and the ATNAV transponder attached to the BPP.

The riser leg payout continued with frequent stops for winch repairs. Maximum north and west positioning offsets were reached, and a controlled drift continued in the semi-automatic mode. The deployment was complicated somewhat when the riser line was found to be nearly one kilometer longer than specified. Over seven kilometers of the heavy braid had been paid out when the beginning of the 7/8" grapnel leg braid was reached and the "A" crown buoy group was attached. As payout of the three kilometer grapnel leg began, the vessel moved out of range of the positioning beacon and rate of drift was controlled in semi-automatic by monitoring tension on the line. When the " $B$ " crown buoys at the anchor end of the grapnel leg had been launched, a $16 \mathrm{kHz}$ beacon was dropped to aid in fixing the position of the IRR acoustic release and in deploying the anchor leg. The beacon failed within minutes after launch and was replaced by a $13.5 \mathrm{kHz}$ unit. The acoustic release/ATNAV transponder link assembly was then put over and deployment of the three-kilometer anchor leg began while the beacon was falling. Unfortunately the beacon signal became 
weakened, distorted and unusable approximately one hour after launch--probably on landing at the seafloor. The teamwork of pilothouse and winch personnel, together with excellent weather, allowed the deployment to be completed without loss of control. The end of the anchor line was removed from the winch and attached to the anchor. When the slow, controlled drift of the vessel had produced the proper tension in the IRR, the anchor was released at 0858 hours, February 12 .

MELVILLE had been standing by to observe and report submergence of the crown buoys before departing for her scheduled port call in Tahiti. After a tension charged wait around the radio, CHALLENGER personnel heard the report that the final "B" crown buoy had disappeared at 0948 hours. As MELVILLE steamed away, CHALLENGER returned to the " $\mathrm{B}$ " crown buoy area and began a search while interrogating the ATNAV transponder. The minimum range to the transponder recorded during the two-hour search was about $900 \mathrm{~m}$, verifying the success of the deployment.

The vessel then returned to the area of the BPP for the final task of placing ATNAV transducers on either side of the BPP to be used in its recovery by MELVILLE. This proved to be much more difficult and time-consuming than had been anticipated. The ATNAV transponder on the BPP was to be used as a reference in positioning to launch the other transponders, but thrusters and other ship's noise made effective communication with the transponder impossible in the $5600 \mathrm{~m}$ water depth. Using semi-automatic DPS positioning on a distant, intermittent beacon, transponders were finally emplaced in the approximate positions of $2750 \mathrm{~m}$ from the BPP on True bearings of $017^{\circ}$ and $251^{\circ}$. At 1700 hours, February 12, DARPA operations for Leg 91 had been successfully completed.

Hole 596

An additional hole had been planned at Site 595 as an attempt to improve upon the poor recovery of the lower sediment section in the earlier holes. Discussion with geophysicists on board MELVILLE disclosed they were concerned about interference of drilling noise with the recording of teleseismic events by their nearby ocean bottom seismometers (OBS). A drill site was selected about $7 \frac{1}{2}$ miles west-southwest of Hole $595 \mathrm{~B}$ on the basis of earlier profiling by MELVILLE. Sediment thickness appeared to be at least as great as at Site 595. CHALLENGER moved to the new area using only the PDR's for profiling. After crossing the location, an additional $1 \frac{1}{4}$ hours were spent profiling to verify optimum sediment thickness. The positioning beacon was launched at 1909 hours, February 12.

The PDR reading was $5711 \mathrm{~m}$, and the pipe was lowered to $5706.4 \mathrm{~m}$ for a seafloor HPC core attempt. The VLHPC assembly was deployed and run to position at the bit, but attempts to pressure the drill pipe and actuate the corer were unsuccessful. It was speculated that the corer's shear pins had failed on the trip down the pipe as a result of swell-induced vessel motion. This possibility was eliminated when the corer was recovered unstroked and with the shear pins intact. A second HPC attempt was made at the same depth with the same initial results. The corer was picked up and seated with some force, resulting in apparently normal pressuring and actuation of the VLHPC. The corer was then 
found to be stuck in the BHA. Overshot release pins were sheared on the initial attempt and on a second wireline retrieval try.

A round trip of the pipe was necessary to dislodge the HPC assembly, resulting in the loss of 26-hours of precious remaining operating time. On recovery the corer was found to be fully extended through the bit, with the core barrel bent but containing a $5.4 \mathrm{~m}$ core. The top of the core barrel was tightly jammed in the bit throat by parts of the broken float valve flapper.

The damaged components were removed, the core was removed to the laboratory, the bit subassembly was made up (without a valve flapper), and the bit was inspected and reinstalled. The drill string was then run back to the seafloor and piston coring resumed at the depth reached by the initial core.

Four additional piston cores were taken in red to dark brown clay before refusal depth was reached as the first thin chert strata were encountered. Core quality was good despite low and inconsistent actuation pressures and considerable vessel heave. The entire contents of Core No. 4 were lost because the sticky clay plastered both core catchers open.

At 40-meters BSF, the VLHPC was retired in favor of the Extended Core Barrel (XCB) for coring the chert/clay sequence and into basement. Three cores in the sediment interval produced disappointing results roughly equivalent to the performance of the standard rotary coring system at Site 595 . Basement was encountered at about $71 \mathrm{~m} \mathrm{BSF}$, about two meters into Core No. 9. Although the penetration rate had been an acceptable two meters per hour, coring was terminated after five meters of basement penetration because time was running out and recovery of basal sediments still had top priority. On recovery, the XCB hard formation cutter shoe was found to be tightly jammed with basalt, with the cutting structure totally destroyed.

Hole 596A

Drilling parameters had indicated that the lowermost four to five meters of sediment were free of hard strata. Since this was considered to represent the most important single core of the site, a last-ditch effort was made to recover at least some of the basal sediment.

The core bit was pulled above the seafloor and a new hole was spudded immediately at 0853 hours, February 15. The hole was drilled to $66 \mathrm{~m} \mathrm{BSF}$ with no core barrel in place and with the acknowledged risk of obstructing the open core throat with broken chert. The cherty section drilled much more easily than had been anticipated, and the drilling was stopped as soon as the bit had broken through the lowermost hard streak, based on the drilling of Hole 596 . The VLHPC was lowered to the bit and pressured past the normal actuation point. The pressure failed to bleed off, indicating incomplete stroke of the corer, and it was inferred that the core barrel had been stopped by the basement rock. The corer was brought back to the rig floor and the core barrel, containing nearly $8 \frac{1}{2} \mathrm{~m}$ of sediment, was laid down. 
When the core had been split (some time later), it was found that only the upper four meters were relatively undisturbed and that the remainder exhibited flow-in type disturbance. On the basis of this evidence, the lack of damage to the core catcher shoe and the record of the previous hole, it was deduced that the corer had been stopped by the stiff clay within one meter of the basement contact.

Hole 596B

Operations had proceeded so quickly in Hole 596A that time for one more core was squeezed into the schedule. The bit again was pulled momentarily above the seafloor and Hole 596B was spudded at 1145 hours. The soft clay was washed away to the depth of $24.7 \mathrm{~m} \mathrm{BSF}$. The piston corer was deployed and the interval of Core No. 4 of Hole 596 was recored. A core of over nine meters was recovered, and coring operations were complete for Leg 91.

The final pipe trip was uneventful and was concluded with a magnaflux inspection of the BHA connections and the power sub/swivel assembly. The rig floor was then secured and CHALLENGER departed for Tahiti at 0252 hours, February 16.

Site 596 to Papeete

The transit of just over 1000 miles into Tahiti was uneventful except that the track passed through the Cook Island group. Early risers were treated to a view of land as CHALLENGER passed about four miles from the small island of Atiu on the morning of February 18. On February 19, the ship profiled across two previously uncharted guyots that stood only 400-600 m below the sea surface.

Consistent winds from off the starboard bow and moderate to heavy swells held the average speed to 9.3 knots for the distance. Leg 91 came to its official end at 1448 hours, February 20, when the first mooring line was put over at Berth L-1 in Papeete Harbor, Tahiti.

\section{Drilling and Coring Equipment}

The basic DSDP drilling/coring BHA was used at Holes 595, 595A and 595B (second bit). This consisted of a bit, bit sub, one $8 \frac{1}{4} "$ drill collar fitted with top and head subs for outer core barrel use, three $8 \frac{1}{4} "$ drill collars, one Baash-Ross five foot-stroke bumper sub, three 8 $\frac{1}{4} "$ drill collars, two bumper

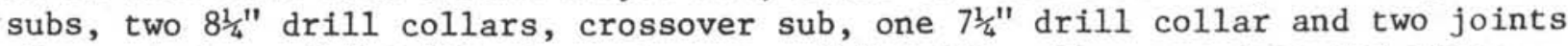

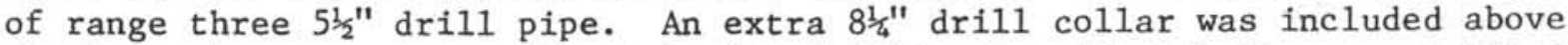
the lower bumper sub to add weight for drilling basalt with the second bit in Hole 595B. Alteration of the BHA was necessary for running the re-entry cone and 16" casing assembly at Hole 595B. That configuration was: bit, bit sub, outer core barrel assembly, two 3 -foot $8 \frac{1}{4} "$ drill collar spacers, two $8 \frac{1}{4} "$ drill collars, casing running tool assembly, two bumper subs, two $3 \frac{1}{4} " \mathrm{drill}$

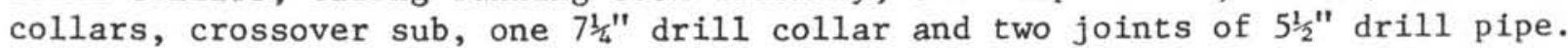
At Site 596 (all holes), the BHA was designed to accommodate both VLHPC and 
XCB systems and consisted of a special bit, bit sub, two $8 \frac{1}{4} "$ drill collars, two 3-foot $8 \frac{1}{4} "$ spacers, top sub, head sub, three $8 \frac{1}{4} "$ drill collars, two bumper subs, two $8 \frac{1}{4} "$ drill collars, crossover sub, one $7 \frac{1}{4} "$ drill collar and two joints of $5 \frac{1}{2} "$ drill pipe.

Five jaints of undergauge drill pipe were removed from the string. They have been downgraded and labeled Grade Two along with one joint designated suspect by the Tuboscope inspection in Wellington.

The only serious malfunction of coring equipment was the float valve failure at Hole 596. The failed flapper was a special padded unit designed to protect the polycrystalline diamonds of the hard formation XCB shoe. Part of the steel thickness of the flapper had been sacrificed for the addition of soft plastic material. The plexiglass rod used to hold the valve open during the trip apparently became dislodged or broken during the initial pipe trip and the pipe did not fill with water. The abnormally slow increase in string weight went unnoticed until after the flapper had been forced upward past its seat and the string weight had suddenly increased by about 100,000 pounds (based on the drilling recorder chart).

Overshot shear pins failed unexpectedly on the retrieval of three of the 31 cores attempted, with about one hour of lost time on each occasion. Pins that were sheared during attempts to retrieve the stuck piston corer performed normally. Two of the unexpected failures were at Hole 596 with the VLHPC and $\mathrm{XCB}$ corers. The combination of heavy coring assemblies and vertical surge from vessel heave may simply have been too much for the pins.

The heave compensator system remained out of service during Leg 91 despite concerted efforts to prepare it for the anticipated operations. The air pressure limitations had been upgraded and the air banks had been charged at the beginning of the voyage to adequate pressures for the anticipated drill string loads. However only one hydraulic pump could be operated due to the lack of a solenoid which had not been received at sailing time, and it was found that the hydraulic side of the operation could not be sustained wi.th one pump. The ship's engineers made use of the extended inoperative period to perform a comprehensive overhaul of the high pressure air compressing system.

\section{Core Bits}

In general, core bit performance was as good as could be expected considering the hostile drilling environment and the lack of heave compensation. No holes were lost or terminated early because of bit failure but, with the exception of the $14-7 / 8^{\prime \prime}$ bit at Hole 595B, all bits were recovered in moderate to advanced stages of bearing failure.

The most significant bit problem was the loss of a complete cutter leg assembly from the special 11-7/8" XCB/HPC bit used at Site 596. The welds holding the top of the leg into its pocket into the bit body had broken and the cutter had disappeared without a trace. The bit showed no particular signs of drilling on junk, and it is considered probable that the cutter leg was pushed 
into the side of the hole soon after separation in the sticky clay of the lower portion of Hole 596. Although the bit is the first of a new configuration, the fault appears to be one of fabrication, rather than design.

$\underline{\text { Special Tools }}$

The variable length hydraulic piston corer was used for only eight cores on Leg 91 (all in the $9.5 \mathrm{~m}$ configuration). These cores accounted for virtually all the cored sediment interval that was not either highly disturbed or poorly recovered, and included the basal sediment core of Hole 596A. This material is believed to be Jurassic--certainly the oldest sediment cored by HPC methods and possibly the oldest sediment ever cored over oceanic crust.

The moderate swell conditions and long drill string produced considerable vertical pipe motion. This is blamed for some moderate core disturbance and for the low and inconsistent actuation pressures observed. The shear pins, which also support the weight of the coring assembly, were apparently being partially sheared by heavy surge loading during the wireline trip to the bit.

The Extended Core Barrel (XСB) System was utilized for the four deepest cores in Hole 596. After the highly encouraging results with the XCB system on Leg 90 , it was hoped that a tool was finally available that would core and recover interbedded hard and soft lithologies. However, results in the clay/ chert sequence at Site 596 were no better than with the standard rotary coring setup at Site 595. The first core barrel was nearly full of intensely disturbed soupy. clay with a few chert fragments, while the next two cores contained only a few centimeters each of clay and broken chert. The fourth core recovered a few centimeters of clay before basement was encountered. Only enough basalt to fill the cutting shoe/core catcher assembly was cored before the core jammed the assembly. On recovery the cutting structure of the shoe was found to have been destroyed, and the dryness of the material in the core catcher indicated that inadequate fluid circulation may have been a factor. Assessment of the XCB performance is complicated by the fact that one of the bit's four cutter legs was apparently lost in the hole at some time during the $\mathrm{XCB}$ coring period.

\section{$\underline{\text { Re-entry }}$}

The three re-entries into Hole 595B were the deepest ever made. Hardware problems were few and the cone and casing systems were installed according to design. On recovery of the 16" casing running tool, the load-bearing corners of the release paddles were found to be severely deformed. The damage was attributed to the severe pounding noted during the pipe trip as vessel heave caused the re-entry cone to "float" and work the bumper subs. This was caused primarily by the brevity of the casing string, which placed relatively little weight below the bumper subs, and was aggravated by the elasticity of the very long drill string. A design review of the paddles has been in progress and has been expanded to consider this latest phenomenon. 
A variety of electrical and electronic failures were experienced in the course of the three Leg 91 re-entries. The first sonar tool failed on the rig floor check due to a faulty transducer driver transistor. This re-entry was successfully accomplished with a backup sonar. The second re-entry attempt was aborted after a sonar malfunction on the 1800-meter check. This was later traced to a broken wire in the transducer. The backup sonar functioned normally for 3-3/4 hours before the logging cable was damaged by vertical pipe motion effects. Another backup tool was used to make the re-entry after the cable had been reheaded. Both sonar tools suffered rather severe internal structural damage as a result of the pounding, but remained fully functional except that one $45^{\circ}$ transducer was disabled. On the third re-entry, operations were delayed nine hours because of two torsional failures of logging cable conductors. This was probably the final operational misfortune attributable to the late lamented string of defective drill pipe. Because of the undergauge drill pipe, the sonar spacing and adapter assembly for the MSS re-entry sub had been redesigned since the successful Leg 78B deployment. The sonar is now suspended from the top of the re-entry sub by a long length of two-inch pipe. The arrangement is difficult to handle and assemble, and the first cable head damage occurred as the sonar was screwed into the pipe adapter after the cable head had been attached. More care was taken with this step after the cable had been reheaded, but a similar failure manifested itself after the tool had been started down the pipe. The second failure may have been a repeat of the first or may have been the result of a buildup of torque in the cable as the tool was lowered. During the second cable rehead, a spring centralizer on the spacer pipe was modified to permit free rotation and retorquing of the cable. No further malfunctions occurred.

Dynamic Positioning

The vessel's Dynamic Positioning System (DPS) was essentially trouble-free for the entire voyage following some minor remedial work during the Wellington port call. On one occasion during Hole 595B cooupancy, a pattern of longperiod oscillatory excursions (of up to 60 meters in $1 \frac{1}{2}$ hours) developed. This was diagnosed by the GMI electronics technician as servo instability resulting from excessively high gain settings. The gains were reduced and the oscillations gradually disappeared. No vertical reference gyro failures occurred, but one noisy unit was replaced.

Two of the six ORE positioning beacons launched were defective and a third unit failed on a predeployment "soak" test. The signal of a $16 \mathrm{kHz}$ beacon, dropped during the IRR deployment, began to "double pulse" and was lost within minutes after launch. A backup $13.5 \mathrm{kHz}$ unit produced a normal signal for about an hour while falling to the seafloor, but then the pulse became severely attenuated in amplitude and developed a "tail". A second $16 \mathrm{kHz}$ beacon failed when it was checked by lowering it over the side. It will be returned to the manufacturer.

During the DARPA operations, a number of acoustic devices were employed for data telemetering, navigation, bortom-finding and other purposes. In general, the effectiveness of these instruments was greatly diminished or completely voided because the signals interfered with the DPS or because they could not 
be heard. The attenuation caused by the great water depth, together with the ambient noise of CHALLENGER'S machinery and six propellers of ten resulted in an unacceptably low signal-to-noise ratio. It appears that planning for similar deep water operations from noisy platforms should not rely too heavily upon acoustic transmissions.

\section{Engineering}

The ship's power generating and propulsion equipment was virtually free of problems having operational significance. Early in the voyage, fuel was detected leaking into the bilge "rose box" in the gymnasium area from fuel tank N6F. Small leaks, resulting from metal wastage, were found in the floor of the rose box. It was necessary to pump the contents into other tanks, gas-free the tank, and weld a doubler plate over the leaking plate. The tank was then pressure tested with satisfactory results. More permanent repairs will be effected during the Papeete port call. A faulty sealed relay $(7 \mathrm{H} 3)$ was replaced in the propulsion switchboard during Hole 595B operations when it was found that the port shaft would not answer bells from the pilothouse.

As on many past occasions, the special contributions of the ship's Machinist/ Oiler merit recognition. A considerable amount of machine work for repair and modification of parts and fabrication of spare parts was done in support of the DARPA operation. Machining was done on components of the Scripps seismic profiling system in addition to the normal shipboard workload.

\section{Weather and Currents}

No severe weather was experienced during Leg 91, but severe weather is not required for operations to be affected. The operating area was under the influence of prevailing southeasterly and easterly winds and northwesterly current. It also frequently received moderately large swells from the south or southwest, and multiple swells were sometimes experienced. Vessel motion and/or positioning conditions reached marginal levels on three or four occasions for as long as three days when wind and swell(s) were out of alignment. The single 17-hour weather delay occurred at a time when good conditions were required for the MSS re-entry. Operating limits for coring would have been approached, but probably not exceeded on this occasion.

Current meter data were available (for the first time in DSDP history) from MELVILLE and were useful in planning the MSS deployment. Currents generally were toward the northwest with a velocity of approximately $\frac{1}{2}$ knot. The current meter indicated that the velocity decreased with depth to nil at about $700 \mathrm{~m}$. Current forces occasionally put drill pipe and casing strings under considerably stress at the moonpool restraint. They also became a factor in positioning the vessel when they were misaligned with wind and/or swell.

Daily weather advisory messages were received from U. S. Navy Fleet Weather Center, Pearl Harbor by special request of NORDA. Several facsimile maps, mostly from New Zealand, were copied daily and photos from the orbiting NOAA -7 satellite were received. 
Swell-induced vertical pipe motion was an important operational factor. It was responsible for mechanical damage to the casing running tool, the logging cable and sonar tools; it decreased the bearing life of core bits and it added cycles to the fatigue life of the drill pipe.

\section{Personnel}

The successful operations of Leg 91 were a team effort involving personnel from GMDC, GMDI, NORDA, DSDP (scientific and technical groups), Gould DED, Teledyne Geotech, and SIO. If the acronyms are confusing, consider that at least one representative of each entity was a supervisor. Friction was minimal, however, despite numerous oppportunities for contention. The professionalism of CHALLENGER'S crew and of the various visiting personnel was evident in the selfless cooperation displayed in pursuit of a common goal Morale remained generally high for the duration of the relatively short cruise, and there were no serious injuries or illnesses.

Glen N. Foss

Cruise Operations Manager

Deep Sea Drilling Project 
Swe11-induced vertical pipe motion was an important operational factor. It was responsible for mechanical damage to the casing running tool, the logging cable and sonar tools; it decreased the bearing life of core bits and it added cycles to the fatigue life of the drill pipe.

\section{Personne1}

The successful operations of Leg 91 were a team effort involving personnel. from GMDC, GMDI, NORDA, DSDP (scientific and technical groups), Gould DED, Teledyne Geotech, and SIO. If the acronyms are confusing, consider that at least one representative of each entity was a supervisor. Friction was minimal, however, despite numerous oppportunities for contention. The professionalism of CHALLENGER'S crew and of the various visiting personnel was evident in the selfless cooperation displayed in pursuit of a common goal Morale remained generally high for the duration of the relatively short cruise, and there were no serious injuries or illnesses.

Glen N. Foss

Cruise Operations Manager

Deep Sea Drilling Project 
INTERNATIONAL PHASE OF OCEAN DRILLING

DEEP SEA DRILLING PROJECT

OPERATIONS RESUME

LEG 91

Total Days (January 9 - February 20, 1983) . . . . . . . .

43. 17

Total Days in Port . . . . . . . . . . . . . . . . . . . .

6.94

Total Days Cruising Including Site Survey . . . . . . . . . .

10.91

Total Days on Site......................

25.32

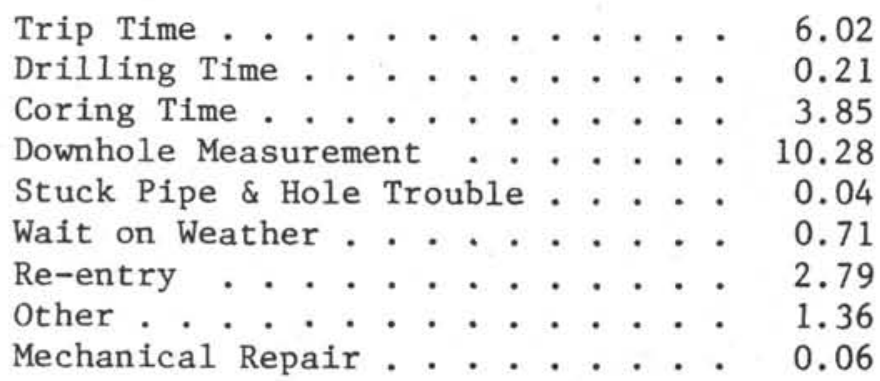

Total Distance Traveled Including Survey (nautical miles). . . .

2521.0

Average Speed (Knots) . . . . . . . . . . . . . . .

Number of Sites ........ . . . . . . . . . . . . . . . .

Number of Holes Drilled . . . . . . . . . . . . . . . .

2

Number of Cores Attempted . . . . . . . . . . . . . . . .

Number of Cores With Recovery .. . . . . . . . . . . . . 30

Total Meters Cored . . . . . . . . . . . . . . . . . . . . . 236.6

Total Meters Recovered . . . . . . . . . . . . . . . . . . . . 110.5

Percent Becovery... . . . . . . . . . . . . . . . . 57.6

Total Meters Drilled . . . . . . . . . . . . . . . . . 188.6

Total Meters of Penetration . . . . . . . . . . . . . 425.2

Percent of Penetration Cored ....... . . . . . . . . . . 46.8

Maximum Penetration (meters) ............... 123.8

Minimum Penetration (meters) . . . . . . . . . . . . 32.5

Maximum Water Depth (meters) . . . . . . . . . . . 5710.5

Minimum Water Depth (meters) . . . . . . . . . . . . 5613.5 
INTERNATIONAL PHASE OF OCEAN DRILLING

DEEP SEA DRILLING PROJECT

TOTAL TIME DISTRIBUTION

LEG 91

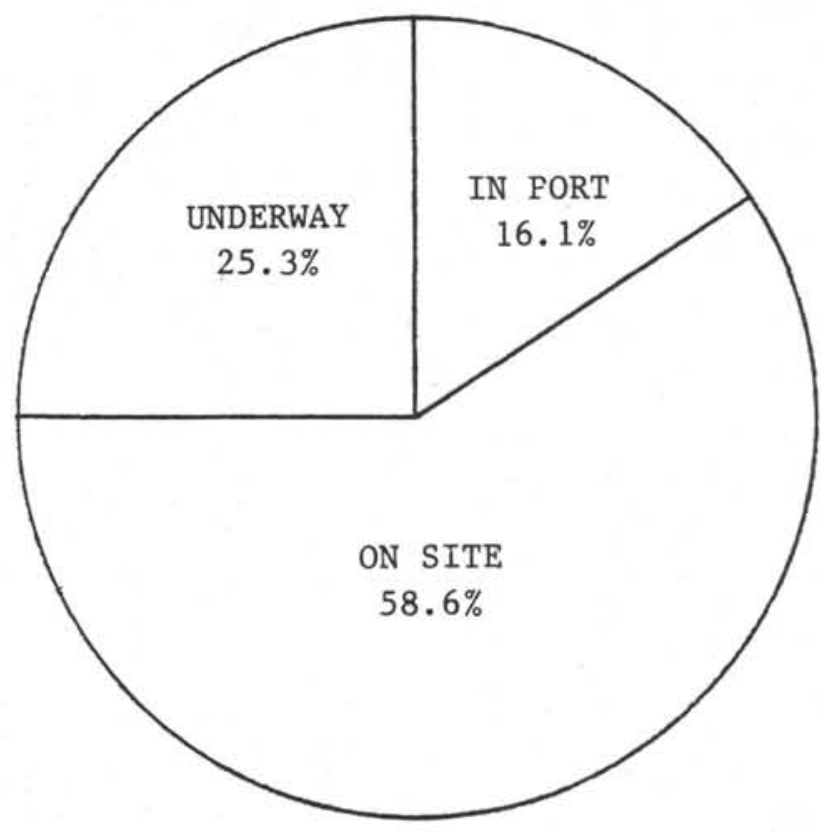

ON SITE TIME BREAKDOWN

LEG 91

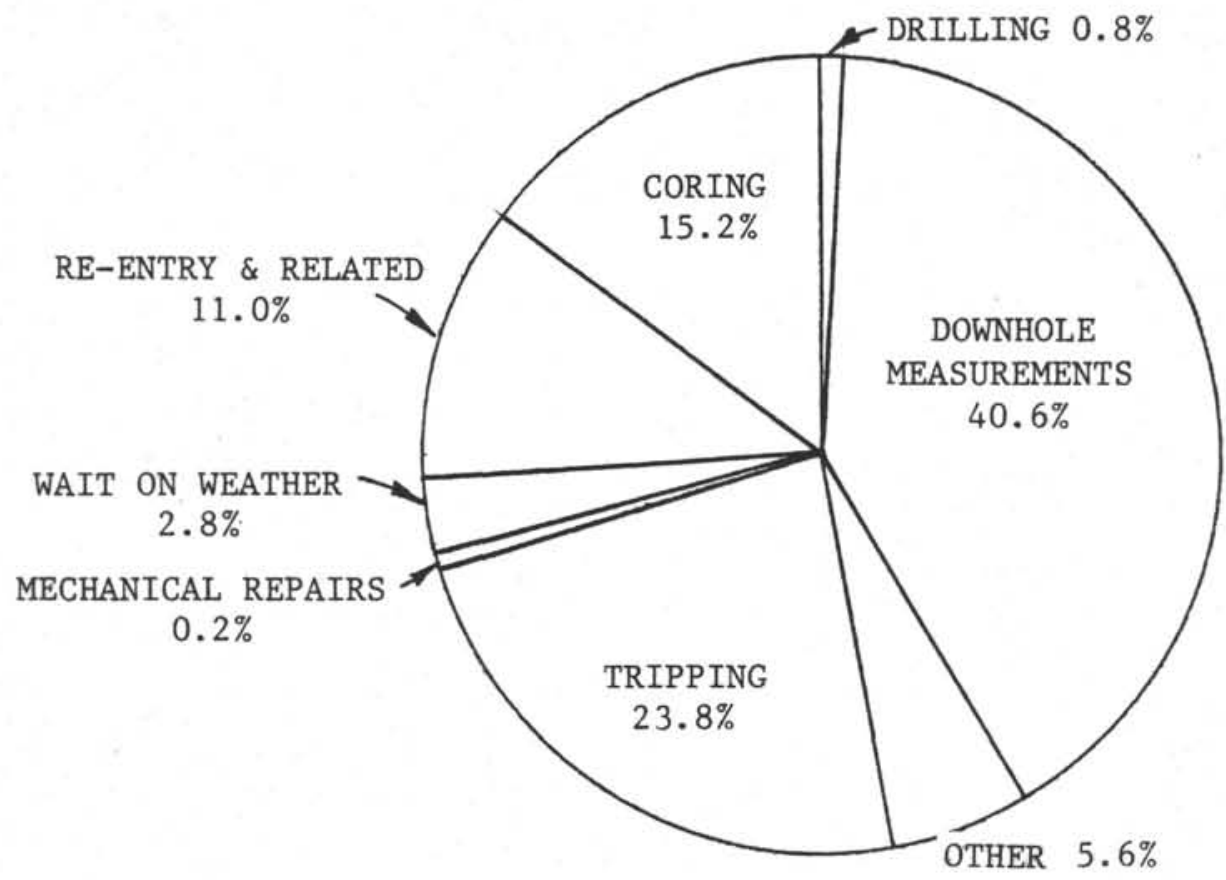


DEEP SEA DRILLING PROJECT

TIME DISTRIBUTION (HOURS)

$\angle E G-{ }^{\prime} 1$

\begin{tabular}{|c|c|c|c|c|c|c|c|c|c|c|c|c|c|c|}
\hline Da.te & \begin{tabular}{|l|} 
site \\
$1 / 0$.
\end{tabular} & cruise & Trips & Drill & Core & \begin{tabular}{|l|} 
Stuck \\
Ploe \\
\end{tabular} & w.0.15 & $\begin{array}{l}\text { Position } \\
\text { Shis }\end{array}$ & $\begin{array}{l}\text { Mech. } \\
\text { Reparr }\end{array}$ & $\begin{array}{l}\text { Port } \\
\text { Time }\end{array}$ & $\begin{array}{l}\text { He- } \\
\text { Eniry }\end{array}$ & ortier & $\begin{array}{l}\text { Toral } \\
\text { Tims }\end{array}$ & Pemarks \\
\hline \begin{tabular}{|l|}
$01 / 09 / 83$ \\
$01 / 21 / 83$
\end{tabular} & & 151.5 & & & & & & & & 166.5 & & 0.3 & 318.3 & to Site .595 \\
\hline & & & & & & & & & & & & & & \\
\hline $\begin{array}{l}0 \\
.01 / 22 / 73 \\
\end{array}$ & 595 & & 11.8 & & 1.1 & & & & & & 2.2 & 1.9 & 17.0 & $\begin{array}{l}\text { First expI. } \\
\text { hole. }\end{array}$ \\
\hline $01 / 22183$ & & & & & & & & & & & & & & \\
\hline $\begin{array}{l}01 / 24 / 83 \\
\end{array}$ & 595A & & 10.8. & & 26.9 & & & 0.3 & 0.4 & & 3.5 & 5.8 & & $\begin{array}{l}\text { Second expl. } \\
\text { hole. }\end{array}$ \\
\hline & & & & & & & & & & & & & & \\
\hline $02 / 12 / 83$ & 595E & & 82.3 & 3.8 & 40.4 & 1.0 & 17.0 & 246.5 & 1.0 & & 61.3 & 10.7 & 464.0 & DARPA Hole. \\
\hline & & & & & & & & & & & & & & \\
\hline No1/12/83 & & 1.9 & & & & & & & & & & 0.3 & 2.2 & $\begin{array}{l}\text { site } \\
\text { sites }\end{array}$ \\
\hline & & & & & & & & & & & & & & \\
\hline $\begin{array}{l}02 / 15 / 83 \\
02 / 5\end{array}$ & 596 & & 31.1 & & 21.2 & & & & & & & 9.3 & 61.5 & $\mathrm{HPC} / \mathrm{SCB}$ : Hole \\
\hline & & & & & & & & & & & & & & \\
\hline $02 / 15 / 83$ & $596 \mathrm{~A}$ & & 0.4 & 0.9 & 1.6 & & & & & & & & 2.9 & sedinient. \\
\hline & & & & & & & & & & & & & & \\
\hline $\begin{array}{l}02215 / 13 \\
02 / 16 / 83\end{array}$ & $596 \mathrm{~B}$ & & 8.8 & 0.2 & 1.3 & & & & & & & 4.9. & 15.2 & $\begin{array}{l}\text { Recore lost } \\
\text { HeC int. }\end{array}$ \\
\hline & & & & & & & & & & & & & & \\
\hline $\begin{array}{l}02 / 16 / 33 \\
02 / 20 / 83\end{array}$ & & 107.9 & & & & & & & & & & & 107.9 & $\begin{array}{l}\text { Site 596 to } \\
\text { Papeate. }\end{array}$ \\
\hline & & & & & & & & & & & & & & \\
\hline TOTALS & & 261.3 & 144.5 & 4.9 & 92.5 & 1.0 & 17.0 & 246.8 & 1.4 & 166.5 & 67.0 & 33.2 & 1036.1 & rOTALS \\
\hline & & & & & & & & & & & & & & \\
\hline
\end{tabular}


INTERNATIONAL PHASE OF OCEAN DRILLING

DEEP SEA DRILLING PROJECT

$$
\text { SITE SUMAARY }
$$

LEG 91

\begin{tabular}{|c|c|c|c|c|c|c|c|c|c|c|c|c|c|c|}
\hline Hole & Latitude & Long1tude & $\begin{array}{l}\text { Water } \\
\text { Depth } \\
\text { Meters }\end{array}$ & $\begin{array}{l}\text { Number } \\
\text { of } \\
\text { Cores }\end{array}$ & $\begin{array}{l}\text { Cores } \\
\text { With } \\
\text { Recovery }\end{array}$ & $\begin{array}{l}\text { Percent of } \\
\text { Cores hith } \\
\text { Recovery }\end{array}$ & $\begin{array}{l}\text { Meters } \\
\text { Cored }\end{array}$ & $\begin{array}{c}\text { Meters } \\
\text { Recovered }\end{array}$ & $\begin{array}{c}\text { Percent } \\
\text { Recovered }\end{array}$ & $\begin{array}{l}\text { Meters } \\
\text { Drilled }\end{array}$ & $\begin{array}{l}\text { Total } \\
\text { Penet } \\
\text { Meters }\end{array}$ & $\begin{array}{l}\text { Avg. } \\
\text { Rate } \\
\text { Penet }\end{array}$ & $\begin{array}{l}\text { T1ura } \\
\text { On } \\
\text { Hole }\end{array}$ & $\begin{array}{l}\text { Time } \\
\text { On } \\
\text { Site }\end{array}$ \\
\hline \multirow[t]{2}{*}{$\begin{array}{l}595 \\
595 \mathrm{~A} \\
595 \mathrm{~B}\end{array}$} & $\begin{array}{l}23^{\circ} 49.4^{\prime} \mathrm{s} \\
23^{\circ} 49.3^{\prime} \mathrm{s} \\
23^{\circ} \\
49.3^{\prime} \mathrm{s}\end{array}$ & $\begin{array}{ll}165^{\circ} & 31.9^{\prime} \mathrm{W} \\
165^{\circ} & 31.6^{\prime} \mathrm{W} \\
165^{\circ} & 31.6^{\prime} \mathrm{W}\end{array}$ & $\begin{array}{l}5613.5 \\
5629.0 \\
5630.0\end{array}$ & $\begin{array}{r}1 \\
12 \\
7\end{array}$ & $\begin{array}{r}1 \\
12 \\
7\end{array}$ & $\begin{array}{l}100.0 \\
100.0 \\
100.0\end{array}$ & $\begin{array}{r}0.5 \\
33.5 \\
57.9\end{array}$ & $\begin{array}{r}0.1 \\
37.5 \\
16.4\end{array}$ & $\begin{array}{l}10.0 \\
42.3 \\
28.3\end{array}$ & $\begin{array}{c}32.0 \\
65.9\end{array}$ & $\begin{array}{r}32.5 \\
88.5 \\
123.8\end{array}$ & $\begin{array}{r}195.0 \\
10.1 \\
6.0\end{array}$ & $\begin{array}{r}17.0 \\
47.0 \\
464.0\end{array}$ & \\
\hline & TOTALS 595 & & & 20 & 20 & 100.0 & 146.9 & 54.0 & 36.8 & 97.9 & 244.8 & & & 528.0 \\
\hline \multirow[t]{3}{*}{$\begin{array}{l}596 \\
596 \AA \\
596 \mathrm{~B}\end{array}$} & $\begin{array}{ll}23^{\circ} & 51.2^{\prime} \mathrm{s} \\
23^{\circ} & 51.2^{\prime} \mathrm{s} \\
23^{\circ} & 51.2^{\prime} \mathrm{s}\end{array}$ & $\begin{array}{ll}165^{\circ} & 39.3^{\prime} \mathrm{W} \\
165^{\circ} & 39.3^{\prime} \mathrm{W} \\
165^{\circ} & 39.3^{\prime} \mathrm{W}\end{array}$ & $\begin{array}{l}5710.5 \\
5710.5 \\
5710.5\end{array}$ & $\begin{array}{l}9 \\
1 \\
1\end{array}$ & $\begin{array}{l}8 \\
1 \\
1\end{array}$ & $\begin{array}{r}88.9 \\
100.0 \\
100.0\end{array}$ & $\begin{array}{r}76.1 \\
4.0 \\
9.6\end{array}$ & $\begin{array}{r}39.0 \\
8.5 \\
9.0\end{array}$ & $\begin{array}{r}51.2 \\
211.5 \\
96.4\end{array}$ & $\begin{array}{r}0.0 \\
66.0 \\
24.7\end{array}$ & $\begin{array}{l}76.1 \\
70.0 \\
34.3\end{array}$ & -- & $\begin{array}{r}61.6 \\
2.9 \\
15.2\end{array}$ & \\
\hline & TOTALS 596 & & & 11 & 10 & 90.9 & 89.7 & 56.5 & 63.3 & 90.7 & 180.4 & -- & & 79.7 \\
\hline & GRAND TOTALS & & & 31 & 30 & 96.8 & 236.6 & 110.5 & 57.6 & 188.6 & 425.2 & -- & & 607.7 \\
\hline
\end{tabular}


INTERNATIONAL PHASE OF OCEAN DRILLING

DEEP SEA DRILLING PROJECT

$\frac{\text { BIT SUSEARY }}{\text { LEG } 91}$

\begin{tabular}{|c|c|c|c|c|c|c|c|c|c|c|c|c|}
\hline Holè & Mfg. & & ize & Type & & $\begin{array}{l}\text { Serfal } \\
\text { Number }\end{array}$ & $\begin{array}{l}\text { Meters } \\
\text { Cored }\end{array}$ & $\begin{array}{l}\text { Meters } \\
\text { Drilled }\end{array}$ & $\begin{array}{l}\text { Meters } \\
\text { Tota1 } \\
\text { Penet. }\end{array}$ & $\begin{array}{l}\text { Hours } \\
\text { On } \\
\text { B1t }\end{array}$ & Condition & Remarks \\
\hline $\begin{array}{l}595 \\
595 \mathrm{~A}\end{array}$ & $\begin{array}{l}\text { MSDS } \\
\text { MSDS }\end{array}$ & & $\begin{array}{l}7 / 8 \\
7 / 8\end{array}$ & $\begin{array}{l}\text { F93Cl } \\
\text { F93Cl }\end{array}$ & & $\begin{array}{l}S-47 \\
S-47\end{array}$ & $\begin{array}{r}0.5 \\
99.5\end{array}$ & $\begin{array}{l}32.0 \\
34.2\end{array}$ & $\begin{array}{l}32.5 \\
88.5\end{array}$ & $\begin{array}{l}0.2 \\
8.7\end{array}$ & TO-B5-0 $1 / 16$ & Respud without round trip. \\
\hline & & & & & - & & & & 2143.7 & 15.8 & TOTALS & \\
\hline $\begin{array}{l}595 B \\
595 B\end{array}$ & $\begin{array}{l}\text { Smith } \\
\text { Smith }\end{array}$ & $\begin{array}{r}14 \\
9\end{array}$ & $\begin{array}{l}7 / 8 \\
7 / 8\end{array}$ & $\begin{array}{l}\text { F94 CK } \\
\text { F94 CK }\end{array}$ & & $\begin{array}{l}361 \mathrm{FK} \\
\text { AN16342 }\end{array}$ & $\begin{array}{r}15.6 \\
. \quad 42.3\end{array}$ & $\begin{array}{c}65.9 \\
0\end{array}$ & $\begin{array}{l}81.5 \\
42.3\end{array}$ & $\begin{array}{l}19.6 \\
20.6\end{array}$ & $\begin{array}{l}\text { TO-B1SE-I } \\
\text { T1-B6-014 }\end{array}$ & $\begin{array}{l}32 \mathrm{~m} \text { chert/clay, } 13.5 \mathrm{~m} \text { basalt \& andesite } \\
\text { Basalt }\end{array}$ \\
\hline 596 & MSDS & 11 & $7 / 16$ & $\begin{array}{l}\text { Type } \\
\text { XCB } S\end{array}$ & $\begin{array}{l}93 \\
\text { Spc. }\end{array}$ & S-55 & 76.1 & 0 & 76.1 & $\cdots$ & Not Tripped & $\cdot$ \\
\hline $\begin{array}{l}596 \mathrm{~A} \\
596 \mathrm{~B}\end{array}$ & $\begin{array}{l}\text { MSDS } \\
\text { MSDS }\end{array}$ & $\begin{array}{l}11 \\
11\end{array}$ & $\begin{array}{l}7 / 16 \\
7 / 16\end{array}$ & $"$ & $"$. & $\begin{array}{r}S-55 \\
S-55\end{array}$ & $\begin{array}{l}4.0 \\
9.6\end{array}$ & $\begin{array}{l}66.0 \\
24.7\end{array}$ & $\begin{array}{l}70.0 \\
34.3\end{array}$ & $\overline{--}$ & $\begin{array}{l}\text { Not Tripped } \\
\text { B8-T8-one cutter } \\
\text { leg gone. }\end{array}$ & $19788 \mathrm{~m}$ total, $5 \mathrm{~m}$ basalt. \\
\hline
\end{tabular}




\section{INTERNATIONAL PHASE OF OCEAN DRILLING \\ DEEP SEA DRILLING PROJECT \\ BEACON SUMMARY

$$
\text { LEG } 91
$$

\begin{tabular}{|c|c|c|c|c|c|c|}
\hline & $\begin{array}{l}\text { Site } \\
\text { No. }\end{array}$ & Make & $\begin{array}{l}\text { Freq. } \\
\mathrm{kHz}\end{array}$ & $\begin{array}{l}\text { Serial } \\
\text { Number }\end{array}$ & $\begin{array}{l}\text { Site Time } \\
\text { Hours }\end{array}$ & \\
\hline \multirow{9}{*}{ 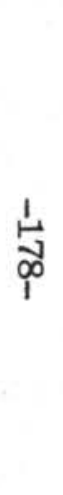 } & 595 & ORE & 16.0 & 148 & 17.0 & Double life. \\
\hline & $595 \mathrm{~A}$ & ORE & 16.0 & 148 & 46.0 & \\
\hline & $595 \mathrm{~B}$ & ORE & 16.0 & 148 & 418.6 & 481.6 hours total - good beacon. \\
\hline & $595 \mathrm{~B}$ & ORE & 13.5 & 156 & 61.6 & $\begin{array}{l}\text { Single life--dropped at } 1345 \text { hours, February } 9 \\
\text { by R/V Melville--good beacon. }\end{array}$ \\
\hline & $595 \mathrm{~B}$ & ORE & 16.0 & $103 \mathrm{~A}$ & & Single life--lost signal shortly after diop. \\
\hline & 596 & ORE & 16.0 & 144 & -- & Single life--failed on soak test. \\
\hline & 596 & ORE & 13.5 & $118 \mathrm{~A}$ & 61.6 & Double life. \\
\hline & $596 \mathrm{~A}$ & ORE . & 13.5 & $118 \mathrm{~A}$ & 2.9 & \\
\hline & 596B & ORE & 13.5 & $118 \mathrm{~A}$ & 15.2 & Good beacon. \\
\hline
\end{tabular}


INTERNATIONAL PHASE OF OCEAN DRILLING

DEEP SEA DRILLING PROJECT

BEACON SUMMARY

LEG 91

\begin{tabular}{|c|c|c|c|c|c|c|}
\hline & $\begin{array}{l}\text { Site } \\
\text { No. }\end{array}$ & Make & $\begin{array}{l}\text { Freq. } \\
\mathrm{kHz}\end{array}$ & $\begin{array}{l}\text { Serial } \\
\text { Number }\end{array}$ & $\begin{array}{c}\text { Site Time } \\
\text { Hours }\end{array}$ & \\
\hline \multirow{10}{*}{$\frac{\stackrel{1}{\sim}}{1}$} & 595 & ORE & 16.0 & 148 & 17.0 & Double life. \\
\hline & $595 \mathrm{~A}$ & ORE & 16.0 & 148 & 46.0 & \\
\hline & $595 B$ & ORE & 16.0 & 148 & 418.6 & 481.6 hours total - good beacon. \\
\hline & $595 \mathrm{~B}$ & ORE & 13.5 & 156 & 61.6 & Single life--dropped at 1345 hours, February 9 \\
\hline & $595 \mathrm{~B}$ & ORE & 16.0 & $103 \mathrm{~A}$ & & $\begin{array}{l}\text { by R/V Melville--good beacon. } \\
\text { Single life--lost signal shortly after drop. }\end{array}$ \\
\hline & $595 \mathrm{~B}$ & ORE & 13.5 & 158 & 0.9 & Double life--pulse sent bad on landing at seafloor. \\
\hline & 596 & ORE & 16.0 & 144 & -- & Single life--failed on soak test. \\
\hline & 596 & ORE & 13.5 & $118 \mathrm{~A}$ & 61.6 & Double life. \\
\hline & $596 \mathrm{~A}$ & ORE & 13.5 & $118 \mathrm{~A}$ & 2.9 & \\
\hline & $596 \mathrm{~B}$ & ORE & 13.5 & $118 \mathrm{~A}$ & 15.2 & Good beacon. \\
\hline
\end{tabular}




\author{
INTERNATIONAL PHASE OF OCEAN DRILLING \\ DEEP SEA DRILLING PROJECT \\ OPERATIONS RESUME \\ LEG 92
}

The principle objective of GLOMAR CHALLENGER'S Leg 92 was to study the hydrogeology of the fast-spreading East Pacific Rise along a transect at $19^{\circ} \mathrm{S}$ latitude (Figure 1). The past several years of geological and geochemical research concentrating on chemical processes near the spreading center have demonstrated that seawater circulates deep within the crust, is heated by the cooling basalts with which it reacts and precipitates hydrothermal minerals within the crust, the sediment column, and at the sediment/ seawater interface.

The sites selected for drilling on Leg 92 were designed to study ridge flank hydrothermal processes as a function of age along a single flow line and to study sediments which directly or indirectly reflect ridge crest activity.

Secondary goals of Leg 92 were to recover sediments useful for interpretation of the paleoceanography, paleoclimatology of the South Pacific sub-tropical gyre and to drill relatively deep into the oceanic basement in order to determine the petrology and permeability of an intermediate age, fast-spread crust.

The final objective of Leg 92 was to return to Hole 504B, which was drilled to a depth of $836 \mathrm{~m}$ in 1979 (Legs 69, 70) and then deepened to $1350 \mathrm{~m}$ (1075.5 m sub-basement) in 1981 (Leg 83). Efforts at 504B were centered around obtaining downhole temperature measurements and large-volume samples of formation water in the hole.

In addition, an oblique seismic experiment (OSE) was performed. The object of this experiment was to determine the seismic velocity structure of the crust in the vicinity of the site as a function of azimuth and depth.

A packer flow test was conducted on this site as well as logging runs with a multi-channel sonic tool.

The voyage commenced at 1448 hours on February 20, 1983 at Papeete, Tahiti and ended at 2348 hours on April 27, 1983 in Norfolk, Virginia. Total length of the leg was 66.3 days, of which 30.9 days were spent on site, 3.4 days in port and 32.0 days in transit. Weather delay accounted for 0.1 day.

\title{
Papeete, Tahiti Port Call
}

Leg 92 began at 1448 hours on Sunday, February 20, 1983 with the first line on the dock Berth L-1 Pepeete, Tahiti. One hundred twenty thousand pounds of freight were loaded during the port call. Included were GMI dry stores and reefer stores, 5 joints of $16^{\prime \prime}$ casing and ten $8 \frac{1}{2} "$ drill collars. All fresh and drill water tanks were topped off. No fuel was taken during this 
port call. A fire and bcat drill was conducted dockside and witnessed by the GMI Project Manager.

Underway to Site NR 597 (HY-1)

At 0906 hours, the last line was off the dock at Papeete, Tahiti, and the vessel proceeded to the outer reefs. The vessel cleared the outer reefs at 0936 hours and at 1045 hours, the vessel was stopped and all thrusters were successfully tested. At 1100 hours on Thursday, February 24, 1983, the GLOMAR CHALLENGER was underway for Site 599 (HY-1) with 45 GMI and 29 Scripps personnel aboard.

By 2400 hours that evening, the vessel was proceeding to the site at reduced speed of $6 \mathrm{kts}$, pitching moderately in a heavy easterly swell under the influence of tropical storm "Nisha".

The following evening, the vessel continued under the influence of "Nisha". Speed was reduced to $3 \mathrm{kts}$ as the vessel pitched heavily and winds of 45 to $50 \mathrm{mph}$ were encountered along with frequent heavy rain squalls. Constant contact with SSB Radio Mahina, Tahiti was maintained as the storm was expected to pass approximately 80 miles ahead of the CHALLENGER.

By 1630 hours on Friday, February 25, 1983, conditions had rapidly deteriotated. "Nisha" passed 105 miles dead ahead of the vessel on a south southeasterly heading at $6 \mathrm{kts}$ and carried with it $90 \mathrm{mph}$ winds at its center. The CHALLENGER'S speed had been reduced to $1.5 \mathrm{kts}$ in 30 feet seas and was experiencing $72 \mathrm{mph}$ winds.

By 2400 hours the weather was moderating, the vessel began riding easily with moderate pitch and swell. Speed was constantly increasing.

On Saturday, February 26, the clocks were advanced one hour to plus nine zulu. Weather continued to moderate and vessel speed had increased to 9.5 knots. By Monday, the weather was good and at 0918 hours on Wednesday, March 3, a $16.0 \mathrm{kHz}$ beacon No. 146 was dropped at Site 597 (HY-1). Total steaming time was six days 22.7 hours at a total average speed of 7.0 knots.

Site Operations No. 597 (HY-1)

Upon dropping the beacon, a limited on-site profile was conducted. At 1115 hours on March 2, the profiling gear was retrieved and the vessel returned to the beacon. Since the location of this site was critical to achieving the scientific objectives, it was located very accurately utilizing previously emplanted sonar transponders. When one transponder failed to respond, the site was determined using one transponder and the CHALLENGER positioning beacon. The method was very similar to re-entry operations where various offsets are put into the positioning computer and vesse 1 position is plotted utilizing a maneuvering board and great circle plotting techniques. Site 597 was eventually located correctly and at 2100 hours, we began running in the hole. To ensure compatibility of all coring equipment to be used, and provide an accurate drill pipe measurement of the mudiline, 
the drill pipe was strapped and drifted on this first trip in the hole. No joints were identified as being undersized. The average length of a drill pipe stand ( 3 joints) was 28.73 meters.

After one full core barrel and one empty barrel, attempted 9.6 meters higher, Hole No. 597 was finally spudded at 0210 hours on March 3. Drill pipe mudline was established at 4157.1 meters. Continuous coring with the Variable Length Hydraulic Piston Corer (VLHPC) and the Extended Core Barrel (XCB) ensued until drilling was terminated in basalt rubble (54.7 m BSF).

Two VLHPC (Von Herzen) heat flow measurements were taken. Both were unsuccessful due to damaged wiring. Hole 597 was terminated at 1630 hours when the core bit cleared the mudline.

After an offset of approximately 100 feet to the southwest, Hole 597A was spudded at 1735 hours. Four heat flow measurements were successfully taken using the VLHPC and Uyeda systems. Two in situ pore water samples were also successfully taken. Coring was accomplished again using the VLHPC and the XCB. Hole 597A terminated $48.6 \mathrm{~m} \mathrm{BSF}$ again in the basalt rubble. The drill string was pulled and the core bit was on deck at 1945 hours on March 4, ending Hole 597A.

After changing the BHA into that used for standard rotary coring, the pipe was again run to bottom. This was to be an exploratory pilot hole to see if drilling conditions were good enough to allow deployment of a re-entry cone and a major drilling effort into basement. Operations were halted briefly when a pipe dope brush handle broke with the handle falling into the open ended pipe at the rig floor. The object was successfully "fished" from the pipe and run in hole (RIH) operations resumed.

At 0710 hours on March 5, Hole 597B was spudded. The pipe was then washed down to basement $(4208 \mathrm{~m})$ and two joints of knobby drill pipe were picked up and placed in the string. Coring continued in basement with considerable torquing of the drill string. In general, the hole conditions seemed to improve with depth. One particularly bad rubble zone, approximately $9 \mathrm{~m}$ thick, seemed to be the most responsible for the poor drilling conditions. As the zone stabilized, conditions improved significantly. The pilot hole (597B) was terminated at $4232.6 \mathrm{~m}(72.6 \mathrm{~m} \mathrm{BSF}) 24.6 \mathrm{~m}$ into basement. Penetration rates were approximately $1.5 \mathrm{~m}$ per hour. Prior to pulling out of the hole, the mechanical bit release (MBR) was actuated, dropping off the core bit, and allowing a test of the 12-channel sonic logging tool. The test was unsuccessful when the tool could not be deployed into the open hole. It is possible the end of the drill pipe was in the rubble zone during the logging attempt preventing the tool from cleanly entering the borehole. A stiffer assembly was also required. Future deployments were to be modified eliminating the flexible cable link between the source unit and the receiver assembly. The drill pipe was pulled and Hole 597B concluded with the MBR on deck at 0015 hours, Monday, March 7.

A re-entry cone with $39.81 \mathrm{~m}$ of $16^{\prime \prime}$ casing was made and deployed without incident. The re-entry hardware performed flawlessly. At 2018 hours, the cone/casing assembly was released from the drill pipe and continuous rotary coring again was initiated. For future reference the cone was set at mudline 
$(4160 \mathrm{~m})$ placing the top of the cone at $4157 \mathrm{~m}$ and the casing shoe at $4201 \mathrm{~m}$ $7 \mathrm{~m}$ above basement. Drilling conditions continued to be the same as in the pilot hole, although they did improve with depth. Some torquing was evident, again, probably due to the rubble zone directly overlying the more massive basaltic flow unit. Penetration rates were again $1.5 \mathrm{~m} / \mathrm{hr}$. At 1915 hours, March 9, coring operations were halted at $109.5 \mathrm{~m}$ BSF for a bit change ( $57 \mathrm{~m}$ into basement). Indications were that the core bit was fine, however, it was decided not to risk the hole and the bit was pulled earlier than normal. It was also felt that re-entering with a new bit and a heavier BHA, the penetration rate may be improved. It should be noted that special "abbreviated" BHA's were used on the pilot hole (597B) and the first run on Hole 597C. These shorter, lighter weight assemblies were employed to minimize the risk of spudding and drilling in areas of very limited sediment support. For details see the BHA section of the report. At 0500 hours, the bit was on deck. A bit of a scare went through the rig crew when the flow thru latch sleeve did not come back hanging on the running tool as it was suppose to. Apparently both tools had been worn by the rotation of the drill collars and drill pipe enough to allow the latch sleeve to rotate aligning the flats in both assemblies. The sleeve slipped past and hung up on the drill bit while coming out of the hole. On March 11, a routine re-entry had been made and coring operations had again been initiated. The hole condition was surprisingly good. No fill was evident and coring proceeded uneventfully. Core recovery was good exceeding 50 per cent and penetration rates did improve, as suspected, averaging 2.1 to $2.6 \mathrm{~m} / \mathrm{hr}$. At 2215 hours, March 11, drilling was terminated so that the packer experiments and logging could be accomplished. Total depth of Hole 597C was $5303.5 \mathrm{~m}$ (143.5 m BSF), $91.0 \mathrm{~m}$ into basement.

At 2036 hours on Saturday, March 12, the pipe was back to the seafloor and the EDO sonar re-entry tool had been run in and seated. Just as scanning operations were about to begin, a line squall crossed over the CHALLENGER blowing the vessel 280 feet off station. Intermittent loss of acoustics continued to hamper operations. Several heading changes were eventually required to move back over the site and reduce vessel motion. Incredible as it may seem, we had lost two hours due to inclimate weather. At 225 hours, the vessel had settled down reasonably well enough to begin scanning for the re-entry cone. After one additional move off the hole, again weather induced, the cone was re-entered. The EDO tool was retrieved and the pipe was run to bottom verifying that there was no fill in the hole. Three knobby drilling joints were picked up and the drill bit placed at $4332 \mathrm{~m}$. The logging sheaves were picked up and the caliper tool was run in the hole. Four caliper runs were made in basement. Two at $4800 \mathrm{FPH}$ and two at $2400 \mathrm{FPH}$. The latter speed gave by far the better data. By 1130 hours on Mardh 13, the caliper tools were on deck and preparations were made to run in the hole with the televiewer. The televiewer made two runs in basement. The first was with the $1.2 \mathrm{kHz}$ transducer and the second with a $500 \mathrm{kHz}$ transducer. The logging rate was $300 \mathrm{FPH}$ on both runs and all data was good. At 2015 hours, the televiewer was on deck and the 12-channel sonic tool was ready for deployment. While running in the hole, the sonic tool did not appear to be functioning correctly. This was confirmed when the tool left the BHA and went into open hole. The tool was retrieved and was on deck at 2400 hours, March 13 . Because use of the 12-channel tool was a high priority for this site, the 
Co-Chiefs agreed to standby for a short period of time to see if the tool could be repaired quickly. After 45 minutes, the verdict arrived. The receiver section had suffered severe damage to the hydrophone wiring, probably during assembly, although this was unconfirmed. Repairs could not be made in a short period of time. The decision was made to proceed with the Lynes packer experiments.

While running to set on bottom, the drill bit stopped six meters shy. Several attempts to get past this point failed. A quick check of the logging records indicated that this was where the logging tools were setting down as well. It was assumed that either a "belly" in the drill pipe or fill from above had resulted in the change in bottom depth. The safety go-devil was run in the hole and efforts continued to set the packer. At 0205 hours on March 14, the go-devil was seated and 1400 psi pressure was applied using the "BJ" cementing unit. This should have set the packer. All pressure was bled off and the flow test manifold was rigged. The driller was then notified that the flow test was about to begin and was advised to watch the Martin-Decker weight indicator closely for a weight loss indicating the packer was being pumped up the hole. If so, the pressure was to be vented at the standpipe manifold immediately. Procedures set, the drill string was pressured up to 2200 psi to shear the circulating plug in the safety go-devil and allow circulation below the packer. The plug appeared to shear when suddenly the pressure gauge fell to zero. A quick check with the rig floor indicated the drill string weight had begun to increase and the bumper subs were pounding. The pressure had been vented off at the rig floor standpipe. At that point, it was believed that the bit had broken through a bridge six meters off bottom causing the bumper subs to scope out, increasing the string weight. The drill string was immediately picked up to the nearest connection requiring $50,000 \mathrm{lbs}$ pull. The circulating head was broken out and one knobby drill pipe joint was added, to again put the bumper subs in neutral. When pumping was again initiated for the flow test, a pressure build up could not be achieved. Fearing the packer element had been damaged, a pull test was conducted with the drill string to verify a good packer seat. No noticeable pull indicated the packer was not set. Disappointed, the crew rigged down the test gear, layed out the knobby joints and began to pull out of the hole (POOH).

At 1300 hours on Marcy 14, the drill bit was back on deck. The packer element was all right but the deflate plug in the packer body had sheared at some point causing the packer to deflate. Coincident with this, a message from the beach arrived. Sure enough, just as suspected would happen, the French rendezvous ship PAPANOO had been delayed. Scientific plans had to be discussed and options considered. To save time, the rig crew began redressing the packer, efforts were already underway to repair the 12-channel sonic tool, and the Scripps' ET's were instructed to begin readying the wireline re-entry hardware just in case.

At 1530 hours, the decision was made to proceed with deployment of the Wireline Re-entry System (WRS). At 2330 hours, after several attempts at reheading the logging cable and all hardware had been assembled, the WRS package deployment began.

Efforts to achieve the first wireline re-entry from the CHALLENGER failed 
when the EDO tool would not receive a return signal. This was not readily apparent until efforts to pick-up 2. mudline signal were to no avail. It was later determined that a faulty cablehead was the culprit. Details on the WRS trials can be found later in the report. Just prior to retrieving the WRS system, the first communication with the PAPENOO (0300 hours) was made. She was, in fact, going to arrive early now with an estimated ETA of 0530 hours on March 15. The WRS system was immediately retrieved and was on deck at 0555 hours. By 0630 hours, the logging sheaves were rigged down and the rig floor was secured. By 0800 hours, two personnel and one teletype had been embarked aboard the CHALLENGER and two personnel had been disembarked to the PAPENOO.

Efforts were then geared towards the interrogation and release of the two transponders placed on site during last year's site survey. One transponder was recovered, the other did not give any indication that a release had been effected. At 1438 hours on Mardh 15, efforts to recall the last transponder were curtailed and the vessel got underway for Site 598 (HY-1A).

Underway to Site 598 (HY-1A)

At 0000 hours on March 16, while enroute to Site 598, the clocks were advanced one hour to plus $8 \mathrm{zulu}$. Steaming proceeded without incident until 0320 hours on the sixteenth, when the No. 5 DC Generator flashed to ground. The No. 5 propulsion motor was immediately taken off line and the speed of the vessel was reduced. At 0345 hours, the port shaft was completely secured and speed was reduced further. By 0715 hours, the port shaft was back on line with all three propulsion motors and the No. 10 generator. At 0740 hours, the vesse 1 had resumed full speed, with the total loss of time due to the breakdown estimated at two hours. At 1500 hours that evening, the No. 5 generator had been thoroughly tested; all circuits were in apparent good order. Cause of the flash was undetermined, however, it is suspected that a carbon buildup under the brush holders was responsible. Transit to the site was further hampered by very strong headwinds and at 0650 hours on March 17, the vesse1 arrived on site. A total distance of 304.7 miles had been covered at an average speed of 7.5 knots. After a short 1.8 hour on site profile, the beacon, a $16.0 \mathrm{kHz}$ No. 144 , was let go at 0823 hours.

\section{Site Operations No. 598 (HY-1A)}

Operations at Site 598 consisted of one VLHPC hole continuous to basement and one hole devoted strictly to heat flow measurements in in situ pore water sampling. This method ensured the least possible disturbance to the piston cored interval and required very little additional time since the sediment section was so thin.

By 0950 hours on March 17, the vessel was positioning nicely in automatic and the drill pipe was started in the hole. At 1245 hours, while running in hole $(\mathrm{RIH})$, the drawworks drill line backlashed. This resulted in the blocks having to be hung off and the line straightened out. One hour of time was lost. The accident occurred when the driller failed to hear the derrickman 
indicate that a "double", not a full "stand", was being picked up. The driller therefore had to stop the drawworks rapidly causing the line to backlash. Both men were experienced and had been performing admirably prior to the accident. No negligence was apparent.

At 1932 hours on Thursday, March 17, Hole 598 was spudded using a "green" highly adorned $9.5 \mathrm{~m}$ VLHPC barrel. Luck of the green held true and the hole was spudded, first try, on this St. Patrick's Day 1983. Curiously enough $6.16 \mathrm{~m}$ of "Kelly Green" clay bearing nannofossil ooze was recovered. Drill pipe mudline was placed at $3703.4 \mathrm{~m}, 2.6 \mathrm{~m}$ above PDR. VLHPC coring continued without incident until 0230 hours on the 18th of March. This last VLHPC Core No. 6 did not scope fully, indicating hard rock had been reached at $3748.2 \mathrm{~m}$ or $44.8 \mathrm{~m} \mathrm{BSF}$. The next two cores were attempted utilizing the Extended Core Barrel (XCB) coring system. There was no recovery on the first attempt. The second provided only two limestone "disks". Hole 598 was terminated when the bit cleared the mudline at 0735 hours that same day. Total depth was $3755.8 \mathrm{~m}$ (52.4 m BSF).

Hole 598A was spudded with the in situ pore water sampler/heat flow barrel at 0847 hours. Four heat flow readings and two pore water samples were taken without incident on two separate wireline runs. All data was successful except for the No. 1 pore water sample which recovered drill water due to the sample valve opening too early in the deployment cycle. At 1415 hours the mudline was cleared and at 2225 hours, the bit was on deck terminating Hole 598A.

Underway to Site 599 (HY-2)

By 2305 hours on March 18, the profiling gear was streamed and the vessel was proceeding at full speed to Site 599. Strong headwinds and a heavy southwesterly swell impaired the vessel's speed consistently all the way to the site location. A short 1.1 hour survey was again run to ensure the correct location was located prior to beacon drop. At 0949 hours, a $16.0 \mathrm{kHz}$ beacon No. 147 was let go. A total distance of 289.8 nautical miles had been transited at an average speed of 8.26 knots.

Site Operations No. 599 (HY-2)

Profiling continued after beacon drop for 0.6 hours when the gear was retrieved and the vessel returned to the beacon. Interrogation of the previously emplaced sonar transponders indicated the CHALLENGER'S position to be slightly off of the optimum location desired.

Offsets of 1500 feet north and 1500 feet east, were initiated into the CHALLENGER'S positioning computer, affectionately known as "ELMER", and by 1200 hours, the vessel was over the hole positioning in automatic. Unfortunately the heading required to maintain station was not conducive to running and handling drill pipe. Winds were gusting to $35 \mathrm{mph}$ and three distinct sets of swells were affecting the operation. With the vessel's bow into the wind, the roll and pitch was unacceptable, approaching $10^{\circ}$ on occasion. Waiting on weather (WOW) was terminated 1.3 hours later at 1320 hours on March 20 . 
The wind had abated enough to allow the vessel's heading to be swung around to the northeast reducing the roll and pitch to more acceptable limits. The BHA was made up, the drill pipe RIH, and at 2100 hours, Hole 599 was spudded. Drill pipe mudline was placed at 3643.7 meters, 4.3 meters above PDR. Continuous VLHPC coring proceeded uneventfully until Core No. 5 terminated on basement at $3684.5 \mathrm{~m}$ ( $40.8 \mathrm{~m} \mathrm{BSF})$. The pipe was pulled clear of the mudline at 0345 hours ending Hole 599. Since a dedicated heat flow/ pore water hole had worked out well on the previous site, this format was continued. Hole 599A was spudded at 0420 hours with the heat flow/pore water barrel. Three heat flow measurements and one in situ pore water sample were taken. All were successful. Since the turnaround time on deck for the pore water sampler was to be approximately one hour, it was felt best to pull clear of the mudline. This occurred at 0800 hours terminating Hole 599A.

While redressing the $\mathrm{HF} / \mathrm{PW}$ barrel, time was taken to repair a blower on the No. 2 bow thruster which had been making noises as if it was not in complete health. This was done in short order. A damaged fan blade was replaced well before the $\mathrm{HF} / \mathrm{PW}$ barrel was ready with no lost time accrued. At 0945 hours, Hole 599B was spudded. One heat flow measurement and one in situ pore water sample was taken both successful. One additional VLHPC core was then taken just above basement attempting to recover some of the semi-lithified sediment overlying the basement contact. Basement was verified at $3684.5 \mathrm{~m}$ ( $40.8 \mathrm{~m} \mathrm{BSF}$ ) both with the core barrel and the drill pipe. At 1415 hours on March 21, the XCB was RIH for attempted basement drilling. XCB No. 1 recovered $1.52 \mathrm{~m}$ of basement rubble and basalt cuttings with a penetration rate of 1.6 meters per hour. When XCB No. 2 reached bottom, it was discovered that six meters of fill were in the hole. After 8.2 hours, the original total depth had just been reached. Severe torquing and sticking of the drill pipe was evident. The drill pipe had been stuck twice, the first time for ten minutes requiring 75,000 lbs of overpull to free; the second time for 18 minutes requiring $125,000 \mathrm{lbs}$ of overpull to free. Not liking the slope of the curve and suspecting that we were living on borrowed time, the decision was made to abandon drilling on this site. The XCB No. 2 was recovered with 0.56 meters of basalt rubble after a penetration rate of 0.84 meters per hour.

At 1545 hours, the bit was on deck terminating Hole 599B with a total depth of $3693.5 \mathrm{~m}$ ( $49.8 \mathrm{~m} \mathrm{BSF})$. Two beacons were soaked and efforts to recall the two transponders were initiated. The first transponder released but was unobserved on the surface, indications being the strobe light was probably not functioning. The second transponder released and upon reaching the surface was spotted almost immediately blinking away in the distance. By 2235 hours, the transponder was aboard and at 2242 hours on Tuesday, March 22, the CHALLENGER got underway for Site 600 (HY-3).

Underway to Site 600 (HY-3)

The move to Site 600 was uneventful. Headwinds again limited the vessel's speed, however this did not significantly affect travel time since the transit was relatively short. The total distance traveled was 117.3 nautical miles at an average speed of 8.7 knots. At 1840 hours on March 23, a 13.5 $\mathrm{kHz}$ beacon NR159 was dropped marking the future Site 601. This beacon was 
dropped enroute to Site 600 due to its close proximity. In the interest of accuracy, it was best to drop both beacons on the profile line as the approach to the area was made. At 1858 hours the second beacon, a $16.0 \mathrm{kHz}$ No. 149 was let go initiating Site 600 . By 2255 hours, the vessel location had been adjusted again using transponders and RIH operations were begun with total offsets of 820 feet east of the beacon.

Site Operations No. 600 (HY-3)

Since little sediment cover was expected at this site and even less was apparent on the PDR, it was decided the first order of business would be to identify the depth of basement. This helps to optimize where the VLHPC heat flow shoe can be run when there is little sediment cover and high risk at hitting basement with the shoe. The PDR readings on this site were extremely ambiguous due to the position on the side of a slope and in close proximity to a ridge crest. Several shadows and indications of mudline were present. At 0800 hours, basement was established at $3380.5 \mathrm{~m}$. PDR indicated a possible mudline at 3346 meters. Since 35 meters of sediment at this site was not out of the question, this was assumed to be close. After pulling three empty core barrels, Hole 600 was finally spudded at 1236 hours on March 24. Drill pipe measurement to mudline at 3372.3 meters, a mere 8.2 meters above basement. A VLPHC heat flow shoe was run on this core barrel and did indicate a much higher than average reading confirming that this was indeed the high heat flow spot that was being sought after. Since core barrel No. 2 was expected to impact on basement, the shorter $5.0 \mathrm{~m}$ VLHPC was deployed. This barrel did in fact hit basement but unfortunately left the lowermost "core barrel" portion of the tool in the hole. It had broken off at the last engaged thread of the inner barrel box connection. The pipe was pulled clear of the mudline at 1525 hours ending Hole 600 .

Undaunted and encouraged by the success of the first core attempt, it was decided to attempt coring the $8.2 \mathrm{~m}$ section all in one core utilizing the $9.5 \mathrm{~m}$ system. At 1554 hours on March 24 , Hole $600 \mathrm{~A}$ was spudded. At 1557 hours the bit was pulled clear of the mudline to minimize the risk of breaking off another barrel, ending Hole 600A. By 1620 hours, the core barrel was on deck again, having left the lower portion in the hole. The failure again occurred in an inner barrel connection. This time the one connecting the two core barrels in the $9.5 \mathrm{~m}$ system.

It was at this time that a theory was set forth proposing that the barrels were, in fact, breaking off due to too high an impact force rather than pipe motion. It seems three shear pins (the maximum possible) had been used on the last two attempts. Another $9.5 \mathrm{~m}$ VLHPC barrel was made up and RIH with two shear pins for one "last ditch" effort at coring the section. Every precaution was taken to withdraw the barrel immediately after the core was taken. At 1705 hours, the barrel was shot off spudding Hole $600 \mathrm{~B}$ and at 1706 hours, the bit was clear of the mudline ending Hole 600B. Upon retrieval the barrel had but 1.9 meters of sediment. No explanation for this was apparent other than pipe motion. It was obvious. This particular spot was not to be trusted for any additional coring attempts and was, in fact, only fought, as long as it was, due to its high scientific priority. 
It was hence decided to offset 170 meters downslope, check the position with the transponders, and hope this would be a better location. From 1855 to 1940 hours, attempts were made to sense mudline while running in to tag basement. When neither had been located within a reasonable proximity to PDR, fears began to surface that we may be laying out the BHA on the seafloor. It was decided to shoot one $9.5 \mathrm{~m}$ VLHPC barrel from $3400.8 \mathrm{~m}$. This was slightly above one of many PDR reflectors at $3408 \mathrm{~m}$. The barrel came up empty but had traces of mud on the flapper core catcher. A second spud attempt from 5.0 meters lower recovered 9.38 meters of sediment. Hole $600 \mathrm{C}$ had indeed been spudded at 2127 hours on March 24. Actual offsets were 280 . feet north and 340 feet west of Holes $600 \mathrm{~A}$ and 600B. Core No. 2 on this hole, recovered 2.42 meters of sediment including fragments of glassy basalt cemented with calcium carbonate. By 0545 hours on March 25, the bit was on deck and by 0600 hours, the vessel was underway for Site No. 601 and the previously emplaced positioning beacon.

\section{Site Operations No. 601 (HY-3)}

Because of the close proximity of the two sites, only two hours were spent underway and by 0800 hours on March 25, the vessel was positioning in automatic over the previously dropped positioning beacon. Offsets of 2990 feet east and 860 feet south were in affect. At 1420 hours, basement was tagged, however no noticeable mudline was apparent. Basement was indicated at about $3470 \mathrm{~m}$ and PDR was 3443.0 meters. The first spud attempt was empty but with traces of mud on the flapper core catcher. At 1621 hours on March 25, Hole 601 was spudded. Drill pipe mudline was determined to be $3447.5 \mathrm{~m}$. For the first time this leg mudline was actually found lower than PDR. VLHPC coring continued until Core No. 3 hit basement at $3468.1 \mathrm{~m}$. A successful VLHPC head flow reading was taken on Core No. 2. At 2005 hours, the bit cleared the mudline ending Hole 601 .

Hole $601 \mathrm{~A}$ was consequently spudded at 2055 hours, again utilizing the heat flow/pore water sample barrel. Three heat flow measurements were obtained and one in situ pore water sample. All were successful. The mudline was cleared at 2224 hours ending Hole 601A.

Hole $601 \mathrm{~B}$ was spudded at 2225 hours and immediately washed to a point 8.6 meters above basement. The XCB was then used on Core No. 1 in an attempt to recover the basement/sediment interface. XCB No. 1 recovered 3.85 meters of sediment and basement including the desired contact. Two additional $\mathrm{XCB}$ cores were taken at this site before coring was terminated at 2475.0 meters (27.0 BSF). By 1530 hours on March 26, the drill bit was on deck and by 1620 hours, the CHALLENGER was underway to Site 602 .

Site Operations No. 602 (Hy-3)

Again, the transit between sites was short taking a mere 38 minutes from underway to beacon drop. At 1620 . hours, a $16.0 \mathrm{kHz}$ beacon No. 150 was let go officially establishing Site 602. A short on site survey was conducted and by 1705 hours, the vessel was back over the beacon. A position check 
with the sonar transponders again necessitated offsets, this time 2990 feet south and 1600 feet west. By 1855 hours, RIH operations had commenced.

At 0135 hours on March 27, just after having picked up the Bowen power sub, the positioning beacon abruptly quit. Immediately a $13.5 \mathrm{kHz}$ beacon No. 160 was let go and while waiting for it to reach bottom, another transponder check of our position was made. New offsets of 1170 south and 540 feet north were initiated into the computer and operations were again set. PDR depth for this hole was 3551 meters, however, while washing in to tag basement, a very hard layer was encountered at $3546 \mathrm{~m}$. This is the first time basement has ever been verified five meters above the seafloor. A truly remarkable area.

It was decided to attempt one core from 10 meters above the basement indication. When this barrel was retrieved empty all concerned agreed that there was no sediment cover at this location.

All offsets were removed from the positioning computer in the hopes of finding a better area to spud. Unfortunately a study of the PDR records did not look promising for this location either.

At this point, a "desperation" offset of 1000 feet due east was applied. The $\mathrm{XCB}$ barrel was placed in the pipe for the attempts to find basement hoping some indication of mud would be recovered. Based on previous experience, the PDR records were "adjusted" and it was decided that a possible reflector existed at 3543 meters. Basement was contacted at approximately 3550 meters.

This XCB barrel punch cored into sediment spudding Hole 602 at 0638 hours on March 27. Recovery was 6.19 meters and mudline was placed at $3543.8 \mathrm{~m}$. The mudline was cleared at 0642 hours ending Hole 602.

Hole $602 \mathrm{~A}$ was spudded at 0750 hours with the $9.5 \mathrm{~m}$ VLHPC coring system. Recovery was $2.28 \mathrm{~m}$ of sediment and some hard fragments. The barrel did not scope out fully and it was obvious that this was another area of very thin sediment cover.

It was decided that coring with the $5.0 \mathrm{~m}$ VLHPC system may get a better core since the amount of water at the top of the sediment would be minimized. With this in mind, Hole $602 \mathrm{~B}$ was spudded at 0930 hours when the barrel would not pull free from the BHA. The worst was expected; a bent barrel. When the overshot shear pin eventually sheared, the decision was made to POOH. A "wet trip" all the way. A surprise was in store for scientists and drilling crew alike when the bit finally reached the floor. The VLHPC barrel was not, in fact, bent but somehow, probably during the rapid retrieval method, sand had been sucked up around the seal area jamming the barrel in its seal sleeve. Recovered was a magnificent core covering mudline to basement including basalt pieces. This core, in fact, recovered the entire sediment column not once but three times, (probably due to vessel heave and/or corer rebound) and the sediment/basement interface twice.

With the last core on deck and the BHA magnafluxed, preparations were again made for transponder recovery. While this was in progress, the smaller subs and power sub were magnafluxed thus saving time. 
At 1745 hours on March 27, transponder recovery efforts commenced. "Red", although successfully released, would not make itself visible on the surface. A faulty strobe light was again suspected since "blue" was readily identifiable when it arrived. By 2330 hours the "blue" transponder was aboard and at 2340 hours, the vessel was underway for Hole 504B completing operations on Hole 602B.

Underway to Site 504B (CR-1)

The transit to Site 504B was uneventful except for two relatively unique events. First the CHALLENGER'S speec, which was slowed to 8.5 knots at one point due to strong head winds, actually achieved 12.0 knots. An unheard of event! Secondly, at 2248 hours LCT on April 6, 1983, the vessel eased its way across that great central meridian of latitude $00^{\circ}$, otherwise known as "the equator". There, before the great King Neptune and his royal court, 16 CHALLENGER polliwogs entered the realm of the Shellback. After making the last time change of the cruise (plus $5 \mathrm{zulu}$ ), the CHALLENGER arrived on station Thursday, April 7, 1983. A $13.5 \mathrm{kHz}$ beacon No. 162 was let go at 1235 hours. The total distance steamed was 2305.1 nautical miles at an average speed of 9.25 knots.

Site Operations No. 504B (CR-1)

Immediately upon beacon drop, the profiling gear was retrieved and the vessel returned to position over the hole. The drill pipe was started in the hole and an offset of 1100 feet west was introduced based on the latest Sat Nav fix. The $13.5 \mathrm{kHz}$ beacon dropped on arrival, began to lose signal strength rapidly so a $16.0 \mathrm{kHz}$ beacon, No. 151, was readied. At 1809 hours on April 7, the second beacon was let go since the first beacon had lost 50 percent of its signal strength in just three hours. At 1943 hours, an attempt was made to switch to the new beacon. No signal was detected so a third beacon No. 107A $(16 \mathrm{kHz})$ was released. This beacon was on bottom and the vessel operating in automatic by 2025 hours, April 7. After slipping the drill line, the pipe was run to bottom and the Schlumberger sheaves were rigged. At 2200, the EDO scanning sonar was RIH and at 0107 hours on April 8, scanning operations commenced. At 0156 hours, a target was spotted on the 200 foot range scale. Total offsets of 800 feet south and 1500 feet west were required. By 0351 hours, the vessel had maneuvered to within 35 feet of the target and verified that it was, in fact, a re-entry cone. Since there was another cone (504A), known to be just 300 meters distant from 594B, it was decided it would be wise to locate both cones and ensure that the proper one was re-entered. offsets of 800 feet south and 2400 feet west were entered into the positioning computer and by 0412 hours, a target was sited on the 200 foot range scale. By 0424 hours, the target was verified as the hole $504 \mathrm{~A}$ re-entry cone.

Offsets were introduced to bring the vessel back to the $504 \mathrm{~B}$ cone and by 0528 hours, the pipe was placed within ten feet of the re-entry cone. Almost two hours were spent watching the pipe skirt the edges of the cone. Four times coming within five feet of the center but not close enough to attempt a stab. 
It should be noted that because of the wide variety of tools to be run on this hole and to ensure that an adequate amount of time would be available to complete all scientific objectives, a special BHA configuration was used. The BHA was terminated with a cleanout bit. A standard support bearing was bored out to 3.675 inches. This allowed sufficient clearance to pass the borehole seismometer tools and yet left sufficient shoulder material to land the in situ pore water sampler/heat flow barrels, the large volume water sampler and the packer safety go-devil. Finally, the drill pipe packer (Lynes) was made up directly above the bit. It was recognized that the landing shoulder was marginal, therefore new landing subs were utilized and watched carefully, occasionally requiring replacement with other new subs. This configuration allowed all the 504B operations to be done on one pipe trip and one re-entry, saving valuable time which was later needed to complete the science objectives.

Finally, at 0706 hours on April 8, the cone and pipe were one. A stab was effected. All indications of a positive re-entry were apparent. The re-entry sonar was retrieved and two stands of pipe were RIH confirming that a re-entry was made. The Schlumberger sheaves were rigged down and at 0900 hours, a very comprehensive heat flow/geochemistry program was initiated. The first measurements to be taken were "Von Herzen" (VLHPC shoe) heat flow, "Uyeda" heat flow, and a porewater sample. In addition three large volume water samples were taken. These were contaminated with gel mud apparently unsuccessfully circulated out of the hole Leg 83. To supplement the heat flow data deeper in the hole, six maximum reading thermometers were deployed.

Contact with the E1len B. Scripps was made and at 0930 hours, Two scientists were aboard to begin planning the packer and oblique seismic experiments scheduled for the site.

By 0030 hours on April 10, the geochemistry/heat flow program was complete (see figure 2).

A total of 25 heat flow stations were taken and 4 in situ pore water samples were attempted, recovering three. Upon completion of geochemistry/heat flow program, the drill pipe was lowered downhole to ensure that the hole was open for the oblique seismic and the multichannel sonic logging programs. At 0135 hours on April, the pipe detected a bridge in the hole at 4765 meters. Four unsuccessful attempts to break through the bridge utilizing $50 \mathrm{spm}$ circulation were made before abandoning the attempt. No rotation was used and the bridge was left intact since it was not planned to run any of the remaining tools that deep.

After setting back the power sub, the drill pipe was pulled to $3579 \mathrm{~m}$. Five joints of heavy wall pipe were then picked up placing the bit at $3624 \mathrm{~m}$ or approximately $150 \mathrm{~m}$ into the casing. The Schlumberger sheaves were rigged and by 0630 hours on April 10, the borehole seismic tool had been rigged and deck tested. The oblique seismic refraction program was to consist of approximately 20 hours of shooting at each of four depths within the borehole. 
The seismic experiment was hampered by consistent cablehead adapter problems. This problem first arose when the required high temperature, pressure tight connectors could not be found aboard ship. These connectors were necessary in rebuilding the head with high temperature teflon wiring. Without the connectors a competent electrical seal could not be maintained within the tool.

Since the proper connectors were not available, the only solution remaining was to create a chamber in which the connections themselves would be isolated from the seawater. This chamber had to withstand over 6900 psi hydrostatic pressure and $165^{\circ} \mathrm{C}\left(329^{\circ} \mathrm{F}\right)$ temperatures.

Several attempts to provide this seal were tried with all but the last eventually ending in failure of the electrical continuity of the tool. The first 0-ring seal failed when the tack welds locking the connection caused flat spots on the 0-ring. The second attempt utilized a locking ring rather than the tack welds. This time data was collected and everthing appeared good until both the primary and secondary magnetic tape recorders failed. These were eventually repaired and the program resumed until the 2-147 0-ring extruded causing electrical failure of the tool. A third attempt at sealing the cablehead adapter (CHA) once and for all entailed using a larger viton 0-ring (2-332) in the hope that it would not extrude. Back-up rings, normally utilized, in this case were not available

At 0930 hours on April 12, the tool was RIH. However, electrical failure again occurred, this time almost immediately. Two causes were found to be responsible. $A$ bad connection in the Schlumberger winch slip ring and the logging cab was found. Also a bad "Mecca" connector was found in the lower section of the seismic tool. With those problems corrected, the tool was again RIH. However the tool again shorted to ground. When recovered, a failed 0-ring in the cablehead itself was found responsible.

Upon repair, the tool was again deployed. Excellent data was collected until the tool began losing channels. Eventually all were shorted to ground. Due to complete power failure to the tool, the unclamping operation could not be accomplished. The tool was retrieved by slowly dragging the tool out of the hole. A problem was encountered when the tool reached the bit, however this was soon overcome and the tool was eventually dragged inside the bit and retrieved. The CHA had again flooded and the pin connecting the motor linkage to the clamping arm had sheared rather than the "shear pin" designed into the system.

While repairing the system, the multi-channel logging tool was displayed. Excellent data was recovered on video tape and beautiful wave forms were recorded with the aid of the poleroid camera and ocilliscope. Problems with the software package prevented storing the data on disk. The logging rate was 450 feet per hour and the downhole tool worked perfectly.

For the next CHA attempt, it was decided to abandon trying to cut accurate 0 -ring grooves on the ship and utilize other than the correct 0 -rings to seal high pressures in the high temperature environment. Instead a new design, utilizing a welded connection was used. An internal pressure test indicated some startling information. Water droplets were oozing out of the weld area, including the parent metal! This caused two downhole failures of the new design prior to being discovered. Apparently the one portion of the CHA was 
made of a casting or had a permeable metal structure. This was eliminated. A final design was assembled utilizing the 17-4 ph SS part of the CHA and a thread protector from the seismic tool. These were welded together, pressure tested, the cavity filled with aqualube and the tool was RIH for the final time.

In spite of all of the problems encountered, 997 seismic shots were recorded on 14 magnetic tapes, more than any other downhole seismic program in the history of the CHALLENGER. The recorded data quality was excellent. The attached table summarizes the oblique seismic experiment.

\section{Drilling \& Coring Equipment}

Al1 of the sites proposed for Leg 92 had very limited sediment cover. The bottom hole assemblies utilized on this leg therefore were abbreviated as much as possible to minimize the chances of a failure in the BHA either during "spud-in" attempts or while rotary (ХCB included) drilling operations were taking place.

The Following BHA's were utilized on Leg 92. The total length of each in parentheses.

Hole 597A

XCB bit, bit sub, two outer core barrels, two spacers, top sub, three $8 \frac{1}{4} "$ drill collars, one bumper sub, three $8 \frac{1}{4}$ drill collars, two bumper subs, two 8 $\frac{1}{4} "$ drill collars, crossover sub, one $7 \frac{1}{4} "$ drill collar, and two $5 \frac{1}{2} "$ drill pipe $(146.27 \mathrm{~m})$.

Hole 597B

Rotary bit, mechanical bit release, head sub, outer core barre1, top sub, head sub, three $8 \frac{1}{4} "$ drill collars, two bumper subs, two $8 \frac{1}{4} "$ drill collars, crossover sub, one $7 \frac{1}{4} "$ drill collar, two $5 \frac{1}{2} "$ drill pipe (103.57m).

Hole 597C - No.1

Rotary bit, bit sub, head sub, outer core barrel, top sub, head sub,

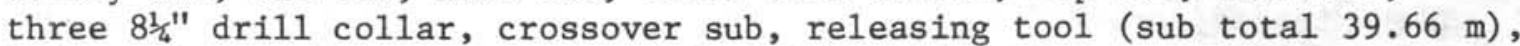

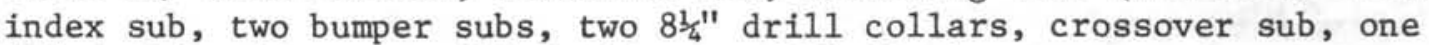
$7 \frac{1}{4} "$ drill collar, two $5 \frac{1}{2} "$ drill pipe (104.76 m).

16" Casing for Hole 597C

Casing hanger, joint No. 1 without collar, joint No. 2, joint No. 3 , joint No. 4 (crossover joint), casing shoe $(39.81 \mathrm{~m})$.

Hole 597C - No. 2 (First Re-entry)

Rotary bit, bit sub, head sub, outer core barrel, top sub, head sub,

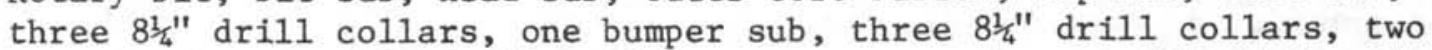

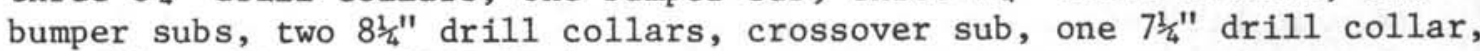
two $5 \frac{1}{2} "$ drill pipe $(135.79 \mathrm{~m})$. 
Hole 597C - No. 3 (Packer)

Cleanout bit, short bit sub, two outer core barrels, packer, jars, crossover sub, three $8 \frac{1}{4} "$ drill collars, two bumper subs, two $8 \frac{1}{4} "$ drill collars, crossover sub, one $7 \frac{1}{4} "$ drill collar, two $5 \frac{1}{2} "$ drill pipe $(116.41 \mathrm{~m})$.

Hole 598A, 599A, 599B, 601A, 601B, 602A, 602B

Extended core barrel bit, bit sub, two outer core barrels, two spacers, top sub, head sub, three $8 \frac{1}{4} "$ drill collars, two bumper subs, two 8/4"

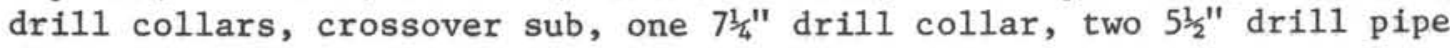
$(113.74 \mathrm{~m})$.

Hole 504B

Cleanout bit, short bit sub, packer, jars, crossover sub, three $8 \frac{1}{4} "$ drill collars, two bumper subs, two $8 \frac{1}{4} "$ drill collars, crossover sub, one $7 \frac{1}{4} "$ drill collar, two $5 \frac{1}{2} "$ drill pipe $(98.17 \mathrm{~m})$.

NOTE: For this BHA a standard support bearing was bored out to an I.D. of 3.675 inches to permit passage for the seismic tools and yet still provide a landing shoulder for the heat flow/pore water, safety go-devil and water sampler tools.

\section{Core Bits and Bit Releases}

Two extended core barrel core bits (11 7/16" $\times 3.8 "$ ) and three standard F94CK core bits ( $97 / 8 "$ × $27 / 16 ")$ were utilized this leg. All bits performed admirably on the fractured, rubbly basement formations. One extended core barrel bit (No. 52) was totaled after 15.8 rotating hours. The second (No. 53), is still in service. One rotary core bit was successfully rleased utilizing a mechanical bit release. Two others are not considered suitable for rerun but could be used if necessary in a short penetration attempt.

Extended Core Barrel (XCB)

The Extended Core Barrel (XCB) was used a total of nine times on five different holes. Some basement material was recovered in each hole in which the XCB was deployed. On a tenth deployment, Hole No. 602, the XCB was used only as a "punch" corer with no rotation intended. The XCB proved its worth by saving a minimum of five round trips of the drill string or approximately 3.5 days of ship's time. The XCB also demonstrated the capability of recovering the sediment/basement interface on Hole $601 \mathrm{~B}$.

The $\mathrm{XCB}$ did not have a high core recovery percentage. Recovering 17.34 meters of core out of 44.4 meters attempted for 39.1 percent. However, in view of the fractured basalt and rubble formations cored, any recovery at all should be considered good. In fact, on Site 597 where both the XCB and the standard rotary system were utilized in the same interval, the XCB cut $2.0 \mathrm{~m}$ and recovered $2.1 \mathrm{~m}$, whereas the standard system cut $6.4 \mathrm{~m}$ and recovered zero. 
The XCB can be used interchangeably with the VLHPC piston coring system and has demonstrated its value in obtaining "a piece" of basement. It is definitely not a hard rock coring system, where significant penetration is required. The $\mathrm{XCB}$ capability can probably be expanded to signifiant hard rock coring with improvements in cutting shoes, core bits and the wear resistance of the latch dogs and drive sleeve. A longer stroke length and an improved, more automatic, circulation system both under study would significantly improve the XCB potential. Improvements in the latch drive system have been excellent except in the area of reliability during free fall deployment. The latch still can intermittently "hang up" at any point in the drill string or BHA and did so on several occasions during Leg 92. Design improvements are underway in this area and the problem should be corrected by Leg 94. A tabular record of XCB deployments for Leg 92 is as follows:

\begin{tabular}{cccl}
$\begin{array}{c}\text { Hole/Core } \\
\text { Number }\end{array}$ & $\begin{array}{c}\text { Amount } \\
\text { Cored }\end{array}$ & $\begin{array}{c}\text { Amount } \\
\text { Recovered }\end{array}$ & \multicolumn{1}{c}{ Remarks } \\
\hline $597 / 1$ & 2.0 & 2.07 & Basalt rubble/cuttings \\
$597 \mathrm{~A} / 1$ & 1.0 & 0.21 & Basalt chunks \\
$598 / 1$ & 5.6 & 0.0 & \\
$598 / 2$ & 2.0 & 0.04 & Basalt chunks \\
$599 \mathrm{~B} / 1$ & 9.0 & 1.52 & Basalt chunks \\
$599 \mathrm{~B} / 2$ & 6.0 & 0.56 & Basalt chunks \\
$601 \mathrm{~B} / 1$ & 9.6 & 5.82 & Sediment/basement contact \\
$601 \mathrm{~B} / 2$ & 1.5 & 0.75 & Basalt chunks \\
$601 \mathrm{~B} / 3$ & 1.5 & 0.18 & Basalt chunks \\
$602 / 1$ & 6.2 & 6.19 & Punch core-ooze
\end{tabular}

Wireline Re-entry

The Wireline Re-entry System (WRS) was deployed once on Leg 92 with no success. The package, after being keelhauled, was run to near bottom with the logging line at $6000 \mathrm{ft} / \mathrm{hr}$. A $12 \mathrm{kHz}$ bottom finding pinger was not used because there were no batteries located onboard the vessel. It was hoped that this could be overcome by utilizing the EDO tool to pick up a mud ring. A position check placed the package 180 feet from the vessel with the vessel holding steady over the hole. This proved to be more difficult than anticipated because of the substantial offsets already in the positioning computer. All offsets must be removed prior to switching beacon frequencies. After the sled position has been checked, the frequency must be switched back to that of the positioning beacon and all offsets reintroduced. A total of $4400 \mathrm{~m}$ of 1 ogging cable was played out in a water depth of $4160 \mathrm{~m}$. It was felt that this was more than 
enough cable to reach bottom even with a significant wire angle. At no time was there any indication of bottom (i.e., weight loss or sonar reflection). The "north seeker" capability of the WRS System also did not appear to be functioning. After 4.1 hours of attempting to find bottom or a cone reflector, the test was abandoned and the tool was retrieved at $10,000 \mathrm{ft} / \mathrm{hr}$. It was believed that EDO scanning sonar tool was not receiving any kind of a return signal. Upon arrival on deck, the re-entry package was found to have penetrated approximately 1.5 feet into a stiff dark brown clay (measured on WRS structure), hence the reputation as a "wireline sampler tool" was achieved. Problems in the Gearhart-Owen cablehead confirmed that the sonar tool was, in fact, not working correctly, thus negating an important test of the WRS system.

\section{$\underline{\text { Re-entry }}$}

Re-entry operations on Site 597, Hole 597C, were routine. The re-entry cone with $39.81 \mathrm{~m}$ of $16^{\prime \prime}$ casing (conductor pipe) was deployed and washed into position without incident and the running/relasing hardware performed flawlessly. A deficiency with the "flow thru" latch sleeve design was identified, however, when the sleeve came out of the hole resting on the core bit rather than on the running tool where it belongs. The latch sleeve was able to slip over the running tools when drill pipe and drill collar wear on the latch sleeve I.D. eventually allowed relative rotation between the latch sleeve and the running tool. When the "flats" of each tool were lined up the two were able. to pass each other leading to a potential catastrophe. This can not occur with the standard latch sleeve design since the landing shoulder is full round without portions being machined away to provide for additional circulation. The flowthru design is under study so as to prevent this occurrence in the future. The re-entry cone was re-entered twice. The first re-entry requiring 2.6 hours and the second requiring 4.7 hours. On both occasions, the EDO scalling sonar equipment performed flawlessly. Re-entry No. 2 was hampered consistently by frequent loss of acoustics (due to sea state generated by frequent line squalis) and was delayed 2.0 hours when the vessel was blown 280 feet off station during a passing line squall.

\section{Multichannel Sonic Logging}

After several false starts on Holes 597B and 597C, the multichannel sonic logging tool came into its own on Hole 504B. Overcoming earlier problems with rugged, reliable packaging, the sonic tool demonstrated a unique capability. The downhole tool, utilizing 8-channels, worked beautifully in 504B. Although software loops and trigger problems prevented real time computer recording, the top $150 \mathrm{~m}$ of the hole, including the Layer $2 \mathrm{~A}$ aquifer, was 1 ogged using polaroids and video tape. Later debugging allowed digitizing from video thru the Zonic A to $\mathrm{D}$ converter to the Minc computer. Results were spectacular with clearly observable P, S, and stonely Code changes related to zones of fracturing as well as normal moveouts across the array.

Dynamic Positioning

No problems with the dynamic positioning system were encountered this trip. Temporary loss of acoustics to the transducers occurred on occasion, always 
as a result of weather and sea state rather than hardware deficiencies. Seven ORE positioning beacons performed well with strong signals, however, three failures did occur. The first was on Site No. 502, just prior to spudding. A $16.0 \mathrm{kHz}$ beacon, No. 150, failed after only nine hours in the water.

The second, a $13.5 \mathrm{kHz}$ beacon, No. 161, began losing signal strength almost immediately after deployment on Site 504B. This beacon 1 ost $50 \%$ of its signal strength in three hours. The third, a $16.0 \mathrm{kHz}$ beacon, No. 151 . had no signal when it reached bottom.

\section{Engineering}

The engine room on Leg 92 was relatively trouble free. The only "lost time" incident occurred while underway to Site No. 598 when the No. 5 generator and the No. 5 D.C. motor flashed. The cause was undertermined but a carbon buildup under the brush holders on No. 5 generator was suspected. On initial inspection signs of arcing were present. The ground fault relay was tripped and megger readings were poor but not zero. The motor and generator was both thoroughly clearned. The commutators on both units were stoned and one brush holder was replaced on the No. 5 motor. New brushes were installed on both units. The final megger readings of the motor, generator, and all related circuitry through the propulsion board were good to excellent. The mechanical condition of the No. 5 generator was good and the No. 5 motors was excellent. Both units were tested and put back in service with no further problems.

While coring on Hole No. 599, it was noticed that the blower unit on the No. 2 bow thruster was noisy. The slow deterioration of the unit allowed repairs to be made at an opportune time when there was no risk to the hole or potential lost time to the operation. When inspected, a damaged fan was found in the blower unit. This was replaced in short order.

One minor problem with a motor assignment on drill board "A" was corrected with no lost time. This incident required the change out of a defective air booster for the No. 1 DC generator.

\section{Weather}

Weather conditions during Leg 92 can best be described as a surprise. Seventy two mile per hour winds and 30 foot seas greeted the CHALLENGER three days after departing Papeete, Tahiti. Tropical storm "NISHA" passed 105 miles ahead of the vessel reducing the speed of advance at one point to 1.5 knots. The CHALZenger was under NISHA's influence for 3.5 days of the total 6.9 days steaming to the first site 597 (HY-1). As a result, the average speed for the transit was only 7.0 knots, putting Leg 921.4 days behing schedule right from the start.

Although sunshine and clear skies prevailed for the majority of the leg, operations were still frequently hampered by seastate. Three prominent sets of swells made finding a suitable heading for operations difficult at best. The problem was easily handled when the winds were not blowing strongly. 
However, the wind speed (20 to $35 \mathrm{mph}$ ) consistently exceeded that charted for this time of year (19 to $20 \mathrm{mph}$ ), forcing the vessel to keep her bow into the wind in order to maintain station.

Line squalls in the last afternoon and evening were not uncommon, and always were present during some critical operation such as re-entry or cone deployment. In fact, 2.0 hours waiting on weather were spent, on one occasion, when the vessel was rapidly blown 180 feet off station. After regaining position, loss of acoustics delayed re-entry operations even further. In general, again due to the multiple swell conditions predominant throughout the leg, the vessel's rolling and pitching motion was much higher than normal.

Weather conditions, while occupying the last site (504B), were outstanding with the typical "doldrums" a welcome relief.

\section{Communications}

Communications during Leg 92 were excellent. WWD was able to handle all traffic in spite of working three other ships in addition to the CHALLENGER. Propagation was generally good with no major problems.

Communications with the French vessel, Papenoo, were a frustration. No communication, in spite of all efforts, with the Papenoo was achieved until two hours prior to her arrival on site. The rendezvous was successfully carried out, however the lack of contact earlier played havoc with the operational scheduling of Hole 597C.

Communications with the second rendezvous ship the EZlen B. Scripps were established early and no problems were encountered. Brief interruptions in the WWD communication schedule were experienced during the seismic experimentation phase of Hole 504B. This was due to mandatory radio silence during the EZZen $B$. Scripps "shooting" schedule.

\section{Personne1}

The success of Leg 92 was a direct result of the skill and professionalism of the GLOMAR CHALLENGER crew. From the beginning, the scientific objectives of the leg emphasized the difficult task ahead. Spudding, drilling and setting a re-entry cone in very young, fractured crustal rock remains as one of the more remarkable achievements of the leg. Coring in areas where the sediment cover was as thin as 2.5 meters is a testimonial to the technical expertise and dedication this crew has developed in the past 15 years of scientific drilling. When the chips were down, and the success or failure of the downhole seismic program was at stake, this crew showed they had a lot of "heart" as we11. The entire drilling crew participated in the repair and rebuilding of the primary seismic tool. The welder, rig mechanic and drilling superintendent were invaluable in fabricating the components required to get the tool "in the hole" and operating. This was successfully accomplished in spite of the very limited shipboard machining capability. The newly promoted drillers, derrickmen and the two new rotary helpers all performed admirably in their new positions. 
The captain and marine crews were equally dedicated to the success of the scientific mission. Spending inordinate amounts of time calculating, checking, and rechecking travel times in an effort to provide the most accurate estimates possible and provide the maximum amount of time to the "on site" operations. Their skill and seamanship also led directly to the successful recovery of two sonar transponders recalled after one year on the seafloor.

The lab officer and technical staff performed with diligence and unparalleled dedication. The operation of the temperature probes and water samplers on 504B was a credit to the pride and skill of the technical staff. Total credit for the successful sampling and measurements programs belongs to the technicians of Leg 92 .

If ever there were an example of "teamwork" and what accomplishments can be achieved through cooperation and pride, then the staff and scientific party of Leg 92 would head the 1 ist.

Michael A. Storms

Operations Manager

Deep Sea Drilling Project 


\section{INTERNATIONAL PHASE OF OCEAN DRILLING \\ DEEP SEA DRILLING PROJECT \\ OPERATIONS RESUME \\ LEG 92}

Total Days (February 20, 1983-April 27, 1983). . . . . . . . 66.3

Total Days in Port . . . . . . . . . . . . . . . . . . .

Total Days Cruising Including Site Survey . . . . . . . . . .

Total Days on Site . . . . . . . . . . . . . . . . . .

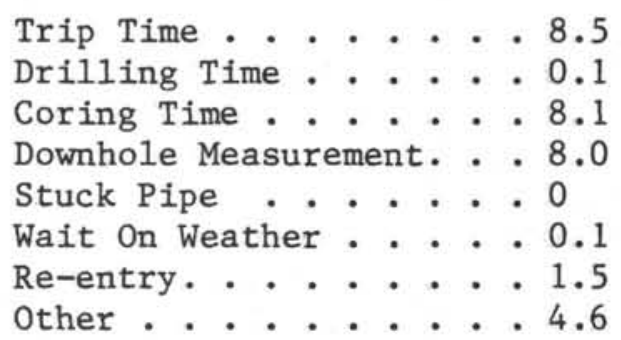

Total Distance Traveled Including Survey (nautical miles). . . . . 6495.2

Average Speed (knots . . . . . . . . . . . . . . 8.6 Number of Sites. . . . . . . . . . . . . . . . . 6 Number of Holes Drilled . . . . . . . . . . . . . . . 19 Number of Cores Attempted. . . . . . . . . . . . . . . . . 55 Number of Cores With Recovery ................ . 51 Total Meters Cored . . . . . . . . . . . . . . . 382.7 Total Meters Recovered . . . . . . . . . . . . . . 279.56 Percent Recovery .. . . . . . . . . . . . . . 73.0 Total Meters Drilled . . . . . . . . . . . . . . . 208.7 Total Meters of Penetration . . . . . . . . . . . . . . . 591.4 Percent of Penetration Cored . . . . . . . . . . . . . . . 64.7 Maximum Penetration (meters) . . . . . . . . . . . . . 109.5 Minimum Penetration (meters) . . . . . . . . . . . . . . . 0 Maximum Water Depth (meters) . . . . . . . . . . . . . . 4157.1 Minimum Water Depth (meters) . . . . . . . . . . . . 3372.3 


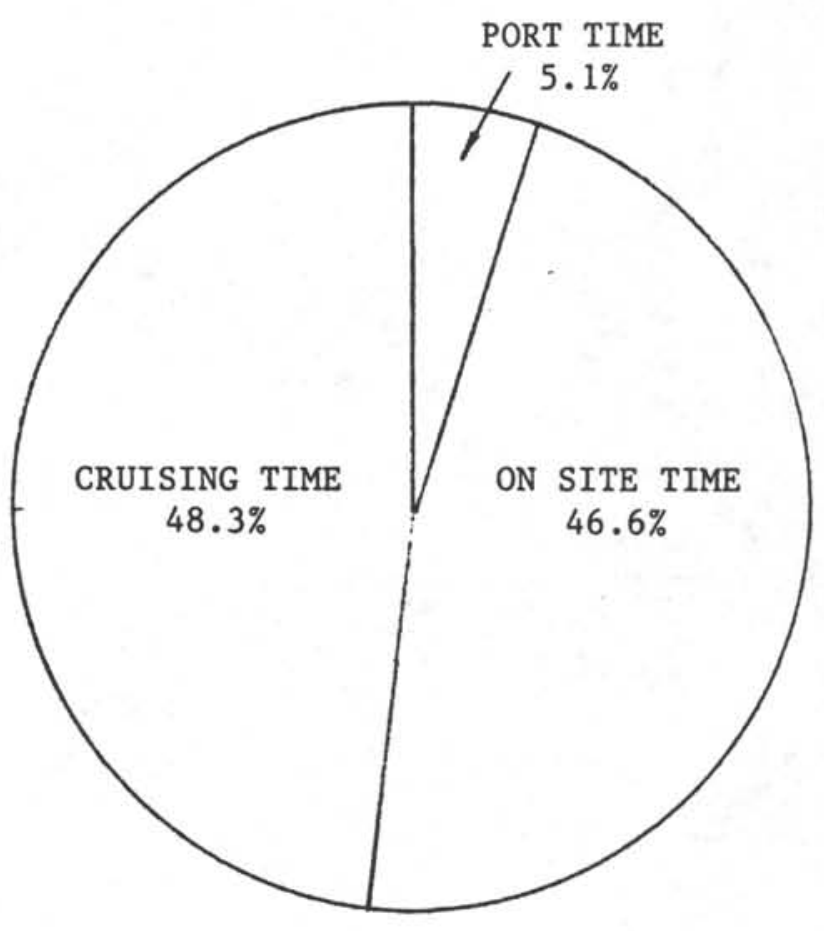

ON SITE TIME BREAKDOWN

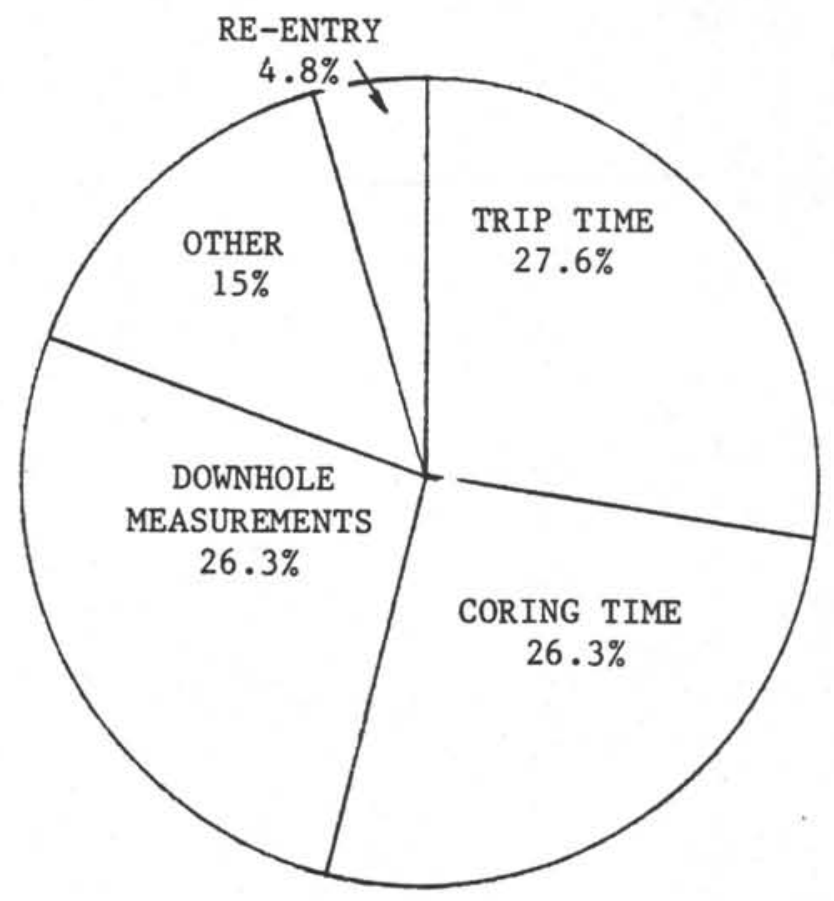




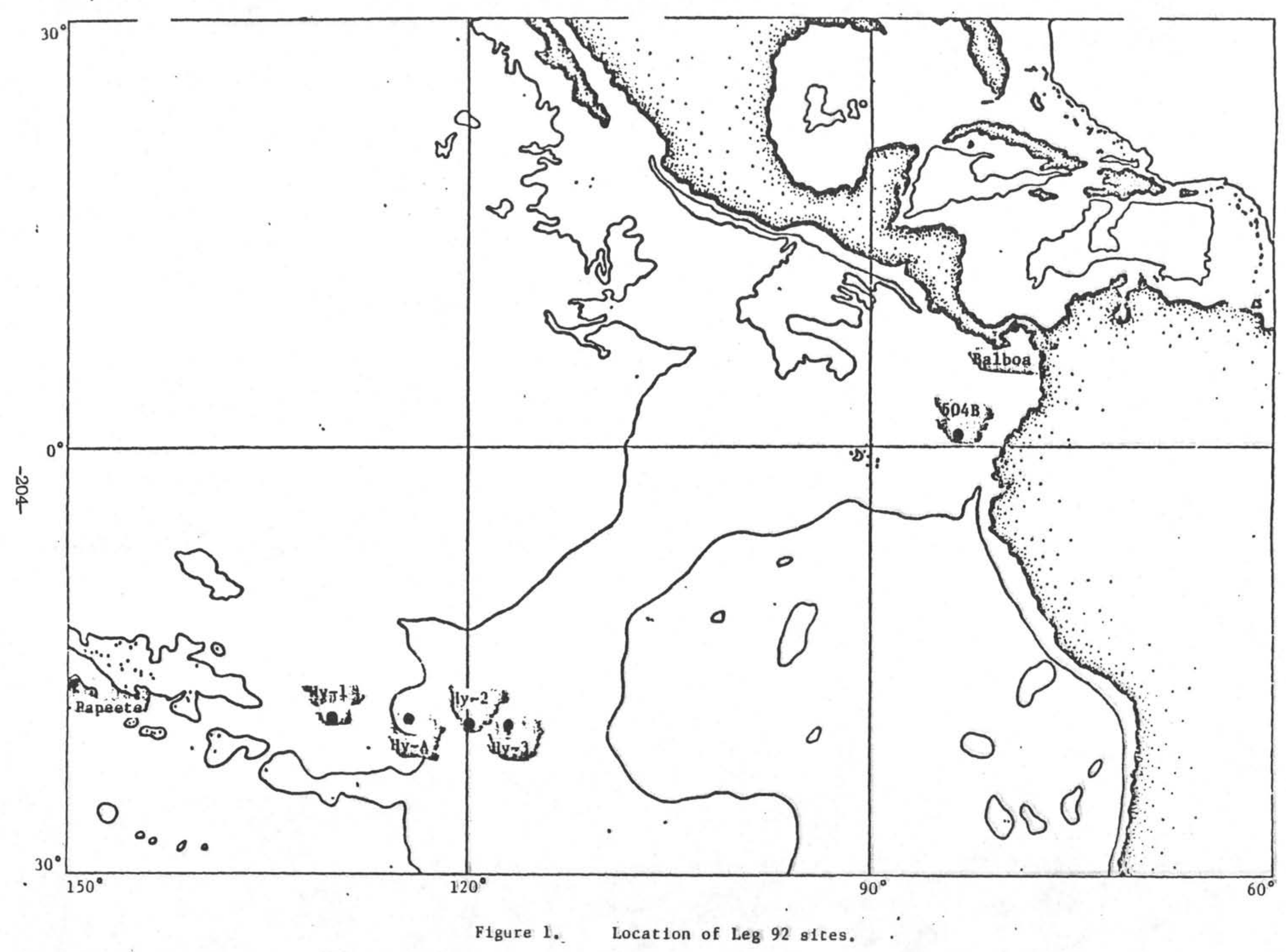


LEG 92

OBLIQUE SEISMIC EXPERIMENT

\begin{tabular}{|c|c|c|c|c|c|c|c|c|}
\hline & $\begin{array}{l}\text { Run } \\
\text { No. }\end{array}$ & $\begin{array}{l}\text { Data } \\
\text { Collected }\end{array}$ & Cause of Failure & $\begin{array}{l}\text { Maximum } \\
\text { Depth (m) }\end{array}$ & $\begin{array}{l}\text { Max Press. } \\
\text { (psi) }\end{array}$ & ${ }^{\operatorname{Max}}$ & $\begin{array}{l}\text { Temp } \\
{ }^{\circ} \mathrm{C}\end{array}$ & Remarks - Damage \\
\hline \multirow{7}{*}{$\begin{array}{l}1 \\
\text { Nิ } \\
\text { ํํ }\end{array}$} & 1. & None & Tack welds flattened 0 -ring. & $\mathrm{N} / \mathrm{A}$ & N/A & N/A & N/A & CHA flooded \\
\hline & 2. & Excellent Data & 0 -ring extruded $(2-147)$ & 4415 & 6445 & & & $\begin{array}{l}\text { CHA flooded \& mag tape } \\
\text { recorders malfunctioned. }\end{array}$ \\
\hline & 3. & None & $\begin{array}{l}\text { Schlumberger slip ring and } \\
\text { Mecca connector on selsmic tool. }\end{array}$ & - N/A & N/A & N/A & N/A & No damage. \\
\hline & 4. & None & Cablehead shorted, bad 0-ring. & N/A & N/A & $\mathrm{N} / \mathrm{A}$ & $\mathrm{N} / \mathrm{A}$ & CHA ok, no damage. \\
\hline & 5. & Excellent data & 0 -ring extruded $(2-332)$ & 4415 & 6445 & & $135^{\circ}$ & $\begin{array}{l}\text { CHA slow flood eventually } \\
\text { lost all channels. Tool } \\
\text { wouldn't unclamp. Mechanical } \\
\text { damage to seismic tool. }\end{array}$ \\
\hline & 6. & None & Porous weld & N/A & N/A & N/A & N/A & CHA flooded \\
\hline & 7. & Excellent data & $\begin{array}{l}\text { Tool eventually would not } \\
\text { function, probably electronic } \\
\text { component failure due to }\end{array}$ & 4775 & & & $+165^{\circ}$ & $\begin{array}{l}\text { CHA ok, electronic component } \\
\text { failure in seismic tool. }\end{array}$ \\
\hline
\end{tabular}


SITE 504B - LEG 92

GEOCHEMISTRY - HEAT FLOW PROGRAM

\begin{tabular}{|c|c|c|c|c|c|c|c|}
\hline & $\begin{array}{c}\text { Depth (m) } \\
\text { From Rig Floor }\end{array}$ & $\begin{array}{c}\text { Depth (m) } \\
\text { Below Seafloor }\end{array}$ & $\begin{array}{l}\text { Von Herzen } \\
\text { Heat Flow }\end{array}$ & $\begin{array}{l}\text { Uyeda } \\
\text { Heat Flow }\end{array}$ & $\begin{array}{l}\text { Max Read. } \\
\text { Thermom. }\end{array}$ & $\begin{array}{l}\text { In-Situ } \\
\text { Pore Water }\end{array}$ & $\begin{array}{l}\text { Lg. Volume } \\
\text { Water Sampler }\end{array}$ \\
\hline \multirow{26}{*}{$\begin{array}{l}1 \\
\text { Nે } \\
\text { }\end{array}$} & WL Run No. 1 & & & & & & \\
\hline & 3580 & 107 & $\mathrm{x}$ & $x$ & & & \\
\hline & 3638 & 164 & $\mathrm{X}$ & $\mathrm{x}$ & & & \\
\hline & 3666 & 193 & $\mathrm{X}$ & $\mathrm{x}$ & & & \\
\hline & 3695 & 221 & $\mathrm{x}$ & $\mathrm{x}$ & & & \\
\hline & 3724 & 250 & $\mathrm{X}$ & $\mathrm{X}$ & & & \\
\hline & 3752 & 279 & $\mathrm{X}$ & $\mathrm{x}$ & & & \\
\hline & 3781 & 307 & $\mathrm{x}$ & $\mathrm{x}$ & & & \\
\hline & 3809 & 336 & $\mathrm{x}$ & $\mathrm{x}$ & & & \\
\hline & 3838 & 364 & $\mathrm{X}$ & $\mathrm{X}$ & & & \\
\hline & 3866 & 393 & $\mathrm{x}$ & $\mathrm{x}$ & & & \\
\hline & 3894 & 421 & $\mathrm{x}$ & $\mathrm{x}$ & & $\mathrm{x}$ & \\
\hline & 3923 & 449 & $\mathrm{x}$ & $\mathrm{x}$ & & & \\
\hline & \multicolumn{7}{|l|}{ WL Run No. 2} \\
\hline & 3980 & 507 & & $\mathrm{x}$ & & & \\
\hline & 4009 & 535 & & $\mathrm{x}$ & & & \\
\hline & 4037 & 564 & & $\mathrm{x}$ & & $\mathrm{x}$ & \\
\hline & \multicolumn{7}{|l|}{ WL Run No. 3} \\
\hline & 4066 & 592 & & $\mathrm{x}$ & & & \\
\hline & 4095 & 621 & & $\mathrm{x}$ & & & \\
\hline & 4123 & 650 & & $\mathrm{x}$ & & $\mathrm{x}$ & \\
\hline & 4152 & 679 & & $\mathrm{x}$ & & $\mathrm{x}$ & \\
\hline & \multicolumn{7}{|l|}{ WL Run No. 4} \\
\hline & 4210 & 736 & & $\mathrm{x}$ & & $\mathrm{x}$ & \\
\hline & 4238 & 765 & & $\mathrm{x}$ & & & \\
\hline & 4267 & 794 & & $\mathrm{x}$ & $x$ & & \\
\hline
\end{tabular}


SITE 504B - LEG 92

GEOCHEMISTRY - HEAT FLOW PROGRAM

CONTINUED

\begin{tabular}{|c|c|c|c|c|c|c|c|}
\hline & $\begin{array}{c}\text { Depth (m) } \\
\text { From Rig Floor }\end{array}$ & $\begin{array}{c}\text { Depth (m) } \\
\text { Below Seafloor }\end{array}$ & $\begin{array}{l}\text { Von Herzen } \\
\text { Heat Flow }\end{array}$ & $\begin{array}{c}\text { Uyeda } \\
\text { Heat Flow }\end{array}$ & $\begin{array}{l}\text { Max. Read. } \\
\text { Thermom. }\end{array}$ & $\begin{array}{l}\text { In-Situ } \\
\text { Pore Water }\end{array}$ & $\begin{array}{l}\text { Lg. Volume } \\
\text { Water Sampler }\end{array}$ \\
\hline \multirow{13}{*}{ 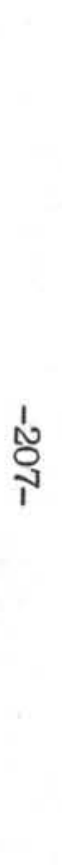 } & WL Run No. 5 & & & & & & \\
\hline & 4400 & 926 & & & & & $\mathrm{x}$ \\
\hline & WL Run NO. 6 & & & & & & \\
\hline & 4478 & 1004 & & $\mathrm{x}$ & & & \\
\hline & 4507 & 1033 & & $\mathrm{x}$ & $\mathrm{x}$ & & \\
\hline & WL Run No. 7 & & & & & & \\
\hline & 4526 & 1052 & & $\mathrm{x}$ & $\mathrm{x}$ & & \\
\hline & WL Run No. 8 & & & & & & \\
\hline & 4572 & 1100 & & & $\mathrm{x}$ & & $\mathrm{x}$ \\
\hline & WL Run No. 9 & & & & & & \\
\hline & 4621 & 1148 & & & $\mathrm{x}$ & & \\
\hline & WL Run No. 10 & & & & & & \\
\hline & 4678 & 1204 & & & $\mathrm{x}$ & & $\mathrm{x}$ \\
\hline
\end{tabular}


INTERNATIONAL PHASE OF OCEAN DRILLING

DEEP SEA DRILLING PROJECT

$$
\text { SITE SUMMARY }
$$

$$
\text { LEG } 92
$$

\begin{tabular}{|c|c|c|c|c|c|c|c|c|c|c|c|c|c|c|}
\hline Hole & Latitude & Long1tude & $\begin{array}{l}\text { Water } \\
\text { Depth } \\
\text { Meters }\end{array}$ & $\begin{array}{l}\text { Number } \\
\text { of } \\
\text { Cores }\end{array}$ & $\begin{array}{l}\text { Cores } \\
\text { W1th } \\
\text { Recovery }\end{array}$ & $\begin{array}{l}\text { Percent of } \\
\text { Cores With } \\
\text { Recovery }\end{array}$ & $\begin{array}{c}\text { Meters } \\
\text { Cored }\end{array}$ & $\begin{array}{c}\text { Meters } \\
\text { Recovered }\end{array}$ & $\begin{array}{c}\text { Percent } \\
\text { Recovered }\end{array}$ & $\begin{array}{c}\text { Meters } \\
\text { Drilled }\end{array}$ & $\begin{array}{c}\text { Total } \\
\text { Penet } \\
\text { Meters }\end{array}$ & $\begin{array}{l}\text { Avg. } \\
\text { Rate } \\
\text { Penet }\end{array}$ & $\begin{array}{l}\text { T1me } \\
\text { On } \\
\text { Hole }\end{array}$ & $\begin{array}{l}\text { Time } \\
\text { On } \\
\text { S1te }\end{array}$ \\
\hline $\begin{array}{l}597 \\
597 \mathrm{~A} \\
597 \mathrm{~B} \\
597 \mathrm{C}\end{array}$ & $\begin{array}{ll}18 & 48.39^{\prime} \mathrm{s} \\
18^{\circ} & 48.39^{\circ} \mathrm{s} \\
18^{\circ} & 48.39^{\prime} \mathrm{s} \\
18^{\circ} & 48.39^{\prime} \mathrm{s}\end{array}$ & $\begin{array}{ll}129^{\circ} & 46.23^{\prime} \mathrm{W} \\
129^{\circ} & 46.23^{\prime} \mathrm{W} \\
129^{\circ} & 46.23^{\prime} \mathrm{W} \\
129^{\circ} & 46.23^{\prime} \mathrm{W}\end{array}$ & $\begin{array}{l}4157 \\
4157 \\
4157 \\
4157\end{array}$ & $\begin{array}{l}8 \\
7 \\
3 \\
8\end{array}$ & $\begin{array}{l}7 \\
7 \\
2 \\
7\end{array}$ & $\begin{array}{r}87.5 \\
100.0 \\
66.7 \\
87.5\end{array}$ & $\begin{array}{l}54.7 \\
48.6 \\
24.6 \\
66.0\end{array}$ & $\begin{array}{r}42.1 \\
48.64 \\
5.43 \\
3 \% .78\end{array}$ & $\begin{array}{r}77.0 \\
100.1 \\
22.0 \\
57.2\end{array}$ & $\begin{array}{l}0 \\
0 \\
48.0 \\
43.5\end{array}$ & $\begin{array}{r}54.7 \\
48.6 \\
72.6 \\
109.5\end{array}$ & $\begin{array}{l}1.5 \\
1.5 \\
1.5 \\
1.5\end{array}$ & $\begin{array}{r}31.2 \\
27.2 \\
52.5 \\
206.4\end{array}$ & $\begin{array}{c}\overline{-} \\
\overline{-} \\
31 \overline{7} .3\end{array}$ \\
\hline $\begin{array}{l}598 \\
593 \mathrm{~A}\end{array}$ & $\begin{array}{l}19^{\circ} 00.28^{\prime} \mathrm{s} \\
19^{\circ} 00.28^{\prime} \mathrm{s}\end{array}$ & $\begin{array}{l}124^{\circ} 40.6 i^{\prime} \mathrm{W} \\
124^{\circ} 40 / 61^{\prime} \mathrm{W}\end{array}$ & $\begin{array}{l}3703 \\
3703\end{array}$ & $\begin{array}{l}8 \\
0\end{array}$ & $\begin{array}{l}7 \\
0\end{array}$ & $\begin{array}{c}87.5 \\
0\end{array}$ & $\begin{array}{c}52.4 \\
0\end{array}$ & $\begin{array}{l}41.29 \\
0\end{array}$ & $\begin{array}{c}79.0 \\
0\end{array}$ & $\begin{array}{c}0 \\
33.0\end{array}$ & $\begin{array}{l}52.4 \\
33.0\end{array}$ & 1.5 & $\begin{array}{l}23.2 \\
15.0\end{array}$ & $\overline{38.3}$ \\
\hline $\begin{array}{l}559 \\
599 \mathrm{~A} \\
599 \mathrm{~B}\end{array}$ & $\begin{array}{l}19^{\circ} 27.09^{\prime} \mathrm{s} \\
19^{\circ} 27.09^{\prime} \mathrm{s} \\
19^{\circ} 27.09^{\prime} \mathrm{s}\end{array}$ & $\begin{array}{ll}119^{\circ} & 52.88^{\prime} \mathrm{W} \\
119^{\circ} & 52.88^{\prime} \mathrm{W} \\
119^{\circ} & 52.88^{\prime} \mathrm{W}\end{array}$ & $\begin{array}{l}3644 \\
3644 \\
3644\end{array}$ & $\begin{array}{l}5 \\
0 \\
3\end{array}$ & $\begin{array}{l}5 \\
0 \\
3\end{array}$ & $\begin{array}{c}100.0 \\
0 \\
100.0\end{array}$ & $\begin{array}{l}40.8 \\
0 \\
23.6\end{array}$ & $\begin{array}{l}34.76 \\
0 \\
11.57\end{array}$ & $\begin{array}{l}85.0 \\
0 \\
49.0\end{array}$ & $\begin{array}{c}0 \\
22.6 \\
32.2\end{array}$ & $\begin{array}{l}40.8 \\
22.6 \\
55.8\end{array}$ & $\overline{-}$ & $\begin{array}{r}17.9 \\
4.3 \\
38.7\end{array}$ & $\begin{array}{c}- \\
60.9\end{array}$ \\
\hline $\begin{array}{l}600 \\
500 \mathrm{~A} \\
5003 \\
6000\end{array}$ & $\begin{array}{ll}18^{\circ} & 55.74^{\prime} \mathrm{s} \\
18^{\circ} & 55.74^{\prime} \mathrm{s} \\
18^{\circ} & 55.74^{\prime} \mathrm{s} \\
18^{\circ} & 55.70^{\prime} \mathrm{s}\end{array}$ & $\begin{array}{ll}116^{\circ} & 50.37^{\prime} \mathrm{N} \\
116^{\circ} & 50.37^{\prime} \mathrm{N} \\
116^{\circ} & 50.37^{\prime} \mathrm{N} \\
116^{\circ} & 50.45^{\prime} \mathrm{N}\end{array}$ & $\begin{array}{l}3372 \\
3372 \\
3372 \\
3406\end{array}$ & $\begin{array}{l}1 \\
0 \\
1 \\
2\end{array}$ & $\begin{array}{l}1 \\
0 \\
1 \\
2\end{array}$ & $\begin{array}{c}100.0 \\
0 \\
100.0 \\
100.0\end{array}$ & $\begin{array}{l}5.4 \\
0 \\
1.9 \\
19.0\end{array}$ & $\begin{array}{l}5.38 \\
0 \\
1.90 \\
11.8\end{array}$ & $\begin{array}{c}99.6 \\
0 \\
100.0 \\
62.0\end{array}$ & $\begin{array}{l}0 \\
0 \\
0 \\
0\end{array}$ & $\begin{array}{l}5.4 \\
0 \\
1.9 \\
19.0\end{array}$ & $\begin{array}{l}- \\
- \\
-\end{array}$ & $\begin{array}{r}20.4 \\
1.6 \\
1.6 \\
11.4\end{array}$ & $\begin{array}{l}\overline{-} \\
\overline{35.0}\end{array}$ \\
\hline $\begin{array}{l}601 \\
601 \mathrm{~A} \\
601 \mathrm{~B}\end{array}$ & $\begin{array}{l}18^{\circ} 55.22 \text { 's } \\
18^{\circ} 55.22^{\prime} \mathrm{s} \\
18^{\circ} 55.2^{\prime} \mathrm{s}\end{array}$ & $\begin{array}{l}116^{\circ} 52.111^{\prime} \mathrm{W} \\
116^{\circ} 52.11^{\prime} \mathrm{W} \\
116^{\circ} 52.11^{\prime} \mathrm{W}\end{array}$ & $\begin{array}{l}3448 \\
3448 \\
3448\end{array}$ & $\begin{array}{l}3 \\
0 \\
3\end{array}$ & $\begin{array}{l}3 \\
0 \\
3\end{array}$ & $\begin{array}{c}100.0 \\
0 \\
100.0\end{array}$ & $\begin{array}{c}20.4 \\
0 \\
12.6\end{array}$ & $\begin{array}{l}19.45 \\
0 \\
6.75\end{array}$ & $\begin{array}{l}95.0 \\
0 \\
54.0\end{array}$ & $\begin{array}{l}0 \\
15.0 \\
14.4\end{array}$ & $\begin{array}{l}20.4 \\
15.0 \\
27.0\end{array}$ & $\overline{-}$ & $\begin{array}{r}12.0 \\
2.2 \\
17.5\end{array}$ & $\overline{-}$ \\
\hline $\begin{array}{l}602 \\
602 \mathrm{~A} \\
602 \mathrm{~B}\end{array}$ & $\begin{array}{l}18^{\circ} 54.41^{\prime} \mathrm{s} \\
18^{\circ} 54.41^{\prime} \mathrm{s} \\
18^{\circ} 54.41^{\prime} \mathrm{s}\end{array}$ & $\begin{array}{l}116^{\circ} 54.68^{\prime} \mathrm{W} \\
116^{\circ} 54.68^{\prime} \mathrm{W} \\
116^{\circ} 54.68^{\prime} \mathrm{W}\end{array}$ & $\begin{array}{l}3544 \\
3547 \\
3547\end{array}$ & $\begin{array}{l}1 \\
1 \\
1\end{array}$ & $\begin{array}{l}1 \\
1 \\
1\end{array}$ & $\begin{array}{l}100.0 \\
100.0 \\
100.0\end{array}$ & $\begin{array}{l}6.2 \\
2.3 \\
4.2\end{array}$ & $\begin{array}{l}6.19 \\
2.28 \\
4.24\end{array}$ & $\begin{array}{r}99.8 \\
99.0 \\
101.0\end{array}$ & $\begin{array}{l}0 \\
0 \\
0\end{array}$ & $\begin{array}{l}6.2 \\
2.3 \\
4.2\end{array}$ & - & $\begin{array}{r}14.5 \\
1.1 \\
15.8\end{array}$ & $\overline{-}$ \\
\hline 5043 & $2^{\circ} 13.63^{\prime} \mathrm{N}$ & $83^{\circ} 43 / 81^{\prime} \mathrm{W}$ & 3474 & 0 & 0 & 0 & 0 & 0 & 0 & 0 & 1280.5 & - & 226.0 & 226.0 \\
\hline
\end{tabular}


DEEP SEA DRILLING PROJECT

BIT SUMMARY

LEG 92

\begin{tabular}{|c|c|c|c|c|c|c|c|c|c|c|}
\hline Hole & Mfg. & Size & Type & $\begin{array}{l}\text { Serfal } \\
\text { Number }\end{array}$ & $\begin{array}{c}\text { Meters } \\
\text { Cored }\end{array}$ & $\begin{array}{l}\text { Meters } \\
\text { Drilled }\end{array}$ & $\begin{array}{l}\text { Meters } \\
\text { Total } \\
\text { Penet. }\end{array}$ & $\begin{array}{l}\text { Hours } \\
\text { On } \\
\text { B1t }\end{array}$ & Condition & Reinarks \\
\hline $\begin{array}{l}597 \\
597 \mathrm{~A}\end{array}$ & $\begin{array}{l}\text { HSDS } \\
\text { USDS }\end{array}$ & $\begin{array}{l}11-7 / 16 \\
11-7 / 16\end{array}$ & $\begin{array}{ll}\text { XCB } & \mathrm{F} 94 \\
\text { XCB } & \text { F94 }\end{array}$ & $\begin{array}{l}S-53 \\
S-53\end{array}$ & $\begin{array}{l}54.7 \\
48.6\end{array}$ & $\begin{array}{l}0 \\
0:\end{array}$ & $\begin{array}{l}54.7 \\
48.6\end{array}$ & $\begin{array}{l}\mathrm{N} / \mathrm{A} \\
1.0\end{array}$ & $\begin{array}{l}\text { N/A } \\
\text { T2B2 I }\end{array}$ & $\begin{array}{l}\text { HPC only. } \\
\text { HPC plus one XCB. }\end{array}$ \\
\hline $597 \mathrm{~B}$ & Saxt: & $9-7 / 8$ & $\mathrm{P} 94 \mathrm{CK}$ & $832 \mathrm{KV}$ & 24.6 & 48.0 & 72.6 & 17.0 & RIH & W/MBR \\
\hline $597 \mathrm{C}$ & MSD3 & $9-7 / 8$ & F94CK & $S-56$ & 66.0 & 43.5 & 109.5 & 32.7 & BT3B4 0 & First bit. \\
\hline $597 \mathrm{C}$ & MSDS & $9-7 / 8$ & F94CK & s-5? & 34.0 & 0 & 34.0 & 16.2 & T2BS I & Second bit (total $143.5 \mathrm{~m}) /$ \\
\hline $\begin{array}{l}598 \\
598 \mathrm{~A}\end{array}$ & $\begin{array}{l}\text { USDS } \\
\text { MSDS }\end{array}$ & $\begin{array}{l}11-7 / 16 \\
11-7 / 16\end{array}$ & \begin{tabular}{l|l}
$\mathrm{XCB}$ & $\mathrm{F} 94$ \\
$\mathrm{XCB}$ & $\mathrm{F} 94$
\end{tabular} & $\begin{array}{l}s-53 \\
s-53\end{array}$ & $\begin{array}{c}52.4 \\
0\end{array}$ & $\stackrel{0}{33.0}$ & $\begin{array}{l}52.4 \\
33.0\end{array}$ & $\begin{array}{l}1.4 \\
\mathrm{~N} / \mathrm{A}\end{array}$ & $\begin{array}{l}\text { N/A } \\
\text { T2B2 I }\end{array}$ & $\begin{array}{l}\mathrm{HPC} \text { plus } 2 \text { XCB. } \\
\mathrm{HF} / \mathrm{PW} \text { on } 1 \mathrm{y} .\end{array}$ \\
\hline $\begin{array}{l}599 \\
599 \mathrm{~A} \\
599 \mathrm{~B}\end{array}$ & $\begin{array}{l}\text { MSDS } \\
\text { MSDS } \\
\text { MSDS }\end{array}$ & $\begin{array}{l}11-7 / 16 \\
11-7 / 16 \\
11-7 / 16\end{array}$ & $\begin{array}{ll}X C B & F 94 \\
X C B & F 94 \\
X C B & F 94\end{array}$ & $\begin{array}{l}s-52 \\
s-52 \\
s-52\end{array}$ & $\begin{array}{l}40.8 \\
0 \\
17.6\end{array}$ & $\begin{array}{c}0 \\
22.6 \\
32.2\end{array}$ & $\begin{array}{l}40.8 \\
22.6 \\
49.8\end{array}$ & $\begin{array}{r}\text { N/A } \\
\text { N/A } \\
15.8\end{array}$ & $\begin{array}{l}\text { N/A } \\
\text { N/A } \\
\text { T6BTB7 } 0\end{array}$ & $\begin{array}{l}\text { HPC only. } \\
\text { HF/PW only } \\
\text { Recored same interval. }\end{array}$ \\
\hline $\begin{array}{l}600 \\
600 \mathrm{~A} \\
600 \mathrm{~B} \\
600 \mathrm{C}\end{array}$ & $\begin{array}{l}\text { MSDS } \\
\text { MSDS } \\
\text { MSDS } \\
\text { MSDS }\end{array}$ & $\begin{array}{l}11-7 / 16 \\
11-7 / 16 \\
11-7 / 16 \\
11-7 / 16\end{array}$ & $\begin{array}{ll}\text { XCB } & \mathrm{F} 94 \\
\mathrm{XCB} & \mathrm{F} 94 \\
\mathrm{XCB} & \mathrm{F} 94 \\
\mathrm{XCB} & \mathrm{F} 94\end{array}$ & $\begin{array}{l}s-53 \\
s-53 \\
s-53 \\
s-53\end{array}$ & $\begin{array}{l}5.4 \\
? \\
1.9 \\
19.0\end{array}$ & $\begin{array}{l}0 \\
0 \\
0 \\
0\end{array}$ & $\begin{array}{l}5.4 \\
? \\
1.9 \\
19.0\end{array}$ & $\begin{array}{l}\text { N/A } \\
\text { N/A } \\
\text { N/A } \\
\text { N/A }\end{array}$ & $\begin{array}{l}\text { N/A } \\
\text { Broke barrel off downhole } \\
\text { N/A } \\
\text { T2B2 I }\end{array}$ & $\begin{array}{l}\text { HPC only. } \\
\text { HPC only. } \\
\text { HPC only. }\end{array}$ \\
\hline $\begin{array}{l}501 \\
601 \mathrm{~A} \\
601 \mathrm{~B}\end{array}$ & $\begin{array}{l}\text { MSDS } \\
\text { MSDS } \\
\text { MSDS }\end{array}$ & $\begin{array}{l}11-7 / 16 \\
11-7 / 16 \\
11-7 / 16\end{array}$ & $\begin{array}{ll}\mathrm{XCB} & \mathrm{F} 94 \\
\mathrm{XCB} & \mathrm{F} 94 \\
\mathrm{XCB} & \mathrm{F} 94\end{array}$ & $\begin{array}{l}S-53 \\
S-53 \\
S-53\end{array}$ & $\begin{array}{c}20.4 \\
0 \\
12.6\end{array}$ & $\begin{array}{l}0 \\
15.0 \\
14.4\end{array}$ & $\begin{array}{l}20.4 \\
15.0 \\
17.0\end{array}$ & $\begin{array}{l}\mathrm{N} / \mathrm{A} \\
\mathrm{N} / \mathrm{A} \\
5.2\end{array}$ & $\begin{array}{l}\text { N/A } \\
\text { N/A } \\
\text { T3B4 I }\end{array}$ & $\begin{array}{l}\text { HPC only } \\
\text { HF/PN only. } \\
\text { Three XCB cores. }\end{array}$ \\
\hline $\begin{array}{l}602 \\
602 \mathrm{~A} \\
602 \mathrm{~B}\end{array}$ & $\begin{array}{l}\text { MSDS } \\
\text { MSDS } \\
\text { MSDS }\end{array}$ & $\begin{array}{l}11-7 / 16 \\
11-7 / 16 \\
11-7 / 16\end{array}$ & $\begin{array}{ll}\mathrm{XCB} & \mathrm{F} 94 \\
\mathrm{XCB} & \mathrm{F} 94 \\
\mathrm{XCB} & \mathrm{F} 94\end{array}$ & $\begin{array}{l}S-53 \\
S-53 \\
S-53\end{array}$ & $\begin{array}{l}6.2 \\
2.3 \\
4.2\end{array}$ & $\begin{array}{l}0 \\
0 \\
0\end{array}$ & $\begin{array}{l}6.2 \\
2.3 \\
4.2\end{array}$ & $\begin{array}{l}\text { N/A } \\
\text { N/A } \\
5.2\end{array}$ & $\begin{array}{l}\text { N/A } \\
\text { N/A } \\
\text { T3B4 I }\end{array}$ & $\begin{array}{l}\text { One XCB punch core. } \\
\text { HPC only. } \\
\text { HPC only. }\end{array}$ \\
\hline
\end{tabular}


INTERNATIONAL PHASE OF OCEAN DRILLING

DEEP SEA DRILLING PROJECT

BEACON SUMMARY

LEG 92

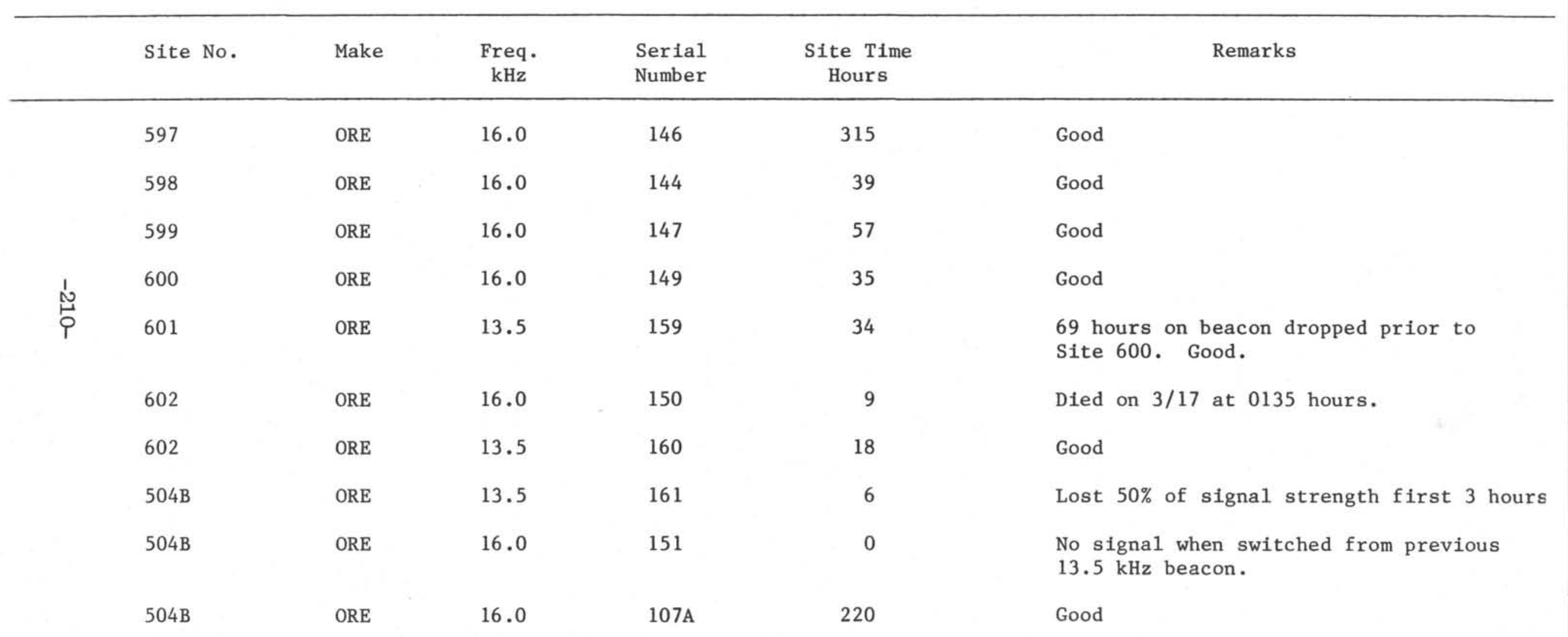




\section{INTERNATIONAL PHASE OF OCEAN DRILLING \\ DEEP SEA DRILLING PROJECT \\ OPERATIONS RESUME \\ LEG 93}

Leg 93 of the Deep Sea Drilling Project was dedicated to deep continental slope objectives off the Atlantic coast of the United States. The primary drill site was targeted for penetration through jurassic sediments to sample old oceanic crust. Contingency sites off the New Jersey shore were designated for the study of various aspects of the evolution of the North Atlantic Ocean.

The cruise was marked by major achievements and misfortunes. Site 603 had one of the deepest penetrations in DSDP history and produced a record amount of core before it was prematurely terminated by the disastrous loss of the drill string. Two attempts to reach target horizons at Site 604 were aborted by flowing sand in the hole. Site 605 yielded an extraordinarily complete Eocene/Paleocene section, including the Cretaceous/Tertiary boundary, but only at the expense of a one-day cruise extension. It was a work-intensive expedition, with the greatest percentage of site time and the fewest miles traveled of any DSDP leg.

The voyage commenced on April 27, 1983 at Norfolk, Virginia and terminated on June 17, 1983 at Norfolk. Total length of the leg was 50.7 days, of which, 41.3 days were spent on site, 5.7 days in port and 3.7 days in transit. Mechanical breakdown accounted for 2.5 days and weather delay for 1.2 days.

\section{Norfolk Port Call}

Leg 93 had its official beginning at 2303 hours, April 27, 1983 with the first mooring line on arrival at Pier N, Lambert's Point Docks, Norfolk, Virginia. Principal work items for the port call included a major overhaul of No. 8 engine, repairs to fuel tanks $\mathrm{N}-6-\mathrm{F}$ and $\mathrm{N}-20-2-\mathrm{D}$, and the installation of a new port bank/full bank air valve and high-pressure relief valves for the heave compensator system.

In addition to the off-loading of cores and samples and the normal arriving and departing shipments, 15 joints of 11-3/4" casing, eleven bumper subs and 1000 sacks of bulk barite were loaded. The vessel was bunkered from barges with 501,000 gallons of marine gas-oil.

With repairs, logistics and crew change functions complete, sailing time was set for 1400 hours, May 3. Nonavailability of tugs resulted in a delay of nearly one hour, and the last line was cast off the dock at 1456 hours. 
Norfolk to Site 603

A brief stop was made just seaward of the Chesapeake Bay Bridge/ Tunnel to test the functioning of the positioning system, thrusters and acoustic beacons. CHALLENGER then proceeded seaward across the continental shelf toward the drill site. A second stop was made the following morning to jettison old sandline. The geophysical gear was then streamed and profiling commenced. With approximately 24 miles remaining to the site, the vessel slowed to about seven knots. Five miles later, a slight turn was made to retrace a reference seismic profile, approaching the site from the northwest. A positioning beacon was dropped on the first pass at 0411 hours, May 5 . The profile was extended two miles beyond the drop point before the towed gear was retrieved and the CHALLENGER returned to take station over the beacon.

Average speed for the 330 -mile transit was 8.9 knots. The drill site, formerly designated ENA-3, was the primary objective of the voyage and is located about 270 miles east of Cape Hatteras, North Carolina and 310 miles northwest of Bermuda.

\section{Hole 603 - Lower Continental Rise}

The initial pipe trip was slowed somewhat as the pipe was "strapped" to ensure accurate depth measurements. During the trip, the vessel's position was refined using information from the satellite navigation system (SATNAV) and the precision depth recorder (PDR). Offsets of 365 meters north and 215 meters were entered into the positioning system. The corrected PDR depth from the rig floor was 4643 meters.

Spudding was delayed by about $2 \frac{1}{4}$ hours by mechanical difficulties with the heave compensator system. At 2012 hours, a seafloor punch core was attempted by lowering the core bit to 4653 meters. The inner core barrel was retrieved completely full of sediment $(9.6 \mathrm{~m})$. As an accurate depth determination was required for planning the re-entry installation, a second seafloor core was tried (to $4643.3 \mathrm{~m}$ ) after one joint of drill pipe had been laid out. This inner barrel was recovered without a trace of sediment, and water depth was estimated at 4644 meters.

A jet-in test was then conducted to determine the casing point for the 16-inch conductor string which would support the re-entry cone assembly. The bit was jetted without rotation to about 76 meters below seafloor (BSF) before firm resistance was felt.

The hole was then drilled through clay and soft claystone to 5189 meters, with spot cores taken at intervals not greater than 48 meters for stratigraphic and hydrocarbon safety control. Spaced through this interval were five instrumented probe runs for temperature data and in situ pore water samples. Minor hole problems occurred on two occasions during this interval. They were attributed to the adherence of sticky clay to the bottom hole assembly (BHA).

Continuous coring then proceeded to 5390 meters in claystone which became gradually more indurated with depth. It was necessary to deploy the bit deplugger once when core was lost from an inner barrel during retrieval and became lodged inside the drill string. On May 9, with most of the hole's 
objectives achieved, an approaching weather front prompted the decision to stop coring and to pull out of the hole for the safety of the drill string. The hole was filled with weighted mud and the pipe trip was started. Before the bit was pulled from the hole, it became apparent that the weather front was dissipating. The previous core was retrieved from the pipe while the weather continued to improve. Since the rate of penetration (ROP) was still about 30 meters/hour and the hole and core bit were in good condition, further coring was a compelling option.

The bit was then run back to total depth and coring operations were resumed. At about 800 meters BSF, the ROP decreased to the point where there was little advantage in continued coring through a section that would have to be penetrated again in the re-entry hole. Coring was terminated at $832.6 \mathrm{~m} \mathrm{BSF}$. The hole was again displaced full of weighted mud, and the drill string was pulled. About 30,000 to 50,000 pounds overpull or "drag" was noted through much of the hole on the pipe trip. This was thought to be the result of clay in the hole wall swelling in reaction to the fresh water of the drilling mud. The core bit arrived on deck at 0450 hours, May 11 .

Hole 603A

The rig was quickly prepared for the deployment of the preassembled re-entry cone, and keelhaul lines were passed from the moonpool under the hull for the attachment of slings to the cone. The cone was in the water only $2 \frac{1}{2}$ hours after the bit had been brought on deck. When the cone had been hung off beneath the moonpool, a 71.8 meter string of 16-inch casing was made up and hung off beneath the rig floor. The BHA, incorporating the casing running tool, was then assembled and lowered to engage the casing string. The casing was, in turn, lowered until it latched into the re-entry cone. The final slings were cut and the entire assembly was lowered toward the seafloor as the drill string was made up.

Hole 603A was spudded at 2058 hours, May 11, and jetting-in proceeded smooth1y with only moderate resistance to about 30 meters BSF. Then several meters were made at an increased rate with very little resistance. It was then noted that about 30,000 pounds of hanging weight had been lost (approximately that of the cone and casing). Premature shifting of the release sleeve or failure of the casing running tool was suspected. It was soon confirmed that the drill string was free to move downward without the cone/casing assembly, but inability to rotate the drill string indicated that a normal full release had not occurred. Low circulating pump pressure was also a sign of loss of system integrity. It was also found that the BHA could move down through the casing, but not upward, as the latch sleeve remained attached to the casing hanger. With no way to complete the jetting-in operation, two attempts were made to retrieve the shifting tool with the sandline and release the assembly. The shifting tool was found to'be stuck somewhere in the BHA and the overshot safety shear pin failed on both occasions. A third try was made with a backup shifting tool, but the sleeve was not engaged, indicating that the other tool was lodged at or above the sleeve.

As the cone/casing assembly could be neither emplaced nor released, the drill string was recovered to the BHA. The use of divers to attempt to unlatch the cone from the casing was deemed unfeasible due to adverse sea conditions and the safety risks of open-ocean diving. The $7 \frac{1}{4}-i n c h$ drill collar was 
laid out and drill pipe was made up loosely at the lowest accessible BHA connection. The assembly was then lowered by one stand, the pipe was set in slips and the rotary table was turned to the left to back off and release the $\mathrm{BHA} / \mathrm{cone} / \mathrm{casing}$ assembly. (The hardware was dropped about one mile southeast of the drill site.) The pipe was recovered at 1345 hours, May 12 and re-entry system preparations began again from scratch.

Hole 603B

About 18 hours were required to assemble a new BHA, re-entry cone and casing running tool and to test latching of the casing hanger into the cone. The cone was then keelhauled and another seven-joint string of 16-inch casing was run and latched up. Following a routine pipe trip, Hole 603B was spudded at 0136 hours, May 14, on positioning offsets 30-meters west of Hole 603 .

Jetting-in was much more difficult in this case than at Hole 603 or $603 \mathrm{~A}$. It was necessary to raise and lower the pipe repeatedly and to use maximum pump circulation for most of the interval. No further progress could be made after the "mud skirt" of the cone reached a depth of $4642.5 \mathrm{~m}$ below the rig floor, and this was established as seafloor depth. A wireline trip was made with an inner core barrel with a shifting tool attached to release the cone/casing assembly at 0438 hours.

A 14-7/8-inch hole was then drilled, without cores, to the intended depth of the surface casing shoe at 5123 meters. The drilling rate was much slower than expected, and the inner barrel was pulled twice when a full barrel was suspected of slowing penetration. This measure had little effect. Wiper trips for hole conditioning were made at 4956 meters and at total depth. The hole was found to be clean after each trip and was thoroughly flushed with bentonite mud before the pipe trip was made for the surface casing string. The 14-7/8-inch bit was brought on deck at 2100 hours, May 15.

\section{First Re-entry - Surface Casing}

The rig's complete inventory of 53 joints of 11-3/4-inch range two 54-pound casing, plus three expansion joints, was then made up and hung off in the moonpool. A special BHA of drill pipe and bumper subs was then assembled. The purpose of this BHA was to facilitate cementing the casing by directing the slurry through the casing's float shoe. A sealing nipple was held in the top of the shoe by the weight of the BHA. After the carefully measured BHA was made up to the casing running tool and lowered into the casing, it was found to be nine meters too short. The BHA was laid down and the length was rechecked, confirming that the casing string was too long, apparently the result of a systematic error in measurement. As the string was too long for the existing hole, it was necessary to remove the casing hanger and remove one joint of casing before the string could be attached to a new BHA by means of the casing running tool. The entire assembly was then suspended by both a clamp at the moonpool and heavy drill pipe at the rig floor at 1615 hours, May 16.

The wind and seas of an approaching weather system were producing vessel motion and positioning conditions that were prohibitive to deploying and re-entering with the heavy $(425,000$ lb.) combined drill pipe/casing string. 
A delay of 28 hours ensued before weather conditions abated sufficiently. Maximum sustained winds of 35 knots were recorded and vessel roll reached six degrees.

The drill string was then run to put the casing shoe at re-entry depth, and the re-entry sonar tool was lowered through the pipe on the logging cable. On initiation of sonar scanning, the primary (eight degree) transducer was found to be inoperative. The re-entry cone target was acquired at a distance of 80 feet $(24 \mathrm{~m})$ with the 45 degree transducer, however, and standard approach maneuvers were carried out to bring the pipe over the cone. A successful re-entry stab was made after 95 minutes of scanning.

When the sonar tool had been recovered and the re-entry had been verified by the addition of one stand of drill pipe, the logging sheaves were rigged down. The casing was then run into the hole until resistance was felt at 4993 meters. The power sub was rigged and the casing was circulated to within one meter of total depth before progress was arrested. Fairly constant resistance of 30,000 to 40,000 pounds was encountered for the entire distance. (The power sub was set back with the shoe at $5114 \mathrm{~m}$ and was replaced with a "knobby" drilling joint and a circulating head to avoid cementing through the power sub.)

When the entire weight of the casing string had been "taken" downhole, the drill string was raised to check for latch-in of the casing hanger. No additional weight was acquired, indicating that the snap ring of the casing hanger had not engaged the re-entry cone. The shoe was again landed and the string was alternately lowered to the next hub of the drilling joint, set down on elevators and torqued with the rotary table until the casing running tool was slacked enough to rotate and release the casing. This occurred at about $1 \frac{1}{2}$ to 2 meters below the calculated point, and it was felt that the weight of the upper casing string had pulled the conductor pipe and re-entry cone down by this amount. (Two expansion joints had been placed near the center of the surface casing string to permit resting half the weight of the heavy string on the bottom of the hole while only the upper part would be suspended from the cone.) This information, along with the seafloor range reading from the re-entry sonar, was used to revise the water depth measurement for the hole from $4642.5 \mathrm{~m}$ to $4644 \mathrm{~m}$.

The drill string was then raised completely clear of the casing and lowered until the BHA seal nipple landed in the casing shoe. BHA weight loss was noted when the first bumper sub began to close. The pipe was held at this depth while the cementing line was rigged and a ball was dropped to break out the bakelite sleeve that held the float valve open. A batch of 180 barrels of $15 \mathrm{lbs} / g a 1$. cement slurry was then mixed and pumped into the drill string. Next a latch-down displacement plug was launched, followed by ten barrels of slurry and ten barrels of fresh water, and displaced with seawater to the shoe. The plug failed to land and block circulation, however, after an adequate amount of water had been pumped. Pumping was stopped to avoid displacing cement from the hole. The cementing equipment was rigged down and the drill string was recovered. A brief stop was made at the re-entry cone while water was pumped to flush cement from the pipe and cuttings from the cone. The pipe trip was completed at 0015 hours, May 19. 
Second Re-entry - Coring Bottom Hole Assembly

A standard 9-7/8-inch coring bit and BHA ware made up and run to re-entry depth without incident. The re-entry sonar tool, which had been "deck

checked" three times, failed shortly after it had been started down the pipe. The tool was recovered and replaced by a backup unit, with a resultant delay of one hour. The sonar functioned faultlessly and the second re-entry was accomplished without undue difficulty after a scanning/maneuvering time of 104 minutes.

The re-entry equipment was rigged down as an inner core barrel equipped with a center bit was pumped into place at the bit. The core bit was then lowered until cement was contacted at $5094 \mathrm{~m}$. (The volume of cement inside the casing corresponded quite closely with the ten barrels pumped behind the plug.) The cement, plug, and shoe were then drilled out--with somewhat more difficulty than had been anticipated.

Even after the bit was well beyond the casing shoe, difficulty was experienced in drilling new hole. Torquing, slow penetration and erratic pump pressure plagued drilling efforts. The center bit was the only difference in the drilling assembly from that of Hole 603. It was replaced with a standard inner barrel, but little improvement was noted and the ROP remained below that of Hole 603. Sticky clay, adhering to the drill collars and "balling" the bit, was the suspected cause of the problems, but maximum pump pressure and RPM improved the ROP only slightly until a depth of about 5205 meters had been reached. Drilling rate then improved considerably for about 55 meters. After another abrupt drop in ROP, it was suspected that the inner barrel had filled up, and a sandline trip was made to recover it. The barrel was stuck in place and two attempts to retrieve it resulted only in sheared overshot pins. Another joint was drilled down (requiring one hour) and a third retrieval attempt was made. This time the barrel was found to be free. It was recovered filled with claystone and a "fresh" barrel was pumped down the pipe. Anomalously low pump pressure had been noted on pumping down the previous core barrel, and this barrel gave no pressure indication of landing at the bit.

A review of the problems and phenomena experienced in Hole 603B led to the conclusion that a failed bumper sub was probable or (less likely) that a washout existed somewhere in the drill string. The string was therefore pulled, and the washpipe of the second bumper sub was found to be loose inside the body of the telescoping sub. This had permitted pump circulation to pass around the packing of the bumper sub and out through the vented body. A large vertical crack in the top (threaded) part of the washpipe was found to be responsible for the failure of the threaded connection. All three bumper subs were laid out for inspection, and the bit was brought on deck at 0415 hours, May 21 .

\section{Third Re-entry - Core Bit}

The BHA was reassembled with a new core bit and three rebuilt bumper subs. A 9-7/8-inch stabilizer was added 22 meters above the bit in an attempt to alleviate a possible "dogleg" situation in the hole as indicated by a $5 \frac{1}{2}{ }^{\circ}$ single shot survey reading at 5270 meters.

The pipe trip and re-entry were uneventful, with a successful re-entry stab made after 59 minutes of scanning. The trip to total depth continued, with 
the first resistance felt at 5157 meters. The bit was washed down to total depth at 5282 meters without undue difficulty after the power sub was deployed.

Drilling had proceeded to 5337 meters when a malfunction in the dynamic positioning system resulted in the loss of control of the vessel's heading. When the system was shifted to the manual mode of operation, there was no response from the stern thrusters. It was therefore necessary to return to the semiautomatic mode and to try to hold station without heading control. With beam winds gusting to 20 knots, the thrusters were barely able to hold position and the order was given to pull the drill string above the seafloor. There was little hope of accomplishing this, however, with 700 meters of pipe in the hole and both the power sub and heave compensator deployed. By the time the power sub had been set back, heading control had been regained and full automatic positioning resumed. The maximum excursion off station had been about $170 \mathrm{~m}$. Rig operations were then suspended until the stern thruster problem had been rectified. When all problems had been corrected, the power sub was again picked up. Drilling recommenced after a 6-3/4 hour delay.

The hole was then drilled to the total depth of Hole 603 before the center bit was replaced with an inner core barrel. Alternate drilling and spot coring proceeded to 5571 meters, where continuous coring began. About $300 \mathrm{~m}$ of claystones, siliceous claystones and carbonaceous shales were then penetrated at an excellent rate and with generally good recovery. Hole conditions were good, but the hole angle had increased at a rather alarming rate to $17 \frac{1}{2}{ }^{\circ}$, despite the addition of the stabilizer to the BHA. Beginning at about $5870 \mathrm{~m}$, approximately 30 meters of unconsolidated to semiconsolidated turbiditic sand was encountered. The presence of loose flowing sand in the core barrel caused considerable concern because of the rig's minimal hole-cleaning capabilities. Minor torquing and sticking tendencies did occur, but the hole stabilized after a few additional cores had been cut. The sandstone, interbedded with siltstone, claystone and marl, continued for over $100 \mathrm{~m}$ more but became better cemented with depth. Around 6100 meters, the turbidite sequence gradually gave way to a lithology of chalk and laminated marlstone. The material was quite well indurated, but the ROP remained high. The cores began to show signs of bit bearing wear, however, and the core bit was retired at the depth of $6122 \mathrm{~m}$, (1478 m BSF) after an excellent run.

A flush of bentonite and guar gum mud slugs was displaced completely out of the hole and the ten heavy drilling joints were laid out before the power sub and heave compensator were set back. The pipe drug up to 50,000 pounds over hanging weight for the first 13 stands before it came free in the hole. This was felt to be related to the crooked hole conditions. The remainder of the pipe trip was routine, and the bit arrived on deck at 0725 hours, May 29. It was found to have one loose cone. 
Fourth Re-entry - Core Bit

The fourth re-entry was accomplished in 94 milutes of scanning time after a routine pipe trip. After the re-entry, the bit was run to the surface casing shoe where an attempt was made to measure hole deviation with the single shot instrument. The effort consumed $3 \frac{1}{4}$ hours and was unsuccessful due to an instrument malfunction. The trip then continued smoothly until resistance was encountered at $5530 \mathrm{~m}$ ( $886 \mathrm{~m} \mathrm{BSF})$. The pipe was "worked" against heavy drag, using the circulating head, to about 5900 meters, where the power sub and heave compensator were picked up. The bit finally reached total depth at 0915 hours, May 30, and coring resumed with high hydrostatic back pressure which indicated a considerable amount of material suspended in the annulus of the hole.

Hole cleaning conditions improved after three or four cores, and coring continued through early Cretaceous chalk and laminated marl. The ROP remained high to about $1525 \mathrm{~m} \mathrm{BSF}$, where an increased limestone content reduced the penetration rate to about 8 meters per hour. On core No. 83R, the rate dropped further to $6 \mathrm{~m} / \mathrm{hr}$. This interval had just been cored, and the bit was being raised off the bottom of the hole in preparation for retrieval of the core when disaster struck.

The drill string parted just below the power sub (about 12 meters above the rig floor) and the entire drilling assembly was lost. Fortunately, the falling pipe struck nothing between the break and the vessel's keel and there were no injuries. The failure occurred at the box connection of the kelly cock sub and its exact nature and cause have not been determined. The string was lost at 1545 hours, May 31, at a total drill string depth of $6229.2 \mathrm{~m}$.

\section{$\underline{\text { Hole } 603 \mathrm{C}}$}

After the accident, the rig was inspected for damage and minor damage to the traveling block was repaired. The broken connection was removed, the power sub pin and replacement kelly cock sub were magnafluxed and a new kelly sub assembly was made up to the power sub.

At this time, only 24 stands of drill pipe remained on the pipe racker, and the major task of assembling a new drill string had to be accomplished before drilling/coring operations could continue. Nearly two days were required to remove the contents of the casing hold and to assemble the drill pipe and drill collars into stands. The work was slowed further by inclement weather and vessel motion. Finally, at 1400 hours on June 2, enough pipe was on the racker to spud the final hole of Site 603.

The initial pipe trip was slowed by requirements to measure the pipe, to remove rubber protectors from the lower (used) portion of the string and to make up the tool joints of the new pipe twice. The power sub was picked up in preparation for spudding, and the kelly cock sub was removed from the assembly. (The kelly cock, a blowout prevention safeguard, was removed on the recommendation of GMDC management because it had been in use as long as the failed unit and its risks were perceived to outweigh its safety benefits.) The hydraulic piston corer (HPC) assembly was then deployed and run to the bit. Hole $603 \mathrm{C}$ was spudded at 1027 hours, June 3, on positioning offsets about 310 meters northwest of the re-entry cone. 
A shallow penetration at Site ENA-3 (603) had been planned from the beginning for detailed stratigraphic and paleontological work. Enough drill pipe remained on board to accomplish this before moving to shallower water to finish the cruise. A combination of the HPC and extended core barrel (XCB) coring techniques was employed.

The HPC system was utilized in the relatively soft clay section and provided excellent recovery of undisturbed cores from the seafloor to 91 meters BSF. At this point, full stroke of the 9.5 meter corer was no longer achieved and overpul1 of 35,000 pounds was noted on withdrawing the core barrel.

The XCB system was then substituted for the HPC and coring continued. Initial attempts produced low core recovery until the proper combination of drilling parameters was found. Excellent recovery of relatively undisturbed core was then enjoyed to about 250 meters BSF. Recovery remained good in the underlying soft claystone, but rather severe rotational disturbance prevailed after the corer began operating in the rotating mode.

Runs were made with a modified core barrel for temperature measurements at 85 and 146 meters BSF. The self-contained shoe was used in lieu of the probe, and the special runs reduced the risk of equipment failure that has been experienced in the past when the shoe was attached to a HPC barrel. Excellent data were recorded at both points to supplement the Hole 603 data.

Coring was terminated at 366 meters BSF to provide enough time to complete another drill site before returning to Norfolk. The XCB system was then rigged down and the drill string was recovered. The vessel got under way for Site 604 at 2330 hours, June 6.

Site 603 to site 604

After a $1 \frac{1}{2}$-hour departure survey, the course was set for the second and supposedly final drill site, which was to be located about 100 miles southeast of Atlantic City, New Jersey. The weather deteriorated rapidly, and winds reached 40 knots in squalls which persisted for most of June 7 . This reduced vessel speed to less than six knots at times and hampered rig floor operations as the crew struggled to make up the remaining drill pipe into stands on the pipe rack. By evening conditions had improved vastly, and speed had increased to nearly ten knots. Upon arrival in the operating area, another $1 \frac{1}{2}-$ hour survey was conducted to locate the site. The positioning beacon was launched at 0616 hours, June 8 .

Hole 604 - Upper Continental Rise

A standard rotary coring BHA was assembled and the bit was run to spudding position based on a PDR reading of 2366 meters. The bit was lowered to 2371.9 meters for a seafloor punch core and the inner barrel was recovered. No sediment was present in the barrel, so a pipe connection was made for a second attempt. At 1500 hours, June 8, the rig weight indicator registered solid bottom at about 2374 meters, and this was used for the official water depth-although the core barrel contained only 5.3 meters after reaching a depth of 2380.5 meters. Unusually firm Pleistocene clay made coring operating slow and tedious for the first 65 meters, as only very light weight could be applied with the unsupported BHA while rotation and strong circulation were required to achieve penetration. 
Coring continued through Pleistocene and Pliocene clay and sandy clay with only fair core recovery but good hole conditions. At about $260 \mathrm{~m}$ BSF, the drill encountered soft sand in an apparent Miocene slump deposit. Two additional cores (without recovery) were attempted before the sand began packing off and sticking the BHA. This occurred despite mud flushes and all attempts to stabilize the hole. As the bottom of the sand stratum had not been reached, prospects of successfully deepening the hole appeared dim.

The hole was then filled with weighted mud, and the core bit was pulled clear of the seafloor.

$\underline{\text { Hole } 604 \mathrm{~A}}$

Study of the New Jersey Transect reference profile disclosed that the sand body appeared to pinch out rapidly to the northwest. An optimum relocation site was chosen by the scientists about $2.5 \mathrm{~km}$ northwest of Hole 604 . The profile indicated that the sand body could be avoided at this location while all other target strata could be cored. Unfortunately a move of $2.5 \mathrm{~km}$ was not technically feasible because a second positioning beacon had been dropped during Hole 604 operations to replace the malfunctioning original beacon. With beacons transmitting on both operating frequencies, about six kilometers is considered to be a minimum distance to avoid interference with the new beacon. The only option open for a second attempt to core Site NJ-4 was therefore a maximum offset to the northwest to the approximate location of the edge of the sand body. The vessel was consequently offset about $1.2 \mathrm{~km}$ northwest along the seismic line as depth was monitored on the PDR.

Hole 604A was spudded at 0515 hours, June 10. A firm seafloor was again "felt" with the weight indicator at 2350 meters, as compared with a PDR reading of 2338 meters. The previously cored clay section was drilled to 249.6 meters before coring commenced. Only three cores were cut in the Miocene material before the bit again broke into sand. The sand acted more quickly in sticking the drill string this time, and 15 minutes were required to work the pipe loose at the bottom of the first full core interval in the sand. Another core was attempted after the hole had been cleaned to total depth and a mud flush had been circulated. The pipe became stuck again, however, after six meters had been penetrated. Freeing the pipe was more difficult the second time, and it was apparent that the site was not drillable with CHALLENGER'S drilling system.

This hole was also filled with weighted mud in accordance with hydrocarbon safety policy. The drill string was recovered and, after additional positioning beacons were tested, the vessel departed Site 604.

Hole 605

The vessel, under way at slow speed, was moved five $\mathrm{km}$ further to the westnorthwest along the reference profile to a total distance of about six $\mathrm{km}$ from the closest Site 604 beacon. LORAN C, the PDR and the positioning system were monitored during the move, and a new beacon was launched at 0013 hours, June 11 .

Water depth by PDR was $2203 \mathrm{~m}$, and Hole 605 was spudded at 0708 hours the same morning. The seafloor was detected by the weight indicator at 2207 
meters. The heave compensator was used, as at Site 604, to maintain a steady weight on the bit during the touchy spudding operation in the stiff clay.

The Pleistocene clay layer was drilled to 154.3 meters BSF before coring began. After another 48 meters of clay, soft Eocene chalk was encountered. The chalk was cored with excellent ROP and recovery for about 150 meters, before it became much harder, with properties approaching those of limestone. The Eocene limestone continued, with phenomenal recovery, to about 565 meters BSF, where Paleocene calcareous claystone was reached. Recovery remained very high, but the continued low penetration rate caused the "target" Cretaceous strata to remain tantalizing out of reach as operating time ran out.

Paleocene rock was still being cored at the time scheduled for termination of operations. A last minute phone call to DSDP in La Jolla resulted in a cruise extension of one day to attempt to penetrate through the lowermost Tertiary strata. Coring continued through the night with little apparent change in the age or nature of the sediment. Then, early in the morning, the drill reached Cretaceous rocks. The final site objectives were fulfilled with only a few hours remaining.

The hole was then filled with barite-weighted mud. The drill string was recovered, and the BHA connections received their bi-monthly magnetic inspection as preparations were made for getting under way. GLOMAR CHALLENGER departed Site 605 at 1915 hours, June 16.

\section{Site 605 to Norfolk}

A brief PDR profile was made to the west-northwest across Site NJ-3 and along the USGS reference seismic line. At 1935 hours, course was set for Norfolk. As most of the return trip was to be made across the shallow waters of the continental shelf and heavy traffic was anticipated, the geophysical gear was not deployed. Weather during the transit was nearly flat calm, with fog and haze prevailing. The smooth waters and following current produced an average speed of over ten knots, and it required only about 19 hours to reach the Chesapeake Bay pilot station. Leg 93 came to its official end at 1610 hours, June 17 with the first mooring line across to Pier B, Sewell's Point Docks, Norfolk, Virginia.

\section{$\underline{\text { Drilling and Coring Equipment }}$}

Various BHA configurations were used during Leg 93. The standard DSDP BHA used for coring at Holes 603,603B, 604,604A, and 605, consisted of: bit, bit sub, one $8 \frac{1}{4} "$ drill collar adapted to an outer core barrel with top and

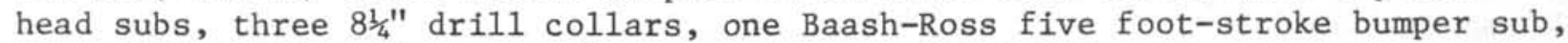

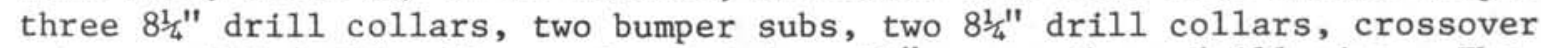
sub, one $7 \frac{1}{4} "$ drill collar and two joints $5 \frac{1}{2} "$ range three drill pipe. The $\mathrm{HPC} / \mathrm{XCB}$ assembly used at Hole $603 \mathrm{C}$ had to be "spaced out" to exact measurements to accommodate the XCB. This BHA was made up of: bit, bit sub, two $8 \frac{1}{4} "$ drill collars, two three-foot drill collar spacers, top sub, seal/latch sub, one twelve foot by $8 \frac{1}{4}$ " gammaloy drill collar (for magnetic orientation), two bumper

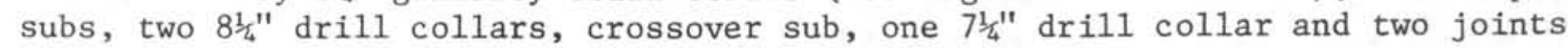
$5 \frac{1}{2} "$ range three drill pipe. Special configurations were used at Holes $603 \mathrm{~A}$ and 603B to emplace re-entry cones and drill surface hole. The bit and standard outer core barrel assembly were followed by drill collars spaced to 
place the bit at the casing shoe, then a release sub, index sub, two bumper

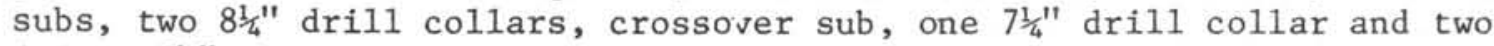
joints $5 \frac{1}{2} "$ range three drill pipe.

The most serious drilling equipment problem was, of course, the failure of the kelly cock sub which resulted in the loss of a 6230 -meter drill string. The cause of the break was not obvious, though age and fatigue are suspected factors. The failure mode is currently under investigation.

The drill string assembled following the loss consists of a replacement BHA as described above, 151 joints of premium grade used pipe that earlier had been removed from the working string for varying degrees of tool joint shoulder damage, 59 joints of aluminum drill pipe (on board for testing and evaluation), 72 joints of premium grade pipe that had remained on the pipe rack following the failure and 299 joints of new drill pipe from storage in the hold. Total length of this drill string is about 5600 meters, but additional pipe has been dispatched to Norfolk and will be on board for Leg 94 .

Bumper subs were also a trouble source on Leg 93. The cracked washpipe that became disconnected in a rebuilt unit caused difficulty in emplacing the second re-entry cone/casing assembly and then resulted in a very low ROP in subsequent drilling, finally forcing a premature round trip and re-entry. The anomalously high hole angle that subsequently developed was probably the result of early drilling with inadequate circulation. An attempt was made to incorporate two new bumper subs into the BHA following the Hole 603A loss, and it was discovered that the rotary-shouldered connections of the eleven new bumper subs received in Norfolk had not been cut to specification. These subs are not usable in their present condition; they will be reworked during the Leg $93 / 94$ port call.

The heave compensator system again required a great deal of repair and maintenance during the first half of the voyage. Electrical problems in the raise/lower system, leaky valves at various locations and hydraulic hose failures were the major trouble sources. The compensator was out of the string for two days on Hole 603B when a malfunctioning antislingshot valve had to be replaced.

Once again the TOTCO Drilling Recorder System failed to perform adequately with resultant lost data and frustration for all concerned. The chronic inability of the clock drive to produce a record within one or two hours of the time recognized by the rest of the world was paramount among the recorder's shortcomings.

\section{Special Tools}

The Hydraulic Piston Coring and Extended Core Barrel Systems were both utilized in Hole 603C. The weather cooperated, and excellent core recovery and quality were attained with the HPC. At 91 meters BSF, HPC refusal was defined by incomplete stroke of the 9.5 meter system and by resistance to withdrawal of about 35,000 pounds. The XCB then extended the interval of relatively undisturbed core to about 250 meters at that site. Good recovery persisted with the XCB in its rotary mode to total depth at 366 meters. No operational problems were encountered with either system, except for the tendency of the XCB latch to become fouled inside the drill pipe. This proclivity cost considerable 
wireline time, but the problem area has been defined and improvements are in progress.

The performance of the "single shot" tool for hole drift surveys and core orientation was even more disappointing than usual. Malfunctioning clock timers, poor quality photographs and faulty batteries led the list of grievances.

A prototype gyroscopic orientation tool made two successful test runs on wireline trips in Hole 605. Minor mechanical and electrical problems were identified and will be addressed in the next few weeks. The gyro concept appears viable and may be available for HPC core orientation on Leg 95 and/or 96 .

Core Bits

The core bits utilized on Leg 93 were of the F93CK configuration with only two exceptions. The longer chisel-type inserts of this model were instrumental in producing a good ROP in the indurated claystones and hemipelagics of the continental slope. One bit accrued a total of 2228.2 meters in 80.7 rotating hours. Spudding into the very firm, almost rubbery Pleistocene clay of the New Jersey transect area would probably have been much more difficult with a shorter-toothed bit. The low ROP in the surface hole of $603 \mathrm{~B}$ was attributed at the time to the shorter teeth of the 14-7/8" F94CK bit in use, but inadequate circulation due to the subsequently discovered bumper sub failure was probably the primary cause. A used and badly worn 11-7/16" special HPC/XCB bit was used in Hole 603C. Bit cutting structure is a minimal factor in penetrating such soft and semi-consolidated sediments, and its performance was entirely satisfactory. No holes were terminated by bit failure.

\section{$\underline{\text { Re-entry Equipment }}$}

A serious failure in the re-entry cone/casing running tool assembly resulted in the loss of the cone, casing and BHA on the first installation attempt at Site 603. Unfortunately the failed component(s) could not be recovered for analysis of the failure. Observed pheonomena would indicate a failure of the load-bearing paddles in the latch sleeve assembly or of the roller spindles of the shifting sleeve in the release sub. The concurrent, but apparently unrelated, problem that prevented actuation of the release sub was the sticking of the wireline shifting tool in a bumper sub. As these parts were also unrecovered, it is unknown whether the fault lay in the shifting tool or in the bumper sub.

Four successful re-entries were made into Hole 603B. The EDO sonar re-entry equipment performed well, with only minor problems. An eight degree transducer failed on the first re-entry, but the operation was completed on the alternate $\left(45^{\circ}\right)$ transducer. A power regulator burned out in the sonar tool shortly after it was started down the pipe for the second re-entry. It was summarily replaced by a backup unit and only one hour was lost.

$\underline{\text { Positioning Beacons }}$

Five ORE acoustic beacons were deployed during Leg 93. All performed acceptably, except for $16 \mathrm{kHz}$ double-life unit No. 152 which was replaced after $1 \frac{1}{2}$ days 
at Site 604. The signal pulse included an undesirable "tail" and was fluctuating in strength. Positioning was maintained with only occasional failures, but lack of confidence in the signal prompted the launching of a replacement. The original Site 603 beacon ( $16 \mathrm{kHz}$ double-life) maintained a strong signal for 20 days before it began to weaken fairly rapidly and was replaced. Another $16 \mathrm{kHz}$ double-1ife unit (No. 109A) was found to have a dead battery when it was rigged for testing at the beginning of the leg. It has been returned to the manufacturer.

\section{Dynamic Positioning}

Only two malfunctions occurred which were directly related to the dynamic positioning system (DPS) itself. Unfortunately they had to be dealt with simultaneously. Loss of heading control in automatic and semi-automatic modes was originally thought to be temperature-related. This was not borne out in testing carried out after the drill string had been recovered. A faulty circuit card or card contact were the remaining possibilities, and all cards which could have caused the problem have been replaced. The manual mode stern thruster malfunction was remedied by replacing a diode bridge in the throttle control circuit.

An apparent heading-related systematic positioning error of 150-200 feet radius was noted at Site 603. This was based on the DPS offsets required to make re-entries on various headings. At Site 605, offsets totaling over 200 feet were required to take lateral stress out of the drill pipe after a heading reversal during drilling operations. This appears to be somewhat in excess of the headingrelated error of ten noted in the past, but not alarmingly so. The error is inherent in the system and is thought to be due to imperfect alignment of the vertical reference gyro and/or deviation of the plane of the hydrophone array from horizontal (with reference to the vessel).

\section{Engineering}

The most significant incidence involving power generation and propulsion equipment was the loss of D.C. Generator No.9B. A failure of the binding wire in the armature caused the armature to expand physically as it rotated and finally to seize up within the stator. The generator was used primarily for drilling assignments and other generators could be assigned to the same functions. The loss was therefore primarily one of reserve capability. The function of Generator 9A was not affected and generally good weather conditions permitted adequate power assignments for the remainder of on-site operations.

During the cruise, an accumulation of diesel fuel was found on top of the drill water in tank N-8-D. An investigation found the cause to be a minor leak in the common bulkhead with fuel tank $\mathrm{N}-10-\mathrm{F}$. The tanks have been prepared for repairs in Norfolk. Also to be investigated and repaired as necessary in Norfolk is apparent communication between ballast tanks in the moonpool area.

Weather and Currents

Weather conditions during Leg 93 were generally good, with wind/sea conditions reaching levels that were marginal for on-site operations on three or four occasions. The weather system that caused the only weather delay (28 hours) 
arrived shortly after the heavy surface casing string had been assembled at Hole 603B. Based on predictions of the on-board weather forecaster, the pipe trip was delayed to avoid undue tensional stress on the drill string from vessel motion and string weight. The predictions proved accurate, and conditions approached maximum limits even for less critical operations. Other periods of marginal operating weather occurred following the loss of the drill string at Site 603 (while the new string was being assembled) and while the rig was under way for Site 604 .

Currents were a definite factor in dynamic positioning at Site 603. The proximity of the Gulf Stream apparently produced a variety of eddy and countercurrent effects. The currents, which occasionally approached two knots in speed, were highly variable in direction, velocity and temperature. They were primarily toward the south and east quadrants. Surface water temperatures varied by about $10^{\circ} \mathrm{F}$ during the period of site occupancy. The relatively low occurrencce of significant long-period swells helped to avert vessel motion/positioning problems when wind and current directions were at high angles. Currents were only a minor factor at Sites 604 and 605 .

\section{Hydrocarbons}

As Leg 93 operations were conducted on a continental margin with a thick sediment cover, hydrocarbons were monitored carefully. At Site 603, small to moderate amounts of outgassing from the cores was noted. The gas was almost entirely methane, and the proportions of other component gases indicated normal biogenic composition. The gas was confined to approximately the upper 1000 meters of the sediment section. Similar biogenic methane was found in small amounts in the Pleistocene clay overburden at Sites 604 and 605 . Unexpected sand units with apparently good reservoir properties were encountered at Sites 603 and 604, but there was no indication of the presence of hydrocarbons in either case.

All holes were filled with weighted mud upon abandonment except, of course, for Hole $603 \mathrm{~B}$ where this was not possible and $603 \mathrm{~A}$ where only 82 meters was penetrated.

\section{$\underline{\text { Communications }}$}

Reliable CW radio communication with Scripps radio station WWD were again not possible, and it was necessary to rely on the U.S. Coast Guard to relay message traffic most of the time. Traffic was somewhat lighter than normal, and no serious difficulties or backlogs were experienced. Voice radiotelephone calls were made on occasions when operational or scientific priorities dictated. About half of these were made through WWD and half through Miami commercial station WOM. Numerous private amateur radio phone patches were made. This was facilitated by the proximity to the U. S. mainland. There were no signifcant communications equipment failures. 
The voyage was a demanding one for all hands, with only one short transit break between sites. Rig operations were nearly continuous, and it was necessary to start from "scratch" with a new re-entry cone/casing assembly once and again with a new drill string. Work attitudes and morale of the GMDI crew and the technical staff remained positive throughout the tedious cruise despite rumors (and confirmations) of the forthcoming end of the Project, probable layoffs, etc. The professionalism of the crew was a major factor in salvaging valuable science from a string of operational misfortunes. The scientific staff remained philosophical despite the disappointment of losing the principal objectives at Site 603.

There were no serious illnesses or injuries during the expedition. Two minor accidents to rig personnel occurred within two days after the grueling task of making up the new drill string in rough weather. This, after 35 consecutive twelve-hour working days, may have produced a kind of "battle fatigue".

Glen N. Foss

Cruise Operations Manager

Deep Sea Drilling Project 


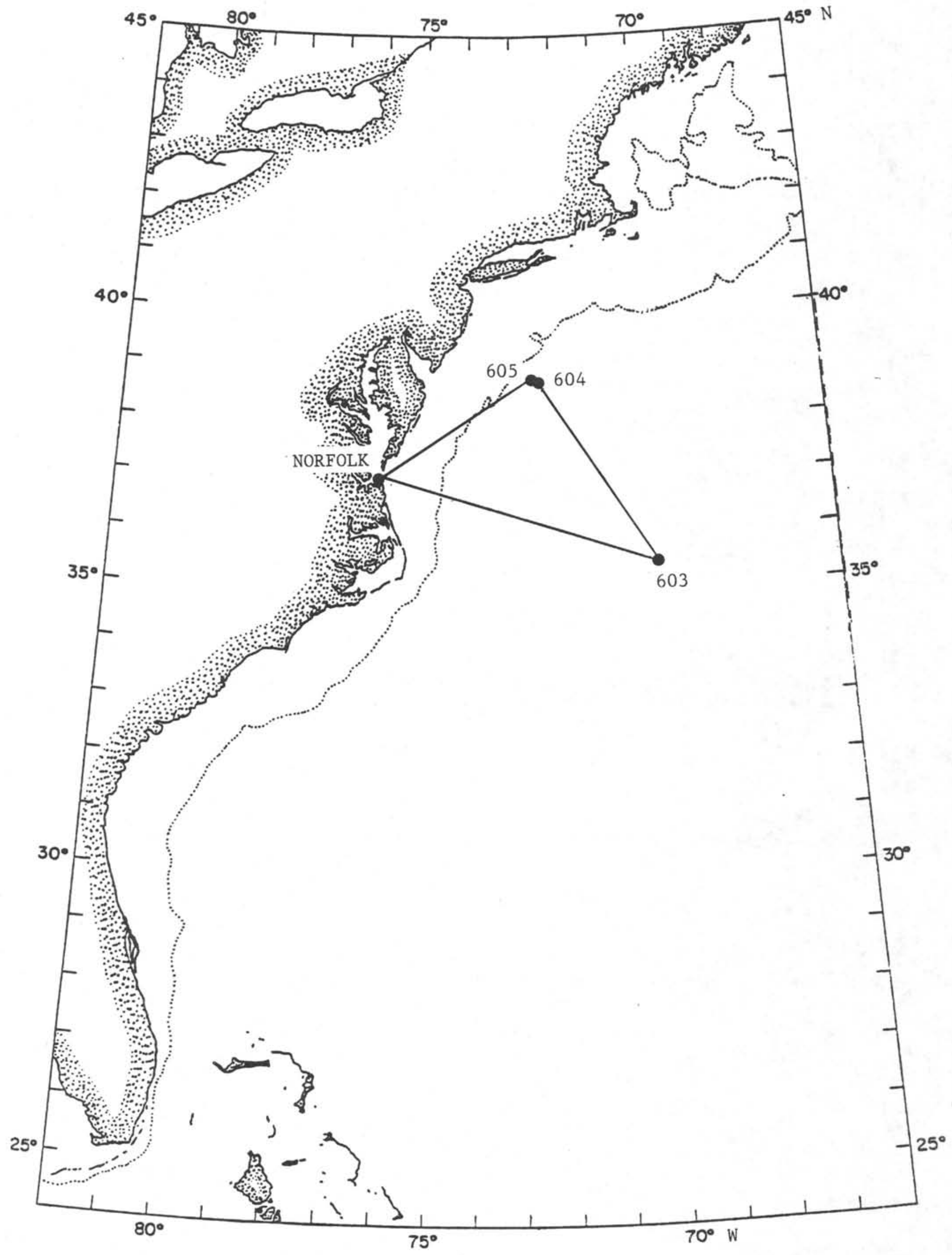

LEG 93 OPERATING AREA 
TOTAL TIME EISTRIBUTION

LEG 93

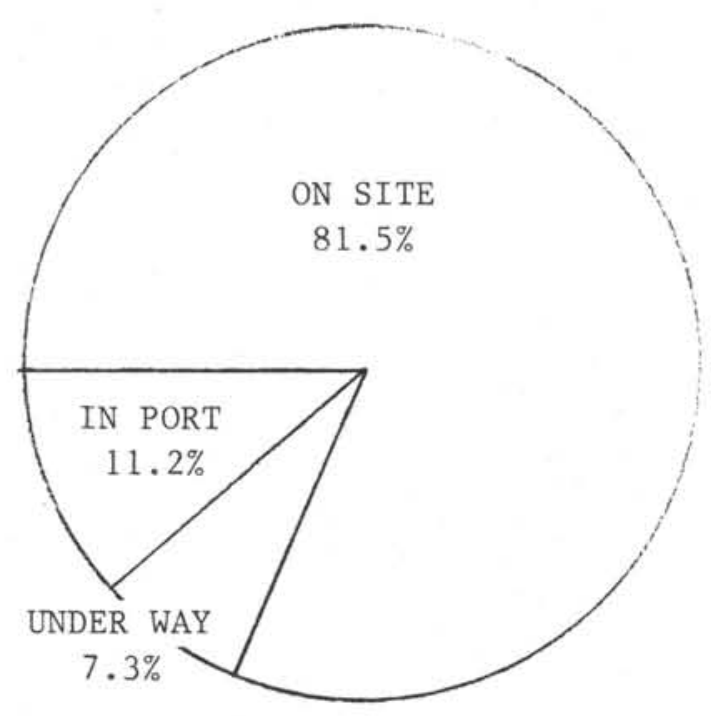

ON-SITE TIME DISTRIBUTION

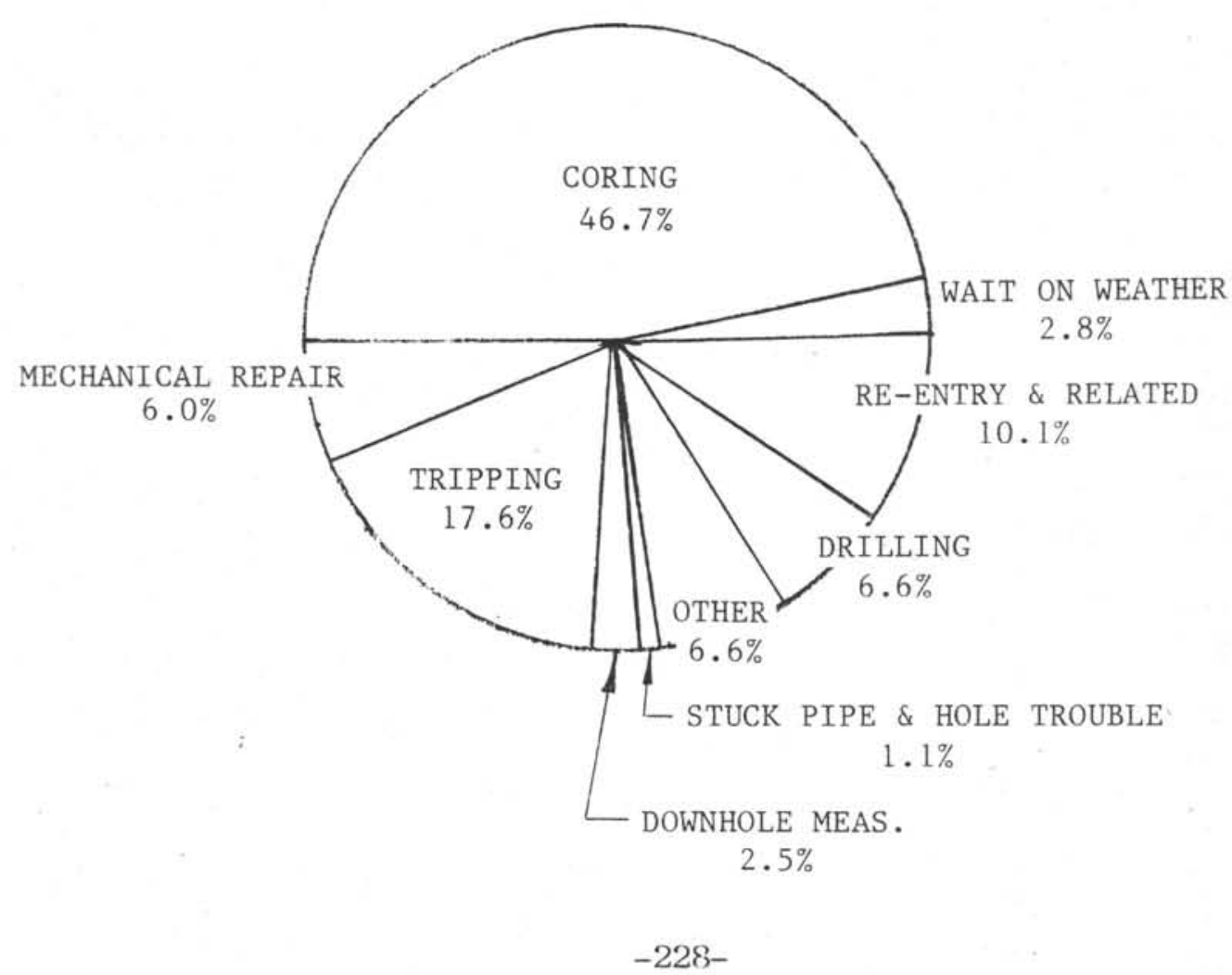




\section{INTERNATIONAL PHASE OF OCEAN DRILLING \\ DEEP SEA DRILLING PROJECT \\ OPERATIONS RESUME \\ LEG 93}

Total Days (April 27, 1983-June 17, 1983)................ 50.72

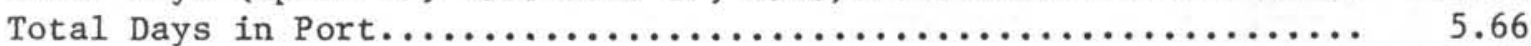

Total Days Cruising Including Site Survey................. 3.67

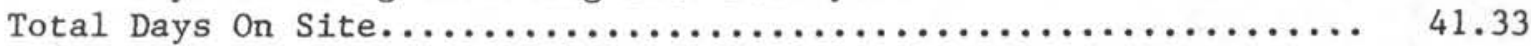

\begin{tabular}{|c|c|}
\hline & \\
\hline Drilling Time.. & \\
\hline g Time.... & 19 \\
\hline le Measurement & \\
\hline Pipe........... & \\
\hline 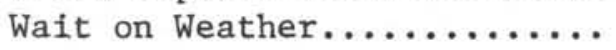 & \\
\hline$r y \ldots \ldots \ldots \ldots \ldots \ldots \ldots$ & \\
\hline$\ldots \ldots \ldots \ldots$ & \\
\hline al Repair.... & \\
\hline
\end{tabular}

Total Distance Traveled Including Survey (nautical miles).......

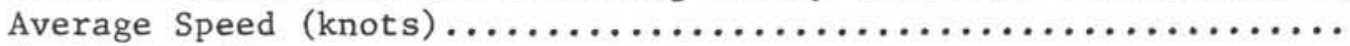

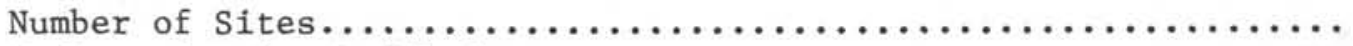

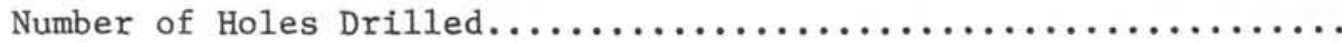

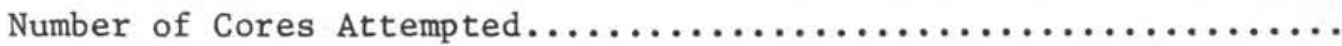

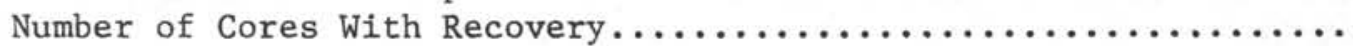

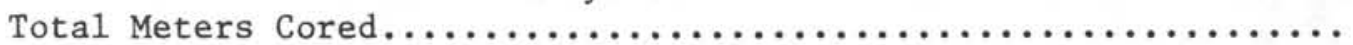

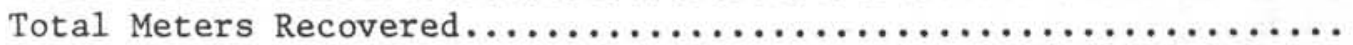

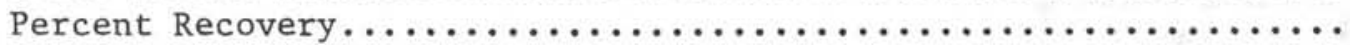

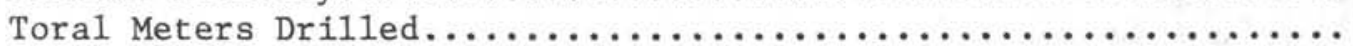

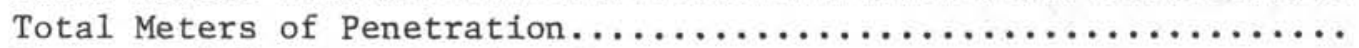

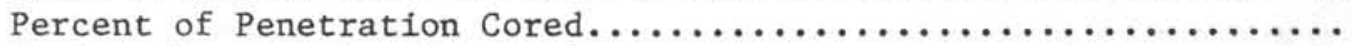

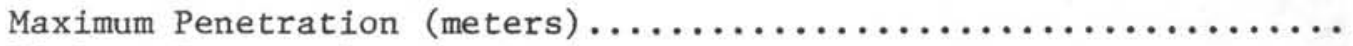

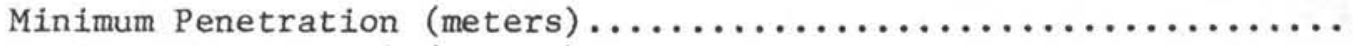

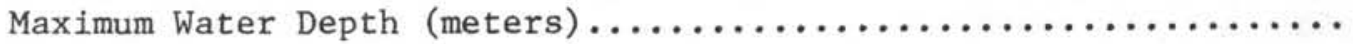

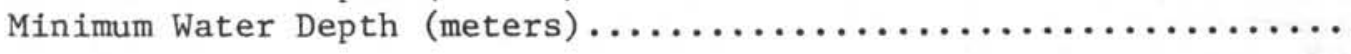

813.7

9.4

69.0

1827.0

4261.3

57.1

1585.2

81.9

4649.5

2207.0 


\section{DEEP SEA DRILLING PROJECT \\ TIME DISTRIBUTION}

$$
\angle E G-93
$$

\begin{tabular}{|c|c|c|c|c|c|c|c|c|c|c|c|c|c|c|}
\hline Date & $\begin{array}{l}\text { Site } \\
\text { No. }\end{array}$ & cruses & Trips & Drill & Core & $\begin{array}{l}\text { Stuck } \\
\text { ploe }\end{array}$ & W.0.Wr. & $\begin{array}{l}\text { POWNIOLE } \\
\text { MEAS. }\end{array}$ & $\begin{array}{l}\text { Mech. } \\
\text { Pepair }\end{array}$ & $\begin{array}{l}\text { Port } \\
\text { Time }\end{array}$ & $\begin{array}{l}\text { Pe- } \\
\text { Entry }\end{array}$ & orher & $\begin{array}{l}\text { Total } \\
\text { Time }\end{array}$ & Pemarks \\
\hline $\begin{array}{l}4 / 25 / 83 \\
5 / 05 / 83 \\
\end{array}$ & & 35.9 & & : & & & & & & 135.8 & & 1.4 & 173,1 & $\begin{array}{l}\text { Norfolk to } \\
\text { Site } 603\end{array}$ \\
\hline $\begin{array}{l}5 / 05 / 83 \\
5 / 11 / 83 \\
\end{array}$ & 603 & & 25.2 & 8,2 & 84.5 & 3.6 & & 10.7 & 3.1 & & 1.4 & 7.9 & 144.6 & Hele 603 \\
\hline $\begin{array}{l}5 / 11 / 83 \\
5 / 12 / 83\end{array}$ & $603 \mathrm{~A}$ & & 17.0 & 0,8 & & & & & & & 15.2 & & 33.0 & Ha $603 A$ \\
\hline $\begin{array}{l}5 / 12 / 83 \\
5 / 31 / 83 \\
\end{array}$ & $603 \mathrm{~B}$ & & 87.4 & 45.0 & 161.5 & 5.0 & 27.2 & 7.2 & 8.7 & & 83.3 & $32 \Omega$ & 458.0 & $\mathrm{H}=1 \mathrm{C}-603 \mathrm{~B}$ \\
\hline $\begin{array}{l}5 / 31 / 83 \\
6 / 06 / 83\end{array}$ & $603 c$ & & 17.8 & & 67.6 & & & 5.1 & 67.0 & & & 142 & 1517 & Hole $603 \mathrm{C}$ \\
\hline $\begin{array}{l}6 / 06 / 83 \\
6 / 08 / 83\end{array}$ & & 30.8 & & & & & & & & & & & 30.8 & $\begin{array}{l}\text { Site } 603 \text { to } \\
\text { Site } 604\end{array}$ \\
\hline $\begin{array}{l}6 / 08 / 83 \\
6 / 10 / 83 \\
\end{array}$ & 604 & & 7.9 & & 31.5 & 0.5 & & 0.3 & 0.6 & & & 2.9 & 43.7 & Hole 604 \\
\hline $6 / 10 / 83$ & $604 \mathrm{~A}$ & & 8.0 & 6.4 & 3.7 & 0.7 & & 0.4 & & & & 2.6 & 21.8 & Hole 604A \\
\hline $\begin{array}{l}6 / 10 / 83 \\
6 / 11 / 83\end{array}$ & & 0.5 & & & & & & & & & & & 0.5 & $\begin{array}{l}\text { Site } 604 \\
\text { Site } 605\end{array}$ \\
\hline $\begin{array}{l}6 / 11 / 83 \\
6 / 16 / 83 \\
\end{array}$ & 605 & & 11.4 & 4.9 & 114.4 & 1.5 & & 1.0 & & & & 5.2 & 139.1 & Hole 605 \\
\hline $\begin{array}{l}6 / 16 / 83 \\
6 / 17 / 83\end{array}$ & & 20.9 & & & 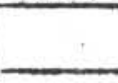 & & & & & & & & 20.9 & $\begin{array}{l}\text { Site } 605 \\
\text { to Norfolk }\end{array}$ \\
\hline TOTALS & & 88.1 & 174.7 & 65.3 & 463.2 & 11.3 & 27.9 & 24.7 & 59.4 & 135.8 & 99.9 & 66.9 & 1217.2 & \\
\hline & & & & & & & & & & & & & & \\
\hline & & & & & & & & & & & & & & \\
\hline & & & & & & & & & & & & & & \\
\hline & & & & & & & & & & & & & & \\
\hline & & & & & & & & & & & & & & \\
\hline & & & & & & & & & & & & & & \\
\hline
\end{tabular}




\section{DEEP SEA DRILLING PROJECT \\ TIME DISTRIBUTION \\ $\angle E G-93$}

\begin{tabular}{|c|c|c|c|c|c|c|c|c|c|c|c|c|c|c|}
\hline Date & \begin{tabular}{|l|} 
Site \\
No. \\
\end{tabular} & Cruise & Trips & Drill & Core & $\begin{array}{l}\text { Stuck } \\
\text { Ploe }\end{array}$ & W.0.SW. & $\begin{array}{l}\text { POWNHOLE } \\
\text { MEAS. }\end{array}$ & $\begin{array}{l}\text { Mech. } \\
\text { Pepair }\end{array}$ & $\begin{array}{l}\text { Port } \\
\text { Time }\end{array}$ & $\begin{array}{l}\text { Pe- } \\
\text { Entry }\end{array}$ & orher & $\begin{array}{l}\text { Total } \\
\text { Time }\end{array}$ & Remarks \\
\hline $\begin{array}{l}4 / 25 / 83 \\
5 / 05 / 83\end{array}$ & & 35.9 & & & & & & & & 135.8 & & 0.1 .4 & 173.1 & $\begin{array}{l}\text { Norfolk to } \\
\text { Site } 603\end{array}$ \\
\hline $\begin{array}{l}5 / 05 / 83 \\
5 / 11 / 83 \\
\end{array}$ & 603 & & 25.2 & 8.2 & 84.5 & 3.6 & & 10.7 & 3.1 & & 1.4 & 7.9 & 144.6 & $\begin{aligned} & . \\
&\end{aligned}$ \\
\hline $\begin{array}{l}5 / 11 / 83 \\
5 / 12 / 83 \\
\end{array}$ & $603 \mathrm{~A}$ & & 17.0 & 0.8 & & & & & & & 15.2 & 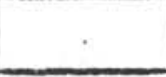 & 33.0 & Hele $603 \mathrm{~A}$ \\
\hline $\begin{array}{l}5 / 12 / 83 \\
5 / 31 / 83 \\
\end{array}$ & $603 \mathrm{~B}$ & & 87.4 & 45.0 & 161.5 & 5.0 & 27.2 & 7.2 & 8.7 & & 83.3 & 32.0 & 458.0 & $\mathrm{HOCle}$ GO3B \\
\hline $\begin{array}{l}5 / 31 / 83 \\
6 / 06 / 83 \\
6 / 06 / 83\end{array}$ & $603 c$ & & 17.8 & & 67.6 & & & 5.1 & 47.0 & & & 142 & 1512 & Hole $603 \mathrm{C}$ \\
\hline$\frac{6 / 08 / 83}{6 / 08 / 83}$ & & 30.8 & & . & & . & & : & & & & & 30.8 & $\begin{array}{l}\text { Site } 60.3 \\
\text { Site } 604 \\
\end{array}$ \\
\hline $6 / 10 / 83$ & 604 & & 7.9 & & 31.5 & 0.5 & & 0.3 & 0.6 & & & 2.9 & 43.7 & Hole 604 \\
\hline $6 / 10 / 83$ & $604 \mathrm{~A}$ & & 8.0 & 6.4 & 3.7 & 0.7 & & 0.4 & & & & 2.6 & 21.8 & Hole $604 \mathrm{~A}$ \\
\hline $\begin{array}{l}6710 / 83 \\
6 / 11 / 83 \\
\end{array}$ & & 0.5 & & & & & & & & & - & - & 0.5 & $\begin{array}{l}\text { Site } 604 \\
\text { Site } 605 \\
\end{array}$ \\
\hline $\begin{array}{l}6 / 11 / 83 \\
6 / 16 / 83 \\
\end{array}$ & 605 & & 11.4 & 4.9 & 114.4 & 1.5 & & 1.0 & & . & & 5.2 & 139.2 & Hole 605 \\
\hline $\begin{array}{l}6 / 16 / 83 \\
6 / 17 / 83 \\
\end{array}$ & & 20.2 & : & & & & & & & & & & 20.9 & $\begin{array}{l}\text { Site } 605 \\
\text { to Norfolk }\end{array}$ \\
\hline TOTALS & & 88.1 & 174.7 & 65.3 & 463.2 & 11.3 & 27.9 & 24.7 & 59.4 & 135.8 & 99.9 & 66.9 & 1217.2 & \\
\hline & & & & & & & & & & & & & & \\
\hline & & & & & & . & & & & & & & . & \\
\hline & & . & & & & & & & & & & & & \\
\hline & & $?$ & & & & & & & & & & & & \\
\hline & & & & & & & & & & & & & & \\
\hline & & & & & & & . & & & & & & . & \\
\hline & & & & & & & & & & & & & & \\
\hline
\end{tabular}


INTERNATIONAL PIUSE OF OCEAN DRILLING

DEEP SEA DRILLING PROJECT

SITE SUMMARY

LEG 93

\begin{tabular}{|c|c|c|c|c|c|c|c|c|c|c|c|c|c|c|}
\hline Hole & Latitude & Longitude & $\begin{array}{l}\text { Water } \\
\text { Depth } \\
\text { Meters }\end{array}$ & $\begin{array}{c}\text { Number } \\
\text { of } \\
\text { Cores }\end{array}$ & $\begin{array}{c}\text { Cores } \\
\text { with } \\
\text { Recovery }\end{array}$ & $\begin{array}{l}\text { Percent of } \\
\text { Cores W1th } \\
\text { Recovery }\end{array}$ & $\begin{array}{l}\text { Meters } \\
\text { Cored }\end{array}$ & $\begin{array}{c}\text { Meters } \\
\text { Recoverd }\end{array}$ & $\begin{array}{l}\text { Percent } \\
\text { Recovery }\end{array}$ & $\begin{array}{l}\text { Meters } \\
\text { Drilled }\end{array}$ & $\begin{array}{l}\text { Total } \\
\text { Penet. } \\
\text { Meters }\end{array}$ & $\begin{array}{l}\text { Avg. } \\
\text { Rate } \\
\text { Penet }\end{array}$ & $\begin{array}{l}\text { Time } \\
\text { on } \\
\text { Hole }\end{array}$ & $\begin{array}{l}\text { T1me } \\
\text { on } \\
\text { S1te }\end{array}$ \\
\hline $\begin{array}{l}603 \\
603 \mathrm{~A} \\
603 \mathrm{~B} \\
603 \mathrm{C}\end{array}$ & $\begin{array}{ll}35^{\circ} & 29.7^{\prime} \mathrm{N} \\
35^{\circ} & 29.7^{\prime} \mathrm{N} \\
35^{\circ} & 27.7 \\
35^{\circ} & 29.8^{\prime} \mathrm{N}\end{array}$ & $\begin{array}{ll}70^{\circ} & 01.7^{\prime} \mathrm{W} \\
70^{\circ} & 01.7^{\prime} \mathrm{W} \\
70^{\circ} & 01.7^{\prime} \mathrm{W} \\
70^{\circ} & 01.9^{\prime} \mathrm{W}\end{array}$ & $\begin{array}{l}4644 \\
4644 \\
4644 \\
4649.5\end{array}$ & $\begin{array}{r}41 \\
0 \\
75 \\
40\end{array}$ & $\begin{array}{r}40 \\
0 \\
74 \\
39\end{array}$ & $\begin{array}{c}97.6 \\
-- \\
98.7 \\
97.5\end{array}$ & $\begin{array}{l}393.0 \\
0 \\
683.6 \\
366.0\end{array}$ & $\begin{array}{c}226.4 \\
0 \\
486.4 \\
314.4\end{array}$ & $\begin{array}{c}57.6 \\
-- \\
71.2 \\
85.9\end{array}$ & $\begin{array}{r}439.6 \\
81.9 \\
901.6 \\
.0\end{array}$ & $\begin{array}{r}832.6 \\
81.9 \\
1585.2 \\
366.0\end{array}$ & $\begin{array}{r}5: .0 \\
204.8 \\
21.2 \\
--\end{array}$ & $\begin{array}{r}144.6 \\
33.0 \\
458.0 \\
151.7\end{array}$ & -- \\
\hline 603 & TOTALS & & & 156 & 153 & 98.1 & 1442.6 & 1027.2 & 71.2 & 1423.1 & 2865.7 & -- & - & 787.3 \\
\hline $\begin{array}{l}604 \\
604 i\end{array}$ & $\begin{array}{l}38^{\circ} 42.8^{\prime} \mathrm{N} \\
38^{\circ} 43.1^{\prime} \mathrm{N}\end{array}$ & $\begin{array}{l}72^{\circ} 33.0^{\prime} \mathrm{W} \\
72^{\circ} 33.6^{\prime} \mathrm{W}\end{array}$ & $\begin{array}{l}2374 \\
2350\end{array}$ & $\begin{array}{r}31 \\
4\end{array}$ & $\begin{array}{r}29 \\
3\end{array}$ & $\begin{array}{l}93.5 \\
75.0\end{array}$ & $\begin{array}{r}294.5 \\
34.8\end{array}$ & $\begin{array}{r}117.6 \\
2.1\end{array}$ & $\begin{array}{r}39.9 \\
6.1\end{array}$ & $\begin{array}{c}0 \\
249.6\end{array}$ & $\begin{array}{l}294.5 \\
284.4\end{array}$ & $\begin{array}{l}52.1 \\
80.1\end{array}$ & $\begin{array}{l}43.7 \\
21.8\end{array}$ & - \\
\hline 604 & TOTALS & & & 35 & 32 & 91.4 & 329.3 & 119.7 & 36.3 & 249.6 & 578.9 & -- & -- & 65.5 \\
\hline 605 & $38^{\circ} 44.5^{\prime} \mathrm{N}$ & $72^{\circ} 36.6^{\prime} \mathrm{W}$ & 2207 & 70 & 68 & 97.1 & 662.4 & 532.1 & 80,3 & 154.3 & 816.7 & 14.8 & . 139.1 & 139.1 \\
\hline & GRAND TOTALS & & & 261 & 253 & 96.9 & 2434.3 & 1679.0 & 69.0 & 1827.0 & 4261.3 & -- & +- & 991.9 \\
\hline
\end{tabular}


INTERNATIONAL PHASE OF OCEAN DRILLING

DEEP SEA DRILLING PROJECT

$$
\text { BIT SUMMARY }
$$

$$
\text { LEG } 93
$$

\begin{tabular}{|c|c|c|c|c|c|c|c|c|c|c|}
\hline Hole & Mfg. & S1ze & Type & $\begin{array}{l}\text { Serial } \\
\text { Number }\end{array}$ & $\begin{array}{l}\text { Meters } \\
\text { Cored }\end{array}$ & $\begin{array}{r}\text { Meters } \\
\text { Drilled }\end{array}$ & $\begin{array}{l}\text { Meters } \\
\text { Total } \\
\text { Penet. }\end{array}$ & $\begin{array}{l}\text { Hours } \\
\text { on } \\
\text { B1t }\end{array}$ & Condition & Remarks \\
\hline 603 & MSDS & $97 / 8 "$ & F93CK & $s-43$ & 393.0 & 439.6 & 832.6 & 16.3 & TO-B1SE-I & Like new-su1table for rerun. \\
\hline $603 \mathrm{~A}$ & Smith & $147 / 8^{11}$ & F९4CK & $361 \mathrm{FK}$ & 0 & 81.9 & 81.9 & 0.4 & (Lost with BHA) & Total 20.0 hours, $163.4 \mathrm{~m}$. \\
\hline $603 \mathrm{~B}$ & Snith & $167 / 8 "$ & F94CK & $177 \mathrm{FK}$ & 0 & 480.5 & 480.5 & 19.8 & TO-BISE-I & Good for rerus. \\
\hline 603в & MSDS & $97 i 8 "$ & F93CK & $s-45$ & 0 & 159.3 & 159.3 & 13.0 & TO-B2SQ-0 $1 / 16$ & $\begin{array}{l}\text { Drilled } 28 \text { m cerent, shoe \& plug; dry } \\
\text { drilling after bumper sub fallure may } \\
\text { have damaged seals. }\end{array}$ \\
\hline $603 \mathrm{~B}$ & MSDS & $97 / 8 "$ & F93cK & $S-46$ & 574.6 & 263.3 & 837.9 & 34.0 & TO-B6-0 $1 / 8$ & One loose cone--good run. \\
\hline 603B & MSDS & $97 / 8 "$ & F93CK & S-44 & 107.5 & 0 & 107.5 & 9.8 & Unknown & Lost with drill string. \\
\hline $603 \mathrm{C}$ & MSDS & $117 / 16^{\prime \prime}$ & $\mathrm{HPC}-\mathrm{XCB}$ & $S-53$ & 366.0 & 0 & 366.0 & -- & $\mathrm{T} 1-\mathrm{B} 8$ & Three cones locked. \\
\hline 604 & Msps & $9718 "$ & $893 \mathrm{CK}$ & $s-43$ & 294.5 & 0 & 2945 & 5,7 & Unknoum & Besnud without ortp \\
\hline \multirow[t]{2}{*}{$604 \mathrm{~A}$} & MSDS & $97 / 8^{\prime \prime}$ & F93CK & $s-43$ & 34.8 & 249.6 & 284.4 & 3.5 & TO-B1SE-I & Kespoud witnodi irip. \\
\hline & & & & & & & & & & s \\
\hline 605 & MSDS & $97 / 8^{\prime \prime}$ & F93CK & $s-43$ & 662.4 & 154.3 & 816.7 & 55.2 & TO-BS-0 $1 / 8$ & 2228.2 m total penet., 80.7 hours \\
\hline
\end{tabular}


DEEP SEA DRILLING PROJECT

BEACON SUMMARY

$$
\text { LEG } 93
$$

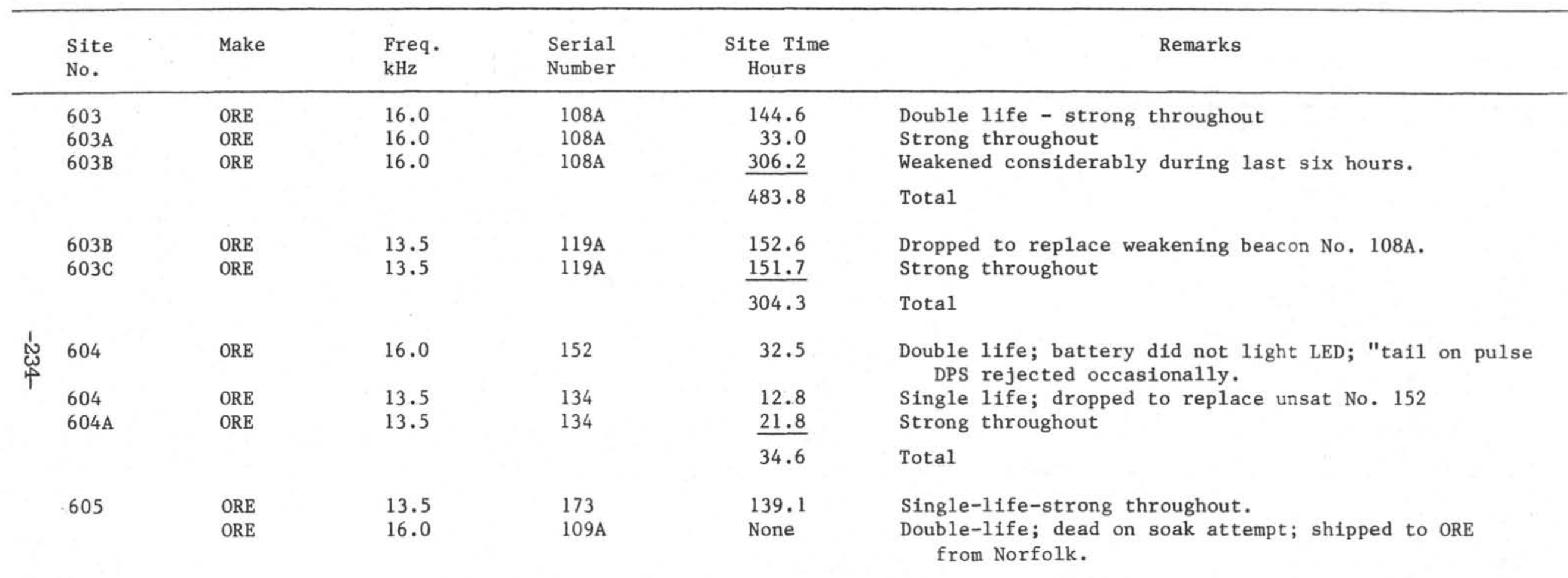


INTERNATIONAL PHASE OF OCEAN DRILLING

DEEP SEA DRILLING PROJECT

OPERATIONS RESUME

LEG 94

NORFOLK PORT CALL

Leg 94 began at 1610 hours, June 17, 1983, with the first line dockside Pier B, Sewalls Point, Norfolk, VA. In addition to the normal transfer of equipment and supplies the following tasks were accomplished:

1. Major overhaul of No. 3 engine.

2. No. 9B generator replaced.

3. Fifty nine joints of aluminum pipe were inspected. Three joints were selected and sent to Richmond for destructive tests. All pipe was within specifications.

4. A third party non-destructive test facility was employed to inspect the connections on two power subs, two swivels, and three double pin subs on board. An internal crack on the pin connection and a surface crack on the box connection were found on the stem of the spare power sub. The unit was offloaded for corrective action. All other connections were found to be in satisfactory condition.

5. Twelve new bumper subs were made up and checked for proper connections. Six subs were found to have defective pin con-nections. Defective subs were corrected at a local machine shop. Defective subs were corrected at a local machine shop.

6. Off-loaded 22 joints of downgraded drill pipe.

7. Loaded 87 joints of premium drill pipe, 265 joints of Grade 2 drill pipe, two knobby joints, and one bumper sub. 
8. Loaded 220,000 gallons of fuel and 1000 sacks of gel.

9. Serviced the TOTCO drilling recorder.

A last minute personnel change was necessitated, due to illness of a member of the scientific party. A replacement was obtained from Lamont to complete shipboard staffing.

\section{NORFOLK TO SITE 606}

At 1652 hours on June 23, the GLOMAR CHALLENGER departed Norfolk The weather was excellent for the entire run. During the transit the drilling crew was trained in the assembly of the new Advanced Piston Corer (APC) and the modified Extended Core Barrel (XCB). All of the fishing and re-entry tools were boxed, listed, and stored in the mud room in accordance with the demobilization schedule work plan. The rig crew attempted to install rubber protectors on the aluminum drill pipe, but it was discovered that they would not fit. The rubbers were sized for 5" $0 . D$. pipe, but the aluminum pipe diameter is slightly larger at the tool joint connection and tapers down in the middle of the joint.

At 2000 hours on July 1, the CHALLENGER slowed to eight knots to begin profiling for Site 606. The site was chosen on the initial west- east pass, but the beacon was not dropped until the second northeast- southwest pass. The positioning beacon was dropped at 2347 hours. Before running in the hole, a calibration was performed to adjust the range limits of the positioning system in manual mode.

The 1972.1 transit miles were covered in 8 days and $11 / 2$ hours, at an average speed of 10.19 knots. Good weather reduced the estimated transit time of 9.4 days.

HOLE 606 (1)

The first site of Leg 94 was located some 210 nautical miles west of the Azores. The operational plan called for double piston coring with the Advanced Piston Corer to refusal; then deepen the second hole to 450 meters with the Extended Core Barrel. This was the first test of the new APC. Its advantages over the VLHPC included:

1. More coring force due to a larger area acted upon by the available pressure. 
2. Flow control holes to calibrate the velocity of the scoping core barrel section.

3. More pull-out strength $(100,000$ lbf with a $40 \%$ safety factor).

4. Ease of operation due to its short length.

5. Operational guide groove along the piston rod to prevent the core barrel from rotating and preserve orientation as it is injected into the sediment.

A special bottom hole assembly was assembled which included a 3.8" diameter Seal Bore Drill Collar and a Landing/Saver Sub which together comprised the outer sealing bore for the APC. Both the APC and the XCB were spaced out in the lower BHA. An initial test of the APC was conducted which involved lowering it with the BHA until it was two stands of collars below the hull, then firing it off and retrieving it with the wireline. The APC was assembled with the grooved piston rod, one 17-4 PH shear pin, and one flow control set screw removed. It shot off at 1000 psi. There was some flow by the seals, for when the pump was shut down before firing, the pressure slowly bled off. The APC was retrieved to find no damage to the seals or landing shoulder.

The drill pipe was strapped while running in the hole. The first 60 stands were run bare; rubber protectors were installed on the last 40 stands. The first core, shot at 3020 meters (3 meters above PDR depth), was full. The second attempt, shot from 9.6 meters higher, was empty. The hole was finally officially spudded at 1857 hours July 2, with the mudline established at 3022.2 meters.

The APC recovered excellent cores, comparable in every way to those taken by its predecessor. One minor problem manifested itself from the start; the shear pin stubs from the cylinder wall of the Outer Shear Pin Sub tended to fall in and land on the inner ledge of that sub. When the tool was scoped back together the stubs became trapped between the ledge and the jam nut on the Inner Shear Pin Sub to prevent the tool from fully closing. A magnet attached to a piece of stiff wire was devised to fish out the stubs. For the first ten runs the magnet also recovered a large quantity of corrosion debris from the drill pipe. The open-topped Outer Shear Pin Sub acted as a scoop during retrieval of the APC. A further problem developed when the shear pin stubs sometimes found their way to the groove on the piston rod, which allowed them to fall through the ledge and lodge in the inner seals. For this reason the alternate grooveless piston rod was used after core 12. The shear pin problem was lessened when the technique was devised to cut the pins in half and splay one end 
of each half before installaticn. The short outer stubs stayed in the wall, but occasionally one of the now-shorter inner stubs would fall onto the ledge.

Several liner collapses and/or fractures were observed. This did not disturb the core except in the immediate interval of the failure. As the sediment stiffened, the number of shear pins used was increased to; two hard (17-4 PH) and one soft (mild steel). Also, more flow control screws were removed until all six holes were open. It was noticed that, when less than three pins were used, the shoot-off signature was very unclear. However, with three pins the indiction was very definite; at 27002950 psi the weight indicator flickered, and the pressure quickly bled off as soon as the pump was killed.

The Kuster orientation tool performance was unsatisfactory. The pictures were either foggy, partially developed, shot too soon, and sometimes did not load into the unit.

Even with the time delays involved with running the Kuster tool and dealing with new concepts in the new APC system the coring rate averaged $11 / 2$ hours per core. The hole was terminated at core No. 18, with a penetration depth of 165.75 meters in stiff nanno ooze.

\section{HOLE 606A}

The ship was offset 100 feet west of the beacon, and Site $606 \mathrm{~A}$ was spudded in at 0205 hours, July 4. The mudline was established with the first core at 3023.8 meters. Piston coring with the APC went smoothly except for frequent liner fractures. The attempts to obtain orientation pictures with the Kuster tool were more successful than those at the previous hole; 7 out of $14 \mathrm{film}$ discs contained useful data.

Again the APC gave positive indication of shoot-off only after three shear pins were installed (core No. 7). Also, beginning on core No. 7, a soft formation core catcher was used along with the flapper core catcher. The previous cores had been averaging about a meter short of full recovery, but starting with core No. 7 , the recovery picked up to average over 9.3 meters. The increased recovery was most likely due to the addition of the soft formation catcher, but there is some speculation that the APC was not achieving full stroke with less than three shear pins--especially in the light of its similar performance on the previous hole.

An overpull of 100,000 lbs was needed to recover core No. 18 . This was the first core to record any appreciable overpull. The APC was designed to safely withstand no more than 100,000 lbs. overpull. Core No. 19 registered only 20,000 lb overpull. While attempting to retrieve core No. 20 , the pin connection on the center piston rod broke at 40,000 lb overpull. The entire 
scoping section and the lower piston rod was lost downhole. An unsuccessful attempt was made to wash over and retrieve the fish before tripping the drill string back to the mudline.

A decision was made to respud and wash down to 3178.8 meters, then to continue with the Extended Core Barrel. The first XCB was go-deviled down and followed with the overshot. A newly designed latch was tried; in order to eliminate the "stickingin-the-pipe" problem. The overshot contacted the XCB about 30 meters too high, and it was first thought that the latch stuck in the pipe. But the tool lifted easily and, when lowered again, stopped in the same place. After several such attempts, it was decided to cut a three meter core to determine if the XCB had landed too high. A full three meters of sediment was recovered, which seemed to signify that the flag on the wireline was in error. The second $X C B$ was go-deviled and again followed by the overshot, but only far enough to ensure that the XCB had not stuck higher in the pipe.

After cutting 6.5 meters, the overshot was lowered and made contact at 22 meters below the depth of the previous barrel, but could not pick up the XCB. The TOTCO recorer showed a $10,000 \mathrm{lb}$ weight loss when the BHA was 30 meters into the hole. The drill pipe was tripped to find that 41 meters of the BHA had broken off at the pin connection on the mandrel of the lowest bumper sub. A complete XCB assembly was lost downhole along with the only Seal Bore Drill Collar and Monel drill collar aboard. Thus APC coring and Kuster orientation were finished for the rest of this leg. There were sufficient XCB components aboard to continue its operation when spaced out to match the length of the VLHPC.

Since an important $3.2 \mathrm{~m} . \mathrm{y}$. objective had already been reached, and the deeper Miocene objective could be satisfied at the next two sites, it was decided to terminate operations and save some time for use later in the cruise.

\section{SITE 606 TO SITE 607}

The ship got under way for Site 607 at 1745 hours, July 5. During the 25-hour transit the rig crew magnafluxed the bottom joint of the middle stand of collars used in the last hole; no flaws were found. The XCB was assembled as follows: The upper section above the quick release consisted of the one remaining new latch and spacers to match it to the length of the VLHPC. One newstyle lower section was assembled, and one old-style (Leg 93 version) lower section was assembled. The main differences between the two versions are that the new-style includes a Vent sub to take the place of the field-modified Bearing Shaft, and the maximum O.D. of the core barrel is $3.5^{\prime \prime}$ instead of $3.75^{\prime \prime}$. 
A beacon was deployed on the first pass at 1905 hours, July 6. A new bottom hole assembly was made up, and the VLHPC and XCB were spaced out in it. It was discovered that the Dogs on the new XCB Latch did not fall in flush with the 3-3/4" diameter Latch Body. This prevented the Dogs from passing through the Landing/Seal Sleeve in the Head Sub. The problem was solved by reducing the thickness of the lower Latch Washer to allow the Dogs to travel all the way down the ramp on the Pulling Neck.

The mudline was established, after one water core, at 3426.1 meters ( 5.1 meters lower than the PDR depth). Piston coring with the VLHPC proceeded smoothly except for frequent liner fractures. The sediment was similar to that of site 606 , and the recovery was excellent. Core No. 15 would not pull free at 40,000 lb overpull--the preagreed limit. It was washed over to retrieve, and the XCB was made ready to continue in the hole.

Unless otherwise noted, the XCB barrels were assembled with the Soft Formation Cutting Shoe OP4458. The first barrel was godeviled down after topping off the pipe with water. It landed hard because the pumps were not shut off before it reached bottom. A circulation rate vs back pressure calibration was conducted by recording the pressure at various flow rates. At 20, 30,40 , and $50 \mathrm{spm}$, the back pressure through 3572.4 meters of pipe was $150,350,600$, and 925 psi respectively. A 9.6 meter core was cut and retrieved to find the upper $1 / 4$ section of liner had shattered. 6.17 meters of firm nanno ooze was recovered. The second XCB landed softly, but the drill pipe was not topped off beforehand. The liner returned completely shattered with little recovery. The subsequent barrels were wirelined down to prevent shattered liners..

Cores 18-24 had excellent recovery. The jet ports in the cutting shoe never clogged with mud. Core No. 25 recovered only about $50 \%$. The jets were clogged, and one cutting tooth was cracked (it was later weld-mended and successfully reused). The recovery was erratic for cores Nos. 26-30. There was no apparent 1ithology change. The Acker Geoset cutting shoe was used for core No. 29; it recovered 4.27 meters. It was decided to terminate the hole after core No. 30, at a subbottom depth of 284.4 meters.

SITE $607 \mathrm{~A}$

The pipe was pulled to clear the mudline, the vessel was offset 100 feet to the north, and Hole $607 \mathrm{~A}$ was spudded at 0400 hours, July 9. Nineteen VLHPC cores were taken to a subbottom depth of 159.0 meters-- a few cores deeper than on the previous site. The last few cores had badly fractured or buckled liners attesting to the stiffness of the nanno ooze.

Two XCB cores were taken to a subbottom depth of 173.6 meters in order to overlap a critical section of the last hole. Then the 
bit was washed down to 258.3 meters, and coring was continued in an attempt to recover some of the lost sections of the previous hole. The recovery this time was much better; it averaged $80.5 \%$. The hole was terminated after core No. 30, with a total penetration of 311.3 meters.

The Core Barrel Pressure Tool (CBPT) was tested twice (XCB) cores 20 and 22). This instrument was designed to be run with the XCB or rotary barrel, and records the pressure every 5 seconds in the core barrel above and below the check ball, and outside the core barrel in the annulus. One XCB lower section was fitted with the CBPT which required shortening the core barrel to 5 meters. Extra time was taken to run the tool downhole in order to mark events such as "tool landed" and "begin coring" with an intentional pressure spike which would hopefully be visible on the recorded data. Pressure data was successfully recorded on both runs, but upon later analysis of the voluminous pages of data it was observed that the transducers responded sluggishly to downhole pressure changes. The cause was traced to clogged pressure lines leading to the transducers. Grease had been applied at the three port inlets to the transducers to prevent clogging from particles in the circulation water. Apparently the grease had been forced into the small diameter tubes behind the ports. Less grease will be used for future runs.

After clearing the mudline, three drop tests wee conducted with the XCB in an effort to determine the exact cause of the shattered liners which occurred when the tool was go-deviled. First, it was dropped down the drill pipe (topped off with water) and retrieved with the overshot before landing. The same test was repeated, but without first filling the pipe. Finally, it was dropped and allowed to land before retrieving. No failures of the liners were noted during the drop tests.

\section{SITE 607 TO SITE 608}

The CHALLENGER got under way at around 0500 on July 11 . A course of 068 degrees was set to cross the mid-Atlantic Ridge towards Site 608 , 300 nautical miles north of the Azores. During the trip the rig crew magnafluxed the two remaining bumper subs (Nos. 2033 and 2099) from the BHA used on Site 606. A crack was found in the mandrel pin of No. 2033; it was broken down and put in the mud room. The VLHPC and XCB barrels were broken down and redressed. Six broken springs were replaced in the XCB. At 0555 hours, on July 13, the beacon was dropped on the first pass at Site 608 .

HOLE 608

The site was located over a small knoll in the basement where the sediment cover was about 500 meters. The coring plan was to VLHPC/XCB to basement, then recore the top of the hole with the 
VLHPC. The BHA was the same as that used on the previous site. One water core was recovered. The next barrel was damaged when set down too hard on the hang-off clamp; the shear pins sheared, and the resulting impact when the tool scoped open sheared the dogs on the Quick Release Shoulder Sub and split open the Quick Release Cap Sub. AT 1542 hours on July 13, Core No. 1 was spud in to establish the mudline at 3533.6 meters.

Sixteen VLHPC cores were taken in nanno fossil marl before switching over to the XCB. Core No. 3 returned empty, though there was evidence of core in the barrel; the flapper core catcher stuck open in the adhesive sediment. A combination flapper/soft formation core catcher was used for subsequent cores. Two liner failures occurred as the sediment stiffened. On core No. 14, the top of the liner was forced past the stop ledge in the Upper Liner Seal Sub, and the piston could not be retracted from the liner. It was freed after about 20 minutes of pulling and heating with a blow torch. On core No. 15, the liner failure consisted of a spiral fracture circling the liner three times in the length of a meter near the top. Core No. 16 would not pull free with $40,000 \mathrm{lb}$ overpull and was washed over to retrieve.

The XCB coring continued to basement at 530.3 meters subbottom . The lithologies became increasingly lithified; cores were split using the saw beginning with core No. 26. Recovery averaged over $90 \%$ to 380 meters. The Geoset cutting shoe with a Modified Core Catcher (OP4487) was tried in the rapidly hardening chalks on core No. 33. Only 3.66 meters were recovered due to jamming in the core catcher. Continued $\mathrm{XCB}$ coring with the soft formation shoe resulted in variable recovery through hard chalk lithologies. There appeared to be a fine line to toe regarding the amount of circulation to use. Occasionally cored intervals were washed away and the cutting shoe would jam. The diameter of the hard chalk was normally $5.5 \mathrm{~cm}$ reflecting the I.D. gage of the horseshoe-borium grit on the cutting shoe. In some sections the I.D. shrunk to $5 \mathrm{~cm}$; probably due to a slight wobble in the $X C B$ when the bit stood longer on harder formations. There was no evident damage to the cutting shoes. The Geoset shoe was again tried for core No. 44, this time using the Acker split ring core catcher; the entire core slipped away.

Erratic pebbles dropping downhole may have caused some of the recovery problems; cores Nos. 52 and 53 were found to have single large glacial erratic pebbles set within a disturbed zone at their tops. Also, in core No. 52, the liner was twisted off in two places. It was assumed the liner was held still while the barrel rotated and failed due to over torquing.

A number of minor excursions from the $13.5 \mathrm{kHz}$ beacon throughout the day of July 16 may have impeded recovery. The weather was not adverse, but there was a strong current at a right angle to the wind. The ship's positioning was erratic even though the beacon appeared to have a good signal. At 2200 hours, a $16 \mathrm{kHz}$ 
beacon was dropped. The positioning became much more steady, though the strong current still required a close monitoring of the positioning system.

By core No. 50, the rotating time per core became appreciable ( 20 plus minutes). Beginning core No. 55, cores were go-deviled, rather than risking damage to the wireline by excessively rotating around it. None of the subsequent core liners shattered. After coring two meters on core No. 57, a very hard formation was encountered; one additional meter was cored before retrieving the barrel. $70 \mathrm{~cm}$ of fairly fresh vesicular basalt with calcite veining was recovered along with 3.8 meters of sediment. The soft formation cutting shoe was replaced with the Acker natural diamond shoe (with jet ports) for the next two cores. Both recovered less than a meter of basalt. In core No. 58, run with the modified core catcher, basalt fragments jammed in the core catcher. In core No. 59, run with the Acker split ring core catcher, the basalt jammed in the lower liner support sleeve. The shoe was destroyed on core No. 59. Cracks had initiated at each jet hole, and the shoe splayed out of gage. Total basalt recovery was 2.2 meters out of 16.2 meters cored. The drill pipe was pulled to clear the mudline at 1230 hours on July 17.

HOLE $608 \mathrm{~A}$

After offsetting 670 feet bearing 247 degrees from the previous hole, 608A was spudded at 1419 hours on July 17. Sixteen VLHPC cores were taken to a depth of 146.4 meters. The coring breaks were staggered with relation to Hole 608 , so that a continuous detailed stratigraphy could be pieced together. The last core was on deck at 0923 hours on July 18, and at 1540 hours the ship was underway.

\section{SITE 608 TO SITE 609}

Upon leaving Site 608 , a short southeasterly run was made to profile over the beacon. A south to north profile was made across the western end of King's Trough complex before getting underway for Site 609. The axis of the trough was crossed at around midnight and the traverse displayed a striking profile on the records. In addition, it provided evidence of a mid-trough basement intrusion unmapped by previous surveys.

During the transit four of the old bumper subs were magnafluxed. Three of them (Nos. 1849, 2044, 2411) were found to have cracks in the mandrel pin. The fourth was okay. The VLHPC and XCB were redressed. Two new core catchers were fabricated for use with the Acker cutting shoes; it was evident from its previous failures that the Acker shoes were gaged slightly too large (2.5" I.D.), so that the core easily jammed in either the core catcher or the liner support sleeve, both of which were also 2.5" I.D. To 
circumvent this problem, two 2-5/8" I.D. sleeveless core catchers were brazed to the threaded sections of two Acker Core Lifters. Future runs of the Acker shoe will have the modified core catcher along with the Alternate Liner Support Sleeve. About one half of the wall thickness will be reamed out of the lower inside of the core liner to accommodate the length of the support sleeve. This assembly will present a minimum 2.6" I.D. between the cutting shoe and the core liner, and should alleviate the jamming problem. At 1647 hours on July 20, a $16 \mathrm{kHz}$ beacon was dropped to mark Site 609.

HOLE 609

The same BHA and core bit were used. After rotating several hours in basalt at the last site, the bit had one slightly loose cone with two chipped teeth, but was still in good condition. The pipe trip to the mudline was slowed by fog and a heavy swell. Spud-in occurred at 0255 hours on July 21. The mudline was established with the first core at 3883.6 meters.

Fourteen VLHPC cores were taken in gradually stiffening marly nanno ooze. Cores Nos. 13 and 14 suffered badly split core liners. Core 14 did not stroke fully and would not pull free with 40,000 lb overpull; it was freed after washing four meters over the barrel. Thus, after penetrating 130.6 meters, operations switched over to XCB coring.

The XCB was run for cores Nos. 15-42. Cores Nos. 15-22 were godeviled, but after the liners shattered on cores Nos. 19 and 22, the core barrels were run in on the wireline. The recovery was very good until core No. 18, which was inadvertently run without a liner and recovered only 1.99 meters. Only 7.2 meters was recovered in the subbottom interval between 188.2 meters and 236.2 meters (cores Nos. 21-25). Two zero recovery cores may have unlatched prior to coring due to heave-induced wireline tension. Recovery increased for cores Nos. 26-30. Then, there were three low recovery cores which appeared to be mostly washed away. The recovery improved again with core 34, averaging $95 \%$ for the bottom nine cores in the hole. Coring was ended at 399.4 meters subbottom depth with the scientific objectives reached.

The Geoset cutting shoe, with the newly modified core catcher, was used for cores Nos. 27, 29, and 31. Fair recovery was achieved, but always lower than the neighboring cores taken with the soft formation shoe.

HOLE $609 \mathrm{~A}$

Fourteen stands of pipe were pulled and the ship was offset 200 feet northwest from the beacon at 1500 hours on July 23. Two mudline cores were taken and discarded since they had not recovered the critical top-most sediment; it was at first believed that it was caused by the ship's heave and or loose 
pebbles which might have been pushed ahead of the corer. The ship was positioned back over the beacon for the third (official) spud-in which occurred at 2020 hours. This mudline core was essentially no different from the previous two, but a second core was taken before it was discovered that the bit was one stand too deep into the hole due to an error in the pipe count; 15 stands should have been pulled to clear the mudline.

At 2240 hours, the pipe was pulled to clear the mudline. Since so much time was spent, and the last two cores were saved, it was decided to call this a site.

\section{HOLE 609 B}

The first core, spudded at 2345 hours on July 23, recovered the elusive top sediment layer. Fourteen vLHPC cores were taken before the overpull limit was reached. The hole was continued with the XCB to a subbottom depth of 354.7 meters. The recovery was generally very good in this hole except for cores Nos. 16, 18,37 , and 38. The intervals of poor recovery were competely different from those in Hole 609, thus emphasizing the apparent randomness of whatever factors account for the sporadic recovery between 140 and 350 meters subbottom depth.

\section{HOLE $609 \mathrm{C}$}

The drill pipe was pulled to clear the mudline at 0430 on July 26. The ship was offset 100 feet and Hole $609 \mathrm{C}$ was spudded at 0545 hours. The bit was washed down 125 meters to the top of an interval that had been irregularly cored both at Holes 609 and 609B. Seven XCB cores were taken to a subbottom depth of 190.4 meters with $52 \%$ recovery. The first four barrels were wirelined down, but after core No. 3 returned empty (probably wireline tension caused pre-release of the latch) the last three barrels were go-deviled down. The liners did not shatter on any of these runs.

Due to the relatively poor recovery, the coring was stopped short of the original objective, which was to take 14 cores through this interval.

\section{SITE 609 TO SITE 610}

The CHALLENGER got underway from Site 609 at 0305 hours on July 27. A brief west southwest course was run to stream the gear, then turned to cross the beacon and proceed on to site 610 .

At 0644 hours on July 24, the vessel slowed to eight knots to make an extensive profile of the site area. At 1724 hours, a $13.5 \mathrm{kHz}$ beacon was let go over the crest of a mud wave to mark Site 610. A few more lines were run across the beacon before the 
gear was pulled. The ship finally settled over the beacon at 2045 hours.

HOLE 610

The objectives of the site were to piston core to the base of the upper sedimentary unit--expected to be comprised of drift material, then to spot core with the XCB through the R-4 reflector to about 690 meters subbottom.

The first core, on deck at 0440 hours on July 29 , was full so another core was taken from 9.6 meters higher; it was empty. The mudline was thus established with the first core to be at 2427.7 meters. Five VLHPC cores were taken to a subbottom depth of 48 meters. Cores Nos. 3, 4, and 5, showed considerable coring disturbance, confined mostly to the upper five meters in each core, which may have been due to the ship's motion ( $10 \mathrm{ft}$ heave and $3-5$ degree pitch). It was decided to wash down to 147 meters and continue with XCB coring. Three continuous XCB cores were taken to 185.4 meters subbottom; all were pelagic nannofossil oozes with no evidence of current deposition. Between cores Nos. 9 and 19 an average of one in five core intervals was cored, such that the cores were spaced approximately 50 meters apart. Rates of recovery slowed from $2-1 / 2$ hours to $5-1 / 2$ hours over the $25-1 / 2$ hour period. The stiffening chalk necessitated running a core barrel for each washed interval. Continuous coring resumed with core No. 19 at 636.6 meters subbottom. The last seven cores were taken over the presumed interval of the $\mathrm{R}-4$ reflector to a terminal depth of 723 meters subbottom. The drill pipe was pulled to clear the mudline at 2200 hours on July 31.

$X C B$ recovery for the lower section of the hole averaged $58 \%$ in very hard chalk. The soft formation cutting shoes, used exclusively, suffered no excess wear or damage. All of the barrels were go-deviled resulting in only one shattered liner (core No. 12). However, several of the liners returned with bulging deformations, sometimes just above the core catcher, sometimes mid-way up the liner. These plastic deformations, apparently caused by the intruding core, did not impede core recovery in comparison with neighboring cores.

The Core Barrel Pressure Tool (CPBT) was run with the wash barrel between cores Nos. 18 and 19. It obtained good pressure data which showed that the intruding core had to overcome a back pressure of $270 \mathrm{psi}$ (at $60 \mathrm{spm}$ ) to lift the check ball at the top of the core barrel.

HOLE 610A

Hole $610 \mathrm{~A}$, with no offset, was spudded in at 2340 hours on July 31. Twenty one piston cores were taken to a depth of 201 meters subbottom. Disturbance was noted in cores Nos. 2, 4, and 5 . 
Below 47 meters the disturbance, now presumed to be due to swell, did not occur. The sediment was very stiff; $10 \mathrm{k}$ overpulls were observed as early as core No. 6, with cores Nos. 17 and 18 registering $40 \mathrm{k}$ overpulls. Nevertheless, the recovery was very good (95\%) and undisturbed throughout the interval of glacial/interglacial carbonate cycles.

HOLE $610 B$

Again with no offset, Hole $610 \mathrm{~B}$ was spudded at 2200 hours on August 2. Sixteen VLHPC cores were taken to a depth of 146.8 meters sub- bottom. In an attempt to reduce the effects of heave in the top-most cores, the VLHPC was rigged with the breakaway piston head for the first six cores. Cores Nos. 1 and 2, were undisturbed, while cores Nos. 3, 4, and 5, were disturbed over part of some sections. The piston head broke away each time, but the sea conditions had also improved, so it was not clear whether the small improvement was due to the breakaway head or the calmer sea.

HOLE $610 \mathrm{C}$

The lack of some critical stratigraphic intervals necessitated still another hole on the sediment wave crest. Hole $610 \mathrm{C}$ was spudded at 1607 hours, with an immediate wash down to eight meters subbottom. The 5-meter long VLHPC was used to take the first two cores through the easily disturbed zone. This time the cores were recovered undisturbed. Four more 9.6 meter-long VLHPC cores were selectively taken to a subbottom depth of 118.2 meters.

HOLE 610D

This hole was offset 800 feet north and 1520 feet west of the beacon to a trough adjacent to the mud wave crest. It was spudded at 0300 hours on August 3. Five VLHPC cores were taken to a subbottom depth of 56.4 meters, with one core interval washed where no useful stratigraphic data were expected. The bit was then washed down to 317.6 meters subbottom where two XCB cores were taken in an attempt to a possible Miocene stratigraphic hiatus identified in hole 610. Dating of the cores revealed that the critical interval had been missed by approximately 40 meters due to a decreased sedimentation rate in the trough. The hole was terminated at a subbottom depth of 386.8 meters.

HOLE $610 E$

This hole was spudded at the same offset at 1543 hours on August 3. The bit was washed to 260 meters before taking seven XCB cores to a terminal depth of 327.2 meters. The stratigraphic 
section missed in the previous holes was successfully recovered. The drill pipe was tripped, and the bit was on deck at 0830 hours on August 4 .

The drill bit was retired from use after penetrating some 2685 meters and a rotating time of 45 hours. It had three loose cones.

\section{SITE 610 TO SITE 611}

The 2.1 day trip to Site 611 was characterized by moderate gale conditions and, at times, dense fog. The three new bumper subs in the BHA were magnafluxed. They had 44-1/2 hours rotating time on the previous three sites. One of the three had a cracked bottom sub pin. The XCB was redressed.

The bottom profile in the area of the site was characterized by mud waves. Since a previous survey of the area existed, the beacon was dropped on the first pass over the crest of a likely mud wave. The gear was retrieved and the ship returned to the beacon without further survey.

Positioning was delayed by about 25 minutes when routine switching of hydrophone arrays caused the beacon to jump off the scope. The hydrophones were checked, but the problem was ultimately traced to a faulty $X-Y$ switching relay. The faulty relay was replaced and corrected the problem.

\section{HOLE 611}

At 2115 hours on August 6, the first piston core was spudded to establish the mudiine at 3202.6 meters below the rig floor. Fourteen VLHPC cores were taken to a total subbottom depth of 125.8 meters before the $40 \mathrm{~K}$ pullout limit was reached. Nearly all of the liners fractured, but recovery was very good in the stiff nanno ooze. In order to take advantage of the good weather, it was decided to pull out and immediately recore the upper section.

\section{HOLE $611 \mathrm{~A}$}

The first core came aboard at 1530 hours on August 7 . Again, 14 cores were attempted, but the last core had no recovery due to a stuck flapper core catcher.

An extra lower liner seal sub with O-rings was added to the bottom of the core barrel in an attempt to reduce the number of fractured liners. The liners fractured a little less frequently, but no conclusive results could be drawn. The liner of core No. 9 was apparently totally shattered. When it was attempted to hydraulically extrude it from the barrel, the plastic shards 
compressed into an immovable plug. The barrel was eventually cleaned out with water and a blow torch which resulted in the loss of nearly the entire core.

HOLE 611B

On 0730 hours on August 8, the bit had cleared the mudline from Hole 611A, and the ship was offset to a new location 2000 feet north-northwest of the beacon in search of an adjacent mud trough. The bottom hardly dropped at all during the move, so several different positions were tried along a general easterly course. Eventually the trough was located 2990 feet south and 2990 feet west of the beacon. Six hours had been consumed by the offset survey.

Hole $611 \mathrm{~B}$ was spudded at 1345 hours at a depth of 3227.7 meters. During the second VLHPC coring attempt, the barrel parted at the pin of the top sub body, leaving nearly the entire tool in the hole. No fishing attempt was made because, if it were still in the BHA, the upward looking component of the fish was the outer swivel body with the broken pin of the top sub. The shallow cavity could not be stabbed by the standard fishing tool, and there was insufficient time remaining to fabricate and attempt to fish with a specialized spear. Thus the hole was terminated after one core.

Hole $611 \mathrm{C}$

The hole was spudded at 1615 hours without any offset from the previous hole. Fifteen VLHPC cores were taken with generally good recovery except for core No. 7, which may have had a stuck core catcher. The first three cores were taken with the five meter VLHPC until a new 9.5 meter VLHPC could be assembled to replace the lost one.

The XCB was used to deepen the hole to 511.6 meters subbottom. Two shattered liners, in cores Nos. 21 and 23 , were observed to be linked with the old-style XCB barrel. Beginning with core No. 25 , the old-style barrel was wirelined, and the new-style barrel was go-deviled. No more shattered liners occurred.

The XCB recovery was generally very good with the exception of two low-recovery cores and one zero-recovery core. In one of the low- recovery cores, a large drop stone (nearly the diameter of the liner) was recovered along with 2.61 meters of sediment. The zero-recovery core was wirelined down, and may have unlatched early due to heave- induced wireline tension.

Considering the high sedimentation rate observed in the cores, it appeared unlikely that the $14 \mathrm{~m} . \mathrm{y}$. objective would be reached within the remaining time. To hasten the progress, two 38.4 meter intervals were washed after cores Nos. 43 and 45 , but the 
hole was eventually terminated short of the primary objective.

HOLE 611D

With the time remaining, it was decided to reposition over the beacon and drill deeper into the mud wave crest. One VLHPC core was taken from $5.5 \mathrm{~m}$ to $15.1 \mathrm{~m}$ subbottom. The bit was then washed down to 128.9 meters to begin continuous XCB coring. Nearly every core was totally full. Only five meters were cored for core No. 6 during an XCB/CBPT run. Good pressure data were obtained by the CBPT. To core off the rest of the 9.6 meter joint, a 4.6 meter core was cut; but core No. 7 recovered 7.2 meters of good core (no slop at the top). Assuming that the bit may have been 2.5 meters too deep for that core; the depth at which the bit took weight was checked and found to be at the proper depth. The next 9.6 meter core had full recovery. Core No. 7 remains a mystery.

A total of 13 XCB cores were taken to a subbottom depth of 244.1 meters.

HOLE $611 \mathrm{E}$

After the mudline was cleared on Site 611D, the bit was spudded to obtain two piston cores from $6.5 \mathrm{~m}$ to $25.7 \mathrm{~m}$ subbottom. The purpose of these cores was to overlap a distorted zone.

At 1030 hours on August 12, the drill pipe was tripped The BHA was magnafluxed while coming out of the hole. A crack was discovered around the middle of the pin thread of the pup joint. The vessel got under way for post site survey at 2146 hours on August 12.

\section{SITE 611 TO ST. JOHNS}

A post site survey was conducted in an attempt to discover the shape of the sediment wave on which the site was located. It became clear that the wave is a broad double-crested feature that extends over one half $\mathrm{n} . \mathrm{m}$. in a south to north direction. It would have been impossible to offset far enough northwards while maintaining the beacon signal, and still reach the trough in that direction. The of fset maneuvers to the north and northwest had all been around the broad sediment wave crest.

The 4.5 day trip to St. Johns was busy with the usual end-of-leg activities. By the second day of the transit the weather had deteriorated to the worst experienced in the last two months. For a full day the CHALLENGER braved force 8 gale winds, 18 foot seas, and 16 degree rolls. The next day was sunny, but with strong head winds. The remainder of the trip was characterized by usually strong head winds and dense fog at times. No icebergs 
were spotted, though concentrations of icebergs were known to be in the area.

The voyage officially ended with the first line dockside in St. Johns at 1051 hours on August 17, 1983.

\section{DRILL STRING}

Eighty seven joints of premium and 265 joints of Grade 2 drill pipe were loaded in Norfolk to partially replace the drill string lost on Leg 93. The Grade 2 pipe was stored in the hold. The racks now contain 299 joints of new pipe, 309 joints of premium pipe, and 56 joints of aluminum pipe. One joint of aluminum pipe was discovered to have a gash located three feet above the lower tool joint. It was marked and will be inspected in port.

One thousand clamp-on type rubber protectors were installed on the premium pipe while running in the fist hole. Four protectors per joint were spaced at intervals of $5^{\prime}, 5^{\prime}, 8^{\prime}$, and $8^{\prime}$, from the top of each of the top two joints in a stand. The spacing for the lower joint in the stand was $5^{\prime}, 5^{\prime}, 7^{\prime}, 7^{\prime}$, in order to miss the fingers of the pipe racker.

The 20' pup joint developed a crack around the middle of the pin thread which was discovered during routine magnafluxing while coming out of the final hole of the leg..

\section{BOTTOM HOLE ASSEMBLY}

All of the sites involved only $\mathrm{HPC} / \mathrm{XCB}$ drilling. A special BHA was used for the first site to accommodate the new Advanced Piston Corer $(A P C)$. It comprised an $\mathrm{HPC} / \mathrm{XCB}$ bit, bit sub (including Guide Ring OL0131, float valve, and a special 3.8" I.D. support bearing), Bit Sub Spacer OG0621, Seal Bore Drill Collar OL1043, Landing/Saver Sub OG0620, 3' spacer, top sub, head sub (including Latch Sleeve OL1013), Monel drill collar, 8-1/4" drill collar stand, bumper sub, 8-1/4" drill collar stand, two bumper subs, two 8-1/4" drill collars, crossover sub, 7-1/4" drill collar, and two heavy wall drilling joints.

In order to correctly space the Kuster orientation tool within the Monel drill collar, it was necessary to move the jars from the top to the bottom of the overshot/sinker bar assembly. This raised the position of the Kuster tool with respect to the APC top sub, which was designed to land lower in the BHA than the VLHPC top sub.

The special BHA was lost in the second hole of the first site. The BHA used for the rest of the cruise included the following: bit, bit sub (including guide ring, padded float valve, and support bearing outer race), outer core barrel, two 3' spacers, outer core barrel, top sub, head sub (including Latch/Seal Sleeve 
OL 1014), two 8-1/4" drill collars, bumper sub, 8-1/4" drill collar stand, two bumper subs, two 8-1/4" drill collars, crossover sub, 7-1/4" drill collar, and two heavy wall drilling joints.

The loss of the BHA was due to a brittle failure the mandrel pin on the lowermost bumper sub. All of the bumper subs in that assembly had been used previously. The two remaining subs were later magnafluxed to find that one had circumferential cracks around the base of the mandrel pin, and the other had a possible crack in the bottom sub body.

New bumper subs were used in the BHA for the remaining sites. These subs wee magnafluxed between Sites 610 and 611 (after 44$1 / 2$ hours rotating hours); one of the three had a crack across the pin-end shoulder and extending approximately one inch up the body of the body of the bottom sub. The four remaining used bumper subs were also magnafluxed; three had cracked mandrel pins. On board at present are eleven new bumper subs, two old ones that are in good condition, and five cracked ones.

\section{CORE BITS}

Three HPC/XCB core bits were used for the 22 holes cored on Leg 94. The first was lost with the lower BHA in Hole 606A. The second was used for Holes 607 through 610E. It had worked a total of 45 hours washing and rotating XCB cores, six hours of which were in basalt. It has three loose cones and a few chipped teeth. It may still be useful for short HPC holes. The third bit, used for the last six holes at Site 611, has two chipped teeth and one slightly loose cone.

\section{POSITIONING AND BEACONS}

No major problems were encountered with the positioning system though on several instances the heavy! seas caused a temporary loss of acoustics. One $X-Y$ switching relay was discovered to be faulty and was replaced while coming on Site 611 .

Seven beacons, $4 \mathrm{ea}, 16 \mathrm{kHz}$, and $3 \mathrm{ea}, 13.5 \mathrm{kHz}$, were used on the six sites of Leg 94. All functioned flawlessly except for the $13.5 \mathrm{kHz}$ beacon (Serial No. 162) dropped on Site 608. Though it maintained a good signal, the ship's positioning was erratic for the 90 hours it was used. A $16 \mathrm{kHz}$ beacon was dropped to replace it, and the positioning improved considerably. The new beacon landed 270 feet north and 610 feet east of the old one, attesting to the strong currents in the area.

\section{EXTENDED CORE BARREL (XCB)}

The success of the cruise essentially hinged upon the success of the XCB since every site had both shallow (HPC) objectives and 
deeper (XCB) objectives. The overall XCB core recovery was excellent. The new latch did not jam in the drill pie during either wireline or go-devil trips. The new vent sub/liner hanger functioned as designed with no problems.

The soft formation cutting shoe also functioned well throughout the entire range of soft sediment through basalt. One reason for the good recovery was that the inner gage bore of the cutting teeth was only about 2-1/4n diameter. The soft cores did not show evidence of this, but the hard cores were typically only 2.16" diameter. In some cases the diameters reduced to less than 2 " when the bit 'stood' on a particularly hard formation longer, allowing more jet scouring and/or more reaming due to a slight wobble in the tool.

The Acker hard formation cutting shoes were tried a few times with poor results. In general, though, the sediments were too soft to use the Acker shoes effectively. In the one case where basalt was cored with a diamond shoe with jet ports, the shoe was destroyed when cracks initiated at each of the ports.

The disc springs, exposed to long hours of continuous operation, were inspected after each site. Sometimes as few as six, and other times as many as 54 springs were found cracked or broken and had to be replaced.

About 50\% of the XCB runs were wirelined because the liners would sometimes shatter when the barrels were go-deviled. The shattered liners occurred erratically. Several drop tests down the pipe were conducted under varying conditions, but, no liners shattered during these tests.. At each hole the XCB was usually go-deviled until the occurrence of one or two shattered liners; then it was wirelined. When the rotation time per core increased significantly near the bottom of the hole, the XCB was again godeviled, usually without suffering shattered liners.

\section{ADVANCED PISTON CORER (APC)}

The APC was very successful in its first sea trials on Holes 606 and $606 \mathrm{~A}$. Its ease of operation, short length and greater coring force definitely make it the piston corer of the future. The antispiral groove on the piston rod prevented core rotation during shoot-off, and will be an asset to paleomagnetic data recovery. Unfortunately the APC was lost in Hole 606A, when the piston rod parted, apparently due to fatiguing from a previous $100 \mathrm{~K}$ overpull.

\section{VARIABLE LENGTH HYDRAULIC PISTON CORER (VLHPC)}

This tool gave its usual good performance, although a high percentage of fractured liners occurred. The fractures usually ran axially along the length of the liner; many times a 'football' 
shaped section popped out and was carried with the core higher up the liner. In a few cases the fractures spiraled around the liner. In one instance a full-recovery core without a damaged liner was layed out on the rack, but it fractured all along its length like a sheet of ice when the technicians began to section it. The core was stiff and clayey; the fracture may have been caused by core expansion in a poor-quality liner.

The piston corer refusal point was determined by excess pullout force ( $40 \mathrm{~K}$ lbs) rather than short stroke. The refusal point was usually reached at about 125 meters subbottom in the stiff, sometimes sticky nanno oozes encountered on all of the sites.

\section{WEATHER}

The weather was surprisingly good for most of the voyage. It seemed that, while on each site, a storm would be occupying the position of the next site, then would move away by the time the ship arrived there. The first half of the cruise, including the eight day transit to the first site, was characterized by calm seas and sunny skies. The sun faded as the leg progressed but the relatively calm conditions remained.

The seas were rough enough, however, to adversely affect VLHPC coring on several sites. Distorted upper core sections and a few cores containing material already cored in the previous barrel were blamed on heave and/or pitch.

\section{COMMUNICATIONS}

Communications steadily worsened as the ship progressed north and east. Contact with WWD was maintained for a fair amount of the time due to the vigilance and determination of the radio officer, who logged long hours at his post. Many times outgoing messages had to be sent via the Coast Guard station in Norfolk, and incoming ones received via Mercast.

\section{PERSONNEL}

The expertise, intercooperation, and high moral of the scientists, technicians, and GMI people played a major role in making Leg 94 a very successful expedition.

Don Cameron

Cruise Operations Manager

Deep Sea Dilling Project 
TOTAL TIME DISTRIBUTION

LEG 94

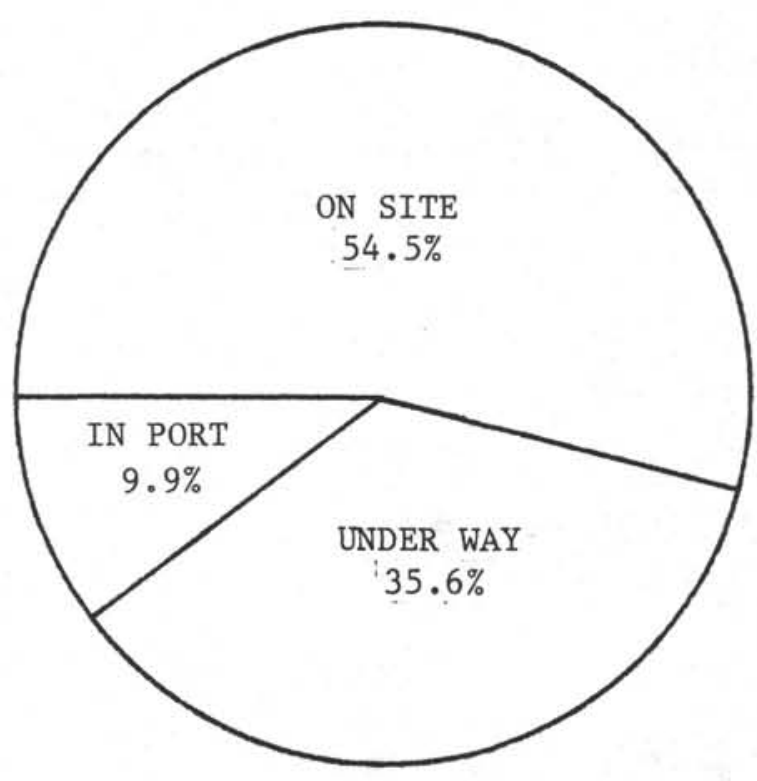

ON-SITE TIME DISTRIBUTION

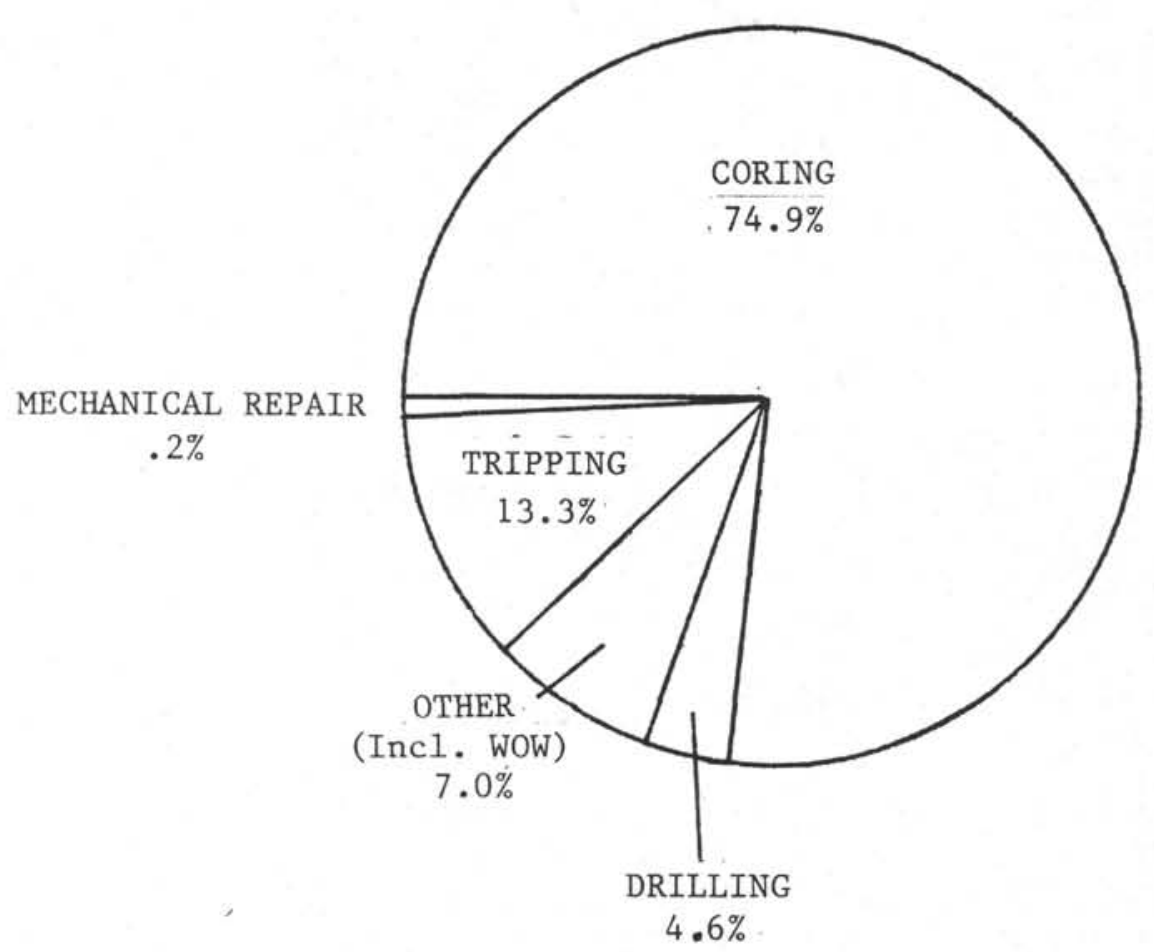




\section{INTERNATIONAL PHASE OF OCEAN DRILLING \\ DEEP SEA DRILLING PROJECT \\ OPERATIONS RESUME \\ LEG 94}

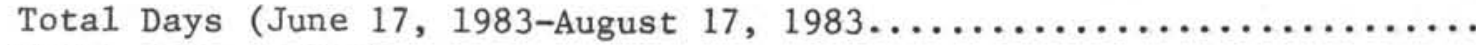

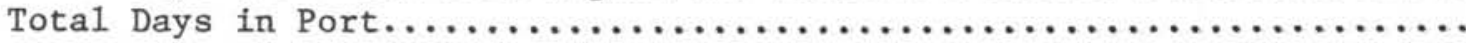

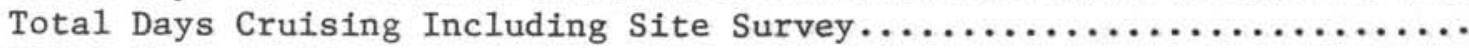

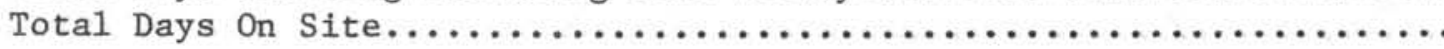

\begin{tabular}{|c|c|}
\hline ip Time... & 4.40 \\
\hline Drilling Time... & 1.5 \\
\hline Coring Time..... & 24.74 \\
\hline Downhole Measuremer & 0 \\
\hline Stuck Pipe........ & 0 \\
\hline Weather.......... & .03 \\
\hline$y \ldots \ldots \ldots \ldots \ldots$ & 0 \\
\hline$\ldots \ldots \ldots \ldots \ldots \ldots \ldots$ & 2.32 \\
\hline Repair.......... & \\
\hline
\end{tabular}

Total Distance Traveled Including Survey (nautical miles) ..........

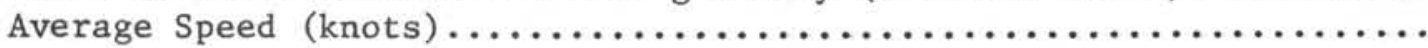

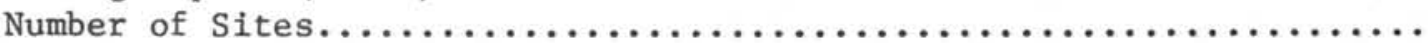

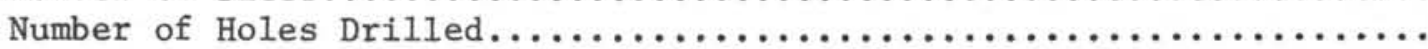

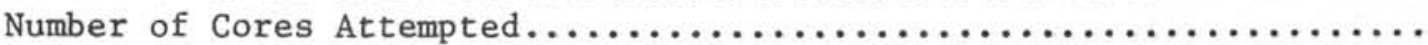

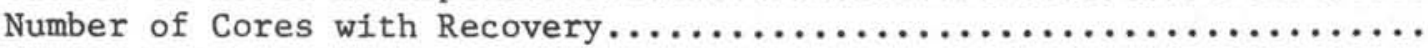

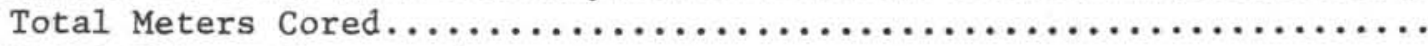

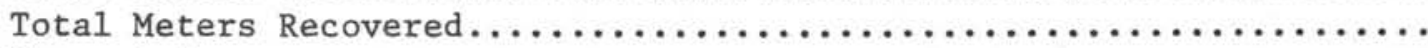

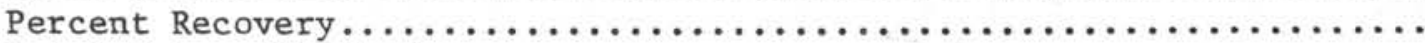

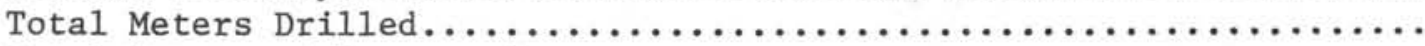

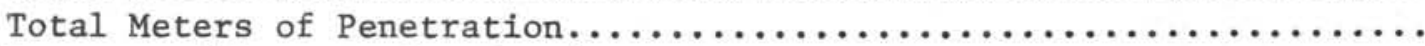

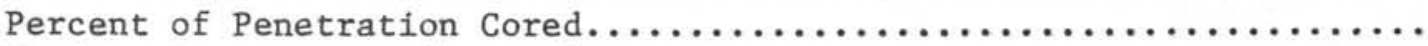

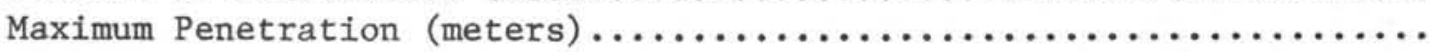

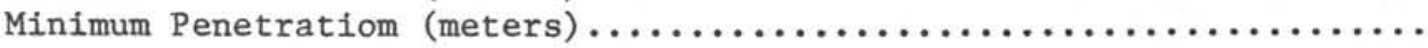

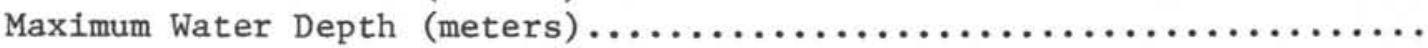
Minimum Water Depth (meters)....

4920.1 


\section{DEEP SEA DRILLING PROJECT \\ TIME DISTRIBUTION \\ $\angle E G-94$}

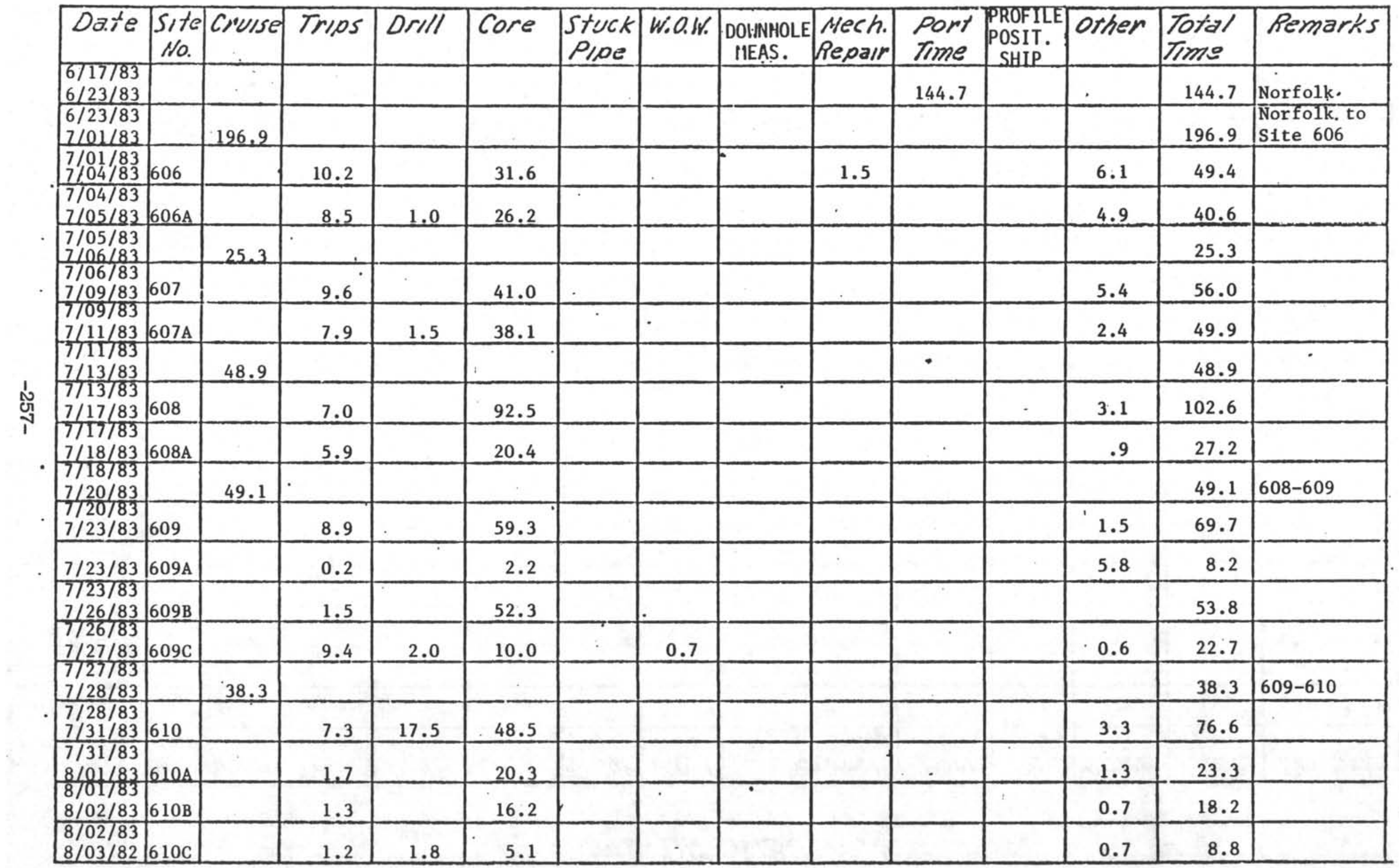


DEEP SEA DRILLING PROJECT

TIME DISTRIBUTION

$\angle E G-94$

\begin{tabular}{|c|c|c|c|c|c|c|c|c|c|c|c|c|c|c|}
\hline Da.te & \begin{tabular}{|c|} 
Site \\
No.
\end{tabular} & Cruise & Trips & Drill & Core & \begin{tabular}{|l|l} 
Stuck \\
Ploe
\end{tabular} & W.OW. & $\begin{array}{l}\text { OWNHOLE } \\
\text { MLAS, }\end{array}$ & \begin{tabular}{|l|} 
Mech. \\
Pepair
\end{tabular} & $\begin{array}{l}\text { Port } \\
\text { Time }\end{array}$ & $\begin{array}{l}\text { Re- } \\
\text { Entry }\end{array}$ & orher & \begin{tabular}{|l|} 
Total \\
Tims
\end{tabular} & Remarks \\
\hline $8 / 03 / 83$ & $610 \mathrm{D}$ & & 2.0 & 4.0 & 7.0 & & & & & & & .1 .7 & 14.7 & . \\
\hline $\begin{array}{l}8 / 03 / 83 \\
8 / 04 / 83\end{array}$ & $610 \mathrm{E}$ & & 6.7 & 3.0 & 8.3 & & & & & & & 0.5 & 18.5 & \\
\hline $\begin{array}{l}880483 \\
8 / 0683\end{array}$ & & 50.6 & & & & & & & & & & 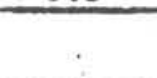 & 50.6 & $610-611$ \\
\hline $\begin{array}{l}8 / 06 / 83 \\
8 / 07 / 83\end{array}$ & 611 & & 6.2 & & 17.5 & & & & $0: 4$ & & & 2.0 & 26.1 & \\
\hline 8 & $611 \mathrm{~A}$ & & 1.3 & & 16.0 & & & & & & & & 17.3 & \\
\hline $8 / 08 / 83$ & $61 \mathrm{~B}$ & & 0.7 & & 2.0 & & & 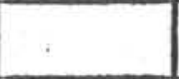 & & & & 5.8 & 8.5 & \\
\hline $\begin{array}{l}8 / 08 / 83 \\
8 / 11 / 83\end{array}$ & $611 \mathrm{c}$ & & 1.6 & 4.2 & 60.5 & & & & & & & .2 & 66.5 & \\
\hline $\begin{array}{l}8 / 11 / 83 \\
8 / 12 / 83\end{array}$ & 6110 & & 1.4 & 1.2 & 16.9 & & & & & & & 1.5 & 21.0 & o \\
\hline $8 / 12 / 8$ & $611 \mathrm{E}$ & & 5.2 & & 1.8 & & & & & & . & 7.3 & 14.3 & \\
\hline $\begin{array}{l}8 / 12 / 8= \\
8117 / 8=\end{array}$ & & 109.6 & & & & & & & & . & & & 109.6 & $\begin{array}{l}\text { S1te bा1 to } \\
\text { St. Johns }\end{array}$ \\
\hline & & & & & & & & & & & & & & \\
\hline & & & & & & & & & & & & & & \\
\hline & & & & & & & & & & & & & & \\
\hline & & & & & & & & & & & & & & \\
\hline & & & & & & & & & & & & & . & \\
\hline & & & & & & & & & & & & & & \\
\hline & & $\div$ & & & & & & & & & & & & . \\
\hline & & & & & & & & & & & & & , & \\
\hline & & & & & & & & & & & & &. & \\
\hline & & & & & & & & & & & & & & \\
\hline
\end{tabular}


INTERNATIONAL PHASE OF OCEAN DRILLING

DEEP SEA DRILLING PROJECT

$$
\text { SITE SURARY }
$$

LEG 94

\begin{tabular}{|c|c|c|c|c|c|c|c|c|c|c|c|c|c|c|}
\hline Hole & Lat1tude & Longitude & $\begin{array}{l}\text { Water } \\
\text { Depth } \\
\text { Meters }\end{array}$ & $\begin{array}{l}\text { Number } \\
\text { of } \\
\text { Corea }\end{array}$ & $\begin{array}{l}\text { Cores } \\
\text { With } \\
\text { Recovery }\end{array}$ & $\begin{array}{l}\text { Percent of } \\
\text { Cores With } \\
\text { Recovery }\end{array}$ & $\begin{array}{l}\text { Metere } \\
\text { Cored }\end{array}$ & $\begin{array}{c}\text { Meters } \\
\text { Recovered }\end{array}$ & $\begin{array}{c}\text { Percent } \\
\text { Recovered }\end{array}$ & $\begin{array}{l}\text { Metere } \\
\text { Drilled }\end{array}$ & $\begin{array}{l}\text { Total } \\
\text { Penet } \\
\text { Meters }\end{array}$ & $\begin{array}{l}\text { Avg. } \\
\text { Rate } \\
\text { Penet. }\end{array}$ & $\begin{array}{l}\text { Time } \\
\text { On } \\
\text { Hole }\end{array}$ & $\begin{array}{l}\text { Fime } \\
\text { On } \\
\text { Site }\end{array}$ \\
\hline $\begin{array}{l}606 \\
606 \mathrm{~A}\end{array}$ & $\begin{array}{l}37^{\circ} 20.322^{\prime} \mathrm{N} \\
\text { of fset } 100^{\prime}\end{array}$ & $\begin{array}{l}35^{\circ} 29.99 \text { 'W } \\
\text { West }\end{array}$ & $\begin{array}{l}3022.15 \\
3023.8\end{array}$ & $\begin{array}{l}18 \\
19\end{array}$ & $\begin{array}{l}18 \\
19\end{array}$ & $\begin{array}{l}100.0 \\
100.0\end{array}$ & $\begin{array}{l}165.8 \\
178.4\end{array}$ & $\begin{array}{l}154.1 \\
156.3\end{array}$ & $\begin{array}{l}92.9 \\
87.6\end{array}$ & . & $\begin{array}{l}165.8 \\
178.4\end{array}$ & & $\begin{array}{l}49.4 \\
40.5\end{array}$ & 90.0 \\
\hline $\begin{array}{l}607 \\
607 \mathrm{~A}\end{array}$ & $\begin{array}{l}41^{\circ} 00.07 ' \mathrm{~N} \\
\text { of f set } 100^{\prime}\end{array}$ & $\begin{array}{l}32^{\circ} 57.55^{\prime} \mathrm{W} \\
\text { North }\end{array}$ & $\begin{array}{l}3426.1 \\
3424.7\end{array}$ & $\begin{array}{l}30 \\
26\end{array}$ & $\begin{array}{l}30 \\
26\end{array}$ & $\begin{array}{l}100.0 \\
100.0\end{array}$ & $\begin{array}{l}284.4 \\
226.6\end{array}$ & $\begin{array}{l}248.2 \\
205.0\end{array}$ & $\begin{array}{l}87.3 \\
90.5\end{array}$ & 84.7 & $\begin{array}{l}284.4 \\
311.3\end{array}$ & & $\begin{array}{l}55.9 \\
50.0\end{array}$ & 105.9 \\
\hline $\begin{array}{l}608 \\
608 \mathrm{~A}\end{array}$ & $\begin{array}{l}42^{\circ} 50.20^{\prime} \mathrm{N} \\
\text { of fset } 670^{\prime}\end{array}$ & $\begin{array}{l}23^{\circ} 05.25^{\prime} \mathrm{W} \\
\text { West }\end{array}$ & $\begin{array}{l}3533.6 \\
3533.0\end{array}$ & $\begin{array}{l}59 \\
16\end{array}$ & $\begin{array}{l}58 \\
16\end{array}$ & $\begin{array}{r}98.3 \\
100.0\end{array}$ & $\begin{array}{l}530.3 \\
146.4\end{array}$ & $\begin{array}{l}428.0 \\
144.0\end{array}$ & $\begin{array}{l}80.7 \\
98.4\end{array}$ & $i$ & $\begin{array}{l}530.3 \\
146.4\end{array}$ & & $\begin{array}{r}102.6 \\
27.2\end{array}$ & 129.8 \\
\hline $\begin{array}{l}609 \\
609 A \\
609 B \\
609 C\end{array}$ & $\begin{array}{l}49^{\circ} 52.67 ' \mathrm{~N} \\
49^{\circ} 52.671 \mathrm{~N} \\
49^{\circ} 52.67^{\prime} \mathrm{N} \\
\text { off set } 100^{\prime}\end{array}$ & $\begin{array}{l}24^{\circ} 14.29^{\prime} W \\
24^{\circ} 14.29^{\prime} W \\
24^{\circ} 14.29^{\prime} w\end{array}$ & $\begin{array}{l}3883.6 \\
3883.0 \\
3883.0 \\
3883.0\end{array}$ & $\begin{array}{r}42 \\
2 \\
38 \\
7\end{array}$ & $\begin{array}{r}40 \\
2 \\
37 \\
6\end{array}$ & $\begin{array}{r}95.2 \\
100.0 \\
97.3 \\
; 85.7\end{array}$ & $\begin{array}{r}399.4 \\
19.2 \\
354.7 \\
67.2\end{array}$ & $\begin{array}{r}301.2 \\
17.9 \\
308.4 \\
35.0\end{array}$ & $\begin{array}{r}75.4 \\
93.2 \\
86.9 \\
58.0\end{array}$ & $\begin{array}{r}23.8 \\
123.2\end{array}$ & $\begin{array}{r}399.4 \\
43.0 \\
354.7 \\
190.4\end{array}$ & & $\begin{array}{r}69.7 \\
8.2 \\
53.8 \\
22.6\end{array}$ & 154.3 \\
\hline $\begin{array}{l}610 \\
610 \mathrm{~A} \\
610 \mathrm{~B} \\
610 \mathrm{C} \\
610 \mathrm{D} \\
610 \mathrm{~B}\end{array}$ & $\begin{array}{l}53^{\circ} 13.30^{\prime} \mathrm{N} \\
53^{\circ} 13.30^{\prime} \mathrm{N} \\
53^{\circ} 13.30^{\prime} \mathrm{N} \\
53^{\circ} 13.30^{\prime} \mathrm{N} \\
\text { of fset } 800^{\prime} \mathrm{N} \\
\text { of fset } 800^{\prime} \mathrm{N}\end{array}$ & $\begin{array}{l}18^{\circ} 53.21^{\prime} \mathrm{W} \\
18^{\circ} 53.21^{\prime} \mathrm{W} \\
18^{\circ} 53.21^{\prime} \mathrm{W} \\
18^{\circ} 53.21^{\prime} \mathrm{W} \\
\times 1520^{\prime} \mathrm{W} \\
\times 1520^{\prime} \mathrm{W}\end{array}$ & $\begin{array}{l}2427: 7 \\
2426.3 \\
2427.5 \\
2427.5 \\
2458: 7 \\
2458: 7\end{array}$ & $\begin{array}{r}27 \\
21 \\
16 \\
6 \\
7 . \\
7\end{array}$ & $\begin{array}{r}27 \\
21 \\
16 \\
6 \\
7\end{array}$ & $\begin{array}{l}160,0 \\
100,0 \\
100,0 \\
100,0 \\
109,0 \\
09: 9\end{array}$ & $\begin{array}{r}259.2 \\
201.0 \\
146.8 \\
48.4 \\
66.0 \\
67.2\end{array}$ & $\begin{array}{r}179.3 \\
191.4 \\
136.3 \\
43.9 \\
54.2 \\
53.3\end{array}$ & $\begin{array}{l}69.2 \\
95.2 \\
92.8 \\
90.7 \\
82.1 \\
79.3\end{array}$ & $\begin{array}{r}69.8 \\
270.8 \\
260.0\end{array}$ & $\begin{array}{l}723.0 \\
201.0 \\
146.8 \\
118.2 \\
336.8 \\
327.2\end{array}$ & & $\begin{array}{r}77.1 \\
22.0 \\
19.2 \\
8.6 \\
15.2 \\
18.0\end{array}$ & 160.1 \\
\hline $\begin{array}{l}611 \\
611 \mathrm{~A} \\
611 \mathrm{~B} \\
611 \mathrm{C} \\
611 \mathrm{D} \\
611 \mathrm{~B}\end{array}$ & $\begin{array}{l}52^{\circ} 50.47 ' \mathrm{~N} \\
52^{\circ} 50.47 \text { 'N } \\
52^{\circ} 50.15^{\circ} \mathrm{N} \\
52^{\circ} 50.15^{\prime} \mathrm{N} \\
52^{\circ} 50.47 ' \mathrm{~N} \\
52^{\circ} 50.47 \text { ' }\end{array}$ & $\begin{array}{l}30^{\circ} 18.58^{\prime} \mathrm{W} \\
30^{\circ} 18.58^{\prime} \mathrm{W} \\
30^{\circ} 19.10^{\prime} \mathrm{W} \\
30^{\circ} 19.10^{\prime} \mathrm{W} \\
30^{\circ} 18.58^{\prime} \mathrm{W} \\
30^{\circ} 18.58^{\prime} \mathrm{W}\end{array}$ & $\begin{array}{l}3202.6 \\
3200.9 \\
3227.7 \\
3227.6 \\
3199.5 \\
3199.5\end{array}$ & $\begin{array}{r}14 \\
14 \\
1 \\
47 \\
14 \\
2\end{array}$ & $\begin{array}{r}14 \\
13 \\
1 \\
44 \\
14 \\
2\end{array}$ & $\begin{array}{r}r 00: 0 \\
92,8 \\
100,0 \\
93,6 \\
10010 \\
100 / 0\end{array}$ & $\begin{array}{r}125.8 \\
132.8 \\
8.9 \\
434.8 \\
124.8 \\
19.8\end{array}$ & $\begin{array}{r}112.2 \\
\mid 98.3 \\
8.9 \\
344.1 \\
122.3 \\
19.2\end{array}$ & $\begin{array}{r}89.2 \\
74.5 \\
100.0 \\
79.1 \\
98.0 \\
100.0\end{array}$ & $\begin{array}{c}16.8 \\
19.3 \\
6.5\end{array}$ & $\begin{array}{r}125.8 \\
132.0 \\
8.9 \\
51.6 \\
24 \% .1 \\
25.7\end{array}$ & & $\begin{array}{r}26.1 \\
17.3 \\
8.5 \\
67.5 \\
20.3 \\
15.7\end{array}$ & 155.4 \\
\hline
\end{tabular}


INTERNATIONAL PHASE OF OCEAM DRILLING

DERP SEA DRILLING PROJECT

BIT SUMMARY

LEG 94

\begin{tabular}{|c|c|c|c|c|c|c|c|c|c|c|c|}
\hline Hole & Mfg. & Size & Type & $\begin{array}{l}\text { Serial } \\
\text { Number }\end{array}$ & $\begin{array}{l}\text { Meters } \\
\text { Cored }\end{array}$ & $\begin{array}{l}\text { Meters } \\
\text { Drilled }\end{array}$ & $\begin{array}{l}\text { Metars } \\
\text { Total } \\
\text { Penet }\end{array}$ & $\begin{array}{l}\text { Hours } \\
\text { on } \\
\text { Bit }\end{array}$ & Condition & Remarks & . \\
\hline $\begin{array}{l}606 \\
606 A\end{array}$ & $\begin{array}{l}\text { MSDS } \\
\text { MSDS }\end{array}$ & $\begin{array}{l}3.8 \times 11-9 / 16 \\
3.8 \times 11-9 / 16\end{array}$ & $\begin{array}{l}\mathrm{HPC} / \mathrm{XCB} \\
\mathrm{HPC} / \mathrm{XCB}\end{array}$ & $\begin{array}{l}s-35 \\
s-35\end{array}$ & $\begin{array}{l}0 \\
0\end{array}$ & $\begin{array}{lll}0 & 0 \\
0 & 0\end{array} !$ & $\begin{array}{l}\mathbf{0} \\
\mathbf{0}\end{array}$ & $\begin{array}{l}0 \\
0\end{array}$ & Unknown & $\begin{array}{l}\text { HPC work ohly. } \\
\text { Lost with BHA. }\end{array}$ & \\
\hline $\begin{array}{l}607 \\
607 \mathrm{~A}\end{array}$ & $\begin{array}{l}\text { MSDS } \\
\text { MSDS }\end{array}$ & $\begin{array}{l}3.8 \times 11-9 / 16 \\
3.8 \times 11-9 / 16\end{array}$ & $\begin{array}{l}\mathrm{HPC} / \mathrm{XCB} \\
\mathrm{HPC} / \mathrm{XCB}\end{array}$ & $\begin{array}{l}S-49 \\
S-49\end{array}$ & $\begin{array}{r}144.0 \\
67.6\end{array}$ & 84.7 & $\begin{array}{l}144.0 \\
152.3\end{array}$ & $\begin{array}{l}1.32 \\
2.21\end{array}$ & $\begin{array}{l}\text { Unknown } \\
\text { T } \varnothing-\mathrm{B} \varnothing \mathrm{SE}-\mathrm{I}\end{array}$ & $\begin{array}{l}\text { Does not Include HPC work. } \\
\text { Does not include HPC work. }\end{array}$ & \\
\hline $\begin{array}{l}608 \\
608 \mathrm{~A}\end{array}$ & $\begin{array}{l}\text { MSDS } \\
\text { MSDS }\end{array}$ & $\begin{array}{l}3.8 \times 11-9 / 16 \\
3.8 \times 11-9 / 16\end{array}$ & $\begin{array}{l}\mathrm{HPC} / \mathrm{XCB} \\
\mathrm{HPC} / \mathrm{XCB}\end{array}$ & $\begin{array}{l}s-49 \\
s-19\end{array}$ & $\begin{array}{c}379.3 \\
0\end{array}$ & $\begin{array}{l}0 \\
0\end{array}$ & $\underset{0}{379.3}$ & $\begin{array}{c}12.79 \\
0\end{array}$ & $\mathrm{~T} 1-\mathrm{B} 4 \mathrm{SE}-\mathrm{I}$ & $\begin{array}{l}\text { Does not Include HPC work. } \\
\text { Does not Include HPC work. }\end{array}$ & $\because$ \\
\hline $\begin{array}{l}609 \\
609 A \\
609 B \\
609 C\end{array}$ & $\begin{array}{l}\text { MSDS } \\
\text { MSDS } \\
\text { MSDS } \\
\text { MSDS }\end{array}$ & $\begin{array}{l}3.8 \times 11-9 / 16 \\
3.8 \times 11-9 / 16 \\
3.8 \times 11-9 / 16 \\
3.8 \times 11-9 / 16\end{array}$ & $\begin{array}{l}\mathrm{HPC} / \mathrm{XCB} \\
\mathrm{HPC} / \mathrm{XCB} \\
\mathrm{HPC} / \mathrm{XCB} \\
\mathrm{HPC} / \mathrm{XCB}\end{array}$ & $\begin{array}{l}s-49 \\
S-49 \\
S-49 \\
s-49\end{array}$ & $\begin{array}{c}268.8 \\
0 \\
226.3 \\
67.2\end{array}$ & $\begin{array}{r}0 \\
0 \\
0 \\
123.2\end{array}$ & $\begin{array}{c}0 \\
0 \\
226.3 \\
190.4\end{array}$ & $\begin{array}{l}5.68 \\
0 \\
1.76 \\
14.76\end{array}$ & T1-B5sE-I & $\begin{array}{l}\text { Does not include HPC work. } \\
\text { Does not Incluwe HPC work. } \\
\text { Does not Include HPC work. } \\
\text { Does not include HPC work. }\end{array}$ & \\
\hline $\begin{array}{l}610 \\
610 \mathrm{~A} \\
610 \mathrm{~B} \\
610 \mathrm{C} \\
610 \mathrm{D} \\
610 \mathrm{E}\end{array}$ & $\begin{array}{l}\text { MSDS } \\
\text { MSDS } \\
\text { MSDS } \\
\text { MSDS } \\
\text { MSDS } \\
\text { MSDS }\end{array}$ & $\begin{array}{l}3.8 \times 11-9 / 16 \\
3.8 \times 11-9 / 16 \\
3.8 \times 11-9 / 16 \\
3.8 \times 11-9 / 16 \\
3.8 \times 11-9 / 16 \\
3.8 \times 11-9 / 16\end{array}$ & $\begin{array}{l}\mathrm{HPC} / \mathrm{XCB} \\
\mathrm{HPC} / \mathrm{XCB} \\
\mathrm{HPC} / \mathrm{XCB} \\
\mathrm{HPC} / \mathrm{XCB} \\
\mathrm{HPC} / \mathrm{XCB} \\
\mathrm{HPC} / \mathrm{XCB}\end{array}$ & $\begin{array}{l}s-49 \\
s-49 \\
s-49 \\
s-49 \\
s-49 \\
s-49\end{array}$ & $\begin{array}{l}211.2 \\
0 \\
0 \\
0 \\
19.2 \\
67.2\end{array}$ & $\begin{array}{r}463.8 \\
0.11 \\
0 \\
69.8 \\
270.8 \\
260.0\end{array}$ & $\begin{array}{r:}675.0 \\
0 \\
9 \\
69.8 \\
29 \\
32.0 \\
32.2\end{array}$ & $\begin{array}{l}4.36 \\
0 \\
0 \\
0.92 \\
1.88 \\
1.33\end{array}$ & T1-B6SQ-I & $\begin{array}{l}\text { Does not Include HPC work. } \\
\text { Does not Include HPC work. } \\
\text { Does not Include HPC work. } \\
\text { Does not Include HPC work. } \\
\text { Does not Include HPC work. } \\
\text { Three loose cones. Ret1red. }\end{array}$ & : \\
\hline $\begin{array}{l}611 \\
611 \mathrm{~A} \\
611 \mathrm{~B} \\
611 \mathrm{C} \\
611 \mathrm{D} \\
611 \mathrm{E}\end{array}$ & $\begin{array}{l}\text { MSDS } \\
\text { MSDS } \\
\text { MSDS } \\
\text { MSDS } \\
\text { MSDS } \\
\text { MSDS }\end{array}$ & $\begin{array}{l}3.8 \times 11-9 / 16 \\
3.8 \times 11-9 / 16 \\
3.8 \times 11-9 / 16 \\
3.8 \times 11-9 / 16 \\
3.8 \times 11-9 / 16 \\
3.8 \times 11-9 / 16\end{array}$ & $\begin{array}{l}\mathrm{HPC} / \mathrm{XCB} \\
\mathrm{HPC} / \mathrm{XCB} \\
\mathrm{HPC} / \mathrm{XCB} \\
\mathrm{HHC} / \mathrm{XCB} \\
\mathrm{HHC} / \mathrm{XCB} \\
\mathrm{HPC} / \mathrm{XCB}\end{array}$ & $\begin{array}{l}s-50 \\
S-50 \\
s-50 \\
s-50 \\
S-50 \\
s-50\end{array}$ & $\begin{array}{l}0 \\
0 \\
0 \\
\beta 07.17 \\
15.2 \\
0\end{array}$ & \begin{tabular}{r|}
$\left.\mid \begin{array}{l}1 \\
0 \\
0 \\
0 \\
76\end{array}\right)$ \\
$119 !$ \\
0
\end{tabular} & $\begin{array}{c}0 \\
0 \\
0 \\
383.97 \\
234.5 \\
0\end{array}$ & $\begin{array}{l}0 \\
0 \\
0 \\
4.73 \\
1.47 \\
0\end{array}$ & TळB1-I & $\begin{array}{l}\text { Does not include xCB work. } \\
\text { Two broken feeth on one cone. }\end{array}$ & \\
\hline
\end{tabular}




\begin{tabular}{|c|c|c|c|c|c|c|}
\hline & \multicolumn{6}{|c|}{$\begin{array}{c}\text { INTERNATIONAL PHASE OF OCEAN DRILLING } \\
\text { DEEP SEA DRILLING PROJECT } \\
\text { BEACON SUMMARY } \\
\text { Leg } 94\end{array}$} \\
\hline & $\begin{array}{l}\text { Site } \\
\text { No. }\end{array}$ & Make & $\begin{array}{l}\text { Freq. } \\
\text { kHz }\end{array}$ & $\begin{array}{l}\text { Serial } \\
\text { Number }\end{array}$ & $\begin{array}{c}\text { S1te T1me } \\
\text { Hours }\end{array}$ & Remarks \\
\hline & $606,606 \mathrm{~A}$ & ORE & 16.0 & 163 & 81 & Double Life \\
\hline & $607,607 \mathrm{~A}$ & ORE & 13.5 & 157 & 105 & Single Life \\
\hline & 608 & ORE & 13.5 & 162 & 90 & Erratic positioning, dropped second beacon. \\
\hline 心 & $608,608 \mathrm{~A}$ & ORE & 16.0 & 164 & 45 & Single Life \\
\hline 官 & $609, \mathrm{ABC}$ & ORE & 16.0 & 165 & 144 & Single Life \\
\hline . & $610, \mathrm{ABCDE}$ & ORE & 13.5 & 174 & 160 & Single Life \\
\hline & $611, \mathrm{ABCDE}$ & ORE & 16.0 & 168 & 157 & Single Life \\
\hline
\end{tabular}




\section{INTERNATIONAL PHASE OF OCEAN DRILLING DEEP SEA DRILLING PROJECT \\ OPERATIONS RESUME \\ LEG 95}

Leg 95, the next to the last of the Deep Sea Drilling Project, was devoted to completion of a marginwide transect of the Baltimore Canyon Trough encompassing the continental slope and shelf of New Jersey. This work was begun during Leg 93 when two of the transect sites were drilled. Another goal of the voyage was to succeed in reaching Jurassic basement at Site 603 (ENA-3), where Leg 93 had met with disaster when a drill string had parted obliterating a re-entry cone at that site.

Five holes were drilled at three sites during the cruise. The first and last were at New Jersey transect locations and were quite successful including the recovery of some 938 meters of core at an overall recovery rate of $82.9 \%$ as well as performing several electronic well logs. Success at Site 603 remained out of reach as three single bit holes were terminated short of the Jurassic.

The voyage began at St. Johns, Newfoundland on August 17, and ended at Ft. Lauderdale, Florida on September 26, 1983; a total of 39.9 days.

St. Johns Port Call

Leg 95 began officially at 1051 hours, August 17, 1983 when the GLOMAR CHALLENGER docked at Pier 9, St. Johns, Newfoundland, Canada. The port call was a brief one involving the routine operations of changing crews, onloading supplies and equipment. The major items accomplished were:

1. A full Tuboscope drill pipe inspection was completed. No suspect joints of pipe were identified.

2. Onloaded and checked out Schlumberger logging equipment.

3. Inspected Cat Engine No. 9 in preparation for overhaul in Ft. Lauderdale.

4. Topped off fresh water.

5. A representative from Pressure Coring, Inc. schooled the drill crew on drilling procedures with a pair of new Polycrystalline Diamond Compact bits which had been brought aboard for use at Site ENA-3. 
All scheduled work items had been completed and the vessel was ready to get underway at 2000 hours on Saturday, August 20. However, departure was delayed until midnight while awaiting a shipment of C-14 and S-35 isotopes ordered by the Organic Geochemist. The material arrived on a delayed flight from Montreal and was delivered to the ship at 2310 hours.

St. Johns to Site $612(\mathrm{NF}-2)$

The GLOMAR CHALLENGER departed St. Johns at 0007 hours, Sunday, August 21. On board were 45 GMI and 29 Scripps personnel. The first two days of steaming were in poor weather with high seas and some fog and drizzle. Speed was reduced to 7 knots at times. The following two days were passed in exceptionally fine weather with temperatures becoming more pleasant as the vessel proceeded southwest toward the first site of the voyage about 100 miles of $f$ the New Jersey coast. Following winds improved the ship's speed so that by the time the turn was made to approach the site on the fifth day, the ship was back on schedule.

Site $612(\mathrm{NF}-2)$ was approached on the evening of August 25 from the southeast along seismic Line 25 starting near old DSDP Site 604. Profiling continued up slope to within about two miles of the site, at which point the ship was forced to maneuver to avoid interference with another seismic survey vesse1, the SOPHIE BRAVO, which was crossing over the site. The beacon was dropped at 2332 hours on the first pass at a point about 0.4 miles to the right (northeast) of the proposed target. The original plan had been to drop the beacon and then profile further up the slope along Line 25 to the $200 \mathrm{~m}$ depth. This was abandoned upon discovering that the area was currently occupied by three seismic survey vessels plus several "long line" fishing vessels making our survey plans inadvisable. The water gun acoustic sources from the nearby SOPHIE BRAVO had already proven to be an interference on the CHALLENGER'S EDO records.

Site $612(\mathrm{NF}-2)$, New Jersey Transect

The vessel returned quickly to the site and steadied up on a strong beacon signal. After the pipe trip, the ship was offset 2990 feet west before spud in to locate the hole more closely to the original target on Line 25 .

Prior to running the BHA, a special test was conducted with the Schlumberger logging tools. The site plans called for piston coring, rotary coring to the Upper Cretaceous and logging. The most time efficient way to do this was with a single hole utilizing the $\mathrm{APC} / \mathrm{XCB}$ system. Since the bit would have a 3.80 inch diameter core guide and the logging tools all were required to pass through a 3.75 inch opening, the possibility existed that logging could be accomplished without having to release the bit if: 1) The Baker Float Valve was deleted from the BHA and, 2) The logging tools could be shown to have no trouble re-entering the bottom of the drill string through the bit itself. This plan had several significant advantages over the conventional technique of logging only after releasing the bit. First, there would be no bit release mechanism in the BHA thus no possibility of either a premature release or failure to release on command. Secondly, no time would be wasted on a potentially balky release operation. Third, the bit would remain on the string for the benefit of wiper trips or drilling out bridges or fill. And lastly, if, following 
logging, a second hole would be desired for spot coring hiatuses or heavily sampled intervals that operation could be carried out immediately without a pipe round trip for a new bit. Thus, a test assembly of logging tools was hung from a cablehead and lowered through the bit with a tugger line. The assembly included the in-line Caliper tool and the Density tool with its onesided bow spring. These were expected to be the most troublesome tool sections in re-entering. This bit was located at the moonpool platform to enable observation as the tool moved into and out of the bit. The procedure was carried off smoothly and the Schlumberger Logging Engineer on board was convinced that the technique was viable.

The pipe was run as normal to just above the seafloor as indicated by a PDR depth reading of $1271 \mathrm{~m}$. Past experience in this region had shown actual depths to be consistently greater than PDR depth, however, so the bit was slowly lowered to feel for bottom. No clear weight indication was encountered, so when the bit had reached a depth of $1413 \mathrm{~m}$, the Advanced Piston Corer (APC) was run in on the wireline and a shot was taken from $1410 \mathrm{~m}$ in hopes of capturing the mudline. Core No. $1 \mathrm{H}$ was recovered at $4.85 \mathrm{~m}$ of core, thus establishing the mudline at $1414.3 \mathrm{~m}$ DPM. The hole was spudded at 1036 hours, August 26 .

The new APC, first deployed on Leg 94, was used to take the first seven cores. At this point partial stroke of the corer and the very firm nature of the glauconite clay being recovered defined the point of piston core refusal. The APC was laid down to rig up a pair of Extended Core Barrel (XCB) tools.

The APC had performed adequately although certain minor design deficiencies were apparent. Unfamiliarity with the tool resulted in a slower turnaround rate than could have been expected with the more commonly used coring tools. Core quality and percentage of recovery were very good.

Starting with core No. $8 \mathrm{X}$, the $\mathrm{XCB}$ was deployed using sawtooth Soft Formation Cutting Shoes. These shoes proved to be adequate to the termination of the hole. Cores $8 \mathrm{X}$ through $35 \mathrm{X}$ were taken in firm glauconite clay changing to siliceous nanno ooze. Penetration and recovery rates were excellent with some cores measured at greater than 100 percent recovery--most likely due to minor swelling of the cored material. Core arrived on deck at 45 minute intervals as the XCB functioned flawlessly maintaining minimum core disturbance.

At core No. 36x, a change in lithology was encountered. An abrupt solidification of the ooze combined with the first appearance of small chert nodules. The chert had no deleterious effect on coring except for causing localized disturbance in the cores. The solidification, however, was apparently responsible for a dramatic reduction in core diameter. Sections of some of the next 16 cores had diameters of less than two inches. The "broomstick" phenomenon was traced to the XCB Cutting Shoes which had Tube Borium (tungsten carbide grit) weld overlay beads intended to function as I.D. gage cutters for unlithified material and provide clearance so that the core could enter the core catchers and liner without jamming. Examination of the three Cutting Shoes in use showed that all were set up to trim cores to significantly less than $2 \frac{1}{4}$ inches diameter. This action had not occurred when the earlier cores had been taken, apparently because the soft clay and ooze had been able to flow past the restrictions in the throat of the Cutting Shoes and then expand again to fill the liners without evidence of major disturbance. The firmer material starting at about $320 \mathrm{~m} \mathrm{BSF}$ was able to retain its trimmed size. 
The problem was solved by introducing a set of three alternate XCB Cutting Shoes with the Tube Borium core trimmers opened up to allow a 2-3/8 inch diameter gage to pass through the throat. The resulting cores were still roughly trimmed but were much larger in overall average diameter. The larger throat Cutting Shoes were continued to the end of the hole.

The scientific objective of reaching the Upper Cretaceous occurred at a shallower depth than expected. The anticipated Paleocene section did not appear and the Maestrichtian was observed at about $550 \mathrm{~m} \mathrm{BSF}$. A dozen more XCB cores were taken terminating at core No. $72 \mathrm{X}$ at $2089.3 \mathrm{~m}$ total depth in the Campanian epoch. The hole had remained clean and trouble free with a maximum drift angle measurement of $2-1 / 2$ degrees. Virtually no gas was detected.

Before preparing to $\log$, the A.PC tool was rigged with two shear pins and pumped down to see if the shear pins could survive the impact of landing at the bit. The tool was retrieved with both pins sheared and the barrel scoped out.

Anticipating a large diameter hole resulting from the $11-7 / 16$ inch $\mathrm{XCB} / \mathrm{HPC}$ bit, the hole was filled with 420 barrels of $10.5 \mathrm{ppg}$ barite mud. The bit was pulled to the logging depth of $104.5 \mathrm{~m} \mathrm{BSF}$. The air spinner tool was used to break the drill pipe connections during the pipe trip rather than the rotary table to avoid disturbing the hole by rotating the bit, which had not been released as is usually the case.

Two problem free Schlumberger logging runs were made in just over thirteen hours. The first run combined Dual Induction, Gamma Ray, Caliper and Sonic tools and the section was repeated for sonic wave forms. The second run included Bulk Density, Neutron and NGT. In both runs the logged interval was from $1489.2 \mathrm{~m}$ (74.9 m BSF) to total depth.

The hole remained open during the entire logging operation although the Caliper tool indicated that the hole had contracted to less than the bit diameter over most of its length and as small as six plus inches diameter in some sections. This was thought to be due to swelling of certain clays as a result of the presence of the fresh water barite mud standing in the hole.

Care was taken in passing the tools into and out of the unreleased bit but no significant problems were encountered.

Following the Schlumberger logging operation, a six to eight hour period was set aside to allow the downhole tools specialist from Lamont-Doherty to deploy his 12-channel Sonic tool and/or the Borehole Televiewer last aboard the CIIALLENGER on Legs 83 and 92. The Sonic tool was lowered into the hole and run to total depth and back to the bit, but software problems in the on-deck monitoring equipment for the tool prevented it from completing the exercise. The allotted time was consumed troubleshooting and testing the equipment. No data were taken.

The Lamont Sonic tool was retrieved and the pipe was pulled out of the hole. The bit was on deck at 0525 hours and the vesse 1 got underway for Site 603 at 0554 hours, August 31 . 
Site 612 to Site 603

A six hour post-site survey was conducted as had been planned at the time of the site approach in the vicinity of Site 612 before the CHALLENGER set course to reoccupy Site 603. Fine weather prevailed as the ship crossed the Gulf Stream. A one hour 16 minute pre-site survey established the desired location and the beacon was dropped at Site 603D at 1107 hours, September 1, 1983.

\section{Site 603D}

The purpose of returning to Site 603 was to attempt to succeed in reaching basement (at an estimated penetration depth of $1800 \mathrm{~m} \mathrm{BSF}$ ) where the efforts of Leg 93 had been thwarted when the entire drill string was lost in re-entry tole 603B. The beacon drop location was carefully selected to be close to Hole $603 \mathrm{~B}$ but about 0.4 miles northeast. This was done to avoid the chance of interference with the tangled drill pipe on the ocean floor which was presumed to have been carried somewhat south of the cone by the prevailing current at the time of failure.

After positioning on the beacon and carefully establishing the ship's location via several timely satellite navigation fixes, offsets of 2500 feet north by 400 feet east were entered into the dynamic positioning system. This placed the vessel back at the beacon drop point and counteracted the fact that the beacon had apparently drifted southwest during its one hour fall to the seafloor.

With the vessel so located, the BHA was made up with an all new Polycrystalline Diamond Compact (PDC) bit specially designed for DSDP by Pressure Coring, Inc. of Midland, Texas. Two bits had been purchased (at a cost of about $\$ 20,000$ each) specifically for use at this site in hopes that the high penetration rates credited to the new PDC bit technology would enable basement to be reached with a single bit--thus eliminating the time required to place a re-entry cone and casing and significantly reducing the time to objective at this site.

The bit was run to the seafloor and a $P X C$ center bit was pumped to the bit. The Bowen Sub was picked up and washing in began with first resistance felt at $4652 \mathrm{~m}$. PDR depth was $4651 \mathrm{~m}$. Spud in occurred at 0717 hours, September 1. Washing down proceeded rapidly to $4851 \mathrm{~m}$ (199 m BSF) although a $2 \frac{1}{4}$ hour delay occurred when the Bowen Sub hydraulic motor had to be replaced. The center bit was then retrieved, an empty core barrel was dropped, and a spot core was taken to correlate stratigraphy with Holes $603 \mathrm{~B}$ and $603 \mathrm{C}$ plus check the ability of the new bit to take a core. More pumped flow was used than normal when cutting a core in soft material to avoid "balling up" the bit. In spite of this a full core barrel was retrieved with a somewhat gassy, soupy core. The center bit, showing absolutely no signs of wear, was again pumped to the bit and washing down again proceeded at the greatest possible rate. The goal was to wash through most of the section already cored at Hole 603B and begin coring at about $1530 \mathrm{~m} \mathrm{BSF}$.

During the morning of September 3 , an unexpected, localized storm began to build up in the vicinity of the vessel. By the time the hole and been deepened to $640 \mathrm{~m} \mathrm{BSF}$, the heave motions began to increase to the point that a steady weight on the bit, said to be critical when using PDC bits, could not be 
maintained. To combat this problem, the heave compensator was picked up. However, before it was completely installed in the derrick, the ship's dynamic positioning system began to lose the acoustic signal from the beacon. This was apparently due to a blanketing effect caused by bubbles swept under the ship by the waves and current as the weather deteriorated into a moderate gale. With only intermittent acoustic signals, the stationkeeping had to be maintained in semi-automatic or manual.

With the situation steadily worsening, the heave compensator was set back so that the pipe could be pulled quickly if the positioning problem did not improve. The weather continued to deteriorate and, after about three hours of positioning with great difficulty in semi-automatic mode with no sign of improvement, the hole was abandoned for the safety of the drill string. The vessel had not wandered more than about 400 feet off station at any time during this period but the inability to get regular updates of the beacon position due to bubble interference made continued operations under the circumstances too risky. The bit cleared the mudline at 1604 hours and the pipe was hung off on three knobby drilling joints at a depth of $4549 \mathrm{~m}$. The pipe was raised and lowered periodically over the next 13 hours while awaiting better weather.

By midnight the seas had calmed enough to allow positioning in the full automatic mode. By 0300 hours on September 4, the high seas built up by the gale had moderated so that vessel motion was once again within prescribed operational limits.

The knobby joints were then set back, the power sub was picked up, and the operation began again. Hole 603E was spudded at 0502 hours at a depth of 4652 meters.

Hole 603E

The bit was washed down again at the highest penetration rate possible using two pumps to produce a flow of better than 600 GPM. At a subbottom depth of $448 \mathrm{~m}$, the heave compensator was added to the drill string to help provide the most controlled weight on the bit. This effort proved fruitless for, although the heave compensator had tested out as functional a few hours earlier, when placed in service it could not develop the necessary hydraulic pressure to lift the drill string. Since the problem was in the heave compensator's pump house, the heave compensator unit in the derrick was locked out and left in place so that drilling could proceed without delay while diagnosis and repair of the hydraulic system was performed.

With steadily improving weather operating without the heave compensator proved to be no problem. Washing with the center bit continued to $936 \mathrm{~m}$ BSF where a spot core was desired to correlate stratigraphy between this hole and the Hole 603B reference cores.

The center bit was retrieved and replaced by a core barrel. Core No. IR was cut and retrieved with about a half meter of firm but disturbed claystone. Core catcher failure apparently accounted for the minimal recovery. A drift angle was recorced by two successful Kuster shots both showing $1 \frac{1}{4}$ degrees of vertical. The center bit, displaying virtually no wear, was pumped to the bit and washing ahead was resumed. 
A single joint encountered firm resistance during this period and required nearly two hours to drill off. This rate of penetration exceeded the limits for drilling without heavy wall "knobby" drilling joints so the four knobbies left on the ship were picked up and added to the drill string one by one. They were used routinely for the remainder of the hole.

Washing continued at an overall penetration rate of $12 \mathrm{~m} / \mathrm{hr}$ to a subbottom depth of $1203 \mathrm{~m}$. At this point, the problem with the heave compensator was identified as complete failure under load of the No. 1 hydraulic pump. It was isolated from the circuit and a trial joint was drilled with only pump No. 2 on the line. This proved effective except for the fact that the air bank had been bled down too low during the heavy compensator trouble shooting procedures. The heave compensator was, therefore, again locked out while the air bank pressure was built back up to near 4000 psi.

At 1400 hours, September 7, with the bit at $1238 \mathrm{~m} \mathrm{BSF}$, a drilling break announced the discovery of an anticipated zone of turbiditic sand reported at Hole 603B. The rate of penetration soon dropped to $2-4 \mathrm{~m} / \mathrm{hr}$. Actual penetration was at a zero rate for many minutes and even hours with advances made in sudden spurts. After picking up the drill string to make connections, the hole was usually found to have taken a meter or so of fill indicating that loose sand was caving in whenever the pumps were stopped.

Progress for the next two days was extremely slow as the bit appeared unable to make any headway in the loose sand interval. Several gel mud slugs were introduced into the hole but had no effect. The center bit was replaced twice with a core barrel both to examine the cutters on the center bit and to see if a core barrel present at the bit would improve penetration. No damage to the center bit's cutting structure was found and no improvement in penetration was derived.

Both wash cores contained mostly loose, coarse sand with some clay and shalelike material. It was the presence of the clay constituents that enabled the 8-fingered core catchers to trap any sand at all. The second core, No. 3W, actually contained some 6-8 inch sections of solid claystone indicating that the sand interval had been penetrated at about $1287 \mathrm{~m} \mathrm{BSF}$.

At 1430 hours on September 9, just as the decision was being made to abandon continued drilling efforts, instructions from DSDP in La Jolla were received to do just that and trip the pipe in order to change to a F93CK roller cone bit for one last desperate attempt at reaching basement at ENA-3.

Estimates were made indicating that the $1800 \mathrm{~m}$ penetration objective could be reached in as little as nine days if the bit lasted that long. Since that was within the operating time remaining for the voyage, the plan was adopted to go ahead on that basis until the objective was reached or the progress fell a full day behind a projected progress curve. If the goal then appeared unobtainable in the time alloted, the effort was to be abandoned.

Thus the hole was filled with barite mud and the PDC bit was pulled out of the hole, clearing the mudline at 2015 hours, September 9 and arriving on deck at 0554 hours, September 10. The condition of the PDC bit quickly explained why penetration had dropped to less than $1 \mathrm{~m} / \mathrm{hr}$. The cutting 
structure, Stratapax buttons mounted on stee1 studs, was $90 \%$ destroyed. On1y the innermost ring of cutters surrounding the core opening remained. The face of the bit had been worn away to a depth of up to three quarters of an inch.

While a F93CK bit was being made up to a new mechanical bit release and refurbished $\mathrm{BHA}$, the vessel was offset 500 feet south, closer to the beacon. The drill line was cut and slipped and the pipe was run to the seafloor for the final attempt to recover the coveted Jurassic basement.

Hole 603F

The mudline was detected at $4650 \mathrm{~m}$, coincidental with the PDR reading, and the hole was officially spudded at 1547 hours, September 10. An initial wash core was taken to a subbottom depth of $32.6 \mathrm{~m} \mathrm{BSF}$, primarily to provide for possible gas sampling. This task accomplished, an empty core barrel was pumped to the bit and washing down commenced. Two pumps were used which produced a continuous flow of more than 600 GPM. All drilling parameters were set to achieve the maximum rate of penetration while helping the bit to do the least possible work in hopes of extending the depth that would be reached before the inevitable failure of the bit. The heave compensator was not used during this period both to speed up the operation and because the seas were especially calm.

At about $980 \mathrm{~m} \mathrm{BSF}$ the previously noted hard, siliceous limestone layer was penetrated. The overall net rate of penetration to that depth had been in excess of $30 \mathrm{~m} / \mathrm{hr}--$ much better than the projected progress curve.

Following the firm limestone layer, the wash barrel was pulled as a routine precaution. The barrel was tound to be stuck in the bit and the overshot shear pin failed on the first retrieval attempt. Before the second wireline run to retrieve the barrel, an extra meter was drilled down. The barrel came free with moderate line overpull on the second attempt.

At the same time the stuck barrel was being dealt with, an error was discovered in the offsets being read by the Dynamic Positioning Computer. Initial offsets used at the time of spud-in were 2000 north by 400 east. Although no problem was detected on the bridge, a routine check of the computer on the teleprinter revealed that the computer itself was working on offsets of 2050 north by 400 west (not east). Further investigation showed that the last two digits of the ship's heading were being added to the 2000 north offset and any eastwest of fset was being read by the computer as west. The problem was isolated to a faulty circuit board within the computer and was quickly rectified.

The exact time of occurrence of the problem was not known though it could be assumed to have happened after spud-in. This left in doubt the exact eastwest position of the hole itself relative to the original offsets. Since the choice of proper eastwest offsets was therefore somewhat arbitrary between 400 east and 400 west, the ship was located so that the apparent angle of the pipe, as it passed through the guidehorn, was most vertical. The offsets were continually adjusted for the duration of the site to alleviate a recurring severe problem of the pipe (or knobby joints) rubbing hard against the upper piccolo. How much of this problem was due to a persistent current was never determined. 
After retrieving the wash barrel from $980.5 \mathrm{~m} \mathrm{BSF}$, a redressed barrel was pumped to the bit and washing ahead continued to $1200.8 \mathrm{~m} \mathrm{BSF}$. The wash barrel was again retrieved and a 50 barrel mud slug was pumped into and out of the hole in preparation for penetrating the turbiditic sand interval which destroyed the PDC bit in Hole 603E. The sand was detected by a distinct drilling break at $1214 \mathrm{~m} \mathrm{BSF}$ and was drilled through with anticlimatic ease. A second gel mud slug was pumped through the system for good measure and routine washing ahead continued as before.

By midnight of September 12, the bit had been washed to $1335 \mathrm{~m} \mathrm{BSF}$. The hole was an amazing 36 hours ahead of the optimistic projected schedule. Use of the heave compensator was attempted for one joint but the anti-slingshot valve would not close, so the heave compensator was drained and set back for repairs.

At $1373.2 \mathrm{~m} \mathrm{BSF}$, the wash barrel was again pulled. The core, made up of sandstone but no loose sand, showed obvious signs of non-horizontal layering suggesting that the hole had kicked off vertical during or after the sand interval. A Kuster single shot photo failed to turn out so the drift angle could only be estimated at 8-10 degrees.

At $1497.8 \mathrm{~m} \mathrm{BSF}$, the wash barrel was retrieved once more. Again sandstone and claystone was recovered with clear signs of hole drift off vertical. This time a Kuster measurement confirmed the visually apparent drift to be 10-3/4 degrees.

The next core was a standard $9.5 \mathrm{~m}$ rotary core. While cutting it, the bit began to exhibit signs of excessive torque when more than $10 \mathrm{~K}$ pounds WOB were used giving the first hint that the bit was nearing its end. The core, No. 6R, had an average diameter of $2-1 / 8$ inches which also suggested that at least one of the four roller cones was getting loose enough on its bearing to wobble-thus overtrimming the core and accounting for the torque problems.

Three more cores were taken, Nos. $7 R, 8 \mathrm{~W}$, and $9 \mathrm{R}$, before the bit was declared too far gone to have even the remotest chance of reaching basement--at least 200 meters deeper. The final core of 5.5 meters, took 80 minutes to painstakingly cut and had an average diameter of $1-7 / 8$ inches.

To compound matters, the weather, which had been excellent for 12 days, was rapidly deteriorating into a moderate gale. To preserve the chance of logging the hole already drilled, the preparations for logging were made immediately. The MBR rotary shifting tool was deployed and the bit was released in textbook fashion. The hole was then filled with barite weighted mud and the bit was pulled to the logging depth. It would have been preferable to have left the fresh water mud out of the hole until after completing the logging exercise since it was assumed that fresh water sensitive clays were present in the hole which would swell and possibly close the hole. This alternative was not feasible, however, as the rapidly worsening weather made even logging somewhat risky. If dynamic positioning could not keep the ship on station as the seas became rougher, abandoning the site would have been necessary before a proper mud plug could be pumped into the hole.

This consideration proved to be academic, however, when the weather held but the logging routine failed. Two attempts were made to lower the first assembly of logging tools into the hole. Both times the sonde could not be induced to 
advance into the hole bel Jw the open ended pipe. A severe mud and/or clay ball built up at the end of the pipe as 2 . result of the ship's heave motions was presumed to be the problem. It could even be argued that the barite mud in the hole had magnified the situation. Whatever the case, the first run ended in a kinked logging cable which severed two of the seven internal conductors. The second run was equally futile in spite of a two hour flush with seawater between runs to wash away any mud ball.

All attempts to improve the situation were frustrated by an apparent abundance of sticky clay in the BHA, so reluctantly the logging tools were rigged down and the pipe was pulled out of the hole.

Site 603 to Site 613

The rig was made secure for sea and the vessel was underway for Site 613 (NF-12) at 2355 hours, September 15. A 3.7 hour presite survey was run in the vicinity of old Site 604 to locate the new site at at a location slightly upslope on Conrad Line 35 between Sites 604 and 605. This location was further refined after the beacon was dropped in an attempt to position the hole where the Miocene sand interval, which prevented success at Holes 604 and 604A, would be very thin or non-existent. Thus, the beacon was dropped at 0445 hours, September 17, after a 25.2 hours, 227.2 mile transit.

\section{Site 613 (NJ-12, New Jersey Transect)}

The vessel returned to the offset position and began running in the hole. The bottomhole assembly was made up identically to the configuration used at Site 612 for combination piston coring and rotary coring with the XCB as desired. Since the big question of success at the site rested on whether or not the Miocene sand interval could be penetrated, it was decided to wash to about $250 \mathrm{~m} \mathrm{BSF}$ as quickly as possible and tackle the big problem with a minimum investment of time. Failure to penetrate the sand, as had occurred at Sites 604 and $604 \mathrm{~A}$, would be cause to abandon the site altogether and proceed without further delay to the next alternate site.

With the $\mathrm{XCB}$ in use, getting through the sand would allow the desired penetration below the sand interval to be accomplished, followed by through-the-bit logging. This would leave open the option of pulling the bit to the mudline and starting a new hole to continuously core the previously washed interval, if time and scientific objectives so dictated.

DSDP in La Jolla was contacted to assure that the plan to wash without continuous coring was acceptable to the JOIDES Safety Panel and did not violate the hydrocarbon monitoring and safety policies of the Project. The approval to proceed was based on the fact that the site was located only about 4.5 miles from Site 604 , which had been carefully monitored for hydrocarbons and found to be safe for CHALLENGER type drilling.

The recent experiences at nearby Sites 604 and 605 , indicated that the seafloor would probably be too firm for piston coring so spud-in was done with the XCB core barrel in place. The heave compensator was used to mitigate the problem of applying weight to the bit so close to the surface without proper stabilization for the BHA. 
The bottom was detected clearly at $2333.2 \mathrm{~m}$ and the hole was officially spudded at 1331 hours, September 17. PDR depth had been a little misleading at $1319 \mathrm{~m}$. An initial surface punch core was carefully taken to a subbottom depth of $9.7 \mathrm{~m}$ to establish an accurate mudline. The core barrel was then retrieved but contained only traces of clay inside the liner. This plus the firmness and drilling characteristics observed at the mudline suggested that the seafloor was overlaid predominately with loose sand which is commonly not recovered by the core catchers. The first core was discounted and the hole was again spudded, this time being washed to ' $19.8 \mathrm{~m}$ before pulling the wash barrel. The wash core contained only $1.39 \mathrm{~m}$ of clay with traces of sand.

A sequence of alternating $\mathrm{XCB}$ and wash cores, using the $\mathrm{XCB}$, were then taken to a depth of $116.0 \mathrm{~m} \mathrm{BSF}$, where continuous coring was done for four cores to locate the Pleistocene/Pliocene boundary. This accomplished, the bit was washed directly to $183.9 \mathrm{~m} \mathrm{BSF}$ where continuous coring began,

Core 19X at $260 \mathrm{~m}$ BSF contained a significant proportion of sand mixed with dark mudstone. The site turned out to have been well selected because this was the only evidence of the troublesome Miocene sand interval. Core 20x contained only $20 \mathrm{~cm}$ of Eocene chalk lodged in the core catchers. The Miocene/Eocene contact had been lost due to core catcher failure and/or jamming.

From that point to the total depth of the hole at $581.9 \mathrm{~m} \mathrm{BSF}$, the formation remained Eocene chalk. Recovery was generally high and penetration rapid until near the end of the hole when both began to suffer degradation. The final three cores were taken using tight throat XCB Cutting Shoes which improved upon the pattern of core jamming that had been developing. Penetration rate fell from an average $7.1 \mathrm{~m} / \mathrm{hr}$ to as low as $3.5 \mathrm{~m} / \mathrm{hr}$ at Core $50 \mathrm{X}$ and the bit exhibited many of the common signs of impending bit failure despite the fact that the Eocene chalk being recovered appeared to be routinely drillable material. No adequate explanation for these difficulties came to light when the bit was examined later-it was in relatively good condition with two cones free (B3) and one loose (B5) but still functional.

With available operating hours running out and the next major scientific objective the Paleocene boundary, still many meters and hours away, the coring was terminated to leave time for logging. The hole was filled with barite weighted. mud and the bit was pulled to the logging depth of $2436.6 \mathrm{~m}$ (103.4 m BSF) for logging. As had been done at Site 612, the pipe was pulled using the air spinner to avoid rotating the bit and unnecessarily disturbing the hole.

The sheaves were rigged for logging and the Schlumberger tools were assembled and run down the pipe. The tool combination was the same as the first run at Site 612; Dual Induction, Sonic, Gamma Ray and Caliper. The hole was found to be tight in spots, probably due to swelling of fresh water sensitive clays, but the sonde was worked to total depth in less than two hours. Within $5 \frac{1}{2}$ hours, the run was complete including a repeat for sonic wave forms and the tools were retrieved.

The Multichannel Sonic (MCS) logging tool from Lamont, was then rigged and run down the pipe. Although the hole had been "swabbed" by the Schlumberger tools, it proved to be too tight for the MCS tool, which was much lighter (about $4501 \mathrm{bs}$. compared to the Schlumberger tool weight of 2000 1bs.) and was further hampered 
by its flexible, rubberized receiver string. Continuous working of the tool managed to get it down to a depth of $2519 \mathrm{~m}$ or $82 \mathrm{~m}$ below the bit but no further penetration could be achieved without risking severe damage to the tool. One of the 12 acoustic receivers was rendered inoperative before the exercise was completed. The $82 \mathrm{~m}$ of open hole was logged twice and a third run was attempted before the tool was retrieved. Both the Schlumberger and Lamont logging tools passed into and out of the pipe through the unreleased XCB/HPC bit with no trouble.

The pipe was then pulled out of the hole and the BHA components were given the routine end of leg Magnaflux inspection before the vessel departed the site bound for Port Everglades at 0436 hours, September 22.

Site 613 to $\mathrm{Ft}$. Lauderdale

The transit to Ft. Lauderdale's Port Everglades was uneventful, the vessel making good time in pleasant autumn weather helped out by following seas. The seismic gear was streamed until the ship entered the Florida Straits near the Bahamas. The trip was completed in 98.1 hours, the average speed having been 9.1 knots. Leg 95 terminated at 0645 hours, September 26, when the first line was secured at Berth Two at Port Everglades, Ft. Lauderdale, Florida.

\section{$\underline{\text { Drill string }}$}

The drill strings assembled at Sites 612 and 613 were made up of premium steel pipe from the port side pipe racker and were completely routine. In order to provide the long drill string required for the reoccupation of Site 603, an arrangement was devised prior to the cruise which would result in adequate string length, using the limited amount of pipe aboard the vessel at this time while guaranteeing the safest top of the string load conditions. The string, from bottom to top, included the BHA, 13 stands of Grade 2 pipe removed from the casing hold and made up on the racker during transit, $28-2 / 3$ stands of premium pipe, $18-1 / 3$ stands of aluminum pipe, $94-1 / 3$ stands of premium pipe and the remainder, new pipe. Ninety nine and two thirds stands of new pipe were available to be used at the top of the string for a total length of $6790 \mathrm{~m}$ if required, but the maximum length used was only $6195.7 \mathrm{~m}$. The Grade 2 pipe was broken down and returned to the casing hold during the transit to $\mathrm{Ft}$. Lauderdale.

One joint of aluminum pipe had been culled in St. John's and placed in the casing rack due to a bad gouge found in the tube section. For the first time the aluminum drill pipe was allowed to penetrate the seafloor. The joints that did go subbottom came back in a condition visibly different from those that did not. They appeared to have a new coating of powdery corrosion products not present on the other aluminum joints. The aluminum pipe was left made up on the pipe rackers at the end of the voyage.

Making up the long string for Site 603 also included removing old drill pipe rubbers from the lower portion of the string and installing new rubbers on the stands of new pipe that did not have them. This labor added approximately nine hours to the initial pipe trip. By the end of the site many dozens more of the old rubbers had been removed when they interferred with drilling operations because of being loose or displaced on the pipe. In addition, pipe drag on the piccolo was unusually severe at the site and caused the demise of many of the new rubbers. 
Drilling and Coring Equipment

Bottom Hole Assemblies

A variety of drilling techniques were employed during the voyage and each called for a different bottom hole assembly (BHA). At Sites 612 and 613, the BHA was set up to accommodate the XCB and new APC coring systems thus: bit, bit sub, bit sub spacer, seal bore drill collar, landing/saver sub, 3-ft. drill collar spacer, top sub, head sub, three 8 $\frac{1}{4} "$ drill collars, bumper sub, three $8 \frac{1}{4} "$ drill

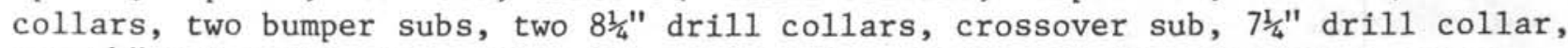
two $5 \frac{1}{2} " \mathrm{R}-3$ drill pipe. This BHA performed normally and provided ideal spaceout for both the APC and the short version XCB. Three all new elements had been added to the assembly during Legs 94 and 95; the bit sub spacer, which allows for proper APC spacing and makes the MBR and HBR interchangeable with the bit sub without requiring respacing the coring tools; and the seal bore drill collar with its landing/saver sub, which are functional elements of the APC system.

For Holes 603D and 603E, a special lightweight BHA was used to provide for more delicate weight-on-bit control suggested for optimum performance of the new Polycrystalline Diamond Compact (PDC) bit being used; PDC bit, MBR, OCB, top sub, head sub, three $8 \frac{1}{4} "$ drill collars, two bumper subs, three $8 \frac{1}{4} "$ drill collars,

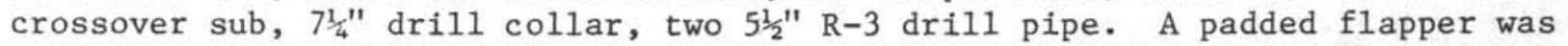
used in the Baker Float Valve to protect a PDC center bit which was run in and out of the pipe on a dummy core barrel.

For Hole 603F, a F93CK bit was run with the following conventional BHA: bit, MBR, OCB, top sub, head sub, three $8 \frac{1}{4} "$ drill collars, bumper sub, three $8 \frac{1}{4} "$ drill collars, two bumper subs, two $8 \frac{1}{4} "$ drill collars, crossover sub, $7 \frac{1}{4} "$ drill collar, two $5 \frac{1}{2} " \mathrm{R}-3$ drill pipe.

\section{Bit Releases}

Logging plans at Site 603 called for bit release capability, thus both an HBR and MBR were prepared and tested. The HBR could not be released in the mudroom because the new wedge seal go devils delivered in St. Johns would not hold enough pressure to achieve initial activation of the seals. Later, investigation showed that the seals were loose enough on the go devil mandrels for a leak path to exist under their I.D.'s which may have caused no problem at the high downhole flow rates expected, but leaked too much for the small test pump to overcome. Thus, no mudroom release test could be done. Without this assurance, use of the HBR was deemed too risky and the MBR was included in the site 603 BHA. The MBR was released downhole at the end of Hole 603F with textbook efficiency.

\section{Heave Compensator (HC)}

The heave compensator lived up to its notorious reputation during Leg 95 . It was tested on the stand both at the start of the cruise and again immediately before being picked up at Site 603--no problems were noted. When placed into service, it failed immediately. Several days of troubleshooting finally revealed that the No. 1 hydraulic pump was suffering from severe internal back flow. The HC was tested using only No. 2 pump and worked fine except for low air bank pressure which had been bled down during the troubleshooting procedures. While 
rebuilding the air bank pressure, the No. 1 pump was replaced with a spare. The Drilling Superintendent and Rig Mechanic deserve credit for an excellent and very quick completion of a tough job. By the time the HC was back in service, it was no longer needed, since the PDC bit died shortly thereafter.

At Hole 603F, the HC was picked up after the upper sediment had been washed at high speed. The Anti-Slingshot Valve would not close and clearly required replacement, so the unit was drained and set back again. By the time Hole 613 was started, the HC was finally fully operational and functioned very faithfully for that site.

Bowen Power Sub and Swive1

Several operating hours were lost when the hydraulic drive motor on the Bowen Sub leaked hydraulic fluid and had to be replaced twice. One change was to install the rebuilt spare and the, when it leaked through failing seals, the original motor, which had been rebuilt, was reinstalled.

The swivel washpipe packings began to leak at Site 603 and were replaced in two separate operations.

Special Tools - Coring Systems

Advanced Piston Corer (APC)

The APC, the latest generation of the hydraulic piston corer, was used on Leg 95 after successful prototype trials on Leg 94. Results of its usage on this voyage were generally favorable. A few design deficiencies and operating encumberances were noted, but the tool could be considered operational. It was used at Site 612 to take seven cores before the sediment became too firm for piston coring.

One of the features, the anti-spiral grooved rod, was abandoned when the alignment of the groove between the rod sections could not be maintained. An ungrooved rod is available to be used for Leg 96 and the grooved assembly remains a viable backup if used without the key which tracks in the groove.

The Seal Bore Drill Collar and Landing/Saver Sub, both of which have honed bores 3.80 inches in diameter, were stored in the casing rack filled with fresh water and sealed by gasketed thread protectors to minimize deterioration of the honed working surfaces.

At the end of Site 612, the APC was picked up and go-deviled to the bit as 25 strokes/min without the wireline attached to test if this could be done without preshearing the shear pins. If successful, the APC could be operated without the wireline in the pipe, thus making piston coring compatible with the heave compensator during bad weather operations where core disturbance is always a problem. The APC had two 17-4 PH shear pins installed and all four pluggable speed control holes were plugged. The tool was retrieved with the shear pins sheared. A11 evidence pointed to the probability that the pins were sheared at the moment of impact at the landing shoulder. The landing impact was thus calculated to have been greater than $39.5 \mathrm{~g}$ 's. 
Breakaway Piston Head

The new Breakaway Head for the piston coring systems was tested quite successfully at Site 612 with the APC. It is adaptable to either the APC or VLHPC with minor hardware exchanges. The breakaway portion of the head, designed to come off when suction is applied to the top of the core, performed exactly as intended and was found "broken away" on top of the core inside the liner after each piston core run.

The assembly was designed to use only Polypak seals which were not satisfactory. A redesign to V-packing seals will be done before future use. Further testing will determine if flow-in disturbance after partial strokes is effectively eliminated by this new device, but early indications after Leg 95 testing are positive. Use of the Breakaway Piston Head causes no distinct rig floor problems as long as several head portions are available for redressing with the single upper assembly attached to the Piston Rod.

Extended Core Barrel (XCB)

The XCB was a rea1 workhorse at Sites 612 and 613 . The redesigned XCB latch, introduced on Leg 94 to eljminate problems of hanging up in the pipe or BHA which plagued the original latch design, worked extremely well. The XCB was deployed a total of 117 times. Each time the tool latched in at the Latch Sleeve as expected and released when pulled by the overshot. Several cases of split and/or slightly collapsed liners were observed, but these were not serious and did not hamper coring operations or severely detract from core quality. One set of latch dogs were retired after they underwent pronounced wear over the course of three or four cores at Site 613. The replacement dogs did not suffer the same fate and an explanation for the sudden wear phenomenon was not found. A few broken Belleville Spring Washers were removed after each of the two times the tool was redressed, but this problem was deemed manageable.

The only Cutting Shoes available and used for the XCB were the latest sawtooth Soft Formation type which give excellent service in mud, ooze, clay, chalk, claystone and sandstone. In soft, elastic, or semi-fluidic sediments (mud, clay, ooze), the main problem was avoiding jamming the shoes with core thus precluding full recovery. Tube borium bead gage cutters in the throats of the Shoes (with I. D. < 2.25 inch) did a good job of preventing core jams. In stiffer sediment and semi-lithified chalk, limestone and claystone, the throat gage cutters overtrimmed the cores. This problem was eliminated by opening up the throat of the three shoes to pass a 2-3/8 inch diameter gage. These shoes significantly improved core diameter and quality in the appropriate formations.

With both the XCB and APC, proper space-out in the dual purpose BHA is vital. Both were checked on deck before the BHA was run at the first site.

Core Bits

The bits used at Sites 612 and 613 , were MSDS made XCB/HPC bits 11-7/16 inch 0.D. $x 3.80$ inch I.D. to enable use of the XCB and/or APC as required. At Site 612 , the bit functioned normally without any problems. At Site 613 , the bit performed as expected until about $500 \mathrm{~m} \mathrm{BSF}$, where its penetration rate fell off markedly despite the fact that the formation being cored and recovered was 
firm chalk--normally easy to penetrate. Later examination of the bit showed the teeth to be unworn but three cones were loose on their bearings. It is possible that the bearings were loose enough to allow the cones to lock up slightly against the side of the XCB Cutting Shoes and not rotate freely. Gouges found on the sides of some of the Cutting Shoes substantiates this theory. If fully lithified material had later been encountered, the Cutting Shoes could have been forced inside the bit and the cones would have been free to rotate again.

At Site 603, a new, state-of-the-art Polycrystalline Diamond Compact (PDC) bit was employed specifically chosen to maximize the possibility of reaching Jurassic basement (at about $1800 \mathrm{~m} \mathrm{BSF}$ ) with a single bit. The bit failed catastrophically in a loose turbiditic sand interval at $1289 \mathrm{~m} \mathrm{BSF}$ after being used in Hole 603D, abandoned due to weather, and Hole 603E, for a total of 1929.4 meters penetration and 103.8 rotating hours. Most of this was accomplished with both mud pumps on line producing 600 plus GPM flow at the bit.

The performance evaluation of the PDC bit was further denigrated when a conventional F93CK roller cone bit significantly outperformed it in Hole $603 \mathrm{~F}$ in one last ditch attempt to reach basement with a single bit. The F93CK gave up the ghost after penetrating 1545.7 meters in 44.7 rotating hours. It was released for logging.

\section{$\underline{\text { Logging }}$}

Logging was attempted at all three sites of the voyage but successful only at Sites 612 and 613. At both of these, a previously untried technique of passing the logging tools into and out of an unreleased $\mathrm{XCB} / \mathrm{HPC}$ bit was carried out very successfully. The only difficulty came when attempting to re-enter the bit with the Schlumberger tool at the first site. An apparent mud ball had collected under the caliper arms and held the tool up momentarily. Steady strain on the logging cable apparently extruded the mud because the tool suddenly entered the bit smoothly. All exits and re-entries through the bit thereafter, at both sites, were uneventful.

Logging at Site 603 was not successful because the tools could not be induced to exit the pipe through the open-ended MBR Top Connector. An apparently tenacious ball of mud and/or clay at the pipe end and inside the BHA prevented movement of the tool into the hole, even after hours of working the tool. The tool did get a meter or so into open hole briefly, but even this advance was soon lost not to be regained. The first run ended when the spud attempts resulted in a kinked logging cable. While the tool was retrieved and reheaded, the pipe was flushed for two hours with seawater to wash away the mud ball, but conditions did not improve and logging was abandoned after the second run failed as the first had.

Both Schlumberger with the normal logging tool assortment and Lamont-Doherty, with the Multichannel Sonic tool and Borehole Televiewer, ran logging exercises during the leg. 
$\underline{\text { Schlumberger Logging }}$

The tools onloaded in St. Johns included:

1 - CSU - Cyber Service Unit
2 - DITD - Dual Induction Tools
2 - MCDB - In Line Caliper Devices
2 - SLTL - Long Spaced Sonic Tools
2 - PGTH - Formation Density Tools
2 - CNTA - Compensated Neutron Tools
2 - SGTE - Natural Gamma Ray Tools
2 - DLTB - Dual Laterolog Tools
2 - HRTB - High Resolution Temperature Tools
1 - NGTA - Natural Gamma Spectroscopy Tools

At Site 612, Schlumberger rigged up and ran a Dual Induction, Sonic, Gamma Ray, Caliper tool. After resistivity, sonic, caliper, and gamma ray curves were recorded another pass through open hole was made to record sonic wave forms. A second run was made using Formation Density, Compensated Neutron and Gamma Ray tools. With the information recorded downhole, it was possible to run a Cyberlook Pass One which corrects the neutron and gamma ray porosity curves for borehole and temperature effects. At the same time, Rfa (resistivity of intrinsic fluid) and RT (total resistivity) are calculated and plotted. The ratio between Rt and Rfa in the Formation Factor.

At Site 613, Schlumberger logged Dual Induction, Sonic, Gamma Ray, and Caliper along with sonic wave forms. Due to restrictions in the hole, some spudding of the tool was required to reach total depth. Along with the downhole logs, resistivity of interstitial water was measured using a Schlumberger Electronic Mud Tester normally used to measure the resistivity of drilling fluids. These samples were taken from the chemist's interstitial water samples from cores and were plotted with the total resistivity (measured with the same instrument) and a Formation Factor was calculated. Calculated porosity and water salinity were also plotted.

\section{Multichannel Sonic Logging}

The 12-channel sonic logging operation at Site 612 penetrated smoothly to total depth but electronic handshake problems between the computer driver and the digitizer, while recording wave forms, disabled the possibility of real time recording. Two video tape machines malfunctioned so, although continued downhole diagnosis identified the problem, no waveforms were recorded.

At Site 613, successful spudding of the tool, through a blockage immediately below the bit and again in a swollen interal at $75 \mathrm{~m}$ below the bit, offered a limited $82 \mathrm{~m}$ interval of open hole where wave forms were recorded. The flexible receiver string was damaged during attempts to lower the tool further. Preliminary inspection of the successfully recorded wave forms shows them to have recognizable phases and move out for later prosessing and effective analysis. 
Dynamic positioning of the vessel was, for the most part, routine during the voyage. Impact on operations was only felt on two occasions. Hole 603D had to be abandoned prematurely when a moderate gale, coupled with predominate currents aligned with the wind direction, caused turbulence bubbles to be swept under the hydrophones. These bubbles resulted in intermittent losses of accoustic tracking and forced the bridge crew to keep station in manual mode-essentially flying blind for periods up to several minutes. This condition was tolerated for as long as possible but eventually forced abandonment of the hole for the protection of the drill string.

At Site $603 \mathrm{~F}$, a quirk in the computer electronics resulted in a misinterpretation by the computer regarding the offsets being used. North offset was altered by a factor equal to the last two digits of the ship's heading and any east of fset was transposed as west by the computer. This problem was quickly solved by changing one circuit board. No detriment to operations resulted.

\section{Weather and Currents}

The weather was better than had been anticipated for the voyage. The hurricanes fortunately confined themselves to the Gulf of Mexico and the Pacific near Baja California during the time the CHALLENGER operated in the east coast hurricane region. Only two real gales were experienced and only one of these affected operations; Hole 603D was prematurely abandoned.

Currents were minor or nonexistent at the New Jersey Transect sites but were a constant headache at Site 603 . The southerly current there continuously forced the pipe to an angle where it rubbed fiercely on the piccolo. Backing the ship down current, permissible in the deep water, did not significantly improve the situation. After Site 603, the upper section of the piccolo had to be repaired by the ship's welder because several holes had been worn in it. This drag on the pipe also severely damaged many of the new drill pipe rubbers which had just been installed.

\section{Communications}

Radiotelegraph communications with WWD in La Jolla were carried out with no difficulties on a daily basis after the vessel reached the New Jersey operating area and remained good throughout the cruise. Ham radio communications were especially clear and the nightly phone patch hour was sufficient to allow everyone on board to contact friends and relatives whenever desired. Several commercial phone calls were also made.

\section{$\underline{\text { Personnel }}$}

As always, the ship's crew, scientists and Scripps staff performed their duties with professionalism and a cheerful attitude. The scientific staff responded more positively than might have been expected to some rather high-handed political maneuvering from the beach where priorities were reset midway through the cruise concerning Site 603. Nonetheless, the emotional, political, and professional hurdles were taken in stride and the general attitude remained good. 
This being the last time at sea for the Scripps staff and GMI crew, a "short timer's" attitude might have been expected. It was surprising that, if anything, the opposite effect was observed. The nostalgia of a good thing coming to an end promoted in all an increased desire to do a good job. This was the tone of the entire voyage and reflects well on all concerned.

David P. Huey

Deep Sea Drilling Project Cruise Operations Manager

Leg 95 


\section{INTERNATIONAL PHASE OF OCEAN DRILLING \\ DEEP SEA DRILLING PROJECT \\ OPERATIONS RESUME \\ LEG 95}

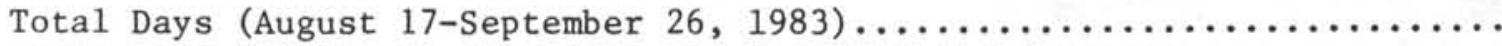

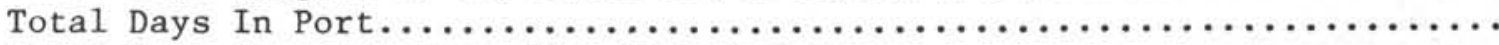

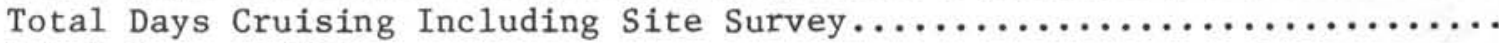

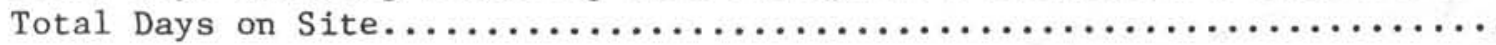

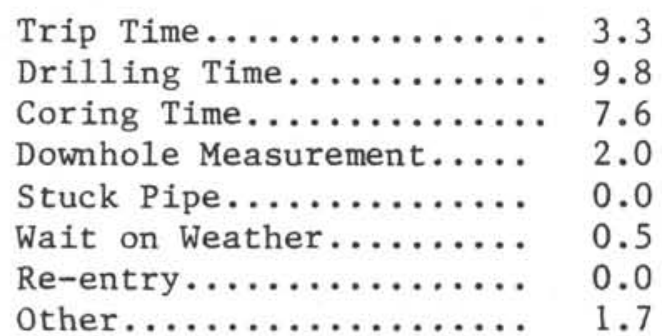

Total Distance Traveled Including Survey (Nautical Miles) $\ldots \ldots \ldots \ldots \ldots \ldots$

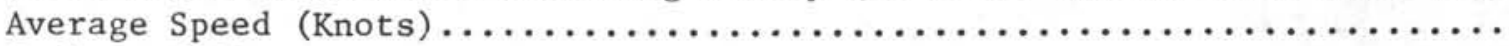

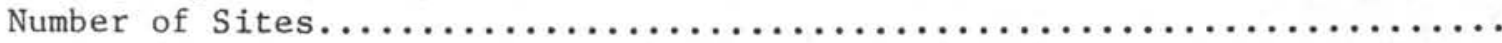

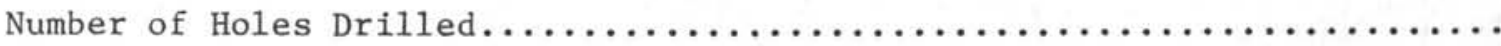

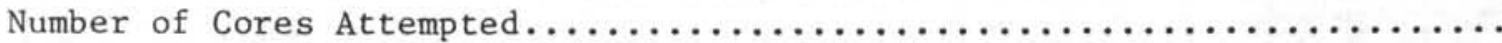

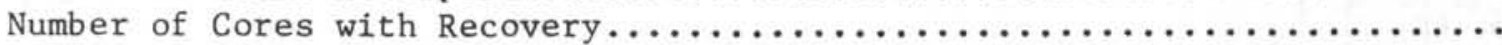

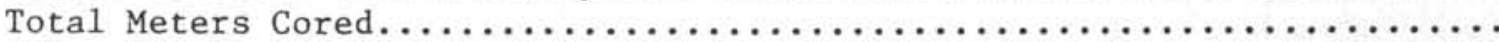

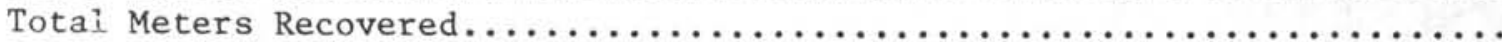

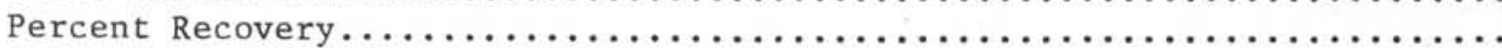

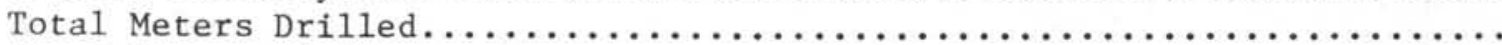

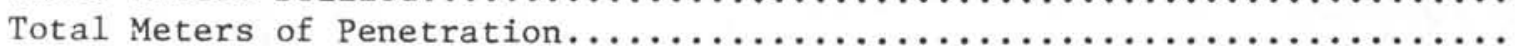

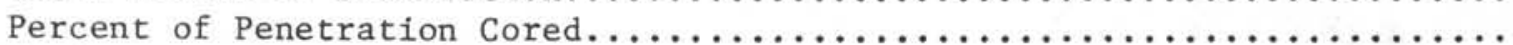

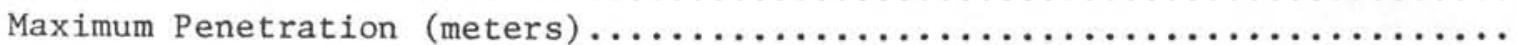

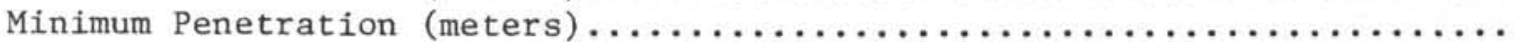

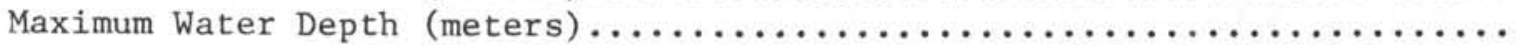
Minimum Water Depth (meters). 


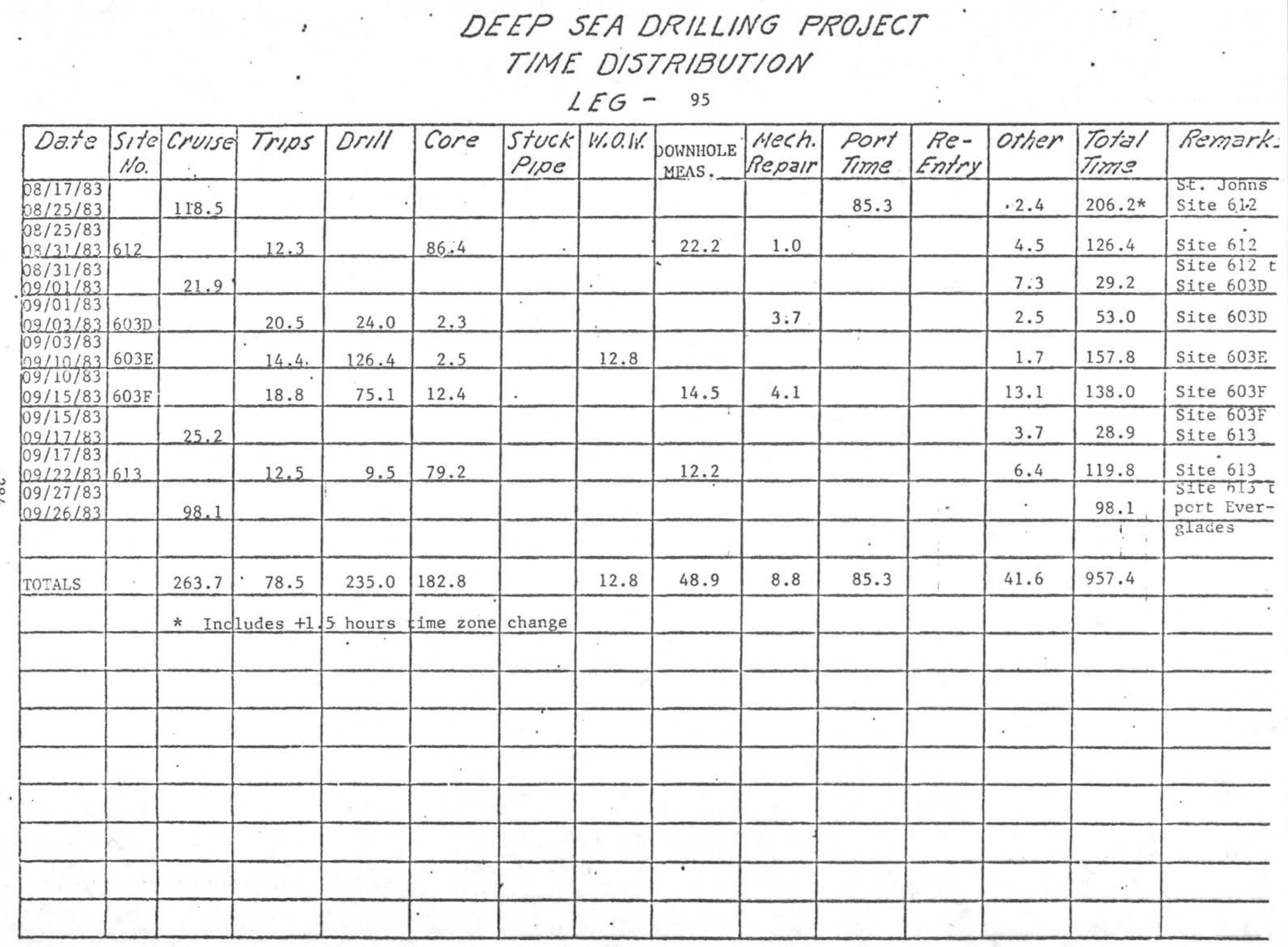




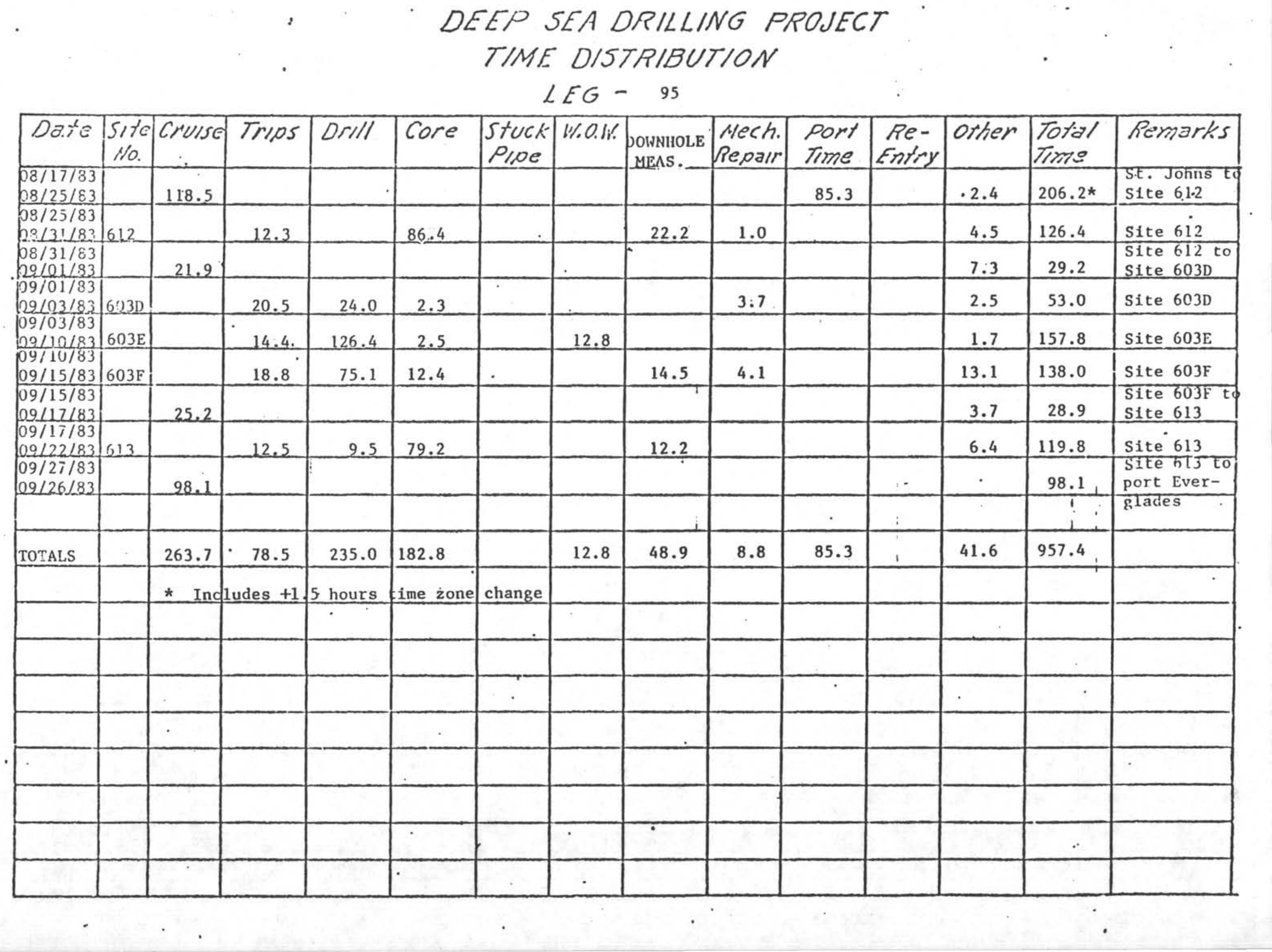


INTERNATIONAL PHASE OF OCEAN DRILLING

DEEP SEA DRILLING PROJECT

SITE SURMARY

LEG 95

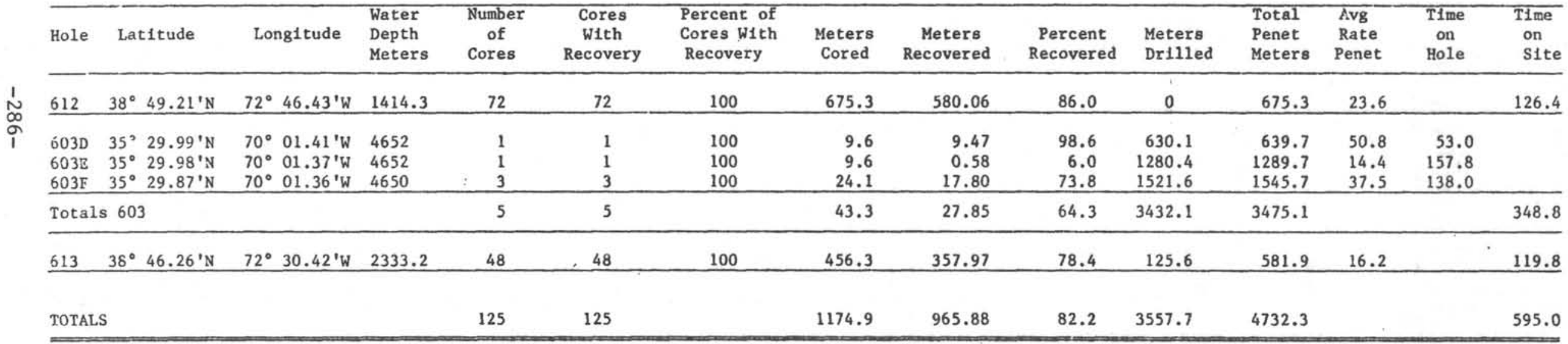


INTERNATIONAL PHASE OR OCEAN DRILLING DEEP SEA DRILLING PROJECT

$$
\begin{aligned}
& \text { BIT SUMMARY } \\
& \text { LEG } 95
\end{aligned}
$$

LEG 95

\begin{tabular}{|c|c|c|c|c|c|c|c|c|c|c|}
\hline Hole & Mfg. & S1ze & Type & $\begin{array}{l}\text { Ser1al } \\
\text { Number }\end{array}$ & $\begin{array}{l}\text { Meters } \\
\text { Cored }\end{array}$ & $\begin{array}{l}\text { Meters } \\
\text { Drilled }\end{array}$ & $\begin{array}{l}\text { Meters } \\
\text { Total } \\
\text { Penet. }\end{array}$ & $\begin{array}{l}\text { Hours } \\
\text { on } \\
\text { B1t }\end{array}$ & Condition & Remarks \\
\hline \multirow{3}{*}{ 603D } & MSDS & $117 / 16 \times 3.80$ & $\mathrm{XCB} / \mathrm{HPC}$ & $s-51$ & 675.3 & 0 & 675.3 & 28.6 & $\mathrm{~T} 1-\mathrm{B} 3$ & Rerun for HPC only. \\
\hline & $\begin{array}{c}\text { PCI } \\
\text { (Syntech) }\end{array}$ & $97 / 8$ & PDC & $R-1$ & 9.6 & 630.1 & 639.7 & 17.8 & Unknown & Respud without trip. \\
\hline & PCI & $97 / 8$ & PDC & $R-1$ & 9.6 & $\begin{array}{l}1280.1 \\
\text { TOTALS }\end{array}$ & $\frac{1289.1}{1929.4}$ & $\frac{89.0}{103.8}$ & LT-E & $\begin{array}{l}\text { 90\% of stratapax - stud cutting } \\
\text { structure destroyed. See engr } \\
\text { report. Died in loose sand. }\end{array}$ \\
\hline $603 \mathrm{~F}$ & MSDS & $97 / 8$ & F93CK & $s-60$ & 24.1 & 1521.6 & 1545.7 & 44.7 & $\begin{array}{l}\text { Released for } \\
\text { logging. }\end{array}$ & $\begin{array}{l}\text { Single b1t attempt to reach } \\
\text { Jurassic - washed at } 600 \text { GPM } \\
\text { over } 1500 \mathrm{~m} \text {. }\end{array}$ \\
\hline 613 & MSDS & $117 / 16 \times 3.80$ & $\mathrm{XCB} / \mathrm{HPC}$ & $s-36$ & 456.3 & 125.6 & 581.9 & 35.9 & $\mathrm{~T} 1-\mathrm{B} 5-\frac{1}{2}$ OG & $\begin{array}{l}\text { Three loose cones scarred XCB } \\
\text { shoes, ROP very low in firm } \\
\text { chalk near end. No rerun. }\end{array}$ \\
\hline
\end{tabular}


INTERNATIONAL PHASE OF OCEAN DRILLING

DEEP SEA DRILLING PROJECT

BEACON SUMMARY

LEG 95

\begin{tabular}{|c|c|c|c|c|c|c|}
\hline & $\begin{array}{l}\text { Site } \\
\text { No. }\end{array}$ & Make & $\begin{array}{l}\text { Freq } \\
\mathrm{kHz}\end{array}$ & $\begin{array}{l}\text { Serial } \\
\text { Number }\end{array}$ & $\begin{array}{c}\text { Site Time } \\
\text { Hours }\end{array}$ & Condition \\
\hline & 612 & ORE & 13.5 & 175 & 126.4 & Single life; strong throughout. \\
\hline & $\begin{array}{l}603 \mathrm{D} \\
603 \mathrm{E} \\
603 \mathrm{~F}\end{array}$ & $\begin{array}{l}\text { ORE } \\
\text { ORE } \\
\text { ORE }\end{array}$ & $\begin{array}{l}16.0 \\
16.0 \\
16.0\end{array}$ & $\begin{array}{l}169 \\
169 \\
169\end{array}$ & $\begin{array}{r}53.0 \\
157.8 \\
138.0 \\
\end{array}$ & $\begin{array}{l}\text { Double 1ife; strong throughout. Lost } \\
\text { Hole } 603 \mathrm{D} \text { when heavy weather caused acoust } \\
\text { loss due to bubble interference. }\end{array}$ \\
\hline $\begin{array}{c}1 \\
N \\
\infty \\
\infty \\
1\end{array}$ & $\begin{array}{l}613 \\
613\end{array}$ & $\begin{array}{l}\text { ORE } \\
\text { ORE }\end{array}$ & $\begin{array}{l}16.0 \\
13.5\end{array}$ & $\begin{array}{l}166 \\
176\end{array}$ & $\begin{array}{l}348.8 \\
119.8 \\
\text { None }\end{array}$ & $\begin{array}{l}\text { Single life; strong throughout. } \\
\text { Failed to activate during soak test, } \\
\text { Boxed for return to ORE. }\end{array}$ \\
\hline
\end{tabular}


DEEP SEA CPILLING PROJECT LOGGING SUIMARY

\begin{tabular}{|c|c|c|c|c|c|c|c|c|c|c|c|}
\hline HOLE & $\begin{array}{l}\text { TOTAL } \\
\text { OEPTH } \\
\text { (Mii) }\end{array}$ & $\begin{array}{c}\text { WATER } \\
\text { DEPTH } \\
(W)\end{array}$ & $\begin{array}{c}\text { OPEN } \\
\text { ENDED } \\
\text { PIPE AT } \\
(\text { (i. })\end{array}$ & $\begin{array}{c}\text { FL.UID } \\
\text { IN } \\
\text { HOLE }\end{array}$ & $\begin{array}{c}\text { BIT } \\
\text { SIZE }\end{array}$ & $\begin{array}{l}\text { TOTAL } \\
\text { TIME FOR } \\
\text { LOGGING } \\
\text { (HOURS) }\end{array}$ & $\begin{array}{l}\text { RUN: } \\
\text { NO. }\end{array}$ & $\begin{array}{c}\text { LOGS } \\
\text { RECORDED }\end{array}$ & $\begin{array}{l}\text { FROM } \\
(M)\end{array}$ & $\begin{array}{l}\text { TO } \\
\text { (ii) }\end{array}$ & OBSERVATIOHS \\
\hline 612 & 2089.6 & 1414.3 & 1489.7 & $\begin{array}{l}\text { Barite } \\
\text { Mud }\end{array}$ & $\begin{array}{l}11-7716 \\
\times 3.80 \\
\end{array}$ & 8.2 & 1 & $\begin{array}{l}\text { DI-Sonic- } \\
\text { GR-Calip. }\end{array}$ & 1518 & 2088 & Logged thru unreleased bit. \\
\hline & & & & & & & 2 & $\begin{array}{l}\text { Sonic } \\
\text { Wave Forms }\end{array}$ & 1518 & 2088 & All logs successful. \\
\hline & & & & & & 5.0 & 3 & $\begin{array}{l}\mathrm{BD}-\text { Neutron } \\
\mathrm{NGT} \\
\end{array}$ & 1518 & 2088 & \\
\hline & & & & . & & 9.1 & $4 *$ & & & & *Attempted Lamont MCS-tool failed. \\
\hline $603 \mathrm{~F}$ & 6195.7 & 4650 & 4783 & $\begin{array}{l}\text { Barite } \\
\text { Mud }\end{array}$ & $97 / 8$ & 6.9 & 1 & None & & & BHA Dlugged with gumbe, calld rat get \\
\hline & & & & & & & & & & & tool out MBR top conn. after separato \\
\hline & & & & & & & & & & & attempts: \\
\hline . & & & & & & & & & 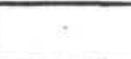 & & \\
\hline 613 & 2915.1 & 2333.2 & 2436.6 & $\begin{array}{l}\text { Barite } \\
\text { Mud }\end{array}$ & $\begin{array}{c}11-1716 \\
3.80 \\
\end{array}$ & 2.8 & 1 & $\begin{array}{l}\text { DI-Sonic- } \\
\text { GR-Calip. }\end{array}$ & 2445 & 2913 & Logged thru unreleased bit. \\
\hline & & & & & & & 2 & $\begin{array}{l}\text { Sonic } \\
\text { Wave Forms }\end{array}$ & 2445 & 2913 & Forced down tight hole-all logs \\
\hline & & & & & & & & & & & successfu1. \\
\hline & & & & & & 5.9 & $3 *$ & $\begin{array}{l}\text { Multi- } \\
\text { Channel Soni }\end{array}$ & 2437 & 2519 & *Lamont MCS tool too light \& flexible \\
\hline & & & & 1 & & & & & $\cdot$ & & to force down restrictive hole- \\
\hline & & & & 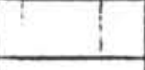 & 1 & $i$ & & $r$ & & & $82 \mathrm{~m}$ finally logged. \\
\hline & & & & . & & & & . & & & 1 \\
\hline & & LOG PRE & PARATION & TIME & & 3.4 & & 1 & & & 4 \\
\hline & & & & & TOTAL & 48.9 & & & & & \\
\hline & & & & & & & & & & & \\
\hline & & & & & & & & & & & \\
\hline$\sqrt{2}$ & & & & & & & & & & & \\
\hline & & & & & & & & & & & \\
\hline & & & & . & & & & - & & . & \\
\hline & & & & & & & & 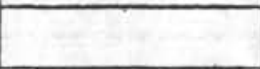 & & & 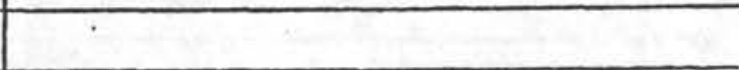 \\
\hline & & & & - & & & - & & & & \\
\hline & & & & & & & & & & & \\
\hline
\end{tabular}


DEEP SEA DRILLING PROJECT LOGGING SUHAARY

\begin{tabular}{|c|c|c|c|c|c|c|c|c|c|c|c|}
\hline HOLE & \begin{tabular}{|c|} 
TOTAL \\
DEPPIH \\
(M)
\end{tabular} & $\begin{array}{l}\text { HATER } \\
\text { DEPTH } \\
\text { (M) }\end{array}$ & \begin{tabular}{|c|} 
PPENA \\
ENDED \\
PIPE AT \\
(II) \\
\end{tabular} & $\begin{array}{c}\text { FLUID } \\
\text { IN } \\
\text { HOLE }\end{array}$ & $\begin{array}{l}\text { BIT } \\
\text { SIZE }\end{array}$ & \begin{tabular}{|c|} 
TOTAL \\
TIME FOR \\
LOGING \\
(HOURS) \\
\end{tabular} & $\begin{array}{l}\text { RUN } \\
\text { NO. }\end{array}$ & $\begin{array}{c}\text { LOGS } \\
\text { RECORDED }\end{array}$ & $\begin{array}{l}\text { FROM } \\
\text { (M) }\end{array}$ & $\begin{array}{l}\text { TO } \\
\text { (M) }\end{array}$ & OBSERVATIOHIS \\
\hline \multirow[t]{4}{*}{612} & 2089.6 & 1414.3 & 1489.7 & $\begin{array}{l}\text { Batrite } \\
\text { Mud }\end{array}$ & $\begin{array}{l}1179716 \\
\times 3.80 \\
\end{array}$ & 8.2 & 1 & $\begin{array}{l}\text { DI-Sonic- } \\
\text { GR-Cal1D. } \\
\text { Sontc }\end{array}$ & 1518 & 2088 & Logged thru unreleased bit. \\
\hline & & & & & & & 2 & $\begin{array}{l}\text { Sonic } \\
\text { Wave Forms }\end{array}$ & 1518 & 2088 & All logs successful. \\
\hline & & & & & & 5.0 & 3 & $\begin{array}{l}\mathrm{B}-\mathrm{BD} \text {-Neutron } \\
\mathrm{NGT}\end{array}$ & 1518 & 2088 & \\
\hline & & & & & & 9,1 & $4 *$ & & & & ${ }_{\text {Attempted Lamont MCS-tool falled. }}$ \\
\hline & & & & & & & & & & & \\
\hline \multirow[t]{3}{*}{$603 \mathrm{~F}$} & 6195.7 & 4650 & 4783 & $\begin{array}{l}\text { Barite } \\
\text { Mudd } \\
\end{array}$ & $27 / 8$ & 6.9 & 1 & None & & & BHA Dlugged with gumbe, could not pet \\
\hline & & & & & & & & & & & tool out MBR top conn. after separate \\
\hline & & & & & & & & & & & attempts. \\
\hline . & & & & & & & & & 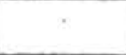 & & \\
\hline \multirow[t]{6}{*}{613} & 2915.1 & 2333.2 & 2436.6 & $\begin{array}{l}\text { Barite } \\
\text { Yud }\end{array}$ & $\begin{array}{l}\mid 1-1 / 16 \\
3.80\end{array}$ & 2.8 & 1 & $\begin{array}{l}\mathrm{I}-\mathrm{S} \text { onde- } \\
\text { GR-callp. }\end{array}$ & 2445 & 2913 & Logged thru unreleased bit. \\
\hline & & & & & & & 2 & $\begin{array}{l}\text { Sonic } \\
\text { Wave_Forms }\end{array}$ & 2445 & 2913 & Forced down tight hole-all logs \\
\hline & & & & & & 1 & & & & & successfu1. \\
\hline & & & & & & 5.9 & $3 *$ & $\begin{array}{l}\text { Multi- } 1 \text { Soni } \\
\text { Channe1 }\end{array}$ & 2437 & 2519 & ${ }_{\star}$ Lamont MCS tool too light \& flexible \\
\hline & & & & í & & + & & 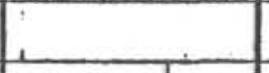 & $\cdot \cdot$ & & to force down restrictive hole- \\
\hline & & & & & & 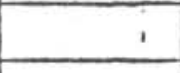 & & 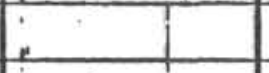 & & & $82 \mathrm{~m}$ finally logged. \\
\hline & & & & . & & & & : & & & 1 \\
\hline & & LOG PRE & ARATION & TIME & & 3.4 & & 1 & & & $: 11$ \\
\hline & & & & & TOTAL & 48.9 & & & & & \\
\hline & & & & & & & & & & & \\
\hline & & & & & & & & & & & \\
\hline & & & & & & & & & & & \\
\hline & & & & & & & & & & & \\
\hline & & & & & & & & & & . & \\
\hline & & & & & & & & & & & $\cdot$ \\
\hline & & & & & & & & & & & \\
\hline & & & & & & & & & & & \\
\hline
\end{tabular}


DEEP SEA DRILLING PROJECT

- ALUMINUM DRILL PIPE USAGE REPORT

LEG 95

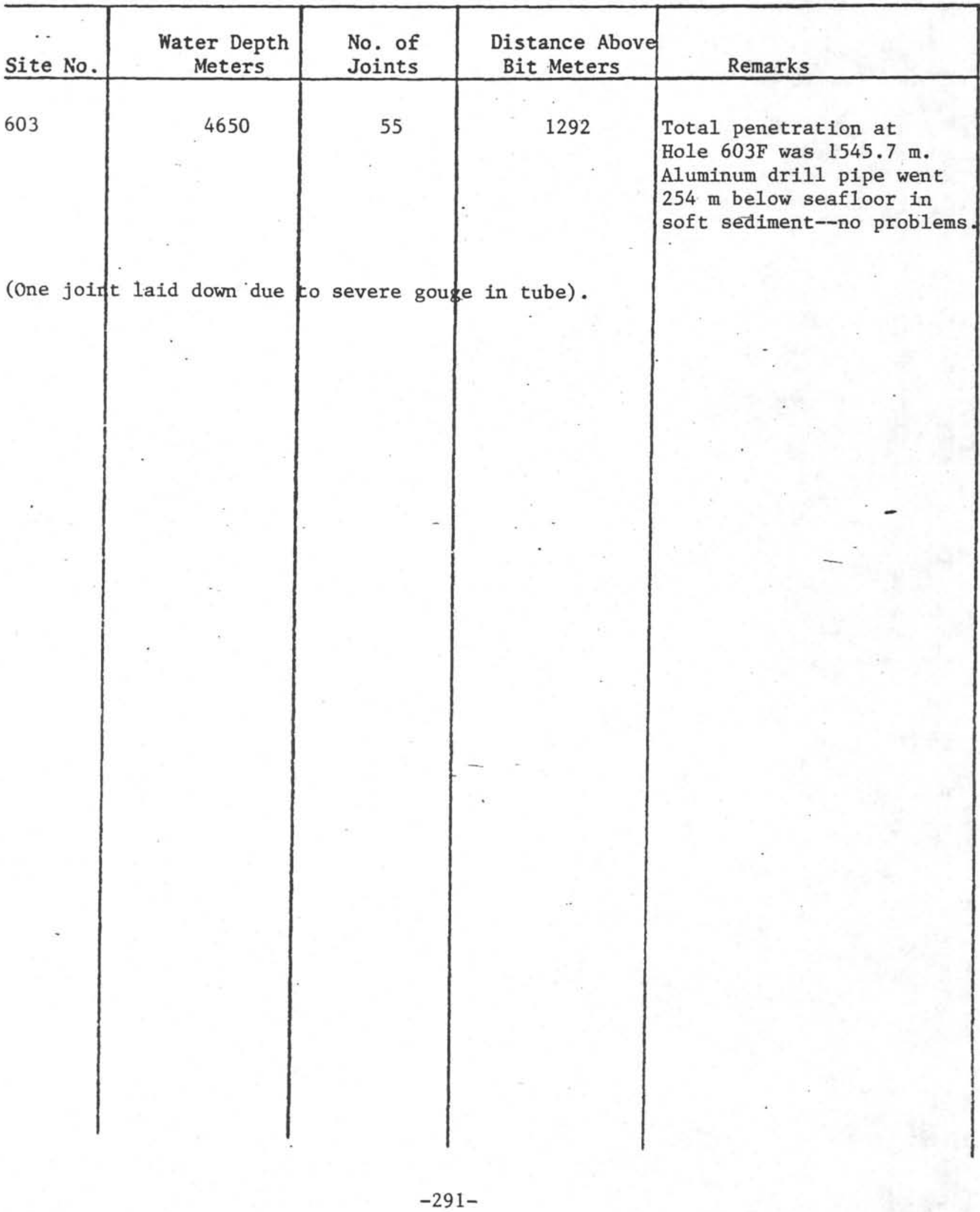




\section{INTERNATIONAL PHASE OF OCEAN DRILLING \\ DEEP SEA DRILLING PROJECT \\ OPERATIONS RESUME \\ LEG 96}

The 96 th and final scientific expedition of the Deep Sea Drilling Project concluded $151 / 2$ years of continuous worldwide geological coring operations by the drillship GLOMAR CHALLENGER. For the final voyage, the vessel returned "home" to the Gulf of Mexico. The primary focus of study was the sedimentary and biostratigraphic nature of the Mississippi Fan, the huge accumulation of sediment extending across the Gulf from the outlet of the Mississippi River.

Twenty holes were cored at eleven sites on the Mississippi Fan and in the Orca and Pigmy intraslope basins. The scientific goals of the cruise were achieved despite powerful currents that taxed the vessel's positioning system to the limit and unstable hole conditions that frequently threatened to stick the drill string and halt operations. A successful logging program was carried out that produced successful well logs from seven holes.

The voyage commenced on September 26, 1983 at Port Everglades, Florida and terminated on November 8,1983 at Mobile Alabama. Total length of the leg was 43.1 days, of which 32.3 days were spent on site, 3.5 days in port and 7.3 days in transit. Mechanical breakdown accounted for only 0.5 hour.

Ft. Lauderdale Port Call

Leg 96 had its official beginning at 0654 hours, September 26, 1983 with the first mooring line at Berth Two of Port Everglades in Fort Lauderdale, Florida. Shortly after arrival, it was necessary to shift to Berth One. This was accomplished by 1000 hours, and port call activities then commenced in earnest.

Principal work items included the top overhaul of No. 9 engine, repair of No. 1 gyro compass, U.S. Coast Guard inspection of GLOMAR CHALLENGER, crew change, offloading of cores, on-loading of 1000 sacks of barite and miscellaneous freight and an open house for local visitors. With all scheduled work completed, the vessel departed her berth at 1808 hours, September 29.

Ft. Lauderdale to Site 614

Excellent speed was achieved on the transit to the initial operating area. A nearshore countercurrent of the Gulf Stream combined with a following wind and calm seas to produce a speed 
of over 11 knots as CHALLENGER rounded the Florida Peninsula and turned west past the Florida Keys. A few hours after leaving the countercurrent, the vessel encountered arother current which carried her toward the operating area at speeds increasing to about 13 knots. This unexpectedly strong current hampered maneuvering for the relatively complex preliminary profiling survey. After a $4-1 / 2$ hour survey, a positioning beacon was launched at 1332 hours, October 1, marking arrival at Site 614. The drill site was located about 120 miles west-northwest of the Dry Tortugas Islands and about 150 miles north-northwest of Cuba.

\section{Hole 614 - Lower Mississippi Fan}

The approach profile was extended about 15 minutes beyond the beacon drop point before the vessel was turned and the towed seismic gear was retrieved. As the vessel began to approach the beacon to take station, the beacon's acoustic signal weakened abruptly and developed pulse characteristics that were rejected by the positioning system. Using LORAN C navigation, the ship struggled back to the drop coordinates against the strong current and an alternate frequency beacon was dropped at 1510 hours.

Satisfactory positioning was finally achieved at 1645 hours, and the pipe trip began. The current pushed the bottom hole assembly (BHA) so strongly against the moonpool bracing that it was necessary to let the vessel drift momentarily to facilitate setting the upper guide horn into position. The drill string continued to be forced strongly against the pipe restraint and to vibrate violently for the duration of the pipe trip.

The precision depth recorder (PDR) reading placed the seafloor between 3310 and $3320 \mathrm{~m}$ below the rig floor. The core bit was positioned at $3314 \mathrm{~m}$ for the first attempt with the advanced hydraulic piston corer (APC). The corer stroked to $3323.5 \mathrm{~m}$ and was recovered nearly filled with core $(9.33 \mathrm{~m})$. One joint of pipe was set back and another core was "shot" from $9.5 \mathrm{~m}$ higher to ascertain that no sediment had been missed. It was necessary to interrupt this operation for one hour when the current and wind pushed the vessel about 60 meters off station. The corer was recovered with no trace of sediment, and the water depth was established at $3314.1 \mathrm{~m}$. Two additional mud cores of good quality were taken to $27 \mathrm{~m} \mathrm{BSF}$ (below seafloor), where soft, loose sand was encountered. Penetration and recovery were reduced to nil, and the same interval was cored three times before a twometer sand core was recovered. As the corer was being lowered for the next attempt, a sudden drop in sandline weight indicated that the coring assembly had been lost. On recovery of the sandline, it was found that the wireline swivel had come apart, leaving the APC, the sinker bar assembly and the lower portion of the swivel in the pipe. The dimensions of the swivel prohibited recovery from the pipe by wireline fishing. A round trip was therefore necessary to continue operations. In the meantime, however, the dressed corer had settled into position in the outer 
core barrel. The bit was lowered to the bottom of the hole and the pipe was pressured to actuate the corer before the drill string was recovered.

The corer was recovered from the BHA at the drill floor at 1700 hours, October 2, containing about eight meters of loose sand.

\section{Hole $614 \mathrm{~A}$}

With the round trip complete, Hole $614 \mathrm{~A}$ was spudded at 2341 hours, October 2. The bit was "washed" down to $37 \mathrm{~m} \mathrm{BSF}$, the total penetration of Hole 614. Another ten meters of loose sand was cored before mud and clay strata were again encountered. APC coring continued through the day in sediments consisting of alternating sand and mud beds, with sand predominating. Core recovery was unexpectedly high, though penetration of the corer, as expected, was limited. This was held to as little as two meters in the cleaner and coarser sands. At about $115 \mathrm{~m}$ BSF, the clay became much stiffer and became a factor in both reduced penetration and increased overpull on retrieval. At $131 \mathrm{~m}$ BSF, the APC was retired in favor of the extended core barrel (XCB). Two XCB cores were attempted with only a few centimeters recovered each time. At this point, the scientific objectives were considered to be accomplished and coring operations were terminated at a total drill string depth of $3464.4 \mathrm{~m}$. The drill string was recovered and the vessel was under way at 0140 hours, October 4 .

\section{Site 614 to Site 615}

The next intended drill site lay only about eleven miles to the northeast of Site 614. Because of extensive preliminary profiling, only the $3.5 \mathrm{kHz}$ echosounder was used to supplement LORAN C navigation for final site location. At 0459 hours, a $13.5 \mathrm{kHz}$ acoustic beacon was dropped at the desired location. The approach profile was extended 2.5 miles beyond the drop point before the ship turned to return to the beacon. During this time the beacon's signal was monitored as it fell to the seafloor. The pulse width was noted to be too short for acceptance by the dynamic positioning system (DPS) and the signal rapidly dropped to a low level. More PDR profiling was then done to locate a proper drilling location and a $16 \mathrm{kHz}$ beacon was launched at 0547 hours. As the vessel waited to take station while the second beacon fell through the water column, the original $(13.5 \mathrm{kHz})$ unit began to transmit a strong usable pulse which obliterated the now very weak $16 \mathrm{kHz}$ signal. Optimistically acknowledging that flexibility is a virtue and that one of two is not bad, the GMI staff switched the DPS back to $13.5 \mathrm{kHz}$ and took station on the nearby original beacon.

The pipe trip began at 0700 hours. At 0750 hours, the $13.5 \mathrm{kHz}$ signal degenerated to a completely unusable level. The $16 \mathrm{kHz}$ 
beacon was now acquired at a distance of $760 \mathrm{~m}$ and the DPS was shifted back to that frequency. It soon became apparent that the $16 \mathrm{kHz}$ pulse was too weak to be heard through the thruster noise and frequent loss of acoustics occurred. With beacons transmitting unusable signals on both operating frequencies, it was necessary to abandon the location and to find an alternate drill site out of acoustic range of the two beacons. The BHA was recovered and CHALLENGER got under way profiling at 0900 hours.

A target area was selected about $1.3 \mathrm{~km}$ north of the beacons. The towed seismic gear was streamed as less geophysical information was available for the new location. A new $13.5 \mathrm{kHz}$ beacon was launched at 1037 hours, and an additional 1-1/4 hour of surveying was done before the gear was retrieved and final station was taken. The pipe trip commenced at 1245 hours.

Hole 615 - Lower Mississippi Fan

With the PDR depth at 3279 meters, the core bit was positioned at 3275 meters to ensure recovery of the sediment/water interface in the first 9.5 meter APC core. The core barrel was recovered with only traces of sediment in the core catcher, indicating that the very soft material had been washed out during retrieval. A second core was "shot" from two meters deeper and 2.6 meters of core was recovered, establishing water depth at $3283.9 \mathrm{~m}$.

Continuous APC cores found sand beginning at only 19 meters BSF, but good penetration and recovery were realized to about $105 \mathrm{~m}$ BSF through alternating sand and mud strata. Performance then dropped sharply, with the APC apparently unable to make significant penetration. At $143 \mathrm{~m} \mathrm{BSF}$, the XCB system was deployed. Recovery remained low, but representative cores, averaging about two meters, were obtained to about $210 \mathrm{~m}$ BSF. Below this depth only traces of sand and clay were generally recovered. Desperation attempts with the APC were met with full barrels of flow-in sand or very short cores of hard clay. At about $495 \mathrm{~m} \mathrm{BSF}$, an abrupt lithology change to carbonate ooze resulted in a return to excellent core recovery with the XCB.

Hole conditions had remained good, considering that the penetrated section consisted of over $60 \%$ uncemented sand. Up to five meters of hole fill had been noted between cores, but periodic mud flushes had been fairly effective in cleaning the hole. As the bit (which was not equipped with a float valve) approached 500 meters BSF, back pressure could no longer be controlled and shut in pipe pressures to $400 \mathrm{psi}$ were noted. It was necessary to slug the pipe with weighted mud before core barrels could be dropped against the back flow. Core barrel No. 52 became stuck at the bit and two wireline trips were required to retrieve it. With most of the scientific objectives of the site achieved, coring operations were terminated at $523.2 \mathrm{~m}$ BSF for the safety of the drill string. 
The lack of core recovery had lent increased importance to the logging program for the delineation of lithologic units. The apparent poor hole conditions made prospects of getting to bottom for open-hole logs look slim. Preparations were therefore made to run a through-pipe formation density/compensated neutron/gamma ray (FDC/CNP/GR) log. The hole was flushed with mud to counteract the back pressure. One stand of pipe was then set back to allow for cumulative hole fill. By the time the logging sheaves had been rigged and the sonde started down the pipe, shut in back pressure had increased from zero to 260 psi and the drill string had become stuck. It was necessary to abort the logging attempt to attempt to free the drill pipe. About 35 minutes of "working" the pipe was required to free it and the through-pipe logging concept was abandoned.

The hole was then filled with 300 barrels of barite weighted mud and the bit was pulled to 3330 meters. The dual induction/longspaced sonic/gamma ray (DIT/LSS/GR) tool was then assembled. About $2-1 / 4$ hours were spent in tracing an intermittent electrical leak to a connection in the cabling between the winch and recording cabs. The long logging sonde stopped abruptly only a few meters after its lower end had passed through the bit and would go no further. The tool was manipulated with little progress for about one half hour but, just before efforts were abandoned, it broke through into open hole. To the surprise of everyone, the hole was then found to be absolutely clear as the sonde descended to only 17 meters off total depth. A log of excellent quality was then recorded for the length of the hole. The upper portion of the logging sonde had already started into the pipe when the lower portion became firmly stuck at the same spot that had given trouble on the down trip. After over two hours of effort, the tool was finally freed by moving the core bit up and down over the logging tool.

When the first sonde had been recovered, two joints of pipe were added to place the bit below the interval of tight hole. The FDC/CNL/GR tool was then deployed, but the run was aborted when a special spectral gamma ray module malfunctioned. It was replaced by a standard gamma ray cartridge and adapter. This second logging tool also encountered obstructions in the first 20 meters of open hole. It broke into smooth going after much effort, and another good log was recorded from the same depth as the first run.

With logging operations completed, the sheaves were rigged down and the bit was pulled clear of the seafloor in preparation for respudding.

\section{Hole 615A}

Hole $615 \mathrm{~A}$ was spudded at 1317 hours, October 9, in 3285.9 meters of water after the vessel had been offset 19 meters to the northeast. The hole was drilled to collect cores for 
geotechnical studies at a later date. Since sand was of little interest for this purpose, coring efforts were concentrated on the more clay-rich intervals. Recovery performance of the APC and XCB systems was consistent with that of the first hole as $615 \mathrm{~A}$ was drilled and spot cored to a total depth of 3494.4 meters. The drill string was recovered, and GLOMAR CHALLENGER departed for the next drill site at 2035 hours, October 10 .

\section{Hole 616 - Flank of Middle Mississippi Fan}

The new drill site was located about 190 miles southeast of the tip of the Mississippi River delta. The transit.was made in 11$1 / 4$ hours, and a beacon was let go at 0745 hours, October 11. After an additional 1-1/2 hours of profiling, the vessel returned to take station on the beacon (which was functioning perfectly).

Following the pipe trip, two unsuccessful attempts were made to capture the sediment/water interface with the APC. Both core barrels were recovered without core and with the breakaway piston head resting at the bottom of the liner. The first barrel stroked to $3000.5 \mathrm{~m}$ and bore traces of sediment on the core catcher. The second extended to $2997.5 \mathrm{~m}$ and was recovered without a trace. For the third attempt, a fixed piston head was installed, and the bit was positioned at $2995.5 \mathrm{~m}$. The 9.5 meter corer recovered 6.1 meters of core, and water depth was established at 2998.9 m (compared with 2993 m PDR depth).

Good results were obtained with the APC through clay and silt to about $75 \mathrm{~m} \mathrm{BSF}$, where recovery dropped to about 50\%. The APC was replaced by the XCB system at $104 \mathrm{~m}$ BSF, but four consecutive cores produced a total of only $1.36 \mathrm{~m}$. Three APC cores then achieved about one half stroke before a withdrawal overpull of 95,000 pounds again prompted a switch to XCB coring. Three consecutive XCB cores yielded $4.9 \mathrm{~m}$ of sand and clay core. With recovery low, the XCB was retrieved on each second pipe joint to $296 \mathrm{~m} \mathrm{BSF}$. Continuous XCB cores then gave increasingly good recovery to $371 \mathrm{~m}$ in very stiff clay. The XCB was then dropped for the final planned core, and a 40 barrel mud flush was pumped into the pipe to condition the hole for logging.

As the connection was being made for the final core, the drill string abruptly became stuck. This was completely unexpected, as no hole problems had been encountered up to that time. Two hours of working the pipe failed to budge it, and it became evident that the BHA was permanently emplaced. Lack of bumper sub action indicated that the stuck point was more than $50 \mathrm{~m}$ above the bit. Because of low core recovery through the lower two thirds of the section, well logs had again become increasingly important for the fulfillment of the site's scientific objectives. The stuck pipe now precluded open-hole logging, but a through-pipe gamma ray log could still be run to delineate the sand/clay boundaries. The logging sheaves were rigged, and a FDC/CNP/GR log was recorded. Surprisingly there was only about four meters of fill 
and nine meters of open hole was logged below the bit. The natural gamma ray curve was quite readable and was even more useful than had been anticipated.

The severing apparatus was then assembled and run down the pipe. The prima-cord charge successfully parted the string in the lowermost joint of 5-1/2 inch drill pipe. When the logging cable was retrieved, it was found that the line had parted just above the cable head, resulting in the loss of the casing collar locator and the shooting sinker bar assembly.

The drill pipe was then recovered, with the severed joint arriving on deck at 0930 hours, October 14.

\section{Hole 616A}

The second borehole was added to the drilling program to obtain an oriented core in a shallow zone of steeply dipping beds and to recore the interval of low recovery at 114-142 $\mathrm{m} \mathrm{BSF}$ in Hole 616 .

Assembling and spacing out the replacement BHA added about four hours to the "down" trip time and Hole $616 \mathrm{~A}$ was spudded at 1917 hours. The hole was drilled without coring to $34.6 \mathrm{~m} \mathrm{BSF}$, where the oriented core was desired.

The special non-spiraling APC assembly and the prototype gyro orientation tool were then deployed. The coring assembly was retrieved after an apparently normal actuation. Disappointment prevailed when the core barrel was found to contain only $39 \mathrm{~cm}$ of sediment. The sticky clay had held the core catchers open, allowing the core to fall out during retrieval. The misadventure was compounded when it was found that no orientation data had been recorded. The wiring of the gyro tool had been damaged during final assembly. It was further discovered that a pressure case 0-ring seal had failed. The pressure case had flooded and the gyro was damaged beyond repair.

The hole was then drilled to $94 \mathrm{~m} \mathrm{BSF}$, where the pipe began torquing. A bentonite mud flush freed the pipe after a delay of one half hour. Continuous coring began at $103.5 \mathrm{~m}$, but operations were again interrupted after two cores when the APC became stuck in the drill pipe as it was lowered for core No. 4H. Two additional wireline trips were made in attempts to dislodge the corer, but each time the overshot pin sheared and no progress was made. The APC was finally knocked to the bottom by pumping a standard inner barrel down the pipe at high speed. Core No. 4H was "shot" and retrieved routinely, and no evidence was found as to the cause of the sticking. The following core attempt produced an incomplete stroke indication and no core was recovered. As this was to be the final core of the hole, no further attempt was made and coring operations were terminated to maintain the operating schedule. The core bit was then pulled clear of the seafloor for respudding. 
The final hole at Site 616 was a planned 200 meter penetration dedicated to geotechnical purposes. Continuous APC cores were taken to about $95 \mathrm{~m} \mathrm{BSF}$, where complete stroke of the corer was no longer achieved. Coring then continued in the APC mode with uncored intervals drilled of to maintain the operating pace of one pipe connection per core. At $165 \mathrm{~m} \mathrm{BSF}$, the withdrawal overpull following core No. $19 \mathrm{H}$, reached 90,000 pounds. Coring force was reduced somewhat for the remaining four cores by using $2-1 / 2$ shear pins instead of the maximum three. Overpull then remained within operating limits to the total depth of $204.3 \mathrm{~m} \mathrm{BSF}$ (3203.1 m pipe depth).

Excessive torque was required to rotate the drill string on three occasions during the coring of Hole 616B. In each case, operations were interrupted to flush the hole with bentonite mud and the hole trouble disappeared.

After a routine pipe trip, the vessel got under way for Site 617 at 1445 hours, October 16 .

\section{Site 616 to site 617}

The middle fan operating area lay about 105 miles to the westsouthwest of Site 616. The approach course was altered slightly to bring the vessel to a turning point just to the northeast of the operating area. A southwesterly profile then crossed the closely spaced proposed Sites $M F-7 A, M F-6 A$, and $M F-5$ in order. $A$ reciprocal line was run back across the latter two sites. Another turn was made and beacons were dropped for Sites MF-6A and MF-5 (617). The transit and survey were made in $15-1 / 2$ hours. The seismic gear was then retrieved and the vessel was positioned on offsets $575 \mathrm{~m}$ south and $720 \mathrm{~m}$ west of the second beacon.

Hole 617 - Middle Mississippi Fan

At 1334 hours, October 17, the 9.5 meter APC was shot from the PDR depth of 2477 meters. The eight meters of sediment recovered established water depth at $2478.5 \mathrm{~m}$.

Before the second core could be attempted, shifting winds from heavy rain squalls combined with a strong local current to carry the vessel about 120 meters off station. Weather conditions stabilized and positioning became sufficiently steady to resume coring after a delay of 1-1/2 hours.

APC coring then proceeded smoothly through clay and silty mud to a depth of $191.2 \mathrm{~m} \mathrm{BSF}$, where the scientific objectives were considered accomplished. The power sub was left in the string to lay out doubles, and the bit was pulled clear of the seafloor at 
1227 hours, October 19 to end Hole 617 operations.

Hole $617 \mathrm{~A}$

The unexpected absence of sand in Hole 617 led to reconsideration of plans to drill an additional hole at Site MF-7A for geotechnical studies. The known favorable conditions prompted the decision to relocate the middle fan geotechnical hole to site 617 . The vessel was therefore offset 30 meters to the southwest to avoid the Hole 617 disturbed area, and Hole $617 \mathrm{~A}$ was spudded at 1303 hours.

Continuous APC cores were taken to $74 \mathrm{~m}$ BSF without significant problems. Two core attempts at this depth met with no recovery or apparent penetration. The corer was being lowered for a core attempt one joint $(9.5 \mathrm{~m})$ deeper, when operations were interrupted by weather.

The wind, which had been almost exactly opposing the strong current, shifted about 30 degrees to the vessel's port quarter and increased in velocity. The ship's thrusters were unable to maintain heading against the resultant turning moment and the vessel broached. It was then quickly carried about 360 meters off station by the current before action could be taken to arrest the excursion.

The rig was brought back over the hole after a $3 / 4$ hour delay, and the APC was run down the pipe. With the BHA not yet fully supported by the hole, damage to the BHA can be expected from a large positioning excursion. Suspicions were confirmed when the APC stopped at the approximate location of the bumper subs, indicating a bent sub. This, of course, meant that no more coring could be done in Hole $617 \mathrm{~A}$ and that a pipe trip was necessary.

The APC was retrieved and the drill string was recovered. It was found that the mandrel of the upper bumper sub was, indeed, slightly bent. As the next stand of drill collars was brought through the rig floor, it was discovered that the lowermost drill collar and the entire outer core barrel assembly had been lost when bending forces had caused the rotary shouldered connection to fail.

During the pipe trip, it had been determined that positioning could not be maintained within operating limits under the existing current and weather conditions. The only alternative was therefore to move to the Orca and Pigmy Basin operating areas to the west and to hope for improved conditions upon the vessel's return to the middle fan.

Hole 618 -Orca Basin

The 148-mile transit was made in 16 hours. Site 619 was located 
about 130 miles south-southwest of the South Louisiana coast in a totally enclosed basin on the Texas-Louisiana slope. The basin was known to contain several hundred meters of highly saline water, which made the PDR depth of 2391 meters highly suspect.

The wind and current conditions were far less than ideal at the new site, but the current was not so strong as at Site 617 . Satisfactory positioning was attained after 2-1/2 hours of effort, and the pipe trip began. Since both of the special outer core barrel drill collars required for the APC had been lost, a different BHA configuration was made up for the VLHPC (variable length hydraulic piston corer). In addition, the connections of the upper BHA were inspected for damage from bending stress.

The estimated depth correction for the velocity of brine filling the basin proved to be too conservative, and two "water cores" were taken before the APC found the seafloor. Unfortunately, on this run the two shear pins that held the VLHPC together had failed due to pipe surge resulting from vessel motion. The inner barrel was thus stroked to full length and was stabbed into the seafloor while the attempt was made to pressure up and actuate the corer. The corer was retrieved as soon as pressure failed to build normally, but drill string motion had already broken off the inner core barrel just below its point of emergence from the core bit. The VLHPC was then redressed with the alternate inner barrel and the maximum three shear pins. After a one half hour delay to stabilize marginal positioning following a wind shift, the VLHPC actuated normally to spud Hole 618 at 1331 hours, October 20. The recovered core was measured to determine water depth at $2422.4 \mathrm{~m}$.

Continuous cores were taken to $63 \mathrm{~m}$ BSF with incomplete stroke beginning at $50 \mathrm{~m}$. Below $63 \mathrm{~m}$ each remaining uncored interval was drilled off to the next pipe connection. The material cored was gray and black sandy mud which had been slump deposited under anoxic conditions. The malodorous sediment contained considerable methane gas, which decreased in quantity with depth, and some gas hydrate. After 11 cores $(92.5 \mathrm{~m})$, the scientific objectives were declared complete.

Hole $618 \mathrm{~A}$

As additional samples of the upper sediments were desired, a second shallow hole was planned at the same location. The "mudline" core again proved difficult; the shear pins again failed on the initial descent and the soft sediment washed out of the core barrel on the second attempt. Three cores were eventually recovered between the seafloor and $47.5 \mathrm{~m}$ BSF. Gas hydrate samples were collected.

The drill string was then pulled and GLOMAR CHALLENGER departer for site 619 at 1212 hours, October 21 . 
Site 619 was located in a nearby basin only about 12 miles to the northwest of Site 618. The track was lengthened by about four miles by a "dogleg" to permit approach to the site from the east along an existing seismic profile. The move was made in only 107 minutes, and the positioning beacon was launched at 1359 hours, October 21. The profile was extended for one half hour beyond the drop before the vessel turned to take position over the beacon.

Hole 619 - Pigmy Basin

Current and wind conditions were found to be favorable for positioning (for the first time on the voyage) and the pipe trip was uneventful. Since PDR depth had been consistently somewhat shallow on previous sites, the bit was lowered to the PDR depth of 2274 meters for the first VLHPC core attempt. The core barrel was recovered nearly full, and there were indications that the sediment/ water interface had not been recovered. One joint of pipe was set back and a second core was "shot" from 9.5 meters higher. No core was recovered, but a water depth of $2273 \mathrm{~m}$ was estimated on the basis of traces of sediment in the lower meter of the plastic core liner.

Continuous piston cores were taken in gray mud to about $74 \mathrm{~m} \mathrm{BSF}$, where complete 9.5 meter stroke of the corer was no longer achieved. Beyond that depth, the uncored interval was drilled off to each following pipe connection. The installation of a shear pin sub modified to take $3-1 / 2$ pins kept penetration /recovery at four to five meters to about $155 \mathrm{~m} \mathrm{BSF}$. At about 185 meters, recovery and penetration dropped to very low levels. Coring operations were terminated at a drill pipe depth of 2481.7 $m$ due to depth limitations and low core recovery.

Small amounts of methane gas were sampled from the cores below about $120 \mathrm{~m} \mathrm{BSF}$, but no measurable increase in gas quantity or ethane content was noted.

\section{Hole 619A}

As considerable paleontological interest persisted in a "mudline" core, the pipe trip was halted just above the seafloor. The VLHPC was run to the bit and a core attempt was made from 2269.5 m. A good core containing the interface and 5.3 meters of sediment was recovered. The pipe trip then resumed and was completed at 0400 hours, October 23. The vessel departed 15 minutes later for a return to the middle fan operating area. 
The 77 mile eastward transit took only $7-3 / 4$ hours, and the positioning beacon was let go at 2040 hours, October 23. As the ship was brought onto station, it became apparent that the strong current persisted in the area and that it remained an operational factor.

Prospectus Site MF-7A was to be the deepest penetration of the voyage, with a target depth of $774 \mathrm{~m}$ below the seafloor--which was indicated at $2608 \mathrm{~m}$ by the PDR. A standard rotary coring bit and BHA were made up, and the drill string was run toward the seafloor.

The bit was lowered to $2615.4 \mathrm{~m}$ for a "mudline punch core", and the three meters of sediment recovered set the water depth at $2612.4 \mathrm{~m}$. Continuous coring then progressed through soft, sticky "gumbo" clay. Cores were highly disturbed and recovery was only fair. Very low circulation rates were required to prevent washing the core away, but only one mud flush was required to clean the hole until a sand/silt interval was penetrated at about 260$270 \mathrm{~m} \mathrm{BSF}$. This zone was apparently overpressured, as persistent torquing problems occurred each time rotation was stopped for the recovery of a core barrel. High back pressure on the drill pipe indicated that the sediment was "heaving" and closing off the pipe/hole annulus. This repeated a pattern noted on earlier holes, with the problem becoming more severe with depth. By the time a depth of $422.7 \mathrm{~m} \mathrm{BSF}$ had been reached, it was apparent that chances of reaching the deep objective were slim and that chances of losing the hole (and BHA) were good. It was therefore decided to terminate drilling operations and to $\mathrm{log}$ the hole before the opportunity was lost.

The bit release shifting tool was pumped to the bit on an inner core barrel. The barrel was then retrieved with the sandline, actuating the mechanical bit release routinely to leave the pipe open-ended for logging. The end of the drill string was then pulled to about $100 \mathrm{~m} \mathrm{BSF}$ and the logging equipment was rigged.

The first attempt--for a DIT/LSS/CAL/GR log--was aborted when the sonde apparently found an obstruction in the drill pipe at about $2290 \mathrm{~m}$ below the rig floor. The logging tool had been worked and "spudded" for about 60 meters when electrical problems developed in the sonic and gamma ray presentations. The tool was retrieved and was found to be covered with soft, sticky clay. The circulating head was rigged and the pipe was circulated to clear the "mud ball" that had apparently been forced up the pipe by the high formation pressure. (No resistance to pumping was noted.) The 10/31 pin adapter below the cable head was replaced after troubleshooting revealed that it was the source of the tool trouble. The two caliper modules were removed from the tool, and it was started back down the pipe.

No obstruction was encountered in the pipe, but the tool stopped 
in the hole just a few meters below the end of the pipe. The sonde was worked past about 20 meters of tight hole and two other obstructions before it encountered a solid bridge at about $2900 \mathrm{~m}$ (288 m BSF). A log of good quality was then recorded, but the homogeneity of the sediment and the shortness of the open hole interval indicated that a second $\log$ would have been of little value.

The logging equipment was then rigged down and the drill string was recovered. The ship was under way for site 621 at 1400 hours, October 26.

\section{Site 621 - Middle Mississippi Fan}

Site 621 was located only eight miles southwest of Site 620, at the positioning beacon that had been placed on October 17, concurrent with the Site 617 beacon. Two passes over the site coordinates were required to lock onto the acoustic signal. The beacon signal strength was found to be only about ten percent of normal, but the pulse characteristics were good and quite satisfactory for positioning.

The hole was spudded at 2316 hours, October 26, with a piston core that stroked to $2488.5 \mathrm{~m}$. Core recovery was 3.5 meters, making the water depth $2485.0 \mathrm{~m}$. VLHPC coring operations continued in clay and mud, which became sandy below $135 \mathrm{~m}$ BSF. The amount of sand increased with depth, with loose sand strata beginning around 200 meters. Zones of coarse gravel were also cored and recovered with the sand. Not unexpectedly, hole trouble began almost immediately with torque and bottom fill. As there was little chance of reaching the projected 250 meter target, coring was terminated to obtain well logs before serious difficulties could begin.

The first logging run was with the LSS/CAL/GR tool. The induction sonde, normally run in this tool configuration, was omitted to place the gamma ray module at the bottom of the tool string. As usual, bridges and ledges in the washed-out hole impeded the logging tool's progress, but it was eventually worked down to just a few meters short of total depth. A good quality log was recorded and the cable was recovered to change logging sondes. The second run was made with the FDC/CNP/GR tool. This time more trouble was encountered in getting down the hole. It was necessary to "spud" the tool to break through a bridge, and the cable was damaged at the cable head. The damaged conductors eliminated the neutron and gamma ray curves completely. The formation density trace was later found to be out of calibration and useless. The logging equipment was then rigged down and the pipe was pulled. GLOMAR CHALLENGER departed the site for a short move at 0115 hours, October 29. 
The next desired drill site was located just across the submarine channel from Site 621. The proximity of the Sites 617 and 621 beacons (both frequencies) was a matter of concern. The rig was therefore moved to the proposed location and allowed to drift in a "listening" mode. Both beacon signals were detected easily, and it was decided that the risk of interference with a new beacon was too great to attempt operations. An alternate site was selected at an analogous position on the next bend in the channel. This opened the range from the Site 621 beacon sufficiently that a new $13.5 \mathrm{kHz}$ beacon could be launched at 0445 hours. Difficulty was again experienced in finding an acceptable positioning "combination" due to strong current and wind forces at high angles, and the pipe trip did not begin until 0630 hours.

The initial piston core established the water depth at $2495.0 \mathrm{~m}$. A considerable sea had built during prolonged windy conditions, and the resultant vessel motion had an adverse affect on coring operations. Coring progressed through a sediment section similar to that of Site 621, but penetration and core recovery were both decreased from the previous site. Partial failure of the corer's shear pins, due to surge during descent, resulted in reduced actuation pressures (therefore less penetration). There were also indications that more core was being lost during retrieval than in calm weather operations. Sandy strata first appeared at about $95 \mathrm{~m} \mathrm{BSF}$ and increased downhole, but the gravel and coarse sand of Hole 621 were not encountered. Penetration was terminated at $2703 \mathrm{~m}$ pipe depth with objectives achieved and the depth limit reached.

A log was again desired to "fill in" portions of the section lost to low core recovery. Preparations were made and the LSS/GR/CAL tool configuration used in the first Hole $621 \mathrm{log}$ was deployed. Some hole obstructions were hit in the lower 40 meters of the hole, but the sonde was lowered to just three meters off total depth without undue difficulty. A good log was recorded and the tool was pulled into the pipe with no problem. The tool was then run back to bottom for a repeat run. As the upper caliper module was pulled into the bit the second time, it became firmly stuck and the tool could not be moved up or down. The tool was finally freed after cable pull had been increased to dangerously near the cable head weak point failure tension. When the sonde assembly had been recovered, one caliper leaf spring was found to be broken off and missing.

The logging equipment was then rigged down and the bit was pulled clear of the seafloor.

Hole 622A

As the first few meters of sediment were again of great interest

to the paleontologists, a repeat of the "mudline" core was 
requested. The vessel was offset 30 meters to the southsoutheast and the power sub and VLHPC were redeployed. The corer was "shot" from $2491.5 \mathrm{~m}$ to $2501.0 \mathrm{~m}$ and a $5.6 \mathrm{~m}$ core of excellent quality was recovered. The drill string was then recovered, and the vessel headed south at 0734 hours, October 31 .

Site 622 to Site 623

With most of the middle fan objectives accomplished, scientific priorities again shifted to the lower fan area. The area of prospectus Site MF-9, an alternate site bypassed earlier, was chosen as the best location to spend the voyage's remaining site time. The transit of 164 miles to the east-southeast of Site 622 was slowed by choppy seas and adverse currents, with an average speed of only 7.9 knots made good. On arrival in the area, a 3$1 / 2$ hour preliminary survey was made to pinpoint the two planned drill sites. A positioning beacon was let go at 0434 hours, November 1 .

\section{Site 623 - Lower Mississippi Fan}

After a routine pipe trip, the initial spud attempt was unsuccessful and resulted in a "water core". The second VLHPC core found the seafloor at $3198.0 \mathrm{~m}$, eleven meters below PDR depth. Clay and silty mud were cored to about $150 \mathrm{~m} \mathrm{BSF}$, with beds of sand appearing at about $45 \mathrm{~m}$ and becoming thicker and more numerous with depth. Incomplete VLHPC strokes began at about 55 $\mathrm{m}$. Below $150 \mathrm{~m}$, corer penetration and recovery dropped to very small amounts in apparent silt and fine sand. Cores were attempted with little success after drilled intervals of about ten meters to total depth at $3390.2 \mathrm{~m}$ pipe depth.

Again the inability to recover core made logs the only real source of information about the lower portion of the penetrated section. After the usual preparations, the LSS/GR/CAL sonde was again run for a single log attempt. In this case the tool met no obstruction until it came to rest on apparent solid fill at 3371 m. A good log was recorded and, when the tool was lowered for a repeat log, an additional six meters of fill had accumulated. Following the logging operation, the drill string was pulled for the move to nearby site 624.

Hole 624 - Lower Mississippi Fan

The final drill site of the Deep Sea Drilling Project was located only three miles southwest of site 623, and the rig was moved in just 27 minutes. This was about half the time required for the beacon to fall to the seafloor and stable positioning to be achieved.

The PDR depth was found to be even further in error than at Site 
623, and a "water core" was again taken before the seafloor was found at $3199.2 \mathrm{~m}$, thirteen meters below PDR.

Incomplete VLHPC stroke was achieved below about $65 \mathrm{~m}$ BSF. Clay and mud with silt laminae were cored, with sand beds beginning at about $45 \mathrm{~m}$ and becoming thicker and more numerous with depth. Core recovery was very low below $110 \mathrm{~m}$ BSF due to incomplete VLHPC penetration and loss of core from the barrel resulting from vessel motion in choppy seas and sticky core which tended to hold the core catchers open. Recovery was almost nonexistent below $170 \mathrm{~m}$, and at $190 \mathrm{~m}$ it was decided that the XCB system was the only hope for recovering the incompressible but uncemented sands. The XCB was reassembled and deployed, and one core was cut. When the sand line was run to retrieve the XCB, however, it was found to be stuck in place in the outer core barrel. Two retrieval attempts resulted only in failed overshot shear pins, and it became apparent that a pipe trip would be necessary to recover the corer. This precluded the planned logging operations for the hole. On recovery of the BHA, it was found that the XCB could not be recovered because the latch dogs had become slightly deformed at the top and could no longer be retracted sufficiently to clear the latch sleeve. The outer core barrel was dismantled, and the inner core barrel was recovered containing only a large handful of sand.

\section{Hole 624A}

The BHA was immediately reassembled and run back to the seafloor to spud Hole 624A at 0210 hours, November 5. The second hole at the site was cored for geotechnical purposes. Core recovery and (apparently) VLHPC penetration were significantly better than in Hole 624. This was attributed primarily to calm weather conditions. Satisfactory representative cores were recovered to about $170 \mathrm{~m} \mathrm{BSF}$. Cores attempted below this depth did not penetrate well and recovered only traces of sand. Following recovery of the final core from $197 \mathrm{~m}$ BSF, the hole was drilled to $3305.6 \mathrm{~m}$ pipe depth to provide "rathole" for logging.

The pipe was pulled to logging depth, and two runs were made for a full suite of well logs. The first run (LSS/DIT/CAL/GR) found bridges in the hole at $174 \mathrm{~m}$, but the tool was "worked" to $193 \mathrm{~m}$ to log the lower sand unit. The second log run, with the FDC/CNP/GR tool, was stopped ten meters shallower. This again indicated a high rate of progressive hole fill, but good logs were recorded and operations ended on a successful note.

As the logging equipment was being rigged down, the ship's inventory of explosives (primacord severing charges and fuses) was dropped and circulated down the pipe for disposal in the borehole. The drill string was then recovered for the final time. As the BHA was being broken down, it was discovered that the severing charges had somehow become lodged in the lowermost joint of 5-1/2" drill pipe. All but one of the charges were 
removed and jettisoned, but one remained firmly stuck in the pipe. To avoid the hazards involved in further removal efforts, the pipe joint was released through the mouse hole.

After a final check to insure that the BHA was clear of obstructions, the rig lights were turned off and GLOMAR CHALLENGER departed for Mobile, Alabama and demobilization.

\section{Site 624 to Mobile}

The transit to Mobile was uneventful except for passage through heavy rain showers and rough seas on November 7 . The harbor pilot boarded the vessel at the Mobile Bay seabuoy at 0500 hours, November 8. Leg 96 came to its official end at 0952 hours, with the first mooring line over to Berth $J$ of the Alabama Drydock and Shipbuilding Company yard.

\section{Drilling and Coring Equipment}

The various coring systems used on Leg 96 required different outer core barrel configurations; therefore several variations of the bottom hole assembly were used. Because the soft sediment required little bit weight for drilling and because adverse hole conditions were expected, fewer drill collars than normal were incorporated in the BHA. The BHA used on most of the holes consisted of the bit and outer core barrel assembly, three $8-1 / 4$ inch drill collars, two Baash-Ross five foot-stroke bumper subs, two 8-1/4 inch drill collars, crossover sub, one 7-1/4 inch drill collar and two joints of 5-1/2 inch range three drill pipe. An extra stand of three 8-1/4 inch drill collars was run below the bumper subs in Holes $614 \mathrm{~A}$ and 616 . All holes at Sites 614,615 and 616 and Hole 617 were drilled with an OCB equipped with spacer and adapter subs for compatibility with the APC and XCB coring assemblies. Sites $618,619,621,622,623$ and 624 were cored with the VLHPC system, and the BHA was configured for VLHPC/XCB compatibility. Hole 620, a scheduled deep penetration, was the only hole drilled with the standard DSDP rotary coring setup. This BHA was also somewhat abbreviated due to low bit weight requirements. It consisted of: bit, mechanical bit release, one 8-1/4 inch drill collar, top sub, head sub, four 8$1 / 4$ inch drill collars, two bumper subs, two 8-1/4 inch drill collars, crossover sub, one 7-1/4 inch drill collar and two joints of range three 5-1/2 inch drill pipe.

Few problems were experienced with drilling and coring equipment. The very first hole was aborted when the failure of a locking device permitted the wireline swivel to unscrew internally, leaving the lower portion of the swivel at the bottom of the pipe with the APC and the sinker bar assembly. Most of an APC inner core barrel assembly was lost at Hole 618 on a seafloor core attempt. The VLHPC had apparently arrived at the bit in the 
stroked-out condition while the bit was positioned above the seafloor. Pipe swing during the attempt to actuate the corer apparently broke off the barrel, which had been imbedded in the sediment. BHA losses occurred at Holes 616 and $617 \mathrm{~A}$, but in neither case was any equipment at fault.

\section{Core Bits}

The new style 11-3/4 inch HPC/XCB core bits were used in all holes except 620. The shallow penetrations in soft sediment placed little demand on the bits and no failures occurred. The new F93CK rotary coring bit used in Hole 620 was released for logging after only 2-1/2 rotating hours.

Special Tools

The vast majority of the cores collected were hydraulic piston cores. Both the advanced piston corer (APC) and the variablelength hydraulic piston corer (VLHPC) were used extensively. The improved design of the APC offers advantages of lighter weight, shorter handling length, fewer parts, greater stroking power and increased tensile strength for overpull on withdrawal from sediment. These features qualify it to render the VLHPC obsolete. Negative features that require further attention are the problem of shear pin stubs which fall down around the rod (interfering with redressing the tool) and the outer seal design. Excessive drag of the outer seals results in increased wireline trip time and the necessity to lay out the corer for frequent seal replacements. The APC also requires a special seal bore drill collar as an outer core barrel. Two of these were aboard at the beginning of the voyage, but both were lost in the BHA casualties. This necessitated a switch to the VLHPC for the remainder of the cruise. The VLHPC, a proven system, performed well and dependably, salvaging the coring objectives of the leg. The extra "punch" of the APC was demonstrated early on and was missed on the later VLHPC holes. The nature of the sediment at all VLHPC sites was such that withdrawal overpull limits were not reached due to limited penetration. Penetration and recovery of sands with the HPC systems were much better than anticipated at some sites, but very limited at others. Thick beds of coarse sands and even gravels were recovered, but fine sand and silt beds seemed to repel the cutter shoe. The combination of a flapper core catcher and a standard soft formation core catcher with a sailcloth "sock" was effective in retaining loose cored material.

The extended core barrel system was used in four holes at the first three sites with a total cored interval of 456.4 meters. Total core recovery was just $20 \%$ with the XCB, and there was often no core in the barrel at all. In addition the rotating core barrel often produced "drilling biscuits" and other types of core disturbance in the soft clay and mud sediments. Although good results have been achieved with the XCB on earlier voyages, 
the performance on Leg 96 was disappointing and further deployment was foregone in favor of incomplete HPC cores. As the spacing of the VLHPC/XCB-compatible outer core barrel assembly was being checked at Site 618, it was found that the XCB latch could be forced past the latch sleeve with relatively little resistance. Unlatching of the corer could explain much of the difficulty experienced.

The XCB was reassembled to attempt to recover the deeper sand/clay sequence in Hole 624. Light bit weight was applied to prevent forcing the latch dogs past the sleeve. It is certain that the barrel was not forced out of place as the assembly could not be pulled loose after the first core was cut and a pipe trip was necessary. On inspection it was found that the dogs had become deformed at the top by contact with the sleeve during the coring operation. They could not be retracted far enough to clear the I.D. of the latch sleeve.

The newly-developed gyro orientation tool was deployed once--at Hole 616A. Unfortunately the gyroscope was irreparably damaged when the pressure case leaked. The electrical wiring at the top of the tool was also damaged as the final pressure case connection was made up. Both of the failures suffered could be prevented in the future by an improvement in the design of the mechanical/electrical pressure case connection. A connection similar to those used on well logging tools would be a reasonable choice. Though no usable data have been produced by this system, the concept appears to be viable and it should eventually produce results far superior to the present photographic single-shot system.

The core barrel pressure instrumentation package (CBIP) was run once in Hole 620. Two deployments during rotary coring operations had been requested by the DSDP Development Engineering Group. Electronic malfunctions delayed the first run and resulted in unusable data. Troubleshooting was in progress when operations were terminated due to hole conditions. No other rotary coring was done, so no further runs were made. Improvements to the electronics are still needed. Problems also were encountered with galled threads on the stainless steel pressure case/core barrel adapters.

\section{Positioning Beacons}

Leg 96 was off to a shaky start when four of the first five acoustic beacons that were unboxed were found to have defects. As there was not a sufficient number of beacons remaining for the proposed sites of the voyage, an operational emergency resulted. A crewboat was sent out from Morgan City, Louisiana on October 7 , to transfer five beacons ashore for shipment to ORE in Massachusetts where they were refurbished. Two of the units remaining on board had failed to start when they were switched on, two had produced unacceptably short pulses on "soak" testing and the 
fifth beacon was operational but had a loose electronics chassis inside the pressure case. All five were returned to the vessel by boat at the scientific crew change on October 18. Three of them were used for positioning on later sites with no problem. The other two were not launched. Two $13.5 \mathrm{kHz}$ beacons (Nos. 177 and 178) developed unacceptable pulse characteristics and weak signals shortly after launch and could not be used for positioning. The signal of $16.0 \mathrm{kHz}$ unit No. $109 \mathrm{~A}$ had acceptable characteristics, but was never strong enough to use and the beacon was replaced by a $13.5 \mathrm{kHz}$ backup. The signal strength of $13.5 \mathrm{kHz}$ beacon No. 179 had decreased to about ten percent of normal on the ship's return to Site 621 nine days after the beacon was launched. The unit was a double-life model and should have been at full strength after that interval.

Dynamic Positioning

The vessel's positioning system performed dependably for the entire voyage and was not, in itself, responsible for any positioning problems. The excursions and stationkeeping problems experienced were the result of current and wind forces that overtaxed the power available to maintain heading and position and were in no way the fault of the DPS. On October 20 a short circuit in the cutput side of the $400 \mathrm{~Hz}$ power supply for the vertical reference unit caused the power supply to catch fire, damaging it beyond repair. The system was forced to operate temporarily without benefit of the reference gyro while a backup unit was connected, but positioning remained within operating limits.

\section{$\underline{\text { Logging }}$}

Nine successful well logging runs were made at seven sites. Logging was particularly useful on Leg 96 because the sand/clay/silt sequences were presented with good contrast on the logs and because core recovery was highly selective in favor of the clay. The difficulty in penetrating and retaining the loose sand would certainly have resulted in misinterpretation of the relative amount of sand and of the nature of the sedimentary sequences had the logs not been available to compliment the core observations.

The holes were all in poor condition, but in most cases the tool was manipulated to a depth sufficient to log the zones of major interest. At Hole 615 the tool became stuck in the hole just below the pipe after a good log had been recorded, and it was necessary to pull nearly to weak point failure before the tool was dislodged. The caliper assembly fouled on entry to the bit following the logging of Hole 622. It was again necessary to pull dangerously hard before a caliper leaf spring broke and freed the tool. The first log attempt at Hole 620 was stopped by a sediment ball that apparently had been pushed about $400 \mathrm{~m}$ up the pipe by formation back pressure following release of the bit. 
The second run in Hole 621 failed when the cable was damaged. It was necessary to "spud" the sonde to get it past bridges/ledges in the hole and although it eventually traveled nearly to total depth, no useful data were recorded. False starts and relatively minor delays were attributable to problems in a Mohole winch cable connection, a 10/31 pin adapter below the cable head and a special spectral gamma ray module. Altogether the logging efforts were highly successful and problems were minimal considering the nature of the operations.

\section{Hydrocarbons}

One of the major operational concerns of Leg 96 was the expectation of shallow gas in considerable amounts and the possibility of migrated hydrocarbons from deeper structures in the thick Gulf of Mexico sediments. For this reason, penetration at most of the drill sites was limited to 200-250 meters. It was unexpectedly found that gas was almost absent from the sediments cored in all the middle and lower Mississippi Fan sites. Only at Sites 618 and 619 (Orca and Pigmy Basins, respectively) was there sufficient gas in the core liners to sample. As expected, the shallow sediments at Site 618 were quite gassy and some gas hydrates were recovered, but the amount of gas decreased with depth. Only a relatively small amount of gas was found in the cores at Site 619 , and this also decreased with depth. The scarcity of gas may have been a disappointment to the organic geochemists, but it was considered an operational blessing.

\section{Weather and Currents}

Adverse weather and current conditions had not been anticipated to be an operational factor, with the possible exception of a late-season tropical cyclone. No tropical storms ever threatened, but the expedition found the Gulf to be a veritable whirlpool of strong currents. Current was an important operational factor at all sites except 619 (Pigmy Basin), 623 and 624. In addition to causing the BHA loss and abandonment of site 617, currents interacted with light to moderate winds to keep vessel positioning marginal for much of the voyage and to cause occasional excursions and delays. Drill pipe stress and fatigue were also of considerable concern because of strong lateral displacement and severe vibration. Current direction and velocity were unrelated to anything predicted by pilot charts or any other means, with velocities in excess of two knots. At Site 614 the current, aligned with a 15 knot wind, pushed the vessel off station and it was necessary to use four engines at full power ( 150 shaft RPM) to regain position. This is normally sufficient to move the vessel at six knots.

Weather conditions were generally quite good. Without the complication of currents, winds were strong enough to affect positioning on only one or two brief occasions in line squalls. 
Radic communications were routine, with both incoming and outgoing traffic handled daily with SIO station WWD by CW transmission. The Radio officer also completed several radiotelephone calls through U.S. commercial radio stations for various members of the shipboard party for scientific, operational and personal reasons. The ship's surgeon (and principal amateur radio operator) assisted with numerous personal "ham" telephone patches to locations throughout the United States.

\section{Small Boat Transfers}

On three occasions oilfield "crewboat" supply vessels ventured to near maximum range from home base to rendezvous with CHALLENGER on location. M/V CANDY MOUNTAIN from near Morgan City, Louisiana made the first stop on October 7 to transport defective positioning beacons to shore for shipment to the vendor. On October 19, $M / V$ SHIRLEY arrived for a crew change of six of the scientific staff and to return the repaired beacons. A third transfer was scheduled for October 29, when CANDY MOUNTAIN returned to transport a spare AC generator for shipment to another Global Marine rig. sea conditions (the worst day of the voyage) made the transfer too hazardous, however, and the operation was cancelled.

Except for the solution of the "beacon crisis", these rendezvous had little effect on operations. CANDY MOUNTAIN arrived low on fuel for the first transfer; it was necessary to improvise a fueling arrangement and to pump sufficient diesel oil from CHALLENGER'S tanks to enable the crewboat to reach port.

\section{Personnel}

Justice cannot be done to the subject in this final paragraph of the final report. The pride and dedication of the Global Marine Drilling Corporation officers and crew is exemplified by CHALLENGER'S arrival in port freshly scrubbed and painted after just one day's transit from the final drill site--despite the fact that she was bound for demobilization and probable layup. Closer inspection would reveal that, after 15 years of continuous and arduous service, she is in superior material condition to most vessels and rigs half her age. The DSDP technical staff handled the cores, samples, and reports of 11 sites and 20 holes in less than 40 days at sea without signs of slacking or "shorttimers' attitude". The multinational company of scientists worked harmoniously and maintained a positive attitude in the face of temporary setbacks. This was an important factor in enabling the prime and subcontractor's staffs to support the accomplishment of virtually all the scientific objectives of the voyage. The professionalism of all on board is testimony to their recognition that they have played a vital role in an important event that is unique in history. The Deep Sea Drilling Project 
may be continued in some form--but it can never be repeated.

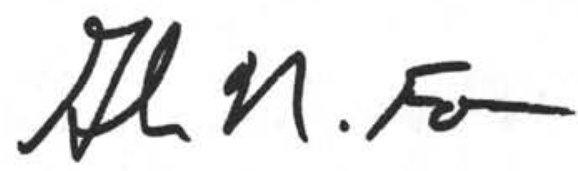

Glen N. Foss

Cruise Operations Manager

Deep Sea Drilling Project 


\section{INTERNATIONAL PHASE OF OCEAN DRILLING DEEP SEA DRILLING PROJECT \\ OPERATIONS RESUME \\ LEG 96}

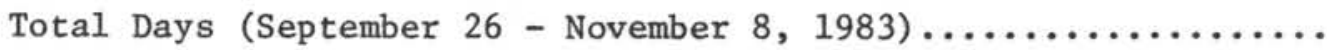

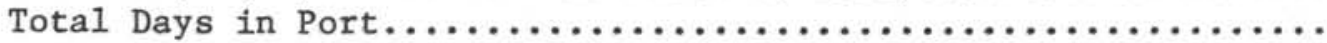

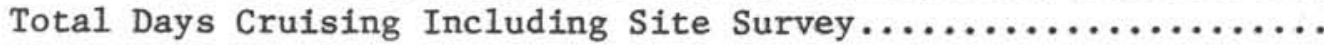

\begin{tabular}{|c|c|}
\hline Drilling Time... & \\
\hline Coring Time.......... & \\
\hline Downhole Measurement....... & \\
\hline Pipe/Hole Trouble.... & \\
\hline n Weather........... & \\
\hline ical Downtime....... & 0. \\
\hline 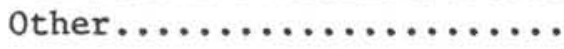 & \\
\hline
\end{tabular}

Total Distance Traveled Including Survey (nautical miles).....

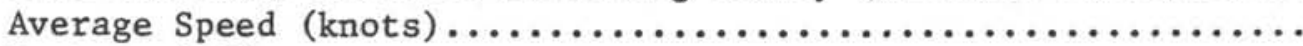

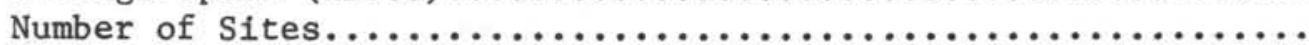

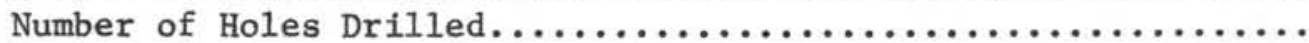

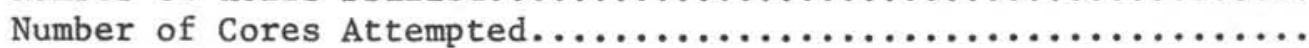

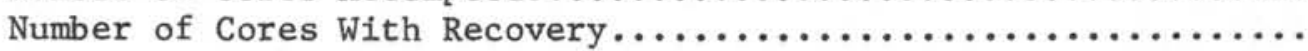

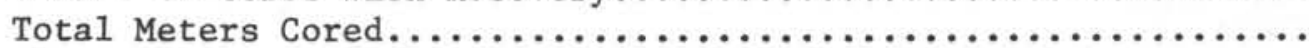

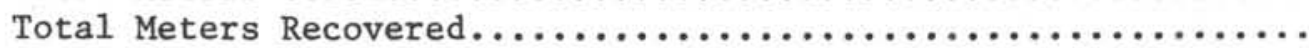

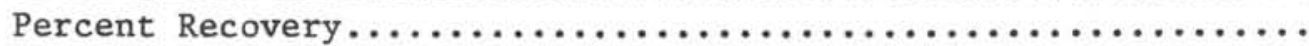

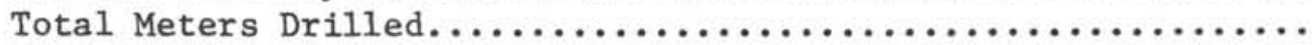

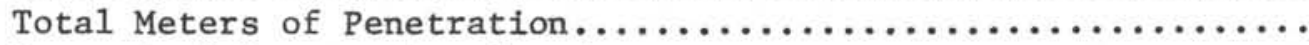

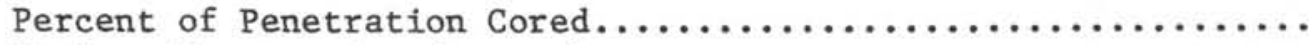

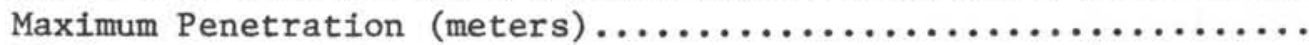

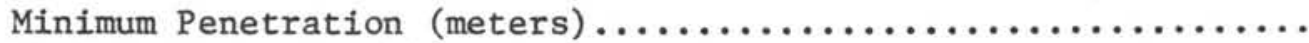

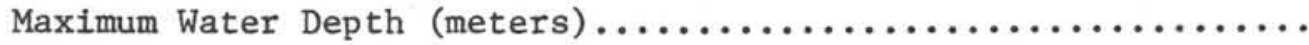
Minimum Water Depth (meters).

1546.8

8.8 


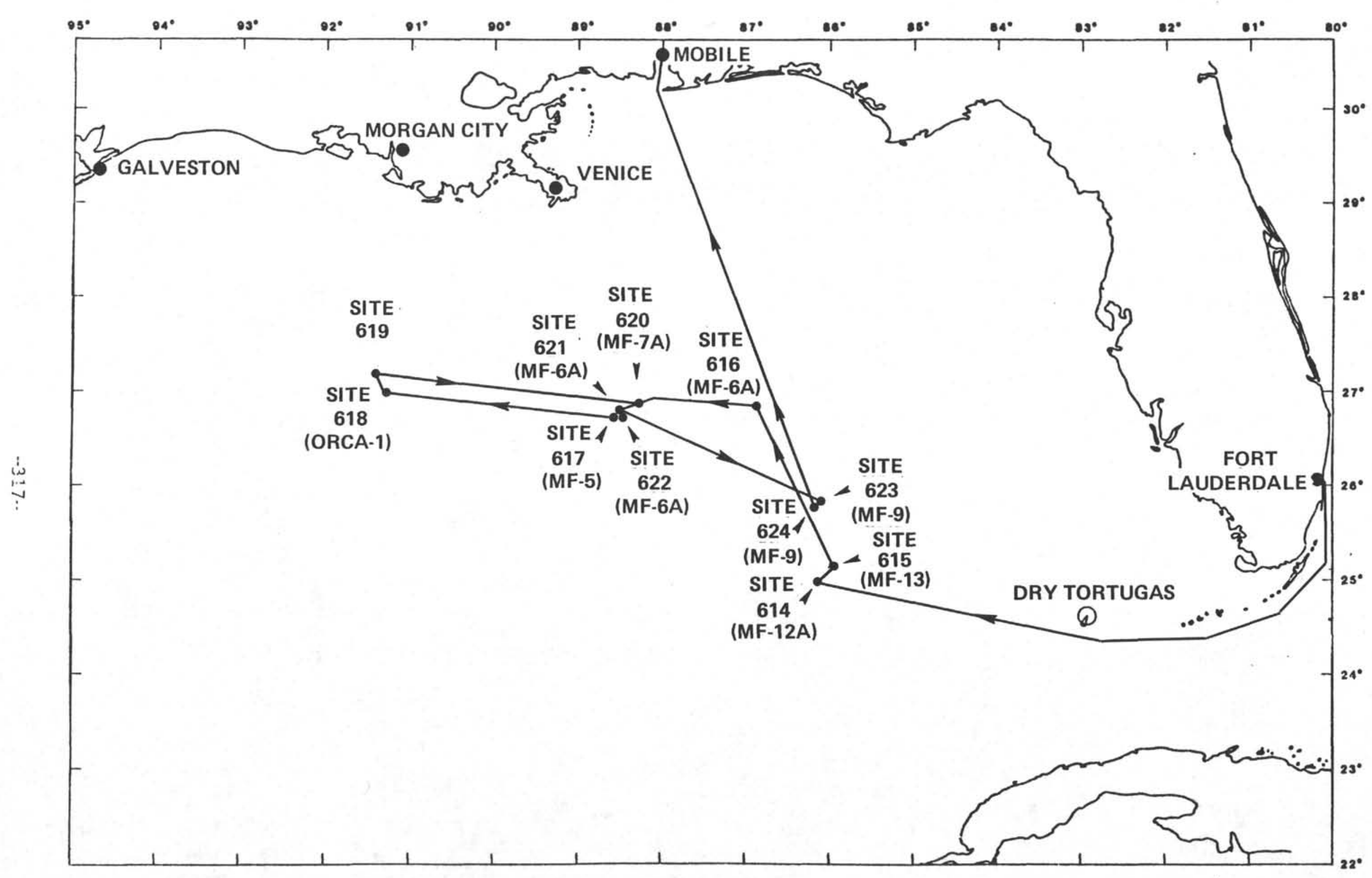

LEG 96 OPERATING AREA 

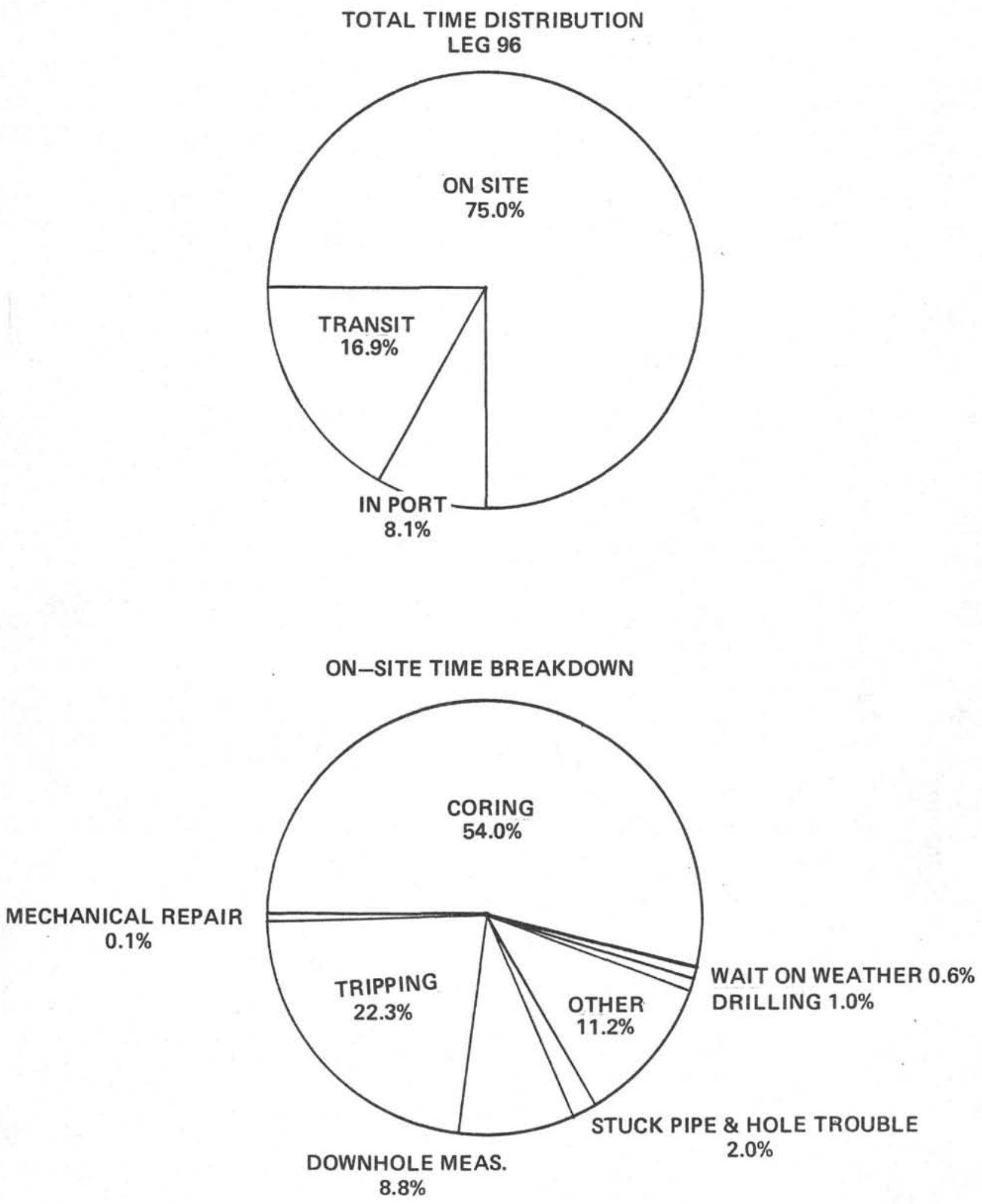


\section{DEEP SEA DRILLING PROJECT}

TIME DISTRIBUTION

$\angle E G-96$

\begin{tabular}{|c|c|c|c|c|c|c|c|c|c|c|c|c|c|c|}
\hline Daite & \begin{tabular}{|c|} 
Site \\
No.
\end{tabular} & cruise & Trips & Drill & Core & $\begin{array}{l}\text { Stuck } \\
\text { Pipe }\end{array}$ & W.0.1r. & $\begin{array}{l}\text { POWNHOLE } \\
\text { MEAS. }\end{array}$ & $\begin{array}{l}\text { Mech. } \\
\text { Pepair }\end{array}$ & $\begin{array}{l}\text { Port } \\
\text { Time }\end{array}$ & $\begin{array}{c}\text { Re- } \\
\text { Entry }\end{array}$ & other & $\begin{array}{l}\text { Totial } \\
\text { Time }\end{array}$ & Remarks \\
\hline \begin{tabular}{|l|}
$09 / 26 / 83$ \\
$10 / 01 / 83$ \\
\end{tabular} & & 44.1 & & & & & & & & 83.3 & & .0 .3 & 127.7 & $\begin{array}{l}\text { FE. Lauderda } \\
\text { to Site } 614\end{array}$ \\
\hline $\begin{array}{l}10 / 01 / 83 \\
10 / 02 / 83 \\
\end{array}$ & 614 & & 12.9 & & 7.8 & & 1.0 & & & & & 5.8 & 27.5 & Hole 614 \\
\hline $\begin{array}{l}10 / 04 / 83 \\
\end{array}$ & $614 \mathrm{~A}$. & & 13.1 & 0.7 & 17.8 & & & & 0.5 & & & 0.6 & 32.7 & Hole $614 \mathrm{~A}$ \\
\hline $10 / 04 / 83$ & & 4.9 & & & & & & & & & & & 4.9 & 614 to 615 \\
\hline $\begin{array}{l}10 / 04 / 83 \\
10 / 09 / 83 \\
\end{array}$ & 615 & & 8.8 & 1.3 & 74.2 & 4.0 & & 21.3 & & & & 15.6 & 125.2 & Hole 615 \\
\hline $\begin{array}{l}10 / 09 / 83 \\
10 / 10 / 83 \\
\end{array}$ & 615 & & 7.2 & 2.0 & 23.0 & & & & & & & 0.6 & 32.8 & Hole $615 \mathrm{~A}$ \\
\hline $\begin{array}{l}10 / 11 / 83 \\
\end{array}$ & & 11.2 & & & & & & & & & & & 11.2 & 615 to 616 \\
\hline $10 / 14 / 83$ & 616 & & 10.4 & 1.5 & 40.7 & 9.8 & & 4.0 & & & & 7.3 & 73.7 & Hole 616 \\
\hline $\begin{array}{l}10 / 15 / 83 \\
10 / 1\end{array}$ & $616 \mathrm{~A}$ & & 7.4 & 1.6 & 4.3 & 0.6 & & & & & . & 8.0 & 21.9 & Hole $616 \mathrm{~A}$ \\
\hline $\begin{array}{l}10 / 16 / 83 \\
\end{array}$ & 616 B & & 5.3 & & 24.2 & 1.2 & & & & & & 0.7 & 31.4 & Hole $616 \mathrm{~B}$ \\
\hline $\begin{array}{l}10 / 16 / 83 \\
10 / 17 / 83\end{array}$ & & 15.3 & - & & & & & & & & & & 15.3 & 616 to 617 \\
\hline $\begin{array}{l}10 / 18 / 83 \\
10 / 18\end{array}$ & 617 & & 6.0 & & 20.9 & & 1.6 & & & & & 1.9 & 30.4 & Hole 617 \\
\hline $10 / 19 / 83$ & $617 A$ & & 6.3 & & 6.3 & & 1.1 & & & & & 3.7 & 17.4 & Hole $617 \mathrm{~A}$ \\
\hline $10 / 19 / 8$ & & 16.0 & & & & & & & & & & & 16.0 & 617 to 618 \\
\hline $\begin{array}{l}10 / 19 / 83 \\
10 / 21 / 8 \\
\end{array}$ & 618 & & 7.6 & & 11.4 & & 0.5 & & & & & 8.2 & 27.7 & Hole 618 \\
\hline $10 / 21 / 8$ & $618 \mathrm{~A}$ & - & 5.1 & 0.1 & 2.4 & & & & & & & 3.0 & 10.6 & Hole $618 \mathrm{~A}$ \\
\hline $10 / 21 / 83$ & & 1.8 & & & & & & & & & & & 1.8 & 618 to 619 \\
\hline $\begin{array}{l}0 / 21 / 83 \\
10 / 22 / 83\end{array}$ & 619 & & 6.0 & 0.1 & 23.6 & & & & & & & 1.9 & 31.6 & Hole 619 \\
\hline $\begin{array}{l}10 / 22 / 83 \\
10 / 23 / 83 \\
\end{array}$ & $619 \mathrm{~A}$ & & 5.8 & & 0.6 & & . & & & & & 0.3 & 6.7 & Hole 619A \\
\hline $10 / 23 / 83$ & & 16.4 & & & & & & & & & & & 16.4 & 619 to 620 \\
\hline
\end{tabular}




\section{DEEP SEA DRILLING PROJECT \\ TIME DISTRIBUTION \\ $\angle E G-96$ (Continued)}

\begin{tabular}{|c|c|c|c|c|c|c|c|c|c|c|c|c|c|c|}
\hline Daite & $\begin{array}{l}\text { Site } \\
\text { No. }\end{array}$ & Cruise & Trips & Drill & Core & $\begin{array}{l}\text { Stuck } \\
\text { Ploe }\end{array}$ & W.0.85 & $\begin{array}{l}\text { POWNHOLE } \\
\text { MEAS, }\end{array}$ & $\begin{array}{l}\text { Mech. } \\
\text { Peparr }\end{array}$ & $\begin{array}{l}\text { Port } \\
\text { Time }\end{array}$ & $\begin{array}{l}\text { Pe- } \\
\text { Entry }\end{array}$ & Orher & $\begin{array}{l}\text { Total } \\
\text { Time }\end{array}$ & Remarks \\
\hline $\begin{array}{l}10 / 23 / 83 \\
10 / 26 / 83 \\
\end{array}$ & 620 & . & 11.2 & $\therefore$ & $37: 3$ & & & 10.6 & & 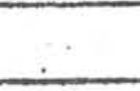 & & .6 .2 & 65.3 & Hole 620 \\
\hline $10 / 26 / 83$ & & 2.1 & & & & 1. & & 1 & & & & - & 2.1 & 620 to 621 \\
\hline $\begin{array}{l}10 / 26 / 83 \\
10 / 29 / 83 \\
\end{array}$ & 621 & & 10.7 & & 32.1 & & & 10.3 & & & & 4.1 & 57.2 & Hole 621 \\
\hline $10 / 29 / 83$ & & 3.5 & & & & & & & -2 & & & & 3.5 & 621 to 622 \\
\hline $10 / 29 / 83$ & 622 & & 6.4 & 0.3 & 25.7 & - & & 5.9 & & & & 4.6 & 42.9 & Hole 622 \\
\hline $\begin{array}{l}10 / 29 / 83 \\
10 / 31 / 83 \\
\end{array}$ & $622 \mathrm{~A}$ & & 6.9 & . & 0.7 & . & & & & & & 0.3 & 7.9 & Hole $622 \mathrm{~A}$ \\
\hline $\begin{array}{l}10 / 31 / 83 \\
11 / 01 / 83\end{array}$ & & 22.7 & & & & & & ! & & & & & 22.7 & 622 to 623 \\
\hline $\begin{array}{l}11 / 01 / 83 \\
11 / 03 / 83 \\
\end{array}$ & 623 & & 12.9 & & 23.2 & & & 6.5 & & & & 3.5 & 46.1 & Hole 623 \\
\hline $11 / 03 / 83$ & & 0.5 & & & & & & 1 & & & - & - & 0.5 & 623 to 624 \\
\hline $\begin{array}{l}11 / 03 / 83 \\
11 / 04 / 83\end{array}$ & 624 & & 11.3 & 0.2 & 20.4 & & & ! & & & & 7.4 & 39.3 & Hole 624 \\
\hline $\begin{array}{l}11 / 04 / 83 \\
11 / 06 / 83 \\
\end{array}$ & $624 \mathrm{~A}$ & & - 12.3 & 0.1 & 23:1 & & & 9.9 & & & & 2.9 & 48.3 & Hole $624 \mathrm{~A}$ \\
\hline $\begin{array}{l}11 / 06 / 83 \\
11 / 08 / 83\end{array}$ & & 36.4 & & {$[+$} & & & & : & & & & & 36.4 & \begin{tabular}{|l|}
624 to \\
Mobile \\
\end{tabular} \\
\hline TOTALS & & 174.9 & 173.6 & 7.9 & 419.7 & 15.6 & 4.2 & 68.5 & 0.5 & 83.3 & & 86.9 & 035.1 & TOTALS \\
\hline & & & & & & . & & & & & & . & . & \\
\hline & & . & & & & & & & & & & & & \\
\hline & & $\cdot$ & & & & & & & & & & & & . \\
\hline & & & & & & & & & & & & & & \\
\hline & & & & & & & & & & & & & $\because$ & \\
\hline & & & & & & & & & & & & & & \\
\hline
\end{tabular}


INIERNATIONAL PIASE OF OCEAN IRIIING

DEFP SRA DRILLING PROACT

SITE SUMAIARY

LEG 96

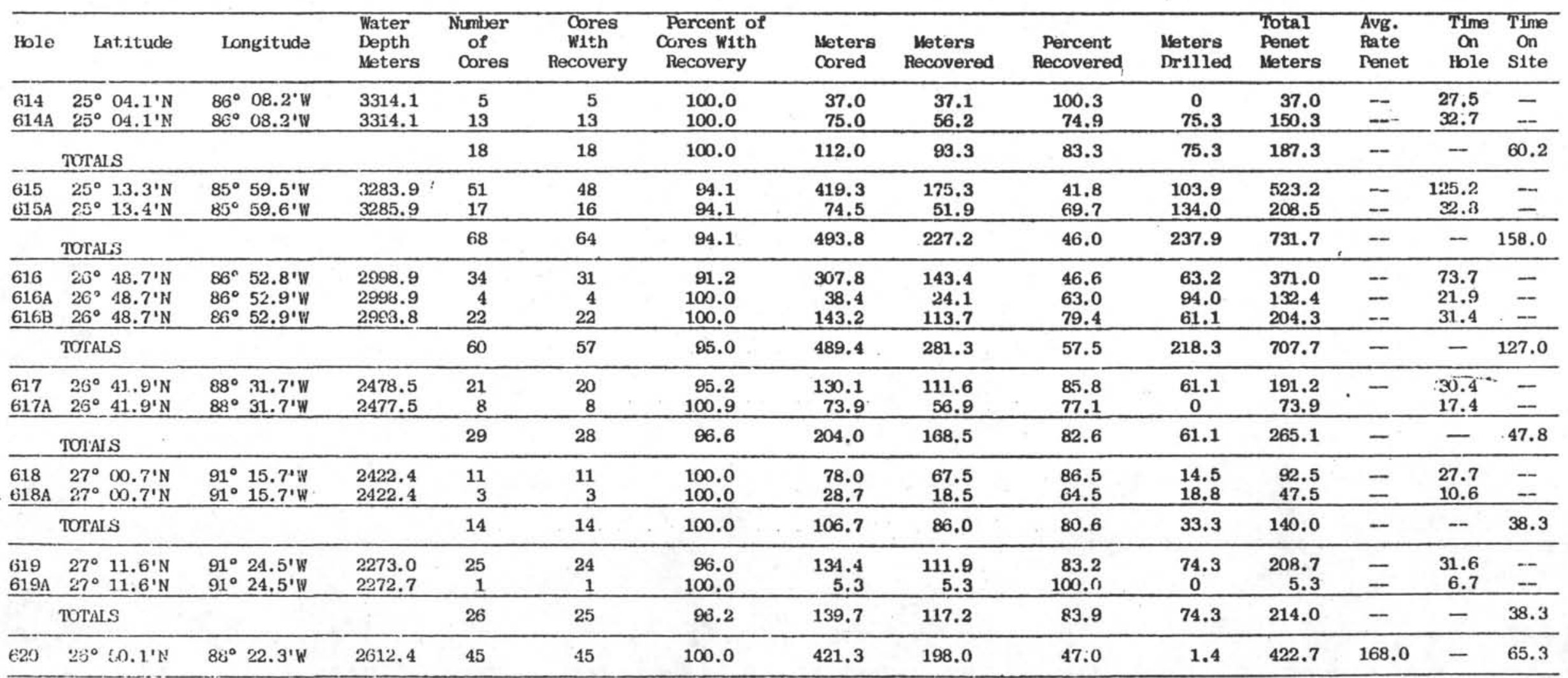


INIERNATIONAL PHASE OF OCBAN DAIULING

LEFEP SEA DRILLING PROJECT

SITE SUMMARY

$$
\text { LDG } 96
$$

(Cont Inued)

\begin{tabular}{|c|c|c|c|c|c|c|c|c|c|c|c|c|c|c|}
\hline Hole & Latitude & Longitude & $\begin{array}{l}\text { Water } \\
\text { Depth } \\
\text { Meters }\end{array}$ & $\begin{array}{l}\text { Number } \\
\text { of } \\
\text { Cores }\end{array}$ & $\begin{array}{c}\text { Cores } \\
\text { With } \\
\text { Recovery }\end{array}$ & $\begin{array}{l}\text { Percent of } \\
\text { Oores With } \\
\text { Resovery }\end{array}$ & $\begin{array}{l}\text { Meters } \\
\text { Cored }\end{array}$ & $\begin{array}{l}\text { Meters } \\
\text { Recovered }\end{array}$ & $\begin{array}{l}\text { Percent } \\
\text { Recovered }\end{array}$ & $\begin{array}{l}\text { Meters } \\
\text { Lrilled }\end{array}$ & $\begin{array}{l}\text { Total } \\
\text { Penet } \\
\text { Meters }\end{array}$ & $\begin{array}{l}\text { Avg. } \\
\text { Rate } \\
\text { Penet }\end{array}$ & $\begin{array}{c}\text { Time } \\
\text { On } \\
\text { Hole }\end{array}$ & $\begin{array}{l}\text { Time } \\
\text { On } \\
\text { Site }\end{array}$ \\
\hline 621 & $26^{\circ} 43.9^{\prime} \mathrm{N}$ & $88^{\circ} 29.8^{\prime} \mathrm{W}$ & 2485.0 & 33 & 33 & 100.0 & 157.3 & 138.8 & 87.0 & 57.5 & 214.8 & - & - & 57.2 \\
\hline $\begin{array}{l}622 \\
622 \mathrm{~A} \\
\end{array}$ & $\begin{array}{ll}26^{\circ} & 41.4^{\prime} \mathrm{N} \\
26^{\circ} & 41.4^{\prime} \mathrm{N} \\
\end{array}$ & 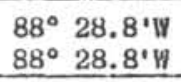 & $\begin{array}{l}2495.0 \\
2495.4 \\
\end{array}$ & $\begin{array}{r}26 \\
1 \\
\end{array}$ & $\begin{array}{r}25 \\
1 \\
\end{array}$ & $\begin{array}{r}96.2 \\
100.0 \\
\end{array}$ & $\begin{array}{r}132.7 \\
5.6 \\
\end{array}$ & $\begin{array}{r}100.2 \\
5.6 \\
\end{array}$ & $\begin{array}{l}75.5 \\
99.1 \\
\end{array}$ & $\begin{array}{c}75.3 \\
0 \\
\end{array}$ & $\begin{array}{r}208.0 \\
5.6 \\
\end{array}$ & - & $\begin{array}{r}42.9 \\
7.9 \\
\end{array}$ & - \\
\hline \multicolumn{2}{|c|}{ 'TOI'AIS } & & & 27 & 26 & 96.3 & 138.3 & 105.8 & 76.5 & 75.3 & 213.6 & - & - & 50.8 \\
\hline 623 & $25^{\circ} 46.11 \mathrm{~N}$ & $86^{\circ} 13.8^{\prime} W$ & 3188.0 & 20 & 19 & 9.5 .0 & 110.2 & 89.2 & 81.0 & 92.0 & 202.2 & - & - & 46.1 \\
\hline $\begin{array}{l}624 \\
624 \mathrm{~A} \\
\end{array}$ & $\begin{array}{rr}25^{\circ} & 45.2^{\prime} \mathrm{N} \\
25^{\circ} & 45.2^{\prime} \mathrm{N} \\
\end{array}$ & $\begin{array}{lll}86^{\circ} & 16.6^{\prime} \mathrm{K} \\
86^{\circ} & 16.6^{\prime} \mathrm{W} \\
\end{array}$ & $\begin{array}{l}3198.2 \\
3193.0 \\
\end{array}$ & $\begin{array}{l}23 \\
22 \\
\end{array}$ & $\begin{array}{l}21 \\
22 \\
\end{array}$ & $\begin{array}{r}91.3 \\
100.0 \\
\end{array}$ & $\begin{array}{l}109.8 \\
103.7 \\
\end{array}$ & $\begin{array}{l}75.3 \\
86.7 \\
\end{array}$ & $\begin{array}{l}68.6 \\
83.6 \\
\end{array}$ & $\begin{array}{r}90.1 \\
103.9 \\
\end{array}$ & $\begin{array}{l}199.9 \\
207.6 \\
\end{array}$ & - & $\begin{array}{l}39.3 \\
48.3 \\
\end{array}$ &.- \\
\hline \multicolumn{2}{|c|}{ TOYAALS } & & & 15 & 43 & 95.6 & 213.5 & 162.0 & 75.9 & 194.0 & 407.5 & - & - & 87.6 \\
\hline & RAND TOI'AIS & & & 385 & 372 & 96.6 & 2586.2 & 1665.3 & 64.4 & 1120.4 & 3706.6 & $\div$ & - & 776.6 \\
\hline
\end{tabular}


INTERNATIONAL PHASE OP OCEAN DRILLING

LEEP SEA DRILLING PROJECT

BIT SUMPARY

LEG 96

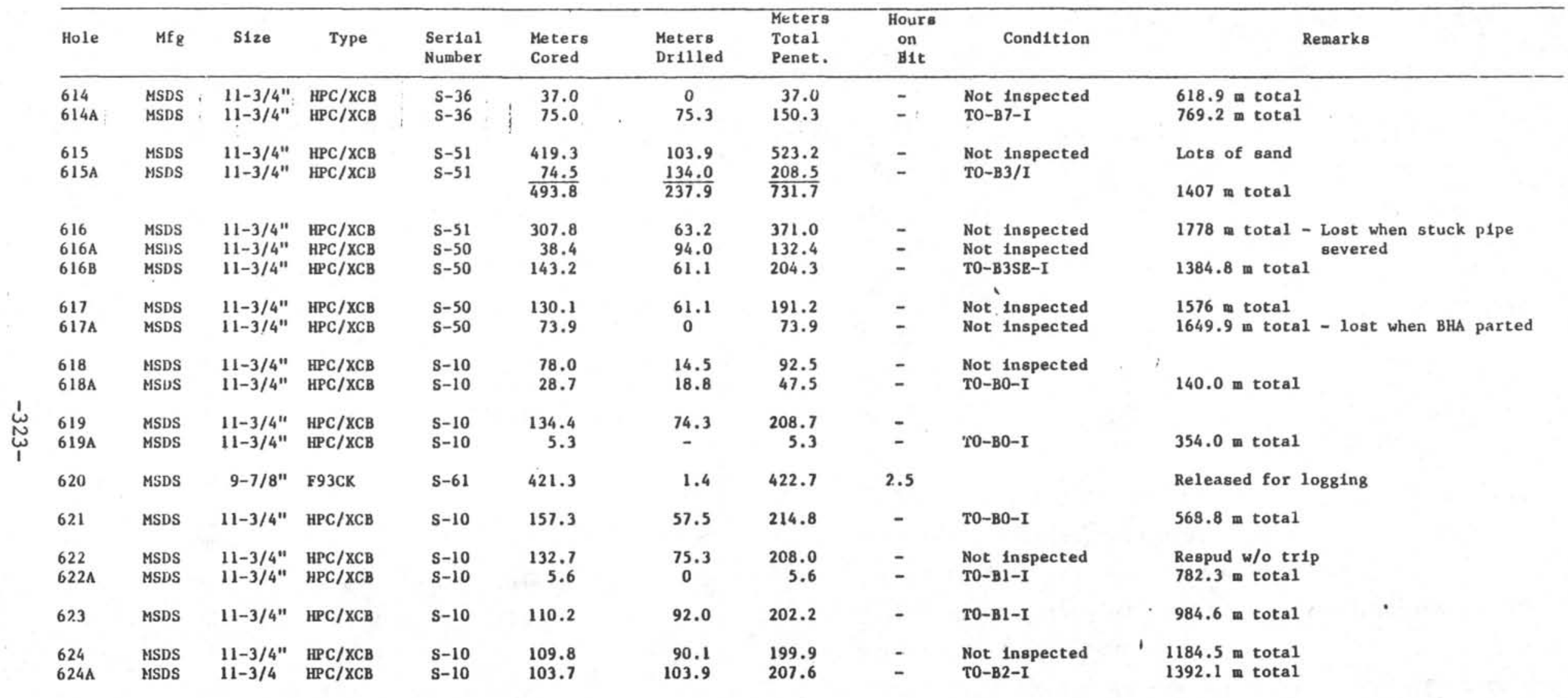


INTERNATIONAL PHASE OF OCEAN DRILLING

DEEP SEA DRILLING PROJECT

BEACON SUMMARY

LEG 96

\begin{tabular}{|c|c|c|c|c|c|c|}
\hline & $\begin{array}{l}\text { Site } \\
\text { No. }\end{array}$ & Make & $\begin{array}{l}\text { Freq. } \\
\mathrm{kHz}\end{array}$ & $\begin{array}{l}\text { Serial } \\
\text { Number }\end{array}$ & $\begin{array}{l}\text { Site Time } \\
\text { Hours }\end{array}$ & Remarks \\
\hline \multirow{13}{*}{ 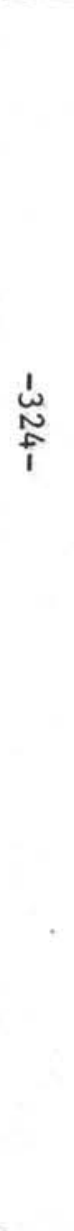 } & 614 & ORE & 13.5 & 178 & 0.8 & Double life; developed bad pulse \& weak signal after landing. \\
\hline & 614 & ORE & 16.0 & 167 & 59.4 & Single-life; good beacon \\
\hline & 615 & ORE & 13.5 & 177 & -- & Single life; falled on launch; pulse width only $1 / 2 \mathrm{~ms}$ \\
\hline & 615 & ORE & 16.0 & 171 & -- & Double life; would not start up for launch \\
\hline & 615 & ORE & 16.0 & $109 \mathrm{~A}$ & 2.9 & Double-1ife; signal too weak to use \\
\hline & $\begin{array}{l}615 \\
615 A\end{array}$ & $\begin{array}{l}\text { ORE } \\
\text { ORE }\end{array}$ & $\begin{array}{l}13.5 \\
13.5\end{array}$ & $\begin{array}{l}185 \\
185\end{array}$ & $\begin{array}{r}121.2 \\
\frac{32.8}{154.0}\end{array}$ & $\begin{array}{l}\text { Single 11fe; good beacon } \\
\text { TOTAL }\end{array}$ \\
\hline & $\begin{array}{l}616 \\
616 \mathrm{~A} \\
616 \mathrm{~B}\end{array}$ & $\begin{array}{l}\text { ORE } \\
\text { ORE } \\
\text { ORE }\end{array}$ & $\begin{array}{l}16.0 \\
16.0 \\
16.0\end{array}$ & $\begin{array}{l}172 \\
172 \\
172\end{array}$ & $\begin{array}{r}73.7 \\
21.9 \\
31.4 \\
127.0\end{array}$ & $\begin{array}{l}\text { Single life } \\
\text { TOTAL - Good Beacon }\end{array}$ \\
\hline & $\begin{array}{l}617 \\
617 \mathrm{~A}\end{array}$ & $\begin{array}{l}\text { ORE } \\
\text { ORE }\end{array}$ & $\begin{array}{l}16.0 \\
16.0\end{array}$ & $\begin{array}{l}183 \\
183\end{array}$ & $\begin{array}{l}30.4 \\
17.4 \\
47.8\end{array}$ & $\begin{array}{l}\text { Single life } \\
\text { TOTAL - Good Beacon }\end{array}$ \\
\hline & $\begin{array}{l}618 \\
618 A\end{array}$ & $\begin{array}{l}\text { ORE } \\
\text { ORE }\end{array}$ & $\begin{array}{l}13.5 \\
13.5\end{array}$ & $\begin{array}{l}186 \\
186\end{array}$ & $\begin{array}{l}27.7 \\
10.6 \\
38.3\end{array}$ & $\begin{array}{l}\text { Single 1ife } \\
\text { TOTAL - Good Beacon }\end{array}$ \\
\hline & 619 & ORE & 16.0 & 184 & 31.6 & Single Life \\
\hline & $619 \mathrm{~A}$ & ORE & 16.0 & 184 & $\frac{6.7}{38.3}$ & TOTAL - Good Beacon \\
\hline & 620 & ORE & 13.5 & 180 & 65.3 & Double-11fe \\
\hline & 621 & ORE & 13.5 & 179 & 283.6 & $\begin{array}{l}\text { Double } 11 \text { fe; dropped } 0539 \text { hrs, October } 17 ; 10 \% \text { of normal } \\
\text { strength on return to Site, October } 26 . \text { Held strength for } \\
\text { site operations. }\end{array}$ \\
\hline
\end{tabular}


INTERNATIONAL PHASE OF OCEAN DRILLING

DEEP SEA DRILLING PROJECT

BEACON SUMMARY

LEG 96

(Continued)

\begin{tabular}{|c|c|c|c|c|c|c|c|c|c|c|c|}
\hline & & & & & & & & & & & \\
\hline & & & & & & & & & & & \\
\hline & & & & & & & & & & & \\
\hline & & & & & & & & & & & \\
\hline & & & & & & $\begin{array}{l}\text { Site } \\
\text { No. }\end{array}$ & Make & $\begin{array}{l}\text { Freq. } \\
\mathrm{kHz}\end{array}$ & $\begin{array}{l}\text { Serial } \\
\text { Number }\end{array}$ & $\begin{array}{l}\text { Site Time } \\
\text { Hours }\end{array}$ & Remarks \\
\hline & & & & & & $\begin{array}{l}622 \\
622 \mathrm{~A}\end{array}$ & $\begin{array}{l}\text { ORE } \\
\text { ORE }\end{array}$ & $\begin{array}{l}13.5 \\
13.5\end{array}$ & $\begin{array}{l}176 \\
176\end{array}$ & $\begin{array}{r}42.9 \\
7.9 \\
50.8\end{array}$ & $\begin{array}{l}\text { Single-1ife } \\
\text { Good beacon } \\
\text { TOTAL }\end{array}$ \\
\hline & & & & & & 623 & ORE & 16.0 & 171 & 46.1 & Double-11fe; good beacon \\
\hline & & & & & & $\begin{array}{l}624 \\
624 \mathrm{~A}\end{array}$ & $\begin{array}{l}\text { ORE } \\
\text { ORE }\end{array}$ & $\begin{array}{l}13.5 \\
13.5\end{array}$ & $\begin{array}{l}181 \\
181\end{array}$ & $\begin{array}{l}39.3 \\
48.3 \\
87.6\end{array}$ & $\begin{array}{l}\text { Double-11fe } \\
\text { TOTAL - Good Beacon }\end{array}$ \\
\hline
\end{tabular}

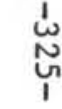


I)EEP SEA DRILLIING PROJECT

LOGGING SUIMARY

LEG 96

\begin{tabular}{|c|c|c|c|c|c|c|c|c|c|c|c|}
\hline HOLE & $\begin{array}{c}\text { TOTAL } \\
\text { DEPTII } \\
\text { (M) }\end{array}$ & $\begin{array}{l}\text { WATER } \\
\text { DEPTH } \\
\text { (M) }\end{array}$ & \begin{tabular}{|c|} 
OPEN \\
ENDED \\
PIPE AT \\
(M)
\end{tabular} & $\begin{array}{c}\text { FLUID } \\
\text { IN } \\
\text { HOLE }\end{array}$ & $\begin{array}{l}\text { BIT } \\
\text { SIZE }\end{array}$ & $\begin{array}{c}\text { TOTAL } \\
\text { TIME FOR } \\
\text { LOGGING } \\
\text { (HOURS) }\end{array}$ & $\begin{array}{l}\text { RUN } \\
\text { NO. }\end{array}$ & $\begin{array}{c}\text { LOGS } \\
\text { RECORDED }\end{array}$ & $\begin{array}{l}\text { FROM } \\
\text { (M) }\end{array}$ & $\begin{array}{l}\text { T0 } \\
\text { (M) }\end{array}$ & OBSERVATIONS \\
\hline 614 & 3351.1 & 3314.1 & & & & & & & & & No 1 ogs requested \\
\hline $614 \mathrm{~A}$ & 3464.4 & 3314.1 & & & & & & & & & No $\log 8$ requested \\
\hline 615 & 3807.1 & 3283.9 & 3329 & Ppg mud & $113 / 4$ & 11.0 & 1 & GIT, LSS-GR & 3789 & 3329 & 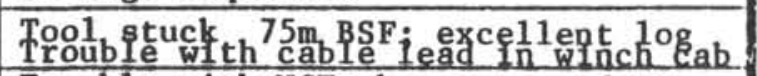 \\
\hline 615 & 3807.1 & 3283.9 & 3347 & Ppg mud & $113 / 4$ & 9.3 & 1 & $\mathrm{FDC}, \mathrm{CNL}, \mathrm{GR}$ & 3789 & 3347.8 & $\begin{array}{l}\text { Trouble with NGT; change to std GR } \\
\text { Caliper no good; Other curves good }\end{array}$ \\
\hline $615 \mathrm{~A}$ & 3494.4 & 3285.9 & & & & & & & & & No $\log s$ requested \\
\hline 616 & 3369.9 & 2998,9 & 3355 & seawtr & $113 / 4$ & 4.0 & 1 & EDE,GNL,GR & 3364 & 2998 & $\begin{array}{l}\text { Logged thyu stuck pipe } \\
\text { Good sand shale resolution }\end{array}$ \\
\hline $616 \mathrm{~A}$ & 3131.3 & 2998.9 & & & & & $\cdot$ & & & & No $\log 8$ requested \\
\hline $616 \mathrm{~B}$ & 3203.2 & 2998.9 & & & & & & . & & & No $10 \mathrm{gs}$ requested \\
\hline 617 & 2669.7 & 2478.5 & & & & & & & & & No $\log 8$ requested \\
\hline $617 \mathrm{~A}$ & 2551.4 & 2377.5 & & & & & & & & & No $\log 8$ requested \\
\hline 618 & 2514.9 & 2422.4 & & & & . & & & & & No $\operatorname{logs}$ requested \\
\hline $618 \mathrm{~A}$ & 2469.9 & 2422.4 & & & & & & $\therefore$ & & & No logs requested \\
\hline 619 & 2481.7 & 2273.0 & & & & & & i & & & No $\log 8$ requested \\
\hline $619 \mathrm{~A}$ & 2278.0 & 2272.7 & & & & & & & . & & Mudline core only \\
\hline \multirow[t]{2}{*}{620} & 3055.1 & 2612.4 & 2688.0 & seawtr & $97 / 8$ & 4.2 & 1 & DIT,LSS,GR & & & $\begin{array}{l}\text { Too1 stopped by mudbal1 in pipe }{ }^{2300} \\
\text { Water } \text { In }^{10-31} \text { pin adapter Caused }\end{array}$ \\
\hline & & & & & & & & & & & LSS/GR : fallure \\
\hline \multirow[t]{2}{*}{620} & 3055.1 & 2612.4 & 2688.0 & seawtr & $97 / 8$ & 5.2 & 2 & DIT, LSS, $\dot{G R}$ & 2899 & 2688 & $\begin{array}{l}\text { Could not get past bridge at } 2900 \mathrm{~m} \text {, } \\
\text { good log, calipers removed to help }\end{array}$ \\
\hline & & & & & & & & & & & get down \\
\hline 621 & 2699.8 & 2485.0 & 2547 & seawtr & $113 / 4$ & 5.1 & 1 & LSS, GR, CAL & 2693 & 2547 & $\begin{array}{l}\text { Good log, omitted DIT to get GR to T. } \\
\text { Trouble getting down; (GR to seafloor }\end{array}$ \\
\hline 621 & 2699.8 & 2485.0 & 2547 & seawtr & $113 / 4$ & 5.2 & 1 & FDC, CNL, GR & 2689 & 2547 & $\begin{array}{l}\text { Log no good, cable damaged, } \\
\text { Spudding tool to get down }\end{array}$ \\
\hline \multirow[t]{2}{*}{622} & 2703.0 & 2495.0 & 2547 & seawtr & $113 / 4$ & 5.9 & 1 & $\mathrm{LSS}, \mathrm{GR}, \mathrm{CAL}$ & 2699 & 2547 & $\begin{array}{l}\text { Some trouble getting down; good log, } \\
\text { caliper stuck coming into bit, }\end{array}$ \\
\hline & & & & & & & & & & & One spring broke of $f$ \\
\hline $622 \mathrm{~A}$ & 2501.0 & 2495.4 & & & & & & & & & Mudline core only \\
\hline 623 & 3390.2 & 3188.0 & 3243.9 & seawtr & $113 / 4$ & 6.5 & 1 & LSS, GR, CAL & 3371 & 3244 & Hole open; good $10 \mathrm{log}$ GR to seafloor \\
\hline \multirow[t]{2}{*}{624} & 3398.1 & 3198.2 & & & & & & & & & Hole loos ost when XCB stuck in pipe \\
\hline & & & & & & & & & & & - \\
\hline
\end{tabular}


DEEP SEA DRILLING PROJECT

LOGGING SUPMARY

\begin{tabular}{|c|c|c|c|c|c|c|c|c|c|c|c|}
\hline HOLE & \begin{tabular}{|c|} 
TOTAL \\
DEPTII \\
(M)
\end{tabular} & $\begin{array}{l}\text { WATER } \\
\text { DEPTH } \\
\text { (M) }\end{array}$ & \begin{tabular}{|l|} 
OPEEN \\
ENDED \\
PIPE AT \\
(M) \\
\end{tabular} & \begin{tabular}{|c} 
FLUID \\
IN \\
HoLE
\end{tabular} & $\begin{array}{l}\text { BIT } \\
\text { SIZE }\end{array}$ & $\begin{array}{l}\text { TOTAL } \\
\text { TIME FOR } \\
\text { LOGGING } \\
\text { (HOURS) } \\
\end{array}$ & $\begin{array}{l}\text { RUN } \\
\text { NO. }\end{array}$ & $\begin{array}{c}\text { LOGS } \\
\text { RECORDED }\end{array}$ & $\begin{array}{l}\text { FROM } \\
(M)\end{array}$ & $\begin{array}{l}\text { T0 } \\
\text { (M) }\end{array}$ & OBSERVATIONS \\
\hline $624 \mathrm{~A}$ & 3405.6 & 3198.0 & 3253.5 & seawtr & $113 / 4$ & 5.0 & 1 & DIT/LSS/GR & 3390 & 3253 & Good log; GR to seafloor \\
\hline $624 \mathrm{~A}$ & 3405.6 & 3198.0 & 3253.5 & seawtr & $113 / 4$ & 4.4 & 1 & $\mathrm{FDC} / \mathrm{CNL} / \mathrm{GR}$ & 3380 & 3253 & Good log: GR to seafloor \\
\hline & & & & & & & & & & & \\
\hline & & & & & & & & & & & \\
\hline & & & & & & & & & & & \\
\hline & & & & & & & & & & & $\therefore$ \\
\hline & & & & & & & & : & & & \\
\hline & & & & & & & & & & & \\
\hline & & & & & & & & & & & \\
\hline & & & & & & & & & & & \\
\hline & & & & & & & & & & & \\
\hline & & & & & & & & & & & \\
\hline & & & & & & & & & & & \\
\hline & & & & & & & & & $\cdot$ & & \\
\hline & & & & & & & & & & & \\
\hline & & & & & & & & & & & \\
\hline & & & & & & & & & & & \\
\hline & & & & & & & & & & & \\
\hline & & & & & & & & & & & \\
\hline & & & & & & & & & & & \\
\hline & & & & & & & & & & & \\
\hline & & & & & & & & & & & \\
\hline & & & & & & & & & & & \\
\hline & & & & & & & & & & $\cdot$ & \\
\hline & & & & & & & & & & & \\
\hline & & & & & & & 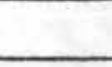 & & & & \\
\hline
\end{tabular}

